DENIS GERAGE AMORIM

\title{
SUSTENTABILIDADE URBANA NO PLANEJAMENTO DE RODOVIA PERIMETRAL EM REGIÃO METROPOLITANA
}




\section{DENIS GERAGE AMORIM}

Sustentabilidade Urbana no Planejamento de Rodovia Perimetral em Região Metropolitana

Dissertação apresentada ao Programa de PósGraduação Ambiente, Saúde e Sustentabilidade, da Faculdade de Saúde Pública, da Universidade de São Paulo, para a obtenção do título de Mestre em Ciências.

Orientador: Prof. Dr. Arlindo Philippi Júnior

\section{VERSÃO REVISADA \\ SÃO PAULO}

2019 
É expressamente proibida a comercialização deste documento, tanto na sua forma impressa como eletrônica. Sua reprodução, total ou parcial, é permitida exclusivamente para fins acadêmicos e científicos, desde que na reprodução figure a identificação do autor, título, instituição e ano da dissertação.

Catalogação na Publicação (CIP)

Biblioteca/CIR da FSP/USP

Faculdade de Saúde Pública da Universidade de São Paulo

Amorim, Denis Gerage

Sustentabilidade Urbana no Planejamento de Rodovia Perimetral em Região Metropolitana. Arlindo Philippi Jr. - São Paulo - 2019.

$310 \mathrm{f}$.

Dissertação (Mestrado) - Universidade de São Paulo, 2019 
AMORIM, Denis Gerage, Sustentabilidade Urbana no Planejamento de Rodovia Perimetral em Região Metropolitana - Faculdade de Saúde Pública da Universidade de São Paulo, São Paulo, 2019. 


\title{
FOLHA DE APROVAÇÃO (DISSERTAÇÃO)
}

\section{Panus}

\author{
Universidade de São Paulo
}

ATA DE DEFESA

Aluno: 6139 - 6064184 - 2 / Página 1 de 1

Ata de defesa de Dissertação do(a) Senhor(a) Denis Gerage Amorim no Programa: Mestrado Profissional Ambiente, Saúde e Sustentabilidade, do(a) Faculdade de Saúde Pública da Universidade de Săo Paulo.

Aos 04 dias do mês de outubro de 2019, no(a) Sala CEAP 12 - Biblioteca realizou-se a Defesa da Dissertação do(a) Senhor(a) Denis Gerage Amorim, apresentada para a obtenção do título de Mestre intitulada:

"Sustentabilidade Urbana no Planejamento de Rodovia Perimetral em Região Metropolitana"

Após declarada aberta a sessão, o(a) $\operatorname{Sr}(a)$ Presidente passa a palavra ao candidato para exposição e a seguir aos examinadores para as devidas arguições que se desenvolvem nos termos regimentais. Em seguida, a Comissão Julgadora proclama o resultado:

\begin{tabular}{|c|c|c|c|}
\hline Nome dos Participantes da Banca & Função & Sigla da CPG & Resultado \\
\hline Arlindo Philippi Junior & Presidente & FSP - USP & ante \\
\hline Amarilis Lucia Casteli Figueiredo Gallardo & Titular & EP - USP & novodo \\
\hline Ivan Carlos Maglio & Titular & Externo & $80 \mathrm{cos}$ \\
\hline Valdir Fernandes & Titular & UTFPR - Externo & $20 V_{A} D O$ \\
\hline
\end{tabular}

Resultado Final: APROVADO

Parecer da Comissão Julgadora *

Eu, Carlos Alberto da Silva Santos , lavrei a presente ata, que assino juntamente com os(as) Senhores(as). São Paulo, aos 04 dias do mês de outubro de 2019.

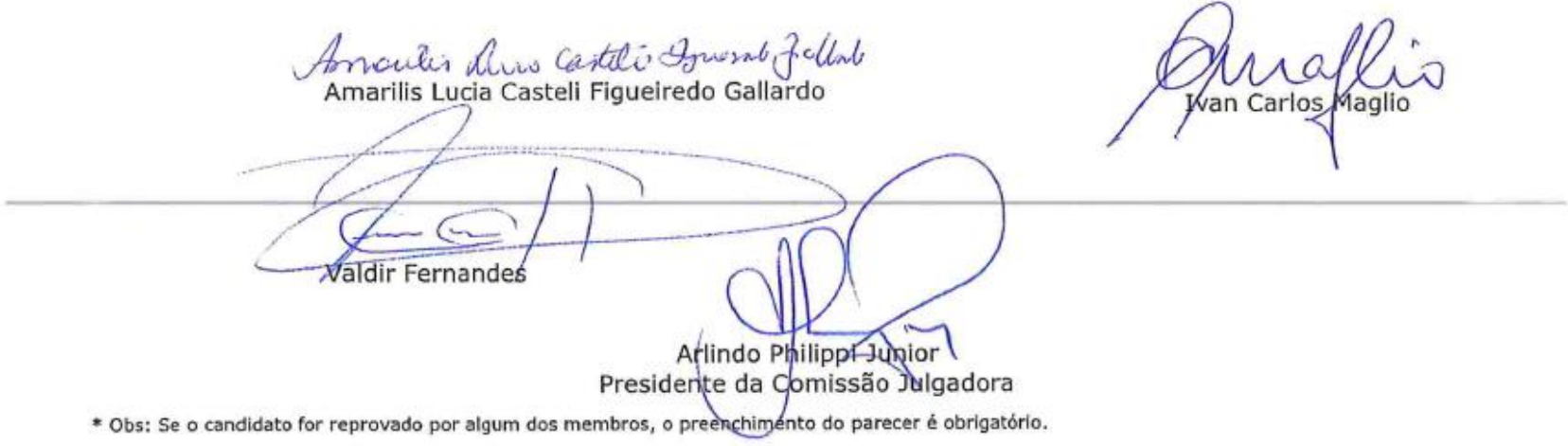




\section{DEDICATÓRIA}

Ao Governo do Estado de São Paulo, por proporcionar minha graduação, pósgraduação e experiências profissionais na área de meio ambiente, segurança $e$ transporte. 


\section{AGRADECIMENTOS}

Ao professor e orientador Arlindo Philippi Jr., pela oportunidade e confiança para a realização deste trabalho e, sobretudo, por me mostrar a importância da sustentabilidade urbana, incentivando-me a contribuir para melhorar a qualidade de vida nas cidades.

À Faculdade de Saúde Pública da Universidade de São Paulo (FSP/USP), por me proporcionar um ambiente de aprendizado ideal para o desenvolvimento deste projeto.

Aos colegas Amanda Carbone, Sonia Maria Coutinho, Mary Dias Lobas de Castro, Fernanda Bertaco Bueno, Debora Sotto e Eduardo Neder, pelas contribuições e discussões durante as reuniões do grupo de pesquisa do professor Arlindo Philippi Jr.

Aos Professores, Ivan Carlos Maglio e Karin Regina de Casas Castro Marins, pelas valiosas contribuições na etapa de qualificação deste trabalho, que ajudaram a aprimorar o desenvolvimento desta pesquisa.

Aos membros da banca examinadora, Amarilis Gallardo, Valdir Fernandes e Ivan Maglio, por aceitarem o convite e pelas recomendações científicas, que contribuíram muito para a melhoria deste trabalho.

À Natália, minha amada companheira, pela compreensão da minha ausência, ainda que presente fisicamente.

Ao meu filho Bento, que me presenteou com sua chegada e benção durante essa jornada, e por reforçar a importância das ações do presente para as futuras gerações.

Aos meus pais, pelo amor, apoio e viabilização do meu aprendizado.

Ao Eng. Marcelo Arreguy Barbosa, por me ajudar a entender o equilíbrio, a razoabilidade e a sensatez nas tomadas de decisões em empreendimentos de infraestrutura de transporte.

À equipe da DERSA e consultores, pela convivência, ensinamentos e contribuições na elaboração deste trabalho.

A todos os autores de trabalhos, científicos e técnicos, que trouxeram as informações e descobertas que deram a base para o desenvolvimento deste trabalho.

A todos que direta ou indiretamente contribuíram para que o produto deste trabalho pudesse ser concluído. 


\section{RESUMO}

\section{AMORIM, D. G. Sustentabilidade Urbana no Planejamento de Rodovia Perimetral}

em Região Metropolitana. 2019. 310 f. Dissertação (Mestrado) - Faculdade de Saúde Pública, Universidade de São Paulo, São Paulo, 2019.

Empreendimentos rodoviários oferecem diversos benefícios à população quanto à mobilidade, acessibilidade, melhoria da qualidade de vida e desenvolvimento socioeconômico. Contudo, trazem consigo uma série de impactos e riscos socioambientais que, normalmente, são bastante polêmicos, especialmente em regiões metropolitanas, que interferem com grandes aglomerados urbanos. Essas intervenções impõem altos custos para as pessoas, grupos ou comunidades impactadas, principalmente quando se encontram em situação de vulnerabilidade social e econômica. É nesse sentido que a adoção de uma abordagem de sustentabilidade urbana na tomada de decisão no desenvolvimento de infraestrutura rodoviária é primordial para atender aos anseios da população e às necessidades econômicas, sociais e ambientais. Visando contribuir para sistematização de informações que subsidiem decisões no planejamento de infraestrutura rodoviária, este trabalho teve como objetivo elaborar uma estrutura conceitual composta por objetivos, metas e indicadores. Para tanto, foram definidos os seguintes objetivos específicos: (i) Revisar os princípios da sustentabilidade urbana e de transporte sustentável, bem como os principais métodos de avaliação de sustentabilidade utilizados na fase de planejamento; (ii) Analisar as interfaces urbano-rodoviárias frente à implantação de rodovia perimetral em uma região metropolitana brasileira; e (iii) Definir os indicadores de sustentabilidade que representem as questões relevantes nas interfaces urbano-rodoviárias. O estudo utilizou-se uma abordagem qualitativa, de caráter exploratório, combinando os procedimentos técnicos de pesquisa bibliográfica e estudo de caso. Como produto da pesquisa, foram elaboradas fichas de avaliação para cada indicador selecionado, contendo orientações gerais para aplicação e medidas de desempenho mensurável, de forma desagregada, para orientar o processo de avaliação por agências de transporte. Esta pesquisa contribuiu para iniciar uma longa discussão de estruturas que auxiliem na avaliação de desempenho de sustentabilidade no planejamento de infraestrutura de transporte. Assim, a estrutura não deve considerada um produto definitivo, mas sim uma ideia em construção, que abarca as principais questões relacionadas ao tema e avança nas discussões sobre planejamento de transporte e desenvolvimento territorial.

Palavras-chave: Transporte sustentável, sustentabilidade urbana, rodovias, avaliação de sustentabilidade, indicadores. 


\section{ABSTRACT}

AMORIM, D. G. Urban Sustainability in the Planning of Perimeter Highway in Metropolitan Region. 2019. 310 f. Dissertação (Mestrado) - Faculdade de Saúde Pública, Universidade de São Paulo, São Paulo, 2019.

Highways offer many benefits to the population in terms of mobility, accessibility, quality of life and socioeconomic development. However, they bring with them many social and environmental impacts and risks that are usually quite controversial, especially in metropolitan regions, which interfere with large urban agglomerations. These interventions impose high costs on impacted people, groups or communities, especially when they are in situation of social and economic vulnerability. Therefore, the adoption of an urban sustainability approach in decision-making in road infrastructure development is essential to meet the needs of the population and the economic, social and environmental needs. Aiming to contribute to the systematization of information that supports decisions on road infrastructure planning, this work aimed to elaborate a framework composed by objectives, goals and indicators. To this end, the following specific objectives were defined: (i) Review the principles of urban sustainability and sustainable transport, as well as the main sustainability assessment methods used in the planning phase; (ii) Analyze the urban-road interfaces of the implementation of a perimeter highway in Brazilian metropolitan region; and (iii) Define the sustainability indicators that represent the relevant issues at the urban-road interfaces. The study used a qualitative and exploratory approach, combining the technical procedures of bibliographic research and case study. As a result of the research, evaluation sheets were prepared for each selected indicator, containing general application guidelines and measurable performance measures, disaggregated, to guide the evaluation process by transportation agencies. This research contributed to initiate a long discussion of structures that aid in the assessment of sustainability performance in transport infrastructure planning. Thus, the structure should not be considered a definitive product, but rather an idea under construction that encompasses the main issues related to the theme and advances in discussions about transport planning and territorial development.

Keywords: Sustainable transport, urban sustainability, highways, sustainability assessment, indicators. 


\section{LISTA DE ILUSTRAÇÕES}

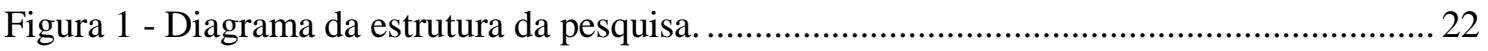

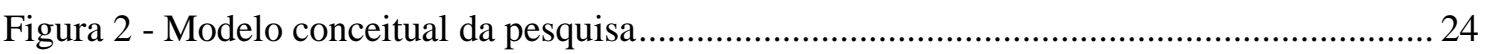

Figura 3 - Rodoanel Mário Covas - Localização por Trechos....................................................... 29

Figura 4 - Etapas do processo de elaboração da estrutura conceitual. .......................................... 32

Figura 5 - Fontes de levantamento dos elementos de sustentabilidade urbana e de transporte... 33

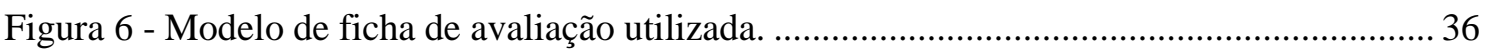

Figura 7 - Objetivos de Desenvolvimento Sustentável - ODS. ……............................................ 39

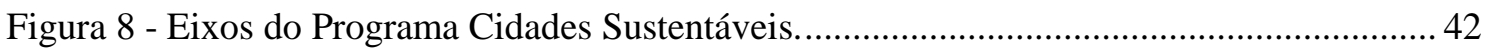

Figura 9 - Processo de planejamento estratégico tradicionalmente utilizado................................ 86

Figura 10 - Estrutura para ferramentas de avaliação de sustentabilidade. .................................... 91

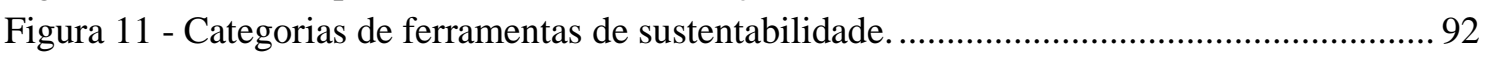

Figura 12 - A hierarquia da informação através do prisma de indicadores sustentáveis............ 100

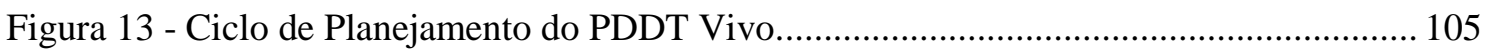

Figura 14 - Esquema Metodológico da AAE do Programa Rodoanel. ....................................... 111

Figura 15 - Fases de tomada de decisão em transporte de uso potencial da estrutura conceitual.

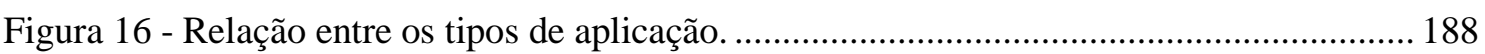

Figura 17- Modelo conceitual de aplicação potencial da estrutura. .......................................... 190

Figura 18 - Grupos de partes interessadas de empreendimentos rodoviários, seguindo a classificaçãão de El-Gohary et al. (2006). ............................................................... 196

\section{LISTA DE QUADROS}

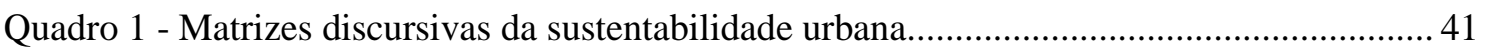

Quadro 2 - Exemplos de definições de transporte sustentável................................................. 45

Quadro 3 - Recomendações para Desenvolvimento e Implementação de Políticas..................... 48

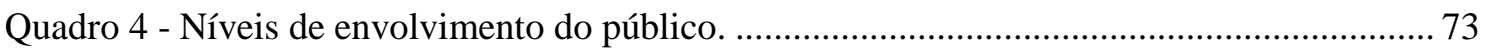

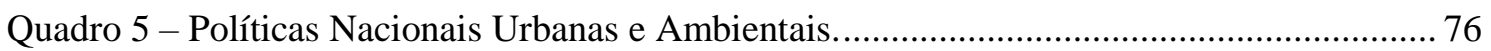

Quadro 6 - Princípios e objetivos da Política Nacional de Mobilidade Urbana (2012).............. 81

Quadro 7 - Análise das principais ferramentas de avaliação da sustentabilidade ........................ 94

Quadro 8 - Exemplos de ferramentas de classificação e certificação de sustentabilidade.......... 96

Quadro 9 - Relação entre objetivos e indicadores utilizados no PDDT Vivo.............................. 108

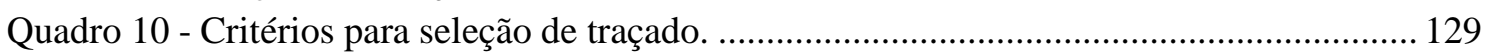

Quadro 11 - Impactos potenciais identificados nos estudos ambientais. ..................................... 130

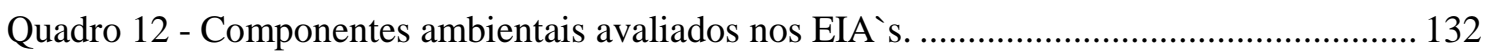

Quadro 13 - Impactos ambientais selecionados do EIA`s...................................................... 133

Quadro 14 - Variáveis, Unidades e Periodicidade do Monitoramento da Dinâmica Demográfica.

Quadro 15 - Relação dos fatores de avaliação com Políticas, Normas ou Metas de

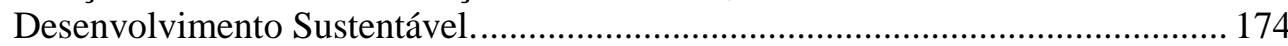

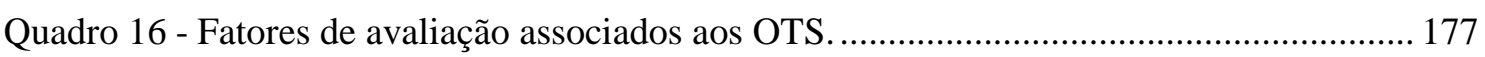

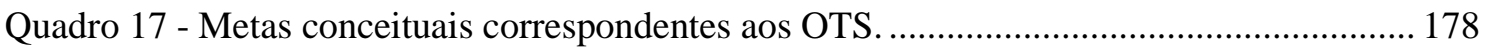

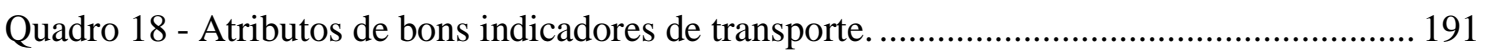




\section{LISTA DE TABELAS}

Tabela 1 - Objetivos e Respectivos Pesos Adotados no PDDT Vivo. 107

Tabela 2 - Matriz de critérios de avaliação da cobertura vegetal nativa. 166 


\section{SUMÁRIO}

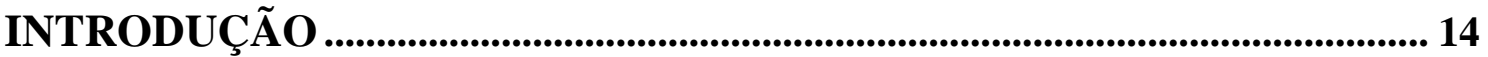

Problematização da pesquisa................................................................................................................ 17

Objetivos......................................................................................................................................................... 20

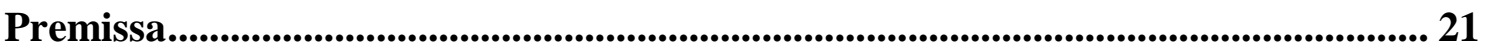

Organização da dissertação ............................................................................................ 21

CAPÍTULO 1 - ABORDAGEM METODOLÓGICA ......................................... 23

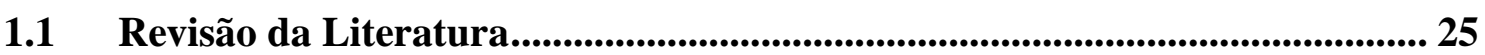

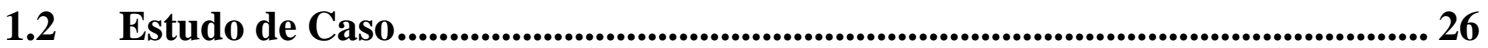

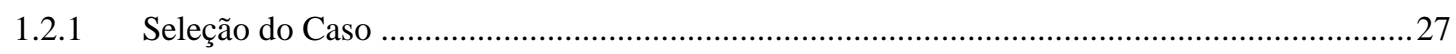

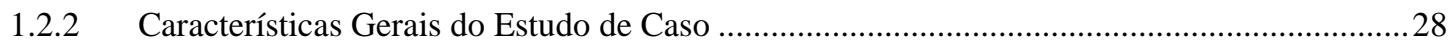

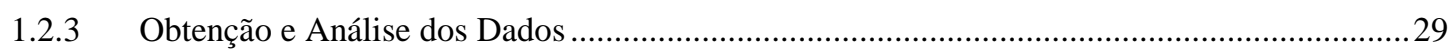

1.3 Processo de Desenvolvimento da Estrutura ...................................................... 31

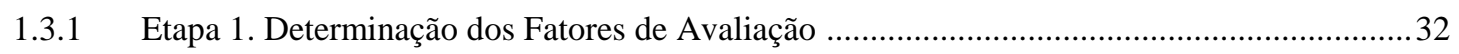

1.3.2 Etapa 2. Elaboração de Objetivos de Transporte Sustentável (OTS) .....................................33

1.3.3 Etapa 3. Estabelecimento das Metas Conceituais ....................................................................3 34

1.3.4 Etapa 4. Seleção dos indicadores-chave e medidas de desempenho .......................................34

CAPÍTULO 2 - TRANSPORTE E SUSTENTABILIDADE URBANA: FUNDAMENTOS TEÓRICOS .................................................................................... 37

2.1 Sustentabilidade Urbana e Cidades Sustentáveis ................................................. 37

2.2 Transporte Sustentável: Princípios e Definições ........................................... 43

2.3 Questões Emergentes no Planejamento de Transporte para Sustentabilidade Urbana .............................................................................................................. 50

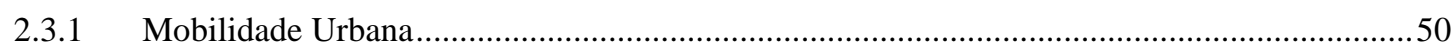

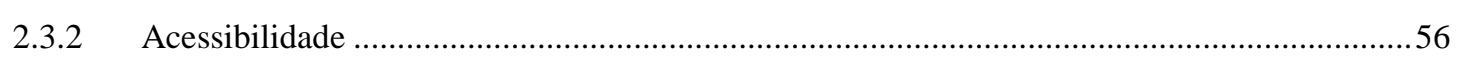

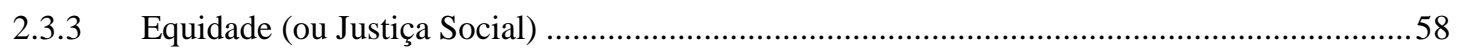

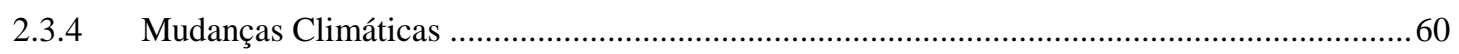

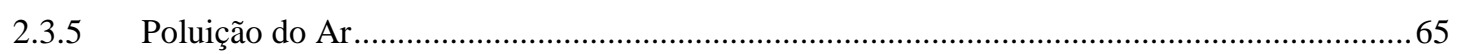

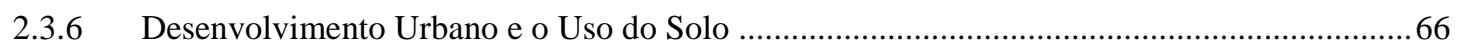

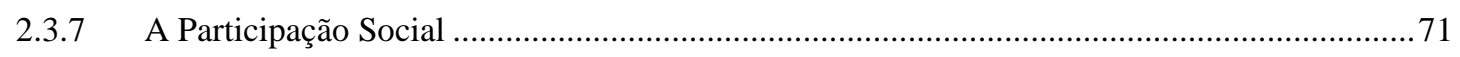

2.4 Principais Políticas Públicas Nacionais Aplicáveis............................................ 74

2.4.1 Políticas Urbanas e Ambientais .......................................................................................... 75

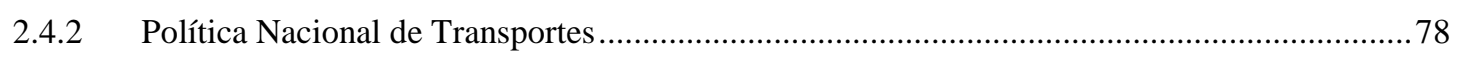

2.4.3 Política Nacional de Mobilidade Urbana...............................................................................81

2.5 Planejamento de Infraestrutura Rodoviária no Brasil .................................. 82

2.6 Ferramentas de Avaliação de Sustentabilidade em Transporte ................... 89

2.6.1 Sistemas de Classificação e de Certificação de Sustentabilidade............................................95

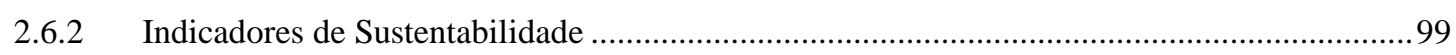


3.1 Plano Diretor de Desenvolvimento de Transportes - PDDT Vivo............... 104

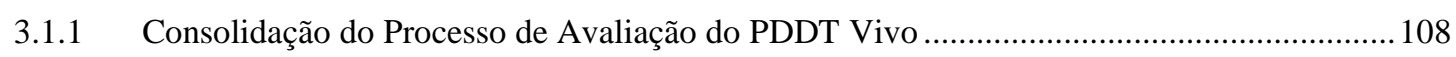

3.2 Avaliação Ambiental Estratégica (AAE) ........................................................... 109

3.2.1 Objetivos e Processo Metodológico ...................................................................................109

3.2.2 Questões Socioambientais Estratégicas .............................................................................112

3.2.3 Avaliação Ambiental do Programa .....................................................................................115

3.2.4 Consolidação do Processo de Avaliação da AAE ...……………………………………....120

3.3 Estudos de Impacto Ambiental (EIA) ............................................................. 123

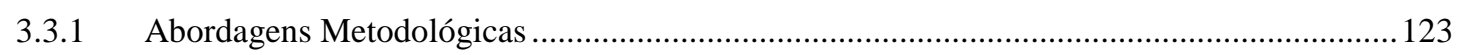

3.3.2 Estudo de Transporte e os Benefícios Socioeconômicos...................................................... 125

Estudo de Alternativas de Traçado .................................................................................. 127

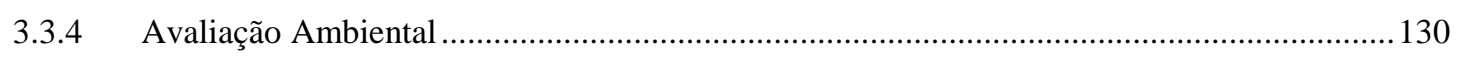

3.1.1 Os Fatores e Impactos Significativos Avaliados no EIA .................................................... 132

3.1 Estudo de Análise de Riscos (EAR) ............................................................. 156

3.2 Plano Básico Ambiental (PBA) ..................................................................... 158

3.3 Monitoramento da Expansão da Mancha Urbana ........................................... 158

3.3.1 Definição das Áreas Monitoradas ....................................................................................... 159

3.3.2 Metodologia de Monitoramento das Áreas de Interesses ...................................................... 160

3.4 Sistema de Avaliação de Sustentabilidade: Envision ....................................... 167

CAPÍTULO 4 - ESTRUTURA DE AVALIAÇÃO DE DESEMPENHO DE

SUSTENTABILIDADE ....................................................................................... 170

4.1 Sobre a Estrutura de Avaliação ……………………....................................... 170

4.2 Construção da Estrutura Conceitual.............................................................. 173

4.2.1 Fatores de Avaliação de Desempenho ................................................................................ 173

4.2.2 Objetivos de Transporte Sustentável (OTS) ...................................................................... 177

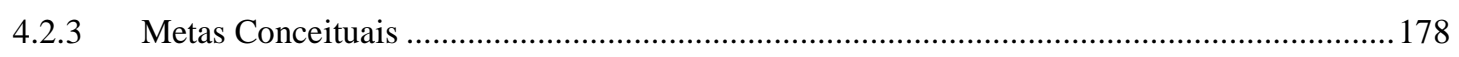

4.2.4 Indicadores de Sustentabilidade Selecionados ................................................................ 180

4.3 Orientações Gerais para Aplicação da Estrutura Conceitual ....................... 187

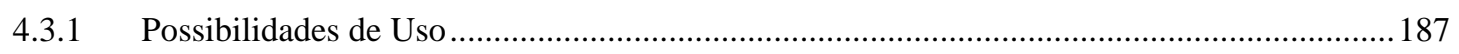

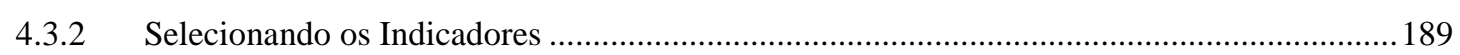

4.3.3 Principais Técnicas de Coleta e Tratamento de Dados ............................................................ 193

4.3.4 Comunicação com as Partes Interessadas...................................................................... 195

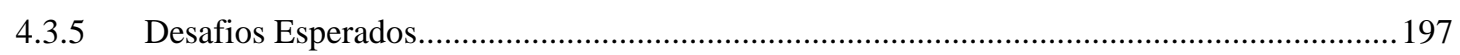

CAPÍTULO 5 - CONSIDERAÇÕES FINAIS ................................................... 199

5.1 Recomendações de Trabalhos Futuros............................................................. 202

REFERÊNCIAS ........................................................................................... 204

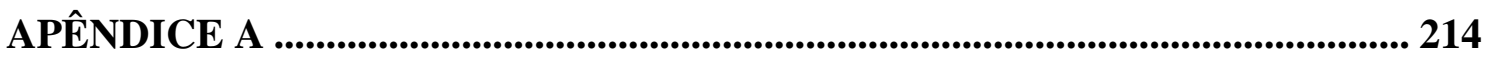

APÊNDICE B ...................................................................................................... 220

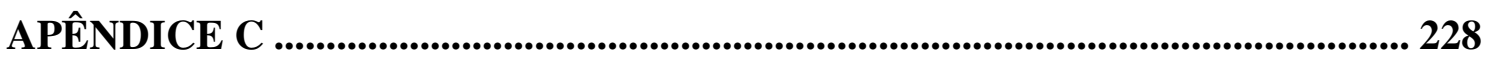

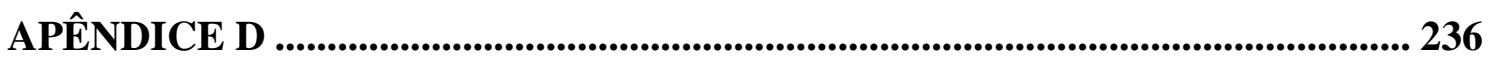




\section{INTRODUÇÃO}

Os meios de transportes têm papel fundamental para o desenvolvimento dos vários setores da economia, influenciando as atividades comerciais, industriais e de serviços, além de exercer um importante papel nas relações sociais pela mobilidade e acessibilidade que promove. De acordo com a Confederação Nacional do Transporte (2015), o desenvolvimento socioeconômico de um país ou região está intimamente ligado às políticas de governo voltadas para a infraestrutura, sobretudo aquelas direcionadas para os meios de transporte rodoviário. A rede viária e as infraestruturas logísticas a ela associadas funcionam como meios imprescindíveis para a vitalidade social e econômica da Nação (PNT, 2018).

No entanto, embora o desenvolvimento das infraestruturas rodoviárias seja atualmente necessário para facilitar o crescimento econômico, a sua implantação causa efeitos ambientais e sociais adversos, tanto na escala local como global, que devem ser tratados adequadamente para assegurar um desenvolvimento sustentável. Os desafios se impõem em um contexto de demandas crescentes por infraestruturas de transportes e serviços logísticos eficientes, seja em função da necessária expansão da malha viária - e seu provável corolário de indução de maiores fluxos de pessoas e bens -, seja em razão do incremento natural esperado de crescimento econômico e demográfico do país (PNT, 2018).

Tradicionalmente, o planejamento de infraestrutura de transporte é baseado em diretrizes que minimizem o custo inicial e o tempo de entrega, e que maximize o padrão de qualidade e a funcionalidade do produto acabado, enfatizando a mobilidade do tráfego com poucas considerações pelas necessidades sociais e ambientais. Contudo, os sistemas de transporte implementados de maneira inadequada podem resultar em infraestruturas e serviços que venham a agravar as condições de pobreza, impactar sobremaneira o meio ambiente, ignorar as mudanças das necessidades de seus usuários e exceder a capacidade das finanças públicas e/ou privadas.

Preocupações globais sobre mudanças climáticas, uso de energia, impactos socioambientais e limites para recursos financeiros para infraestrutura de transporte exigem novas e diferentes abordagens para planejar, projetar, construir, operar e manter soluções e sistemas de transporte. Infraestruturas rodoviárias são, geralmente, muito dispendiosas e implicam a utilização de grandes quantidades de recursos, levam muitos anos para serem desenvolvidos e construídos, envolvem várias partes interessadas e os projetos podem afetar, direta ou indiretamente, milhões de pessoas que vivem em regiões metropolitanas.

É nesse contexto que tratar a sustentabilidade urbana em sistemas de transporte é fundamental, haja vista que o setor tem uma conexão fundamental com o desenvolvimento urbano e regional, além de ser alto consumidor de combustíveis fósseis, gerador de poluição do ar e de gases de efeito estufa, entre outros impactos locais e 
globais. Dentre os sistemas de transporte, o modo rodoviário detém um expressivo consumo energético, emissões de GEE e externalidades causadas à sociedade, com potenciais impactos significativos no uso do solo urbano.

Segundo VTPI (2005), as estratégias que aumentam a eficiência do sistema de transporte e reduzem os impactos negativos do transporte estão entre as formas mais eficazes de avançar em direção aos objetivos de sustentabilidade. A adoção de uma abordagem de sustentabilidade urbana na tomada de decisão na fase de planejamento de empreendimentos rodoviários é primordial para atender aos anseios da população.

É consenso entre os especialistas que a redução global de viagens de automóvel é desejável em se tratando de sustentabilidade. No entanto, existem outros aspectos que podem contribuir para tornar uma infraestrutura rodoviária mais sustentável, que vão desde o uso e ocupação do solo, impactos na qualidade do ar, mobilidades, entre outros, cujas atividades podem ser influenciadas pelas agências de transporte.

As pressões populares, de órgãos ambientais e de agências financiadoras estão exigindo cada vez mais uma abordagem diferente na seleção de soluções de transporte. Por isso, as agências possuem maior esforço sobre os impactos ambientais do que a sustentabilidade como um todo, sobretudo em função das regulamentações ambientais brasileiras e da maturidade dos sistemas de gestão que vem se conquistando.

Atualmente, muitas agências de transporte estão, ainda que tímidas, reconhecendo a importância da sustentabilidade, com maiores preocupações ligadas à saúde e vitalidade da comunidade, adicionalmente ao desenvolvimento econômico e aos aspectos ambientais. Enquanto a atenção para a sustentabilidade tem crescido, definir e incorporar a sustentabilidade nos empreendimentos de infraestrutura rodoviárias se apresentam como grandes desafios para as agências brasileiras, que são bastante vulneráveis e influenciadas por mandatos políticos. Elas podem desempenhar o seu papel na promoção de um futuro sustentável aplicando os princípios gerais de sustentabilidade dentro de seu contexto de transporte específico, e definindo seus próprios objetivos para apoiar a sustentabilidade.

Globalmente, a sustentabilidade exige uma abordagem abrangente e multi e transdisciplinar, além da participação de um amplo conjunto de atores. O que não é diferente para o setor de transporte, um dos principais fatores responsáveis por afetar a sustentabilidade urbana. Zietsman \& Ramani (2011) citam duas abordagens divergentes observadas entre literatura e práticas quando se aborda a sustentabilidade em relação ao transporte - uma centrada no transporte e outra que considera o transporte em apoio a uma agenda mais ampla para a sustentabilidade (ou seja, uma visão holística).

Em que pese as diferentes abordagens, este trabalho adota uma abordagem centrada no transporte, visando fornecer elementos que orientem o desenvolvimento de políticas e programas de transporte, sem requerer grandes dependências de outros setores para suas implementações em nível local e regional. Entende-se que essa abordagem favorece aplicações práticas de avaliação e medição de sustentabilidade, considerando o 
transporte como parte de um sistema maior, permitindo vincular a sustentabilidade ao processo de planejamento de transporte.

Segundo Zietsman e Rilett (2002, apud RAMANI et al., 2011), "a implementação bem-sucedida do transporte sustentável requer o entendimento, a quantificação e a aplicação dos conceitos básicos de sustentabilidade relacionados ao transporte". Dessa forma, faz-se necessária uma compreensão mais clara dos princípios de sustentabilidade e sua relação com as funções das agências de transporte, responsáveis pelo planejamento do setor.

Ramani et al. (2011) alerta que, embora abordar o "transporte sustentável" seja útil na perspectiva de uma agência de transporte, deve-se reconhecer que a sustentabilidade é definida por uma agenda mais ampla do que apenas o transporte e, portanto, é necessário equilibrar esta agenda com questões que são realmente relevantes para as agências de transporte, especialmente àquelas em que as mesmas possuem controle / jurisdição.

O presente estudo se concentrou nas questões consideradas mais relevantes para a sustentabilidade urbana que devem ser abordadas no planejamento de transporte, com ênfase no modelo rodoviarista, dada sua reconhecida ineficiência intrametrópole e elevado impacto, diretos e indiretos, em área urbana. Para tanto, procurou-se integrar os princípios da sustentabilidade urbana e de políticas de transportes, com o objetivo de criar mecanismos de avaliação dos efeitos do transporte nas regiões metropolitanas brasileiras.

O modelo rodoviarista tem sido amplamente criticado pelos estudiosos da linha de pensamento da "sustentabilidade urbana", que enfatiza cada vez mais a importância de sistema de transporte não motorizado e coletivo. Em pese o antagonismo e controvérsias de rodovias com a sustentabilidade urbana, trata-se de uma realidade a ser encarada na realidade do setor de transporte no Brasil, por ser a matriz de transporte do País, cujo modo é o mais utilizado e que tem grande potencial de afetar negativamente a sustentabilidade no ambiente urbano.

De acordo com o Plano Nacional de Energia 2050 (PNE), o uso de veículos automotivos ainda será a prática predominante no País nas próximas décadas, podendo chegar a 130 milhões de veículos individuais e comerciais leves (EPE, 2014), que corresponde a um acréscimo de aproximadamente três vezes a quantidade atual. Essas projeções mostram a urgência na adoção políticas públicas de mobilidade urbana e de transporte de cargas, visando reduzir danos e potencializar seus benefícios sociais.

A adoção dos princípios da sustentabilidade urbana no planejamento de transporte requer o enfrentamento de enormes barreiras, especialmente em virtude do distanciamento que ainda existe entre as políticas de transporte com os instrumentos de gestão urbana e ambiental, e a ausência de articulação institucional entre as agências responsáveis. Além disso, em qualquer agência de transporte, a sustentabilidade pode ser influenciada por decisões tomadas em vários níveis de processos e de departamentos, que, 
geralmente, são formadas por unidades organizacionais separadas e compartimentalizadas, sem a devida integração que a sustentabilidade requer.

Dessa forma, o trabalho apoiou-se em uma revisão bibliográfica, e nas ferramentas e metodologias de avaliação com importância reconhecida, bem como na experiência de uma rodovia perimetral localizada na Região Metropolitana de São Paulo (RMSP), com vistas a propor uma estrutura de avaliação que possa facilitar as agências de transporte a vencer essas barreiras, integrando soluções que contribuam com a qualidade de vida da população e melhorem as conexões e intra e interinstitucional.

\section{Problematização da pesquisa}

Os investimentos em infraestrutura de transportes têm impactos positivos sobre o crescimento econômico, a acessibilidade e mobilidade, mas devem ser devidamente planejados, com vistas a maximizar o crescimento econômico e minimizar o impacto socioambiental negativo.

O planejamento de transporte requer uma abordagem mais amplas sobre o bemestar da sociedade, e a infraestrutura precisa ser entregue em um contexto de respeito ao meio ambiente, à justiça social e a um futuro de longo prazo. Essas necessidades, muitas vezes conflitantes, devem ser consideradas em conjunto, cujo equilíbrio é a essência do desenvolvimento sustentável (FIDIC, 2012). A análise abrangente ajuda a identificar estratégias que atingem objetivos múltiplos de planejamento.

A aplicação bem-sucedida dos princípios do desenvolvimento sustentável reside em traduzi-los em ferramentas práticas para a tomada de decisões. O processo de alcançar resultados mais sustentáveis depende crucialmente de boas técnicas de tomada de decisão, que oferece uma perspectiva sistêmica para abranger a complexidade de políticas de transporte, equilibrar trades-off e gerenciar prioridades concorrentes.

Ainda que seja amplamente reconhecida cientificamente a necessidade de implementar política integrada para alcançar os objetivos de sustentabilidade, na prática é bastante difícil garantir um desenvolvimento equilibrado em empreendimentos de infraestrutura de transporte no Brasil. As competências técnicas, a estrutura institucional e os procedimentos de planejamento muitas vezes levam a soluções que atendem a objetivos fragmentados, em vez de um objetivo de sustentabilidade global.

De modo geral, não há uma preocupação com a consolidação das informações técnicas e científicas necessárias para a fundamentação das decisões, as quais são habitualmente tomadas baseadas em fatores econômicos. Contudo, o critério econômico, isoladamente, não é suficiente para fundamentar um processo decisório sustentável, ainda que seja relevante ao processo. A seleção e/ou priorização de projetos deve ser realizada num processo de tomada de decisão em que a racionalidade econômica se constitua em apenas uma das racionalidades pelas quais se pauta a decisão, e que nem sempre é a mais 
importante. Assim, é imprescindível que as agências de transporte também considerem as questões socioambientais em suas decisões.

Ao avaliar os impactos socioambientais, é comum que os profissionais se deparem com muitas incertezas sobre quais previsões e ações devem ser tomadas. Ações definidas para mitigar o impacto em um determinado aspecto podem ter um efeito contrário em outro. Por exemplo, ações voltadas para proteger ou melhorar o ambiente para uma determinada espécie podem ter um efeito prejudicial à outra. Ou mesmo, ao se evitar afetação de um fragmento florestal preservado pode resultar em deslocamento indesejado de pessoas ou atividades econômicas.

As decisões, normalmente, são tomadas em função de critérios de decisão ou objetivos com grande variedade de metas. As decisões para a implantação de infraestrutura rodoviária em regiões metropolitanas, usualmente marcadas por um dinamismo de ocupação urbana e pelo limite de suporte ambiental, envolvem diferentes sujeitos sociais, normalmente com interesses e objetivos conflitantes. Assim, a decisão por uma determinada alternativa demanda trocas compensadas (trade-off), com o objetivo de alcançar a melhor escolha para todos os agentes envolvidos no processo.

Portanto, deve-se buscar o equilíbrio entre cada uma das influências geradas por um novo empreendimento. É esse equilíbrio (ou trade-off) que representa um grande desafio ao profissional da área de infraestrutura de transporte, particularmente quando confrontados com decisões críticas. Por isso, a abordagem a ser adotada ao longo do processo de planejamento deve se apoiar nos objetivos principais da sustentabilidade.

Sabe-se, porém, que para definir a escolha (tomar a decisão propriamente dita), o setor precisa conhecer a opinião dos demais sujeitos sociais envolvidos no processo. $\mathrm{O}$ processo de implantação de projetos de transporte é marcado pelo envolvimento de múltiplas partes interessadas, onde cada uma delas tem prioridades, preocupações e interesses próprios, resultando em expectativas e percepções diferentes. Logo, adotar uma perspectiva de sustentabilidade desde o início do planejamento, que incentive a consideração de todos os interesses, riscos e oportunidades, reduz as chances de ter que responder às pressões por mudanças em etapas posteriores.

Ainda que muitas agências de transporte reconheçam a importância da sustentabilidade nas políticas de transporte, muitas vezes enfrentam dificuldades para compreender, avaliar e aplicar os conceitos de sustentabilidade em suas atividades rotineiras. As informações no processo de implantação de políticas de transporte são habitualmente complexas, excessivas, difusas e até mesmo divergentes nas organizações, dificultando a compreensão dos objetivos estratégicos de sustentabilidade e sua aplicação concreta pelos profissionais envolvidos e, consequentemente, comprometendo a eficácia dos processos decisórios.

Em virtude da complexidade e quantidade de estudos e informações geradas ao longo das fases de desenvolvimento de empreendimentos de infraestrutura de transporte, os principais tomadores de decisão dificilmente conseguem considerar adequadamente os 
aspectos sociais e ambientais, priorizando, normalmente, as questões técnicas e econômicas.

De acordo com Lim (2009), as perspectivas multidimensionais da sustentabilidade, combinadas com a complexidade nas diferentes etapas da implantação de infraestruturas e com as demandas operacionais e administrativas exigentes aos gestores e tomadores de decisão, fazem com que os objetivos de sustentabilidade sejam muitas vezes negligenciados. Sob tais condições, as políticas e estratégias sobre sustentabilidade permanecem em grande parte ideológicas e não podem ser suficientemente refletidas na efetiva entrega do empreendimento.

As tomadas de decisão para o desenvolvimento sustentável requerem, portanto, novas abordagens que sejam capazes de integrar e sintetizar todas as dimensões e diferentes pontos de vista, de uma maneira holística. Para tanto, métodos de avaliação com uso de indicadores têm se demonstrado relevantes para orientar processos decisórios baseados nos preceitos da sustentabilidade, fornecendo informações sintetizadas que subsidiem suas decisões. Uma maneira de aplicação de indicadores de sustentabilidade é utilizando uma estrutura conceitual para orientar tomadas de decisão, na qual os indicadores são selecionados de acordo com os objetivos estratégicos.

Nota-se na literatura um progresso considerável na pesquisa e um número crescente de organizações em todo o mundo que estão desenvolvendo e utilizando sistemas de indicadores para avaliar o seu desempenho em direção à sustentabilidade. Essa prática tem sido bastante utilizada internacionalmente para avaliação da sustentabilidade no planejamento de transportes, especialmente nos países mais desenvolvidos. Contudo, essas ferramentas internacionais de avaliação da sustentabilidade nem sempre podem representar de forma adequada o contexto brasileiro, uma vez que os aspectos ambientais, políticos, jurídicos, sociais e econômicos diferem entre si.

Em que pese a importância do uso de indicadores, a seleção e a aplicação ainda é uma questão a ser discutida no Brasil, tanto para uso na elaboração de estudos técnicos como para debate com o público geral. Enquanto diversos sistemas de avaliação de sustentabilidade com uso de indicadores estão ganhando impulso em vários países, não há nenhum sistema atual que considere as condições específicas do Brasil, que contenha informações relevantes de sustentabilidade e indicadores padronizados para aplicação no planejamento de infraestrutura de transporte.

Com o objetivo de preencher essa lacuna, esta pesquisa focou no desenvolvimento de uma estrutura de avaliação conceitual composta por objetivos, metas, indicadores e medidas de desempenho, que sirva como ferramenta para apoiar tomadas de decisão com abordagens mais sistemáticas na fase de planejamento, e que estejam baseadas nos princípios da sustentabilidade urbana.

Essa estrutura conceitual é particularmente útil às agências de planejamento de infraestrutura de transporte, em especial as rodoviárias. Para sua elaboração, foram 
definidas as seguintes questões de pesquisa que orientaram o desenvolvimento deste trabalho:

(i) Quais são as questões relevantes para a sustentabilidade urbana na implantação de rodovias em regiões metropolitanas? A natureza complexa do desenvolvimento das infraestruturas rodoviárias dificulta o alcance dos objetivos da sustentabilidade urbana. Logo, compreender como a implantação de rodovia em região metropolitana pode afetar os princípios da sustentabilidade urbana é primordial para se definir as medidas para o enfrentamento dos fatores que comprometem a concretização desses objetivos.

(ii) Quais são os critérios e indicadores que podem ser utilizados para avaliar os resultados da sustentabilidade urbana no planejamento de infraestrutura rodoviária? Para se obter melhores resultados de sustentabilidade urbana em empreendimentos rodoviários, é importante utilizar ferramentas operacionais que forneçam dados e informações sobre as questões relevantes. Portanto, a identificação de critérios e indicadores de sustentabilidade aplicáveis ao planejamento de empreendimentos rodoviários fornecerá a base para melhorar os processos decisórios e de gestão destinados a alcançar resultados mais satisfatórios para a sustentabilidade urbana.

\section{Objetivos}

O objetivo principal deste trabalho é desenvolver uma estrutura conceitual de avaliação de sustentabilidade composta por objetivos, metas, indicadores e medidas de desempenho, que promova abordagens mais sistemáticas e integradas para tomadas de decisões no planejamento de infraestrutura de transporte, com ênfase em rodovias localizadas em regiões metropolitanas, baseada nos princípios da sustentabilidade urbana.

Para alcançar o objetivo geral, foram definidos os seguintes objetivos específicos:

(i) Revisar os princípios fundamentais da sustentabilidade urbana, as diretrizes para um transporte sustentável e as ferramentas de avaliação de sustentabilidade aplicáveis à infraestrutura de transporte;

(ii) Analisar as interfaces urbano-rodoviárias frente à implantação de uma rodovia perimetral em região metropolitana brasileira;

(iii) Definir os indicadores de sustentabilidade que representem as questões relevantes nas interfaces urbano-rodoviárias. 


\section{Premissa}

A aplicação dos princípios de sustentabilidade pelas agências de transporte é muitas vezes limitada pela compreensão do próprio conceito da sustentabilidade por seus colaboradores e pela falta de um método claro de como ele pode ser integrado em suas funções regulares. Do ponto de vista das agências de transporte, existe a necessidade de desenvolver uma abordagem prática para avaliação e aprimoramento da sustentabilidade. Nessa perspectiva, a operacionalização da sustentabilidade com o uso de indicadores tem se demonstrado relevante, pois permite a medição objetiva e consistente do progresso em direção às metas de sustentabilidade.

Nesse sentido, este trabalho tem como premissa que o desenvolvimento de uma estrutura de avaliação conceitual, organizada de forma flexível para sua operacionalização, pode ajudar as agências de transporte a definirem e avaliarem suas próprias metas considerando os princípios de sustentabilidade. A estrutura proposta pode servir de base para a definição de critérios e indicadores de sustentabilidade que permitam orientar tomadas de decisão mais adequadas no planejamento de rodovias frente às problemáticas urbanas.

Ao se compreender os princípios de sustentabilidade e as motivações das várias partes interessadas, as agências podem utilizar a estrutura para operacionalizar a sustentabilidade em seus planejamentos, considerando os aspectos estratégicos. Quanto mais objetividade houver em relação ao entendimento dos atributos envolvidos, mais objetivas poderão ser as discussões com a população, e mais fáceis serão os processos de planejamento e gestão. A transparência e a responsabilidade na tomada de decisões sobre transporte são fundamentais para a construção de credibilidade com as partes interessadas e o público em geral, e o uso de indicadores pelas agências fornece essas condições.

Embora concebida às agências de transporte, a estrutura de indicadores também pode ser útil a outros órgãos ambientais, regionais, metropolitanos e urbanísticos, à medida que aborda questões de impactos ao meio ambiente, na comunidade local, de desenvolvimento urbano e uso do solo.

\section{Organização da dissertação}

Esta dissertação é iniciada por esta parte introdutória, onde são apresentados a contextualização da pesquisa, a problematização que motivou o seu desenvolvimento, os principais objetivos e as premissas que balizaram o desenvolvimento da pesquisa. Para além desta introdução, o trabalho foi organizado em cinco capítulos.

No Capítulo 1 está detalhada a abordagem metodológica, com os métodos utilizados para a elaboração da pesquisa, até alcançar o seu objetivo principal. 
O Capítulo 2 consiste no aporte teórico da pesquisa, abordando os conceitos e os princípios abordados na sustentabilidade urbana e no transporte sustentável, discutindo brevemente as questões emergentes, desafios e políticas de enfrentamento de problemas metropolitanos, particularmente relacionados ao planejamento de transporte. Além disso, apresenta brevemente as principais ferramentas para avaliação de sustentabilidade de infraestrutura de transporte, com ênfase àquelas aplicadas em infraestruturas rodoviárias. Para cada ferramenta, são discutidas as principais aplicações e as suas limitações, com as vantagens e desvantagens de uso.

O Capítulo 3 apresenta o processo de condução do planejamento da rodovia Rodoanel Mário Covas, uma rodovia perimetral localizada na RMSP, enfatizando as bases conceituais e metodológicas das ferramentas que foram adotadas durante a fase de planejamento da infraestrutura. Com essas informações, foi possível entender o processo de desenvolvimento de infraestrutura rodoviária, as principais questões urbanas e ambientais que se relacionam com o modo rodoviário e os impactos avaliados.

Na tentativa de sintetizar as práticas de avaliação de sustentabilidade, o Capítulo 4 apresenta o resultado do processo de desenvolvimento de uma estrutura de avaliação para auxiliar tomadas de decisão, contemplando objetivos, metas e indicadores. Complementarmente, são fornecidas algumas orientações gerais para sua aplicação.

Por fim, o Capítulo 5 apresenta as considerações finais da pesquisa e recomendações para trabalhos futuros.

A Figura 1 sintetiza a estrutura e organização desta dissertação.

Figura 1 - Diagrama da estrutura da pesquisa.

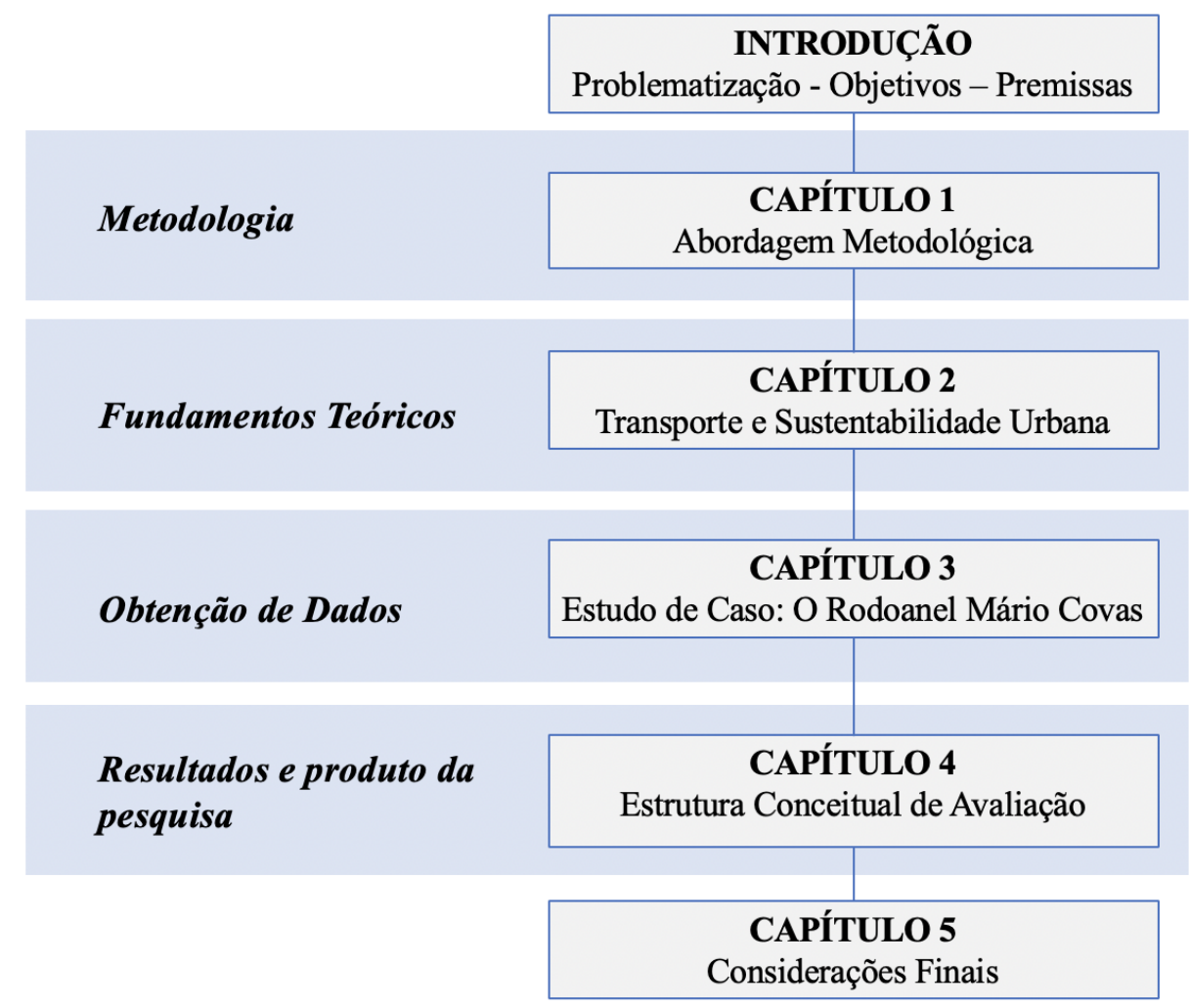




\section{CAPÍTULO 1 - ABORDAGEM METODOLÓGICA}

Para responder aos problemas da pesquisa e alcançar os objetivos estabelecidos, o estudo adotou uma abordagem qualitativa, de caráter exploratório e descritivo, segundo seus objetivos (GIL, 2002), utilizando-se dados secundários. Para tanto, foram adotados os procedimentos técnicos combinados de pesquisa bibliográfica e estudo de caso. Saunders et al. (2000) argumentam que as abordagens e estratégias de investigação não existem isoladamente e, por conseguinte, podem ser misturadas e combinadas, o que frequentemente é benéfico para a pesquisa.

As fontes de dados e informações foram provenientes de estudos e artigos científicos, de documentos publicados em Website de agências de transporte internacionais e de documentos técnicos disponíveis na agência de transporte responsável pelo caso estudado.

De modo geral, o processo metodológico desta pesquisa consistiu nas seguintes etapas de trabalho: (a) a revisão da literatura, (b) estudo de caso e (c) desenvolvimento de uma estrutura conceitual de avaliação de sustentabilidade.

Inicialmente, foi realizada a revisão bibliográfica com o propósito de identificar os princípios e questões relevantes para a sustentabilidade urbana e para o setor de transportes. Além disso, foram analisadas as ferramentas de avaliação aplicáveis ao planejamento de infraestrutura de transporte, com ênfase em empreendimentos rodoviários. Essa etapa estabeleceu uma base teórica para a pesquisa, fundamentando a proposição de indicadores aplicáveis ao planejamento de transporte.

Uma vez estabelecida a base teórica da pesquisa, analisou-se as interfaces urbanorodoviárias com vistas a compreender os fatores que podem afetar os princípios da sustentabilidade urbana decorrentes da implantação de rodovias e os métodos de avaliação. Para tanto, foi adotado o procedimento metodológico de estudo de caso, cujos resultados consistiram na identificação dos métodos de avaliação e mensuração dos efeitos e impactos considerados mais relevantes para cada fase de planejamento, resultante das práticas de avaliação de sustentabilidade adotadas. O caso analisado foi o Rodoanel Mário Covas, que consiste em uma rodovia perimetral localizada na RMSP, reconhecidamente, com alta complexidade de mobilidade e uso e ocupação do solo.

O levantamento de dados secundários na bibliografia e no estudo de caso permitiu constituir uma matriz genérica de indicadores e medidas de desempenho com potencial de aplicação em empreendimentos de transporte, com ênfase em infraestrutura rodoviária. Essa matriz genérica foi refinada, mantendo-se apenas aqueles ligados aos objetivos e às metas estabelecidos. Por fim, os indicadores selecionados foram organizados em fichas de avaliação, contendo informações orientativas para sua aplicação, baseadas em fatores estratégicos para a tomada de decisões.

O modelo conceitual do projeto de pesquisa é apresentado na Figura 2. 


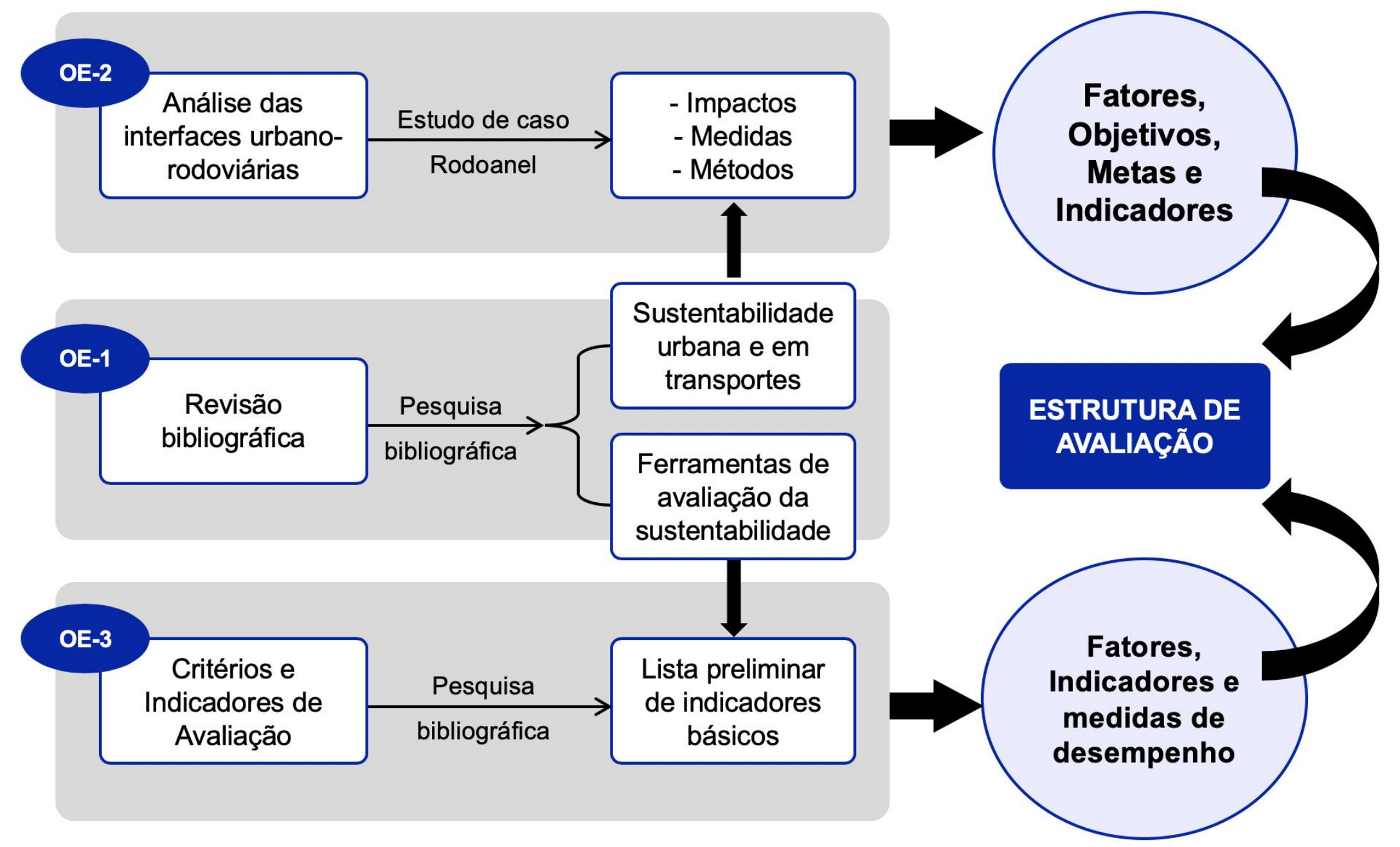

Legenda: OE - Objetivo Específico. 
As etapas metodológicas estão detalhadas nos itens subsequentes.

\subsection{REVISÃO DA LITERATURA}

O principal objetivo da revisão da literatura nesta pesquisa foi compreender os princípios da sustentabilidade urbana, captar as diretrizes que busquem a sustentabilidade no setor de transporte e conhecer as aplicações e limitações das ferramentas de avaliação de sustentabilidade aplicáveis no planejamento de infraestrutura de transporte, a fim de estabelecer uma base teórica para orientar este trabalho nas fases subsequentes.

A revisão bibliográfica teve como principais fontes de dados e informações livros, periódicos e artigos científicos publicados em revistas nacionais e internacionais, teses e dissertações disponibilizados em bibliotecas e em sistemas de bases de dados eletrônicos. As pesquisas se concentraram nas seguintes bases eletrônicas: Portal da CAPES, Dedalus, Revistas Eletrônicas, Web of Science, SciELO, Elsevier e Scopus, utilizando-se os descritores chaves listados a seguir: "Avaliação da Sustentabilidade"; "Indicadores de Sustentabilidade"; "Sustentabilidade Urbana"; "Transporte Sustentável"; "Rodovias". A partir dos descritores chaves, outros descritores secundários foram utilizados para complementar temas específicos, sempre que julgado necessário.

Outro grupo importante de fonte de dados foram os websites das agências de transporte selecionadas, especialmente as agências estaduais dos EUA, para identificar questões, possíveis abordagens e melhores práticas aplicáveis ao desenvolvimento de uma estrutura de sustentabilidade.

A partir de um levantamento bibliográfico preliminar, foi possível delimitar o escopo do trabalho, formulando-se o problema de pesquisa. Essa etapa da pesquisa tentou responder minimamente as seguintes perguntas: Quais são os princípios de sustentabilidade urbana? O que caracteriza um transporte sustentável? Quais são as ferramentas de avaliação utilizadas no planejamento de infraestrutura de transporte que contribuem para a sustentabilidade?

O levantamento bibliográfico partiu de uma leitura exploratória, seguindo a classificação de Gil (2002), visando selecionar os estudos que estavam alinhados ao objetivo da pesquisa, analisando-se títulos, sumários, resumos e introduções. Com esses elementos, foi possível ter uma visão global dos documentos e temas abordados. Esses documentos foram organizados por temas em pastas no computador, quando eletrônicos. Os documentos selecionados foram sendo consultados ao longo do desenvolvimento do trabalho, conforme os subitens da pesquisa foram sendo discorridos. Sempre que considerados insuficientes, novas pesquisas eram realizadas.

A revisão bibliográfica foi orientada em três grandes temas: (i) sustentabilidade urbana e cidades sustentáveis, (ii) transporte sustentáveis e (iii) ferramentas de avaliação de sustentabilidade aplicadas a infraestruturas de transportes. 
Como resultado desta etapa, foram discutidos os principais fundamentos da sustentabilidade urbana. A partir da compreensão geral sobre "transporte sustentáveis", foram discutidas as questões emergentes no planejamento de transporte para a sustentabilidade urbana, consistindo nos fatores encontrados com maior frequência na literatura. Para auxiliar no desenvolvimento de uma estrutura de avaliação, foram apresentadas as "ferramentas de avaliação de sustentabilidade" utilizadas em planejamento de sistemas de transporte, consideradas por pesquisadores como de maior importância para operacionalização dos princípios da sustentabilidade.

A revisão bibliográfica contribuiu para identificar as ferramentas adotadas e com potencial de serem melhor exploradas nas práticas brasileiras, para identificar os principais pesquisadores e instituições que estudam o tema, para coletar informações e ideias relevantes para a pesquisa, para consolidar os indicadores e as medidas de desempenho que pudessem ser utilizados, entre outros.

Em suma, a revisão bibliográfica forneceu a base teórica necessária a todas as etapas da pesquisa. Mais do que isso, contribuiu para atender um dos objetivos específicos desta pesquisa, que é foi o de uniformizar os conceitos relacionados à aplicação da sustentabilidade no setor de transporte, com foco nas questões urbanas.

\subsection{ESTUDO DE CASO}

Estudo de caso é uma metodologia de pesquisa que explora casos reais usando uma variedade de métodos de coleta de dados durante um determinado período de tempo. Yin (1989) define o método de estudo de caso como uma investigação empírica que investiga um fenômeno contemporâneo dentro de seu contexto de vida real, quando as fronteiras entre fenômeno e o contexto não são claramente evidentes, e em que múltiplas fontes de dados são utilizadas. Conforme GIL (1996), “o estudo de caso é caracterizado pelo estudo profundo de um ou de poucos objetos, de maneira que permita o seu amplo e detalhado conhecimento [...]".

Neste trabalho, o estudo de caso foi realizado utilizando o procedimento técnico de pesquisa documental, método que melhor se identificou com o objeto desta pesquisa. De acordo com Vergara (1991), a pesquisa documental é definida como aquela realizada em documentos no interior de órgãos públicos. Segundo Gil (2002), a pesquisa documental se assemelha muito à pesquisa bibliográfica, tendo como diferença essencial a natureza das fontes. Enquanto a pesquisa bibliográfica se utiliza fundamentalmente das contribuições dos diversos autores sobre determinado assunto, a pesquisa documental vale-se de materiais que não receberam um tratamento analítico, ou que ainda podem ser reelaborados de acordo com os objetos da pesquisa. Vale ressaltar que o método de pesquisa documental neste estudo de caso foi reforçado pelo acompanhamento direto do 
autor na gestão da implantação do empreendimento e dos seus programas socioambientais.

Esse processo metodológico possibilitou o conhecimento e seleção de documentos e informações produzidos pela agência de transporte responsável pelo planejamento do empreendimento analisado. Buscando-se compreender melhor o objeto da pesquisa, foram analisados documentos elaborados pelo empreendedor e/ou empresas por ele contratadas, entre outros.

Os objetivos do estudo de caso foram levantar as práticas e os métodos utilizados com a perspectiva da sustentabilidade, identificar as questões urbanas relevantes avaliadas no planejamento da rodovia e conhecer as medidas e os programas adotados para o enfrentamento dos impactos identificados. Yin (2003) observa que a tendência central de todos os tipos de um estudo de caso é iluminar decisões considerando o porquê elas foram tomadas, como foram implementadas e com quais resultados.

\subsubsection{Seleção do Caso}

Yin (2003) sugere que a seleção do caso a ser estudado precisa se relacionar com o problema e questão de pesquisa e identificar os atributos que são mais susceptíveis de produzir dados relevantes. Portanto, é importante a determinação dos critérios rigorosos para garantir um grau de adequação na seleção de um de estudo de caso. Nesse sentido, os critérios abaixo foram usados para selecionar o estudo de caso:

1. Ser um empreendimento rodoviário com significativa influência em alguma região metropolitana brasileira;

2. Ser uma rodovia concluída em um prazo inferior a 15 anos ou estar em construção;

3. Garantia no fornecimento de dados confiáveis e com facilidade de acesso às informações pelo autor desta pesquisa.

O caso que atendeu aos critérios estabelecidos e que, portanto, foi objeto de estudo foi o processo de planejamento do empreendimento Rodoanel Mário Covas, localizado na RMSP. Trata-se de um empreendimento de alta complexidade de implantação, que contém todos os elementos construtivos (pontes, viadutos, túneis, cortes, aterros, etc.), contorna a maior região metropolitana do País e possui uma interface bastante representativa com áreas urbanas e áreas ambientalmente protegidas. Além disso, destaca-se que a RMSP é a maior e mais povoada região metropolitana do Brasil e uma das maiores do mundo, e concentra os impactos socioambientais e urbanos típicos de grandes centros urbanos, tornam a experiência uma grande fonte de informações. 
Por fim, mas não menos importante, há que se ressaltar que o empreendimento obteve recursos do Banco Interamericano de Desenvolvimento (BID), uma agência financiadora bastante exigente com relação aos aspectos socioambientais, forçando robusto processo de avaliação e gestão socioambiental.

\subsubsection{Características Gerais do Estudo de Caso}

O Rodoanel Mário Covas é uma rodovia perimetral, que possui, no total, cerca de $180 \mathrm{~km}$ de extensão, duas pistas separadas por canteiro central, com três a quatro faixas de rolamento por sentido de tráfego, velocidade diretriz de $100 \mathrm{~km} /$ hora e intersecções com as grandes rodovias e cruzamentos com viário local exclusivamente em desnível.

O Rodoanel se localiza no anel peri-urbano da RMSP, composta por 39 municípios, que juntos possuem a maior concentração urbana do país e uma das maiores do mundo, totalizando cerca de 21,4 milhões de habitantes (IBGE, 2017).

São objetivos principais do Rodoanel (DERSA/FESPSP, 2004a):

- ordenar o tráfego de transposição da RMSP, separando-os dos fluxos internos e aliviando o sobrecarregado sistema viário metropolitano;

- hierarquizar e estruturar o transporte de passageiros e cargas na RMSP, servindo de alternativa para os fluxos de longa distância entre as sub-regiões da metrópole;

- articulado com o Ferroanel e com Centros Logísticos Integrados (CLI), permitir a integração intermodal do transporte de cargas.

Além dos objetivos setoriais de transportes supracitados, agregam-se os seguintes objetivos voltados à proteção e recuperação urbano-ambiental (DERSA/FESPSP, 2004a):

- contribuir para a melhoria da qualidade ambiental das áreas do anel periurbano em sua área de influência direta;

- contribuir para assegurar eficácia às políticas e ações destinadas à proteção e recuperação de mananciais de abastecimento de água da RMSP;

- contribuir para ampliação das áreas naturais, para a proteção e melhoria da gestão de áreas protegidas na RMSP;

- contribuir para a integração das ações públicas em curso em sua área de influência direta, buscando sinergias que otimizem os investimentos públicos e a proteção dos recursos naturais.

Do ponto de vista do setor de transportes, o Rodoanel é um empreendimento que visa facilitar e reduzir o custo da transposição da RMSP para os fluxos de transporte, podendo trazer, dentre seus benefícios, a melhoria na eficiência econômica e competitividade das cadeias produtivas e a redução das deseconomias e impactos impostos pela passagem das cargas pela área central da região metropolitana, como, por 
exemplo, a redução dos tempos de percurso, dos custos de operação dos veículos e de manutenção das vias urbanas.

Além disso, ao reduzir a quantidade de veículos que atravessam a capital e minimizar o tráfego de passagem, essa rodovia favorece a fluidez no trânsito em toda a RMSP, melhorando a mobilidade, com reflexos positivos nos transportes coletivo e individual e nas condições de segurança do trânsito e do meio ambiente urbano, reduzindo acidentes e emissão de gases poluentes. Por diminuir o congestionamento, pode contribuir para as questões climáticas ao reduzir a emissão de gases causadores do efeito estufa.

Para fins de gestão em sua implantação, o Rodoanel foi dividido em quatro (4) trechos - Oeste, Sul, Leste e Norte -, conforme visualizados na Figura 3.

Figura 3 - Rodoanel Mário Covas - Localização por Trechos.

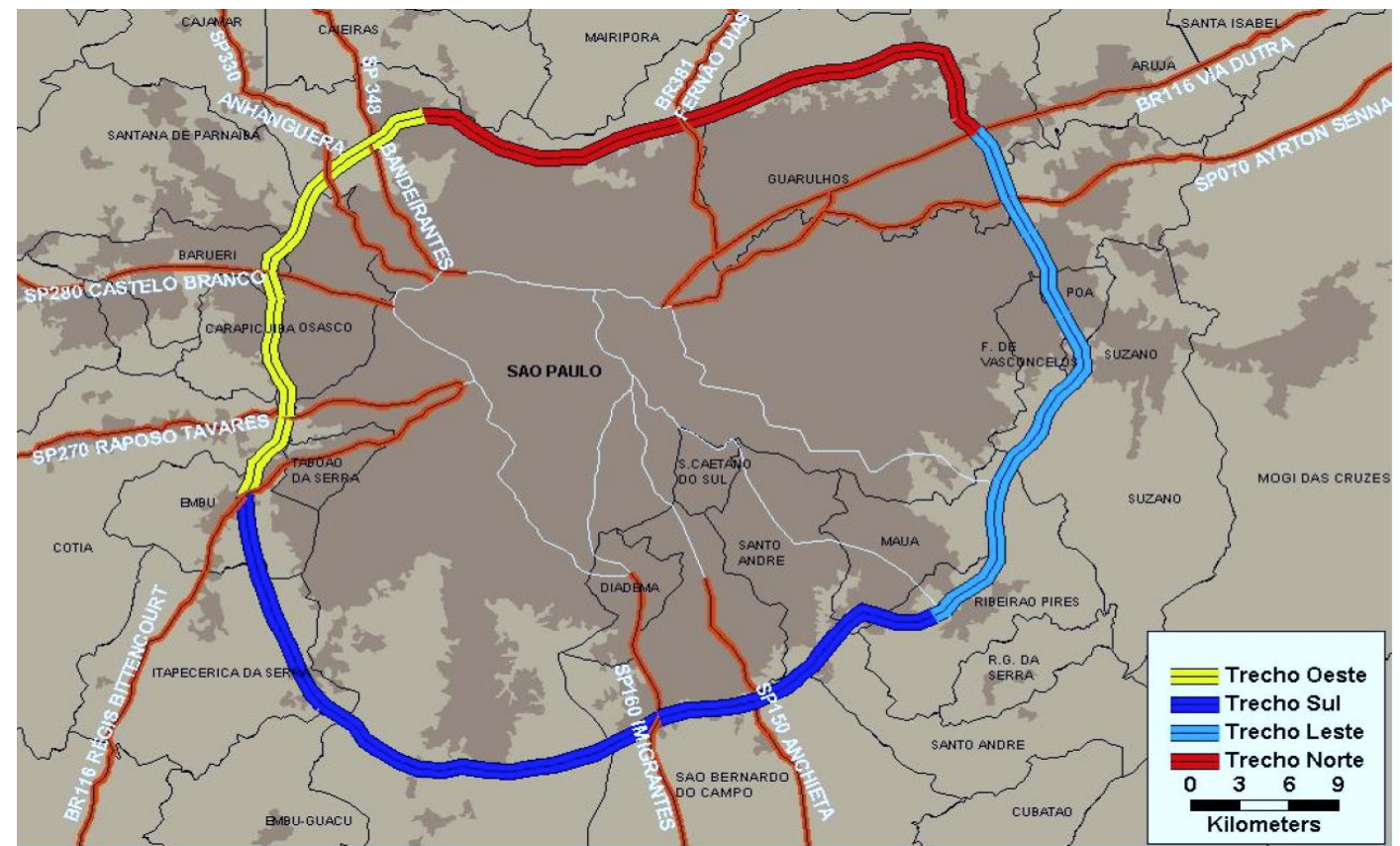

Fonte: SÃO PAULO (2000).

A complexidade da obra exigiu que cada um desses trechos fosse dividido por lotes, sendo cada um deles sob a responsabilidade de uma construtora ou consórcio construtor, revelando-se fundamental para a agilidade da construção e para superação das dificuldades técnicas, típicas de um empreendimento rodoviário do porte e grau de intervenção como o Rodoanel.

\subsubsection{Obtenção e Análise dos Dados}

A obtenção de dados e informações provenientes do estudo de caso contou com a análise de documentos que contribuíram com resultados para a sustentabilidade urbana.

As questões que orientaram a busca de dados e informações foram: 
(i) Quais foram os estudos realizados na fase de planejamento que contribuem para alcançar resultados mais sustentáveis para o meio urbano?

(ii) Quais foram os procedimentos metodológicos adotados para realização desses estudos, considerando o nível de detalhamento exigido em cada etapa do processo de planejamento?

(iii) Quais foram os principais efeitos e impactos socioambientais avaliados em cada estudo elaborado, considerados relevantes para tomada de decisão em cada etapa do processo?

(iv) Quais medidas foram estudadas ou adotadas para o enfrentamento dos efeitos e impactos identificados?

Como resposta ao item (i), os documentos selecionados e utilizados para extrair as informações relevantes para o objetivo deste trabalho foram: Plano Diretor de Desenvolvimento de Transporte (PDDT), Avaliação Ambiental Estratégica (AAE), Estudos de Impacto Ambiental (EIA's), Plano Básico Ambiental (PBA's), relatórios de monitoramento e práticas de avaliação de sustentabilidade (Envision). Esses documentos foram selecionados por serem considerados pela literatura como importantes ferramentas de avaliação de sustentabilidade na fase de planejamento.

As questões (ii) e (iii) contribuíram para fornecer os métodos de avaliação e identificar os impactos mais significativos provocados no contexto metropolitano por uma nova rodovia e, sobretudo, as respectivas ações e os processos realizados para abordar as questões relevantes em um empreendimento real. Tais resultados foram importantes para fornecer as diretrizes para a construção de uma estrutura conceitual, fornecendo indicadores e medidas de desempenho, haja vista que se trata de um empreendimento complexo e com estudos extensivos e abrangentes.

Os dados e as informações coletados foram, sempre que possível, codificados, categorizados e organizados em quadros, a fim de assegurar a coerência das informações e permitir que os resultados fossem corretamente analisados.

Vale ressaltar que não foram realizadas a avaliação quali-quantitativa e a mensuração dos indicadores de sustentabilidade propostos neste trabalho ao caso analisado, dado ao caráter exploratório da pesquisa e ao foco de análise centrado nos aspectos conceituais e metodológicos, e não na avaliação dos resultados da sustentabilidade do empreendimento. Em outras palavras, não foi objetivo desta dissertação a aplicação da estrutura conceitual no estudo de caso, mas sim o de identificar quais foram os estudos e abordagens metodológicas de avaliação adotados, para fundamentar a estrutura proposta e embasar o desenvolvimento de estudos futuros.

Ademais, os aspectos metodológicos descritos no caso analisado poderão contribuir para a aplicação da estrutura, uma vez que serve como exemplo para quantificação de indicadores e medidas de desempenho. 


\subsection{PROCESSO DE DESENVOLVIMENTO DA ESTRUTURA}

Com os dados disponíveis, foi dado sequência ao desenvolvimento da estrutura de avaliação. Conforme discutido na seção introdutória, este projeto procura criar uma estrutura a ser implementada como uma ferramenta de avaliação da sustentabilidade por agências de transporte. Com base nos princípios da revisão de literatura, pode-se argumentar que o amplo conceito da sustentabilidade dificulta a implementação e operacionalização de avaliações da sustentabilidade no transporte. Portanto, é interessante desenvolver uma estrutura para avaliação da sustentabilidade que possa ser usada por agências responsáveis pelo planejamento de infraestrutura de transporte.

Este item discute o processo de desenvolvimento da estrutura conceitual para avaliação de sustentabilidade aplicáveis à infraestrutura rodoviária, incluindo a seleção de indicadores de sustentabilidade alinhada às metas de planejamento. Segundo Jeon e Amekudzi (2005), diversos autores desenvolveram estruturas ou tipologias para a seleção e uso de medidas de desempenho, incluindo: estruturas denominadas Pressão-EstadoImpacto-Resposta (PEIR), estruturas baseadas em impacto, estruturas orientadas em influências e estruturas baseadas em metas, estratégias e ações.

Uma das abordagens comumente aplicada para a tomada de decisões no contexto do transporte é a estrutura baseada em objetivos e metas predeterminados, a partir de critérios de avaliação definidos. Assim, no caso deste trabalho, a estrutura de avaliação de sustentabilidade foi composta por indicadores e medidas de desempenho alinhados aos objetivos e metas de planos, programas e projetos de agências de transporte.

Para a sua construção, estabeleceu como escopo do projeto os seguintes critérios:

- A estrutura deve contribuir para análise no nível de planejamento de rodovias;

- A análise deve ser aplicada à novas infraestruturas rodoviárias, embora estradas em operação também possam ser eventualmente consideradas em alguns fatores;

- A estrutura de análise não deve ser uma ferramenta de tomada de decisão, mas sim uma "ferramenta de avaliação de fatores de sustentabilidade", que forneça a base para o desenvolvimento de ferramentas específicas para auxiliar processos decisórios e participativos;

- A estrutura foca em questões sociais e ambientais ligados ao contexto urbanometropolitano, não considerando o processo orçamentário e questões econômicas do projeto.

O processo de desenvolvimento da estrutura conceitual de avaliação de desempenho de sustentabilidade na interface urbana-rodoviário foi composto basicamente por quatro etapas (ver diagrama simplificado na Figura 4):

- Etapa 1: Determinação dos Fatores de Avaliação;

- Etapa 2: Elaboração de Objetivos de Transporte Sustentável; 
- Etapa 3: Estabelecimento de Metas Conceituais; e

- Etapa 4: Seleção de indicadores-chave.

Ressalta-se que essas etapas não foram desenvolvidas necessariamente em ordem cronológica. Por vezes, algumas delas foram elaboradas concomitantemente.

Figura 4 - Etapas do processo de elaboração da estrutura conceitual.

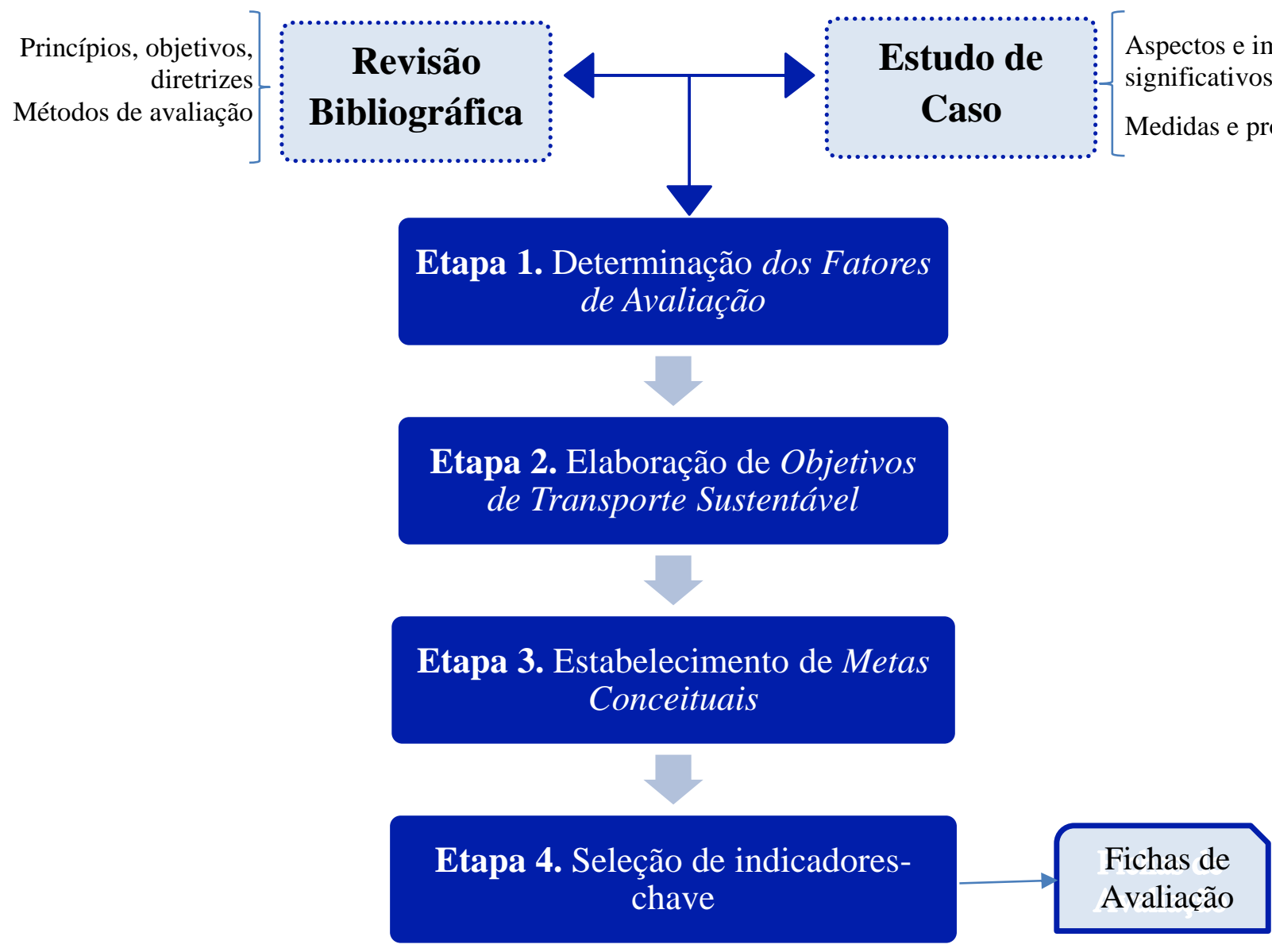

\subsubsection{Etapa 1. Determinação dos Fatores de Avaliação}

Para a determinação dos Fatores de Avaliação, adotou-se como um ponto de partida a compreensão das políticas que sustentam os princípios da sustentabilidade urbana e de transporte, bem como das ferramentas de avaliação de sustentabilidade aplicadas no setor de transporte e os componentes abordados no estudo de caso.

A partir do levantamento de princípios, diretrizes e objetivos das políticas nacionais, os quais expressam as linhas de ação a serem seguidas, bem como os fatores abordados nas ferramentas de avaliação e avaliados no estudo de caso, foi possível conhecer os elementos básicos considerados no planejamento infraestrutura de transporte e nas questões urbanas (ver Figura 5). 


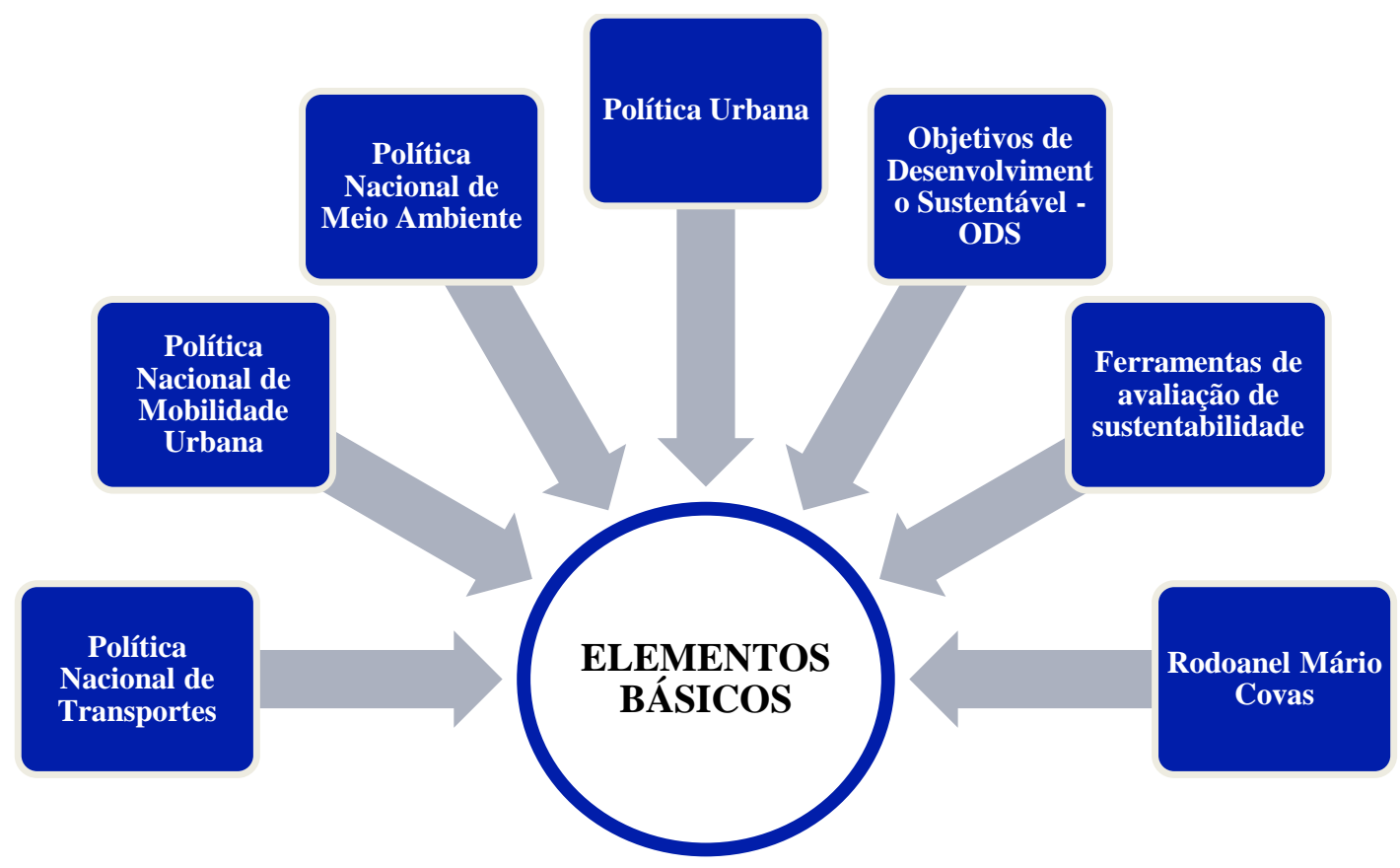

Os elementos básicos de sustentabilidade, aplicáveis à infraestrutura rodoviária em escala local e metropolitana, com abordagem recorrente na fase de planejamento de ferramentas de avaliação e do estudo de caso, foram estabelecidos como fatores de avaliação, desde que suportados pelas políticas nacionais e pelos ODS da Agenda 2030. Dentre as políticas nacionais consideradas, os fatores deveriam atender, minimamente, os princípios da Política Nacional de Mobilidade Urbana (PNMU) e da Política Nacional de Transporte (PNT), observando os seus objetivos e diretrizes.

Os fatores de avaliação foram então selecionados baseado na inserção sóciourbano-ambiental de empreendimento rodoviários, como ponto central da estrutura de avaliação, representando questões estratégicas de planejamento.

\subsubsection{Etapa 2. Elaboração de Objetivos de Transporte Sustentável (OTS)}

Para cada fator de avaliação, foi estabelecido um objetivo específico, denominado neste trabalho como Objetivos de Transporte Sustentável (OTS). A elaboração dos objetivos se baseou na fundamentação teórica, nos objetivos e diretrizes de políticas, nas ferramentas de avaliação e no estudo de caso. Esses objetivos expressam, de modo geral, onde se pretende chegar ou a direção desejada, refletindo as situações a serem alteradas pela implementação de metas, estratégias e ações gerenciais. Esses objetivos foram direcionados para os fins e não para os meios.

Esses objetivos deram suporte à definição dos indicadores, uma vez que permitiram fazer o link entre o Fator de Avaliação e as Metas Conceituais. 


\subsubsection{Etapa 3. Estabelecimento das Metas Conceituais}

Tendo em vista que os Objetivos de Transporte Sustentável (OTS) estabelecidos são muito genéricos para operacionalização no planejamento de transporte com uso de indicadores, os mesmos foram desmembrados em Metas Conceituais, sem valores de referências, como forma de instituir os "caminhos" para alcançar os OTS. MARSDEN et al. (2011) explica que a definição de metas é uma parte crucial do processo, pois permite que as agências de transporte deliberem sobre como as metas da organização se relacionam com a sustentabilidade.

Enquanto os OTS são desenvolvidos numa abrangência mais amplas, as Metas Conceituais são usadas para definir como os objetivos podem ser alcançados a partir do planejamento de infraestrutura de transporte. As metas são, portanto, mais específicas e mensuráveis, e estabelecem as bases para ligar os indicadores aos objetivos.

A elaboração das metas foi motivada principalmente pelo reconhecimento dos impactos gerados por um empreendimento rodoviário, em particular aqueles identificados no estudo de caso.

\subsubsection{Etapa 4. Seleção dos indicadores-chave e medidas de desempenho}

O processo de seleção dos indicadores partiu da elaboração de uma lista preliminar e abrangente de indicadores e medidas de desempenho, obtidos a partir de pesquisa bibliográfica, que estão sendo aplicados por agências de transporte no contexto da sustentabilidade. Como o número de indicadores e medidas de desempenho foram elevados, oriundos de diferentes instituições, sendo que muitos deles se repetiam, a listagem foi organizada em planilhas eletrônicas do software Microsoft Office Excel®.

As publicações que mais contribuíram para a consolidação da lista preliminar foram aquelas realizadas pelas agências de transporte internacionais, em especial a Federal Highway Administration (FHWA), a American Association of State Highway and Transportation Officials (AASHTO) e as estaduais norte-americanas, as quais vêm utilizando sistemas de avaliação de sustentabilidade. Dentre os trabalhos acadêmicos e técnicos consultados, os autores que mais se destacaram foram: Amekudzi, Jeon, Litman, Gudmundsson, Ramani, Marsden e Zietsman, os quais vêm se dedicando no fornecimento e compilação de listas abrangentes de medidas de desempenho de transporte sustentáveis.

Com relação ao caso analisado (Rodoanel Mário Covas), compilou-se os métodos de avaliação de cada impacto/efeito sócio-urbano-ambientais contemplados nos estudos que contribuíram para avaliação da sustentabilidade na fase de planejamento do empreendimento, a saber: Plano Diretor de Desenvolvimento de Transporte (PDDT), Avaliação Ambiental Estratégica (AAE), Estudos de Impacto Ambiental (EIA), 
Monitoramento da Mancha Urbana, Estudo de Análise de Riscos Ambientais (EAR) e sistema Envision.

Especificamente com relação aos Estudos de Impacto Ambiental (EIA's), tendo em vista a extensa lista de impactos identificados nos estudos, sendo muito deles com baixa significância, adotou-se como critério o princípio da intergeracionalidade, visando selecionar apenas os impactos mais significativos. Dessa forma, foram analisados apenas os impactos que apresentaram um dos seguintes atributos:

a. Intensidade: alta;

b. Reversibilidade: irreversível;

c. Tempo de permanência: longo ou permanente.

A análise desses impactos está apresentada no Apêndice A.

Indicadores que refletiam os impactos relacionados à execução de obras, tais como os impactos temporários, com baixa significância e aqueles relacionados aos insumos e tecnologia para construção e operação, bem como referente à viabilidade econômica do empreendimento, que não representassem externalidades, foram desconsiderados neste trabalho.

Nesse sentido, não se propôs neste estudo criar um conjunto de indicadores de sustentabilidade dissociados dos que já vêm sendo utilizados nas principais agências de transporte. Assim, os indicadores selecionados consistiram de estruturas constituídas, e outros aplicados no caso estudado, para os quais o seu uso já foi considerado viável tecnicamente pelas agências responsáveis, com aplicabilidade em agências de planejamento de transporte comprovada. Portanto, podem ser considerados factíveis, tendo em vista sua aplicação comprovada por agências de transporte e/ou recomendada pela literatura.

Os indicadores mapeados foram organizados por Fatores de Avaliação, sendo utilizados na estrutura apenas aqueles que se ligaram às Metas Conceituais preestabelecidas. De acordo com Malheiros, Philippi Jr. e Coutinho (2008), o papel dos indicadores como ferramenta é o estabelecimento de uma visão de conjunto que exige um processo de avaliação de resultados em relação às metas de sustentabilidade estabelecidas.

Por fim, para cada indicador mensurável, ligado a uma meta específica, foi elaborada uma ficha de avaliação, contendo diversas informações para orientar sua aplicação de forma flexível, conforme modelo apresentado na Figura 6. As fichas fornecem informações para mensuração dos indicadores de forma prática, que resultem em resultados que sejam úteis para tomadas de decisão ou comunicação com as partes interessadas.

As fichas de avaliação consistiram no produto final desta pesquisa, e estão apresentadas no Apêndice D. 
Figura 6 - Modelo de ficha de avaliação utilizada.

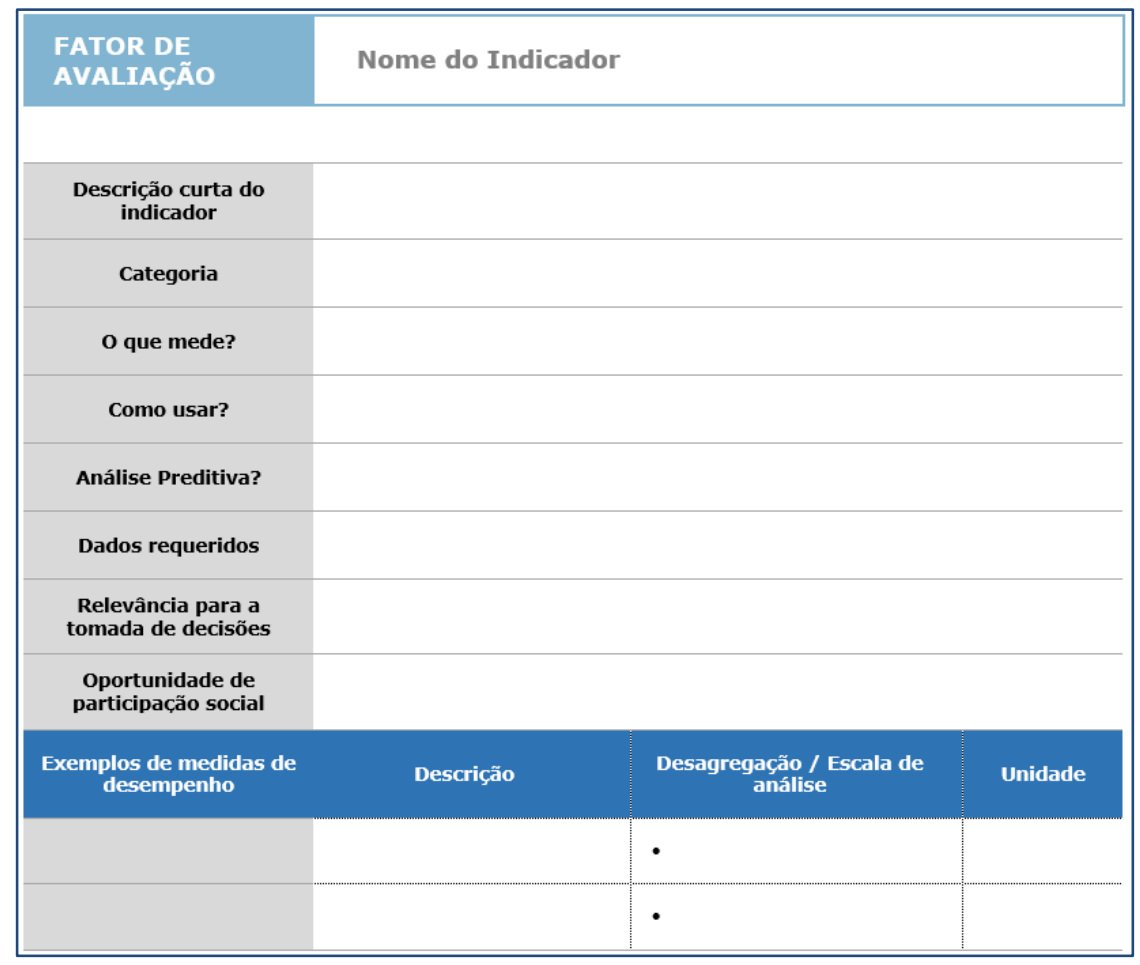

O fluxograma abaixo mostra, de forma sintetizada, o processo adotado para seleção dos indicadores e medidas de desempenho, que resultou na elaboração das fichas de avaliação, produto desta pesquisa.

\section{Identificação os indicadores utilizáveis}

Análise de Ferramentas de Avaliação, Estudos Científicos e Estudo de Caso

\section{Elaboração de Lista Preliminar}

Compilação e classificação em planilha por fatores de avaliação

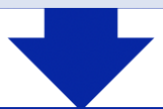

\section{Seleção dos Indicadores}

Ligados às Metas Estabelecidas

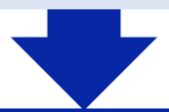

\section{Estruturação dos Indicadores}

Elaboração de Fichas de Avaliação 


\section{CAPÍTULO 2 - TRANSPORTE E SUSTENTABILIDADE URBANA: FUNDAMENTOS TEÓRICOS}

Atualmente, mais da metade da população mundial vive em áreas urbanas, contribuindo com elevadas taxas de produção e de consumo, e, consequentemente, aumentando e concentrando os problemas ambientais e socioeconômicos. Ocupando menos de $2 \%$ da área terrestre em 2015, as áreas urbanas concentravam $80 \%$ da produção econômica, entre 60 e $80 \%$ do consumo de energia e aproximadamente $75 \%$ das emissões de CO $^{2}$ (PNUMA, 2011 apud HABITAT-III, 2015).

As cidades concentram sérios problemas globais como pobreza, desigualdade social, poluição, dificuldades de mobilidade, falta de saneamento básico, habitações precárias, violência e impacto das mudanças climáticas. Esses diversos problemas têm afetado a qualidade de vida e o meio ambiente nas áreas urbanas. A problemática se agrava nas regiões metropolitanas, onde há maior concentração de pessoas e abrangência territorial.

Com a maior parte da população brasileira vivendo nas cidades, as questões urbanas tornam-se fundamentais para o desenvolvimento sustentável no país. Esse paradigma de desenvolvimento está aumentando progressivamente, tendo como principais expoentes os Objetivos de Desenvolvimento Sustentável (ODS) 2030.

De acordo com Mörtberg et al. (2013), para iniciar a construção de competência para a avaliação da sustentabilidade dos sistemas urbanos é fundamental o reconhecimento da interação entre a forma urbana, uso do solo e transporte. É nesse sentido, que o presente item visa analisar as questões emergentes do planejamento de transporte frente aos princípios da sustentabilidade urbana, de forma a fundamentar o estabelecimento de objetivos e metas de sustentabilidade em empreendimentos rodoviários.

\subsection{SUSTENTABILIDADE URBANA E CIDADES SUSTENTÁVEIS}

O conceito de sustentabilidade de questões relacionadas ao espaço urbano vem sendo impulsionado pelos diversos fóruns internacionais liderados pelas Nações Unidas, desde a década de 70, com a Conferência de Vancouver 1976 (Habitat I - Vancouver, Canadá), tomando mais força a partir da década de 90, mais especificamente em 1996 com o Habitat II em Istambul, Turquia, em 2001 com o Istambul+5 em Nova Iorque, EUA, e em 2016 com o Habitat III em Quito, Equador.

A Comissão Mundial sobre Meio Ambiente e Desenvolvimento (WCED, 1987), reunida em virtude da elaboração do relatório Nosso Futuro Comum (The Bruntland Report) identificou um grupo de desafios comuns necessário para o desenvolvimento 
sustentável, incluindo, dentre eles, o desafio urbano. Neste capítulo, constam diversas propostas que buscam uma gestão urbana sustentável, "baseada essencialmente no fortalecimento dos governos locais, na descentralização administrativa e na inclusão social”" (SOTTO e PHILIPPI JR., 2018).

Fruto das iniciativas internacionais, foram desenvolvidas a Agenda 21 e a Agenda Habitat, que são documentos balizadores das diretrizes das políticas públicas e das práticas urbanas de diversas cidades e metrópoles, voltados ao estabelecimento de mecanismos de coordenação setorial, descentralização na tomada de decisões e de incremento da participação popular na gestão urbana.

A Agenda 21 ampliou a importância das questões urbanas no discurso e na formulação de políticas que objetivam o desenvolvimento sustentável, dedicando o Capítulo 7 à questão da sustentabilidade dos assentamentos humanos, elencando oito objetivos essenciais para a gestão urbana sustentável.

As recomendações da Agenda 21 para os assentamentos humanos foram retomadas e aperfeiçoadas pela Convenção Habitat II, realizada na cidade de Istambul/Turquia em 1996, que estabeleceu um Plano Global de Ação dedicado à consecução de dois objetivos até 2016: (i) habitação digna para todos e (ii) desenvolvimento sustentável dos assentamentos humanos.

A Agenda 21 brasileira, redigida a partir da ECO-92, identificou seis temas centrais, incluindo o tema "Cidades Sustentáveis". Os resultados desse trabalho foram sistematizados e consolidados em seis publicações, conforme os seis eixos temáticos identificados, sendo um deles o documento Cidades Sustentáveis - Subsídios à Elaboração da Agenda 21 Brasileira, publicado no ano de 2000.

Em 2012, na Conferência das Nações Unidas sobre o Desenvolvimento Sustentável (Rio+20), realizada na cidade do Rio de Janeiro no ano de 2012, foi editada a declaração "O futuro que queremos". Nesta oportunidade, também foi tratado sobre o tema "Cidades e Assentamentos Humanos Sustentáveis", dedicando os itens 134, 135, 136 e 137 exclusivamente ao tema. Por ocasião da Rio+20, os Estados signatários da declaração "O futuro que queremos" assumiram o compromisso de indicar os Objetivos de Desenvolvimento Sustentável (ODS) até o ano de 2015, a vigorar até o ano de 2030, em substituição aos Objetivos do Milênio (ODM), que devem orientar as políticas nacionais e atividade de cooperação internacional nos próximos quinze anos, sucedendo e atualizando os Objetivos de Desenvolvimento do Milênio (ODM).

Em setembro de 2015, a partir da publicação da Resolução A/RES/70/1, a Assembleia Geral da Organização das Nações Unidas - ONU aprovou o documento "Transformando Nosso Mundo: A Agenda 2030 para as Nações Unidas e o Desenvolvimento Sustentável", que elegeu 17 ODS, desdobrados em 169 metas, compatíveis com os diversos documentos internacionais relacionados ao tema, tais como: a Agenda de Ação de Addis Abeba (2015), voltada ao financiamento do desenvolvimento sustentável; a Declaração de Sendai (2015), focada na redução de desastres; o Protocolo 
de Paris (2015), focado no combate às mudanças climáticas; a Declaração "O futuro que queremos" (2012) e a Agenda 21 (1992). No total, 193 países signatários se comprometeram em adaptar, adotar, mobilizar governos, empresas e sociedade civil para o cumprimento dos objetivos (ONU, 2015).

Os 17 ODS publicados pela ONU estão apresentados na Figura 7.

Figura 7 - Objetivos de Desenvolvimento Sustentável - ODS.
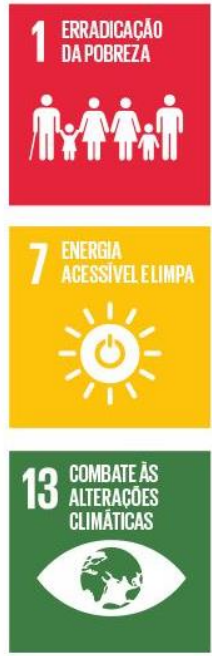
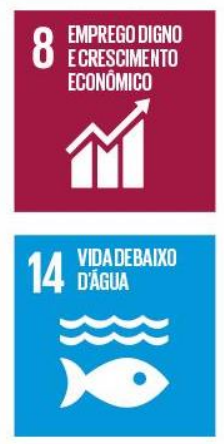
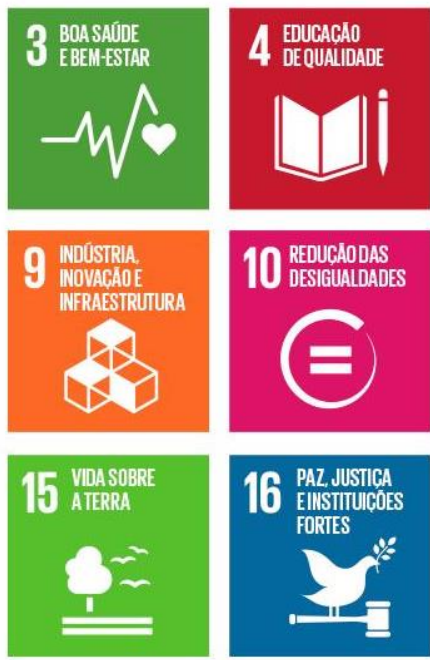
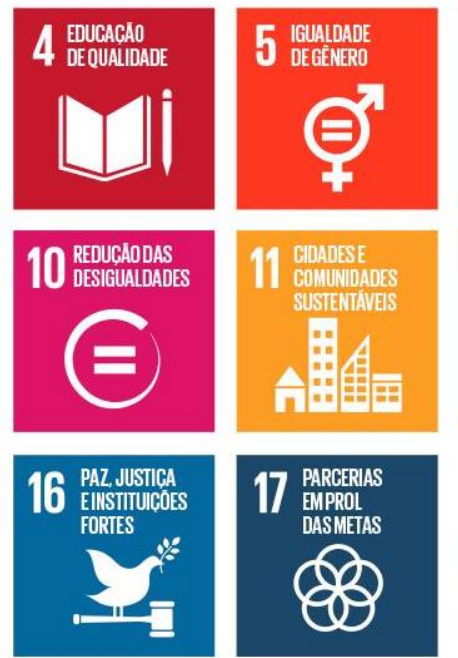
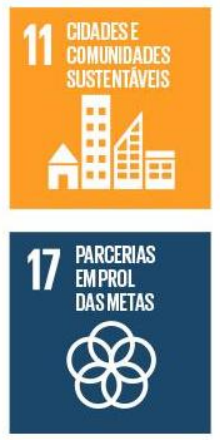

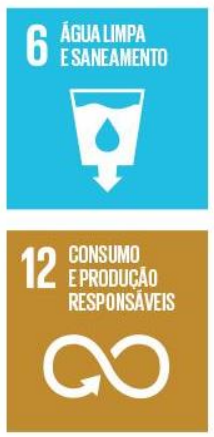

(4)

OBJETIVGS DE DESENVOLVIMENTO

Fonte: ONU (2015).

Dentre os seus 17 ODS eleitos, o ODS 11 refere-se especificamente às cidades, que visa "Tornar as cidades e os assentamentos humanos inclusivos, seguros, resilientes e sustentáveis", acompanhado com 7 metas específicas, que abordam temas como: habitação, sistema de transporte, urbanização, patrimônio cultural e natural do mundo, desastres, impacto ambiental negativo per capita das cidades - com especial atenção à qualidade do ar e gestão de resíduos municipais -, espaços públicos e outros.

Como desdobramento da Agenda 2030, por ocasião da Conferência das Nações Unidas para a Habitação e o Desenvolvimento Urbano Sustentável (Habitat III), a ONUHabitat, responsável pelo ODS 11, lançou, em outubro de 2016, na cidade de Quito, a Nova Agenda Urbana (NAU), que irá vigorar até 2036, em substituição à Agenda Habitat II. A NAU é um documento orientado para ação que define padrões globais para alcance do desenvolvimento urbano sustentável, repensando a forma como construímos, gerenciamos e vivemos nas cidades. Ele oferece orientações especialmente para os atores envolvidos no desenvolvimento urbano construírem seus planos de ação, com diretrizes para a urbanização sustentável, além de promover um planejamento urbano e territorial que garanta o uso sustentável do solo e dos recursos naturais, baseando-se nos conceitos de cidades compactas, policêntricas, com densidade e conectividade adequadas e controle da dispersão urbana.

No ordenamento jurídico brasileiro, o "conceito" de cidade sustentável surgiu, explicitamente, com a regulamentação dos dispositivos constitucionais da política urbana 
(artigos 182 e 183 da Constituição Federal de 1988), por meio da Lei nº 10.257 de 2001, conhecida como Estatuto da Cidade, que prevê, no art. $2^{\circ}$, inciso I, o que vem a ser uma cidade sustentável em uma das seguintes diretrizes gerais:

"garantia do direito a cidades sustentáveis, entendido como o direito à terra urbana, à moradia, ao saneamento ambiental, à infra-estrutura urbana, ao transporte e aos serviços públicos, ao trabalho e ao lazer, para as presentes e futuras gerações;" (BRASIL, 2001)

A partir desta Lei, o tema do desenvolvimento urbano sustentável ou da sustentabilidade urbana passou a destacar-se na agenda dos municípios brasileiros, propiciando uma progressiva atenção ao meio ambiente artificial por parte dos gestores públicos e dos cidadãos, objetivando a construção de cidades sustentáveis.

Haughton (1999) examinando diferentes abordagens políticas para avançar em direção à cidade sustentável, resume as ideias do desenvolvimento sustentável em cinco princípios baseados na equidade: 1) futuridade - equidade intergeracional; 2) justiça social - equidade intrageracional; 3) responsabilidade transfronteiriça - equidade geográfica; 4) equidade processual - pessoas tratadas de forma aberta e justa; 5) equidade entre espécies - importância da biodiversidade.

Na visão de Rogers (2009, apud SAETA, 2012), uma cidade sustentável é:

- Justa: onde justiça, alimentação, abrigo, educação, saúde e esperança sejam distribuídos de forma justa e onde todas as pessoas participem da administração;

- Bonita: onde arte, arquitetura e paisagem incendeiem a imaginação e toquem o espírito;

- Criativa: onde uma visão aberta e a experimentação mobilizem todo seu potencial de recursos humanos e permitam uma rápida resposta a mudança;

- Ecológica: que minimize seu impacto ecológico, onde a paisagem e a área construída estejam equilibradas e onde os edifícios e a infraestrutura sejam seguros e eficientes em termos de recursos;

- Fácil: onde o âmbito público encoraje a comunidade, a mobilidade, e onde a informação seja trocada tanto pessoalmente quanto eletronicamente;

- Compacta e policêntrica: que proteja a área rural, concentre e integre comunidades nos bairros e maximize a proximidade;

- Diversificada: onde uma ampla gama de atividades diferentes gere vitalidade, inspiração e acalentem uma vida pública essencial.

Para UNISDR (2012), urbanização sustentável é um processo que promove uma abordagem integrada, sensível ao gênero e em prol dos pobres para os pilares sociais, econômicos e ambientais da sustentabilidade, baseando-se no planejamento participativo e nos processos de decisão, incluindo governança. Os princípios de urbanização sustentável envolvem: 
- Terra, infraestrutura, serviços, mobilidade e habitação acessível em prol dos pobres;

- Desenvolvimento seguro e saudável, sensível e socialmente inclusivo;

- Ambiente criado ambientalmente saudável e eficiente em termos de carbono;

- Processos de planejamento e tomada de decisão participativos;

- Economias locais dinâmicas e competitivas promovendo trabalho decente e subsistência;

- Garantia dos direitos de não discriminação e equitativos para a cidade;

- Capacitação de cidades e comunidades para planejar e administrar eficazmente adversidades, e mudança para construir resiliência.

Acselrad (1999, 2009a), ao investigar os discursos sobre a sustentabilidade urbana, sintetizou três representações das cidades ou matrizes discursivas, conforme a seguir: (i) tecno-material das cidades; (ii) a cidade como espaço da "Qualidade de Vida"; e (iii) a cidade como espaço de legitimação das políticas urbana. O Quadro 1 apresenta as matrizes discursivas proposta por Acselrad (1999), suportadas pelos diferentes conceitos da sustentabilidade urbana.

Quadro 1 - Matrizes discursivas da sustentabilidade urbana.

\begin{tabular}{|c|c|c|}
\hline Representações & Modelos & Descrição \\
\hline \multirow[b]{2}{*}{$\begin{array}{l}\text { Representação } \\
\text { tecno-material das } \\
\text { cidades }\end{array}$} & $\begin{array}{l}1.1 \text { Racionalidade } \\
\text { Ecoenergética }\end{array}$ & $\begin{array}{l}\text { Eficiência e conservação da matéria e da energia, com redução de } \\
\text { rejeitos }\end{array}$ \\
\hline & $\begin{array}{l}1.2 \text { Equilíbrio } \\
\text { Metabólico }\end{array}$ & $\begin{array}{l}\text { Representação ecossistêmica das cidades, que se organiza pelo } \\
\text { recurso à metáfora biológica da "resiliência" e procura descrever } \\
\text { a capacidade adaptativa dos "ecossistemas urbanos" para superar } \\
\text { suas condições de vulnerabilidade a choques externos. }\end{array}$ \\
\hline \multirow{3}{*}{$\begin{array}{l}\text { A cidade como } \\
\text { espaço da } \\
\text { "Qualidade de } \\
\text { Vida" }\end{array}$} & 2.1 Pureza & Vista como espaço das externalidades negativas \\
\hline & 2.2 Cidadania & $\begin{array}{l}\text { Se expressa em políticas construídas por meio do diálogo e da } \\
\text { negociação social entre os diferentes agentes sociais }\end{array}$ \\
\hline & 2.3 Patrimônio & $\begin{array}{l}\text { Tratada como caráter imaterial, relacionado à identidade dos } \\
\text { lugares: valores e heranças construídas, estéticas e culturais }\end{array}$ \\
\hline \multirow[t]{2}{*}{3.} & 3.1 Eficiência & Está relacionada à eficiência na gestão dos recursos públicos \\
\hline & 3.2 Equidade & $\begin{array}{l}\text { Democratização do acesso aos serviços urbanos, demonstrando a } \\
\text { capacidade de equilibrar a oferta de serviços urbanos à } \\
\text { quantidade e à qualidade das demandas da sociedade. }\end{array}$ \\
\hline
\end{tabular}

Fonte: Baseado em Acselrad (1999).

Maclaren (1996) lista algumas características chave relacionadas à sustentabilidade urbana encontradas frequentemente na literatura, tais como:

- Equidade entre gerações;

- Equidade intragerações, incluindo equidade social, geográfica e governamental;

- Proteção ao ambiente natural e respeito aos seus limites;

- Minimização do uso de recursos não-renováveis;

- Vitalidade e diversidade econômica;

- Autoconfiança por parte da comunidade;

- Bem-estar individual; 
- Satisfação das necessidades básicas.

Percebe-se que o conceito de sustentabilidade urbana pressupõe que as cidades devam ser analisadas como um sistema integrado. Tomando-se como base os seus aspectos físicos e urbanísticos, a sustentabilidade de aglomerados urbanos deve levar em consideração a forma de ocupação do território e a disponibilidade de insumos para o seu adequado funcionamento, o grau de mobilidade e de acesso da população aos equipamentos sociais e serviços públicos, a qualidade dos espaços coletivos e o correto dimensionamento e controle das fontes geradoras de resíduos e os seus destinos finais.

Independentemente dos conceitos ou discursos atribuídos à sustentabilidade urbana, o que se percebe é que os principais desafios estão centrados em integrar a dinâmica social de uso e produção do espaço urbano com as estratégias que promovam a conservação ambiental e a qualidade de vida das comunidades.

Para auxiliar no enfrentamento dos diversos desafios na busca de uma cidade mais sustentável, desde 2011, a Rede Nossa São Paulo, a Rede Social Brasileira por Cidades Justas, Democráticas e Sustentáveis e o Instituto Ethos, em parceria com outras organizações e redes nacionais e internacionais, disponibilizam um conjunto de ferramentas para contribuir com a construção dessa visão de futuro aliada a processos transparentes e participativos: o Programa Cidades Sustentáveis (PCS). Este programa propõe um processo baseado em diretrizes, indicadores e metas, organizados em 12 eixos temáticos, representados na Figura 8.

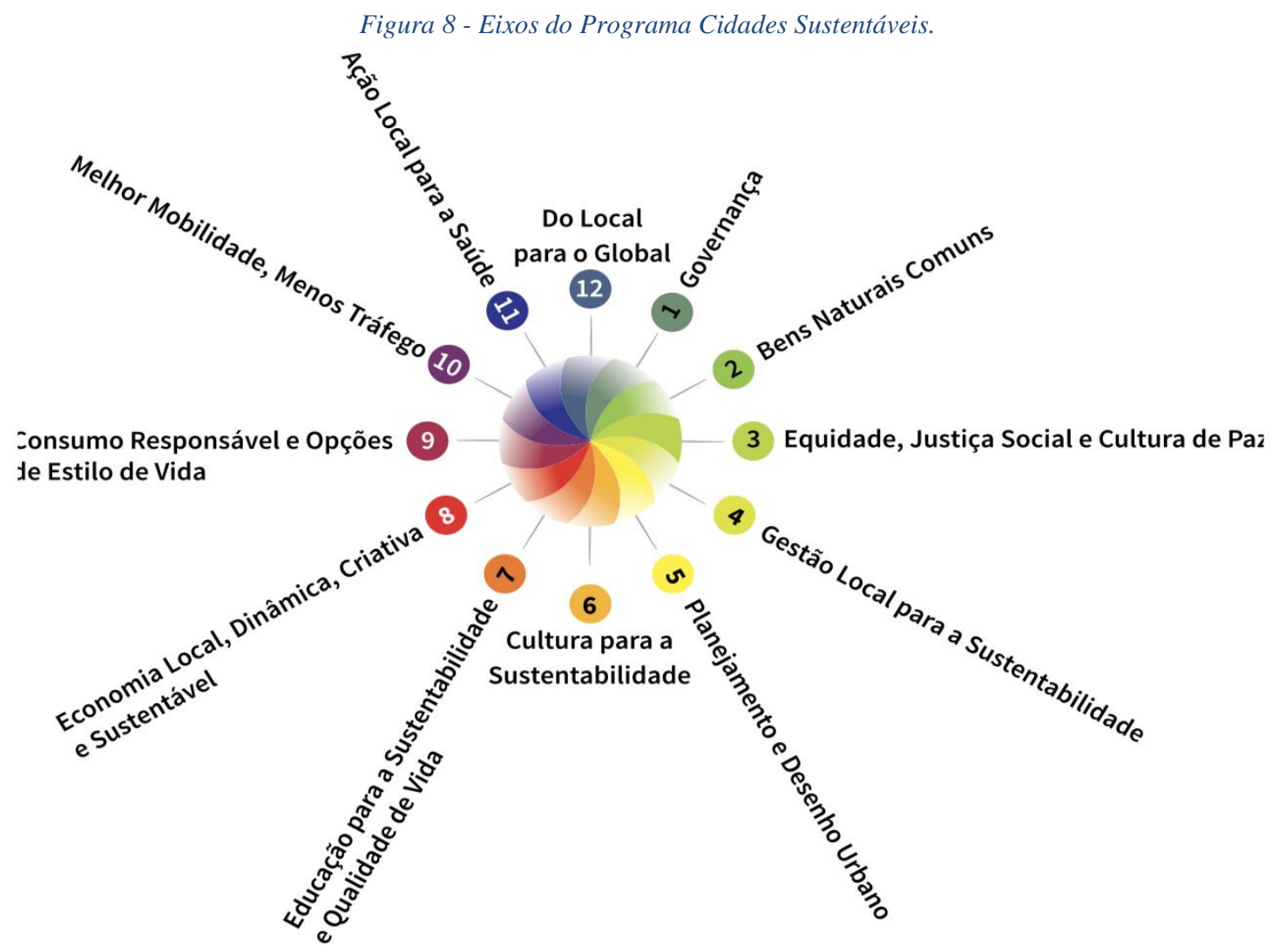

Fonte: PROGRAMA CIDADES SUSTENTÁVEIS (2016). 
O PCS apresenta um total de 260 indicadores básicos, divididos pelos 12 eixos, e traz informações úteis para gestores e outros públicos interessados em conhecer ou usar uma plataforma como ferramenta de gestão e aprimoramento da administração municipal. Os indicadores do PCS estão associados aos Objetivos de Desenvolvimento Sustentável (ODS) e às respectivas metas estipuladas pela ONU, organizados de modo que facilitem a leitura e a compreensão de sua aplicação nos sistemas públicos de gestão.

\subsection{TRANSPORTE SUSTENTÁVEL: PRINCÍPIOS E DEFINIÇÕES}

O transporte impulsiona o desenvolvimento, liga as pessoas, conecta as comunidades locais ao mundo, constrói mercados e facilita o comércio. De acordo com a Política Nacional de Transportes (2018),

"O Setor de Transportes se configura como elemento fundamental na
organização e dinâmica do Estado brasileiro, uma vez que funciona
como instância essencial para os deslocamentos das pessoas, das
matérias-primas e dos produtos finais, vinculando-se ao abastecimento
interno, à segurança alimentar, ao direito de ir e vir, à provisão de
insumos para as produções agropecuárias e industriais e aos
movimentos de importação e de exportação, por exemplo".

A importância que o transporte detém no contexto urbano é reconhecida pelas Nações Unidas em seu relatório lançado em 2006 denominado "Mobilizando o Transporte Sustentável para o Desenvolvimento", que trata das perspectivas de transporte sustentável na escala global, abordando todos os modos de transporte, tanto em países desenvolvidos como em desenvolvimento. Os autores destacam que:

"Transporte não é uma finalidade em si, mas um meio que permite às pessoas acesso a qualquer necessidade: emprego, mercados e bens, interação social, educação e uma série de outros serviços que contribuem para vidas saudáveis e plenas".

Logo, o transporte é uma atividade meio, que surge para atender a outras necessidades dos indivíduos, coletividades ou organizações. Portanto, deve ser planejado de forma a satisfazer aos objetivos coerentes com as demandas sociais (LITMAN e BURWELL, 2006). Um planejamento de transporte eficaz combina a necessidade de entregas a curto prazo com uma visão de longo prazo.

Contudo, há muitos desafios a serem enfrentados no setor de transporte visando resultados mais sustentáveis nas áreas urbanas, especialmente nas regiões metropolitanas dos países em desenvolvimento, dentre os quais se destacam: poluição, congestionamentos, acidentes, declínio na qualidade dos transportes públicos, degradação ambiental, alterações climáticas, esgotamento de energia, poluição visual, e falta de acessibilidade para a população urbana de menor poder aquisitivo. 
O cenário atual apresentado por ONU (2016) é que todos os anos, 1,24 milhões de pessoas morrem em acidentes viários e 3,5 milhões de pessoas morrem prematuramente devido a poluição do ar, tendo o transporte como um dos principais responsáveis; $23 \%$ das emissões de gases de efeito estufa relacionados à energia que vem do transporte; congestionamentos acarretam em encargos para a economia.

Resultado do RIO+20 ocorrido em 2012, o documento "O Futuro que Queremos" abordou o tema "O transporte sustentável”, por meio dos itens 132 e 133. A Agenda 2030 para o Desenvolvimento Sustentável estabeleceu 17 Objetivos de Desenvolvimento Sustentável (ODS), cujo cumprimento depende dos avanços no transporte sustentável.

O transporte pode ser um agente de desenvolvimento urbano sustentado que priorize metas de equidade e enfatize a acessibilidade, a segurança no trânsito e a economia de tempo para os pobres, com mínimo prejuízo ao meio ambiente e à saúde humana, reduzindo as emissões (AMEKUDZI et al., 2011; LI, 2011; KANE, 2010 apud IPCC, 2014).

O transporte sustentável tende a ser definido de diferentes maneiras por diferentes agências de transporte dependendo de suas prioridades ou restrições específicas, embora a maioria das definições contemple os fatores do Triple Bottom Line (TBL): economia, meio ambiente e social.

De acordo com AASHTO (2009), ao pensar em fornecer soluções de transporte e infraestrutura de maneira mais sustentável, agências e empresas estão considerando cada um dos elementos da seguinte forma:

- Economia - Apoiar a vitalidade econômica e, ao mesmo tempo, desenvolver a infraestrutura de maneira econômica. Os custos da infraestrutura devem estar dentro da capacidade e disposição de pagar da sociedade. Os custos do usuário precisam estar dentro da capacidade das pessoas e das famílias de pagarem.

- Social - Satisfazer as necessidades sociais tornando o transporte acessível e seguro; incluir o fornecimento de opções de mobilidade para todas as pessoas (incluindo pessoas com desvantagens econômicas); e desenvolver infraestrutura que seja um ativo para as comunidades.

- Ambiente - Criar soluções que sejam compatíveis com o ambiente natural, reduzam as emissões e a poluição do sistema de transporte e reduzam os recursos materiais necessários para suportar o transporte.

Mais recentemente, alguns pesquisadores têm considerado as questões institucionais como um dos fatores fundamentais no contexto do desenvolvimento sustentável, nas quais são abordados a estrutura e o funcionamento das instituições.

Como alternativa ao TBL, Gibson (2001, apud POPE et al., 2004) promove o uso de uma abordagem baseada em princípios para avaliação de sustentabilidade, em que os critérios de sustentabilidade são derivados de princípios de sustentabilidade em vez de objetivos de TBL. Ele argumenta que uma abordagem baseada em princípios enfatiza as 
interconexões e as interdependências entre as áreas do pilar em vez de promover conflitos e trade-offs, podendo evitar limitações conceituais e desafios práticos inerentes da abordagem TBL.

Os princípios do desenvolvimento sustentável que estão implícitos em sua definição incluem equidade intergeracional e multidimensionalidade (ZIETSMAN \& RILETT, 2002). Esses autores discutiram os princípios do desenvolvimento sustentável que são relevantes e precisam ser abordados a partir de uma perspectiva de transporte, a saber: Equidade intergeracional; Multidimensional; Dinâmico; e Contínuo (Continuum).

Marsden et al. (2011) propõe um conjunto de princípios na perspectiva dos transportes, com o objetivo de garantir que o setor de transportes incentive, apoie e mantenha o progresso em direção à sustentabilidade, conforme fornecidos abaixo:

"A sustentabilidade implica atender às necessidades humanas para o presente e o futuro, enquanto:

- Preservação de sistemas ambientais e ecológicos,

- Melhorar a qualidade de vida,

- Promover o desenvolvimento econômico, $e$

- Garantir a equidade entre grupos populacionais e em gerações".

Jeon (2007) e Amekudzi et al. (2011) compilaram diversas definições de transporte sustentável, as quais estão apresentadas no Quadro 2 a seguir.

Quadro 2 - Exemplos de definições de transporte sustentável.

Organização

Mesa Redonda sobre Meio Ambiente e Economia de Ontário (ORTEE) 1995. Canadá.

Organização para Cooperação e Desenvolvimento Econômico (OCDE) 1999.

\section{Definições de Transporte Sustentável}

(1) Produzir saídas (emissões) em um nível capaz de ser assimilado pelo meio ambiente. (2) Ter uma baixa necessidade de insumos de recursos não renováveis (quando não renováveis são usados, seu uso será para investimentos não consuntivos e eles serão reciclados quando não forem mais úteis ou necessários). (3) Minimizar a interrupção dos processos ecológicos, o uso de terra (e área de água) também é minimizado, bem como o uso de habitats sensíveis.

O transporte ambientalmente sustentável é definido como: "Transporte que não comprometa a saúde pública ou ecossistemas e que atenda às necessidades de acesso consistentes com (a) uso de recursos renováveis abaixo de suas taxas de regeneração, e (b) uso de recursos não renováveis abaixo das taxas de desenvolvimento de substitutos renováveis"

(1) No ambiente natural: limite de emissões e resíduos (que poluem o ar, o solo e a água) dentro da capacidade da área urbana de absorver / reciclar / limpar; fornecer energia aos veículos a partir de fontes de energia renováveis ou inesgotáveis (como a energia solar a longo prazo); e reciclar recursos naturais utilizados em veículos e infraestrutura (como

Associação de Transporte Canadá (TAC) 1999. Canadá. plástico, etc.). (2) Na sociedade: prover equidade de acesso para as pessoas e seus bens, nesta geração e em todas as futuras gerações; melhorar a saúde humana; ajudar a apoiar a mais alta qualidade de vida compatível com a riqueza disponível; facilitar o desenvolvimento urbano à escala humana; limitar a intrusão de ruído abaixo dos níveis aceitos pelas comunidades; e seja seguro para as pessoas e suas propriedades. (3) Na economia: ser financeiramente acessível em cada geração; ser projetado e operado para maximizar a eficiência econômica e minimizar 


\begin{tabular}{|c|c|}
\hline ção & Definições de Transporte Sustentável \\
\hline & $\begin{array}{l}\text { os custos econômicos; e ajudar a apoiar uma economia forte, vibrante e } \\
\text { diversificada. }\end{array}$ \\
\hline $\begin{array}{l}\text { Departamento de Transporte } \\
\text { da Califórnia (2001) }\end{array}$ & $\begin{array}{l}\text { Um sistema de transporte sustentável atende às necessidades básicas } \\
\text { de mobilidade e acessibilidade das gerações atuais e futuras. }\end{array}$ \\
\hline $\begin{array}{l}\text { O Centro de Transporte } \\
\text { Sustentável (CST) 2002. Canadá. }\end{array}$ & $\begin{array}{l}\text { (1) permite que as necessidades básicas de acesso de indivíduos e } \\
\text { sociedades sejam atendidas de forma segura e consistente com a saúde } \\
\text { humana e com o ecossistema, e com equidade dentro e entre gerações; } \\
\text { (2) é acessível, opera de forma eficiente, oferece opções do modo de } \\
\text { transporte e suporta uma economia vibrante; (3) limita as emissões e os } \\
\text { resíduos dentro da capacidade do planeta de absorvê-los, minimiza o } \\
\text { consumo de recursos não renováveis, reutiliza e recicla seus } \\
\text { componentes e minimiza o uso da terra e a produção de ruído. }\end{array}$ \\
\hline $\begin{array}{l}\text { Instituto de Política de } \\
\text { Transporte Victoria (VTPI) } \\
\text { 2003. Canadá. }\end{array}$ & $\begin{array}{l}\text { Proporcionar um futuro material seguro e satisfatório para todos, em uma } \\
\text { sociedade que seja equitativa, atenciosa e atenta às necessidades } \\
\text { humanas básicas. }\end{array}$ \\
\hline $\begin{array}{l}\text { Desenvolvimento Estratégico } \\
\text { Sustentável do Uso da Terra e } \\
\text { Estratégias de Transporte: Manual } \\
\text { Metodológico: Procedimentos } \\
\text { para a Recomendação do } \\
\text { Planejamento Sustentável Ótimo } \\
\text { dos Sistemas Europeus de } \\
\text { Transporte Urbano (2003) }\end{array}$ & $\begin{array}{l}\text { Um sistema sustentável de transporte urbano e uso da terra: (1) fornece } \\
\text { acesso a bens e serviços de maneira eficiente para todos os habitantes } \\
\text { da área urbana; (2) protege o meio ambiente, o patrimônio cultural e } \\
\text { os ecossistemas para a geração atual e (3) não coloca em risco as } \\
\text { oportunidades das futuras gerações de alcançar pelo menos o mesmo } \\
\text { nível de bem-estar dos que vivem atualmente, incluindo o bem-estar } \\
\text { derivado de seu ambiente natural e patrimônio cultural. }\end{array}$ \\
\hline $\begin{array}{l}\text { Departamento de } \\
\text { Desenvolvimento Sustentável. } \\
\text { 2003. Reino Unido. }\end{array}$ & $\begin{array}{l}\text { O desenvolvimento sustentável significa assegurar uma melhor } \\
\text { qualidade de vida para todos, agora e para as gerações futuras. Isso } \\
\text { requer o cumprimento de quatro objetivos-chave ao mesmo tempo no } \\
\text { Reino Unido e no mundo como um todo: (1) progresso social que } \\
\text { reconheça as necessidades de todos; (2) proteção efetiva do meio } \\
\text { ambiente; (3) uso prudente dos recursos naturais e (4) manutenção de } \\
\text { níveis elevados e estáveis de crescimento econômico e emprego. }\end{array}$ \\
\hline $\begin{array}{l}\text { Ministério do Meio Ambiente, } \\
\text { Nova Zelândia } \\
\text { www.mfe.govt.nz/issues/transp } \\
\text { ort/sustainable/ }\end{array}$ & $\begin{array}{l}\text { O transporte sustentável significa encontrar maneiras de mover } \\
\text { pessoas, bens e informações de maneiras que reduzam seu impacto no } \\
\text { meio ambiente, na economia e na sociedade. Algumas opções incluem: } \\
\text { (1) usar modos de transporte que usam energia de maneira mais } \\
\text { eficiente, como caminhar ou andar de bicicleta, e transporte público; } \\
\text { (2) melhorar a escolha de transporte, aumentando a qualidade das } \\
\text { instalações, serviços e ambientes de transporte público, ciclismo e } \\
\text { caminhada; (3) melhorar a eficiência do uso de nossos carros, como } \\
\text { usar veículos mais econômicos, dirigir com mais eficiência, evitar } \\
\text { partidas a frio e lotar os carros; (4) usando combustíveis e tecnologias } \\
\text { mais limpas; (5) usar telecomunicações para reduzir ou substituir } \\
\text { viagens físicas, como teletrabalho ou tele-shopping; (6) planejar o } \\
\text { layout das cidades para aproximar as pessoas e suas necessidades e } \\
\text { tornar as cidades mais vibrantes e tranquilas; e (7) desenvolver } \\
\text { políticas que permitam e promovam essas opções, como a Estratégia } \\
\text { de Transporte da Nova Zelândia. }\end{array}$ \\
\hline $\begin{array}{l}\text { A Rede de Ação de Transporte } \\
\text { Sustentável (Sustran), a } \\
\text { Iniciativa de Pesquisa de } \\
\text { Gestão Ambiental Urbana } \\
\text { (UEMRI), Centro de Pesquisa } \\
\text { de Desenvolvimento Global } \\
\text { (GDRC) }\end{array}$ & $\begin{array}{l}\text { Transporte sustentável diz respeito a sistemas, políticas e tecnologias. } \\
\text { Tem como objetivo o trânsito eficiente de bens e serviços e sistemas } \\
\text { sustentáveis de frete e entrega. O projeto de planejamento urbano sem } \\
\text { veículos, juntamente com o design amigável dos bairros para pedestres } \\
\text { e ciclistas, é um aspecto crítico para as atividades de base, assim como } \\
\text { o teletrabalho e a teleconferência. É mais sobre acessibilidade e } \\
\text { mobilidade do que sobre "transporte". }\end{array}$ \\
\hline
\end{tabular}

Fontes: Baseado em Jeon (2007) e Amekudzi et al. (2011). 
Baseada na definição fornecida pelo Centro de Transporte Sustentável do Canadá (2002), a European Council of Ministers of Transport (Conselho Europeu de Ministros dos Transportes) define transporte sustentável como:

"Um sistema de transporte sustentável é definido como aquele que:

- permite que as necessidades básicas de acesso e desenvolvimento de indivíduos, empresas e sociedades sejam atendidas com segurança e de maneira consistente com a saúde humana e do ecossistema, e promova a equidade dentro e entre as gerações sucessivas;

- é acessível, opera de forma justa e eficiente, oferece opções de modo de transporte e apoia uma economia competitiva, bem como um desenvolvimento regional equilibrado; $e$

- limita as emissões e o desperdício na capacidade do planeta de absorvê-los, utiliza recursos renováveis iguais ou inferiores às suas taxas de geração e utiliza recursos não renováveis iguais ou inferiores às taxas de desenvolvimento de substitutos renováveis, minimizando o impacto sobre o uso da terra e a geração de ruído".

No estudo realizado por Ramani et al. (2009), o transporte sustentável foi definido como "a provisão de acesso e mobilidade seguros, efetivos e eficientes para o futuro, considerando as necessidades econômicas, sociais e ambientais da sociedade". No contexto dos EUA, o Comitê para a Conferência sobre Introdução à Sustentabilidade no Planejamento do Transporte de Superfície definiu um sistema de transporte sustentável como "um em que (a) as necessidades atuais social e econômico de transporte são atendidas de forma ambientalmente consciente e (b) a capacidade das gerações futuras de satisfazer suas próprias necessidades não é comprometida" (MARSDEN et al., 2011).

OCDE (1996) apresenta algumas orientações estratégicas para o transporte sustentável, assim descritas:

a. Acesso: Melhore o acesso a pessoas, bens e serviços, mas reduza a demanda pelo movimento físico de pessoas e coisas.

b. Tomada de decisão: Tomar decisões de transporte de uma maneira aberta e inclusiva que considere todos os impactos e opções razoáveis.

c. Planejamento urbano: limite a expansão, garanta o uso do solo local misto, fortaleça o transporte público, facilite a caminhada e o ciclismo, proteja os ecossistemas, o patrimônio e as instalações recreativas, e racionalize o movimento de mercadorias.

d. Proteção ambiental: Minimize as emissões e reduza o desperdício da atividade de transporte, reduza o ruído e o uso de recursos não renováveis, particularmente os combustíveis fósseis, e garanta a capacidade adequada para responder a derramamentos e outros acidentes.

e. Viabilidade econômica: Internalize todos os custos externos de transporte incluindo subsídios, mas respeite as preocupações com a equidade, promova 
pesquisa e desenvolvimento apropriados, considere os benefícios econômicos, incluindo o aumento do emprego que pode resultar da reestruturação do transporte, e forme parcerias com países desenvolvidos e em desenvolvimento.

Mais recentemente, o Grupo Consultivo responsável pela elaboração do Relatório Mobilizando o Transporte Sustentável para o Desenvolvimento, organizado pela ONU (2016a), definiu transportes sustentáveis como:

"a provisão de serviços e infraestrutura para a mobilidade de pessoas e bens - avançando o desenvolvimento econômico e social para beneficiar as gerações atuais e futuras - de maneira segura, acessível, com preço acessivel, eficiente, e resiliente, minimizando as emissões de carbono e outras e os impactos ambientais."

Esse relatório fornece orientações sobre o transporte sustentável que os países devem seguir até 2030, define diretrizes que podem auxiliar no cumprimento dos Objetivos de Desenvolvimento Sustentável (ODS), da Agenda 2030 para o Desenvolvimento Sustentável e do Acordo de Paris, assim como contempla as tendências globais de urbanização, alterações demográficas, globalização e os progressos tecnológicos, defendendo que há uma necessidade urgente de ações para lidar com os custos sociais, ambientais e econômicos associados à maneira como é encarado o transporte. Para os autores, o transporte sustentável exige avanços em três áreas principais: (a) desenvolvimento e implementação de políticas, (b) financiamento e (c) inovação tecnológica.

No que se refere à área de (a) Desenvolvimento e Implementação de Políticas, que guarda estreita relação com este trabalho, são fornecidas as recomendações apresentadas no Quadro 3.

Quadro 3 - Recomendações para Desenvolvimento e Implementação de Políticas.

(1) Tome decisões de planejamento, políticas e investimentos em transportes com base nas três dimensões de desenvolvimento sustentável - desenvolvimento social, impactos ambientais (incluindo o clima) e crescimento econômico - e uma análise completa do ciclo de vida.

a) Dar a máxima atenção à segurança para todos os usuários de transporte e garantir que as melhorias na qualidade de vida e os avanços contra impactos ambientais negativos sejam fundamentais para as decisões políticas e de investimento.

b) Promover o acesso equitativo (a empregos, mercados, serviços) como um princípio orientador chave para o planejamento e a política de transportes e para investimentos em infraestrutura (manutenção, renovação ou construção, conforme aplicável).

c) Garantir que a resiliência aos impactos climáticos e outros choques naturais e econômicos e estresses crônicos seja essencial para o planejamento da infraestrutura de transporte e o desenvolvimento de redes de transporte e que as oportunidades de "saltar" para uma infraestrutura mais sustentável e sistemas de transporte sejam maximizadas.

d) Tornar a manutenção da infraestrutura existente e a melhoria de sua eficiência como parte integrante da política de transporte e tomada de decisões de investimento.

e) Melhorar a internalização dos custos e benefícios externos do transporte como uma ferramenta para alcançar um transporte sustentável e de baixo carbono, mantendo o acesso equitativo para todos.

f) Priorizar o uso da análise da cadeia de valor total na formulação de políticas de transporte, com o objetivo de aumentar a eficiência de custo do comércio. 
(2) Integrar todos os esforços de planejamento de transporte sustentável com um desenvolvimento adequadamente equilibrado dos modos de transporte: integração vertical entre os niveis de governo e horizontalmente entre os modos, territórios e setores.

a) Desenvolver, adotar e implementar estruturas e estratégias nacionais sustentáveis integradas de transporte para o movimento de pessoas e bens. O planejamento integrado de sistemas de transporte e uso da terra deve promover o transporte sustentável.

b) Promover a integração regional e a cooperação institucional entre os governos nacionais para permitir a movimentação segura e eficiente de pessoas e bens através das fronteiras e ao longo dos principais corredores de transporte, reduzindo os custos econômicos, sociais e ambientais em toda a cadeia de valor.

c) Desenvolver planos de mobilidade urbana sustentável que suportem redes de transporte intermodais e interconectadas para mobilidade e conectividade "porta-a-porta" e conectividade de pessoas e bens, alinhadas com as políticas nacionais e apoiadas pelos governos nacionais através de orientação, apoio financeiro e capacitação técnica.

d) Alinhar, nos níveis de governo nacional e local, tarefas e responsabilidades das autoridades de transporte e uso da terra, com vistas a uma autoridade conjunta única em cada nível, com supervisão de todos os aspectos de política e planejamento.

e) Promover o diálogo regional e internacional sobre desenvolvimento sustentável e a logística que sustenta o movimento de pessoas e bens, reconhecendo que a logística eficiente impulsiona o crescimento econômico e o desenvolvimento social.

(3) Criar estruturas institucionais de apoio, legais e regulamentares para promover um transporte sustentável e eficaz.

a) Devolva a autoridade aos níveis apropriados de governo, assegurando que as autoridades nacionais, subnacionais e locais tenham financiamento, recursos e capacidade adequados para cumprir suas responsabilidades, inclusive para a aquisição de serviços de transporte público.

b) Melhorar a transparência e responsabilidade de todos os ministérios e autoridades nacionais e locais relevantes.

c) Definir parâmetros claros, em um processo liderado por governos e autoridades públicas, para o envolvimento do setor privado na prestação de serviços de transporte.

(4) Desenvolver capacidade técnica de planejadores e implementadores de transportes, especialmente em países em desenvolvimento, por meio de parcerias com organizações internacionais, bancos multilaterais de desenvolvimento e governos em todos os níveis, para garantir acesso equitativo a mercados, empregos, educação e outras necessidades.

a) Garantir que os esforços de capacitação sejam um requisito fundamental para projetos de transporte sustentáveis e sustentáveis, especialmente em países em desenvolvimento.

b) Promover a coleta, análise e compartilhamento de dados relevantes, especialmente nos países em desenvolvimento, para uma política de transportes bem informada e tomada de decisões de investimento, e para o desenvolvimento de indicadores de segurança dos transportes, equidade, qualidade de vida e resiliência.

c) Dar prioridade a soluções de transporte de baixa emissão, eficientes e equitativas, mudando para os modos mais apropriados às circunstâncias locais e nacionais e que melhor promovam o desenvolvimento sustentável.

(5) Reforçar os esforços para prevenir mortes e lesões no trânsito.

a) Priorizar a prevenção de mortes e ferimentos em usuários de estradas, usando a meta dos Objetivos de Desenvolvimento Sustentável de reduzir as mortes e lesões no trânsito em 50\% até 2020 como um guia, e seguir uma abordagem sistêmica para melhorar a segurança no trânsito.

b) Promover o desenho de sistemas rodoviários e de transporte que priorize e enfatize a proteção das pessoas contra a morte e os ferimentos, levando em conta a falibilidade e a vulnerabilidade humanas.

c) Divulgar para as partes interessadas locais melhores práticas sobre legislação de segurança no trânsito e políticas públicas.

d) Garantir que os padrões mínimos de segurança para veículos e embarcações sejam estabelecidos e aplicados, com atenção especial ao mercado secundário nos países em desenvolvimento. Os governos nacionais lideram esses esforços.

e) Reduzir os fatores de risco comportamentais que levam a mortes e lesões no trânsito por meio de legislação, conscientização, sinalização e regras e regulamentos. Governos e organizações da sociedade civil trabalham juntos nesses esforços. 
(6) Promover um público informado e engajado como um parceiro crucial no avanço de soluções sustentáveis de transporte.

a) Desenvolver e promover campanhas de conscientização pública e programas de educação para informar e engajar pessoas de todas as idades sobre o imperativo de fornecer acesso equitativo a oportunidades sociais e econômicas, bem como sobre a importância e os benefícios da mobilidade sustentável. Os temas a serem abordados pelos governos e pelas organizações internacionais e da sociedade civil incluem a segurança no trânsito; os benefícios do transporte público, caminhada e ciclismo; e oportunidades para reduzir as emissões de carbono.

b) Buscar formas eficazes de buscar insumos, compras e, quando possível, cocriação, de uma ampla gama de grupos de partes interessadas ao tomar decisões de planejamento de transporte, políticas, infraestrutura e sistemas.

(7) Estabelecer estruturas de monitoramento e avaliação para o transporte sustentável e desenvolver capacidade para coletar e analisar dados e estatísticas confiáveis.

a) Estabelecer metodologias abrangentes de monitoramento e avaliação para o transporte sustentável pelos governos nacionais e locais, vinculando estruturas de monitoramento, metas e indicadores, quando apropriado, aos Objetivos de Desenvolvimento Sustentável.

b) Fazer um balanço regular (em alguns casos anual) do progresso em direção aos objetivos de transporte dentro dos governos nacionais e locais e ajuste políticas e práticas em resposta às lições aprendidas com o objetivo de impulsionar a melhoria contínua, focada nas necessidades da sociedade.

c) Ajudar a desenvolver a capacidade de monitoramento e avaliação nos governos em todos os níveis, inclusive por meio do compartilhamento de lições aprendidas, melhores práticas, treinamento e orientação de organizações e empresas internacionais e da sociedade civil.

Fonte: Elaborado a partir de ONU (2016a).

Nota-se que, até o momento, não há uma definição universalmente reconhecida do transporte sustentável. Os conceitos de Transporte Sustentável, em virtude da sua complexidade, estão sempre em construção, podendo variar de acordo com a sua aplicação e prioridades de uma determinada agência. Embora não exista uma definição padrão de transporte sustentável, a sustentabilidade é amplamente capturada em termos de eficácia do sistema de transporte e impacto do sistema na produtividade econômica, integridade ambiental e na qualidade de vida social (JEON e AMEKUDZI, 2005).

\subsection{QUESTÕES EMERGENTES NO PLANEJAMENTO DE TRANSPORTE PARA SUSTENTABILIDADE URBANA}

Com o objetivo de contribuir com as discussões acerca da sustentabilidade urbana no planejamento de rodovias, bem como direcionar de maneira embasada a formação de um conjunto de indicadores, o presente item discute as questões de transporte encontradas com frequência na literatura que influenciam resultados da sustentabilidade urbana.

\subsubsection{Mobilidade Urbana}

Existem várias definições e acepções acerca do termo mobilidade. Neste item será abordado o termo em uso nas políticas públicas como forma de valorizar princípios 
universais e sustentáveis para as cidades brasileiras, ou seja, não se restringindo à ação de ir e vir, mas acrescido da preocupação com a sustentabilidade.

O Ministério das Cidades em conjunto com o Instituto Polis conceitua a mobilidade urbana conforme descrito a seguir:

"A mobilidade urbana é um atributo das cidades e se refere à facilidade de deslocamentos de pessoas e bens no espaço urbano. Tais deslocamentos são feitos através de veículos, vias e toda a infraestrutura (vias, calçadas etc.) que possibilitam esse ir e vir cotidiano. Isso significa que a mobilidade urbana é mais do que chamamos de transporte urbano, ou seja, mais do que o conjunto de serviços e meios de deslocamento de pessoas e bens. É o resultado da interação entre os deslocamentos de pessoas e bens com a cidade". (MINISTÉRIO DAS CIDADES, 2005)

Nota-se que o conceito tradicional de mobilidade está associado à disponibilidade de meios ou condições que facilitem o movimento ou deslocamento das pessoas e bens. Por isso, as estratégias de mobilidade se concentram, normalmente, as questões de tráfego, melhoria das condições do fluxo, aumento da velocidade e redução do tempo de deslocamento.

Existem alguns conceitos desenvolvidos internacionalmente sobre Mobilidade Urbana Sustentável. Mas no Brasil, as iniciativas em difundir o conceito têm sido coordenadas pelo Ministério das Cidades, representado pela Secretaria Nacional de Transporte e da Mobilidade Urbana (SEMOB), a qual tem se empenhado em formular uma definição para o tema, fornecendo diretrizes às políticas públicas. Para o Ministério das Cidades, a Mobilidade Urbana Sustentável pode ser definida como:

“...o resultado de um conjunto de políticas de transporte e circulação que visam proporcionar o acesso amplo e democrático ao espaço urbano, através da priorização dos modos não-motorizados e coletivos de transporte, de forma efetiva, que não gere segregações espaciais, socialmente inclusiva e ecologicamente sustentável."

Ao incorporar o nome sustentável ao conceito de mobilidade urbana, busca-se reforçar outros valores que devem ser levados em conta, como: aspectos sociais, políticos, econômicos e ambientais; os modos não-motorizados e coletivos de transporte e o planejamento integrado da cidade.

A mobilidade urbana garante o direito das pessoas de usufruírem dos serviços e oportunidades disponíveis nas cidades, assim como de manterem as relações sociais e econômicas. Assim, possui papel significativo na efetivação do direito à cidade, na superação da segregação e da fragmentação urbana. Portanto, deve ser considerada como um direito social que demanda políticas públicas eficazes.

Para o Ministério das Cidades (2005), a mobilidade urbana deve ser pensada em como se organizam os usos e a ocupação da cidade e a melhor forma de garantir o acesso 
das pessoas e bens ao que a cidade oferece - emprego, escolas, hospitais, praças e áreas de lazer-, e não apenas pensar os meios de transporte e o trânsito.

Os usuários de transporte de cargas exercem forte pressão nos sistemas de transportes, tendo seu crescimento relacionado à situação econômica do país. Contudo, é mais usual encontrar na literatura estudos de sustentabilidade urbana centrados no transporte de passageiros, sem muita atenção dada à movimentação de cargas. Pensar em cidades sustentáveis exige um planejamento de cargas e sua relação com o uso e ocupação do solo, emissões atmosféricas, mudanças climáticas, geração de emprego, preservação ambiental e impactos na comunidade.

O modelo de circulação de pessoas e cargas dentro do território urbano interfere no desenvolvimento econômico do País, pois dele dependem a logística de distribuição de produtos, a saúde e a produtividade de sua população, dentre outros (SeMob, 2015). Um sistema de transporte de mercadorias eficaz é necessário, uma vez que desempenha um papel significativo na competitividade de uma área urbana e é um elemento importante em sua economia, tanto em termos de rendimentos gerados quanto nos níveis de emprego que suporta (SHIBAO et al., 2018). Além disso, por garantir o acesso das pessoas aos bens e locais desejados, é fator preponderante na qualidade de vida dos cidadãos.

A importância da mobilidade urbana para o desenvolvimento econômico e a equidade social, além dos muitos impactos que podem causar ao meio ambiente, têm exigido uma abordagem mais sustentável pelos gestores públicos. De acordo com UNHABITAT (2013) citado por SeMob (2015), sob a perspectiva ambiental, a mobilidade urbana sustentável aponta para três macroestratégias complementares de ação:

i. redução da necessidade de viagens motorizadas;

ii. mudança de viagens para os modos de transporte público coletivo e os não motorizados;

iii. inovações tecnológicas dos veículos e utilização de combustíveis mais limpos (incorporação de tecnologias de controle de emissões e de melhoria da eficiência energética).

No entanto, essa nova forma de entender e abordar a mobilidade no espaço urbano é recente. Diversos tratados, convenções e declarações internacionais, tais como a Agenda 21, a Convenção-Quadro das Nações Unidas sobre Mudanças Climáticas, as Conferências das Nações Unidas sobre Assentamentos Humanos (UN-Habitat), dentre outros, vêm alertando sobre a necessidade de alteração dos padrões de comportamento do setor, cobrando investimentos em tecnologias mais limpa e sistemas de circulação que reduzam os impactos negativos sociais, ambientais e urbanos associados à mobilidade urbana.

A partir da década de 1950 desencadeou nas regiões metropolitanas brasileiras um padrão de urbanização de expansão horizontal, caracterizado por crescimento de baixa densidade, o qual foi marcado pela metropolização. As políticas de transporte e os processos de urbanização, por sua vez, basearam-se no modelo rodoviarista, privilegiando 
o uso de veículos particulares para a mobilidade urbana. Investiu-se em obras de grandes vias expressas, túneis e viadutos para auxiliar no escoamento do tráfego, com baixo investimento em infraestrutura de transportes coletivos e não-motorizados.

De acordo com Cavalcanti et al. (2018), ainda se vive no Brasil um paradoxo em que figuram de um lado uma indústria automobilística com alta capacidade de produção aliada a programas econômicos de estímulo ao consumo e, de outro, cidades com sistemas viários ultrapassados, assim como transporte coletivo ineficiente e de baixa qualidade. Aliado a isso, a popularização do automóvel parece estar relacionada a fatores psicológicos pela população brasileira, tais como o prazer, a privacidade, o controle pessoal, status social e a representatividade, acarretando na resistência à coletivização do transporte. Assim, muitos habitantes continuam optando pelo uso do veículo particular.

Esse modelo de mobilidade urbana favorece o espraiamento das cidades e a fragmentação do espaço devido à flexibilidade dos deslocamentos automobilísticos, forçando as cidades se estruturem e se desenvolverem para assegurar-lhe a melhor condição possível de deslocamento de veículos particulares nas áreas urbanas. Com isso, questões como segregação espacial das atividades e serviços urbanos, altos índices de congestionamentos, ineficiência do transporte coletivo e poluição atmosférica e sonora estão cada vez mais presentes no contexto das metrópoles.

Muitos dos problemas atuais de mobilidade decorrem, segundo Costa et al., (2005), dos seguintes aspectos: o foco no transporte privado e não no transporte público, com forte concentração de investimentos em infraestrutura para o automóvel; o crescimento urbano descontrolado e não planejado; e a mudança contínua para modos de transporte insustentáveis. Esses problemas estão acentuados nas metrópoles, onde a maior concentração de pessoas gera números mais elevados de deslocamentos, tanto com transporte de carga, quanto de passageiros.

Fica cada vez mais evidente que a sustentabilidade urbana no contexto de regiões metropolitanas depende, dentre outros, de uma redução drástica no número de carros particulares, uma redução no número de viagens e nos quilômetros totais percorridos pelos veículos motorizados. Alcançar esses objetivos implica em novas alternativas de mobilidade, carros mais eficientes e maior integração do transporte com os usos do solo.

A crise de mobilidade urbana que as metrópoles brasileiras têm enfrentado nos últimos anos decorrem, sobretudo, do processo contínuo de crescimento periférico, com atividades dispersas e pulverizadas em uma grande mancha urbana, associado à priorização do modo de transporte motorizado individual em detrimento das formas coletivas de deslocamento.

No que se refere ao transporte de cargas, Shibao et al. (2018) afirmam que, ainda hoje, o modo rodoviário é fundamental para as atividades econômicas e sociais que ocorrem em áreas urbanas, porque abastece lojas, locais de trabalho ou lazer, entrega de mercadorias nas residências, transporta o lixo e assim por diante. Em que pese o modo rodoviário apresentar restrições em função da tipologia da carga, do volume e do peso, 
"o modo rodoviário possui um papel fundamental no transporte de cargas por ser, em essência, o único capaz de realizar o serviço porta-a-porta” (PNT, 2018).

Com a intensificação da urbanização voltada aos automóveis e uma rede de transporte público insatisfatória, o cidadão metropolitano tem vivenciado um aumento progressivo dos índices de congestionamentos, comprometendo o fluxo de pessoas e de carga. Os congestionamentos, apesar de afetar toda a população, atinge com maior intensidade os trabalhadores que residem distantes do local de trabalho, em sua maioria moradores das regiões periurbanas, que desperdiçam horas diárias no trânsito, amontoados nos precários meios de transporte coletivos, reduzindo assim consideravelmente sua qualidade de vida.

Como consequência do alto índice de congestionamento pelo uso predominante dos automóveis, há maior perda de tempo nas viagens, consumo desnecessário de combustíveis e o aumento da emissão de poluentes na atmosfera, afetando significativamente a saúde urbana. Logo, esse padrão de transporte urbano gera impactos insustentáveis sobre a qualidade de vida nas cidades.

As políticas de incentivo e intensificação do uso do automóvel em detrimento do transporte público e do não motorizado causam grandes iniquidades sociais, desequilíbrios econômicos frequentes nos serviços e orçamentos públicos e, ainda por cima, agridem bastante o meio ambiente, em função das emissões de poluentes, ruídos e intrusão visual (IPEA, 2016).

Embora o transporte público coletivo reduza a ocupação do espaço das vias e transporte um número maior de pessoas, o histórico privilégio dado ao uso do automóvel particular nas cidades influenciou os investimentos em transporte coletivo por ônibus, visto que se tornou a maneira mais simples e com menores investimentos iniciais de se viabilizar, por utilizar a mesma infraestrutura dos automóveis. Entretanto, não se resolveu os inúmeros impactos negativos provocados por esse modo, em especial a poluição atmosférica (e sonora), agravada pelo uso do combustível a diesel, e a sobrecarga da infraestrutura viária.

Os chamados modos não-motorizados, como a locomoção por meio da caminhada ou de bicicleta, além de serem os modos mais acessíveis e baratos, colaboram para redução da emissão de gases na atmosfera, reduzem o nível de ruído, permitem uma maior interação com o espaço urbano, trazem benefícios à saúde de seus usuários, dentre outros benefícios relacionados à qualidade de vida da população e aos custos de implantação e manutenção dos sistemas viários.

Embora as evidentes vantagens de uso, os modos não-motorizados têm sido historicamente desprezados nas políticas de transporte, sendo muitas vezes negligenciados pelos tomadores de decisão e técnicos envolvidos no planejamento de sistemas de transportes urbanos. Estruturas urbanas voltadas a pedestres e ciclistas, por exemplo, exigem distâncias mais curtas e uma cidade compacta com densidade qualificada, um uso misto do solo equilibrado e um tamanho limitado da sua área total, 
além de caminhos atraentes e seguros, com espaços públicos no entorno com elevada qualidade estética (ECOCITY, 2001).

Para os transportes públicos, é importante, além da expansão da cobertura geográfica do sistema, a seleção apropriada de locais para novas construções, buscando alcançar um desenvolvimento policêntrico e uma concentração descentralizada das empresas, próximas às estações de linhas de transporte público. De acordo com o MCidades (2004), o transporte urbano sendo inserido no planejamento integrado das cidades, incorporando os princípios da sustentabilidade e tendo o seu planejamento e controle submetido aos interesses da maioria da população, pode se tornar um relevante e eficaz instrumento de reestruturação urbana e vetor da expansão controlada ou direcionada das cidades.

Fica evidente que a mobilidade urbana sustentável deve ser tratada como um eixo da política de desenvolvimento urbano. A priorização de ações nas regiões metropolitanas converge, ainda que indiretamente, ao estabelecido no Estatuto da Cidade, que define como obrigatória a elaboração do plano de transporte urbano integrado, compatível com o plano diretor ou nele inserido, para cidades acima de 500 mil habitantes. Além disso, os instrumentos urbanísticos previstos propiciam um maior controle sobre a expansão urbana, indicando um maior aproveitamento da infraestrutura existente, que, somados aos mecanismos de participação da sociedade a partir dos orçamentos participativos e estudos de impacto de vizinhança, cria melhores condições para busca de soluções mais adequadas para o uso do espaço urbano integrado aos sistemas de transportes.

Ainda que os Planos Diretores - instrumentos básicos da política de desenvolvimento e expansão urbana - tradicionalmente veem estabelecendo diretrizes para a expansão/adequação dos sistemas de transporte, o Estatuto da Cidade não trata especificamente sobre a mobilidade urbana. Diante da necessidade de incorporar os princípios da mobilidade urbana, priorizando a mobilidade das pessoas e não dos veículos, o acesso amplo e democrático ao espaço urbano e os meios não-motorizados de transporte, foi necessário conduzir a edição de um normativo autônomo, para ampliar o conceito além dos transportes urbanos, resultando na Política Nacional de Mobilidade Urbana - PNMU, com a promulgação da Lei nº 12.587, de 3 de janeiro de 2012.

Apesar dos avanços nas políticas públicas, ainda há muitos desafios da mobilidade urbana para as regiões metropolitanas brasileiras, visando prover transporte de qualidade aos seus habitantes. Tais desafios não se restringem aos sistemas de transporte e são de naturezas diversas, como questões institucionais, tecnológica, socioeconômica e do uso e ocupação do solo. É preciso repensar o espaço urbano, a fim de ter cidades mais compactas e com o uso do solo mais diversificado de forma integrado aos modos de transporte, e que estes sejam mais equilibrados (intermodalidades) e distribuídos espacialmente. 


\subsubsection{Acessibilidade}

O planejamento convencional de transporte tende a se concentrar na melhoria da mobilidade ou nas viagens de veículos (LITMAN, 2016). Durante décadas, as políticas de transporte buscaram fornecer mobilidade com base no transporte motorizado, visando melhorar a velocidade do tráfego, o nível dos serviços e os custos relativos. Com isso, justificam a ampliação da capacidade das rodovias, tendendo a criar sistemas de transporte e uso do solo mais orientados para o automóvel.

A palavra "acesso" era utilizada, no contexto dos transportes, como sinônimo de construção de novas estradas e outras infraestruturas, beneficiando principalmente a utilização de automóveis particulares. Contudo, ao projetar sistemas que apenas permitam viagens mais rápidas e mais distantes, priorizando os modos motorizados individuais, os não-motoristas podem se tornar socialmente excluídos devido à limitação de acesso e preocupações com segurança.

Uma das principais importâncias do transporte sustentável está no motivo pelo qual o transporte ocorre. De modo geral, as viagens ocorrem por alguma finalidade específica, como ir ao trabalho, levar as crianças na escola, comprar algum produto, entre outras. Assim, se nos concentramos no objetivo final da viagem, ou seja, na real necessidade do usuário do sistema de transporte, podem surgir soluções que permitam que uma pessoa tenha acesso ao bem, serviço, atividade ou destino que está sendo buscado de maneira mais sustentável.

A acessibilidade é uma medida fundamental da equidade social (BARTON, 2000); "refere-se à capacidade de um indivíduo de alcançar bens, serviços e atividades com base em fatores como mobilidade, opções de transporte, conectividade do sistema, substitutos de mobilidade e padrões de uso da terra" (LITMAN, 2012). Difere, portanto, da "equidade", que se refere à justiça com a qual os impactos (benefícios e custos) são distribuídos, e da "mobilidade", que está relacionado ao movimento físico, independentemente do meio utilizado (carro, ônibus, trem, bicicleta ou pé). A mobilidade está associada a acessibilidade, uma vez que se refere "a viagens que fornecem acesso básico a bens, serviços e atividades" (LITMAN, 2016).

A mobilidade não é uma variável independente, mas sim integrada com a acessibilidade. Medidas de mobilidade e acessibilidade são distintos e se complementam. Mobilidade representa a capacidade / facilidade de deslocamento (por exemplo, o tempo de viagem, taxa de viagens); enquanto a acessibilidade é a capacidade / facilidade oferecida para conectar a origem de uma viagem com seu destino, ou seja, de as pessoas obterem bens, alcançarem destinos ou atividades desejadas.

Geurs e Van Wee (2004, apud ANDRADE e TAVARES, 2017) identificaram quatro componentes usados para definir acessibilidade: i) uso do solo, incluindo características das localidades e suas oportunidades; ii) transportes, incluindo a qualidade 
e o desempenho das redes e dos serviços; iii) o componente temporal, incluindo a disponibilidade de oportunidades ao longo do dia; e iv) o componente individual, incluindo as necessidades, capacidades e oportunidades das pessoas.

Logo, muitos fatores afetam a acessibilidade, incluindo mobilidade, fatores de uso do solo (como a localização de atividades) e substitutos de mobilidade (como telecomunicações e serviços de entrega). O planejamento baseado em acessibilidade expande as opções de soluções que podem ser aplicadas para problemas de transporte. Por exemplo, o congestionamento pode ser reduzido através da melhoria da acessibilidade do uso da terra ou das telecomunicações, além de acomodar mais tráfego de veículos.

Nesse sentido, para planejar, dimensionar e operacionalizar um sistema de transporte é fundamental considerar a acessibilidade, com o preceito de garantir acessibilidade da população entre diferentes pontos da cidade, e, especialmente, contribuir estrategicamente para o desenvolvimento urbano por meio da democratização dos deslocamentos de pessoas e cargas. Infraestrutura de transporte, acessibilidade e uso do solo estão inter-relacionados e, idealmente, estas devem ser avaliadas conjuntamente.

Indicadores comuns de acessibilidade incluem a qualidade das opções de transporte disponíveis, distâncias médias de viagem e custos por viagem (LITMAN, 2016; RAMANI et al., 2011). O uso do solo é outro indicador de acessibilidade. As áreas de uso misto e alta densidade permitem que os indivíduos tenham maior acesso a diferentes serviços, como emprego, educação e varejo. De acordo com Marins (2010), o nível de acessibilidade pode ser verificado "pela proximidade de pontos de parada, estações e terminais de transporte dos locais com maior demanda de transporte (acessibilidade física), das possibilidades de pagamento de tarifa (acessibilidade econômica) e também da disponibilidade de destinos para uma dada origem de deslocamento (acessibilidade físico-temporal)".

As regiões metropolitanas brasileiras apresentam condições muito complexas e críticas no que diz respeito aos níveis de acessibilidade e mobilidade urbanas, principalmente em função da diversidade do uso e ocupação do solo e do volume populacional envolvido. Geralmente, quanto melhor é a mobilidade, maior é a acessibilidade, uma vez que quanto mais uma pessoa pode se transportar, mais destinos ela consegue alcançar. Logo, adotar ações e medidas que aumentem a eficiência na mobilidade é também contribuir para melhorar a acessibilidade.

A eficiência na mobilidade pode ser alcançada otimizando o sistema de transporte por diversas maneiras. Uma possibilidade é pelo Gerenciamento de Demanda de Transporte, que consiste em uma série de técnicas que podem ser usadas para solucionar problemas de congestionamento e sustentabilidade, buscando reduzir o número de viagens, sem a necessidade de implantação de novas infraestruturas para aumentar a capacidade operacional, a um custo geralmente menor. As práticas usuais incluem a localização de polos geradores de tráfego perto do transporte público e de outras instalações de transporte, compartilhamento de caronas, o fornecimento de horários de 
trabalho flexíveis, incentivo a videoconferências e teletrabalho, aplicação de pedágios ou aumento de valores de acordo com o nível de congestionamento na rodovia, de forma a incentivar os usuários da rodovia a dirigir durante períodos fora de pico ou a usar modos ou rotas alternativos. Pode-se, ainda, fornecer opções de modos que sejam eficientes em termos de uso de energia, emissões e custo, tais como transporte público, caminhadas ou utilização de bicicletas em áreas urbanas, que contribuem para redução do congestionamento.

Existem também ferramentas úteis para otimização do sistema rodoviário, como aplicativo-comunidade de direção que fornece mapas e informações de tráfego dos usuários (Waze, Google Maps, etc.), estratégias de precificação (pedágios e preços de congestionamento), programa de restrição de uso de veículos, como por exemplo o rodízio no município de São Paulo, que proíbe a circulação de automóveis em um dia da semana de acordo com o número da placa.

\subsubsection{Equidade (ou Justiça Social)}

A equidade é amplamente mencionada como um princípio básico na sustentabilidade de transportes e mobilidade. Equidade social, também chamada justiça social, refere-se à distribuição equitativa de impactos (benefícios, desvantagens e custos) ou, em outras palavras, à distribuição justa dos ônus e bônus pelos efeitos do transporte em grupos espaciais ou demográficos. Pressupõem, portanto, a promoção da qualidade de vida a partir da justa distribuição espacial e entre grupos sociais de oportunidade na acessibilidade e de desenvolvimento econômico, assim como de impactos ambientais negativos, como exposição a poluentes atmosféricos e ruído. Logo, conforme enfatizado por Litman \& Burwell (2006), este é um importante objetivo de planejamento e um requisito para o desenvolvimento sustentável, que equilibra objetivos econômicos, sociais e ambientais.

"O conceito de equidade é fundamental para a estruturação da política de transportes e para o planejamento de transportes" (GUIMARÃES e LUCAS, 2017). Para estes autores, o princípio da equidade também está associado à igualdade de oportunidades na mobilidade, destacando as mulheres, pessoas idosas, pessoas com deficiências físicas e grupos de baixa renda que enfrentam diferentes tipos de restrições que limitam sua mobilidade e seu espaço de oportunidades na sociedade.

Ao planejar o sistema de transportes é importante considerar o princípio da equidade, de forma a reduzir as desigualdades socioespaciais. Contudo, o planejamento convencional de transportes tende a se concentrar em objetivos econômicos (redução de congestionamentos e aumento de velocidade de viagens, redução de custos de viagens e segurança no tráfego), muitas vezes deixando esse princípio em segundo plano, sem a 
preocupação em promover resultados mais equitativos, que contribua para reduzir as desigualdades.

A equidade tem várias implicações potenciais para a política de transporte, mas há poucas diretrizes a serem usadas na avaliação desses vários tipos de equidade de transporte no Brasil. Litman (2018) lista três categorias principais de equidade de transporte:

1. Equidade Horizontal: A equidade horizontal (também chamada de justiça e igualitarismo) diz respeito à distribuição de impactos entre indivíduos e grupos considerados iguais em habilidade e necessidade. De acordo com essa definição, indivíduos e grupos iguais devem ser tratados da mesma forma na distribuição de recursos / benefícios e custos. Isso significa que as políticas públicas devem evitar favorecer um indivíduo ou grupo em detrimento de outros, e que os consumidores devem "obter o que pagam e pagar pelo que recebem" de taxas e impostos, a menos que os subsídios sejam especificamente justificados.

2. Equidade Vertical Com relação à Renda e à Classe Social: A equidade vertical (também chamada de justiça social, justiça ambiental e inclusão social) preocupa-se com a distribuição de impactos entre indivíduos e grupos que diferem, neste caso, por renda ou classe social. Por essa definição, as políticas de transporte são equitativas se favorecerem grupos economicamente e socialmente desfavorecidos. Esta definição suporta melhorias no modo acessível, serviços especiais e descontos para grupos de baixa renda, e esforços para assegurar que os grupos desfavorecidos não suportem custos externos excessivos (poluição, risco de acidente, custos financeiros, etc.).

3. Equidade Vertical em Relação à Necessidade e à Habilidade em Mobilidade: Refere-se à distribuição de impactos entre indivíduos e grupos que diferem em capacidade e necessidade de mobilidade e, portanto, no grau em que o sistema de transporte atende às necessidades de pessoas com mobilidade reduzida.

No Brasil, a equidade é tratada no artigo $5^{\circ}$ como princípio na Política Nacional de Mobilidade Urbana (Lei $\mathrm{n}^{\circ}$ 12.587), promulgada em 2012, tanto de forma explícita nos incisos III ("equidade no acesso dos cidadãos ao transporte público coletivo"); e VIII ("equidade no uso do espaço público de circulação, vias e logradouros"), como implícita nos incisos I ("acessibilidade universal") e VII ("justa distribuição dos benefícios e ônus decorrentes do uso dos diferentes modos e serviços"). 


\subsubsection{Mudanças Climáticas}

O aumento da frequência e intensidade de eventos climáticos extremos vivenciados nos últimos anos em diversas regiões do mundo tiveram sua conexão com as mudanças climáticas confirmadas pelo IPCC (2012), ganhando destaque mundial para a gravidade das previsões relacionadas às mudanças climáticas. A adaptação ao clima e o desenvolvimento sustentável estão ligados de várias maneiras: primeiro, muitos dos determinantes da capacidade adaptativa para responder ao impacto sobre o clima e os indicadores do desenvolvimento sustentável se sobrepõem; segundo, a capacitação adaptativa pode contribuir para o bem-estar dos sistemas sociais e ecológicos; e terceiro, construir capacidade adaptativa dentro de uma estrutura de desenvolvimento sustentável pode exigir mudanças transformacionais (DOVERS e HEZRI, 2010; KATES et al., 2012; LEMOS et al., 2013 apud IPCC, 2014).

Embora o Brasil não estivesse incluído na lista de países necessários para reduzir suas emissões de gases de efeito estufa, o governo brasileiro estabeleceu, em 2010, sua Política Nacional de Mudanças Climáticas (PNMC, Lei no 12.187/2009 e Decreto $\mathrm{n}^{\circ}$ 7.390/2010), definindo como compromisso nacional voluntário ações de mitigação das emissões de gases de efeito estufa, com vistas a reduzir entre 36,1 e 38,9\% as emissões nacionais de Gases de Efeito Estufa (GEE) projetadas até o ano de 2020. Para alcançar esses objetivos, a PNMC estabeleceu os planos de mitigação e adaptação a serem desenvolvidos a nível local, regional e nacional.

Em 2015, reconhecendo a importância sobre as consequências das mudanças climáticas, a ONU incluiu no plano de ação da Agenda 2030, dentre os seus 17 Objetivo de Desenvolvimento Sustentável (ODS), o ODS 13, que visa "Tomar medidas urgentes para combater a mudança climática e seus impactos", prevendo, dentre suas metas, o reforço à resiliência e à capacidade de adaptação a riscos relacionados ao clima e às catástrofes naturais (13.1) e a integração das medidas da mudança do clima nas políticas, estratégias e planejamentos nacionais (13.2).

Ainda em 2015, no município de Paris / França, foi aprovado pelos 195 países participantes o "Acordo de Paris" durante a $21^{\text {a }}$ Conferência das Partes sobre o Clima da ONU (COP-21, do inglês Conference of the Parties), com o objetivo central de fortalecer a resposta global à ameaça da mudança do clima e de reforçar a capacidade dos países para lidar com os impactos decorrentes dessas mudanças. O compromisso principal do Acordo de Paris é o objetivo final de manter o aumento da temperatura média global em menos de $2{ }^{\circ} \mathrm{C}$ acima dos níveis pré-industriais e de envidar esforços para limitar o aumento da temperatura a $1,5^{\circ} \mathrm{C}$ acima dos níveis pré-industriais.

O progresso global na redução das emissões de gases de efeito estufa não pode ser realizado sem uma intervenção eficaz no setor de transportes, e para impulsionar o progresso em direção aos objetivos do Acordo de Paris e da Agenda 2030, a redução das 
emissões de gases de efeito estufa e o avanço da adaptação ao clima devem ser priorizados.

Se por um lado o setor de transporte é um dos principais contribuintes para as mudanças climáticas por meio de emissões de gases de efeito estufa (GEE), por outro, os impactos das mudanças climáticas, como aumento da temperatura, aumento do nível do mar e eventos climáticos mais extremos, podem ter um impacto significativo na infraestrutura de transporte. Dessa forma, as estratégias para reduzir e gerenciar os riscos das mudanças climáticas no setor de transporte requer a atuação em duas frentes distintas: Mitigação e Adaptação, que devem ser tratadas de forma complementar. Essas duas abordagens se constituem como conjuntos de estratégias para que agências de transporte possam lidar com as mudanças climáticas no seu escopo de atuação.

AASHTO (2009) defende que as ações práticas dessas abordagens são, em sua maioria, independentes, e requer a compreensão individual dos principais desafios envolvidos, estudos de cenários, definição de estratégias, previsão de custos e benefícios e planos de ação. Em poucos casos, há sobreposição das estratégias. Segundo IPCC (2014), um fator-chave na integração da mitigação e adaptação das mudanças climáticas na gestão sustentável de riscos é entender os processos de tomada de decisão em diferentes escalas, visto que a distribuição de custos e benefícios de mitigação e adaptação é diferente. Por exemplo, os benefícios de mitigação são mais globais, enquanto os benefícios de adaptação são geralmente mais localizados.

A mitigação à mudança climática no transporte consiste na adoção de medidas para evitar ou reduzir as emissões de GEE, que pode ser por meio da implementação de políticas ou instrumentos que fomentem mudanças nos processos produtivos e no setor energético, com a adoção de tecnologias mais limpas e eficientes. De modo geral, as medidas de mitigação de GEE são essencialmente relacionadas à economia de combustível ou outras economias de energia. Seguindo o consenso científico sobre a necessidade de reduções de emissões de GEE, deve haver um esforço em direção à "descarbonização" de sistemas de transporte (AASHTO, 2009), desde os veículos e combustíveis que movem pessoas e cargas até os processos que envolvem a construção e manutenção de infraestrutura.

Com relação à mitigação, o setor automobilístico merece atenção. De acordo com o Plano Nacional de Energia 2050 (PNE), o uso de veículos automotivos ainda será prática predominante no País nas próximas décadas. "Como resultado do cenário de vendas de veículos leves, estima-se que a frota de veículos leves em 2050 atinja cerca de 130 milhões de unidades, valor que inclui veículos individuais e comerciais leves" (EPE, 2014), o que significa um aumento de aproximadamente três vezes a quantidade atual. Essas projeções mostram a urgência na adoção estratégias de mitigação com foco direcionado à redução da intensidade de emissões deste setor, como, por exemplo, enfoques na frota de veículos automotivos, nos combustíveis utilizados e em políticas públicas de mobilidade urbana e de transporte de cargas. 
Reduzir a intensidade de emissões de GEE por meio de políticas de mobilidade consiste, principalmente, no oferecimento de infraestrutura para a circulação de pessoas e cargas de forma mais carbono-eficiente, podendo abranger dois tipos de abordagens: (i) aquelas que focam em trazer melhorias para a infraestrutura e o uso dos modais de transporte de alta intensidade; ou (ii) que visem uma transferência para modais de baixa intensidade de emissões (GVces, 2015). Quando aplicadas ao modal rodoviário, a primeira contem ações que visam melhorias na malha rodoviária, na fluidez do tráfego e/ou no comportamento de motoristas e, a segunda, visa reduzir o predomínio do modal rodoviário na matriz de transportes brasileira, diversificando outras modalidades com maior eficiência energética.

Por outro lado, as agências de transporte devem se preparar para as incertas e inevitáveis alterações climáticas num futuro próximo. Essa preparação requer a adaptação dos sistemas de transporte, "adaptando-se às mudanças futuras nas realidades físicas sob as quais o sistema de transporte deve continuar a executar" (AASHTO, 2009). A FHWA (2008, apud AASHTO, 2009) definiu a adaptação nos transportes como "Ações de indivíduos ou sistemas para evitar, resistir ou aproveitar as mudanças e impactos climáticos atuais e projetados. A adaptação diminui a vulnerabilidade de um sistema ou aumenta sua resiliência a impactos."

As alternativas de mitigação ou estratégias potenciais para reduzir as emissões de GEE, diretas e indiretas, comumente encontradas na literatura aplicáveis ao setor de transporte podem ser distribuídas da seguinte forma:

- Redução na demanda de transporte - evitando viagens desnecessárias ou sempre que possível. Por exemplo: fazer compras pela internet, reestruturar sistemas logísticos de frete e utilizar tecnologias avançadas de informação e comunicação, encurtar distâncias de viagem com a compactação e densificação urbana e o zoneamento misto das cidades. Estratégias de preços, quando apoiadas por políticas educacionais, podem ajudar a reduzir a demanda de viagens por veículos motorizados individuais e aumentar a demanda por veículos mais eficientes e induzir uma mudança para modos de baixo carbono, quando disponível.

- Eficiência energética (Unidade de Energia/passageiro-km) - aumentar o desempenho dos veículos motorizados por quaisquer vias (terrestres, marítimas ou aéreas) e dos motores pelos fabricantes, em termos de consumo de combustíveis ou energéticos, utilizando materiais leves, otimizando as operações e a logística (especialmente para movimentos de frete), aumentando taxas de ocupação de passageiros, implantando novas tecnologias nos veículos (eletrificação), incentivando a pesquisa e o desenvolvimento no aumento na eficiência energética com adoção de tecnologias mais limpas, etc.

- Fontes de energia de transporte de baixo carbono $\left(\mathrm{CO}_{2} \mathrm{eq} / \mathrm{energia}\right)$ - consiste em aprimorar tecnologias e priorizar o uso de combustíveis com baixo teor de carbono, substituindo os produtos à base de petróleo por gás natural, biometano ou biocombustíveis (etanol, biodiesel), eletricidade (em curto e médio prazo) ou 
hidrogênio (em longo prazo) produzidos a partir de fontes de energia renovável ou outras tecnologias de baixo carbono.

- Sistemas de transporte de baixo carbono e integração do transporte com o uso do solo - priorizar investimentos e o uso de sistema de transporte mais eficientes e de baixo carbono em detrimento aos veículos motorizados individuais contribui para emitir menos GEE por km/passageiro, como transportes coletivos e não motorizados (caminhadas e ciclovias). Tais ações podem ser incentivadas pelo planejamento urbano, com um uso do solo urbano mais denso e compacto, e pelo desenvolvimento de uma infraestrutura segura e eficiente.

- Eficiência e otimização de sistema de transporte existente - consiste no uso de tecnologias (como tecnologia de sistema de transporte inteligente e sua ampla aplicação), em investimentos em gargalos e locais com maior potencial para reduzir o congestionamento, gerenciamento de demanda de tráfego, e modificação de estradas, aeroportos, portos e ferrovias, para se tornarem mais atraentes aos usuários e minimizar o tempo de viagem e/ou as distâncias. Há ainda as políticas de redução de carbono relacionadas ao comportamento dos condutores (limitar de velocidade, evitar marcha lenta e partidas rápidas, evitar uso desnecessário de ar condicionado e incentivar a direção ecológica no geral).

- Práticas de construção e manutenção de infraestrutura, fabricação de veículos e fornecimento de combustiveis, priorizando a utilização de materiais com baixo teor de carbono, fazendo a gestão adequada dos resíduos, promovendo o reflorestamento, reduzindo a supressão vegetal, etc.

Tais estratégias de mitigação das alterações climáticas no setor dos transportes podem resultar em muitos co-benefícios, tendo como mais expressivos os seguintes: redução no tráfego, saúde associada à qualidade do ar e segurança energética. Todavia, a concretização e implementação dessas estratégias depende do contexto regional e institucional, em termos da sua viabilidade econômica, social e política, bem como do acesso e desenvolvimento de tecnologias.

Considerando a predominância da infraestrutura rodoviária, cuja mudança de modal pode ser inviável em curto e médio prazo, apoiar as tecnologias avançadas de veículos e dos combustíveis, os sistemas inteligentes, a conscientização dos motoristas, complementados por um planejamento urbano sustentável, parecem ser bastantes razoáveis para alcançar resultados positivos. Para o transporte de cargas, é importante avançar com políticas fiscais e regulatórias para incentivar empresas a reduzir a intensidade de carbono de seus sistemas logísticos.

Apesar de uma série de possibilidades para a redução da emissão de carbono, a relação custo-eficácia entre as diferentes medidas tende a ser mais precisa para determinar a eficiência energética e as fontes de energia de transporte de baixo carbono, em função da maior facilidade de mensuração e por estar menos susceptível às diferenças regionais e das suas condições. 
As agências de transporte têm atuação limitada na implementação de medidas para mitigação da emissão de GEE, exigindo, muitas vezes, que as medidas sejam amparadas por políticas mais abrangentes. Como estratégia das agências para ações de mitigação, há a possibilidade de melhorar a integração com os demais setores que são mais vulneráveis aos impactos das mudanças climáticas a nível local, como por exemplo a área da saúde, que se beneficia com a redução da emissão de poluentes atmosféricos e da poluição sonora; com o governo, que pode reduzir a cobrança de impostos de práticas tecnológicas e sustentáveis que mitiguem a emissão de GEE, entre outros.

De acordo com IPCC (2014), reduzir as emissões globais de GEE do transporte será um desafio, já que o crescimento contínuo da atividade de passageiros e carga pode superar todas as medidas de mitigação, a menos que as emissões possam ser fortemente desacopladas do crescimento do PIB. Complementarmente, os autores lembram que as barreiras para descarbonização de transportes para todos os modos diferem entre as regiões, sendo que as barreiras financeiras, institucionais, culturais e legais acabam limitando a adoção de tecnologia de baixo carbono e a mudança comportamental.

Como as ações de mitigação por redução de emissões de GEE não são adequadamente gerenciadas pelas agências de transporte e podem levar muito tempo para alcançar resultados positivos, a adaptação aos impactos das mudanças climáticas, em alguns casos, pode ser a única resposta possível e viável para enfrentar o problema. AASHTO (2009) comenta que o artigo do Conselho de Pesquisa de Transporte de Henry Schwartz - Impactos das Mudanças Climáticas nos Transportes dos EUA - descreve várias áreas de adaptação às mudanças climáticas que afetam as agências de transporte: (a) elevação do nível do mar (inundações e impacto de infraestrutura, evacuação, erosão de infraestrutura); (b) aumento na frequência de fortes furacões (serviço aéreo e evacuação, impactos portuários e portuários); (c) aumento em eventos de precipitação intensa (interrupções de tráfego e atrasos de companhias aéreas, inundações); e (d) aumento na frequência de dias quentes (expansão térmica de materiais rodoviários, redução de horas de produtividade de construção e atrasos de construção).

De modo geral, as possíveis alternativas para a adaptação aos impactos da mudança climática incluem:

- Adequação em infraestrutura - projetar infraestrutura em cota compatível com eventual aumento do nível do mar ou de acúmulos de água; projetar sistema de drenagem para precipitações extremas; prever proteção contra corridas de massa e inundações; etc.

- Planejamento estratégico - planejar infraestrutura de transporte a longo prazo que considere os efeitos das mudanças climáticas.

- Retrofit e redesenho - Redesenhar as instalações de transporte para suportar e operar em eventos climáticos extremos, incluindo rotas de evacuação.

- Pesquisa - Realizar pesquisas de adaptação, incluindo o mapeamento de infraestrutura vulneráveis, entre outras. 
As estratégias para adaptação a serem implantadas a curto, médio e longo prazo devem ser baseadas na vulnerabilidade e nos riscos relacionados aos potenciais efeitos, diretos e indiretos, das mudanças climáticas sobre os sistemas de transporte, garantindo que sejam implementadas as medidas de adaptação necessárias. Porém, não é tarefa fácil. É possível que inúmeras barreiras ambientais, econômicas, sociais e culturais possam inviabilizar a adoção das medidas de adaptação e, portanto, precisam ser enfrentadas.

Os custos com investimentos para mitigação e adaptação às mudanças climáticas no setor de transporte são, geralmente, muito elevados, consistindo em barreiras significativas para a efetiva implementação. Contudo, muitos pesquisadores sugerem que esses investimentos podem ser superados em parte pela redução dos custos marginais resultante das medidas implementadas. Como exemplo, podem ser citados os investimentos em infraestruturas, que inicialmente podem parecer caros, mas, se integrado ao planejamento urbano sustentável e demais políticas relacionadas, podem compensar parte ou a totalidade dos custos da mitigação com os co-benefícios relacionados à melhoria da saúde e acessibilidade, entre outros.

Em função da considerável subjetividade que envolve o tema, há grandes desafios para os processos de planejamento e gerenciamento praticados pelas agências no Brasil visando a redução da emissão de GEE e a adaptação dos sistemas de transporte, sobretudo, pela cultura rodoviarista predominante, do baixo investimento em tecnologia e dos custos necessários para a adaptação de infraestruturas.

Contudo, com uma abrangência ainda deficiente em infraestrutura no País, há oportunidades para mudanças estruturais que prevejam sistemas de transporte de baixo carbono. Enquanto mudanças estruturais não são realizadas, pode-se avançar no desenvolvimento contínuo de políticas que incorporem uma combinação de projetos e adequação de infraestruturas, avanços tecnológicos e programas de conscientização envolvendo mudanças comportamentais, a fim de alcançar resultados positivos para o cenário das mudanças climáticas.

\subsubsection{Poluição do Ar}

As regiões metropolitanas enfrentam, periodicamente, episódios críticos de poluição do ar. Essa poluição é decorrente, principalmente, das emissões de veículos automotores que circulam pelas vias urbanas, em grande quantidade, como o principal meio de transporte. A sucessão de políticas urbanas que privilegiam as grandes obras viárias e o transporte veicular, sem investimentos em transporte de massas (metrô e trens urbanos), os veículos automotores passaram a constituir a principal fonte de deterioração da qualidade do ar. Em função das condições físicas, as regiões metropolitanas têm o agravante de dificultar a dispersão de poluentes e expor muitas pessoas, em função do excesso de prédios e da concentração de moradias. 
O uso de combustíveis fósseis pelo sistema de transporte rodoviário está entre os principais responsáveis pela má qualidade do ar nas cidades, além de ser um dos principais contribuintes dos gases de efeito estufa.

O problema da poluição atmosférica é grave. A gravidade do problema se expressa por meio dos prejuízos à saúde da população, especialmente das pessoas mais vulneráveis, como idosas e crianças. A poluição do ar está associada a doenças respiratórias e cardiovasculares com óbitos, tais como: isquemia (doença cardíaca); derrame; doença pulmonar crônica; câncer de pulmão; e infecções respiratórias etc.

Os carros a álcool e a gasolina são importantes emissores de monóxido de carbono (CO), óxido de nitrogênio (NOx) e hidrocarbonetos (HC), enquanto os veículos com motor de ciclo diesel, em especial os caminhões e ônibus, são importantes emissores de óxidos de nitrogênio (NOx) e material particulado (fuligem), e, em menor grau, de monóxido de carbono ( $\mathrm{CO}$ ) e hidrocarbonetos (HC). Os óxidos de nitrogênio têm importância singular, pois, além de possíveis efeitos diretos, contribuem para formação do Ozônio na troposfera por fotólise. São também causadores da formação da deposição ácida (ou mais comum, a chuva ácida).

Os padrões de qualidade do ar no Brasil são estabelecidos pela Lei Federal $n^{\circ}$ 8.028/90, com o Decreto Federal n 99.274/90 e a Resolução CONAMA n 03/90, ampliando o número de parâmetros anteriormente regulamentados pela Portaria GM $\mathrm{n}^{\circ}$ $231 / 76$.

\subsubsection{Desenvolvimento Urbano e o Uso do Solo}

As condições de transporte aparecem como fator decisivo na estruturação do espaço urbano (VILLAÇA, 2001). No Brasil houve diversos planos de integração do território ao longo da história, mas foi o setor rodoviário, a partir da década de 1950, que ganhou mais destaque entre os demais modos de transporte. Os outros modos de transporte, praticamente sem investimento, pouco se ampliaram durante este tempo. $\mathrm{O}$ transporte de cargas e passageiros passou a ser realizado cada vez mais por rodovia, por incentivo do governo de Juscelino Kubitscheck, favorecendo a indústria automobilística que passou a se instalar no País e se constituindo como elemento alavancador do processo de integração e desenvolvimento do país. Por um lado, favoreceu a integração territorial e a dinamização da economia do País, inserindo o Brasil no mercado internacional, por outro lado, tem provocado impactos negativos ao meio ambiente e degradação crescente na qualidade de vida urbana relacionados à circulação viária.

Desde então, conforme observado por Vasconcellos (1996), privilegiar a circulação de automóveis passou a ditar a tônica dos planejamentos territoriais urbanos: as cidades começavam a ser pensadas e construídas para os automóveis. No longo prazo, essa priorização tem se demonstrado ineficiente, especialmente em regiões 
metropolitanas, trazendo consequências negativas para a forma urbana e resultando em territórios cada vez mais distantes fisicamente (e socialmente), com um tecido urbano fragmentado, desconectado e disperso.

A expansão do sistema viário para atender à fluidez para o automóvel, além de consumir espaços territoriais urbanos, promove um padrão de crescimento desordenado, o espraiamento urbano e um processo de suburbanização nas áreas periféricas, e uma menor vinculação do uso do solo à acessibilidade estrutural por meios coletivos. À medida em que se aumenta a expansão urbana para áreas periféricas, aumentam-se as distâncias de deslocamentos em massa, especialmente em direção aos grandes centros empresariais, dificultando-se a ampliação de infraestruturas e serviços de transporte com capacidade adequada.

A suburbanização e a periferização, por sua vez, produzem estruturas de assentamento espacialmente difusas e funcionalmente segregadas na maioria das metrópoles brasileiras, levando à consolidação de um processo de exclusão social e de segregação espacial. O planejamento de transportes incentivou a expansão geográfica ao invés de melhorar a infraestrutura existente para acomodar áreas com maiores concentrações demográficas, levando à descentralização das cidades ou à sua expansão, e, consequentemente, criando barreiras para grupos desfavorecidos terem acesso igualitário a cuidados de saúde, habitação a preços acessíveis e oportunidades econômicas.

Uma cidade fragmentada e dispersa tende a consumir mais energia e ter custos mais elevados com redes de infraestrutura (água, eletricidade, telefonia, infraestrutura de transporte) e com serviços públicos. Esta forma de ocupação leva ao desperdício do solo urbano e ao aumento dos custos de infraestrutura e dos serviços urbanos, além do consumo de energia e, consequentemente, a poluição do ar causada pela utilização de transporte motorizado. Uma metrópole espraiada e dispersa significa maior tempo de deslocamento de seus habitantes, maior tráfego de veículos e maior movimento pendular entre o local de moradia e o local de trabalho (LENCIONI, 2008).

Essa tendência contínua desses padrões de crescimento urbano dissociados à política de transportes causa o consumo irracional de recursos naturais e de terra pela urbanização, além do aumento nos volumes de tráfego, que resulta em maior gasto de tempo e combustíveis (sendo os fósseis não-renováveis os mais prejudiciais) no trânsito congestionado, aumento do número de acidentes e lesões nas vias urbanas e poluição atmosférica, sonora e emissão de gases de efeito estufa (GEE), refletindo nos baixos índices de qualidade de vida da população.

Essa forma de crescimento urbano geralmente acontece de forma contraditória ao conceito de desenvolvimento urbano sustentável, embora este conceito seja direto ou indiretamente abordado em muitas das políticas urbanas e ambientais relevantes. Contudo, para resolver os problemas de congestionamento, adota-se, tradicionalmente, soluções na engenharia de tráfego e rodoviária ou na prestação do serviço de transporte, 
ignorando a forma como as cidades se desenvolvem e o planejamento do uso do solo integrado ao sistema de transporte.

Tal fato demonstra que a ausência de uma política sustentável para o transporte urbano está diretamente relacionada com a falta de qualidade do planejamento urbano praticado na cidade (MAGLIO e PHILIPPI JR., 2018). Enquanto houver uma expansão urbana sem planejamento de transporte, haverá uso desnecessário e dispendioso de recursos naturais associado à ineficiência energética.

Identifica-se, portanto, uma relação em que o uso do solo influencia o transporte, assim como o transporte influencia o uso do solo. Lautso et al. (2004) apresentam, no relatório PROPOLIS, algumas questões teóricas e estudos empíricos que procuram entender as interações entre Transporte e Uso do Solo. Segundo os autores, o impacto do Transporte sobre o Uso do Solo é obtido a partir de uma mudança na acessibilidade a uma localização. Uma melhor acessibilidade aumenta a atratividade para localização de todo o tipo de atividades, influenciando assim, a direção de um novo desenvolvimento urbano. Se, porém, a acessibilidade cresce em toda a cidade, isto resulta numa maior dispersão da estrutura urbana.

Os efeitos das atuais medidas de uso do solo e urbanismo na demanda de viagens são de longo prazo. Isso significa que as medidas de planejamento do uso do solo estabelecem os padrões de mobilidade urbana por gerações. Logo, novas infraestruturas de transportes têm implicações ligadas ao uso do solo e aos requisitos de energia e, portanto, devem ser planejadas de forma estratégica e integrada. Segundo Meyer e Miller (1984), a interação entre transporte e uso do solo é fundamentalmente importante para o planejamento e deveria representar o ponto de partida para as análises de políticas de transporte.

De acordo com WRI (2018), o qual apresenta um guia para inclusão do Desenvolvimento Orientado ao Transporte Sustentável (DOTS) no planejamento urbano, para atingir um desenvolvimento urbano sustentável, as cidades precisam reverter o atual modelo de crescimento 3D (distante, disperso e desconectado) para o modelo 3C (compacto, conectado e coordenado), visto que as cidades 3D levam a maiores deslocamentos diários, maiores índices de poluição, queda na qualidade de vida em geral e atingem principalmente os mais pobres, uma vez que apresentam configurações urbanas distante, com territórios periféricos muito afastados do centro; dispersa, com núcleos urbanos espalhados em todo o território; e desconectada, com núcleos urbanos não muito bem conectados aos demais núcleos e ao centro da cidade. Assim, estabelece os seguintes princípios para se chegar a esse modelo:

- Princípio Territorial 1 - O Crescimento Urbano Compacto: relacionado à contenção da dispersão urbana, à regulação do perímetro urbano e aos incentivos à densificação em áreas que possuem infraestrutura, como áreas próximas aos sistemas de transporte coletivo. Tem como base principal a regulação do adensamento populacional e construtivo ao longo dos eixos de transporte coletivo, 
a diversificação do padrão social e o controle do perímetro urbano, otimizando o território com disponibilidade de infraestrutura.

- Princípio Territorial 2 - Centralidades e Infraestruturas Conectadas: Relacionado à redução da necessidade de deslocamentos motorizados, incentivando o uso misto, aproximando as áreas de moradia e emprego e equilibrando a distribuição das atividades no território. Esse princípio incentiva, ainda, a criação de centralidades, conectadas através de um eficiente sistema de transporte coletivo. Tem como base aumentar a eficiência no uso das infraestruturas urbanas e reduzir a necessidade de deslocamentos, através da mescla de usos em toda a área urbana, da criação de centralidades (território policêntricos) e da estruturação de um sistema de infraestruturas de transporte com atendimento à totalidade do território.

- Princípio Territorial 3 - A Gestão Coordenada: Relacionado à gestão eficiente do território urbano, principalmente as diretrizes vinculadas à gestão social da valorização da terra urbana. Além disso, apresenta normativas para otimização da infraestrutura existente no território urbano. A gestão social da valorização da terra tem como objetivo fazer com que parte da valorização imobiliária gerada pela implantação de infraestruturas e pelo aumento da densidade, do potencial construtivo e das atividades na área, seja revertido em melhorias à coletividade via normas urbanísticas. Ao mesmo tempo, devem-se explorar medidas de indução do desenvolvimento econômico e imobiliário junto às áreas de infraestrutura nos territórios prioritários para o desenvolvimento urbano, considerando também a articulação com outros planos setoriais existentes ou em elaboração.

Há, portanto, um amplo consenso sobre a necessidade de integração entre o planejamento dos transportes e o planejamento e gestão urbanos para uma Cidade Sustentável, tendo como princípios básicos a concentração descentralizada (estrutura policêntrica), uma mistura equilibrada de diferentes usos do solo (uso misto) e uma estrutura urbana compacta que implica curtas distâncias. Tornar as cidades mais compactas, conectadas e eficientes pode gerar melhorias sustentadas na produtividade urbana e uma ampla gama de benefícios econômicos, sociais e ambientais (NCE, 2015).

Uma cidade compacta e com uso misto e vertical do solo estimula modos alternativos de transporte e diferentes padrões de uso da terra, contribuindo para a redução no número de viagens de automóvel e uma diminuição nos quilômetros totais percorridos pelos veículos. As bicicletas e outros modos de transporte não-motorizados devem ser integrados em sistemas urbanos, que atualmente estão voltados apenas para as necessidades, características e dimensões dos automóveis. Esses modos são menores, mais eficientes energeticamente e ambientalmente mais adequado do que os automóveis particulares, com alta eficácia para curtas distâncias. 
Percebe-se então que cada vez mais estudos e práticas defendem a abordagem do uso do solo e do desenvolvimento urbano integrados aos sistemas de transporte, com estratégias de planejamento dos padrões urbanos priorizando os requisitos de modos de transporte sustentáveis, como os transportes público e não-motorizado no espaço urbano. É necessário também entender o transporte como elemento indutor do desenvolvimento e da expansão urbana, e que desempenha um papel fundamental na estruturação do espaço urbano, principalmente no que se refere à orientação da construção de espaços definida pelo mercado imobiliário. Dessa forma, constata-se que as políticas de transporte e urbanas são indissociáveis e, portanto, a integração é imperativa.

É importante ter cautela na adoção de políticas estratégicas que afetem tão significativamente as dinâmicas de ocupação e organização do território, como aquelas relacionadas à mobilidade urbana e transportes, quando o protagonista principal são órgãos de caráter setorial. Quando um órgão setorial se torna o único protagonista de uma política pública mais ampla (que envolve múltiplos temas), certamente haverá limitações à discussão de questões mais abrangentes e interdisciplinares que, por natureza, não são parte do escopo de sua atuação técnica-operacional.

Em outras palavras, a sustentabilidade urbana em sistemas de transporte não pode ser exclusivamente tratada e avaliada por decisores ligados às agências de transporte. É importante que os tomadores de decisão considerem a sustentabilidade do sistema de transporte juntamente com questões mais amplas relacionadas à região onde o mesmo estará inserido. A sustentabilidade, por sua natureza, não deve ser considerada como resultados provenientes de projetos isolados, mas sim como resultados decorrentes de esforços duradouros e interações complexas entre as políticas correlacionadas.

Para esses casos, órgãos de gestão de âmbito regional (ou metropolitano) possuem uma visão mais holística das diversas temáticas envolvidas em determinadas políticas. Assim, a partir de um planejamento e da definição de diretrizes estratégicas gerais pelo órgão de gestão responsável, cada órgão de caráter setorial, em especial aqueles cujas ações afetam diretamente a organização territorial, poderá desenvolver seus projetos em conformidade com essas diretrizes. Ou seja, uma política de transporte e mobilidade em regiões metropolitanas deve ser parte de um plano estratégico maior de organização do território.

A integração de políticas de uso e ocupação do solo urbano com políticas de transporte, utilizando-se de uma abordagem multidisciplinar que combina aspectos urbanísticos, ambientais, sociais e de engenharia de transporte, certamente é o caminho para contribuir para o desenvolvimento urbano de forma sustentável. 


\subsubsection{A Participação Social}

A participação social, enquanto um princípio democrático, foi consagrada com a Constituição Federal de 1988, resultado do clamor de diversas lutas sociais. A participação do cidadão figura como princípio fundamental declarado no art. $1^{\circ}, \S$ único da Constituição da República Federativa do Brasil de 1988 - Todo poder emana do povo que o exerce por meio de representantes eleitos ou diretamente nos termos desta Constituição. Diversos outros artigos da CF tratam da participação direta dos cidadãos no exercício do poder, mas é no art. 225 , que se estabelece, além do poder público, também à coletividade o dever pela defesa e preservação do meio ambiente, para as presentes e futuras gerações. Antes mesmo de ser um princípio constitucional, esse poder é reconhecido como um direito universal, introduzido na Declaração Universal dos Direitos Humanos em seu artigo XXI. 1: "Toda pessoa tem o direito de tomar parte no governo de seu país, diretamente ou por intermédio de representantes livremente escolhidos".

O Princípio 10 da CNUMAD (1992) depreende-se que o acesso à informação é considerado como pré-requisito para a conscientização e participação social efetiva no processo decisório: "A melhor maneira de tratar questões ambientais é assegurar a participação, no nível apropriado, de todos os cidadãos interessados. [...] Os Estados devem facilitar e estimular a conscientização e a participação pública, colocando a informação à disposição de todos" (ONU, 1992).

Em 2015, com a publicação dos Objetivos de Desenvolvimento Sustentável, foi incluído o Objetivo 16 - "Promover sociedades pacíficas e inclusivas para o desenvolvimento sustentável, proporcionar o acesso à justiça para todos e construir instituições eficazes, responsáveis e inclusivas em todos os níveis”, com destaque às metas $16.6,16.7$ e 16.10 .

Não se pode afirmar que um empreendimento de transporte é sustentável se não houver a efetiva participação social. As estratégias de sustentabilidade não podem ignorar a participação popular. Promover práticas sustentáveis que efetivamente vão atender aos anseios da comunidade, é parte importante do relacionamento de um empreendimento com a população, especialmente das comunidades afetadas.

Para Litman e Burwell (2006), a sustentabilidade sugere que o envolvimento do público é cada vez mais importante porque:

- pode resultar em decisões que reflitam com mais precisão os valores da comunidade, dando às pessoas mais oportunidades de afetar as decisões;

- pode contribuir para decisões de transporte mais justas, dando aos grupos desfavorecidos maior envolvimento nas decisões que os afetam;

- pode criar mais suporte público para políticas que exigem mudanças de comportamento ou sacrifícios em uma comunidade. 
Os princípios fundamentais pelos quais se devem pautar o processo de envolvimento público são apresentados por UNEP (2002), conforme segue:

- Inclusivo - cobrindo todas as partes interessadas;

- Aberto e transparente - etapas e atividades são compreendidas;

- Relevante - focada nas questões que importam;

- Justo - conduzido de forma imparcial e sem preconceito em relação a quaisquer partes interessadas;

- Responsivo - aos requisitos e insumos das partes interessadas;

- Credivel - constrói confiança e confiança.

O envolvimento da comunidade afetada em empreendimentos de transporte contribui favoravelmente para a consolidação do processo de avaliação e o encontro de soluções viáveis, justas e democráticas no tratamento dos impactos, tendo em vista que são as pessoas da localidade que vivenciam o espaço urbano e o ambiente em que um novo empreendimento será inserido. Assim, envolver as comunidades impactadas no processo decisório, tornando-as protagonistas de seu próprio destino, constitui-se em fator preponderante para assegurar um empreendimento de transporte sustentável.

O conhecimento dos interesses e valores sociais e culturais da comunidade afetada facilita o desenvolvimento de estratégias para controlar e minimizar os impactos negativos e os riscos a níveis aceitáveis. O fato de haver participação social durante o desenvolvimento de empreendimentos de transporte, unidas em organizações sociais ou não, por si só, contribui para o fornecimento de informações aos empreendedores e, portanto, pode influenciar o projeto.

Em empreendimentos de infraestrutura de transporte, cujas questões socioambientais são extremamente complexas, a participação social e a transparência dos tomadores de decisão contribuem para o conhecimento antecipado dos fatores e aspectos socioculturais e ambientais das comunidades impactadas e, consequentemente, permitem que medidas de controle efetivas sejam consideradas nos programas de gestão do empreendimento, com a viabilização de recursos (humanos, financeiros e materiais) em tempo hábil. Por outro lado, o envolvimento de grupos sociais nos processos decisórios gera e fortalece um sentimento de pertencimento local, bem como contribui para legitimar e resolver conflitos potenciais, colaborando para viabilizar o empreendimento perante os órgãos licenciadores, ainda que nem todos os anseios e expectativas não sejam plenamente atendidos.

Cabe destacar que a participação social não garante propostas assertivas, tampouco garante a definição das melhores alternativas, mas sim fornece informações adicionais aos tomadores de decisões que, juntamente com outras informações (técnicas, financeiras, políticas, etc.), possibilita uma análise mais abrangente do problema e pode contribuir para minimizar certas fontes de distorção e erros de avaliação, além de desperdício de tempo e de recursos financeiros. 
Apesar do discurso quase universal de ampliação de espaços participativos, a prática muitas vezes se mostra desanimadora, seja por parte das instituições coordenadoras e executoras, que não dispõe de tempo, recursos e pessoal capacitado; seja por parte dos atores interessados, que muitas vezes perdem a credibilidade nos processos participativos (MALHEIROS et al., 2012).

$\mathrm{Na}$ prática, os métodos participativos são muitas vezes considerados pelos empreendedores como um obstáculo, pois levam tempo e geram conflitos. Contudo, quando adequadamente coordenados, as propostas tendem a conferir maior aceitação pela comunidade. E, dessa forma, os recursos gastos em um processo de participação popular eficiente podem ser recuperados, evitando-se atrasos, melhorando a qualidade das informações com maior conhecimento local e/ou criando situações que gerem benefícios para todos os participantes.

Os níveis de participação podem ser estabelecidos pelo grau de envolvimento dos públicos e a sua capacidade de influenciar a tomada de decisão, seguindo a ordem crescente de intensidade e interação apresentada no Quadro 4.

\begin{tabular}{|c|c|c|c|}
\hline Níveis & Descrição & Características & Exemplos de instrumentos \\
\hline $1^{0}$ Nível & $\begin{array}{l}\text { Ausência de } \\
\text { participação } \\
\text { popular }\end{array}$ & $\begin{array}{l}\text { Quando o Poder Público toma todas as } \\
\text { decisões de forma unilateral sem } \\
\text { nenhuma forma de interlocução com a } \\
\text { população. }\end{array}$ & - \\
\hline $2^{\circ}$ Nível & $\begin{array}{l}\text { Informativo / } \\
\text { notificação }\end{array}$ & $\begin{array}{l}\text { É unidirecional, do proponente para o } \\
\text { público, em que as informações são } \\
\text { divulgadas e disponibilizadas para a } \\
\text { população. }\end{array}$ & $\begin{array}{l}\text { Política de comunicação para manter } \\
\text { os cidadãos informados sobre os } \\
\text { processos de participação por meio } \\
\text { de comunicados, relatórios, portais } \\
\text { de transparência, páginas oficiais das } \\
\text { instituições, publicações, campanhas } \\
\text { educacionais e publicitárias. }\end{array}$ \\
\hline $3^{\circ}$ Nível & Consultivo & $\begin{array}{l}\text { É um processo bidirecional, pelo qual a } \\
\text { informação é transmitida para a } \\
\text { população, que, por sua vez, encontra } \\
\text { espaços para manifestar suas opiniões. }\end{array}$ & $\begin{array}{l}\text { Ouvidorias das instituições, canais } \\
\text { de reclamações e sugestões, fóruns } \\
\text { de discussão (presenciais ou } \\
\text { virtuais), workshops, pesquisas de } \\
\text { opinião ou de satisfação, grupos } \\
\text { focais, palestras, audiências e } \\
\text { consultas públicas, plebiscitos, } \\
\text { referendos, entre outros }\end{array}$ \\
\hline $4^{0}$ Nível & $\begin{array}{l}\text { Participativo / } \\
\text { Deliberativo }\end{array}$ & $\begin{array}{l}\text { É um processo multidirecional e } \\
\text { colaborativo, com intercâmbio } \\
\text { interativo entre o proponente e o } \\
\text { público, englobando análise } \\
\text { compartilhada e definição de agenda e } \\
\text { o desenvolvimento de posições } \\
\text { entendidas e acordadas sobre a } \\
\text { proposta e seus impactos. }\end{array}$ & $\begin{array}{l}\text { Conselhos de políticas públicas, } \\
\text { comissões e conselhos setoriais, } \\
\text { órgãos colegiados, grupos de } \\
\text { trabalhos, processos conferencistas, } \\
\text { fóruns temáticos, orçamentos } \\
\text { participativos, entre outros }\end{array}$ \\
\hline $5^{\circ}$ Nível & Negociação & $\begin{array}{l}\text { Trata-se de discussão verbal entre o } \\
\text { proponente e as principais partes } \\
\text { interessadas para construir consenso e } \\
\text { alcançar mutuamente uma resolução } \\
\text { aceitável da questão. }\end{array}$ & $\begin{array}{l}\text { Definição das medidas de mitigação } \\
\text { e compensação dos impactos. }\end{array}$ \\
\hline
\end{tabular}

Fonte: Elaborado com base em UNEP (2002) e SeMob (2015). 
Existem várias formas e modalidades de participação, mecanismos, canais ou instrumentos de participação aplicáveis ao setor de transporte, podendo variar quanto à sua adequação e efetividade em função da fase (políticas, planos, programas e projetos), objeto de intervenção, recorte territorial e social, entre outros.

A Política Nacional de Mobilidade Urbana (Lei $n^{\circ}$ 12.587), estabelece, no art. 14, inciso II, que é direito dos usuários do Sistema Nacional de Mobilidade Urbana, "participar do planejamento, da fiscalização e da avaliação da política local de mobilidade urbana" (BRASIL, 2012), devendo assegurar os seguintes instrumentos para participação da sociedade civil, nos termos do art. 15: órgãos colegiados, ouvidorias, audiências e consultas públicas e procedimentos sistemáticos de comunicação, de avaliação da satisfação dos cidadãos e dos usuários e de prestação de contas públicas.

Atualmente, o principal instrumento de gestão pública que garante, minimamente, a participação social em empreendimentos de infraestrutura de transporte no Brasil é o processo de licenciamento ambiental, que estabelece a obrigatoriedade através do artigo 20 da Resolução CONAMA $n^{\circ}$ 237/1997. Esta resolução tem como requisito fundamental, a elaboração do EIA/RIMA, a realização de audiência pública e a decisão pela viabilidade ambiental do projeto a partir de conselhos paritários, compostos por representantes de órgãos governamentais e da sociedade civil. Além disso, exige a elaboração do Plano Básico Ambiental, que geralmente inclui programas de comunicação social durante sua construção e operação.

Segundo UNEP (2002), na prática, o envolvimento na elaboração do EIA em grande parte corresponde ao "consultivo"; a "participação" é apropriado para muitas circunstância, como por exemplo, onde a população local é deslocada ou realocada como resultado do projeto; e a mediação ou "negociação" é realizada em poucos países, tendo uma terceira parte como mediadora. Contudo, as formas de envolvimento podem ser utilizadas de maneira combinada em diferentes estágios do processo de licenciamento.

\subsection{PRINCIPAIS POLÍTICAS PÚBLICAS NACIONAIS APLICÁVEIS}

Para Freiria (2011), a política é compreendida como um conjunto de ações ou medidas que visam realizar objetivos ou metas. Para o autor, o conceito tradicional de política pública ainda está indelevelmente associado à figura do Estado, cuja missão é implementar políticas, ou seja, realizar ações objetivando o interesse público.

As políticas públicas, após desenhadas e formuladas, desdobram-se em planos, programas, projetos, bases de dados ou sistema de informação e pesquisas. Agum et al. (2015) entende que uma política, para ser implementada, passa por fases e processos sociais e que um embate a respeito de ideias e formas de agir, por vezes, irão direcionar certas práticas políticas. 
Portanto, pode-se afirmar que as políticas públicas são instrumentos potenciais para a construção de um processo de desenvolvimento urbano sustentável, podendo incluir em seus objetivos e metas a preocupação com a sustentabilidade, como a necessidade de interação entre justiça social, qualidade de vida, equilíbrio ambiental e o respeito à capacidade de suporte da cidade. Assim, são apresentados a seguir as principais políticas públicas nacionais que se relacionam diretamente com o tema desta pesquisa.

\subsubsection{Políticas Urbanas e Ambientais}

Diante de um cenário cada vez mais amplo da variável ambiental promovido nas convenções mundiais lideradas pela ONU, o Brasil se vê diante da necessidade de se regulamentar internamente para tratar das questões ambientais. Foi então que, em 1981, promulgou a Lei 6.938, que instituiu a Política Nacional do Meio Ambiente (PNMA). Embora regulamentada apenas em 1990 pelo Decreto $n^{\circ}$ 99.274, a PNMA foi responsável pela inclusão do componente ambiental na gestão das políticas públicas e decisiva inspiradora do Capítulo VI - Do Meio Ambiente na Constituição de 1988, apresentando diretrizes, conceitos e instrumentos para a sua aplicação e cumprimento, com vistas a promoção da preservação e a recuperação da qualidade ambiental.

A Constituição Federal de 1988 foi um marco importante para o avanço da política ambiental brasileira, dedicando um capítulo específico sobre o meio ambiente que institucionalizou "o direito ao ambiente sadio como um direito fundamental do indivíduo". Interessante observar que a PNMA, editada pela Lei n 6.938/1981, foi recepcionada integralmente pela Constituição Federal de 1988, após aproximadamente sete anos da sua promulgação.

Com o artigo 23 da CF, que estabeleceu a competência comum da União, dos Estados, do Distrito Federal e dos Municípios, os municípios conquistaram a competência administrativa do exercício do poder em âmbito local, portanto, conferindo-lhes o poder de administrar os bens ambientais. Com isso, as questões urbanas e ambientais passam a ser tratadas de forma mais integrada na escala local, apesar dos inúmeros desafios que as municipalidades ainda precisam enfrentar para poder colocar em prática suas atribuições.

A CF de 1988 propiciou a organização de uma ordem legal urbana que configurou o direito urbanístico brasileiro, conferindo ao Município, por meio dos artigos 30 e 182, um papel preponderante na promoção das políticas de desenvolvimento urbano, no planejamento e ordenamento de uso e ocupação de seu território (urbano e rural), e na promoção de políticas públicas.

A Política Urbana, ou política de desenvolvimento urbano, é tratada no Capítulo II do Título VII - Da Ordem Econômica e Financeira da CF de 1988, artigos 182 e 183. Ao mencionar a garantia do bem-estar dos habitantes da cidade, o art. 182 remete ao caput do art. 225 da $\mathrm{CF}$, mostrando que o modelo de desenvolvimento a ser promovido pela 
Política Urbana Brasileira, ainda que de forma implícita, é baseado no desenvolvimento urbano sustentável, pautado pelo equilíbrio entre crescimento econômico, inclusão social e preservação ambiental e pelo princípio da intergeracionalidade.

Os artigos 182 e 183 da CF foram regulamentados pela Lei $n^{\circ} 10.257$, aprovada em 10 de julho de 2001, denominada Estatuto da Cidade, que representou um passo importante na busca de cidades mais sustentáveis. O Estatuto da Cidade editou as normas gerais voltadas à política urbana estabelecendo normas sobre planejamento urbano, diretrizes, princípios, instrumentos, competências e sanções. Essa lei federal estabeleceu exigências para elaboração do Plano Diretor, o qual é o instrumento central da política urbana, constituindo a base para aplicação dos instrumentos urbanísticos, jurídicos e tributários estabelecidos no Estatuto da Cidade.

A política de desenvolvimento urbano passa a ser assumida como uma questão estratégica pelo governo federal, especialmente a partir da criação do Ministério das Cidades, em 2003, buscando-se, no seu desenho, a articulação de todas as políticas setoriais em âmbito nacional. Vale citar algumas das principais leis nacionais suportadas pela Política Urbana e Ambiental do Brasil:

Quadro 5-Políticas Nacionais Urbanas e Ambientais

\begin{tabular}{|c|c|}
\hline Leis Federais & Disposições \\
\hline $6.766 / 1979$ & Dispõe sobre o Parcelamento do Solo Urbano \\
\hline 7.661/1988 & Institui o Plano Nacional de Gerenciamento Costeiro \\
\hline 9.433/1997 & $\begin{array}{l}\text { Institui a Política Nacional de Recursos Hídricos e cria o Sistema Nacional de } \\
\text { Gerenciamento de Recursos Hídricos }\end{array}$ \\
\hline $9.605 / 1998$ & $\begin{array}{l}\text { Dispõe sobre as sanções penais e administrativas derivadas de condutas e atividades } \\
\text { lesivas ao meio ambiente }\end{array}$ \\
\hline $9.985 / 2000$ & Institui o Sistema Nacional de Unidades de Conservação da Natureza \\
\hline $\begin{array}{l}10.048 / 2000 \\
10.098 / 2000\end{array}$ & $\begin{array}{l}\text { Definem o marco regulatório para a promoção da acessibilidade das pessoas com } \\
\text { deficiência ou mobilidade reduzida }\end{array}$ \\
\hline $10.257 / 2001$ & $\begin{array}{l}\text { Regulamenta os arts. } 182 \text { e } 183 \text { da Constituição Federal e estabelece diretrizes gerais } \\
\text { da política urbana }\end{array}$ \\
\hline $11.124 / 2005$ & $\begin{array}{l}\text { Dispõe sobre o Sistema Nacional de Habitação de Interesse Social (SNHIS), cria o } \\
\text { Fundo Nacional de Habitação de Interesse Social (FNHIS) e institui o Conselho } \\
\text { Gestor do FNHIS }\end{array}$ \\
\hline $11.445 / 2007$ & $\begin{array}{l}\text { Estabelece diretrizes nacionais para o saneamento básico e para a política federal de } \\
\text { saneamento básico }\end{array}$ \\
\hline $11.481 / 2007$ & $\begin{array}{l}\text { Prevê medidas voltadas à regularização fundiária de interesse social em imóveis da } \\
\text { União }\end{array}$ \\
\hline $11.952 / 2009$ & $\begin{array}{l}\text { Dispõe sobre a regularização fundiária das ocupações incidentes em terras situadas } \\
\text { em áreas da União, no âmbito da Amazônia Legal }\end{array}$ \\
\hline $11.977 / 2009$ & $\begin{array}{l}\text { Dispõe sobre o Programa Minha Casa Minha Vida (PMCMV) e a regularização } \\
\text { fundiária de assentamentos localizados em áreas urbanas }\end{array}$ \\
\hline $12.187 / 2009$ & Institui a Política Nacional sobre Mudança do Clima - PNMC \\
\hline $12.305 / 2010$ & Institui a Política Nacional de Resíduos Sólidos \\
\hline $12.424 / 2011$ & $\begin{array}{l}\text { Altera a Lei n }{ }^{\circ} 11.977 \text {, de } 7 \text { de julho de } 2009 \text {, que dispõe sobre o Programa Minha } \\
\text { Casa, Minha Vida - PMCMV e a regularização fundiária de assentamentos } \\
\text { localizados em áreas urbanas }\end{array}$ \\
\hline
\end{tabular}




\begin{tabular}{cl}
\hline $\mathbf{1 2 . 5 8 7 / 2 0 1 2}$ & Institui a Política Nacional de Mobilidade Urbana; \\
& $\begin{array}{l}\text { Institui a Política Nacional de Proteção e Defesa Civil - PNPDEC; dispõe sobre o } \\
\text { Sistema Nacional de Proteção e Defesa Civil - SINPDEC e o Conselho Nacional de } \\
\text { Proteção e Defesa Civil - CONPDEC; autoriza a criação de sistema de informações e } \\
\text { monitoramento de desastres }\end{array}$ \\
\hline $\mathbf{1 2 . 6 0 8 / 2 0 1 2}$ & $\begin{array}{l}\text { Dispõe sobre a proteção da vegetação nativa, contemplando a regularização fundiária } \\
\text { de assentamos urbanos em áreas de preservação permanente (APPs) }\end{array}$ \\
\hline $\mathbf{1 3 . 0 8 9 / 2 0 1 5}$ & Institui o Estatuto da Metrópole \\
\hline
\end{tabular}

Nota-se, portanto, esforços legislativos nos últimos anos, no sentido de incorporar políticas setoriais a temas prioritários na problemática urbana.

Para efetivar políticas territoriais, a governança urbana avançou com a aprovação da Lei de Consórcios Públicos (Lei Federal $n^{\circ}$ 11.107/2005) e sua respectiva regulamentação (Decreto Federal $n^{\circ}$ 6.017/2007), que instituíram novas formas de cooperação entre os entes federativos, ampliando as possibilidades de arranjos institucionais. Apesar dos avanços na governança local, determinados assuntos devem ser tratados na escala regional, que supere os limites físicos e políticos de cada município, com a implantação de ações de cooperação e de integração, que oriente os planos diretores a alcançar objetivos comuns e regionais.

Para que as cidades integrantes de regiões metropolitanas brasileiras avancem no sentido da sustentabilidade, é necessário avançar na reformulação das políticas públicas de intervenção no território metropolitano. Um avanço importante foi a promulgação da Lei Federal no 13.089/2015, que instituiu o Estatuto da Metrópole, aprovado 14 anos depois do Estatuto da Cidade com a pretensão de responder, por meio da regulação supramunicipal, aos problemas resultantes da interação entre os municípios metropolitanos.

O Estatuto da Metrópole inova à medida que estabelece, no seu Art. $3^{\circ}$, a governança interfederativa que busca integrar a organização, o planejamento e a execução de funções públicas de interesse comum, que consiste em "política pública ou ação nela inserida cuja realização, por parte de um Município isoladamente, seja inviável ou cause impacto em Municípios limítrofes" (BRASIL, 2015).

No Capítulo IV, art. 9, a Lei trata dos instrumentos de desenvolvimento urbano integrado, quais sejam: plano de desenvolvimento urbano integrado - PDUI, planos setoriais interfederativos, fundos públicos, operações urbanas consorciadas interfederativas, consórcios públicos, convênios de cooperação, contratos de gestão e parcerias público-privadas interfederativas. Dentre eles, destaca-se o PDUI, um "instrumento que estabelece, com base em processo permanente de planejamento, viabilização econômico-financeira e gestão, as diretrizes para o desenvolvimento territorial estratégico e os projetos estruturantes da região metropolitana e aglomeração urbana" (BRASIL, 2015). 
Giatti et al. (2018) destacam alguns desafios para a implantação do Estatuto. Para os autores, um dos desafios a ser enfrentado pelos municípios é a construção daquilo que se entende por interesse comum entre os municípios integrantes da região metropolitana, em torno da qual acontecerá a gestão interfederativa. Não basta somar as demandas de cada um dos municípios, faz-se necessário identificar seus pontos comuns e a forma de lidar com elas em cooperação, sem malferir a autonomia municipal. Dentre os pontos em comum, destaca-se aqueles relacionados ao transporte e ao uso e ocupação do solo, que são questões que usualmente ultrapassam os limites municipais em região metropolitana.

Em que pese os inúmeros desafios a serem enfrentados, trata-se de uma importante política pública de desenvolvimento metropolitano, que contribui para dar celeridade à execução de ações de cunho urbano-regional.

\subsubsection{Política Nacional de Transportes}

A Política Nacional de Transportes (PNT) é o documento de mais alto nível para o Setor de Transportes do País, onde estão estabelecidos os princípios, objetivos, diretrizes fundamentais e instrumentos para o planejamento e sua implementação. A PNT deve orientar e fomentar o planejamento de transportes, bem como balizar os planos e programas derivados, preocupando-se em garantir que todos os órgãos setoriais tenham clareza dos pressupostos assumidos.

Essa política institucionalizada foi estabelecida em 2018 com vistas a induzir o desenvolvimento socioeconômico sustentável e promover a integração nacional e internacional a partir da oferta de infraestrutura e serviços de transportes, propiciando o aumento da competitividade e a redução das desigualdades do país. Para tanto, teve como premissa a participação dos setores governamentais e da sociedade, e buscou alcançar outras políticas nacionais, nos segmentos de planejamento, desenvolvimento social, econômico, ambiental, integração e defesa.

A PNT está dividida em dois documentos, apresentando, em seu Livro de Estado, princípios, objetivos, diretrizes fundamentais e instrumentos orientados pela Constituição Federal, e, no Caderno das Estratégias Governamentais, as diretrizes especificas, estratégicas e ações prioritárias para o Setor de Transportes em um dado contexto temporal.

Para a PNT, os princípios dizem respeito aos preceitos, leis ou pressupostos considerados universais, sendo incontestáveis e de apreensão imediata. Os princípios elencados expressam as premissas do Estado Nação pelas quais o planejamento das infraestruturas de transportes e dos serviços logísticos (planejamento estratégico setorial), o planejamento estratégico organizacional e a priorização dos investimentos (planejamento estratégico orçamentário) devem ser focalizados, a partir da estruturação de um processo contínuo, permanente e sujeito a avaliações periódicas. 
Assim, os princípios estabelecidos pela PNT estão brevemente descritos a seguir:

I. RESPEITO À VIDA: Princípio nobre e soberano, devendo prover um sistema viário seguro, que deve prezar pela manutenção da integridade das pessoas e bens a serem deslocados pelas vias, de modo a assegurar o mínimo de risco, a confiabilidade e o conforto.

II. EXCELÊNCIA INSTITUCIONAL: preza pelo reconhecimento da qualidade do serviço público do Setor de Transportes do Governo Federal, de modo que as práticas setoriais cumpram o direito social ao transporte. A excelência também implica na necessidade de articulação com as demais políticas públicas que regem as atividades e organização do país. As ações setoriais devem considerar a soberania da cidadania, de modo que as atividades de planejamento, bem como as práticas de avaliação das políticas públicas setoriais, se fundamentem na publicidade e participação pública.

III. PLANEJAMENTO E INTEGRAÇÃO TERRITORIAL: indica que as políticas públicas de transportes devem se pautar na concepção de uma planificação territorial segundo os usos e ordenamentos projetados e pactuados entre os mais diversos atores governamentais e sociais.

IV. INFRAESTRUTURA SUSTENTÁVEL: diz respeito à função essencial do Setor de Transportes no âmbito da organização das atividades públicas, qual seja: a ação vinculada, em última instância, à dotação do território nacional de equipamentos viários e de serviços que permitam acessibilidades e deslocamentos, de cargas e pessoas, em conformidade a padrões de qualidade apropriados, socialmente aceitos e integrados sustentavelmente ao meio ambiente.

V. EFICIÊNCIA LOGÍSTICA: o deslocamento de pessoas e bens ao longo da matriz viária, se configura como um princípio inadiável para o sistema de transportes nacional, demandando, para tanto, a racionalidade na distribuição dos modos de transporte no âmbito do território nacional. Desse modo, um pressuposto universal das ações setoriais calca-se na eficiência e efetividade do ordenamento e organização das infraestruturas viárias, de forma a ensejar inequívocos benefícios sociais, econômicos e ambientais relacionados aos incrementos dos níveis de desempenho e de competitividade do Setor de Transportes.

VI. DESENVOLVIMENTO ECONÔMICO, SOCIAL E REGIONAL: se refere à contribuição para com o desenvolvimento socioeconômico e regional do país, de modo que a rede de transportes e a prestação dos serviços logísticos associados devem contribuir tanto para a indução do desenvolvimento social e econômico em áreas mais carentes, quanto para o fortalecimento do desenvolvimento social e econômico de áreas dinâmicas e consolidadas. Nesse sentido, as particularidades regionais devem ser resguardadas, de modo a identificar e considerar as diversidades, identidades culturais distintas e capacidades instaladas heterogêneas 
dos territórios quando das formulações, execuções e avaliações das políticas públicas setoriais.

VII. RESPONSABILIDADE SOCIOAMBIENTAL: O valor da sustentabilidade configura-se como um princípio de primeira grandeza, de forma que todo e qualquer empreendimento de infraestrutura deve respeitar os valores de minimização dos impactos ambientais gerados, bem como deve se fiar nos ditames da viabilidade econômica, justiça social, diversidade cultural e legitimidade política ante a sociedade nacional.

VIII. INTEGRAÇÃO E COOPERAÇÃO INTERNACIONAL: o sistema viário nacional deve impulsionar uma integração transfronteiriça dos sistemas viários, tanto no que diz respeito à infraestrutura, quanto no que se refere aos serviços logísticos e de transportes prestados e, também, considerando os aspectos de defesa para a soberania do país. Desse modo, estabelece-se como um princípio a integração internacional das infraestruturas viárias, sobretudo com a sulamericana, de modo a fortalecer a coesão geopolítica, socioeconômica e cultural deste subcontinente; além disso, também se incentiva a ampla colaboração internacional como forma de compartilhar e promover o intercâmbio de informações, de expertises e das boas práticas técnicas e de gestão no que se refere à concepção, desenvolvimento, execução e avaliação de políticas públicas.

A PNT estabeleceu objetivos tangíveis, alvos a serem definidos e perseguidos quando da formulação e execução dos planejamentos, planos, programas e ações do Governo Federal. Esses objetivos delineados versam sobre o compromisso de envidar os esforços necessários para que as suas ações sejam refletidas e materializadas em uma rede de transportes eficiente, confiável e sustentável, com segurança e racionalidade.

A seguir estão transcritos os objetivos estabelecidos pela PNT:

1 Prover um sistema acessível, eficiente e confiável para a mobilidade de pessoas e bens.

2 Garantir a segurança operacional em todos os modos de transportes.

3 Prover uma matriz viária racional e eficiente.

4 Promover a participação intra e interinstitucional, considerando sociedade, governo e mercado, no desenvolvimento de uma política de transporte integrada.

5 Planejar os sistemas de logística e transportes a partir de uma visão territorial, integrada e dinâmica.

6 Disciplinar os papéis dos atores do Setor de Transportes do Governo Federal.

7 Dar transparência à sociedade, ao mercado e aos agentes públicos quanto às ações governamentais do Setor de Transportes.

8 Incorporar a inovação e o desenvolvimento tecnológico para o aperfeiçoamento contínuo das práticas setoriais.

9 Promover a cooperação e a integração física e operacional internacional.

10 Considerar as particularidades e potencialidades regionais nos planejamentos setoriais de transportes.

11 Atuar como vetor do desenvolvimento socioeconômico e sustentável do país.

12 Garantir a infraestrutura viária adequada para as operações de segurança e defesa nacional. 


\subsubsection{Política Nacional de Mobilidade Urbana}

Como resposta aos problemas enfrentados na mobilidade urbana e a falta de regulamentação a respeito do tema, o governo brasileiro aprovou a Política Nacional de Mobilidade Urbana - PNMU, com a promulgação da Lei n ${ }^{\circ} 12.587$, de 3 de janeiro de 2012, como o instrumento da política de desenvolvimento urbano, objetivando a integração entre os diferentes modos de transporte e a melhoria da acessibilidade e mobilidade das pessoas e cargas no território municipal.

A Política Nacional de Mobilidade Urbana é um dos eixos estruturadores da Política Nacional de Desenvolvimento Urbano, que deve ser entendida como um conjunto de princípios, diretrizes e normas que norteiam a ação do Poder Público e da sociedade em geral, na produção e na gestão das cidades (SeMob, 2015).

Buscou-se, na formulação da PNMU, formas de racionalização, integração e complementaridade de ações entre os entes federados (municipal, estadual e federal), por meio do incentivo e fortalecimento do planejamento e da gestão local da mobilidade urbana, reconhecendo a gestão democrática e participativa como pilar para garantia de maior nível de integração e compromisso entre as políticas de mobilidade, habitação e uso do solo. $\mathrm{O}$ artigo $7^{\circ}$ da Lei estabelece, como um de seus objetivos, "consolidar a gestão democrática como instrumento e garantia da construção contínua do aprimoramento da mobilidade".

Cabe destacar que há referências aos pressupostos da sustentabilidade urbana nos princípios e objetivos da PNMU, conforme descritos no Quadro 6.

Quadro 6 - Princípios e objetivos da Política Nacional de Mobilidade Urbana (2012).

\begin{tabular}{|l|l|}
\hline \multicolumn{1}{|c|}{ Princípios } & \multicolumn{1}{|c|}{ Objetivos } \\
\hline $\begin{array}{l}\text { I - acessibilidade universal; } \\
\text { II - desenvolvimento sustentável das cidades, nas } \\
\text { dimensões socioeconômicas e ambientais; } \\
\text { III - equidade no acesso dos cidadãos ao transporte público } \\
\text { coletivo; }\end{array}$ & $\begin{array}{l}\text { I - reduzir as desigualdades e promover a inclusão } \\
\text { social; } \\
\text { II - promover o acesso aos serviços básicos e } \\
\text { equipamentos sociais; } \\
\text { IV - eficiência, eficácia e efetividade na prestação dos } \\
\text { serviços de transporte urbano; } \\
\text { V - gestão democrática e controle social do planejamento e } \\
\text { avaliação da Política Nacional de Mobilidade Urbana; } \\
\text { VI - segurança nos deslocamentos das pessoas; } \\
\text { VII - justa distribuição dos benefícios e ônus decorrentes } \\
\text { do uso dos diferentes modos e serviços; } \\
\text { VIII - equidade no uso do espaço público de circulação no que se refere à acessibilidade e à } \\
\text { mias e logradouros; e } \\
\text { IX - eficiência, eficácia e efetividade na circulação urbana. } \\
\text { IV - promover o desenvolvimento sustentável com } \\
\text { a mitigação dos custos ambientais e } \\
\text { socioeconômicos dos deslocamentos de pessoas e } \\
\text { cargas nas cidades; e } \\
\text { V - consolidar a gestão democrática como } \\
\text { instrumento e garantia da construção contínua do } \\
\text { aprimoramento da mobilidade urbana. }\end{array}$ \\
\hline
\end{tabular}

Fonte: BRASIL (2012). 
A PNMU instituiu o Plano de Mobilidade Urbana como um instrumento de efetivação da política aos municípios com população acima de 20 mil habitantes e demais obrigados à elaboração do plano diretor ( $\S 1^{\circ}$ do art. 24), buscando, de forma compatibilizada com o plano diretor municipal, a integração com a política de desenvolvimento urbano e respectivas políticas setoriais de habitação, saneamento básico, planejamento e gestão do uso do solo, priorizando o transporte não motorizado e o transporte coletivo, considerados estruturadores do território e indutores do desenvolvimento urbano integrado, dentre outras diretrizes.

Ao se referir aos "demais obrigados", o $\S 1^{\circ}$ do art. 24 da política obriga que também tenham o Plano de Mobilidade Urbana, em conformidade com o Estatuto da Cidade, as cidades integrantes de regiões metropolitanas e aglomerações urbanas, integrantes de áreas de especial interesse turístico, inseridas na área de influência de empreendimentos significativo impacto ambiental de âmbito regional ou nacional e incluídas no cadastro nacional de Municípios com áreas suscetíveis à ocorrência de deslizamentos de grande impacto, inundações bruscas ou processos geológicos ou hidrológicos correlatos [art. 41 da Lei Federal $n^{\circ}$ 10.257]. O Plano de Mobilidade Urbana deverá, ainda, contemplar medidas destinadas a atender aos núcleos urbanos informais consolidados, nos termos do $\S 5^{\circ}$ do art. 24 .

A política apoia e estimula ações coordenadas e integradas em regiões metropolitanas, além de áreas conurbadas e aglomerações urbanas, bem como incentiva o uso de energias renováveis e menos poluente. Logo, busca-se um enfrentamento das questões de mobilidade para além do plano local, com abordagem de planejamento e gestão em escala metropolitana.

\subsection{PLANEJAMENTO DE INFRAESTRUTURA RODOVIÁRIA NO BRASIL}

O Poder Público tem o dever de buscar a qualidade de vida das mais variadas camadas sociais da população, considerando, em suas tomadas de decisão política, os aspectos social, econômico, cultural e ambiental. No Brasil, a abordagem mais adotada é a de cima para baixo (top-down), já que a tomada de decisão governamental sobre ações estratégicas é realizada em uma sequência, a partir de políticas, planos e programas, e finalmente surgem os projetos dela derivados. Geralmente, a sociedade participa muito pouco e de forma muito restrita dos processos de decisão pública.

Um dos maiores desafios dos tomadores de decisão é a alocação correta dos recursos dentre um conjunto de alternativas existente, de modo que o retorno socioeconômico desses investimentos seja o maior possível. Como os recursos são limitados, tornam-se necessários o estabelecimento de prioridades e a adoção de um conjunto de critérios, visando aumentar os benefícios líquidos. As políticas públicas 
alinhadas ao planejamento institucional em termos de planos, programas e ações dos órgãos integrantes do setor de transporte, bem como ao planejamento orçamentário (notadamente representado pelos Planos Plurianuais) devem ser concatenados e alinhados às iniciativas estratégicas.

A decisão pela alocação de investimentos em infraestrutura no País é definida com base na adoção da sistemática do planejamento, fundamentada majoritariamente por Planos Diretores Setoriais e nas receitas orçamentárias anuais ou plurianuais. O processo de planejamento contribui para que o governo defina prioridades de investimento, estabelecendo a forma como os recursos serão distribuídos. Entretanto, esse processo é extremamente complexo e dinâmico, ocorrendo uma interação entre objetivos, recursos e planos preliminares. Havendo incompatibilidade dos recursos e dos planos com os objetivos almejados, torna-se necessária a obtenção de reforços orçamentários ou, na impossibilidade, os objetivos deverão ser limitados ou postergados, e os planos adaptados às condições prevalecentes.

Ainda que a infraestrutura de transporte no Brasil seja deficiente, o investimento é alto e, por sua vez, acaba utilizando os escassos recursos que poderiam ser aplicados na área da educação, saúde, agricultura, segurança e outros setores relevantes para a sociedade. Assim, a distribuição dos recursos financeiros orçamentários é um processo permanentemente submetido a pressões de grupos setoriais, normalmente de interesses conflitantes, envolvendo comunidade, usuários dos sistemas de transporte, indústrias, governo, sociedade civil organizada, mídia, dentre outros.

Portanto, são muitos os desafios das políticas públicas para providenciar recursos suficientes para manter as infraestruturas de transporte existentes e viabilizar as expansões de capacidade para atender às demandas futuras. Mesmo com as fontes e estratégias de financiamentos existentes, os recursos para sistemas de transporte são limitados em virtude dos altos custos de implantação e manutenção, tornando-se difíceis as decisões de investimentos.

Como resultado do processo de distribuição de recursos e da disputa entre os grupos setoriais, uma parcela de recursos é transferida para investimentos em infraestrutura de transporte, que ainda é competida entre as várias modalidades existentes, como rodovias, ferrovias, hidrovias, portos, aeroportos e dutos. Dentre as modalidades, o setor rodoviário vem historicamente desfrutando de maior participação, principalmente em função da estrutura de transporte adotada no País e das vantagens relacionadas à distribuição espacial, conforto, praticidade, entre outras. Aliado a isso, houve também a popularização e incentivo à compra de automóveis, aumentando a demanda pela infraestrutura rodoviária e, consequentemente, a necessidade de investimentos na ampliação e na manutenção da malha existente, tanto para aumentar a capacidade operacional como para aumentar a segurança dos usuários.

As infraestruturas rodoviárias contribuem para proporcionar mobilidade e melhorias às pessoas na acessibilidade aos equipamentos urbanos, transporte de cargas, 
desenvolvimento e integração socioeconômica, entre outros. Porém, até que as mesmas estejam construídas e operando, muitos fatores devem ser considerados, buscando-se sempre soluções que atendam às necessidades econômicas, a segurança e o conforto, os critérios técnicos de engenharia e as exigências socioambientais, tanto no início do processo de implementação do empreendimento, na sua fase de planejamento, como na sua plena operação e eventual desativação.

As rodovias provocam imensas intervenções urbanísticas e sociais nas regiões metropolitanas do País pela magnitude dos impactos e transformações que ocasionam, interagindo com os diferentes meios (físico, biótico e socioeconômico) em maior ou menor grau, em função do tipo e do porte do empreendimento, bem como das características socioeconômicas e ambientais da região na qual o mesmo será inserido. Adicionalmente, por sua escala e volume de recursos envolvidos, esses empreendimentos têm o potencial de interferir em rendas fundiárias, gerando oportunidades para o mercado imobiliário e provocando mudanças no uso e ocupação do solo.

Os impactos ambientais gerados pelas rodovias têm maior abrangência espacial se comparados a outros modos de transporte (ferroviários e hidroviários, pe.), em virtude de sua grande flexibilidade de deslocamento e do potencial de alteração no desenvolvimento e ordenamento territorial de uma região, caso permita-se a abertura de zonas até então inacessíveis ou com acessos mais restritos.

Por envolver aspectos ambientais, econômicos e sociais e políticos, um novo projeto de infraestrutura rodoviária altera as condições preexistentes, podendo gerar impactos significativos. Essa nova condição afeta interesses públicos e privados, beneficiando alguns setores, grupos ou pessoas, em detrimento a outros. Portanto, tornase um processo de decisão de caráter político, pelo qual os formuladores de políticas devem acomodar esses desejos conflitantes, a fim de equilibrar os impactos positivos e negativos. Nesse sentido, os critérios de sustentabilidade podem auxiliar no processo de decisão, uma vez que ajuda a esclarecer as prioridades de financiamento de longo prazo.

Segundo Meyer e Miller (1984), durante os anos 50 e 60, a maior parte do planejamento de transporte era baseado em métodos de escolhas racionais, ou seja, baseava-se apenas em um critério de escolha, normalmente os de menores custos (critérios monetários), em um processo de decisão centralizado e dominado por processos técnicos. Porém, segundo os autores, a partir do final dos anos 60 e início dos anos 70, um novo conceito de planejamento, baseado na participação pública e na previsão dos impactos causados, começou a substituir o tipo de planejamento adotado até então em muitas cidades.

Silva Júnior (2006) explica que a baixa disponibilidade de recursos para investimentos em transporte e a deficiente instrução da população aliam-se à forma impositiva e tecnocrata com que as decisões públicas são tomadas, fazendo com que os setores dominantes da sociedade imponham mais facilmente seus valores e suas decisões. Assim, em que pese muitos atores poderem participar do estabelecimento, 
desenvolvimento e implementação de políticas de transporte, são os mais "fortes" que influenciam no conteúdo e direcionamento da política estabelecida.

Ainda hoje, nota-se a predominante influência e o papel exercido por políticos na escolha final de um projeto de transporte, levando em consideração fatores não mensurados no processo de tomada de decisão. Sabe-se que no Brasil, assim como em muitas outras localidades do mundo, grandes obras de infraestrutura têm um enorme potencial político-eleitoral, o que faz com que muitas vezes suas definições e decisões estratégicas se guiem mais pelos interesses políticos imediatos do que por alguma estratégia de longo prazo de política pública.

Assim, para que se alcance um planejamento de transporte sustentável, questões relacionadas à definição de transporte sustentável, como as metas e objetivos de curto, médio e longo prazo, devem ser definidas e avaliadas, assim como o tipo de processo de tomada de decisão que deverá ser utilizado. A sustentabilidade requer um planejamento mais abrangente e integrado, o que representa um amplo conjunto de impactos econômicos, sociais e ambientais, incluindo aqueles que são difíceis de medir (LITMAN \& BURWELL, 2006). O planejamento de sustentabilidade exige ainda um envolvimento adequado das partes interessadas para permitir que as diversas perspectivas e preferências sejam incorporadas.

Os objetivos de implantação de infraestrutura de transporte são, geralmente, estabelecidos em Políticas de Transporte. É o processo de planejamento que orienta o desenvolvimento de políticas, planos e programas de transportes. Numa visão mais ampla, o planejamento estratégico busca definir a forma como os objetivos almejados devem ser alcançados, estabelecendo a sistemática de ação e contemplando decisões sobre alocação de recursos e diretrizes de gestão, baseadas em critérios que procuram interpretar as aspirações da sociedade. Essa etapa contribui para compreender os meios de avaliação dos sistemas de transporte e de seleção de alternativas possíveis, considerando as inúmeras alternativas existentes, dentre os modais de transporte, e os efeitos decorrentes previstos.

Contudo, o estabelecimento dos critérios de seleção dessas alternativas é complexo, visto que os efeitos são percebidos de maneira diferente pelas partes interessadas, sendo benéficos para alguns e indesejáveis para outros. Logo, a mensuração dos efeitos de cada alternativa, apontando, qualitativa e quantitativamente, suas vantagens e desvantagens relativas a efetividade e eficiência, se faz necessário para tomada de decisão.

O processo de planejamento tradicional de transportes pode ser sintetizado conforme figura a seguir. 
Figura 9 - Processo de planejamento estratégico tradicionalmente utilizado.

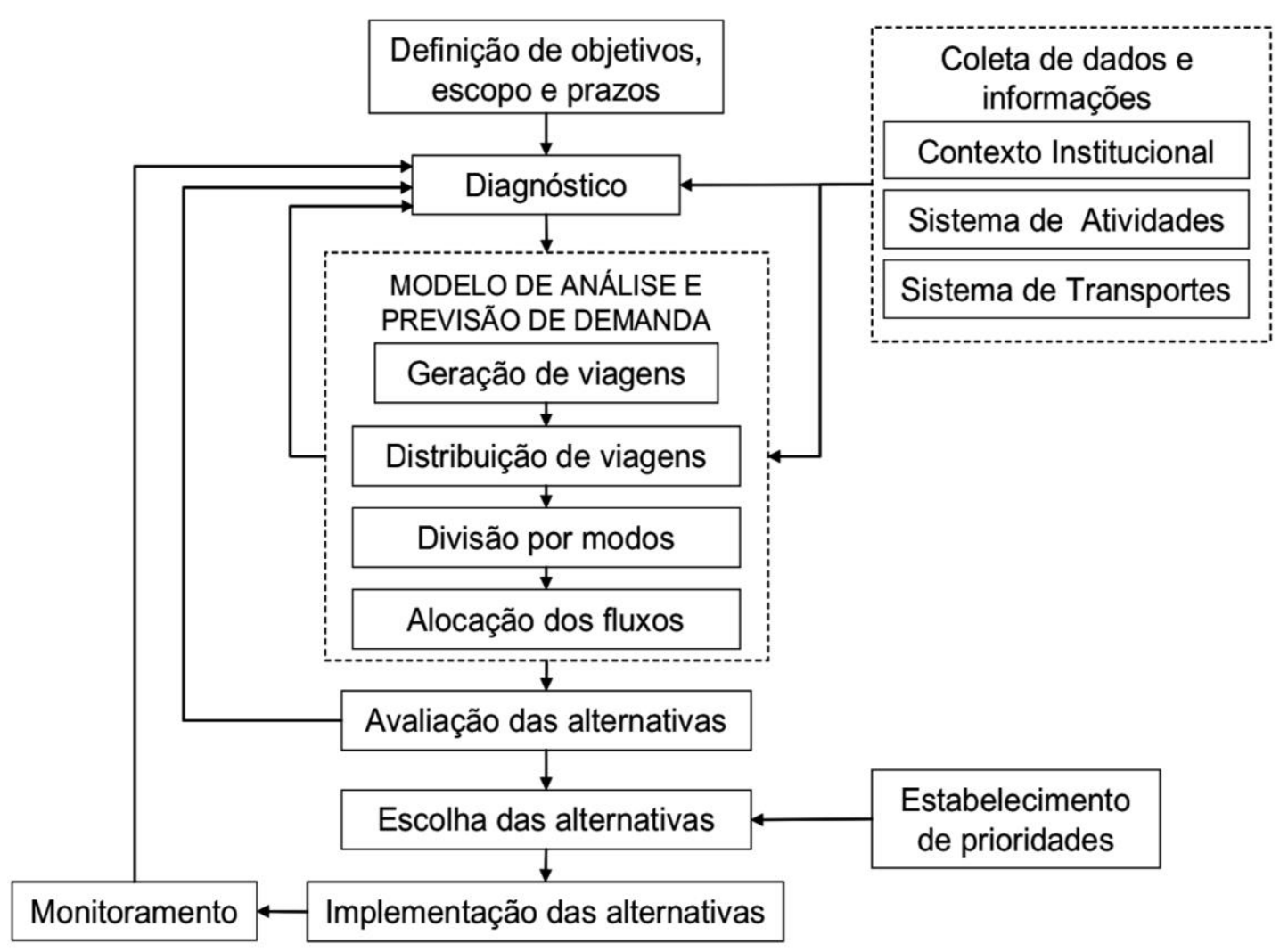

Fonte: Souza e D’Agosto (2013), elaborado a partir de Adler, 1978, Anderson, 1994, FHA, 1999, MT, 2007.

De acordo com DNIT (2006), a fase de planejamento rodoviário, considerando um empreendimento isolado, se caracteriza, em termos de seus objetivos, por:

i. Definir as alternativas tecnicamente possíveis para a realização do empreendimento rodoviário proposto;

ii. Efetuar a avaliação técnico-econômica e ambiental, ao nível de préviabilidade, das soluções ou diretrizes indicadas como adequadas;

iii. Definir ao nível preliminar, sempre que possível, critérios, soluções-tipo e características técnicas básicas a serem adotadas; e,

iv. Selecionar, em nível preliminar, as alternativas operacionais e de traçado inicialmente estabelecidas.

A fase de planejamento de um empreendimento rodoviário corresponde à etapa em que são definidas as alternativas locacionais ou tecnológicas a adotar, incluindo padrões alternativos de projeto, padrões funcionais, alternativas de traçado, estudos de viabilidade técnica, econômica e ambiental, considerando ainda a alternativa de nada a fazer. Sob uma abordagem ambiental, o planejamento de empreendimento rodoviário é entendido por DNIT (2006) como o estabelecimento de ações e atividades a serem desenvolvidas em todas as suas fases, com vistas à prevenção ou mitigação dos impactos negativos das atividades rodoviárias e à maximização dos impactos positivos almejados 
com a implantação do empreendimento, cujo conjunto estabelece a amplitude das responsabilidades técnicas, confrontadas com as atividades ambientais.

A partir da definição pela implantação de uma nova infraestrutura rodoviária dentre as alternativas existentes (escolha de outros sistemas de transporte, melhoria de sistemas existentes, etc.), estima-se os cenários, considerando dados da eficiência operacional e custos, e avalia-se os impactos esperados. A etapa de avaliação dos impactos é realizada por estudos ambientais, com a finalidade de contribuir para o processo de seleção da alternativa.

A seleção das alternativas locacionais deve ser baseada nas trade-offs entre os benefícios operacionais e econômicos do empreendimento (traçado mais direto, mais seguro, de menor custo de implantação e manutenção, com melhor atendimento aos usuários) e a sua inserção urbana-ambiental, de modo a permitir a identificação e mitigação de riscos e impactos socioambientais.

Os estudos ambientais desenvolvidos na fase de planejamento incidem na avaliação prévia dos impactos mais significativos do empreendimento, ao longo de todas as suas etapas, com enfoque nos aspectos mais sensíveis e susceptíveis nas áreas de influência do empreendimento. A identificação dos impactos mais significativos tem caráter estratégico na viabilização ambiental do empreendimento, devendo considerar especialmente as áreas com restrições legais das áreas a serem afetadas, o tipo de uso e ocupação do solo e a natureza da intervenção planejada. Quanto mais cedo forem identificados e avaliados os riscos e os impactos socioambientais significativos, maior será a eficácia na prevenção e controle dos danos potenciais.

De modo geral, pode-se dizer que os estudos socioambientais na etapa de planejamento, quando bem elaborados, podem contribuir para:

- Descartar as alternativas de elevada criticidade em termos socioambientais ou, eventualmente, o próprio empreendimento;

- Evitar dificuldade, atrasos ou a não obtenção de licença ambiental;

- Estimar os recursos necessários à implementação de medidas corretivas, preventivas ou compensatórias, bem como viabilizá-los em tempo hábil;

- Evitar dispêndios vultuosos dos recursos necessários em função das medidas necessárias para mitigação e compensação de impactos, bem como de medidas corretivas e de recuperação de passivos ambientais;

- Prever e indicar as medidas de preservação e de recuperação ou mitigação de impactos que devam ser incorporadas e desenvolvidas na fase de Projeto Básico;

- Reduzir a necessidade de ajustes nos projetos de engenharia para a obtenção das licenças e autorizações ambientais, que, por sua vez, poderiam afetar os custos e o cronograma do empreendimento;

- Subsidiar a elaboração e implementação de planos, programas de gestão e demais estudos das fases subsequentes. 
Um importante instrumento para tomada de decisões a nível de projetos de infraestrutura de transporte, baseado nas premissas do desenvolvimento sustentável, é a Avaliação de Impacto Ambiental (AIA), pois amplia as perspectivas tradicionais da engenharia. Muitos autores propuseram significados para o termo AIA na literatura, enfatizando sua função de avaliar a situação futura do ambiente a partir da ação que se pretende adotar, como: "Um processo sistemático que examina antecipadamente as consequências ambientais de ações humanas" (GLASSON; THERIVEL; CHADWICK, 1999). De acordo com estes autores, a AIA tem como funções: (i) ajudar o processo decisório; (ii) ajudar na elaboração de projetos e propostas de desenvolvimento; (iii) ser um instrumento para o desenvolvimento sustentável.

No Brasil, a introdução formal da AIA ocorreu com a promulgação da Lei Federal $\mathrm{n}^{\mathrm{o}}$ 6.938, em 1981, que dispõe sobre a Política Nacional do Meio Ambiente. Posteriormente, o Decreto $n^{\circ} 88.351 / 83$ (substituído pelo Decreto $n^{\circ}$ 99.274/90) atrelou a AIA ao processo de licenciamento ambiental conduzido pelo poder público, que foi regulamentada pela Resolução CONAMA n ${ }^{\circ}$ 01/86 e pela Resolução CONAMA n ${ }^{\circ}$ 237/97, condicionando a emissão da Licença Prévia (LP) à elaboração e aprovação do Estudo de Impacto Ambiental (EIA). Contudo, o instrumento está regulamentado apenas para etapa de projeto, descartando-se a necessidade de realizar uma AIA para políticas, planos e programas, cujo estudo é denominado Avaliação Ambiental Estratégica (AAE).

A AIA, com o objetivo de analisar as consequências ambientais potenciais de uma atividade humana, fornece informações importantes que devem ser levadas em consideração no processo decisório, juntamente com outras de caráter financeiro, técnico, legal e político. Castro (2018) lembra que a AIA não é um instrumento de decisão, mas sim, de fornecimento de subsídios para o processo de tomada de decisão, com o propósito de suprir informações por meio do exame sistemático das atividades do projeto.

Durante a realização dos estudos prévios, várias decisões são tomadas acerca do projeto visando reduzir a magnitude ou a importância dos impactos adversos. Usualmente esse processo é realizado mediante confrontos entre o empreendedor, o projetista, os consultores ambientais, autoridades licenciadoras e comunidades, constituindo-se uma importante etapa do processo de avaliação de impactos.

A viabilidade econômica e a exequibilidade técnica de projetos devem ser garantidas pelo empreendedor, mediante os estudos financeiros e técnicos necessários. No entanto, a decisão pela viabilidade ambiental cabe a órgãos governamentais com atribuições de licenciamento ambiental, como ocorre com o licenciamento federal (IBAMA) em certos Estados, ou por colegiados que contam com representantes de diferentes segmentos da sociedade civil e representantes governamentais, chamados de Conselhos de Meio Ambiente, os quais se fundamentam em pareceres técnicos elaborados pelo órgão ambiental licenciador. Em outras jurisdições, a decisão pode ser tomada por um organismo setorial, como um Ministério, ou por um conselho de ministros. 
Resta claro que, ao longo do processo de desenvolvimento de infraestruturas de transporte, várias decisões são tomadas, nas suas diferentes etapas, por diferentes protagonistas. Contudo, apesar dos avanços no desenvolvimento de metodologias de Avaliação de Impacto Ambiental (AIA) e da sua crescente utilização em processos decisórios, ainda não existe um consenso sobre como aplicar a sustentabilidade no transporte, de forma a tratar as questões econômicas, ambientais e sociais conjuntamente e integradas.

Diante do exposto, este trabalho focou na fase de planejamento, especialmente por ser uma fase estratégica do ponto de vista de viabilização da infraestrutura e de prevenção de impactos e riscos significativos e, ainda, por ser conduzida de maneira deficiente nas infraestruturas brasileiras.

\subsection{FERRAMENTAS DE AVALIAÇÃO DE SUSTENTABILIDADE EM TRANSPORTE}

As avaliações das infraestruturas de transporte com abordagem em sustentabilidade devem tratar das trade-off entre o crescimento econômico e o aumento do bem-estar ligado à acessibilidade e mobilidade, com suas respectivas consequências negativas, tanto socioambientais como aquelas associadas aos custos de implantação e operacionais. Como as muitas facetas do próprio conceito de sustentabilidade, o desenvolvimento de ferramenta adequada só pode acontecer quando todos os parâmetros são considerados simultaneamente (NESS et al., 2006), o que requer a definição de critérios de sustentabilidade bem específicos.

Com conceitos de sustentabilidade bastante abrangentes e contemplando diversos objetivos e metas a serem cumpridos, torna-se muito difícil definir uma maneira de adotar ações que sejam suficientemente práticas e operacionalizáveis. Por isso, a comunidade científica e as empresas públicas e privadas têm buscado desenvolver ferramentas eficientes e confiáveis para vencer esses desafios. Em resposta, muitas ferramentas têm sido desenvolvidas, proporcionando melhores diretrizes de aplicação, dados e experiências práticas de avaliação da sustentabilidade.

A teoria da Avaliação da Sustentabilidade, como atualmente expressa na literatura, evoluiu em grande parte do trabalho realizado por profissionais de avaliação de impacto ambiental (EIA) e, mais recentemente, Avaliação Ambiental Estratégica (AAE), que por sua vez foi influenciada por técnicas de análise de políticas (SHEATE et al., 2003).

Devuyst (2001) define a Avaliação da Sustentabilidade como sendo “[...] uma ferramenta que pode ajudar os tomadores de decisão e formuladores de políticas a decidir quais as ações devem tomar ou não devem tomar na tentativa de tornar a sociedade mais sustentável". Para Sala, Ciuffo e Nijkamp (2015), a Avaliação da Sustentabilidade é um 
método de avaliação complexo, realizado para apoiar a tomada de decisão e de política em um contexto ambiental, econômico e social amplo, e transcende a avaliação puramente técnica/científica.

Para Gudmundsson (2004), a avaliação do transporte sustentável é geralmente discutida em três etapas: conceituação, operacionalização e utilização, sendo que: a conceituação trata da definição do que a sustentabilidade se refere em um contexto particular; a operacionalização envolve a seleção de parâmetros para medir a sustentabilidade; e a utilização trata do real uso dos resultados para orientar o desenvolvimento e a política.

Segundo Pope et al. (2004), a "avaliação da sustentabilidade" é frequentemente descrita como um processo pelo qual as implicações de uma iniciativa sobre sustentabilidade são avaliadas, em que a iniciativa pode ser uma proposta ou existente política, plano, programa, projeto, peça legislativa ou uma prática ou atividade atual.

Existem inúmeras ferramentas disponíveis que contribuem para a sustentabilidade, sendo que cada uma delas apresenta vantagens e desvantagens de acordo com o tipo e o estágio do empreendimento e aplicação a que se destina. A maioria possui limitações quando se buscam ações direcionadas à sustentabilidade de forma mais completa e abrangente.

Ness et al. (2006) forneceram uma categorização de ferramentas de avaliação de sustentabilidade, cuja estrutura desenvolvida é apresentada na Figura 10. Os autores pretenderam contemplar as ferramentas mais significativas e que aparecem com mais frequência na literatura, e, tanto quanto possível, cobrir a variedade do amplo campo da avaliação da sustentabilidade, sem realizar um inventário exaustivo.

A estrutura sugerida se baseou em três categorias principais: (i) indicadores / índices, que são subdivididos em ferramentas de avaliação não integradas e integradas; (ii) avaliação relacionada ao produto, com foco no fluxo de materiais e/ou energia de um produto ou serviço de uma perspectiva de ciclo de vida; e (iii) ferramentas de avaliação integrada, que é uma coleção de ferramentas geralmente usadas para apoiar decisões relacionadas a políticas ou na implementação de projeto em uma região específica. Além disso, apresentou uma categoria abrangente de ferramentas de avaliação monetária que podem ser usadas como parte de muitas das ferramentas listadas nas três categorias.

Os autores dividiram as ferramentas da seguinte forma: (a) pelas suas características temporais (ex post ou descritivo) ou se é usado para prever resultados futuros (ex ante ou orientado para a mudança); (b) pelo foco (áreas de cobertura, como por exemplo, nível do produto ou mudança de política proposta); e (c) integração dos sistemas sociedade-natureza (integração dos aspectos ambientais, sociais e/ou econômicos). Conforme pode ser verificada na estrutura proposta, a flecha no topo mostra o foco temporal (retrospectivo) e prospectivo ou ambos. 
Figura 10 - Estrutura para ferramentas de avaliação de sustentabilidade.

Foco temporal

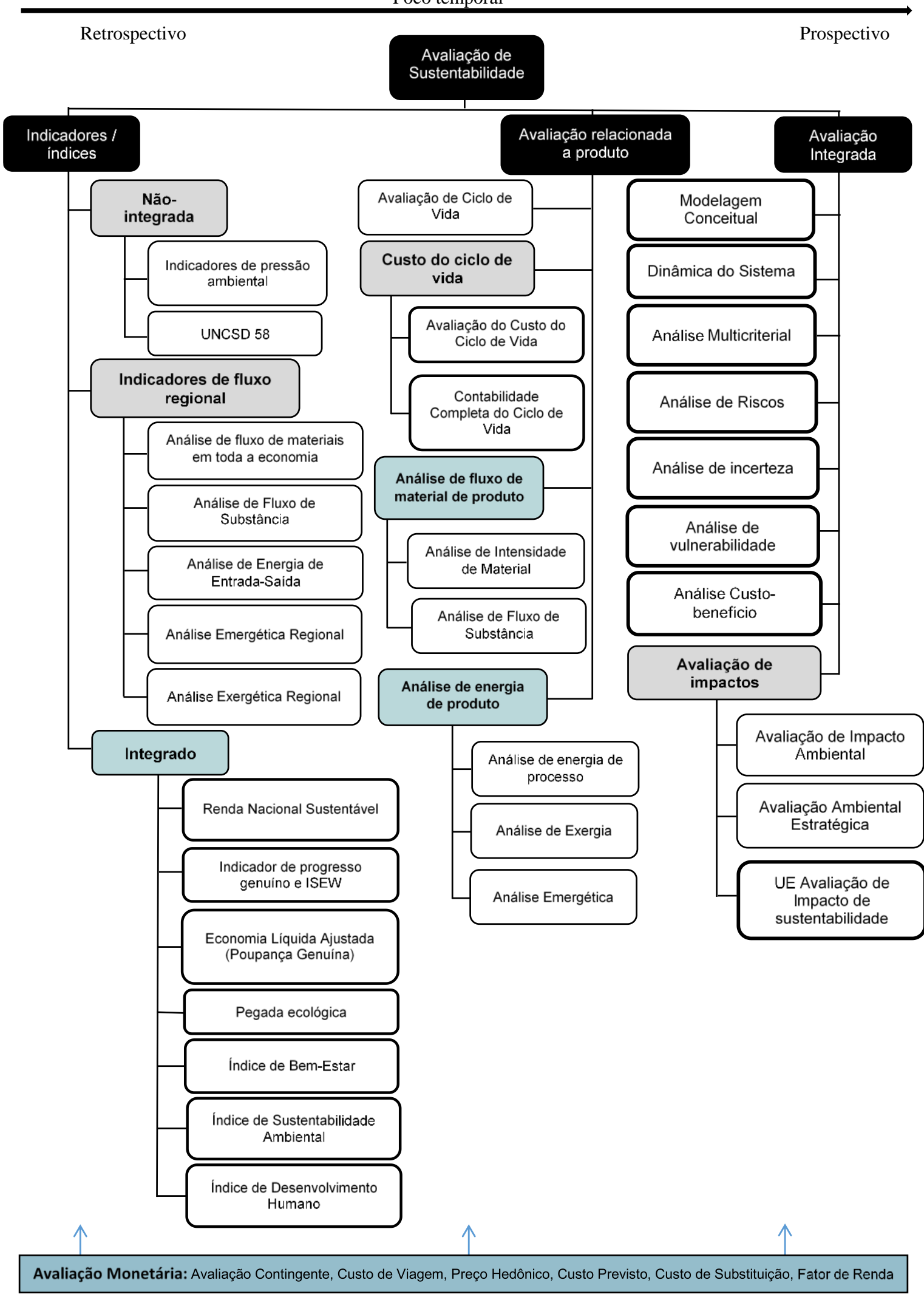

Fonte: Traduzido de NESS et al. (2006). 
Segundo a opinião de Ness et al. (2006), apenas dezessete ferramentas encontradas são capazes de integrar os sistemas natureza-sociedade em uma única avaliação, a saber: aqueles que compõem os Indicadores/Índices Integrados; os Custos de Ciclo de Vida contidos na Avaliação Relacionada ao Produto; aqueles da Avaliação Integrada; e UE Avaliação de Impacto de Sustentabilidade (ver quadros em negrito). Já as ferramentas de "avaliação relacionadas ao produto" geralmente não focam nos atributos espaciais, sendo que os impactos são vinculados apenas em função do produto e não especificamente para os locais onde ocorrem os impactos.

A Federação Internacional de Engenheiros Consultores - FIDIC (2012), após investigar a natureza das ferramentas de sustentabilidade, agrupou as ferramentas de sustentabilidade atualmente disponíveis no mercado nas quatro categorias mostradas na Figura 11, dependendo de sua origem e uso pretendido. Tais ferramentas visam incorporar a sustentabilidade na fase de projeto, para benefícios de longo prazo, redução de riscos de ativos e para maximizar a exploração de oportunidades.

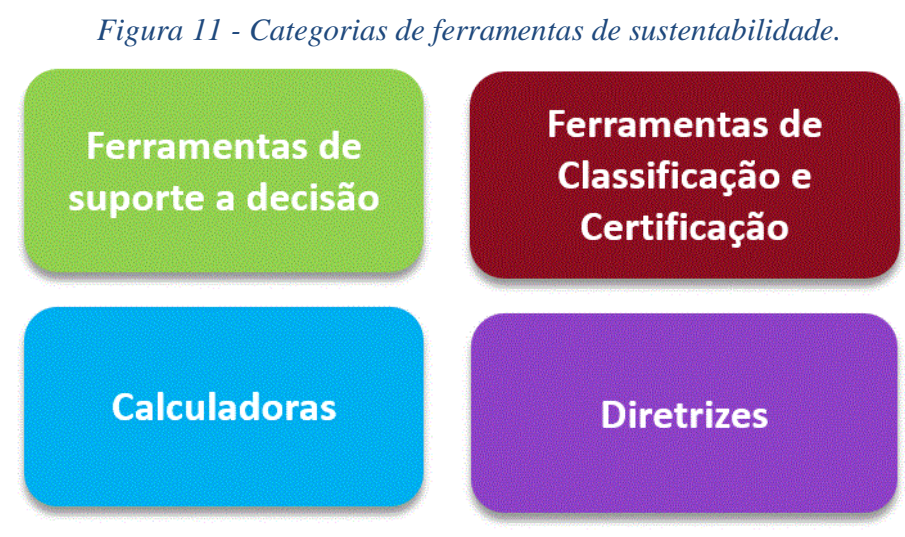

Fonte: Traduzido de FIDIC (2012).

O estudo da FIDIC conceitua "Ferramentas de Suporte à Decisão" como processos que usam diretrizes e metodologias de sustentabilidade para fornecer suporte de consultoria especializada à tomada de decisões ao longo de todo o ciclo do projeto, contando como recurso mais popular uma estrutura de avaliação que usa métodos de análise multicritério para avaliar o desempenho de sustentabilidade de diferentes alternativas de projeto. As "Ferramentas de Classificação e Certificação", por sua vez, pretendem avaliar, classificar e premiar um desenvolvimento planejado ou existente, dependendo de seu desempenho em relação a critérios de sustentabilidade relevantes. Já as "Calculadoras" são importantes para subsidiar as ferramentas de "Suporte à Decisão e de Classificação e Certificação", fornecendo valores quantitativos e qualitativos na forma em que são requeridos, como, por exemplo, emissões de carbono, uso de energia ou consumo de água para uma alternativa de projeto. Por fim, os documentos de "Diretrizes" normalmente informam outras ferramentas de sustentabilidade sobre qualidade, padrões, indicadores ou metodologias de sustentabilidade, como também podem informar sobre regulamentos, tecnologias e estratégias de sustentabilidade específicas do setor, apresentando oportunidades, riscos e estratégias de enfrentamento. 
Furberg et al. (2015) realizaram um estudo com o objetivo de identificar as práticas usuais em avaliação de sustentabilidade de infraestruturas de transporte, juntamente com as questões atuais e lacunas de conhecimento, por meio de uma revisão da literatura internacional científica publicada entre os anos de 2000 a 2014. Segundo os autores, há muitas práticas em curso em avaliações da sustentabilidade das infraestruturas de transporte em todo o mundo, embora as práticas variem em eficácia. As principais práticas relatadas foram: Estudos de Impacto Ambiental (EIA) e Avaliação Ambiental Estratégica (AAE), que, por sua vez, geralmente contêm um ou mais procedimentos de análise, como Análise Custo-benefício (ACB), Análises Multicritérios (AMC) e Análise do Ciclo de Vida (ACV), além de aplicações de sistemas de avaliação, classificação e recompensa em infraestruturas de transporte.

No Quadro 7 são apresentadas as principais ferramentas de avaliação em infraestrutura de transporte que abordam questões relacionadas à sustentabilidade, sem a pretensão de ser exaustivo, identificando os pontos fortes e fracos de cada ferramenta. Conforme demonstrado neste quadro, não há uma solução simples para a avaliação de sustentabilidade de políticas, planos, programas e projetos, quando se trata de empreendimentos de transporte. Apesar do fato de as abordagens atuais oferecerem alguma contribuição para a avaliação de sustentabilidade, nenhuma delas pode ser usada para realizar uma avaliação holística. Cada ferramenta tem suas próprias vantagens e desvantagens.

Assim, ao selecionar uma ferramenta, é preciso ponderar entre as limitações e os benefícios de sua escolha, sendo que a aplicação combinada de ferramentas tende a alcançar resultados melhores e mais completos. A escolha pelo uso de determinada ferramenta requer a verificação das suas obrigações legais, a adaptabilidade, a facilidade de uso, os resultados esperados, a fase do empreendimento, os recursos (humanos, materiais e financeiros) e o tempo disponíveis, a disponibilidade de dados, dentre outros.

Deve-se ter cuidado em replicar abordagens e metodologias, ainda que as práticas tenham alcançado resultados positivos, tendo em vista que pode haver diferenças de prioridades de negócio, nos desafios dos empreendimentos, nas externalidades, na cultura corporativa, dos stakeholders envolvidos e nos sistemas de gerenciamento existentes.

Embora existam muitas abordagens e ferramentas destinadas a avaliar elementos de sustentabilidade no Brasil, atualmente não existe uma metodologia padronizada ou comumente aceita para avaliar a sustentabilidade nas diferentes fases de empreendimentos de transporte. A ferramenta amplamente utilizada e regulamentada no País é o Estudo de Impacto Ambiental (EIA), que adota os métodos de Avaliação de Impacto Ambiental (AIA), concentrando-se especialmente nos temas ambientais aplicáveis à fase de projetos. As demais ferramentas ainda são utilizadas muitas vezes por pressão de organismos financiadores internacionais. 


\begin{tabular}{|c|c|c|c|}
\hline FERRAMENTA & DESCRIÇÃO & VANTAGENS & DESVANTAGENS \\
\hline $\begin{array}{c}\text { Análise de } \\
\text { Custo-Benefício }\end{array}$ & $\begin{array}{l}\text { Computa os benefícios e os custos em valores } \\
\text { monetários de um projeto ou de suas } \\
\text { alternativas, visando compará-los por meio da } \\
\text { relação Benefício-Custo, do Benéfico Liquido } \\
\text { ou da taxa de crescimento esperada. } \\
\end{array}$ & $\begin{array}{l}\text { O uso da ferramenta pode ser útil ao adotar } \\
\text { uma abordagem mais pragmática, sujeita a } \\
\text { determinadas precauções. }\end{array}$ & $\begin{array}{l}\text { Inadequadas para avaliar os impactos sobre o meio } \\
\text { ambiente e social, uma vez que se concentram na } \\
\text { eficiência econômica de uma determinada intervenção e } \\
\text { não conseguem incorporar critérios não quantificáveis } \\
\text { monetariamente. }\end{array}$ \\
\hline $\begin{array}{c}\text { Análise } \\
\text { Multicriterial }\end{array}$ & $\begin{array}{c}\text { Ferramenta utilizada para tomar decisões } \\
\text { baseadas em preferências sobre as alternativas } \\
\text { disponíveis que são caracterizadas por múltiplos } \\
\text { atributos, geralmente conflitantes. }\end{array}$ & $\begin{array}{l}\text { Útil quando o processo de decisão busca } \\
\text { satisfazer um ou múltiplos objetivos e, } \\
\text { portanto, deve se basear na avaliação de um } \\
\text { ou vários critérios. A ferramenta ajuda na } \\
\text { seleção da melhor opção possível. }\end{array}$ & $\begin{array}{l}\text { Possui subjetividade, complexidade e tempo elevado na } \\
\text { atribuição de pesos aos impactos. Como não é capaz de } \\
\text { remover a subjetividade no processo, torna-se altamente } \\
\text { suscetível à manipulação e variação em função da } \\
\text { experiência e interesse dos decisores. }\end{array}$ \\
\hline $\begin{array}{l}\text { Avaliação do } \\
\text { Ciclo de Vida }\end{array}$ & $\begin{array}{l}\text { Avalia os aspectos ambientais e potenciais } \\
\text { impactos associados a um produto, processo ou } \\
\text { serviço. }\end{array}$ & $\begin{array}{l}\text { Ajuda os tomadores de decisão a selecionar } \\
\text { o produto ou processo que resulte no menor } \\
\text { impacto ao meio ambiente, podendo ainda } \\
\text { considerar fatores de custo e desempenho. }\end{array}$ & $\begin{array}{l}\text { Pode demandar recurso e tempo excessivo. Dependendo } \\
\text { da abrangência de análise, a coleta de dados pode ser } \\
\text { problemática e a falta de disponibilidade dos dados pode } \\
\text { afetar a precisão dos resultados finais. }\end{array}$ \\
\hline $\begin{array}{l}\text { Estudo de } \\
\text { Impacto } \\
\text { Ambiental }\end{array}$ & $\begin{array}{l}\text { Destinado a analisar, sistematicamente, os } \\
\text { possíveis impactos da implantação e operação } \\
\text { de um determinado projeto, por meio de } \\
\text { métodos de Avaliação de Impacto Ambiental } \\
\text { (AIA) e técnicas de previsão dos impactos } \\
\text { ambientais. }\end{array}$ & $\begin{array}{l}\text { Adequado para tratar os efeitos do projeto, } \\
\text { construção e operação, na escala da área } \\
\text { diretamente afetada e de influência direta do } \\
\text { empreendimento, identificando e avaliando } \\
\text { os impactos previstos e estabelecendo as } \\
\text { medidas específicas de mitigação e controle. }\end{array}$ & $\begin{array}{l}\text { Desvantagem na avaliação das alternativas tecnológicas, } \\
\text { dos impactos indiretos e dos impactos cumulativos e } \\
\text { sinergéticos é bastante limitada. } \\
\text { Não avalia a viabilidade ambiental de políticas, planos e } \\
\text { programas. }\end{array}$ \\
\hline $\begin{array}{l}\text { Avaliação } \\
\text { Ambiental } \\
\text { Estratégica }\end{array}$ & $\begin{array}{l}\text { Processo formal, sistemático e abrangente de } \\
\text { avaliar os impactos ambientais de uma política, } \\
\text { plano ou programa e de suas alternativas, } \\
\text { incluindo a preparação de um relatório contendo } \\
\text { as conclusões da avaliação, usando-as em um } \\
\text { processo decisório publicamente responsável } \\
\text { (THÉRIVEL et al., 1992) }\end{array}$ & $\begin{array}{l}\text { Fortalece o projeto do EIA e fornece uma } \\
\text { consideração mais ampla de impactos e } \\
\text { alternativas, cujos impactos de grande } \\
\text { abrangência espacial, inclusive impactos } \\
\text { globais. Trata-se de processos antecipatórios } \\
\text { e prospectivos, integrativos, frequentemente } \\
\text { flexíveis. }\end{array}$ & $\begin{array}{l}\text { Falta uma base legal e de regulamentação para seu uso, } \\
\text { da forma de apresentação dos resultados, dos } \\
\text { mecanismos de participação pública e, sobretudo, da } \\
\text { integração dos resultados obtidos à tomada de decisão. }\end{array}$ \\
\hline $\begin{array}{c}\text { Estudo de } \\
\text { Análise de Riscos }\end{array}$ & $\begin{array}{c}\text { Estudo quantitativo de risco, baseado em } \\
\text { técnicas de identificação de perigos, estimativa } \\
\text { de frequências e de efeitos físicos, avaliação de } \\
\text { vulnerabilidade e na estimativa do risco } \\
\text { (CETESB, 2014) }\end{array}$ & $\begin{array}{c}\text { Identifica as causas básicas, sejam elas } \\
\text { técnica, gerencial ou operacional, e } \\
\text { estabelece medidas preventivas e de } \\
\text { controle. }\end{array}$ & $\begin{array}{c}\text { Depende da percepção dos perigos no processo ou } \\
\text { projeto por parte dos envolvidos; da experiência do } \\
\text { grupo participante; pode resultar em medidas excessivas } \\
\text { de proteção. }\end{array}$ \\
\hline
\end{tabular}




\subsubsection{Sistemas de Classificação e de Certificação de Sustentabilidade}

Nos últimos anos, várias ferramentas de avaliação da sustentabilidade de empreendimentos de transporte estão sendo desenvolvidas internacionalmente, em especial sistemas de classificação e de certificação. Esses sistemas utilizam critérios, indicadores e medidas de desempenho baseados em princípios, objetivos e metas.

Um sistema de classificação deve ser visto como uma ferramenta entre muitas que podem ajudar uma organização a medir, gerir e alcançar suas metas de sustentabilidade (ZIETSMAN \& RAMANI, 2011). Os sistemas de classificação permitem que equipes de projeto e construtores estabeleçam prioridades sustentáveis, ao mesmo tempo em que fornecem às partes interessadas um método para analisar o desempenho (REEDER, 2010).

Os sistemas de classificação e certificação estabelecem critérios econômicos, sociais, ambientais, etc. para avaliar a sustentabilidade em transportes, baseados principalmente em indicadores, que são utilizados como meios de mensuração. Os sistemas de classificação concedem créditos por escolhas ou práticas sustentáveis e, geralmente, resultam em uma certificação. Em geral, estes sistemas são projetados para fornecer orientação, pontuação e potenciais recompensas para incluir atributos sustentáveis nas diversas fases de infraestruturas de transporte, comumente em projetos de rodovias.

Um sistema de classificação pode ajudar a incentivar resultados mais sustentáveis, comunicando seus resultados internamente e ao público em geral, além de reconhecer e premiar organizações. Há ainda potencial de uso em benchmarking e na identificação de áreas com oportunidade para melhorias.

Zietsman \& Ramani (2011); Muench et al. (2012) defendem que os sistemas de classificação são atraentes pois:

- Fornecem uma métrica comum (pontos) para toda a gama de soluções sustentáveis;

- Medem a sustentabilidade, tornando-a viável;

- Permitem a comunicação direta de metas de sustentabilidade, esforços e realizações;

- Fornecem um contexto razoável dentro do qual projetistas, empreiteiros e fornecedores de materiais podem ser inovador em suas soluções.

No entanto, esses autores alertam que os sistemas de classificação são frequentemente criticados, pois tendem a sacrificar detalhe para a simplicidade, sendo difícil gerar um consenso sobre os itens a serem incluídos / excluídos; não capturam todo o escopo de soluções sustentáveis; e a busca por pontos em um sistema de classificação pode afetar a qualidade do projeto. 
Bueno et al. (2013) também apontaram alguns problemas dos sistemas de classificação, conforme seguem:

- não há um conjunto comum de critérios para comparação entre sistemas de classificação;

- falta objetividade e transparência nos processos de seleção de critérios e ponderação;

- são mais usados como ferramentas de certificação do que como ferramentas de sustentabilidade;

- não são baseados em métodos padronizados de avaliação de desempenho;

- falta participação de todas as partes envolvidas no ciclo de vida do projeto;

- o número de indicadores geralmente é muito elevado.

No Brasil, o sistema mais conhecido é o Leadership in Energy and Environmental Design (LEED), desenvolvido em 1998 pelo US Green Building Council (USGBC). Esse sistema contempla a certificação para construções sustentáveis, de acordo com os critérios de racionalização de recursos (energia, água, etc.) atendidos por um edifício. A fim de melhorar a qualidade e ampliar a aplicação de sistemas de classificação, diversas outras instituições têm desenvolvido sistemas para aplicação em infraestruturas de transporte, específicos à região ou país a que pertencem.

Como resultado de um levantamento bibliográfico, o Quadro 8 apresenta exemplos de importantes ferramentas de classificação e/ou certificação de sustentabilidade aplicáveis à infraestrutura de transporte e civil, bem como algumas outras ferramentas especializadas para projetos rodoviários.

Quadro 8 - Exemplos de ferramentas de classificação e certificação de sustentabilidade.

\begin{tabular}{|c|c|c|}
\hline Ferramenta & Instituição & Descrição \\
\hline $\begin{array}{l}\text { CEEQUAL - Civil } \\
\text { Engineering } \\
\text { Environmental Quality } \\
\text { Assessment and Award } \\
\text { Scheme }\end{array}$ & Reino Unido & $\begin{array}{l}\text { Sistema internacional de avaliação de sustentabilidade baseada em } \\
\text { evidências, avaliação e prêmios para engenharia civil, infraestrutura, } \\
\text { paisagismo e obras em espaços públicos. }\end{array}$ \\
\hline Envision $^{\mathrm{TM}}$ & $\begin{array}{l}\text { Institute for } \\
\text { Sustainable } \\
\text { Infrastructure (ISI) e } \\
\text { Harvard University / } \\
\quad \text { EUA }\end{array}$ & $\begin{array}{l}\text { Estrutura abrangente de } 60 \text { critérios que abrangem toda a gama de } \\
\text { impactos ambientais, sociais e econômicos que devem ser avaliados } \\
\text { para determinar como um projeto incorporou a sustentabilidade. } \\
\text { Como uma ferramenta de orientação de planejamento e projeto, a } \\
\text { Envision fornece métricas de sustentabilidade para todos os tipos de } \\
\text { infraestrutura. }\end{array}$ \\
\hline $\begin{array}{l}\text { ELASTIC - Evaluative } \\
\text { and Logical Approach to } \\
\text { Sustainable Transport } \\
\text { Indicator Compilation }\end{array}$ & Reino Unido & $\begin{array}{l}\text { Estrutura para identificar e selecionar um subconjunto reduzido de } \\
\text { indicadores de sustentabilidade de transporte com base em } \\
\text { julgamentos das partes interessadas sobre seus pontos fortes } \\
\text { metodológicos e relevância para os princípios-chave do transporte } \\
\text { sustentável. }\end{array}$ \\
\hline Green Guide for Roads & $\begin{array}{l}\text { Transportation } \\
\text { Association of } \\
\text { Canada / Canadá }\end{array}$ & $\begin{array}{l}\text { O quadro inclui áreas onde as práticas de sustentabilidade podem ser } \\
\text { aplicadas, com uma descrição de requisitos e melhores práticas ou } \\
\text { estratégias associadas. Aplica-se a todos os tipos de estradas urbanas } \\
\text { e rurais e inclui considerações de sustentabilidade como melhor } \\
\text { compatibilidade e habitabilidade; acessibilidade universal; equidade } \\
\text { modal; conservação de recursos; acessibilidade; e proteção ambiental. }\end{array}$ \\
\hline $\begin{array}{c}\text { GreenLITES - Green } \\
\text { Leadership in Transport }\end{array}$ & $\begin{array}{l}\text { New York State } \\
\text { Department of }\end{array}$ & $\begin{array}{l}\text { É um programa de auto-certificação que distingue projetos e } \\
\text { operações de transporte com base na extensão em que incorporam } \\
\text { escolhas sustentáveis. Este é principalmente um programa de }\end{array}$ \\
\hline
\end{tabular}




\begin{tabular}{|c|c|c|}
\hline Ferramenta & Instituição & Descrição \\
\hline $\begin{array}{l}\text { and Environmental } \\
\text { Sustainability }\end{array}$ & $\begin{array}{l}\text { Transportation / } \\
\text { EUA }\end{array}$ & $\begin{array}{l}\text { gerenciamento interno para a NYSDOT medir o desempenho, } \\
\text { reconhecer boas práticas e identificar onde precisa melhorar. Também } \\
\text { fornece uma maneira de demonstrar ao público como está } \\
\text { promovendo práticas sustentáveis. Os projetos e operações são } \\
\text { avaliados para práticas sustentáveis e, com base no total de créditos } \\
\text { recebidos, é atribuído um nível de certificação. }\end{array}$ \\
\hline Greenroads $^{\mathrm{TM}}$ & $\begin{array}{c}\text { University of } \\
\text { Washington e } \\
\mathrm{CH}^{2} \mathrm{M} \text { Hill / EUA }\end{array}$ & \begin{tabular}{l} 
Sistema de classificação de sustentabilidade para projetos e \\
construção de rodovias. Apresenta uma coleção de melhores práticas \\
de sustentabilidade, chamada créditos. A obtenção de créditos gera \\
pontos para uma pontuação geral que indica a sustentabilidade da \\
rodovia. \} \\
\hline $\begin{array}{c}\text { I-LAST - Illinois Livable } \\
\text { and Sustainable } \\
\text { Transportation }\end{array}$ & $\begin{array}{c}\text { Illinois Department } \\
\text { of Transportation / } \\
\text { EUA }\end{array}$ & $\begin{array}{l}\text { Um sistema de pontos para avaliar as medidas sustentáveis incluído } \\
\text { em um projeto, que fornece uma lista abrangente de práticas que têm } \\
\text { o potencial para trazer resultados sustentáveis para projetos } \\
\text { rodoviários de todos os tamanhos e todas as fases de desenvolvimento } \\
\text { do projeto (planejamento, projeto e construção). }\end{array}$ \\
\hline $\begin{array}{c}\text { INVEST - Infrastructure } \\
\text { Voluntary Evaluation } \\
\text { Sustainability } \\
\text { Tool }\end{array}$ & $\begin{array}{l}\text { Federal Highway } \\
\text { Administration } \\
\text { (FHWA) / EUA }\end{array}$ & $\begin{array}{l}\text { Ferramenta de auto-avaliação via Web com módulos: sistema de } \\
\text { planejamento, desenvolvimento de projeto, operações e manutenção. } \\
\text { Atribui para cada prática um valor (peso) de acordo com impacto } \\
\text { relativo na sustentabilidade da estrada. Identifica as características } \\
\text { das rodovias sustentáveis e fornece procedimentos e técnicas para } \\
\text { ajudar as organizações a aplicarem melhores práticas de } \\
\text { sustentabilidade. }\end{array}$ \\
\hline Least Cost Planning & $\begin{array}{c}\text { Oregon Department } \\
\text { of Transportation / } \\
\text { EUA }\end{array}$ & $\begin{array}{l}\text { É um processo de planejamento estratégico que usa os princípios da } \\
\text { análise de custo-benefício como uma estrutura de avaliação. } \\
\text { Modelo para uso como ferramenta de tomada de decisão no } \\
\text { desenvolvimento de planos e projetos. Habitabilidade, segurança, } \\
\text { equidade, vitalidade econômica e gestão ambiental são avaliados em } \\
\text { conjunto com considerações tradicionais como custos de capital. }\end{array}$ \\
\hline $\begin{array}{l}\text { MOSAIC - Model of } \\
\text { Sustainability and } \\
\text { Integrated Corridors }\end{array}$ & $\begin{array}{l}\text { Maryland State } \\
\text { Highway } \\
\text { Administration / } \\
\text { EUA }\end{array}$ & $\begin{array}{l}\text { A ferramenta emprega planilha eletrônica do Microsoft Excel. Seis } \\
\text { categorias de indicadores da sustentabilidade: mobilidade, segurança, } \\
\text { impacto socioeconômico, recursos naturais, energia e emissões e } \\
\text { custos. Inclui mais que } 30 \text { medidas de desempenho de } \\
\text { sustentabilidade. }\end{array}$ \\
\hline Project Selection Tool & $\begin{array}{l}\text { State of Rhode } \\
\text { Island / EUA }\end{array}$ & $\begin{array}{l}\text { A ferramenta de seleção de projetos para avaliar e priorizar projetos } \\
\text { que buscam financiamento estatal ou sem fins lucrativos. A } \\
\text { ferramenta inclui as seis categorias: } 1 \text {. Escolha de transporte e } \\
\text { acessibilidade; } 2 \text {. Escolha de habitação e acessibilidade; } 3 \text {. } \\
\text { Desenvolvimento econômico; } 4 \text {. Apoio de comunidades existentes e } \\
\text { centros de crescimento designados; } 5 \text {. Caráter comunitário e } \\
\text { colaboração; } 6 \text {. Proteção ambiental e saúde pública. }\end{array}$ \\
\hline $\begin{array}{c}\text { Sustainability } \\
\text { Enhancement Tool }\end{array}$ & $\begin{array}{c}\text { Texas Department } \\
\text { of Transportation / } \\
\text { EUA }\end{array}$ & $\begin{array}{l}\text { Estrutura baseada em medição de desempenho e metodologia de } \\
\text { avaliação para transporte sustentável, vinculada às metas de } \\
\text { planejamento estratégico da agência de transporte. Aplica } 12 \text { medidas } \\
\text { de desempenho no processo de planejamento de corredor rodoviário, } \\
\text { incluindo medidas de congestionamento, segurança, modos } \\
\text { alternativos e qualidade do ar, para abordar as metas e objetivos do } \\
\text { plano estratégico. A abordagem de tomada de decisão da teoria da } \\
\text { utilidade multi-atributo (MAUT) é aplicada para quantificar e } \\
\text { normalizar as medidas de desempenho selecionadas e calcular os } \\
\text { valores do índice de sustentabilidade para as condições atuais e } \\
\text { previstas de corredor. }\end{array}$ \\
\hline $\begin{array}{l}\text { Sustainable Corridor } \\
\text { Rating System (SCRS) }\end{array}$ & $\begin{array}{c}\text { University of } \\
\text { Delaware, Newark }\end{array}$ & $\begin{array}{l}\text { Metodologia para sistemas de classificação aplicado a corredores } \\
\text { urbanos. Visa alterar o comportamento dos profissionais de transporte } \\
\text { e induzir práticas de transporte sustentável, definindo uma } \\
\text { metodologia para o desenvolvimento de sistemas de classificação } \\
\text { verde. }\end{array}$ \\
\hline $\begin{array}{c}\text { STARS - Sustainable } \\
\text { Transportation Analysis } \\
\text { \& Rating System }\end{array}$ & $\begin{array}{c}\text { Colaboradores do } \\
\text { setor de transporte } \\
\text { de Oregon, } \\
\text { Washington, }\end{array}$ & $\begin{array}{l}\text { Estrutura de planejamento integrado desenvolvida para ajudar } \\
\text { planejadores, comunidades e tomadores de decisão a avaliar os } \\
\text { impactos dos planos e projetos de transporte, identificar estratégias } \\
\text { inovadoras e melhorar a tomada de decisão. Sua estrutura flexível } \\
\text { incentiva os projetos a atingirem vários objetivos de sustentabilidade. }\end{array}$ \\
\hline
\end{tabular}
\end{tabular}




\begin{tabular}{|c|c|c|}
\hline Ferramenta & Instituição & Descrição \\
\hline & $\begin{array}{c}\text { California e Nevada } \\
\text { / EUA }\end{array}$ & $\begin{array}{l}\text { O STARS não concede níveis de certificação com base em pontos. } \\
\text { Em vez disso, cada crédito é ponderado igualmente, permitindo que } \\
\text { os usuários otimizem os benefícios compartilhados em todas as } \\
\text { categorias de crédito. }\end{array}$ \\
\hline $\begin{array}{l}\text { SUNRA - Sustainability - } \\
\text { National Road } \\
\text { Administrations }\end{array}$ & $\begin{array}{l}\text { Diversos países da } \\
\text { Europa }\end{array}$ & $\begin{array}{l}\text { Sistema que visa apoiar e orientar a Administração Nacional de } \\
\text { Rodovias para melhorar o desempenho, fornecendo meios para } \\
\text { considerar prioridades nacionais, questões importantes, preocupações } \\
\text { de partes interessadas e estruturas organizacionais. Fornece uma } \\
\text { maneira comum de definir sustentabilidade, identificar como medir o } \\
\text { desenvolvimento sustentável em um nível estratégico e integrar a } \\
\text { tomada de decisão sustentável nos principais pontos de intervenção. }\end{array}$ \\
\hline $\begin{array}{l}\text { BE }^{2} \text { ST-In-Highways } \\
\text { Building Environmentally } \\
\text { and Economically } \\
\text { Sustainable } \\
\text { Transportation- } \\
\text { Infrastructure-Highways }\end{array}$ & $\begin{array}{l}\text { Universidade de } \\
\text { Wisconsin-Madison } \\
\text { / EUA }\end{array}$ & $\begin{array}{l}\text { Sistema de classificação que emprega técnicas de análise do ciclo de } \\
\text { vida para fornecer uma avaliação quantitativa da sustentabilidade } \\
\text { ambiental e econômica dos projetos de rodovias. O consumo de } \\
\text { energia, as emissões de gases de efeito estufa, o custo do ciclo de vida } \\
\text { e outros fatores são considerados. Com base na pontuação recebida, } \\
\text { um projeto recebe um rótulo proporcional ao nível de sustentabilidade } \\
\text { alcançado. Seu foco principal é quantificar o impacto na } \\
\text { sustentabilidade do uso de materiais reciclados em pavimentos. }\end{array}$ \\
\hline GreenPave & Ontário / Canadá & $\begin{array}{l}\text { Sistema de classificação simplificado baseado em LEED e } \\
\text { GreenRoads, mas customizado para Ontário, com foco em } \\
\text { componentes de pavimento. O objetivo é melhorar a sustentabilidade } \\
\text { da infraestrutura de transportes através da concepção e seleção de } \\
\text { alternativas de tratamento de pavimentos sustentáveis. }\end{array}$ \\
\hline $\begin{array}{c}\text { Infrastructure } \\
\text { Sustainability (IS) }\end{array}$ & $\begin{array}{l}\text { Australian Green } \\
\text { Infrastructure } \\
\text { Council (AGIC) / } \\
\text { Austrália }\end{array}$ & $\begin{array}{l}\text { O sistema apoia a obtenção de resultados sustentáveis no } \\
\text { desenvolvimento de infraestrutura, avaliando e classificando o } \\
\text { desempenho de sustentabilidade de um projeto. O processo de } \\
\text { classificação envolve auto avaliação, seguido por verificação } \\
\text { independente de um verificador nomeado pelo IS e, em seguida, pela } \\
\text { certificação formal. A ferramenta de classificação aborda seis grandes } \\
\text { temas, que são: } 1 \text {. Gestão e Governança, } 2 \text {. Usando Recursos, } 3 \text {. } \\
\text { Emissões, Poluição e Resíduos, } 4 \text {. Ecologia, } 5 \text {. Pessoas e Lugar, } 6 \text {. } \\
\text { Inovação. Dentro destes temas, } 15 \text { categorias compreendem um total } \\
\text { de } 51 \text { créditos. Cada crédito recebe um certo número de pontos. }\end{array}$ \\
\hline
\end{tabular}

Apesar da variedade e quantidade de sistemas existentes no mundo, esses diferentes sistemas empregam métodos distintos para determinar ou quantificar a sustentabilidade e enfatizar diferentes fatores de sustentabilidade (MARTLAND, 2012). Ou seja, não existe uma estrutura universal padrão para avaliar o progresso de uma infraestrutura de transporte em direção à sustentabilidade. Muitos desses sistemas, na verdade, foram desenvolvidos por ou para agências de transporte com foco em necessidades específicas ou no contexto local.

No Brasil, não há um sistema de classificação e certificação de sustentabilidade desenvolvido especificamente à infraestrutura de transporte, com foco a agências de transportes. Portanto, o uso de sistemas existentes em outros países pode não ser apropriados para a realidade brasileira, uma vez que se difere em relação ao clima, uso e ocupação do solo, densidade populacional, vulnerabilidades socioeconômicas, problemáticas urbanas, etc. 


\subsubsection{Indicadores de Sustentabilidade}

Como discutido anteriormente, a sustentabilidade é um conceito amplo e subjetivo e, portanto, a utilização de ferramentas para sua avaliação é de fundamental importância no processo de desenvolvimento de empreendimentos de transporte. As tomadas de decisão incorporam cada vez mais conceitos de sustentabilidade, considerando os impactos econômicos, sociais e ambientais de longo prazo.

Como resultado, há uma demanda crescente por ferramentas de planejamento adequadas, com destaque ao uso de indicadores de transporte sustentáveis. Os indicadores têm se demonstrado importantes instrumentos no nível de planejamento, podendo fornecer informações que podem ser usadas na formulação de planos, políticas, programas voltados à melhoria da qualidade de vida e à operacionalização de conceitos de sustentabilidade.

Por meio do levantamento da literatura, verifica-se que grande parte (talvez a maioria) das pesquisas que tratam da avaliação de sustentabilidade em transportes está relacionada ao uso de indicadores (ou medidas de desempenho), comumente associado a outros métodos de avaliação. Os indicadores de sustentabilidade são importantes ferramentas de mensuração e avaliação do progresso rumo ao desenvolvimento sustentável, sendo necessários para subsidiar a elaboração de políticas públicas e a tomadas de decisões (BELLEN, 2006).

O uso de indicadores é considerado importante para o processamento de informações múltiplas e variadas, permitindo a análise de realidades complexas a partir de uma representação numérica, gráfica e, portanto, mais simples. Segundo Costa (2003), os indicadores reduzem grande quantidade de informação a um número apropriado de parâmetros para análise e tomada de decisão; traduzem conceitos abstratos e difíceis de serem mensurados em entidades operacionais e mensuráveis, fornecendo uma informação sintética sobre determinado fenômeno e, sua utilização permite revelar condições e ao mesmo tempo tendências, apontando aspectos deficientes ou aqueles que necessitam de intervenção.

"Eles [os indicadores] traduzem dados e estatísticas em informação sucinta que seja facilmente compreendido e usado por pessoas de muito diferentes origens, incluindo engenheiros, administradores, políticos e público em geral" (RAMANI et al., 2011). Ao traduzir dados e estatísticas em um formato sucinto e consistente, as medidas de desempenho oferecem uma maneira eficiente de fornecer informações aos tomadores de decisão (EPA, 2011). Por outro lado, os indicadores podem refletir vários outros níveis de análise, como respostas a alguma ação, impactos físicos, os efeitos sociais e ambientais, os impactos econômicos e avaliação de desempenho.

Corroborando com Costa (2003), percebe-se que os indicadores estatísticos tradicionais, amplamente utilizados, tendem a enfocar somente a eficiência econômica 
dos sistemas de transportes (oferta e demanda), deixando de contemplar outras dimensões fundamentais para a sustentabilidade. Os indicadores de sustentabilidade possuem algumas características especiais que os diferem dos indicadores tradicionais, incluindo:

- Integração: permitem visualizar as conexões existentes entre as dimensões econômica, social e ambiental da sustentabilidade;

- Visão a longo prazo: os indicadores permitem acompanhar o progresso em direção à sustentabilidade, ao revelar tendências e ao fornecer informações indiretas sobre o futuro da comunidade;

- Preocupação com as futuras gerações: devem medir a equidade intra e entre gerações. Podem focalizar ainda, diferentes populações ou regiões geográficas;

- Desenvolvido com a contribuição de múltiplos participantes: as experiências têm mostrado que os indicadores de maior influência e confiabilidade têm sido aqueles desenvolvidos a partir da contribuição de diferentes grupos (MACLAREN, 1996 apud COSTA, 2003).

SHRP 2 (2009) alerta que as medidas de desempenho devem ser conduzidas por metas e objetivos estrategicamente alinhados. Os objetivos de uma agência de transporte devem refletir os aspectos mais importantes do que ela deseja realizar, sendo que as medidas de desempenho são o principal meio de avaliar o cumprimento de suas metas.

Zegras et al. (2004) apresentam o Sustainability Indicator Prism (ou Prisma de Indicador de Sustentabilidade) que representa uma hierarquia de objetivos/metas, seguido de índices, indicadores (medidas de desempenho com diferentes graus de especificidade), construídos a partir de dados brutos na base da pirâmide.

Figura 12 - A hierarquia da informação através do prisma de indicadores sustentáveis.

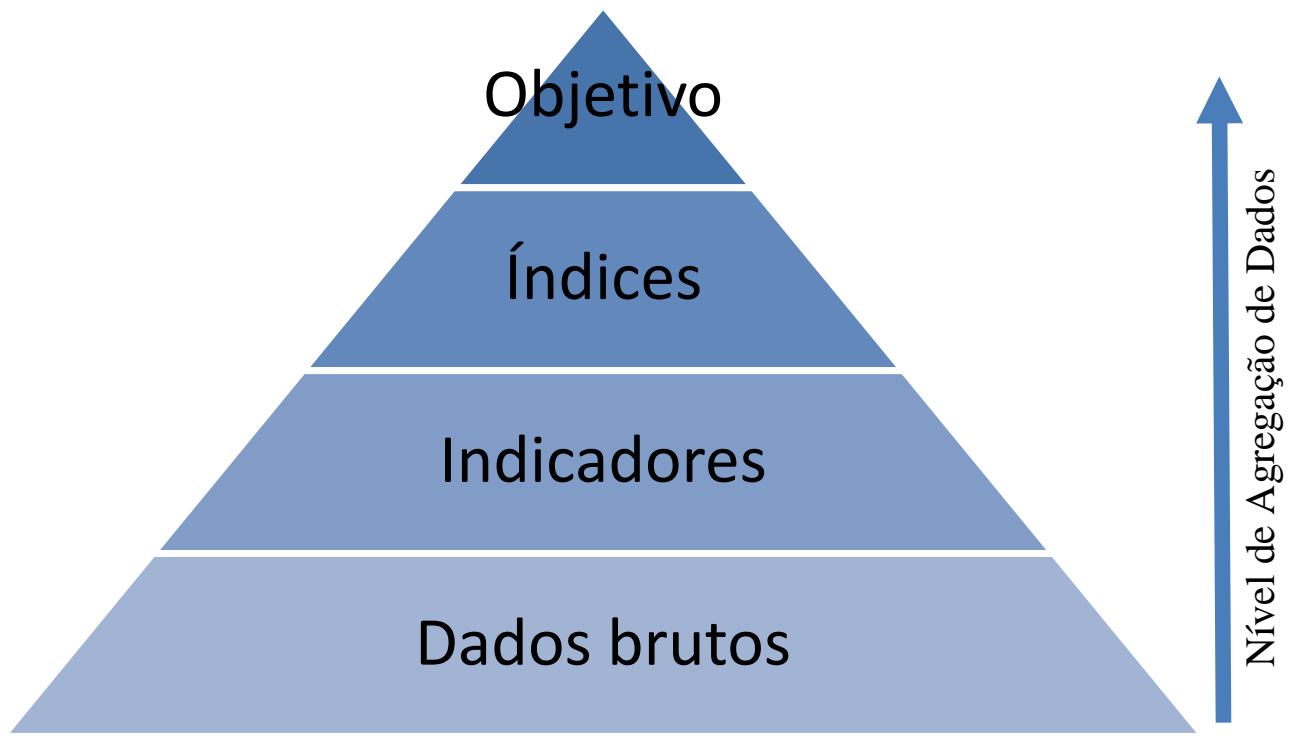

Fonte: Adaptado de Zegras et al. (2004) 
Enquanto as metas do projeto definem a direção, os indicadores do projeto permitem que proprietários, engenheiros e partes interessadas avaliem o progresso rumo ao desenvolvimento sustentável, comparando o desempenho alcançado em um projeto com o desempenho pretendido (FIDIC, 2004 apud LIM, 2009).

Os índices são construídos a partir da agregação de indicadores, usualmente por métodos aritméticos ou regras de decisão, que possibilita uma maior simplificação de parâmetros complexos. Os índices de sustentabilidade composto por múltiplas dimensões fornecem informações agregadas e podem ser utilizados por tomadores de decisão ou analistas para avaliar ou comparar o nível de sustentabilidade associado com alternativas de políticas, planos, programas e projetos.

Os índices são conhecidos por ser mais fácil de usar, simples de interpretar, e têm a capacidade de reduzir a sobrecarga de informação resultante das medidas de desempenho individual (LOMAX, 1997 apud JEON, 2007). Por isso, têm as vantagens de facilitar a comunicação com o público geral, que, usualmente, não está interessado nos detalhes que os compõem, preferindo quadros resumidos.

Contudo, Houghton (1998) destaca os seguintes problemas com o uso de índices:

- "Pode mascarar informações;

- Sua robustez pode ser limitada por diferentes escalas espaciais e temporais; $e$

- Nem sempre é claro como e por quem os índices foram desenvolvidos."

Litman (2016) alerta que pode haver distorção nos resultados em função de conflitos entre conveniência e abrangência na seleção de indicadores. Um índice composto por menor número de indicadores usando dados facilmente disponíveis é mais conveniente de usar, mas pode ignorar impactos importantes e, portanto, distorcer as decisões de planejamento. Por outro lado, um conjunto maior, apesar de sua maior abrangência, tem custos elevados de coleta de dados e é mais difícil a sua interpretação. 


\section{CAPÍTULO 3 - O RODOANEL MÁRIO COVAS}

A Região Metropolitana de São Paulo - RMSP é a maior aglomeração urbana do país. Diariamente, mais de um milhão de pessoas desloca-se entre os municípios da região para trabalhar ou estudar, além de intensos fluxos de veículos de carga que se dirigem e partem de diferentes regiões metropolitanas, com destaque ao Porto de Santos. Como consequência, enormes gargalos podem ser vistos cotidianamente no seu sistema viário e nos congestionamentos das suas principais vias de acesso, agravados pela concentração e polaridade da RMSP.

Para minimizar essa situação e agilizar o trânsito de transposição da RMSP, o governo de São Paulo planejou, no início dos anos 1990, um anel rodoviário, hoje denominado Rodoanel Mário Covas, de forma a convergir as principais rodovias estaduais e federais de ligação da RMSP com o interior e o litoral paulista e com as regiões Sul e Oeste do país, coletando e distribuindo o tráfego na região, além de desviar o tráfego rodoviário das áreas urbanas.

O Rodoanel Mário Covas, em sua atual configuração, começou a ser desenvolvido a partir de 1995, que incorporou, desde o início, uma preocupação com uma adequada inserção urbano-ambiental na RMSP. Previamente, já havia sido proposta a viabilização de inúmeras alternativas para uma via perimetral que articulasse as rodovias de acesso à RMSP entre si e com os principais eixos viários metropolitanos.

Além da importante função de interconexão entre grandes rodovias radiais que afluem à metrópole, apresenta um grande potencial como elemento estruturador do uso e ocupação do solo e do processo de expansão urbana (DERSA, 1998). O empreendimento foi concebido de forma a aproveitar suas potencialidades, sempre que possível, no âmbito de políticas de ocupação do solo, como um elemento catalizador de iniciativas e ações públicas voltadas à recuperação ambiental das áreas atravessadas e à ocupação do solo com melhor qualidade ambiental.

A rodovia cruza território com características heterogêneas e dotado de dinâmica própria, com assentamentos consolidados e em expansão, graves carências de infraestrutura e baixa qualidade ambiental e urbana, em contraste com áreas de melhor padrão e baixas densidades de ocupação, bacias hidrográficas de mananciais de abastecimento (ao sul, leste e norte) e Unidades de Conservação.

A região peri-urbana da RMSP onde o Rodoanel foi inserido é caracterizada por sofrer graves pressões ambientais, especialmente devido à ocupação desordenada e irregular e ao consequente comprometimento de sua cobertura vegetal e áreas ambientalmente protegidas, em especial o trecho Sul, que atravessa a região dos mananciais (represas Billings e Guarapiranga); o trecho Norte, que foi inserido entre a mancha urbana e o Parque Estadual da Cantareira - PEC, Unidade de Conservação de Proteção Integral; e o trecho Leste que afeta as várzeas do Alto Tietê. 
Diante da importância desses bens ambientais, o projeto foi desenvolvido de forma a evitar impactos significativos e minimizar impactos que pudessem comprometer ainda mais a situação ambiental das áreas e mesmo reduzir os impactos existentes, quando possível. Dentre as iniciativas que buscaram cumprir esses objetivos urbano-ambientais, destacam as complexas soluções construtivas - como a passagem elevada e túneis sobre área ambientalmente sensível -; o cadastramento detalhado da situação fundiária e de ocupação das áreas situadas em toda a faixa de domínio da rodovia, contribuindo para sua regularização e melhor organização do espaço urbano e rural; a criação de parques, visando contribuir para impedir o avanço da área urbanizada no entorno do empreendimento e minimizar a pressão da ocupação desordenada junto a mananciais; o aproveitamento do seu efeito barreira para potencializar as ações de outras iniciativas públicas destinadas ao controle do avanço da urbanização e ao aperfeiçoamento dos mecanismos de proteção das unidades de conservação existentes.

Também com vistas a minimizar impactos urbano-ambientais e operacionais, o Rodoanel foi projetado como uma via Classe "0", conforme classificação do Departamento Nacional de Infraestrutura de Transportes (DNIT), ou seja, possui alto padrão técnico e controle total de acessos, sendo bloqueada ao acesso de áreas lindeiras e ao viário local. Devido às suas características de via expressa bloqueada, os usuários somente podem entrar no Rodoanel nas interseções especialmente projetadas para este fim, integradas às rodovias troncais e ao sistema viário principal.

Para que as vias de interesse metropolitano tenham acesso ao Rodoanel, faz-se necessário atenderem a critérios de maior racionalidade para fluxos de transporte e adequação ao desenvolvimento urbano pretendido para sua região de influência. Algumas permissões de acesso direto são destinadas a atividades relacionadas ao segmento de cargas, estruturadas de forma a propiciar a integração inter e intramodal, desde que aprovados pelas Prefeituras e providos de licenciamento ambiental.

Para o crescimento dos bairros previamente existentes e em situação regular, a rodovia foi concebida para não se constituir em uma barreira física. Os estudos de estrutura urbana desenvolvidos no EIA permitiram identificar os principais fluxos transversais ao traçado e as respectivas demandas por cruzamentos transversais, tanto veiculares quanto pedestres, os quais foram mantidos, a menos onde foi recomendado a utilização do Rodoanel como barreira física, visando minimizar os impactos na continuidade da malha urbana futura e evitar a expansão urbana irregular. Por não haver articulação com o entorno, o tráfego do Rodoanel não sofre interferência pelos cruzamentos em nível, semáforos, travessia de pedestres, acessos diretos ao comércio e imóveis lindeiros, entre outros.

Considerando um processo de planejamento intensivo que precedeu a implantação do empreendimento, serão apresentadas a seguir as principais práticas que contribuíram para avaliação da sustentabilidade sócio-urbano-ambiental, bem como as bases conceituais e as abordagens metodológicas das ferramentas adotadas durante a fase de 
planejamento da infraestrutura. As informações obtidas neste estudo de caso contribuíram para identificar os fatores considerados na avaliação, bem como os efeitos e impactos avaliados e os processos metodológicos que foram utilizados, com o objetivo principal de consolidar suas bases para a composição de uma estrutura de indicadores consistente para a avaliação integrada para a sustentabilidade urbana no planejamento rodoviário.

\subsection{PLANO DIRETOR DE DESENVOLVIMENTO DE TRANSPORTES - PDDT VIVO}

O Rodoanel foi concebido num planejamento estratégico de longo prazo, consolidado no Plano Diretor de Desenvolvimento de Transportes - PDDT Vivo, que, juntamente com a implantação do Ferroanel e de Centros Logísticos Integrados (CLI's), constituem os elementos centrais de uma plataforma logística metropolitana voltada para reorganizar a interface entre a RMSP e o restante do Estado e do país.

O Rodoanel é parte integrada de uma política de transportes de alcance estadual, envolvendo outros modais e estratégias, o qual foi preconizado no PDDT Vivo, desenvolvido pela Secretaria de Logística e Transportes do Estado de São Paulo para o período 2000-2020, o qual consiste em um instrumento dinâmico de planejamento para a gestão político-institucional do sistema de transporte do Estado de São Paulo, integrando estratégias públicas e privadas.

O planejamento foi conduzido em duas fases principais: (i) identificação de gargalos e (ii) elaboração do Plano Estratégico. Inicialmente foram identificados os gargalos logísticos mais críticos, de forma a permitir o início imediato das ações para removê-los.

O planejamento começou pela definição dos objetivos da política de transportes, coerentes com os objetivos e estratégias corporativas, e produziu um plano de ação de alcance estratégico, com horizonte de 20 anos. O ciclo de planejamento pode ser visualizado no Figura 13. O Planejamento de Transportes passa a ser conduzido como um processo em caráter permanente, por isso designado como PDDT Vivo. A implementação das ações é monitorada e os resultados são avaliados, originando-se novas propostas de intervenção no sistema de transporte, tanto em infraestrutura como operacional ou institucional. 


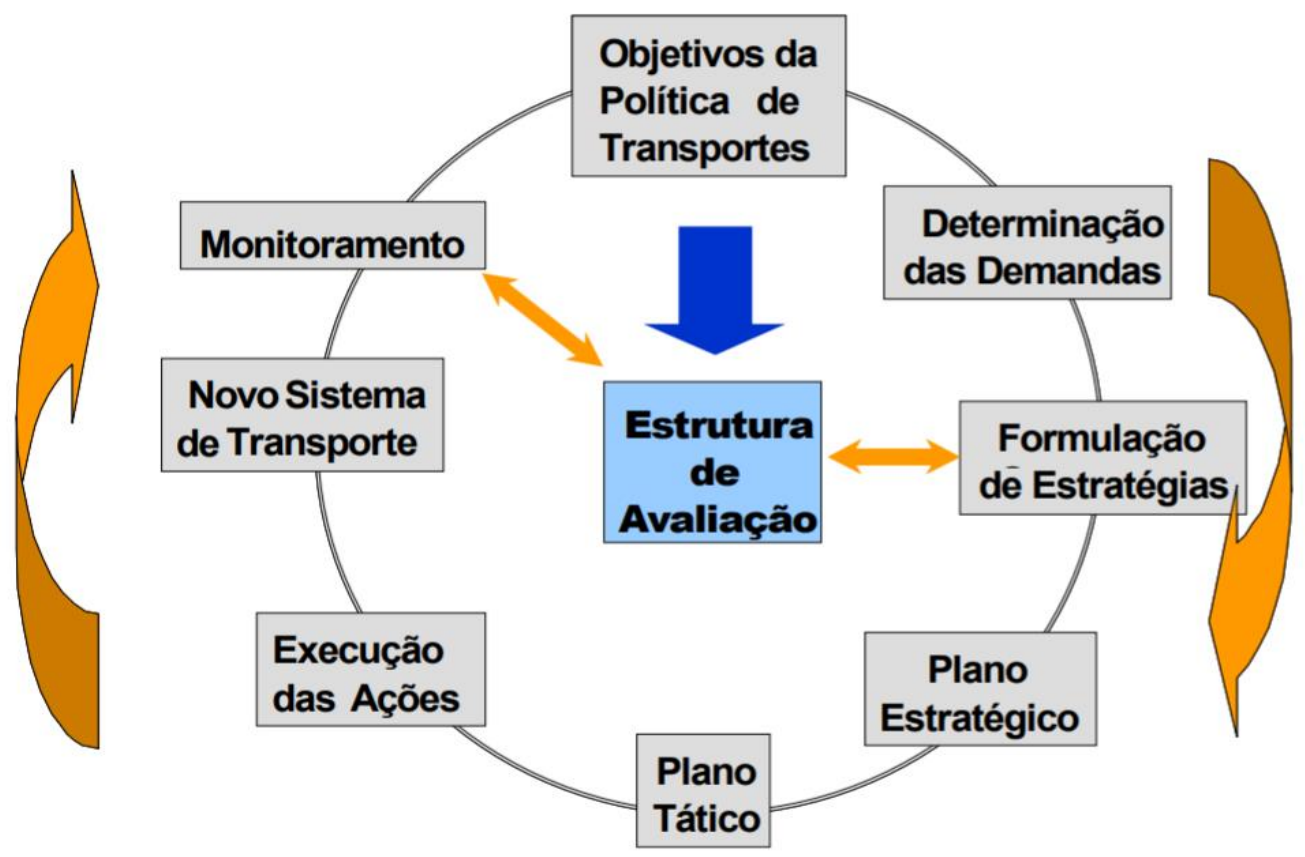

Fonte: SÃO PAULO (2000).

O Plano de Transporte é uma decisão sobre alocação de recursos e diretrizes de gestão, baseada em critérios que procuram interpretar as aspirações da comunidade. Em consideração a esse pressuposto, foram estabelecidos pela Secretaria de Transporte, em conjunto com os agentes do setor, os seguintes objetivos principais da Política de Transportes:

- $\quad$ Promover serviço de qualidade, garantindo a sua adequação (com destaque para a segurança e a eficiência econômica/energética), a fluidez e a acessibilidade.

- $\quad$ Promover o desenvolvimento sustentado, contribuindo para a redução da desigualdade social, a geração de empregados e a valorização da qualidade ambiental.

- $\quad$ Aumentar a competitividade regional e oferecer a integração, via reforço da intermodalidade, redução de preços e transporte e diminuição de perdas agrícolas.

- Adotar propostas factíveis, tanto do ponto de vista político-institucional como da perspectiva financeira.

O Plano abrange estratégias que procuram atender as demandas atuais e futuras de transporte, as quais se agrupam nas três categorias listadas a seguir: 
(i) Implantação de Infraestrutura, envolvendo melhoramentos ou expansão de linhas e rede de transporte, terminais, polos logísticos, centros de controle, introdução de novas tecnologias;

(ii) Medidas de Gestão, que englobam a regulamentação, simplificação administrativa, coordenação entre agentes, racionalização institucional, reforma do aparato jurídico, aprimoramento dos recursos humanos; e

(iii) Política de Preços, que compreendem alíquotas sobre combustíveis, tarifas de pedágios, incentivos ou desincentivos fiscais e outros.

Os elementos enunciados pelo PDDT Vivo, que formam o arcabouço físicooperacional do sistema intermodal, são resumidamente: Centros Logísticos Integrados CLI's; melhoramentos nas infraestruturas de Portos, com melhorias dos acessos rodoferroviários; melhoramentos das conexões ferroviárias entre os terminais do interior do Estado; implementação de serviço ferroviário expresso de cargas entre a RMSP e mercados selecionados do Interior e de outros Estados; e implantação integral do anel rodoviário (Rodoanel) e ferroviário (Ferroanel) em torno da RMSP.

A implantação do Rodoanel, do Ferroanel e de Centros Logísticos Integrados converterá a configuração da logística urbana da RMSP de radial para anelar, ou seja, os eixos rodoviários e ferroviários deixarão de convergirem para o centro para realizar as transações intermodais ou alcançar o destino final, passando para o entorno da RMSP e, assim, permitindo alcançar o destino final na metrópole com veículos mais adequados ao viário urbano. Essa nova plataforma logística, além de retirar veículos pesados das vias urbanas, traz como benefício adicional a retirada de centros logísticos de áreas urbanizadas (e.g. CEAGESP), dando lugar a usos mais nobres, bem como a otimização do fluxo caminhão-trem, reduzindo a emissão atmosférica e interferências com meios urbanos.

Dentre os benefícios do Plano Estratégico, as alternativas analisadas no PDDT levaram em conta aspectos ambientais relevantes, concluindo que a própria introdução de maior racionalidade na matriz de transporte trabalha na direção da melhoria ambiental. A questão ambiental serviu de base para a tomada de decisão quanto às alternativas de intervenção no sistema de transporte, levando-se em conta as delimitações regionais e naturais, as limitações legais de ocupação urbana na região litorânea, bem como a estrutura atual de transportes. Além disso, priorizou-se a expansão da capacidade das malhas rodoviárias e ferroviárias existentes em detrimento à construção de vias em áreas com restrições físicas importantes. Por outro lado, a intensificação da intermodalidade afeta positivamente o meio ambiente na RMSP, que está na dependência da posição das fontes de poluição, das condições de relevo e da dinâmica atmosférica.

Com relação à política de preços, o PDDT estabelece que "idealmente, o preço do transporte deve ser igual ao custo marginal, isto é, cada usuário deve pagar o custo social marginal total do deslocamento por ele provocado, seja na movimentação de pessoas, seja na de cargas". Esse princípio é a base da eficiência econômica de um sistema de 
transportes, uma vez que o usuário toma as suas decisões de produzir ou consumir em função do custo percebido (preço que paga).

No PDDT Vivo 2000-2020, foi utilizada a Avaliação Multicriterial de Auxílio à Tomada de Decisão - MAH para o planejamento de transporte do estado. Para seleção das alternativas preferidas, foi adotada uma estrutura de avaliação das ações propostas, utilizando critérios múltiplos, contemplando os objetivos estratégicos, os objetivos táticos e operacionais, conforme Tabela 1.

Tabela 1 - Objetivos e Respectivos Pesos Adotados no PDDT Vivo.

\begin{tabular}{|c|c|c|c|c|c|c|}
\hline \multicolumn{2}{|c|}{ Objetivos estratégicos } & \multicolumn{2}{|c|}{ Objetivos Táticos } & \multicolumn{2}{|c|}{ Objetivos Operacionais } & \multirow[t]{2}{*}{$\begin{array}{c}\text { Peso global dos } \\
\text { indicadores }\end{array}$} \\
\hline Objetivo & Peso & Objetivo & Peso & Objetivos & Peso & \\
\hline \multirow{5}{*}{ Qualidade } & \multirow{5}{*}{$29,20 \%$} & \multirow{3}{*}{ Serviço Adequado } & \multirow{3}{*}{$38,59 \%$} & Segurança & $53,88 \%$ & $6,07 \%$ \\
\hline & & & & $\begin{array}{l}\text { Eficiência } \\
\text { econômica }\end{array}$ & $24,95 \%$ & $2,81 \%$ \\
\hline & & & & $\begin{array}{l}\text { Eficiência } \\
\text { energética }\end{array}$ & $21,18 \%$ & $2,39 \%$ \\
\hline & & Fluidez/ nível de serviço & $31,61 \%$ & & & $9,23 \%$ \\
\hline & & Acessibilidade & $29,80 \%$ & & & $8,70 \%$ \\
\hline \multirow{4}{*}{ Competitividade } & \multirow{4}{*}{$21,36 \%$} & Integração & $26,63 \%$ & & & $5,69 \%$ \\
\hline & & $\begin{array}{l}\text { Redução de preços custos } \\
\text { generalizados }\end{array}$ & $35,09 \%$ & & & $7,50 \%$ \\
\hline & & $\begin{array}{l}\text { Escoamento da produção } \\
\text { agrícola }\end{array}$ & $22,89 \%$ & & & $4,89 \%$ \\
\hline & & Alcance geográfico & $15,39 \%$ & & & $3,29 \%$ \\
\hline \multirow{4}{*}{$\begin{array}{l}\text { Desenvolvimento } \\
\text { Sustentado }\end{array}$} & \multirow{4}{*}{$27,61 \%$} & Redução de desigualdades & $26,60 \%$ & & & $7,34 \%$ \\
\hline & & Geração de empregos & $29,78 \%$ & & & $8,22 \%$ \\
\hline & & Preservação ambiental & $24,00 \%$ & & & $6,63 \%$ \\
\hline & & Intermodalidade & $19,61 \%$ & & & $5,42 \%$ \\
\hline \multirow{3}{*}{ Factibilidade } & \multirow{3}{*}{$21,82 \%$} & Viab. Político institucional & $34,66 \%$ & & & $7,56 \%$ \\
\hline & & Desempenho financeiro & $32,84 \%$ & & & $7,17 \%$ \\
\hline & & $\begin{array}{l}\text { Factibilidade de } \\
\text { financiamento }\end{array}$ & $32,50 \%$ & & & $7,09 \%$ \\
\hline
\end{tabular}

Fonte: SÃO PAULO (2000).

A determinação dos pesos relativos foi feita a partir de um processo que contou com a participação dos diversos agentes intervenientes, públicos e privados, envolvendo todas as modalidades do setor de transporte (organismos de gestão, organismos operadores de serviços de transporte e logística, usuários do sistema, comunidade técnica, e autoridades públicas).

A partir daí, foram elaboradas uma série de alternativas com projetos combinados, tomando como premissa a intermodalidade em cada alternativa avaliada. A alternativa preferida foi a que obteve pontuação mais elevada, pela qual foi prevista um conjunto de intervenções que devem ser gradualmente implementadas e envolveu: integração rodoviária, recuperação ferroviária, operação de trens expressos integrados por terminais logísticos, construção do Ferroanel, cabotagem, dutos e política de preços. 


\subsubsection{Consolidação do Processo de Avaliação do PDDT Vivo}

Fase de Tomada de Decisão: PLANO DE LONGO PRAZO

Horizonte: 20 anos

Objetivo Geral: Decisão sobre alocação de recursos e diretrizes de gestão

Para cada Objetivo Agregado, foi estabelecido um Objetivo Específico, que, por sua vez, foi associado um ou mais medidas de desempenho ou indicadores, conforme indicado no quadro a seguir. A partir desses indicadores foi montada uma estrutura de avaliação específica para esta fase de planejamento.

Quadro 9 - Relação entre objetivos e indicadores utilizados no PDDT Vivo.

\begin{tabular}{|c|c|c|c|}
\hline $\begin{array}{l}\text { OBJETIVO } \\
\text { AGREGADO }\end{array}$ & $\begin{array}{l}\text { OBJETIVO } \\
\text { ESPECÍFICO }\end{array}$ & DEFINIÇÃO & $\begin{array}{l}\text { MEDIDAS / } \\
\text { INDICADORES }\end{array}$ \\
\hline \multirow{3}{*}{$\begin{array}{l}\text { QUALIDADE - Promover } \\
\text { serviço de qualidade }\end{array}$} & $\begin{array}{l}\text { Mobilidade e } \\
\text { Acessibilidade }\end{array}$ & $\begin{array}{l}\text { Alcançar os destinos desejados com } \\
\text { relativa facilidade, dentro de tempos, } \\
\text { custos e escolhas razoáveis. }\end{array}$ & $\begin{array}{ll}\text { - } & \text { Tempos de viagem } \\
\text { /Demoras } \\
\text { - } \quad \begin{array}{l}\text { Dispêndio por parte do } \\
\text { usuário }\end{array} \\
\end{array}$ \\
\hline & $\begin{array}{l}\text { Eficiência } \\
\text { Econômica e } \\
\text { Energética }\end{array}$ & $\begin{array}{l}\text { - Maximizar os benefícios correntes e } \\
\text { futuros dos investimentos públicos e } \\
\text { privados em transporte. }\end{array}$ & $\begin{array}{l}\text { - } \quad \text { Taxa B/C (econômico) } \\
\text { - Consumo de } \\
\text { combustível }\end{array}$ \\
\hline & $\begin{array}{l}\text { Satisfação e } \\
\text { Segurança }\end{array}$ & $\begin{array}{l}\text { Minimização de riscos de morte, } \\
\text { danos, ou perda de propriedade. } \\
\text { Prover escolhas de transporte que } \\
\text { sejam seguras, convenientes, e } \\
\text { atendam às necessidades dos } \\
\text { consumidores. }\end{array}$ & $\begin{array}{l}\text { - Número de acidentes } \\
\text { (atropelamentos, com } \\
\text { vítimas fatais, com } \\
\text { vítimas não fatais) }\end{array}$ \\
\hline \multirow{4}{*}{$\begin{array}{l}\text { DESENVOLVIMENTO } \\
\text { SUSTENTADO - } \\
\text { Promover o } \\
\text { desenvolvimento } \\
\text { sustentado }\end{array}$} & $\begin{array}{l}\text { Redução de } \\
\text { Desigualdades } \\
\text { Sociais }\end{array}$ & $\begin{array}{l}\text { - Influir em uma melhor distribuição de } \\
\text { benefícios }\end{array}$ & $\begin{array}{l}\text { - } \quad \text { Redução de custos para } \\
\text { regiões com baixa } \\
\text { atividade econômica }\end{array}$ \\
\hline & $\begin{array}{l}\text { Geração de } \\
\text { empregados }\end{array}$ & $\begin{array}{l}\text { Prover novos postos de trabalho } \\
\text { ligados ao empreendimento e a } \\
\text { melhorias macro-econômicas. }\end{array}$ & $\begin{array}{l}\text { - Número de empregados } \\
\text { diretos e indiretos }\end{array}$ \\
\hline & $\begin{array}{l}\text { Uso de modais mais } \\
\text { eficientes }\end{array}$ & $\begin{array}{l}\text { - Indução a formas mais eficientes de } \\
\text { transporte }\end{array}$ & $\begin{array}{l}\text { - Demanda total associada } \\
\text { a modos de transporte } \\
\text { de alto desempenho }\end{array}$ \\
\hline & $\begin{array}{l}\text { Qualidade } \\
\text { Ambiental }\end{array}$ & 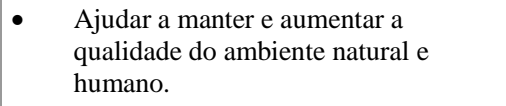 & $\begin{array}{l}\text { - } \quad \text { Padrões Nacional e do } \\
\text { Estado }\end{array}$ \\
\hline \multirow{4}{*}{$\begin{array}{l}\text { COMPETITIVIDADE - } \\
\text { Aumentar a } \\
\text { competitividade regional e } \\
\text { oferecer a integração }\end{array}$} & Integração & $\begin{array}{l}\text { - Contribuir para a Integração dos } \\
\text { Modos de Transporte }\end{array}$ & $\begin{array}{l}\text { - Total de Transferência } \\
\text { nos Terminais }\end{array}$ \\
\hline & Redução de Preços & $\begin{array}{l}\text { - Diminuir os custos do transporte no } \\
\text { preço final do produto/serviço. }\end{array}$ & $\begin{array}{l}\text { - Total de dispêndio por } \\
\text { parte do usuário }\end{array}$ \\
\hline & $\begin{array}{l}\text { Escoamento da } \\
\text { Produção Agrícola }\end{array}$ & $\begin{array}{l}\text { - Contribuir para a diminuição dos } \\
\text { custos de transporte }\end{array}$ & $\begin{array}{l}\text { - Custo de regiões com } \\
\text { grande atividade } \\
\text { agrícola }\end{array}$ \\
\hline & Alcance Geográfico & $\begin{array}{l}\text { - Aumentar a possibilidade de trocas } \\
\text { com outros estados e com o exterior } \\
\text { (cargas de exportação) }\end{array}$ & $\begin{array}{l}\text { - Custo de transporte para } \\
\text { regiões externas ao } \\
\text { Estado }\end{array}$ \\
\hline $\begin{array}{l}\text { FACTIBILIDADE - } \\
\text { Adotar propostas factíveis }\end{array}$ & $\begin{array}{c}\text { Factibilidade } \\
\text { Político Institucional } \\
\text { e de Financiamento }\end{array}$ & $\begin{array}{l}\text { - } \quad \text { Viabilidade Político-Institucional e } \\
\text { Financeira }\end{array}$ & $\begin{array}{l}\text { - Avaliação Qualitativa de } \\
\text { Financiamento }\end{array}$ \\
\hline
\end{tabular}




\subsection{AVALIAÇÃO AMBIENTAL ESTRATÉGICA (AAE)}

O projeto do Rodoanel foi precedido por um trabalho detalhado de Avaliação Ambiental Estratégica - AAE, que possibilitou ao governo do Estado de São Paulo negociar, junto ao Conselho Estadual do Meio Ambiente (CONSEMA), um novo modelo de licença ambiental. Para tanto, a AAE contemplou estudos aprofundados que consideraram o efeito cumulativo da construção e operação da rodovia nas áreas de mananciais, além de outras ações planejadas para a região, como projetos viários e planos de ocupação de solo nas áreas do entorno do Rodoanel.

A AAE contribuiu para a compreensão global do Programa Rodoanel e de seu papel na preservação ambiental da RMSP, concorreu para a definição do traçado da rodovia, balizou os Estudos de Impacto Ambiental (EIA) para todos os seus trechos e propôs recomendações para a gestão da totalidade do projeto. Esse documento foi aprovado pelo CONSEMA e adotado como referência para a elaboração do Estudo de Impacto Ambiental e Relatório de Impacto Ambiental (EIA/RIMA) e dos Planos Básicos Ambientais referentes a todos os trechos do empreendimento.

\subsubsection{Objetivos e Processo Metodológico}

A Avaliação Ambiental Estratégica (AAE) do Programa Rodoanel apresentou os resultados dos estudos realizados com o objetivo de avaliar a viabilidade ambiental do Rodoanel Mario Covas, bem como questões estratégicas associadas à sua implementação gradativa, por trechos, num horizonte de 15 anos.

Este documento foi um marco inicial de um processo contínuo de análise e avaliação de aspectos sociais e ambientais para apoio à tomada de decisões sobre o planejamento, projeto e implantação do empreendimento, bem como de seu licenciamento ambiental, buscando obter:

- uma compreensão global da dinâmica da região atravessada por essa infraestrutura rodoviária;

- uma avaliação da contribuição ambiental do Programa Rodoanel à Região Metropolitana de São Paulo, com sua articulação com as demais políticas públicas em desenvolvimento;

- as diretrizes para definição e seleção de traçados e para elaboração dos estudos de impacto ambiental para os novos trechos do Rodoanel; e

- as diretrizes para a gestão do Programa Rodoanel.

A AAE do Programa Rodoanel teve o papel de identificar os efeitos sobre o ambiente natural e o ambiente construído, com ênfase nos impactos indiretos e de desenvolvimento induzido em escala metropolitana e/ou sub-regional, nas sinergias e/ou 
interferências com outras políticas, programas e empreendimentos previstos nas diversas sub-regiões da RMSP, bem como identificar as ações estratégicas necessárias para mitigar e/ou compensar efeitos adversos e potencializar os efeitos benéficos.

A AAE procurou avançar na avaliação dos efeitos do empreendimento sobre a qualidade ambiental da RMSP, especialmente nos fatores estratégicos para a tomada de decisões e para a formulação de propostas que auxiliassem na definição clara dos compromissos com a sustentabilidade socioambiental, indicando as alternativas para solução das interfaces do projeto com as demais políticas setoriais e ações em curso na área de intervenção.

Diversas ações estratégicas, no entanto, extrapolam a competência setorial de um empreendedor rodoviário, em virtude da natureza dos processos envolvidos e sua abrangência territorial, exigindo uma atuação interinstitucional e um compromisso de governo na execução. Assim, apesar de a AAE contribuir para a elaboração dos EIA`s e dos Programas de Gestão contidos no Plano Básico Ambiental (PBA), instrumentos exigidos no processo de licenciamento ambiental, nem sempre os mesmos são suficientes para aprofundar esses aspectos, ficando mais restritos aos impactos diretos de cada componente do Programa e no detalhamento das medidas mitigadoras e compensatórias.

A AAE destacou que seu escopo foi avaliar o empreendimento numa estratégia de inserção sócio-urbano-ambiental, como um programa de transporte articulado a outros programas setoriais, e não contemplando a avaliação da sustentabilidade global da RMSP e a proposição da eventual reorientação das políticas públicas metropolitanas. Também não tratou da viabilidade econômica do empreendimento.

O documento identificou os temas de âmbito social, urbanística e ambiental relevantes e estratégicos com a proposta de: (i) avaliar de forma ordenada a magnitude e importância relativa dos efeitos e inter-relações estratégicas entre o Programa Rodoanel e o meio ambiente, e (ii) avaliar a sustentabilidade socioambiental do Programa.

Como instrumento técnico e sociopolítico, visou-se alcançar os seguintes objetivos principais:

- Atender à recomendação do Conselho Estadual de Meio Ambiente do Estado de São Paulo (CONSEMA) de preparar estudo ambiental para todos os trechos do Rodoanel no contexto do planejamento integrado de transportes e desenvolvimento metropolitano;

- Fundamentar a estratégia de conceituar a implantação do Rodoanel como um programa articulado de políticas públicas, a ser implementado por etapas ao longo de sucessivas administrações estaduais, o qual inclui recursos, planejamento e ações articuladas com outros atores institucionais para alinhamento de políticas e ação nos espaços territoriais objetos de intervenção;

- Estabelecer diretrizes para orientar a revisão dos projetos de engenharia e a elaboração dos EIA/RIMA's. 
O esquema apresentado na Figura 14 indica a estrutura metodológica adotada.

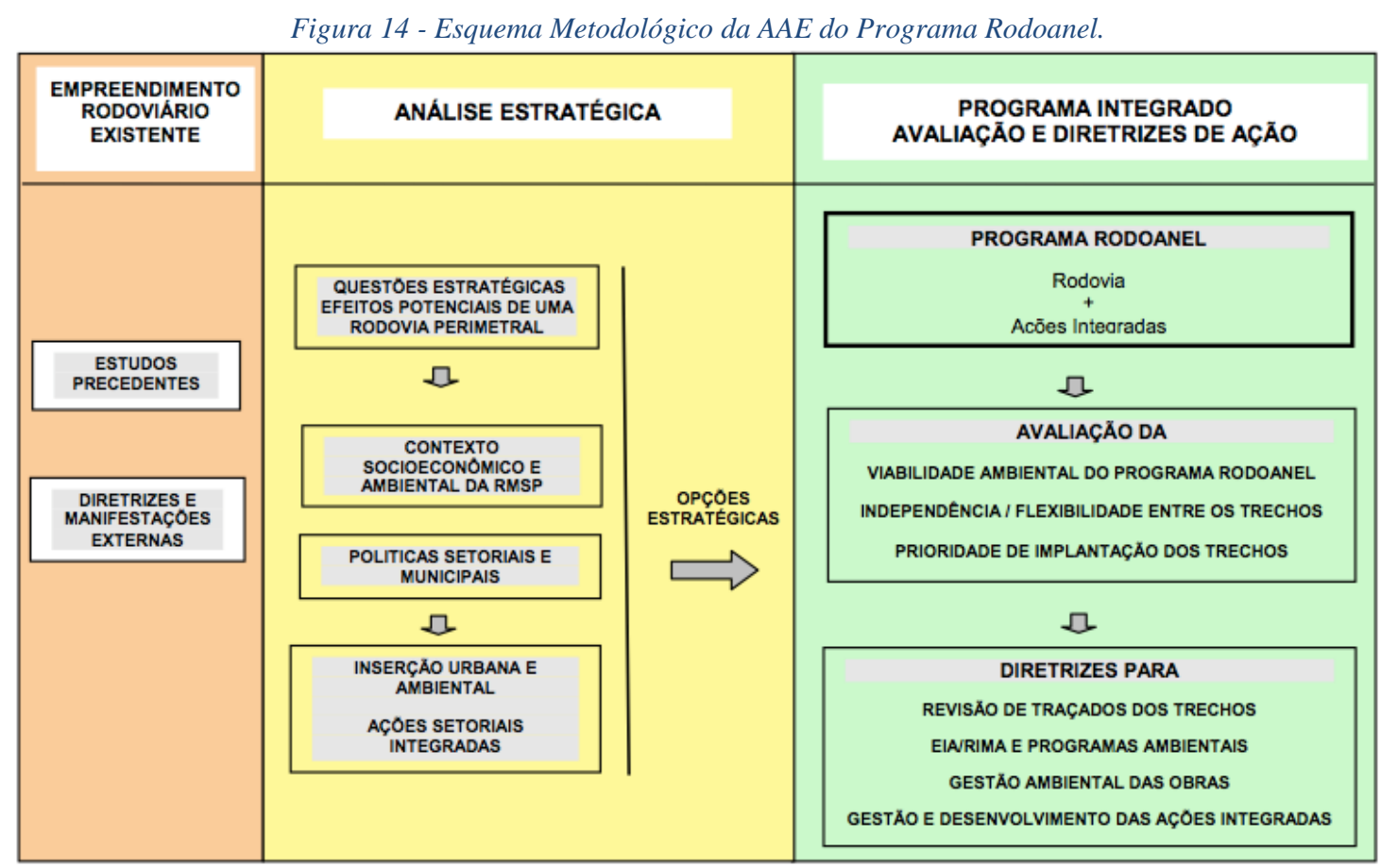

Fonte: DERSA/FESPSP (2004).

Para cada tema abordado, utilizou-se os seguintes cortes territoriais principais: (i) a metrópole como um todo, e (ii) no anel peri-urbano, definido como uma banda de 15 $\mathrm{km}$ ao redor de um traçado de referência, com o pressuposto de que essa largura seria suficiente para abranger as várias alternativas de traçado cogitadas nos estudos precedentes e nos em desenvolvimento.

Na concepção adotada neste processo, coube à AAE uma análise abrangente dos efeitos de longo prazo sobre a geografia física e humana atravessada, permitindo direcionar o esforço de projeto e de avaliação ambiental detalhado dos EIAs, assim como resolver as interfaces do programa com os vários setores e esferas institucionais que interagem com ele na modificação da região atravessada, deixando ao EIA o papel de escolher a alternativa locacional e tecnológica, bem como detalhar os impactos locais e definir as medidas mitigadoras e compensatórias.

Contudo, é expresso no documento o enorme esforço para sua elaboração, em virtude da ausência de exemplos, práticas adotadas e experiências acumuladas no Brasil, bem como da ausência de um plano ambiental metropolitano com diagnóstico e definição de objetivos e ações desejáveis. Assim, durante sua elaboração, houve a necessidade de muitas discussões públicas do projeto e de novas rodadas de articulação com instâncias municipais, sociedade civil e órgãos setoriais, reuniões técnicas de trabalho, busca de consenso entre equipes técnicas multi e interdisciplinares, que contribuíram para definição das questões estratégicas e das opções existentes para tomada de decisões, assim como para o refinamento dos conceitos metodológicos. 


\subsubsection{Questões Socioambientais Estratégicas}

A AAE, com vistas a proporcionar os elementos necessários para apoio ao processo de decisão, inicialmente identificou as questões estratégicas que estavam envolvidas nesse processo. A análise partiu da identificação dos principais efeitos de uma rodovia perimetral na RMSP, da abrangência e importância estratégica de cada um deles, além da natureza das medidas e ações recomendadas para reduzir efeitos adversos e potencializar os efeitos benéficos.

Assim, os principais efeitos e impactos socioambientais do empreendimento para fins de análise foram agregados em três (3) categorias:

(i) os impactos diretos e indiretos relacionados com a implantação da obra: A implantação da obra introduz uma alteração permanente na paisagem e na ocupação do solo na faixa de domínio. Na fase de construção ocorrem impactos sobre o meio físico (principalmente alterações decorrentes das obras de terraplenagem e operação dos canteiros de obras), o meio biótico (perdas de ecossistemas ou remanescentes de áreas naturais) e o meio antrópico (deslocamentos de população e atividades, remanejamento de infraestruturas, geração de emprego e renda). Esses impactos são de abrangência restrita, ocorrendo em sua maioria na região de entorno da faixa de domínio e junto às áreas de apoio à construção. São impactos adversos e benéficos, cuja importância e magnitude dependem das características da via a ser implantada, do traçado escolhido (qualidade e estado de conservação dos ambientes naturais e construídos atravessados) e dos métodos construtivos utilizados. Desses elementos, a escolha do traçado é o que condiciona todos os demais impactos da fase de implantação, constituindo-se num aspecto estratégico.

(ii) os impactos decorrentes da operação do empreendimento: $\mathrm{Na}$ fase de operação, os impactos mais frequentes ao meio ambiente são: o aumento da poluição do ar e dos níveis de ruído nas áreas lindeiras e o risco de acidentes com veículos transportando produtos perigosos, seus reflexos na segurança da população, nas atividades socioeconômicas das áreas lindeiras, na contaminação do solo e dos recursos hídricos. Em áreas naturais, há ainda risco da ocorrência de incêndios em áreas cobertas por vegetação e de atropelamento de fauna. Em áreas de expansão urbana há riscos de ocupação inadequada nas áreas lindeiras e a instalação de acessos irregulares à rodovia.

(iii) os efeitos de médio e longo prazo sobre a:

a) eficiência do sistema de transportes: Os efeitos de médio e longo prazo são impactos diretos e indiretos decorrentes da melhoria da eficiência nos sistemas de transportes, tratados aqui, e da consequente alteração da acessibilidade. Neste grupo se destacam os efeitos benéficos que constituem o objetivo principal do empreendimento: redução dos custos dos transportes rodoviários (cargas e passageiros para transposição e viagens com origem ou destino regional); e 
melhoria da circulação viária urbana da região com o deslocamento das viagens de longa distância, e a consequente redução de congestionamentos, redução da emissão de poluentes, redução do risco de acidentes em áreas densamente habitadas, entre outros.

b) ocupação e uso do solo: a melhoria do sistema de transportes modifica a acessibilidade entre as diversas sub-regiões da entre si e com outras regiões. A alteração de acessibilidade, por sua vez, modifica as vantagens locacionais relativas entre as sub-regiões e sua capacidade de atrair investimentos. Os efeitos da melhoria da acessibilidade são impactos indiretos e se expressam pela possibilidade de atração de atividades produtivas e empreendimentos imobiliários ao longo da faixa da rodovia e nas áreas do entorno das vias por ele interceptadas e pela potencial atração de população e indução de maior ocupação do solo nas regiões beneficiadas. Suscita-se por isso a questão da ocorrência de efeitos indiretos, como: a potencial atração de atividades de logística e produtivas e empreendimentos imobiliários ao longo da faixa da rodovia e nas áreas do entorno das vias por ele interceptadas; a potencial atração de população e indução de maior ocupação do solo nas regiões beneficiadas; o potencial impacto desse efeito de atração sobre a expansão tendencial da ocupação do solo das regiões afetadas; e o potencial impacto desse mesmo efeito sobre a qualidade ambiental do uso do solo nas regiões afetadas.

A magnitude dos impactos indiretos, benéficos ou adversos, depende de:

- maior ou menor articulação da rodovia com suas áreas lindeiras (interligação com outras rodovias, interligação com vias urbanas e acessos diretos das propriedades vizinhas à faixa de domínio);

- $\quad$ as características sociais, econômicas e de infraestrutura que determinam as estratégias de localização de atividades na metrópole (vantagens locacionais relativas entre sub-regiões);

- $\quad$ as características locais de estrutura urbana e ocupação do solo das áreas atravessadas; $\mathrm{e}$

- a natureza formal ou informal, regular ou irregular, da ocupação atraída, e o consequente efeito sobre a qualidade ambiental do uso do solo.

Por se tratar de um impacto com natureza indireta, a efetivação desses impactos só se concretiza com a existência de outros fatores, tal como: disponibilidade de áreas favoráveis à implantação de novas atividades, disponibilidades financeiras e condições econômicas para os investimentos, adequação aos dispositivos legais de ordenamento territorial (legislação de uso do solo dos municípios e de proteção ambiental), bem como de fatores sociais e econômicos mais amplos e a falta de fiscalização e controle de proliferação de assentamentos informais, entre outros.

A partir das análises precedentes dos efeitos e impactos socioambientais, emergiram as questões estratégicas a serem respondidas pela $\mathrm{AAE}$ relativas às decisões sobre a implantação do empreendimento e questões específicas relativas aos efeitos nas diferentes fases. As questões gerais que orientaram o processo de decisão foram: 
a. Há ganho ou perda de sustentabilidade ambiental a longo prazo na RMSP com a implantação do Programa Rodoanel? Deve-se continuar ou não a implantação desse empreendimento?

b. Qual a flexibilidade existente para uma estratégia de implantação por trechos, num horizonte de 10 a 15 anos? É possível deixar para o futuro a decisão sobre a necessidade e o traçado de trechos não prioritários?

c. Qual a prioridade para o próximo Trecho a ser implantado?

As questões examinadas relativas aos efeitos das atividades de construção e operação que têm caráter estratégico foram:

a) Quais requisitos técnicos e condicionantes sociais e ambientais devem ser estabelecidos para a definiç̧ão do traçado nos diversos trechos do Rodoanel?

b) Quais os requisitos para definição de métodos construtivos que considerem as peculiaridades das diversas regiões atravessadas, como áreas de proteção de mananciais, proximidade de unidades de conservação, assentamentos precários e bairros consolidados, entre outros?

c) Como exercer um adequado acompanhamento ambiental das atividades de construção e operação da rodovia que garantam o alcance dos padrões estabelecidos na concepção do projeto?

A AAE buscou esclarecer também as questões relativas aos efeitos de médio e longo prazo decorrentes da melhoria da acessibilidade:

i. Qual a magnitude do efeito isolado do empreendimento na alteração da estrutura urbana e no uso do solo metropolitano?

ii. Que critérios devem orientar a definição das vias com acesso direto ao Rodoanel e o regulamento de acesso de áreas lindeiras de modo a potencializar efeitos benéficos para a estrutura urbana e alcançar padrões de ocupação desejados?

iii. Como articular as interfaces do empreendimento com as demais políticas públicas em desenvolvimento nas regiões atravessadas?

O encaminhamento dos efeitos decorrentes das alterações de acessibilidade e do potencial de desenvolvimento urbano associado à implantação do Rodoanel foram tratados por meio do estabelecimento de diretrizes de macro-traçados, bem como por propostas intervenções específicas para proteção de áreas sensíveis e ações interinstitucionais articuladas no Programa Rodoanel, incluindo a política de acesso.

A partir da identificação dos efeitos do Rodoanel, foram selecionados os temas relevantes para avaliação estratégica do empreendimento, e que, portanto, foram utilizados como referência no processo de avaliação. Os temas relevantes selecionados para avaliação foram:

a) Transportes, circulação e logística metropolitanos;

b) Uso e ocupação do território metropolitano;

c) Uso e consumo de recursos naturais e política de proteção e conservação; 
d) Proteção dos mananciais de abastecimento de água;

e) Qualidade do ar e condições climáticas na RMSP.

Embora de natureza diversa dos demais temas tratados, também foi analisado, do ponto de vista estratégico, os procedimentos administrativos associados ao processo de licenciamento ambiental, especialmente em virtude da sua complexidade, magnitude e grau de importância das ações e medidas mitigadoras e compensatórias necessárias.

Por fim, foram selecionadas algumas alternativas de macro-traçado para atender aos requisitos técnicos da engenharia rodoviária e os requisitos sociais e ambientais decorrentes das análises precedentes.

\subsubsection{Avaliação Ambiental do Programa}

A avaliação estratégica foi o resultado de um processo que analisou o empreendimento sob a ótica de seus efeitos sobre a RMSP como um todo e sobre o anel peri-urbano onde o mesmo está sendo implantado, com foco nos impactos permanentes e de médio e longo prazos, e na sua sinergia com as políticas públicas setoriais, de desenvolvimento urbano e proteção ambiental existentes.

Para tanto, a avaliação foi apoiada em análises comparativas de situações futuras sem a continuidade da implantação do Rodoanel (cenário tendencial) e com a implantação dos novos Trechos do Rodoanel. Essas situações futuras foram construídas por meio de metodologias de projeção e de simulação.

Os efeitos avaliados foram:

\section{- Efeitos sobre os transportes e a circulação viária}

A avaliação dos efeitos no sistema de transportes e circulação viária na RMSP foi estruturada com base na análise de matrizes de viagens/dia e de tempos de viagem entre zonas de tráfego dentro e fora da RMSP nos diferentes cenários avaliados e para tipos de veículos distintos (autos, caminhões e ônibus). Essas informações foram resultados de simulações, que utilizaram as seguintes bases de informações: (i) Pesquisa Origem/Destino realizada em 1997 pela Cia do Metrô, (ii) contagens de tráfego realizadas pela DERSA nos eixos rodoviários de acesso à RMSP, (iii) projeções de viagens realizadas para os estudos que embasaram a elaboração do PDDT, (iv) simulações de tráfego realizadas com o modelo VISUM.

As matrizes O/D (Origem/Destino) foram analisadas para quatro tipos de fluxos:

- Fluxos de Circulação Interna: Origem e Destino das viagens no interior da RMSP;

- Fluxos de Transposição / Geração de viagens na RMSP: Origem das viagens no interior da RMSP e destino em zonas fora da RMSP; 
- Fluxos de Transposição / Atração de viagens na RMSP: Origem das viagens fora da RMSP e destino em zonas no interior da RMSP;

- Fluxos de Transposição / Passagem pela RMSP: Origem e Destino das viagens fora da RMSP, ou seja, zonas externas à RMSP.

Foram avaliados os efeitos em relação às seguintes variáveis:

- Tempos de viagem na RMSP, valores médios e totais, por tipo de fluxo e por tipo de veículo;

- Acessibilidade de áreas específicas: análise de alterações nos tempos de viagens entre regiões de interesse, no interior da RMSP;

- Fluidez do tráfego na RMSP;

- Efeito sobre o custo dos transportes.

As projeções apontaram para um desvio de cerca de metade dos fluxos de caminhões, que têm origem, destino ou ambos fora da RMSP; e para atração progressiva dos fluxos de caminhões com origem e destinos em pontos distantes dentro da própria RMSP, segregando o tráfego de carga de longa distância, que recorre a caminhões cada vez maiores, do transporte urbano de carga. Dessa forma, reduz o número de caminhões de grande porte circulando no viário metropolitano e, consequentemente, contribui para melhoria das condições de trânsito no viário urbano.

Contudo, em função da piora gradativa do trânsito na cidade decorrente do aumento previsto da frota, não se espera que os usuários do viário metropolitano tenham uma grande percepção de melhora do trânsito no longo prazo.

\section{- Efeitos na estrutura urbana e no uso e ocupação do solo}

Os efeitos estratégicos do Rodoanel sobre a estrutura urbana da RMSP e sobre o uso e ocupação do solo possuem estreita relação com os efeitos sobre os transportes e a circulação viária, os quais foram analisados quanto: se o empreendimento modificaria as relações de acessibilidade da RMSP com seu entorno (a macrometrópole) e a acessibilidade relativa entre sub-regiões da própria metrópole, alterando vantagens locacionais para instalação de atividades econômicas e domicílios.

As questões estratégicas analisadas foram:

- O Rodoanel induz maior crescimento econômico à RMSP?

- Qual o papel do Rodoanel na redistribuição de atividades internamente na RMSP? Que áreas seriam mais atraentes?

- Qual o papel do Rodoanel na dinâmica de expansão da ocupação irregular do solo nas áreas de proteção aos mananciais?

- Qual o papel do Rodoanel na indução de ocupação com atividades e padrão compatível com a preservação ambiental?

De uma maneira geral, os resultados obtidos foram:

(i) $\mathrm{O}$ valor absoluto da redução dos tempos de viagem é baixo frente às 
deseconomias existentes na RMSP;

(ii) Há previsão de deslocamento das atividades de logística metropolitana para fora do tecido urbano, junto das vias de acesso ao Rodoanel ou para as áreas lindeiras com acessos regulamentados, resultando na liberação de vias públicas usadas como estacionamento pelas transportadoras, na redução da quantidade de caminhões pesados na distribuição ou coleta de mercadorias e na transferência de áreas de estocagem para regiões especializadas;

(iii) A alteração da acessibilidade proporcionada pelo Rodoanel não se constitui em fator relevante para alteração da dinâmica já instalada de crescimento populacional e de oferta de empregos no anel peri-urbano em que se insere, principalmente em virtude de ser uma via com acessos controlados, sem vantagens direta ao entorno;

(iv) Há um potencial de uso do Rodoanel como apoio às políticas de ocupação do solo, considerando seu potencial de uso como elemento catalizador de iniciativas e ações públicas voltadas à recuperação ambiental das áreas atravessadas e à ocupação do solo com melhor qualidade ambiental, bem como seu potencial como estruturador do espaço, em harmonia com as diretrizes de ordenamento territorial existentes.

\section{- Efeitos sobre os recursos naturais}

Os efeitos sobre os recursos naturais foram avaliados de forma pré-estimada, para os seguintes itens: Recursos Hídricos, Cobertura Vegetal e Interferência em Áreas Protegidas, utilizando-se os traçados alternativos como referência. Essas estimativas foram realizadas nas escalas compatíveis com os objetivos da AAE, indicando a ordem de magnitude dos impactos potenciais. Os impactos efetivos foram levantados em detalhe nos EIA's de cada Trecho, após definição dos traçados, a nível de projeto.

a. Impactos diretos sobre os recursos hídricos: Importou-se conhecer a função do corpo d'água na bacia, sua importância em relação aos usos atuais e futuros. Para a instalação da rodovia é necessária a realização de terraplenagem (cortes e aterros) e, ao modificar a topografia, o escoamento natural da água é alterado. Assim, critérios de projeto para o dimensionamento dos sistemas de drenagem definitiva da rodovia deverão, necessariamente, incorporar as características morfológicas, proporcionando tratamento adequado ao escoamento das águas pluviais. Complementarmente, durante as obras devem ser instaladas bacias de sedimentação e de contenção, para atenuação de erosões, de instabilizações e de inundações nas áreas urbanizadas.

b. Impactos quantitativos sobre a vegetação: Realizou-se uma pré-estimativa dos prováveis números da supressão obrigatória de vegetação e a consequente reposição florestal compensatória, associada à implantação dos empreendimentos objeto da AAE, nas várias alternativas de traçado, com o objetivo de se conhecer previamente sua ordem de grandeza. 
c. Impactos sobre áreas protegidas e biodiversidade: Com relação às áreas protegidas, os traçados estudados evitaram a passagem dentro de Unidades de Conservação legalmente constituídas, especialmente as de Proteção Integral, e áreas-núcleo da Reserva da Biosfera do Cinturão Verde da Cidade de São Paulo. Foi avaliado também a fragmentação de habitats pela supressão linear de vegetação para a implantação do Rodoanel, o aumento do efeito de borda nos fragmentos florestais cortados pela faixa de domínio.

\section{- Efeitos sobre as Áreas de Proteção e Recuperação de Mananciais}

As áreas de proteção de mananciais foram analisadas sob dois aspectos na avaliação dos efeitos do Rodoanel: (i) efeitos sobre a quantidade de água (a produtividade hídrica das bacias) e (ii) efeitos sobre a qualidade da água que aflui aos reservatórios. Os efeitos foram analisados tendo em vista os impactos diretos da implantação da rodovia, e os impactos indiretos, decorrentes de eventual acréscimo de população ou alteração no uso e ocupação do solo.

a. Impactos diretos aos recursos hídricos: Com relação aos impactos diretos da implantação da via, entendeu que não haveria qualquer efeito sobre a redução da produtividade hídrica das bacias, em virtude de a dimensão da área a ser pavimentada e da própria faixa de domínio onde ocorreram as intervenções serem pouco significativa em relação à área das bacias. Além disso, não há interrupção do fluxo dos cursos de água contribuintes dos reservatórios. Com relação à qualidade das águas, há riscos potenciais de poluição de cursos de água afluentes e dos próprios reservatórios durante a construção devido ao carreamento de solos, aumentando a turbidez das águas, e devido a eventuais derrames de combustíveis ou lubrificantes. Esses efeitos são passíveis de ser mitigados com a adoção de técnicas adequadas para contenção de sedimentos e controle das atividades de obra, resultando em impactos de baixa magnitude e importância.

b. Acidentes com produtos perigosos: Os acidentes no transporte de produtos perigosos representam risco ambiental quando associados a acidentes de trânsito, promovendo derramamento da carga e o consequente dano ambiental através de explosão, incêndio, emissão de gases tóxicos, contaminação do solo e de cursos d'água. A avaliação dos efeitos do Rodoanel no transporte de produtos perigosos consistiu em dois aspectos básicos que a nova rodovia proporcionaria na alteração do risco de acidentes: (i) o Rodoanel retira o tráfego de caminhões que transportam produtos perigosos pelas vias urbanas e por áreas densamente ocupadas; (ii) o risco de acidentes em rodovias Classe " 0 " é muito inferior ao das demais rodovias. Além das características próprias do Rodoanel (Classe “0”), medidas operacionais e restritivas são acionadas no caso do transporte de cargas especiais, na prevenção de acidentes e no pronto atendimento às situações de emergência. Logo, o estudo de proteção adequada ao longo das áreas de contribuição dos mananciais, a instalação de dispositivos de contenção tipo caixas 
ou bacias de captação e áreas especiais para estacionamento de veículos em condições de risco para inspeção e retenção provisória dos veículos são medidas aplicáveis nos casos de emergências. Todas as medidas são detalhadas em nível de projeto executivo e no Plano de Gerenciamento de Risco - PGR e Planos de Ação de Emergência - PAE.

c. Impactos indiretos: $\mathrm{O}$ efeito de eventuais acréscimos de população devidos ao Rodoanel na qualidade da água dos mananciais de abastecimento foi avaliado em termos do acréscimo das cargas de Fósforo nas respectivas bacias dos sistemas produtores. Considerou-se ainda que a implantação do Rodoanel poderia contribuir para o controle das cargas poluidoras que afluem aos reservatórios por meio de duas ações: (i) a implantação de estruturas de contenção de sedimentos e cargas difusas junto aos cursos de água atravessados e (ii) pela implantação de parques e preservação da capacidade de autodepuração de sua várzea.

\section{- Efeitos sobre a Qualidade do Ar e Clima}

Os benefícios do Rodoanel em termos de qualidade do ar decorrem de dois efeitos concomitantes: (i) o aumento generalizado da velocidade média do tráfego, reduzindo a duração e a extensão dos congestionamentos, com menores emissões de poluentes pelos veículos; e (ii) o deslocamento de parte das fontes móveis de emissão das áreas mais densamente ocupadas da RMSP para áreas de ocupação esparsa e não contínua.

As emissões veiculares foram calculadas com base nas curvas características de poluição dos seguintes componentes: Monóxido de Carbono (CO), Óxidos de Nitrogênio (NOx) e Hidrocarbonetos (HC), levantadas pelo "Swiss Federal Office for the Environment", que são as utilizadas pelo modelo VISUM e ajustadas para refletir os níveis de emissão estimados pela CETESB para a RMSP. Assim, foram (i) estimadas as emissões dos desses componentes para diferentes cenários; (ii) calculada a densidade de emissões por $\mathrm{km}^{2} \mathrm{de}$ área urbana da macrozona; (iii) calculada a população total beneficiada e afetada, para se ter uma primeira avaliação da apropriação pela população dos benefícios e custos do Rodoanel em termos de qualidade do ar; e (iv) calculada a população próxima às fontes de emissão, residente em uma faixa de 500 m, 1000 m e 2000 m de cada lado do eixo da via em toda a extensão da mesma, utilizando o Censo de 2000.

A análise das emissões de poluentes por macrozonas concluiu que os efeitos do Rodoanel são benéficos em relação à qualidade do ar na RMSP, uma vez que contribui para uma redução geral das emissões de poluentes devido ao ganho de velocidade pelos veículos automotores, bem como promove a desconcentração das fontes, transferindo as emissões para áreas periféricas, onde há áreas com menor ocupação e em condições mais favoráveis em termos de concentração e facilidade de dispersão.

Com relação aos efeitos sobre o clima urbano, avaliou-se a possibilidade de a implantação do Rodoanel provocar alterações no micro-clima junto à faixa de domínio e no âmbito da metrópole. Como resultado, concluiu-se que as alterações na superfície do solo provocada pela implantação de uma rodovia são de alcance local, podendo resultar em acréscimos 
de temperatura que são sentidos apenas para quem esteja na própria plataforma pavimentada da rodovia e em seu entorno imediato. Já efeitos sobre o clima com alcance metropolitano não foram esperados, nem mesmo preocupações quanto à possibilidade de o empreendimento intensificar o fenômeno de "ilhas de calor", uma vez que a área representada pelo próprio Rodoanel é muito pequena, se comparada ao território total da RMSP e insuficiente para modificar processos de escala metropolitana. Por outro lado, aventou-se a possibilidade de o empreendimento trazer algum efeito direto na alteração das temperaturas na metrópole no sentido de reduzir as temperaturas no centro (pela redução das fontes de calor representada pelos veículos) e de aumentar na periferia, atenuando-se as diferenças de temperatura entre o centro e a periferia.

\subsubsection{Consolidação do Processo de Avaliação da AAE}

Fase de Tomada de Decisão: PROGRAMA

Horizonte: 15 anos

Objetivo Geral: Avaliar a viabilidade ambiental do Programa Rodoanel Mario Covas, bem como questões estratégicas associadas à sua implementação gradativa.

A partir da identificação dos principais efeitos e impactos do Rodoanel, foram selecionados os temas relevantes para avaliação estratégica do empreendimento, e que, portanto, foram utilizados como referência no processo de avaliação. Os temas relevantes selecionados foram:

a) Transportes, circulação e logística metropolitanos: abordou-se o tráfego de passagens, as viagens de transposição na região metropolitana, além das viagens internas de longa distância com origem e destino na própria região. Os efeitos esperados estão relacionados à redução do volume de tráfego, alteração nas condições de fluxo, redução de congestionamentos, aumento da velocidade média do fluxo e diminuição dos tempos de viagem. Em suma, avaliou-se as questões relacionadas à mobilidade e eficiência do sistema viário metropolitano.

b) Estrutura urbana e uso e ocupação do território metropolitano: trata-se das alterações das vantagens e desvantagens locacionais para atração de atividades econômicas ou assentamento humano, em função da alteração da acessibilidade. Considera também que a alteração na logística afeta o uso e ocupação do solo, possibilitando a renovação urbana de áreas centrais para uso de atividades mais nobres anteriormente ocupadas por centros logísticos, mas que depende de diversos outros fatores socioeconômicos. Além disso, considerou-se que o traçado pode ser utilizado como efeito barreira para inibir o avanço da expansão urbana em determinados trechos de interesse ambiental e social. Em resumo, a análise dos efeitos potenciais sobre o uso e ocupação do solo deve considerar duas 
categorias básicas: (i) os efeitos sobre os empreendimentos que atendem aos requisitos legais (urbanísticos e ambientais) para sua instalação; e (ii) os efeitos sobre os assentamentos informais, de baixa qualidade ambiental, com significativa presença no anel peri-urbano da metrópole.

c) Uso e consumo de recursos naturais e política de proteção e conservação: Os efeitos sobre a utilização e a qualidade dos recursos naturais foram considerados importantes fator de avaliação de sustentabilidade. Ao mesmo tempo o empreendimento provoca perdas de porções florestadas da metrópole (capoeiras), a reposição compensatória com essências florestais nativas, em número muitas vezes superior ao suprimido, a criação de novas unidades de conservação e o reforço à gestão das existentes, propiciará um real ganho ambiental se implantadas essas ações de forma planejada e integrada com outras políticas já em curso. Além disso, a utilização da rodovia como inibidor de ocupação em áreas frágeis pode significar uma proteção efetiva para áreas sensíveis, como as várzeas de cursos de água em área de mananciais e a preservação de áreas florestadas.

d) Proteção dos mananciais de abastecimento de água: A garantia do abastecimento de água potável em condições adequadas de qualidade é uma questão ambiental fundamental para manutenção da qualidade de vida da população metropolitana. Portanto, é fundamental a preservação da qualidade dos mananciais metropolitanos. $\mathrm{O}$ aspecto central sobre o qual se assenta o eixo da política de preservação dos mananciais é a necessidade de se controlar a ocupação do território das bacias contribuintes aos corpos d'água, de modo a garantir suas funções de produtoras de água bruta, em quantidade suficiente para atender às demandas para as quais foram projetadas, e em qualidade adequada para sua potabilização. Duas diretrizes passaram a ter maior importância nos avanços recentes da política de proteção de mananciais: a recuperação de assentamentos urbanos precários e o controle das cargas poluidoras que afluem aos cursos de água e aos reservatórios de regularização.

e) Qualidade do ar e condições climáticas: Foram dois efeitos potenciais previstos: (i) uma redução das emissões, pela melhor performance dos motores funcionando a velocidades mais altas do que no congestionado trânsito urbano, e (ii) uma distribuição dessas fontes, diminuindo as emissões em áreas já congestionadas e densamente habitadas, e transferindo-as para a faixa de domínio da rodovia e suas imediações, em geral mais abertas e de maior circulação de ventos de superfície, com menor densidade de ocupação.

A avaliação estratégica foi o resultado de um processo que analisou $\mathrm{o}$ empreendimento sob a ótica de seus efeitos sobre a RMSP como um todo e sobre o anel peri-urbano onde o mesmo está sendo implantado, com foco nos impactos permanentes e de médio e longo prazos, e na sua sinergia com as políticas públicas setoriais, de desenvolvimento urbano e proteção ambiental existentes. A consolidação do processo de avaliação utilizada na AAE do Rodoanel, pode ser visualizada no Quadro a seguir: 


\begin{tabular}{|c|c|c|c|}
\hline Fatores Avaliados & Dados utilizados & Indicadores / Medidas de Desempenho & Desagregação / Escala de análise \\
\hline $\begin{array}{l}\text { Transportes e a } \\
\text { circulação viária }\end{array}$ & $\begin{array}{ll}\text { - } & \text { Pesquisa Origem/Destino } \\
\text { - } & \text { Contagens de tráfego } \\
\text { - } & \text { Projeções de viagens } \\
\text { - } & \text { Viagulações de tráfego } \\
\end{array}$ & $\begin{array}{ll}\text { - } & \text { Tempos de viagem } \\
\text { - } & \text { Fluidez do tráfego } \\
\text { - } & \text { Custo dos transportes } \\
\text { - } & \text { Acessibilidade de áreas específicas } \\
\end{array}$ & $\begin{array}{l}\text { - } \quad \text { Entre zonas de tráfego } \\
\text { - } \quad \text { Por tipo de veículo (autos, } \\
\text { caminhões e ônibus) } \\
\text { - } \quad \text { Por tipo de fluxo } \\
\text { - } \quad \text { Para diferentes cenários (períodos) } \\
\end{array}$ \\
\hline $\begin{array}{l}\text { Estrutura urbana e uso } \\
\text { e ocupação do solo }\end{array}$ & $\begin{array}{ll}\text { - } & \text { Número estimado de empregos } \\
\text { - } & \text { Número estimado de domicílios } \\
\text { - } & \text { Salário médio e renda per capita } \\
\text { - } & \text { Divisão territorial em zonas de } \\
\text { tráfego } \\
\text { - } \quad \begin{array}{l}\text { Grau de acessibilidade (tempo } \\
\text { de deslocamento entre zonas) }\end{array} \\
\end{array}$ & $\begin{array}{ll}\text { - } & \text { Indução do crescimento econômico } \\
\text { - } & \text { Redistribuição de atividades de logística } \\
\text { - } & \text { Áreas mais atraentes de ocupação } \\
\text { - } & \text { Expansão da ocupação irregular } \\
\text { - } & \text { Indução de ocupação com atividades e padrão } \\
\text { - } & \text { compatível com a preservação ambiental } \\
\end{array}$ & $\begin{array}{l}\text { - } \quad \text { Na região } \\
\text { - } \quad \text { Em área de proteção a manancial } \\
\text { - } \quad \text { Por cenários }\end{array}$ \\
\hline Recursos Hídricos & $\begin{array}{l}\text { - Função do corpo d'água na } \\
\text { bacia } \\
\text { - Importância em relação aos usos } \\
\text { atuais e futuros } \\
\text { - Área da bacia hidrográfica }\end{array}$ & $\begin{array}{l}\text { - } \quad \text { Produtividade hídrica das bacias (quantidade de água) } \\
\text { - } \quad \text { Qualidade da água que aflui aos mananciais } \\
\text { - } \quad \text { Área a ser pavimentada em relação à área da bacia } \\
\text { - } \quad \text { Acidentes com produtos perigosos } \\
\text { - } \quad \text { Áreas de proteção e preservação de várzeas }\end{array}$ & $\begin{array}{l}\text { - } \quad \text { Por bacia hidrográfica } \\
\text { - } \quad \text { Por área de proteção a mananciais } \\
\text { - } \quad \text { Por curso d'água de interesse } \\
\text { - } \quad \text { Por parâmetro de interesse } \\
\quad \text { (turbidez, óleos e graxas, fósforo) }\end{array}$ \\
\hline Cobertura Vegetal & 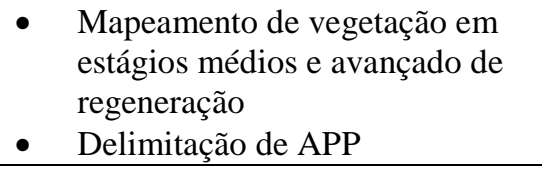 & $\begin{array}{l}\text { - } \quad \text { Número estimado da supressão de vegetação } \\
\text { - } \quad \text { Reposição florestal compensatória } \\
\text { - } \quad \text { Fragmentação de habitats }\end{array}$ & $\begin{array}{l}\text { - } \quad \text { Por alternativas de traçado } \\
\text { - } \quad \text { Escala 1:50.000 }\end{array}$ \\
\hline $\begin{array}{l}\text { Áreas Protegidas e } \\
\text { Biodiversidade }\end{array}$ & $\begin{array}{ll}\text { - } & \text { Delimitação de APP e de UCs } \\
\text { - } & \text { Áreas de floresta nativa } \\
\text { - } & \text { Hidrografia e largura de cursos } \\
\text { d'água }\end{array}$ & $\begin{array}{ll}\text { - } & \text { Aumento do efeito de borda nos fragmentos florestais } \\
& \text { cortados pela faixa de domínio } \\
\text { - } & \text { Intervenção em APP } \\
\text { - } & \text { Travessias de fauna } \\
\end{array}$ & $\begin{array}{l}\text { - } \quad \text { Por número } \\
\text { - } \quad \text { Por áreas estimadas } \\
\text { - Extensão }\end{array}$ \\
\hline $\begin{array}{l}\text { Qualidade do ar e } \\
\text { Clima }\end{array}$ & $\begin{array}{ll}\text { - } & \text { Censo } \\
\text { - } & \text { Volume de tráfego }\end{array}$ & 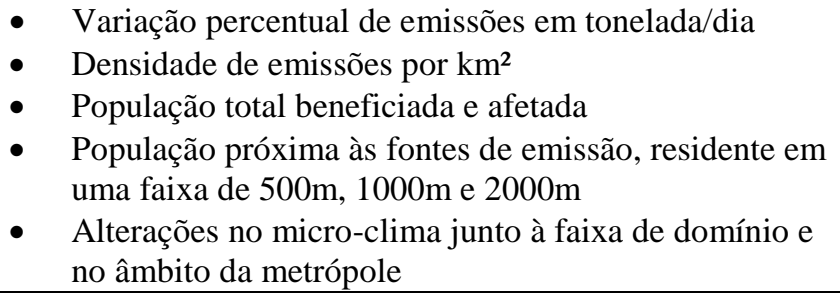 & $\begin{array}{l}\text { - } \quad \text { Por parâmetros }(\mathrm{CO}, \mathrm{NOx} \text { e HC) } \\
\text { - } \quad \text { Por cenários } \\
\text { - } \quad \text { Por área urbana da macrozona }\end{array}$ \\
\hline
\end{tabular}




\subsection{ESTUDOS DE IMPACTO AMBIENTAL (EIA)}

\subsubsection{Abordagens Metodológicas}

Em virtude da estratégia definida para o licenciamento ambiental e implantação do Rodoanel em quatro (4) trechos, foram elaborados quatro (4) Estudos de Impacto Ambiental (EIA's) para o empreendimento completo, que seguiram metodologia similar, seguindo o determinado na Resolução CONAMA $n^{\circ}$ 01/86. Além disso, foram observados os Termos de Referência emitidos pelos órgãos licenciadores (DAIA/SMA e CETESB) e as diretrizes constantes na Avaliação Ambiental Estratégica - AAE.

Tendo em vista que os trechos foram construídos sequencialmente, os procedimentos metodológicos e a estrutura utilizados nos EIA's foram sendo aprimorados com a experiência acumulada da implantação e operação de cada trecho concluído, incorporando as peculiaridades para o trecho estudado.

De maneira geral, os EIA's foram realizados na sequência metodológica consolidada a seguir:

i. As várias equipes especializadas iniciaram os seus trabalhos a partir de informações das características básicas do projeto; de uma revisão dos estudos ambientais já realizados sobre o Rodoanel; das críticas e sugestões apresentadas no processo de discussão dos mesmos; de uma revisão bibliográfica do conhecimento acumulado sobre a região onde o empreendimento se insere, e da experiência acumulada na implantação de projetos rodoviários similares.

ii. Durante os levantamentos de campo e revisões de informações de fonte secundária para o diagnóstico, realizado simultaneamente no nível da Área de Influência Indireta - AII como na Área de Influência Direta - AID, as informações obtidas e analisadas foram sendo consolidadas em base cartográfica (com o uso de ferramentas de GIS e AutoCaD) e consolidadas em textos segundo o seu nível de abrangência. Paralelamente, estas informações permitiram identificar restrições de caráter socioambiental para concepção e análise das macro-diretrizes de traçado, em desenvolvimento concomitante pela equipe de empresas projetistas com a participação da equipe do EIA.

iii. Para este estudo de macro-diretrizes e alternativas de traçado, além de levantamentos e vistorias de campo para o diagnóstico, foram iniciados contatos e consultas com todas as prefeituras dos municípios da AID, que aportaram informações detalhadas sobre seus respectivos municípios e também sobre planos e projetos em desenvolvimento no âmbito municipal. Também outros órgãos da administração pública presentes na gestão de importantes equipamentos ou Unidades de Conservação - UC foram contatados (Fundação Florestal, Instituto Florestal, REBIO, SABESP, INFRAERO e outros). 
iv. Ao final da etapa de diagnóstico, e após balanço multicriterial incluindo variáveis socioambientais e de engenharia, selecionou-se em cada macro-diretriz considerada viável, a melhor alternativa de traçado. O estudo de alternativas foi feito em macro-diretrizes, a partir de informações atualizadas de restrições socioambientais, buscando construir um traçado com menor interferência sobre os componentes do meio físico, biótico e antrópico, e paralelamente, otimizar o projeto de engenharia, com a diminuição das interferências em terrenos. A consulta foi discutida com gestores municipais e estaduais, buscando identificar potenciais restrições e oportunidades para traçado do Rodoanel.

v. Realizou-se, então, uma avaliação comparativa entre a melhor alternativa de traçado segundo critérios de transportes, engenharia e socioambientais.

vi. A etapa final dos estudos de alternativas de traçado compreendeu a otimização da alternativa recomendada, de maneira a construir o traçado a ser avaliado e recomendado pelo EIA.

vii. A avaliação detalhada dos impactos potenciais, medidas preventivas, de mitigação ou de compensação, e o balanço ambiental final foram detalhados e, sempre que possível, quantificados para este traçado otimizado.

Para etapa de estudo detalhado de impactos potenciais, a AID originalmente ampliada para abarcar toda área de estudo de macro-diretrizes e suas alternativas, foi redefinida em função da avaliação de impactos diretamente atribuíveis ao planejamento, construção e operação do traçado rodoviário selecionado. Portanto, um mapeamento da AID da diretriz escolhida, entendida como área sujeita a impactos diretos do traçado recomendado no EIA, foi mapeada em escala compatível e apresentada juntamente com a Área Diretamente Afetada - ADA. Nesta escala deu-se a proposição de medidas de mitigação e compensação ambiental, consolidadas em programas ambientais, e finalmente o balanço ambiental por componentes.

O processo de realização dos estudos ambientais incorporou em sua metodologia de análise o conceito de que o empreendimento, e o seu respectivo projeto de engenharia, são elaborados com base em um diagnóstico prévio das condicionantes ambientais da área de implantação e das respectivas áreas de influência, ao contrário de um conceito de avaliação a posteriori de um projeto de engenharia já definido.

$\mathrm{Na}$ etapa de Avaliação do Impacto Ambiental constante no EIA duas matrizes sintetizaram as interações entre ações, impactos e medidas. Os potenciais impactos sobre cada componente ambiental foram qualificados mediante alguns atributos (vetor, intensidade, abrangência geográfica, duração, reversibilidade). Para cada impacto foi feita uma Matriz, onde aparecem os respectivos atributos e uma listagem das medidas cabíveis. $\mathrm{O}$ balanço ambiental final do empreendimento considerou a correta aplicação das medidas preventivas, mitigadoras e compensatórias durante as fases de implantação e operação do empreendimento, consolidando, para cada componente, o impacto resultante após a aplicação das medidas. 


\subsubsection{Estudo de Transporte e os Benefícios Socioeconômicos}

No presente item, serão apresentadas as informações sobre a abordagem de quantificação de benefícios para o setor de transporte de interesse ao balanço socioambiental do empreendimento.

Inicialmente, foi realizada uma apresentação de dados relacionados com as tendências de crescimento de frota veicular e de redução de velocidade na rede da RMSP. Foram então apresentados resultados das simulações de carregamentos de transportes realizadas para a análise da demanda de tráfego em cada trecho do empreendimento (oeste, sul, leste, norte), e as estimativas expeditas dos benefícios decorrentes da sua implantação, de maneira a permitir a análise dos efeitos do empreendimento no sistema de transporte da RMSP.

A análise da demanda e a modelagem de transportes foram realizadas pela Secretaria de Transporte por meio da utilização do software de análise de transportes "VISUM-PTV". Realizou-se também todas as projeções de variáveis socioeconômicas inerentes aos processos de modelagem de transportes.

Foram adotados dois critérios de cálculo de benefícios derivados da implantação do empreendimento. $\mathrm{O}$ critério de estimativa de benefícios econômicos para efeito de análise de viabilidade socioeconômica do empreendimento; e um segundo critério, baseado nos valores de tempo, para as viagens de autos e caminhões, aplicado em estudos de viabilidade econômica de empreendimentos. Neste segundo caso, o valor do tempo é obtido a partir de uma pesquisa de preferência declarada (stated preference survey).

- Quantificação de benefícios com critérios de avaliação socioeconômica

O benefício socioeconômico gerado pela implantação do empreendimento foi estimado a partir do cálculo da redução anual em dois condicionantes do custo de transporte quando comparadas uma situação base (sem o empreendimento) com a situação futura (após a implantação do projeto):

(i) custos operacionais de viagem $(\mathrm{R} \$ / \mathrm{km})$; e

(ii) custos relacionados ao valor do tempo de viagem ( $\mathrm{R} \$ /$ hora).

O custo operacional de viagem $(\mathrm{R} \$ / \mathrm{km})$ foi aplicado ao indicador "veículo$\mathrm{km} /$ dia" e o custo relacionado ao valor do tempo de viagem ( $\mathrm{R} / \mathrm{hora}$ ) foi aplicado ao indicador "veículo-hora/dia", ambos obtidos a partir dos resultados do processo de modelagem. Para os dois casos, os benefícios foram calculados separadamente para as matrizes de viagens de veículos particulares e comerciais.

Considerou-se por benefício derivados da implantação do empreendimento, no contexto da análise dos EIA's, os seguintes: 
- O valor total das economias de custos operacionais de transporte, como decorrência da redução de tempos e/ou distâncias de viagem;

- O valor atribuído ao tempo economizado pela população nos seus deslocamentos.

Em síntese, a estimativa dos benefícios para veículos privados e veículos comerciais, foi feita, separadamente, pela seguinte expressão:

Onde:

$$
\mathrm{B} a=\operatorname{Cse}(a)-\operatorname{Cce}(\mathbf{a})
$$

$\mathrm{B} a=$ Benefício para o ano $a$

$\operatorname{Cse}(a)=$ Custo generalizado de transporte para a situação sem o empreendimento no ano $a$

Cce $(a)=$ Custo generalizado de transporte para a situação com o empreendimento no ano $a$

O valor do custo generalizado de transporte (C) é o resultado dos cálculos da soma dos (a) custos operacionais e dos (b) custos relacionados ao tempo de viagem, ou seja:

$$
\mathbf{C}=[(\text { veículo-km) } *(\mathbf{R} \$ / \mathbf{k m})]+[\text { (veículo-hora }) *(\mathbf{R} \$ / \text { hora })]
$$

As simulações de velocidades médias foram fundamentais para avaliação ambiental do empreendimento, pois proporcionaram a base para o cálculo das economias de tempos de viagem, que é uma importante variável para representar os benefícios para a qualidade de vida da população. Permitem, também, dimensionar as reduções de custos de transportes, variações nos volumes de emissões atmosféricas de fonte móvel, ganhos sub-regionais de acessibilidade, etc.

Em relação ao tempo de viagem, os ganhos estão relacionados ao aumento da velocidade média e/ou à diminuição das distâncias globais percorridas. Os custos de transporte são reduzidos em consequência da melhoria nas condições das vias, do aumento da velocidade média e/ou redução das distâncias de viagem.

Outros benefícios econômicos não considerados nos estudos de transporte foram analisados ao longo do EIA, tais como as reduções de custos de manutenção do sistema viário intra-urbano, como decorrência da redução do tráfego de caminhões; as economias decorrentes da redução de acidentes de trânsito; e as economias decorrentes da redução dos níveis de contaminação do ar.

Outros parâmetros necessários para as estimativas dos benefícios são:

- Custo operacional dos veículos: O custo operacional é composto por custos fixos e custos variáveis. Os custos fixos mensais incluem depreciação, remuneração de capital, gastos com licenciamento, seguro obrigatório e IPVA, seguro do carro e, para o caso dos veículos comerciais, salário do motorista e respectivos encargos. Já os custos variáveis incluem gastos com manutenção, pneus, câmaras e recapagens, combustível, lubrificantes e lavagens. Para cálculo dos benefícios 
socioeconômicos foram excluídos dos custos operacionais as taxas e tributos incidentes.

- Taxa de Ocupação Veicular: As taxas de ocupação veicular (necessárias para o cálculo dos benefícios decorrentes da redução de tempos de viagem de motoristas e passageiros) foram obtidas por fonte secundária (Revista Frota e Serviços). Os valores adotados foram 1,2 passageiros/veículo (automóveis) e 36 passageiros/veículo (ônibus).

A partir das taxas de ocupação veicular e dos indicadores de tempos de viagens estimaram-se os valores totais do indicador de "custo de tempo gastos em viagens por dia”, expresso em homens x horas.

- Valores Atribuíveis às Economias de Tempo dos Usuários: Os benefícios devidos aos ganhos do tempo de viagem, para cada ano do empreendimento, e para cada categoria de usuários, foram estimados com base no seguinte cálculo:

$$
\text { BT }=(\text { HH TO }- \text { HH TOS }) *(\text { VT })
$$

Onde,

- $\quad \mathrm{BT}=$ benefício devido ao ganho de tempo de viagem (em R\$)

- $\quad$ HH TO = homens horas anuais gastos com transportes na área de estudo para a alternativa básica (situação presente).

- HH TOS = homens horas anuais gastos com transportes na área de estudo para a alternativa com o empreendimento (situação futura)

- $\quad \mathrm{VT}=$ valor do tempo de viagem para uma unidade de homem $\mathrm{x}$ hora (em R\$)

\subsubsection{Estudo de Alternativas de Traçado}

Os estudos de traçado foram desenvolvidos durante as fases iniciais de elaboração do EIA com a participação dos coordenadores da equipe técnica responsável pelo estudo, em conjunto com a agência de transporte responsável e com as empresas projetistas. Esses estudos seguiram procedimentos metodológicos destinados a garantir que:

- a avaliação ambiental comparativa das alternativas contemplasse, de maneira ponderada, todos os critérios de avaliação pertinentes;

- a metodologia de identificação de alternativas garantisse que todas as alternativas tecnicamente viáveis fossem contempladas, incluindo as suas variantes e combinações possíveis.

As variáveis ambientais foram incorporadas ao estudo de alternativas locacionais, contribuindo para otimização do traçado preferencial, com consequente redução da intensidade de impactos socioambientais do empreendimento. A otimização envolveu ajustes de traçado e geometria, sistema de drenagem, posicionamento de obras de arte 
especiais e métodos construtivos. Essa etapa contou com análise multicriterial baseada na consideração simultânea de um amplo conjunto de critérios de formulação e seleção de alternativas de traçado.

Os estudos de alternativas de traçado entre os quatro (4) trechos do Rodoanel, podem se resumir em 5 etapas principais, conforme descritas a seguir:

- $1^{a}$ Etapa: Levantamento de alternativas históricas de traçado e avaliação sintética: Consistiu no levantamento de todas as propostas anteriores de implantação, identificando-se os aspectos favoráveis e desfavoráveis apontados em cada caso e a viabilidade de tais propostas no atual contexto socioespacial.

- $\quad 2^{a}$ Etapa: Identificação e seleção de macro-diretrizes de traçado: $\mathrm{O}$ processo de seleção de traçado foi gradual, contemplando inicialmente a identificação e seleção de macro-diretrizes de traçado, ou seja, de faixas ou corredores sobre os quais é possível o desenvolvimento de um traçado. Na prática, cada macro-diretriz pode ser definida também como uma faixa de busca de alternativas. Os elementos com restrição de interferências significativas considerados foram:

a. Pegada da obra (extensão ou área);

b. Unidades de Conservação de Proteção Integral (Lei 9.985/2000);

c. Áreas com significativa cobertura vegetal nativa (supressão e segmentação e/ou isolamento de fragmentos nativos remanescentes);

d. Áreas de ocupação urbana consolidada, que implicasse na relocação intensiva de população e atividades econômicas, segmentação de áreas urbanas e alteração das condições e do padrão de funcionalidade do espaço urbano afetado, exceto em áreas de ocupação irregular e em áreas de risco;

e. Áreas de elevada fragilidade natural do relevo, tendo como referência o mapeamento das áreas com severas restrições à ocupação, baseado na Carta de Aptidão Física ao Assentamento Urbano (IPT/EMPLASA, 1990);

f. Recursos hídricos, considerando número e extensão de travessias fluviais e sistemas produtores de água.

- $3^{a}$ Etapa: Consulta e discussão com prefeituras municipais e outras partes interessadas: As macro-diretrizes estudadas ou selecionadas subsidiaram as consultas e reuniões técnicas com representantes das prefeituras dos municípios cujos territórios são interceptados pelas macro-diretrizes selecionadas, em especial dos setores responsáveis pelo planejamento urbano e gestão ambiental. As reuniões visaram a apresentação e discussão técnica dos estudos em desenvolvimento e a solicitação de informações relativas aos projetos e planos desenvolvidos pelos municípios, sugestões e eventuais interferências no espaço situado ao longo das macro-diretrizes pré-selecionadas. A interlocução técnica foi mantida também com outras diferentes instituições intervenientes nesta etapa de estudos de engenharia e socioambientais, tanto para coleta de dados como para conseguir subsídios ao desenvolvimento dos estudos. 
- $4^{a}$ Etapa: Identificação e seleção de diretrizes de traçado: Com base na análise de imagens aéreas, inspeções de campo e sobrevoo, foi efetuada a identificação das transposições possíveis e a formulação de diretrizes de traçado mediante interpolação entre os locais de maior restrição. A partir do grupo de diretrizes identificado, desenvolveram-se estudos de engenharia, comparando as características geométricas de cada diretriz, bem como o porte das intervenções sobre os terrenos, a intensidade e magnitude das atividades de terraplenagem.

O Quadro 10 apresenta os critérios que nortearam a realização dos estudos na fase de identificação e seleção de diretrizes de traçado.

Quadro 10 - Critérios para seleção de traçado.

\begin{tabular}{|c|c|}
\hline \multirow{3}{*}{$\begin{array}{l}\text { Aspectos } \\
\text { Gerais }\end{array}$} & - Geometria do projeto \\
\hline & - $\quad$ Sugestões e adequações em função de projetos das municipalidades \\
\hline & - $\quad$ Efeito barreira potencial \\
\hline \multirow{7}{*}{$\begin{array}{c}\text { Aspectos do } \\
\text { Meio } \\
\text { Antrópico }\end{array}$} & $\begin{array}{l}\text { - Interferência com áreas urbanas consolidadas e necessidades de relocação } \\
\text { de população e desapropriações }\end{array}$ \\
\hline & - $\quad$ Segmentação de áreas urbanas \\
\hline & $\begin{array}{l}\text { - Interferência com áreas objeto de concessão de lavra de exploração } \\
\text { mineral }\end{array}$ \\
\hline & - Contiguidade a áreas urbanas com baixo nível de ruído atual \\
\hline & - Necessidade de relocação de indústrias com reduzida mobilidade \\
\hline & $\begin{array}{l}\text { - Interferência com utilidades lineares (gasodutos, oleodutos, linhas de } \\
\text { transmissão e outras pertinentes) }\end{array}$ \\
\hline & - Interferência com Patrimônio Histórico \\
\hline \multirow{4}{*}{$\begin{array}{l}\text { Aspectos do } \\
\text { Meio Biótico }\end{array}$} & $\begin{array}{l}\text { - Interferência com maciços florestais de grande porte e com fragmentos } \\
\text { enquadrados nos estágios sucessionais médio ou avançado }\end{array}$ \\
\hline & $\begin{array}{l}\text { - Interferência com fragmentos florestais inseridos em zonas com } \\
\text { conectividade aparente }\end{array}$ \\
\hline & - Interferências com Unidades de Conservação \\
\hline & $\begin{array}{l}\text { - Zonas de preservação e/ou interesse ambiental estabelecidas na legislação } \\
\text { municipal de ordenamento territorial }\end{array}$ \\
\hline \multirow{9}{*}{$\begin{array}{l}\text { Aspectos do } \\
\text { Meio Físico }\end{array}$} & - Cruzamento de reservatórios \\
\hline & - Cruzamento de várzeas / planícies de inundação \\
\hline & $\begin{array}{l}\text { - Interferência com bacias de contribuição de mananciais de abastecimento } \\
\text { público e proximidade com captações de água para abastecimento público }\end{array}$ \\
\hline & - $\quad$ Travessias de canais de drenagem \\
\hline & - $\quad$ Existência de aterros industriais e sanitários \\
\hline & - Interferência com o relevo e intensidade das atividades de terraplenagem \\
\hline & $\begin{array}{l}\text { - Trechos com terraplenagem desbalanceada e elevada necessidade de áreas } \\
\text { de apoio }\end{array}$ \\
\hline & - Dimensão das áreas fora da faixa sujeitas à movimentação de terra \\
\hline & $\begin{array}{l}\text { - Trechos com necessidade de caminhos de serviço externos à faixa de } \\
\text { domínio }\end{array}$ \\
\hline
\end{tabular}

Observações:

1. O parâmetro qualidade do ar não foi considerado como critério de avaliação comparativa, por entender que a distribuição espacial dos potenciais impactos associados sobre a qualidade do ar seria pouco alterada em função de variações no traçado, não constituindo fator determinante de subsídio à seleção. 
2. Por se tratar de estrutura linear prevista em um espaço geográfico complexo, não foi possível eliminar todas as interferências indesejáveis. Todavia, foi possível minimizar interferências e os impactos ambientais decorrentes, cabendo à análise multicriterial nortear a tomada de decisão do traçado.

- $5^{a}$ etapa - Otimização da diretriz selecionada e seleção final da alternativa: mediante a consideração simultânea dos critérios de formulação e seleção de diretrizes de traçado especificados na etapa anterior, otimizou-se o(s) traçado(s) selecionado(s), reduzindo a intensidade de interferências não completamente eliminadas ou evitadas nas fases anteriores dos estudos.

\subsubsection{Avaliação Ambiental}

A metodologia de análise de impacto ambiental desenvolvida objetivou viabilizar uma avaliação detalhada do impacto resultante em cada componente ambiental da área de influência do empreendimento. Entendeu-se como impacto resultante o efeito final sobre cada componente ambiental afetado, após a execução de todas as ações impactantes e a aplicação ou implementação de todas as medidas preventivas, mitigadoras ou compensatórias propostas para o empreendimento. Os componentes ambientais foram, por sua vez, classificados em três grupos: (a) Componentes do meio físico; (b) Componentes do meio biótico; (c) Componentes do meio antrópico.

O Quadro 11 apresenta a consolidação dos componentes ambientais e os grupos dos impactos ambientais potenciais.

Quadro 11 - Impactos potenciais identificados nos estudos ambientais.

\begin{tabular}{cl}
$\begin{array}{c}\text { Componentes } \\
\text { Ambientais }\end{array}$ & \multicolumn{1}{c}{ Impactos Potenciais } \\
& Impactos Potenciais nos Terrenos \\
Meio Físico & Impactos Potenciais nos Recursos Hídricos Superficiais \\
& Impactos Potenciais nos Recursos Hídricos Subterrâneos \\
& Impactos na Qualidade do Ar \\
Meio Biótico & Impactos Potenciais na Vegetação \\
& Impactos Potenciais na Fauna \\
& Impactos Potenciais na Infraestrutura Viária, no Tráfego e nos Transportes \\
& Impactos Potenciais na Estrutura Urbana \\
& Impactos Potenciais nas Atividades Econômicas \\
Meio Antrópico & Impactos Potenciais na Infraestrutura Física e Social \\
& Impactos Potenciais na Qualidade de Vida da População \\
& Impactos Potenciais nas Finanças Públicas \\
& Impactos Potenciais no Patrimônio Arqueológico e Cultural \\
\hline
\end{tabular}


Para a identificação de impactos ambientais, utilizou-se a Matriz de Interação, que consiste, basicamente, no resultado do cruzamento entre as ações potencialmente impactantes do empreendimento e os componentes ambientais passíveis de serem afetados pelas mesmas. Trata-se de uma adaptação do método desenvolvido por Leopold et al. (1971).

Os impactos foram analisados e, sempre que possível, espacializados em uma única base cartográfica. Para cada impacto resultante, foi elaborada uma Matriz de Consolidação específica, onde aparecem os atributos dos impactos, bem como as listas das ações impactantes e as medidas aplicáveis. Os atributos analisados foram:

- Vetor: Indica se o impacto resultante é Negativo ou Positivo, por vezes pode apresentar dois vetores opostos (positivo e negativo) sobre o mesmo componente.

- Intensidade: Poderá ser Baixa, Média ou Alta. Avalia a relativa intensidade com que os componentes ambientais serão afetados, com base em parâmetros quantitativos (por exemplo, quantidades de populações afetadas) ou qualitativos (fatores relacionados aos diferentes pesos e características de cada impacto, bem como à situação atual de cada componente).

- Abrangência geográfica: Define a difusão espacial de cada impacto resultante. Pode ser mais localizada na ADA, AID ou AII, ou em escala metropolitana (RMSP) ou regional.

- Reversibilidade: Define o grau de reversibilidade do impacto, que está diretamente relacionado à intensidade. No caso de impactos negativos, estes podem ser Totalmente Reversíveis - isto é, o impacto resultante deixa de ocorrer ou apresenta intensidade desprezível depois de cessadas as ações e/ou aplicadas as medidas cabíveis -, Parcialmente Reversíveis - quando as medidas são capazes de atenuar a intensidade dos efeitos negativos residuais e estes têm duração de médio prazo - ou Irreversíveis - quando mesmo após a aplicação das medidas, o impacto residual for significativo em termos de intensidade (média ou alta) em médio e longo prazos.

- Tempo de indução: tempo do impacto potencial em relação ao início das ações impactantes. A indução pode ser: Imediata (o impacto inicia-se com a ação), em Curto Prazo (2 anos), Médio Prazo (2 a 10 anos) e Longo Prazo (mais de 10 anos ou durante a vida operacional do empreendimento);

- Tempo de permanência: tempo do impacto resultante depois de cessadas as ações impactantes e da aplicação de todas as medidas. O impacto poderá cessar imediatamente com o término da ação, em Curto Prazo (até 2 anos), Médio Prazo (2 a 10 anos) ou Longo Prazo (acima de 10 anos). Um impacto de longo prazo pode ser considerado um impacto parcialmente reversível ou irreversível.

Essa análise favoreceu a compreensão mais global e sistêmica entre subgrupos afins de impactos, em uma abordagem que permitiu estabelecer um conjunto de medidas preventivas, mitigadoras e compensatórias, que foi estruturado em Programas Socioambientais. 


\subsubsection{Os Fatores e Impactos Significativos Avaliados no EIA}

Os critérios considerados no estudo de alternativa de traçado devem ser integralmente contemplados em uma estrutura de avaliação, uma vez que a escolha do traçado condiciona todos os demais impactos da fase de implantação, constituindo-se num aspecto estratégico a ser tratado.

Para os impactos resultantes, os fatores avaliados no Estudo de Impacto Ambiental, seguidos da descrição, estão apresentados no quadro a seguir.

Quadro 12 - Componentes ambientais avaliados nos EIA`s.

\begin{tabular}{|c|c|}
\hline $\begin{array}{l}\text { C.1 Componentes } \\
\text { do Meio Físico }\end{array}$ & Descrição \\
\hline $\begin{array}{l}\text { C.1.01 } \\
\text { Terrenos }\end{array}$ & $\begin{array}{l}\text { Reúne os elementos relacionados com o modelado dos terrenos, os materiais de } \\
\text { ocorrência natural e os processos de dinâmica superficial ou fragilidades naturais. }\end{array}$ \\
\hline $\begin{array}{l}\text { C.1.02 } \\
\text { Recursos hídricos } \\
\text { superficiais }\end{array}$ & Corpos d'água cujas bacias de contribuição serão atravessadas pela rodovia. \\
\hline $\begin{array}{l}\text { C.1.03 } \\
\text { Recursos hídricos } \\
\text { subterrâneos }\end{array}$ & $\begin{array}{l}\text { Recursos hídricos subterrâneos sujeitos a potencial impacto decorrente do } \\
\text { rebaixamento do nível freático durante a construção, que pode ocorrer em algumas } \\
\text { porções de planícies aluviais (correção ou substituição de solos) e nos cortes } \\
\text { profundos, bem como da possibilidade de contaminação com produtos perigosos. }\end{array}$ \\
\hline $\begin{array}{c}\text { C1.04 } \\
\text { Ar }\end{array}$ & $\begin{array}{l}\text { Durante a fase de implantação, há a possibilidade de ocorrer impactos negativos na } \\
\text { qualidade do ar nas áreas de maior movimentação de terra e circulação de veículos } \\
\text { pesados, ao longo dos acessos da obra e em torno das instalações industriais } \\
\text { provisórias. Na fase de operação, com a circulação de veículos na rodovia há um } \\
\text { aumento da emissão de poluentes atmosféricos ao longo da mesma, quando } \\
\text { comparado com a situação atual da região. Por outro lado, a utilização da rodovia } \\
\text { em detrimento dos caminhos utilizados no interior da RMSP colabora para a } \\
\text { melhoria da qualidade do ar de uma maneira ampla e difusa na RMSP. }\end{array}$ \\
\hline $\begin{array}{l}\text { C.2 Componentes } \\
\text { do Meio Biótico }\end{array}$ & Descrição \\
\hline $\begin{array}{l}\text { C.2.01 } \\
\text { Cobertura vegetal }\end{array}$ & $\begin{array}{l}\text { Refere-se a toda a cobertura vegetal nativa ou exótica pré-existente na área a ser } \\
\text { diretamente afetada (ADA), nas porções da faixa de domínio da alternativa de } \\
\text { traçado selecionada, e nas áreas de apoio, externas a estas faixas, as quais serão } \\
\text { suprimidas na fase de implantação. }\end{array}$ \\
\hline $\begin{array}{l}\text { C.2.02 } \\
\text { Fauna }\end{array}$ & $\begin{array}{l}\text { Dividida em fauna terrestre e fauna aquática. A fauna terrestre é composta por } \\
\text { representantes diversos dos grupos da mastofauna, avifauna, herpetofauna. Já a } \\
\text { fauna aquática pelas comunidades de ictiofauna, zooplâncton e fitoplâncton, além } \\
\text { de zoobentos associados a macrófitas. }\end{array}$ \\
\hline $\begin{array}{l}\text { C.3 Componentes } \\
\text { do Meio Antrópico }\end{array}$ & Descrição \\
\hline $\begin{array}{c}\text { C.3.01 } \\
\text { Infraestrutura } \\
\text { viária, tráfego e } \\
\text { transportes }\end{array}$ & $\begin{array}{l}\text { Inclui toda tipologia de vias públicas, desde estradas rurais não pavimentadas, vias } \\
\text { urbanas de primeira, segunda e terceira ordem, vias arteriais, e rodovias. }\end{array}$ \\
\hline $\begin{array}{l}\text { C.3.02 } \\
\text { Estrutura urbana }\end{array}$ & $\begin{array}{l}\text { Engloba as características hierárquicas e funcionais e compartimentos diferenciados } \\
\text { da mancha urbana, que incluem centros e subcentros de serviços, os polos } \\
\text { industriais, eixos arteriais, bairros e áreas peri-urbanas, e outros aspectos } \\
\text { vinculados. }\end{array}$ \\
\hline
\end{tabular}




\begin{tabular}{|c|c|}
\hline $\begin{array}{l}\text { C.1 Componentes } \\
\text { do Meio Físico }\end{array}$ & Descrição \\
\hline $\begin{array}{l}\text { C.3.03 } \\
\text { Atividades } \\
\text { econômicas }\end{array}$ & $\begin{array}{l}\text { Enquadram-se como atividades econômicas, todos os estabelecimentos industriais, } \\
\text { comerciais e de serviços e de serviços. As atividades agrícolas, silvicultura e outras } \\
\text { formas de atividade e comércio rural também estão incluídas nesse componente. }\end{array}$ \\
\hline $\begin{array}{l}\text { C.3.04 } \\
\text { Infraestrutura física } \\
\text { e social }\end{array}$ & $\begin{array}{l}\text { Por infraestrutura física entendem-se todas as redes de utilidades públicas, } \\
\text { excluídas as redes viárias que foram classificadas como outro componente. Já a } \\
\text { infraestrutura social compreende os equipamentos públicos e/ou privados de } \\
\text { educação, saúde, e outros serviços de atendimento da população. }\end{array}$ \\
\hline $\begin{array}{c}\text { C.3.05 } \\
\text { Qualidade de vida }\end{array}$ & $\begin{array}{l}\text { Nesse componente agrupam-se aspectos relativos à qualidade ambiental auferida } \\
\text { pela população residente (qualidade do ar, níveis de ruído, paisagem), assim como } \\
\text { outras variáveis potencialmente alteráveis pelo empreendimento, como a situação } \\
\text { patrimonial, os tempos de viagem, entre outros. }\end{array}$ \\
\hline $\begin{array}{c}\text { C.3.06 } \\
\text { Finanças Públicas }\end{array}$ & $\begin{array}{l}\text { O componente finanças públicas remete-se à situação das receitas e despesas fiscais } \\
\text { nas três esferas de governo. As finanças públicas passíveis de impactação pelo } \\
\text { empreendimento são as da esfera Federal, Estadual (São Paulo) e Municipal, nesse } \\
\text { último caso com maior foco nas finanças dos municípios interceptados pelo } \\
\text { traçado, mas podendo envolver também as finanças de outros municípios da AII. }\end{array}$ \\
\hline $\begin{array}{l}\text { C.03.07 } \\
\text { Patrimônio } \\
\text { Arqueológico, } \\
\text { Histórico e Cultural }\end{array}$ & $\begin{array}{l}\text { Compreende os bens patrimoniais, móveis e imóveis (sítios arqueológicos pré- } \\
\text { coloniais, de contato e históricos, sítios de valor etnográfico, edificações e } \\
\text { conjuntos edificados de valor histórico-arquitetônico, edificações e conjuntos } \\
\text { edificados de expressão vernacular e paisagens notáveis), e expressões culturais } \\
\text { coletivas presentes na área de influência do empreendimento. }\end{array}$ \\
\hline
\end{tabular}

Para auxiliar na seleção dos indicadores provenientes do EIA, foram mapeados os impactos e os seus atributos constantes na Matriz de Consolidação, resultante da avaliação dos impactos ambientais. Com base no princípio da intergeracionalidade, os impactos considerados mais relevantes no contexto da sustentabilidade urbana foram aqueles que apresentaram um dos seguintes atributos:

d. Intensidade: alta;

e. Reversibilidade: irreversível;

f. Tempo de permanência: longo ou permanente.

A matriz de análise dos impactos considerados nesta pesquisa está apresentada no Apêndice A. A relação final de impactos resultantes que serviu de base para a seleção dos indicadores-chave, visando auxiliar no desenvolvimento da estrutura de avaliação da sustentabilidade, pode ser verificada no Quadro 13, a seguir. Assim, um total de 49 impactos foram selecionados para o desenvolvimento da estrutura.

Quadro 13 - Impactos ambientais selecionados do EIA`s.

\begin{tabular}{|c|c|}
\hline Componente & \multicolumn{1}{c|}{ Impactos Ambientais } \\
\hline C.1 Meio Físico & I.1 Impactos no Meio Físico \\
\hline C.1.01 Terrenos & \begin{tabular}{l} 
1.03 Aumento das áreas impermeabilizadas \\
\cline { 2 - 2 } perigosos durante a operação
\end{tabular} \\
\hline $\begin{array}{c}\text { C.1.02 Recursos } \\
\text { hídricos superficiais }\end{array}$ & $\begin{array}{l}\text { 2.01 Alterações no regime fluviométrico de cursos d'água } \\
\text { durante a operação }\end{array}$ \\
\hline
\end{tabular}




\begin{tabular}{|c|c|}
\hline & $\begin{array}{l}\text { 2.06 Alteração na qualidade dos corpos hídricos pelo escoamento das águas } \\
\text { pluviais (cargas difusas) durante a operação }\end{array}$ \\
\hline \multirow{2}{*}{$\begin{array}{l}\text { C. } 1.03 \text { Recursos } \\
\text { hídricos subterrâneos }\end{array}$} & 3.01 Alteração no regime de fluxo das águas subterrâneas (rebaixamento) \\
\hline & 3.03 Risco de contaminação do lençol freático durante a operação \\
\hline $\mathrm{C} 1.04 \mathrm{Ar}$ & 4.02 Impactos na qualidade do ar durante a operação \\
\hline C.2 Meio Biótico & I.1 Impactos no Meio Biótico \\
\hline \multirow{5}{*}{$\begin{array}{l}\text { C.2.01 Cobertura } \\
\text { vegetal }\end{array}$} & 5.01 Redução da cobertura vegetal da área diretamente afetada \\
\hline & $\begin{array}{l}5.02 \text { Risco de supressão de espécies protegidas e/ou em listas de ameaça de } \\
\text { extinção }\end{array}$ \\
\hline & 5.03 Ampliação do grau de fragmentação florestal e instalação do efeito de borda \\
\hline & $\begin{array}{l}5.04 \text { Alteração do nível de risco da ocorrência de incêndios nas florestas } \\
\text { remanescentes no entorno da rodovia }\end{array}$ \\
\hline & $\begin{array}{l}5.05 \text { Efeitos nas comunidades ribeirinhas pelas interferências nos cursos d'água e } \\
\text { nas planícies aluviais }\end{array}$ \\
\hline \multirow{4}{*}{ C.2.02 Fauna } & $\begin{array}{l}\text { 6.01 Alteração local do número e da composição das comunidades de vertebrados } \\
\text { terrestres como decorrência da redução e fragmentação de habitats }\end{array}$ \\
\hline & 6.02 Interferências com corredores ecológicos \\
\hline & $\begin{array}{l}\text { 6.03 Afugentamento de fauna, aumento dos riscos de atropelamento e da pressão de } \\
\text { caça durante a implantação }\end{array}$ \\
\hline & $\begin{array}{l}\text { 6.06 Alteração no nível e distribuição espacial do risco de contaminação da fauna } \\
\text { aquática e edáfica por acidentes com produtos perigosos }\end{array}$ \\
\hline C.3 Meio Antrópico & I.1 Impactos no Meio Antrópico \\
\hline \multirow{10}{*}{$\begin{array}{l}\text { C.3.01 Infraestrutura } \\
\text { viária, tráfego e } \\
\text { transportes }\end{array}$} & 7.04 Impactos nos níveis de carregamento do sistema viário da região (AII) \\
\hline & 7.05 Melhoria da acessibilidade entre rodovias radiais da RMSP \\
\hline & 7.06 Benefícios socioeconômicos devidos à redução dos tempos de viagem \\
\hline & $\begin{array}{l}7.07 \text { Alterações no padrão de segurança do tráfego intraurbano e redução de } \\
\text { acidentes }\end{array}$ \\
\hline & $\begin{array}{l}\text { 7.08 Melhoria no grau de confiabilidade dos usuários no sistema viário } \\
\text { metropolitano }\end{array}$ \\
\hline & 7.09 Redução dos custos de manutenção da malha viária intraurbana da RMSP \\
\hline & 7.10 Redução de problemas decorrentes da circulação de cargas altas \\
\hline & 7.11 Favorecimento da intermodalidade no transporte de cargas \\
\hline & 7.12 Interferências com fluxos transversais de pedestres \\
\hline & 7.13 Redução das Emissões de Gases de Efeito Estufa \\
\hline \multirow{5}{*}{$\begin{array}{l}\text { C.3.02 Estrutura } \\
\text { urbana }\end{array}$} & 8.01 Indução à ocupação de terrenos vagos e áreas não urbanizadas \\
\hline & 8.02 Alterações dos valores imobiliários \\
\hline & 8.03 Aumento do grau de atratividade para usos residenciais \\
\hline & 8.04 Aumento do grau de atratividade para atividades econômicas \\
\hline & 8.05 Ruptura da malha urbana \\
\hline \multirow{4}{*}{$\begin{array}{l}\text { C.3.03 Atividades } \\
\text { econômicas }\end{array}$} & 9.01 Melhoria no padrão de acessibilidade às atividades econômicas \\
\hline & 9.03 Geração de empregos diretos e indiretos durante a operação \\
\hline & 9.04 Desativação de atividades econômicas localizadas na ADA \\
\hline & 9.05 Descentralização da oferta de emprego \\
\hline \multirow{2}{*}{$\begin{array}{l}\text { C3.04 Infraestrutura } \\
\text { Física e Social }\end{array}$} & 10.04 Alteração dos perímetros de atendimento dos equipamentos públicos locais \\
\hline & $\begin{array}{l}\text { 10.05 Melhoria no padrão de acesso a equipamentos públicos de importância } \\
\text { metropolitana }\end{array}$ \\
\hline \multirow{3}{*}{$\begin{array}{l}\text { C.3.05 Qualidade de } \\
\text { vida }\end{array}$} & 11.01 Mobilização social durante as etapas de planejamento e implantação \\
\hline & 11.05 Desapropriação \\
\hline & 11.06 Relocação de Moradias \\
\hline
\end{tabular}




\begin{tabular}{|c|c|}
\hline Componente & Impactos Ambientais \\
\hline & 11.07 Aumento dos níveis de ruído durante a operação \\
\hline & $\begin{array}{l}\text { 11.08 Alterações localizadas nas relações sociais entre comunidades de áreas } \\
\text { urbanas consolidadas }\end{array}$ \\
\hline & 11.09 Alterações na paisagem \\
\hline & 11.10 Redução dos tempos de viagem de passageiros \\
\hline & 11.11 Aumento das opções de emprego para a população motorizada \\
\hline \multirow{3}{*}{$\begin{array}{l}\text { C.3.06 Finanças } \\
\text { Públicas }\end{array}$} & 12.01 Aumento nas receitas fiscais durante a construção \\
\hline & 12.02 Aumento nas receitas fiscais durante a operação \\
\hline & 12.03 Impactos nos níveis de investimento privado \\
\hline
\end{tabular}

Esses impactos selecionados do EIA foram considerados para a determinação dos indicadores ou das medidas de desempenho constantes na estrutura de avaliação, visando orientar a mensuração dos mesmos na fase de avaliação ambiental de projetos.

Com vistas a desenvolver a estrutura de avaliação, foi verificado nos EIAs desenvolvidos para o Rodoanel quais foram os métodos de avaliação e mensuração dos impactos considerados mais relevantes para a sustentabilidade urbana. A descrição dos impactos e métodos de avaliação e mensuração estão apresentados a seguir:

\section{- 1.03 Aumento das áreas impermeabilizadas}

A impermeabilização ao longo do traçado compreende principalmente os locais de implantação das faixas de rolamento e acostamento, com exceção das travessias em pontes, viadutos e túneis, onde são mantidas em superfície a permeabilidade. Assim, calculou-se a porcentagem de pavimentação da faixa de domínio do traçado preferencial, verificando-se a taxa de permeabilidade da faixa reservada para a rodovia. Essa porcentagem foi comparada com as áreas das sub-bacias atravessadas pelo traçado proposto, verificando-se o acréscimo mínimo de impermeabilização e a relação as áreas já impermeabilizadas existentes. Dessa forma, foi possível avaliar os impactos na redução da produtividade hídrica das sub-bacias atravessadas e os efeitos sobre os picos de escoamento superficial.

\section{- 1.05 Alteração do risco de contaminação de solo por vazamento de produtos} perigosos durante a operação

No que tange especificamente à circulação de cargas perigosas, o risco de acidentes em vias intra-urbanas tende a ser reduzido em função de dois fatores:

- Redução no número e na extensão das viagens dentro da malha urbana da região metropolitana, em decorrência do desvio do volume de tráfego para o novo empreendimento rodoviário, em particular de veículos com cargas perigosas;

- Melhora relativa no nível de segurança do trânsito nos eixos cujo carregamento venha a ser significativamente aliviado e transferido para uma nova rodovia com melhores padrões de segurança do que em vias intraurbanas de padrão diverso, em geral inadequado à circulação de cargas perigosas. 
Por outro lado, devem ser considerados os riscos de acidentes com cargas perigosas no novo empreendimento, o qual deverá ser projetado com padrão rodoviário e diretrizes de otimização da segurança.

Vale ressaltar que, nos casos de derramamentos de produtos perigosos, o impacto sobre o solo tende a ser pontual, limitado aos locais com solo exposto (canteiros laterais e centrais) uma vez que, as maiores porções a serem mais atingidas pelos derrames correspondem a áreas impermeabilizadas dos pavimentos, os quais são dotados de sistema de drenagem superficial, podendo conter caixas de passagem e caixas de retenção. Além disso, este impacto também é minimizado pelo atendimento a emergências.

Para este impacto, calculou-se os índices de acidentes (IA) a partir do número médio de acidentes/km.ano.

\section{- 2.01 Alterações no regime fluviométrico de cursos d'água}

A drenagem de pistas e das áreas de corte e aterro na faixa de domínio pode reduzir os tempos de concentração e aumentar as áreas das bacias de contribuição de algumas drenagens naturais, resultando na elevação das vazões nos trechos a jusante dos pontos de lançamento do sistema de drenagem da rodovia. Associados a esse impacto, poderão ocorrer problemas pontuais, como desestabilização de margens (erosão fluvial) ou o aumento do risco de inundações.

A análise detalhada das situações concretas e a mitigação desse potencial impacto depende de verificação específica na etapa de detalhamento do projeto executivo de drenagem, cabendo a adequação do mesmo quando isto se mostrar relevante. Contudo, deve-se ter maior atenção em canais de $1^{\mathrm{a}}$ ordem que drenam terrenos de amorreados montanhosos.

\section{- 2.05 Alteração da distribuição do risco de contaminação dos corpos hídricos durante a operação}

Durante a fase de operação da rodovia existe o impacto potencial de contaminação dos cursos de água atravessados em decorrência de acidentes rodoviários com veículos que transportam produtos perigosos, ou também pelo carreamento de cargas difusas pela lavagem das superfícies durante os eventos de chuva.

Assim, a implantação da rodovia pode representar um impacto positivo na redução do risco de acidentes quando a rodovia a ser implantada representa melhores padrões de segurança rodoviária, reduzindo o volume de tráfego e a extensão das viagens de outras vias com padrão de segurança inferior.

Por outro lado, sempre existirá o risco de ocorrência de acidentes envolvendo produtos perigosos na nova rodovia. Assim, no detalhamento do projeto de engenharia, devem ser indicados pontos para instalação de caixas de retenção e retardamento do escoamento desses produtos. 


\section{- 2.06 Alteração na qualidade dos corpos hídricos pelo escoamento das águas pluviais (cargas difusas) durante a operação}

Cargas difusas podem afluir em cursos de água e mananciais decorrente da lavagem pelas chuvas de parcela atribuível das pistas de rolamento da rodovia, da faixa de domínio e do sistema de drenagem do empreendimento. Outros aportes de cargas difusas geradas na própria faixa de domínio podem incluir lixo comum lançado pelos motoristas, e sedimentos gerados em áreas instáveis ou pontos de erosão.

\section{- 3.01 Alteração no regime de fluxo das águas subterrâneas (rebaixamento)}

O principal impacto potencial do empreendimento nas águas subterrâneas é o rebaixamento de aquíferos durante a construção, que poderá ocorrer em algumas das porções das planícies aluviais, em especial naquelas em que os solos serão corrigidos ou substituídos, nos cortes profundos e também nos maciços escavados por túneis.

Os efeitos esperados pelo rebaixamento do aquífero estão relacionados à:

- diminuição da disponibilidade de água para formações florestais do entorno, podendo ocorrer a perda de vitalidade da vegetação;

- perda da disponibilidade hídrica dos aquíferos, em função do rebaixamento do nível de poços do tipo cacimba/cisterna existentes em propriedades lindeiras (junto às cristas dos cortes);

- captura de nascentes.

Para avaliação do impacto relacionado ao rebaixamento do nível freático de porções de planícies aluviais com necessidade de tratamento de solo, calculou-se a extensão do trecho que deveriam ter o solo corrigido e/ou substituído.

No caso dos cortes, a ocorrência deste impacto depende principalmente da profundidade do lençol freático, o qual deverá estar com nível superior à base do corte. De qualquer forma, o risco de rebaixamento do lençol freático é maior no caso da execução de cortes profundos, que podem interferir com o lençol freático onde ele for mais superficial. Para avaliação desse impacto, foram listados os trechos de cortes superiores a $20 \mathrm{~m}$.

Também devem ser consideradas as potenciais alterações no fluxo das águas subterrâneas relacionadas a escavações dos túneis. Caso estas águas sejam interconectadas ao túnel, seja nos pontos de intersecção com o nível freático ou por conexão com fraturas, zonas de falhas e juntas, as mesmas serão drenadas para os túneis, podendo resultar no rebaixamento de lençol freático e captura de nascentes. Para avaliação deste impacto, foram necessários estudos hidrogeológicos que determinaram as características hidráulicas e o comportamento dos aquíferos, possibilitando o estudo de alternativas e procedimentos construtivos e de medidas de controle.

\section{- 3.03 Risco de contaminação do lençol freático durante a operação}

A possibilidade de contaminação durante a fase de operação restringe-se pontualmente aos aquíferos aluvionares adjacentes ao traçado com possibilidade de serem atingidos por 
eventuais acidentes com vazamentos de produtos perigosos. Nos demais trechos, as ações de contingência, incluindo confinamento do vazamento e remoção de eventuais solos contaminados, evitam qualquer risco de deterioração qualidade das águas subterrâneas.

\section{- 4.02 Impactos na qualidade do ar durante a operação}

Os impactos potenciais na qualidade do ar durante a operação de uma rodovia devem ser analisados em dois níveis distintos. De um lado, há uma alteração difusa, de difícil mensuração, na quantidade de emissões atmosféricas de fonte móvel totais na escala regional, em função dos efeitos indiretos gerados pelo empreendimento sobre o padrão geral de circulação do tráfego. Por outro lado, ao longo do traçado da nova rodovia a ser operada e da AID, há um incremento no número de emissões de fontes móveis que passarão a circular na rodovia.

Quanto ao impacto potencial sobre as emissões anuais de poluentes na região, usualmente não se espera que uma nova rodovia represente, necessariamente, um acréscimo de tráfego total da região, mas apenas a transferência de parte das demandas de tráfego, sendo que a dinâmica de crescimento está diretamente associada às condições macroeconômicas do país. Esta transferência de tráfego e, consequentemente, da emissão de poluentes, tem a vantagem de se realizar sob condições de tráfego mais favoráveis quando comparadas ao congestionamento normal da cidade. A maior fluidez do tráfego de veículos implica em menor consumo de combustível, emitindo proporcionalmente menor quantidade de poluentes, além dos benefícios ambientais decorrentes do alívio do tráfego nas vias da cidade, com consequente aumento da velocidade média e redução das emissões dos veículos em circulação nas vias urbanas. Por outro lado, esse ganho pode ser compensado, em parte, por um possível aumento de emissões quando os veículos percorrem trajeto com maior extensão.

Contudo, não se exclui a necessidade prioritária de outras intervenções para melhoria da qualidade do ar a médio e longo prazo com vistas a solucionar o problema de uma maneira geral, tais como a aplicação de tecnologias limpas aos veículos, inspeção veicular ambiental, otimização da integração de diferentes modos de transporte, investimento em sistemas coletivos de transportes, promoção de uso e ocupação do solo compacto e integrado ao transporte, em toda a região.

Para uma avaliação de ambos os impactos potenciais, foram feitos estudos de modelagem visando estimar as emissões potenciais, as concentrações dos poluentes e sua condição de dispersão, considerando cenários de curto e médio prazo. Para tanto, utilizou-se dados da evolução das emissões de fonte móvel na região como um todo e na AID de maneira específica, volumes de tráfego, e fatores de emissão dos veículos brasileiros calculados com base nos dados de certificação da CETESB. Com base nas previsões de VDM (Volume Diário Médio), nas curvas de distribuição horária e nas proporções das diversas classes de veículos que trafegam nessas rodovias, foram calculados os fatores médios de emissão para os diversos cenários dos fluxos médios e máximos diários esperados. 
Utilizou-se também dados medidos nas estações para determinação das condições meteorológicas.

Como resultado, foram calculados os valores máximos de concentração dos seguintes poluentes: $\mathrm{CO}(\mathrm{ppm}), \mathrm{NO}_{2}(\mathrm{ppm}), \mathrm{MP}\left(\mu \mathrm{g} / \mathrm{m}^{3}\right), \mathrm{SO}_{2}\left(\mu \mathrm{g} / \mathrm{m}^{3}\right)$ e $\mathrm{HC}(\mathrm{ppm}$ hexano), diária e média anual.

\section{- 5.01 Redução da cobertura vegetal da área diretamente afetada}

Toda vegetação existente na ADA que sofrerá intervenção direta para construção da rodovia necessitará ser removida. Trata-se de impacto irreversível, porém passível de reposição por meio de plantios compensatórios em outros locais.

O EIA apresentou a quantificação de cada uma das unidades de mapeamento existente na ADA do traçado proposto, considerando tanto as formações nativas como as áreas antropizadas, dentro e fora de áreas de preservação permanente (APP), considerando os seus estágios de regeneração. Os indicadores quantificados para cada unidade de mapeamento de vegetação foram: Área em APP (ha); \% da ADA em APP; Área fora de APP (ha); Área total (ha); \% da ADA.

A opção pela construção de túneis contribuirá para a redução da supressão de vegetação, que ficará restrita praticamente aos emboques de túneis. Assim, pôde-se estimar a vegetação nativa que deixou de ser suprimida a partir da definição desse método construtivo.

\section{- 5.02 Risco de supressão de espécies protegidas elou em listas de ameaça de} extinção

Em algumas comunidades vegetais, principalmente as que compõem os remanescentes florestais nativos, eventualmente podem ocorrer espécies protegidas legalmente e ameaçadas de extinção na área diretamente afetada pela implantação da rodovia.

A listagem destas espécies que podem ocorrer na área de implantação foi obtida a partir do cruzamento da composição florística registrada no levantamento da vegetação na área de influência direta (AID) do empreendimento com as listas oficiais de espécies ameaçadas de extinção, considerando os principais documentos incidentes na área de implantação da rodovia, como Instrução Normativas, resolução estadual, listagens oficiais de espécies com algum tipo de ameaça de extinção. A listagem foi realizada contendo a Família, o Nome Científico, o Nome Popular e a norma que prevê sua ocorrência.

Essa listagem foi apresentada para a AID. Dessa forma, a identificação destas espécies ameaçadas na AID não implica que as mesmas são obrigatoriamente encontradas nas áreas de supressão de vegetação para implantação do empreendimento, mas que existe a possibilidade de ocorrerem nestas áreas. Por outro lado, outras espécies com algum grau de ameaça, tanto de hábitos arbóreos como com outras formas de vida, também podem vir a ser reconhecidas nas áreas de supressão durante a implantação da rodovia. 
Recomendou-se que, quando confirmada a ocorrência de tais espécies ameaçadas durante a supressão de vegetação, elas deveriam ser alvo de medidas específicas de resgate ou de compensação.

\section{- 5.03 Ampliação do grau de fragmentação florestal e instalação do efeito de borda}

A implantação de uma nova rodovia induz à criação de um corredor que se configura como uma barreira física linear a vários dos elementos que compõem a biota, principalmente através do fracionamento de formações vegetais, naturais ou antrópicas, que atuam na manutenção da conectividade dos elementos da paisagem, podendo segregar habitats de populações de fauna, interromper fluxos gênicos e agravar o efeito de borda para ambientes que estavam distantes dos limites florestais ou protegidos.

A avaliação desse impacto considerou o número de fragmentos florestais que seriam interceptados, identificando-se aqueles em que seriam totalmente suprimidos, aqueles tangenciados em sua borda e os remanescentes florestais que teriam efetivamente algum tipo de redução ou seccionamento de sua área total. Para cada um desses fragmentos, foram caracterizados o estágio de regeneração, sendo quantificado, percentualmente, os remanescentes florestais suprimidos com estágio médio a avançado de regeneração. Também foi quantificado o número de fragmentação dos principais remanescentes de vegetação em estágio médio e avançado de regeneração evitados em função da construção de túneis.

As matas em estágio inicial, médio e médio a avançado de regeneração, a serem atingidos com a implantação da rodovia, foram codificadas e classificados em três categorias relacionadas a tamanho: área menor que 20 hectares, área entre 20 e 50 hectares e área maior que 50 hectares, e quantificada a proporção (\%) por classe.

Além disso, quantificou-se o quanto destes fragmentos seria suprimido, a quantidade de fragmentos formados e a área remanescente após a supressão da vegetação. Para as áreas remanescentes, foram quantificadas as reduções percentuais de cada área interceptada em relação ao seu tamanho original.

\section{- 5.04 Alteração do nível de risco da ocorrência de incêndios nas florestas remanescentes no entorno da rodovia}

Este impacto se refere ao aumento de risco potencial que pode afetar negativamente remanescentes e fragmentos florestais pré-existentes ou formados com a implantação da rodovia, localizados no entorno da faixa de domínio da futura rodovia, que poderão se tornar mais vulneráveis a incêndios durante suas obras de implantação e operação.

O aumento no risco de incêndios deve-se à movimentação de trabalhadores e máquinas durante as obras de implantação, principalmente nas etapas iniciais de limpeza de terreno e desmatamento, através de utilização de fogueiras e motores desregulados de máquinas e veículos, dentre outras práticas inadequadas. Posteriormente, durante a operação futura da rodovia, certos usuários circulando com seus veículos podem lançar indevidamente, 
sobre a vegetação herbácea adjacente ao acostamento, bitucas de cigarro ou determinados objetos que possam convergir raios solares (vidros e embalagens metálicas, por exemplo), os quais podem iniciar incêndios acidentais principalmente nas épocas mais secas. Em virtude da rapidez de combustão da vegetação e dificuldade de controle em tempo hábil, o fogo pode extrapolar os limites da faixa de domínio e atingir florestas do entorno. Além disso, episódios de queimadas criminosas em áreas lindeiras a rodovias também são comuns, principalmente em trechos com trânsito de pedestres.

A ocorrência de incêndios em florestas do entorno da faixa de domínio também pode ser favorecida nos trechos em que o desnível é pequeno entre a rodovia e o terreno natural adjacente ou ao longo dos viadutos, o que aproxima estas florestas da rodovia e pode facilitar a chegada de objetos lançados indevidamente pelos usuários e a propagação do incêndio.

Esse impacto é passível de mitigação por meio da construção de faixa não combustível entre a rodovia e os fragmentos mais vulneráveis, e de medida operacionais de conscientização, de prevenção e de planos de emergência para combate a incêndios florestais.

\section{- 5.05 Efeitos nas comunidades ribeirinhas pelas interferências nos cursos d'água e nas planícies aluviais}

Trata-se de impacto decorrente de intervenções em planícies aluviais e cursos d'água, podendo interferir na estrutura e distribuição de algumas comunidades florestais. Nesses trechos, a implantação das travessias de drenagem é usualmente realizada em galerias, bueiros ou pontes, cujas comunidades ribeirinhas podem sofrer danos se as interferências afetarem de forma significativa a dinâmica natural dos cursos d'água.

- 6.01 Alteração local do número e da composição das comunidades de vertebrados terrestres como decorrência da redução e fragmentação de habitats

Com a supressão e descaracterização de parte dessas áreas naturais, os impactos sobre a fauna deverão ocorrer na medida em que o número e a área de tais refúgios diminuam. Ainda, a interferência em áreas já alteradas pode afetar a fauna oportunista sinantrópica.

A diminuição e fragmentação de habitats podem afetar elementos da fauna de duas maneiras distintas: grupos da fauna cujas populações têm, em média, maior requerimento de áreas e maior deslocamento dos indivíduos (e.g. aves e mamíferos); já os demais grupos da fauna terrestre - invertebrados, herpetofauna e pequenos mamíferos - tendem a responder ao tipo de impacto numa escala temporal mais ampla, pois suas populações sobrevivem bem em áreas pequenas, desde que mantidas as condições ecológicas adequadas.

Os efeitos negativos só podem ser avaliados pelo monitoramento continuado, o qual necessita de um programa específico. 


\section{- 6.02 Interferências com corredores ecológicos}

Os corredores são representados por corredores de vegetação que garantem a diversidade genética entre as populações silvestres, pois permitem os deslocamentos da fauna silvestres. Os corredores aumentam a porosidade entre os fragmentos florestais, permitindo uma maior aproximação entre as espécies outrora isoladas. Além disso, os corredores possibilitam também a passagem de doenças, predadores e espécies exóticas que comprometem a dinâmica da metapopulação.

Deve-se evitar interferências em pontos propícios para o trânsito de fauna florestal, como o cruzamento de remanescentes florestais significativos e adotando soluções construtivas alternativas e medidas que melhores as condições para a travessia de animais nesses locais. As medidas consistem em adotar prioritariamente OAEs e túneis na rodovia, e quando exigir a construção de terraplenos (corte e aterro) no trecho, deve-se adotar estruturas de passagens de fauna (subterrâneas ou superiores).

- 6.03 Afugentamento de fauna, aumento dos riscos de atropelamento e da pressão de caça durante a implantação

A maior propensão ao afugentamento de fauna silvestre ocorre durante a construção. $O$ aumento do nível de ruído próximo aos fragmentos florestados diretamente afetados pode resultar no afugentamento da fauna silvestre, principalmente animais com maior poder de deslocamento como aves, aves de sub-bosque e os mamíferos de médio e grande porte, elevando o risco de atropelamentos e acidentes com a fauna durante a construção. No entanto, esse impacto deverá ser temporário e ocorrer principalmente durante a etapa de construção, já que durante a fase de operação, espera-se o retorno dos animais silvestres mais tolerantes, às áreas próximas da futura rodovia.

Levou-se em consideração o aumento do risco de acidentes com atropelamentos de animais silvestres em vias de acesso e estrada de terra nas imediações de fragmentos de vegetação, devido ao aumento de circulação de veículos nas estradas de acesso e na ADA.

Tal impacto pode ser mitigado pela adoção de medidas preventivas e de orientação ao pessoal de obra, no que se refere ao transporte de material, operação das máquinas e emissão de ruídos em áreas próximos aos fragmentos de vegetação. Atividades de caça para fins alimentares ou mesmo para fins de domesticação devem ser coibidas, por meio da educação e conscientização dos trabalhadores.

- 6.06 Alteração no nível e distribuição espacial do risco de contaminação da fauna aquática e edáfica por acidentes com produtos perigosos

Está relacionado às alterações no risco de contaminação acidental dos recursos hídricos superficiais e sua relação direta com a fauna aquática associada. Similarmente, as espécies da fauna edáfica poderão ser impactadas por vazamentos de produtos perigosos sobre o solo próximo de áreas de mata. O risco varia conforme os demais riscos de contaminação do solo, devendo ser observado a qualidade da água e a fauna presente. 


\section{- 7.04 Impactos nos níveis de carregamento do sistema viário da região}

Com relação aos níveis de carregamento do sistema viário, a inserção da rodovia, proporciona as seguintes alterações:

- Alterações nas velocidades médias de tráfego da região;

○ Alterações nos padrões de nível de serviço de tráfego da rede viária regional;

As alterações das velocidades médias de tráfego tiveram suas análises no item benefícios sócio-econômicos derivados da redução nos tempos de viagem. Já as alterações nos padrões de nível de serviço de tráfego da rede viária regional ocorrem de forma difusa. $\mathrm{O}$ percentual relativo do sistema viário principal que se enquadra em cada faixa de relação Volume/Capacidade (V/C - indicador de nível de serviço de tráfego) foi apresentado em proporções (\%) das extensões da rede em cada Nível de Serviço de tráfego. Calculou-se o aumento percentual esperado do sistema viário da relação V/C para cenário de 20 anos.

Na sua desagregação de análise, destacou-se as principais vias que mereciam uma análise especial dada a importância para a região, em que foram realizadas análises expeditas de capacidade dessas vias, com indicadores médios para toda a extensão das mesmas.

\section{- $\quad$ 7.06 Melhoria da acessibilidade entre rodovias radiais da RMSP}

Outro impacto derivado da inserção da rodovia foi a melhoria na matriz de tempos das conexões entre as rodovias radiais da RMSP, decorrente também das reduções nos tempos de viagem na RMSP. Esse impacto, de vetor positivo, configura a função do Rodoanel como elemento facilitador da transposição da RMSP. A análise consistiu do cálculo dos tempos de viagens (em minutos) entre as zonas de tráfego externas onde estão localizadas as conexões das rodovias com a área de estudo e os ganhos percentuais (\%) de tempo de viagem para cada rodovia que chega na região metropolitana, para diferentes cenários.

\section{- 7.07 Benefícios socioeconômicos devidos à redução dos tempos de viagem}

Os benefícios foram calculados a partir da alteração da velocidade média na RMSP $(\mathrm{km} / \mathrm{h})$, a taxa de variação anual (\%/ano) e taxa de variação global (\%), para projeção de cenários com e sem a rodovia. Calculou-se também a alteração das distâncias totais de viagem (expressa em veículo x $\mathrm{km}$ ), e a redução dos tempos totais de viagem (expressos em veículo $\mathrm{x}$ hora) na rede da RMSP, cujos procedimentos metodológicos foram apresentados anteriormente.

- 7.08 Alterações no padrão de segurança do tráfego intraurbano e redução de acidentes

Em função das mudanças nos padrões de carregamento das vias da AII, são previstas alterações no padrão de segurança do trânsito nas vias afetadas pelo início da operação da rodovia, em decorrência da melhora ou da piora da relação volume x capacidade. Trata-se de um impacto de dois vetores, um negativo e outro positivo. 
As melhores condições de circulação de tráfego, e com o deslocamento de parte do tráfego pesado para o novo viário, aumentam as possibilidades de um ganho geral na segurança viária, o que auxilia na redução do número de acidentes na região metropolitana.

Com relação aos impactos de vetor negativo, o aumento de tráfego em certas vias poderá ser prejudicial quanto maior for o risco de comprometimento da capacidade operacional das vias afetadas. Trata-se, neste caso, de um vetor de impacto mais localizado que o positivo, e com maior intensidade nas vias da AID.

- 7.09 Melhoria no grau de confiabilidade dos usuários no sistema viário metropolitano

A operação conjunta de todos os trechos do Rodoanel completa o anel de circulação perimetral de grande capacidade, conectando todas as rodovias que chegam na região metropolitana. Com isso, o sistema viário metropolitano tornar-se menos vulnerável às situações anormais ou aos congestionamentos que possam ocorrer nas vias atuais. Assim, ainda que em patamar baixo, considerou-se que a melhoria do tráfego poderá contribuir para o aumento da confiabilidade do transporte intraurbano entre todas as regiões da RMSP, o que pode acarretar impactos positivos para a atratividade industrial da região.

\section{- 7.10 Redução dos custos de manutenção da malha viária intraurbana da RMSP}

A transferência de veículos pesados da malha intraurbana para a rodovia perimetral poderá trazer redução nos custos de manutenção da malha viária, já que os veículos pesados são os que mais causam deterioração dos pavimentos. Trata-se de um impacto bastante difuso, que deverá se diluir nas finanças públicas dos municípios da RMSP, não comportando, portanto, uma previsão em termos quantitativos, dada a sua complexidade diante do peso dos ganhos locais aferidos.

Há exceções a serem levadas em conta, como vias que poderão ter aumento de seu volume de tráfego e assim demandarão solução específica para ampliar capacidade, e reduzir os impactos com a implantação de alternativa de acesso ao Rodoanel que minimize o tráfego intraurbano.

\section{- 7.11 Redução de problemas decorrentes da circulação de cargas altas}

O sistema viário metropolitano tem como necessidade a circulação de cargas dentro e/ou através da região metropolitana, dentre elas as cargas altas e especiais, que comumente se dirigem aos portos e grandes obras. Contudo, muitas das OAEs (pontes e viadutos) possuem gabarito baixo (inferior a 4,50m), que impedem a passagem desse tipo de carga, acarretando em congestionamentos nas vias intraurbanas, danos a estrutura de vias, maiores riscos no trânsito, prejuízos para redes aéreas de eletricidade e telefonia, entre outros.

Assim, rede especializada para circulação de cargas altas adequadas (gabarito superior a $5,5 \mathrm{~m}$ ), fora do espaço urbano, constitui um impacto positivo do empreendimento. 


\section{- 7.12 Favorecimento da intermodalidade no transporte de cargas}

Conforme foi explicitado na Avaliação Ambiental Estratégica do Programa Rodoanel, a implantação do Rodoanel e do Ferroanel, bem como de centros de logística integrados, converterá a configuração logística metropolitana de radial para anelar: em lugar dos eixos rodoviários e ferroviários convergirem para o centro metropolitano para ali realizar suas transferências intermodais ou alcançar o destino final, a nova plataforma permitirá transferir as transações para o entorno da RMSP e alcançar o centro metropolitano em veículos mais adequados para o viário urbano, com benefícios ao sistema de transportes e ao tráfego de veículos em toda região.

\section{- 7.13 Interferências com fluxos transversais de pedestres}

A concepção do traçado recomendado procurou minimizar o efeito de ruptura da malha urbana consolidada, reduzindo o potencial de impactos aos fluxos de pedestres entre áreas urbanas situadas em margens opostas da nova rodovia. As interferências com os fluxos de pedestres ficaram restritas a alguns pontos onde o traçado afeta franjas de ocupação, interrompeu permanentemente as ligações secundárias entre bairros próximos ou dificultou o acesso, exigindo maiores percursos.

As interferências com os fluxos de pedestres principais foram objeto de verificação e aperfeiçoamento na etapa de detalhamento do projeto de engenharia. Nos casos onde não foram possíveis ajustes no traçado geométrico, as interferências foram mitigadas pela previsão de passarelas elevadas, onde for possível. Contudo, esses dispositivos não eliminam totalmente o impacto, na medida em que a utilização de passarelas elevadas implica em um percurso maior, gerando inclusive a necessidade de colocação de barreiras físicas no nível das pistas de tráfego para evitar travessias irregulares de pedestres nos pontos de maior demanda.

A expansão das áreas ocupadas no entorno da faixa de domínio também gera novos fluxos. Desta forma, as demandas por fluxos transversais de pedestres deverão ser permanentemente monitoradas e, quando necessário, atendidas com novas passarelas.

\section{- 7.14 Redução das Emissões de Gases de Efeito Estufa}

Por meio de modelagem, foi feita uma análise de emissões de gases de efeito estufa (GEE) objetivando comparar os cenários com e sem o Trecho Norte do Rodoanel. Segundo as diretrizes da publicação "2006 IPCC Guidelines for National Greenhouse Gas Inventories," o método Tier 1 foi usado para estimar emissões de $\mathrm{CO} 2$.

Esta abordagem usa a quantidade de combustível consumido e um fator de emissão (EF) para $\mathrm{CO}_{2}$, conforme apresentado na equação abaixo. $\mathrm{O}$ fator de emissão é fornecido pelo IPCC para cada tipo de combustível. Neste caso, foram utilizados fatores de gasool E25 para veículos privados e de diesel para veículos comerciais.

$$
\text { Emissão }=\sum[\text { combustível } * E F]
$$


A quantidade de combustível consumido foi estimada usando os resultados de distância média rodada por dia (veículo*km) nos trechos, utilizando-se a equação a seguir, a seguir.

$$
\text { Combustível }=\sum[\text { veículos } * \text { distância } * \text { taxa de consumo }]
$$

A análise incluiu somente os dados de $\mathrm{CO}_{2}$ para estimar os GEE emitidos, pois, segundo o IPCC, o $\mathrm{CO}_{2}$ é responsável por mais de $97 \%$ das emissões totais de GEE de fontes móveis, e os cálculos das emissões de $\mathrm{N}_{2} \mathrm{O}$ e $\mathrm{CH}_{4}$ têm um alto grau de incerteza. Dessa forma, pela simplicidade e relativa confiabilidade do método a estimativa de emissões é baseada somente nos dados relativos ao $\mathrm{CO}_{2}$.

A avaliação foi realizada para cenários com e sem o empreendimento, num horizonte de até 25 anos, desagregando-se entre veículos privados e comerciais, com resultado do total de emissões por ano ( $\mathrm{tCO}_{2} / \mathrm{ano}$ ), a partir da distância de veículos percorrida (veículo*km/dia). Foi possível calcular a variação porcentual (redução ou aumento) de emissões ao longo do tempo, nos diversos cenários estabelecidos.

Como resultado, constatou-se que haverá uma diminuição nas emissões de $\mathrm{CO}_{2}$, tendo como principal fator a redução da distância rodada.

\section{- 8.01 Indução à ocupação de terrenos vagos e áreas não urbanizadas}

Todo processo de indução à ocupação urbana é contingenciado pela disponibilidade de estoques de terra passíveis de serem ocupados. A indução de processos de expansão urbana, ocupação de terrenos vagos, adensamento, verticalização e mudança de usos se dá em virtude de processos interrelacionados, como o aumento da acessibilidade e da atratividade à instalação de atividades econômicas, a valorização ou desvalorização das localizações residenciais, e as mudanças na legislação incidente sobre o uso e ocupação do solo (legislação urbanística e ambiental).

Este impacto foi tratado na AAE, utilizando-se modelagem com dados estatísticos sobre emprego, domicílios e renda, espacializados em zonas de origem e destino. As principais variáveis utilizadas na modelagem foram:

- Distribuição espacial de empregos por setor e zona de tráfego;

- Distribuição espacial de renda por zona de tráfego;

- Distribuição espacial de domicílio por zona de tráfego;

- Distribuição espacial de desempregados e subempregados por zona de tráfego;

- Matriz de tempos de viagens intra e interzonais;

- Indicadores de estoques para adensamento de empregos e domicílios por zona de tráfego.

Foram estimados os seguintes fenômenos:

- As relações entre a concentração de empregos por setor e a presença de domicílios por classe na própria zona e nos seus vizinhos; 
- A presença de fornecedores e consumidores (de outros setores) na zona e nas vizinhas;

- A densidade de emprego e de domicílios;

- E a própria concentração do emprego nas zonas vizinhas.

Os fenômenos mais importantes ligados à ocupação e à dinâmica urbana foram analisados sem e com a presença da rodovia, considerando as tendências de expansão urbana e a influência do empreendimento nesse processo, considerando o adensamento urbano, o espraiamento, a ocupação dos terrenos vazios e disponíveis e o reforço da requalificação urbana.

De forma geral, a rodovia teria capacidade de alterar de forma generalizada a lógica da localização intra-urbana se fosse uma via de acesso livre, utilizada por rotas de transportes coletivos e dotada de pontos de parada. Assim, poderiam ser criadas novas vantagens locacionais e centralidades efetivas, sobretudo na AID.

Com a implantação dos acessos em rodovias e em pontos estratégicos, o Poder Público atua, portanto, como agente regulador e planejador do crescimento urbano ao limitar ou permitir acesso à via, interferindo significativamente no processo de geração de vantagens locacionais e de valorização imobiliária. Assim, a atratividade de atividades econômicas e a valorização imobiliária, e a consequente potencialização de processos de adensamento e expansão urbana, tenderá a ser maior nas zonas onde haverá ganho real de acessibilidade.

Por se tratar de uma via expressa com poucos pontos de acesso, o impacto sobre o tempo de deslocamento de pessoas e mercadorias, torna-se mais relevante para viagens de longa distância. Nas zonas de tráfego do entorno da via, as variações nos tempos de viagem, induzidas pelo empreendimento, foram consideradas de pouca relevância.

\section{- $\quad 8.04$ Alterações dos valores imobiliários}

Os efeitos a curto prazo previstos pela construção e operação da rodovia, com abrangências geográficas distintas, foram:

- processo difuso de valorização imobiliária nas áreas da AII mais próximas ao centro expandido e em áreas de urbanização consolidada, em função da melhora do trânsito em vias hoje congestionadas;

- processos de valorização imobiliária localizados nas áreas próximas ou relativamente próximas às interseções. A valorização será maior na AID ou nas áreas externas com fácil acesso às intersecções. A intensidade desse impacto depende da importância dos ganhos de acessibilidade aferidos para cada tipo de uso, e dos valores imobiliários em vigor antes da implantação do empreendimento, havendo maior potencial de ganho nas regiões menos valorizadas;

- processos pontuais de desvalorização imobiliária de áreas residenciais de médio e alto padrão adjacentes à faixa de domínio, em função de impactos ambientais permanentes, como o aumento do nível de ruído e as alterações na paisagem; 
- processos de desvalorização de certas localizações residenciais em virtude do aumento no carregamento de tráfego em algumas vias, podendo provocar mudança de usos, especificamente quando as áreas lindeiras apresentam padrão de uso predominantemente residencial. Em contrapartida, dependendo de cada caso e das características locais, o aumento de tráfego poderá resultar em valorização imobiliária, favorecendo o comércio e serviços;

- processos de desvalorização imobiliária pela redução das possibilidades de acesso futuro em áreas de expansão urbana, provocada pela ruptura da malha urbana e ligações existentes em franjas periféricas e áreas de expansão urbana, que poderá ser mitigada com a manutenção de acessos, relocação de vias locais e pela reestruturação do tecido urbano.

\section{- 8.05 Aumento do grau de atratividade para usos residenciais}

A implantação de rodovia proporciona benefícios, em termos de acessibilidade para o automóvel, a determinadas regiões de uso residencial, em função de dois aspectos relacionados aos tempos e velocidades de transporte:

- Inserção de novas alternativas de rotas, com menores tempos de viagem, que passem a incorporar a nova rodovia em parte do seu percurso;

- Incrementos nas velocidades médias de eixos intraurbanos que venham a ter o seu carregamento de tráfego aliviado.

Para um mesmo intervalo de tempo, a área de cobertura para acesso das populações residentes nas zonas beneficiadas passa a ser mais ampla devido aos ganhos de tempo em transporte. Em termos teóricos, essa ampliação da área de abrangência para o acesso significa que, para essas populações beneficiadas, a área de acesso aos locais de oferta de empregos será ampliada.

Adotou-se, portanto, como critério de análise do grau de atratividade para usos residenciais, a estimativa da variação (aumento) do número de empregos que passa a ser possível se ter acesso dentro de um tempo fixo de tempo de viagem nas situações com e sem o empreendimento. Uma redução nos tempos de deslocamento entre residência e trabalho representa um benefício de qualidade de vida que afeta diretamente a população motorizada residente na AII.

Para a análise do impacto referente ao aumento da acessibilidade para usos residenciais, foram utilizadas técnicas de modelagem e de sistemas de informações georreferenciadas (SIG), objetivando quantificar o ganho de acessibilidade para um conjunto de zonas origem e destino (Zonas OD) selecionadas, cujos centros são identificados para facilitar sua localização. Dentro dessas zonas, existem bairros com uso residencial ou predominantemente residencial, a partir das quais se pretende avaliar o aumento da acessibilidade para atingir locais onde há oferta de empregos.

A quantificação do ganho de acessibilidade foi realizada a partir do número de empregos que são possíveis de serem acessados a partir de viagens com e sem o empreendimento, 
em períodos de até 30 minutos, entre 30 e 45 minutos e entre 45 e 60 minutos, durante o horário de pico. A metodologia adotada consiste em elaborar as curvas isócronas (curvas que definem o conjunto de pontos acessados com igual tempo de viagem a partir de uma única origem) a partir de cada um dos locais selecionados. Posteriormente, quantifica-se, a partir de técnicas de geoprocessamento, o número de empregos existentes dentro da região definida por cada curva isócrona.

Os resultados foram apresentados em gráficos e mapas, a partir do cálculo de alteração do número de empregos atingidos nas faixas de tempo (em minutos) no horário de pico e para as zonas selecionadas, com e sem o empreendimento. As porcentagens dessas alterações foram apresentadas.

\section{- 8.06 Aumento do grau de atratividade para atividades econômicas}

Assim como as áreas residenciais, a melhoraria da acessibilidade próximas das novas interseções, em função de aspectos relacionados aos tempos e velocidades de transporte, deverá ocorrer também para atividades comerciais e industriais ou de serviços.

Como critério de análise foi adotado o grau de atratividade de determinadas zonas como polos geradores de viagens, e a estimativa da variação da população que pode acessar como destino os locais selecionados, dentro de um tempo fixo de viagem, nas situações com e sem o empreendimento. Assim, verifica-se que determinadas regiões onde existem atividades com elevado potencial de atração, passarão a ter o seu padrão de acessibilidade melhorado a partir da operação do empreendimento, uma vez que um número maior de pessoas ou empresas poderá ter acesso a elas em um mesmo tempo de viagem.

Os ganhos de acessibilidade a determinadas regiões de uso comercial e/ou industrial ocorre em função de dois aspectos relacionados aos tempos e velocidades de transporte:

- Inserção de novas alternativas de rotas, com menores tempos de viagem, que passem a incorporar a rodovia em parte do seu percurso;

- Incrementos nas velocidades médias de eixos intra-urbanos que venham a ter o seu carregamento de tráfego aliviado.

$\mathrm{Na}$ teoria, os benefícios principais para as atividades industriais resultantes de ganhos de acessibilidade consistem na possibilidade de se optar entre uma gama mais ampla de serviços e fornecedores, e em se ter acesso maior à mão-de-obra da região. Para as atividades comerciais e de serviços, os benefícios ocorrem na medida em que o mercado de clientes potenciais pode ser ampliado na mesma proporção em que o padrão de acesso seja melhorado.

Para esse impacto, foram utilizadas as mesmas técnicas de modelagem $\mathrm{e}$ geoprocessamento para usos residenciais, visando quantificar o impacto de ganho de acessibilidade para um conjunto selecionado de zonas origem e destino (Zonas OD). Contudo, essa quantificação adotou como indicador básico do padrão de acesso o total de população em cada zona que podem atingir o destino escolhido nas situações com e sem 
o empreendimento, em até 30 minutos, entre 30 e 45 minutos e entre 45 e 60 minutos, durante o horário de pico.

Os resultados foram apresentados em gráficos e mapas, a partir do cálculo de alteração da população acessível no horário de pico e para as zonas selecionadas, com e sem o empreendimento. As porcentagens dessas alterações foram apresentadas.

\section{- 8.07 Ruptura da malha urbana}

O empreendimento produz um efeito imediato e permanente de ruptura da malha urbana existente em alguns pontos ao longo do traçado. Esse impacto só tem importância quando afeta indiretamente a localização dos usos nas áreas separadas pelo traçado. Assim, se o traçado separa dois loteamentos vizinhos, e os usos residenciais se mantiverem durante a operação da rodovia, pode-se dizer que não houve impacto sobre a estrutura urbana.

A escolha de traçado contempla a minimização desse impacto, de forma a evitar uma maior fragmentação ou um maior isolamento dos espaços urbanos existentes. $\mathrm{O}$ atendimento às demandas de fluxos transversais deve ser previsto em projeto, com vistas a proporcionar condições satisfatórias de continuidade.

Ao criar situações de descontinuidade e nova configuração de vias e lotes, contingencia a forma de ocupação futura das propriedades remanescentes e dos vazios urbanos adjacentes à faixa de domínio. Mais importante que a configuração resultante são os processos de valorização e desvalorização imobiliária, que podem induzir mudanças de uso, propiciando ou desestimulando determinadas atividades.

\section{- 9.01 Melhoria no padrão de acessibilidade às atividades econômicas}

De forma análoga ao que ocorrer em termos de atratividade, o padrão de acessibilidade aos estabelecimentos de atividades econômicas melhora, reduzindo-se os tempos de viagem entre fornecedores e consumidores e beneficiando as cadeias produtivas locais. Esse impacto ocorre de forma difusa por toda a RMSP, especialmente ao longo dos eixos rodoviários e urbanos estruturais beneficiados pela rodovia, e com maior intensidade em áreas próximas aos novos acessos.

Um aspecto a ser ressaltado é que a rodovia consolida um processo gradativo de equalização da atratividade relativa dos eixos radiais interligados à localização de atividades econômicas. Esse impacto é altamente positivo na escala metropolitana, na medida em que contribui para equilibrar os pesos (em termos de atratividade) das diferentes localizações junto às rodovias, beneficiando eixos menos valorizados e favorecendo a descentralização relativa dos empregos.

\section{- 9.03 Geração de empregos diretos e indiretos durante a operação}

A etapa de operação gera empregos diretos e indiretos para a manutenção e conservação da rodovia. Embora não possa se dispor do montante exato de pessoal requerido, estimouse a geração de empregos com base em informações fornecidas por concessionários que operam outros trechos rodoviários. 


\section{- 9.04 Desativação de atividades econômicas localizadas na ADA}

Em que pese o estudo de traçados ter privilegiado desviar-se sempre que possível de áreas urbanas, de grandes plantas industriais ou comerciais, de equipamentos urbanos e de atividades agrícolas, reduzindo o impacto sobre as atividades econômicas, as rodovias, estruturas lineares, raramente conseguem evitar completamente esse impacto. Assim, estimou-se a quantidade total de edificações com atividades econômicas, tais como depósitos diversos, transportadoras, galpões manejo de sucata, pequenas indústrias urbanas e instalações de comércio e serviços urbanos, além da área (em hectares) ocupadas por atividades agrícolas.

$\mathrm{Na}$ fase do EIA, as estimativas são preliminares, efetuadas com base em fotografias aéreas e inspeção de campo. O cadastro oficial de desapropriação é realizado em etapa posterior ao Licenciamento Prévio. Durante o detalhamento do projeto executivo, adota-se como diretriz a análise de casos específicos buscando minorar as interferências identificadas.

\section{- 9.05 Descentralização da oferta de emprego}

Verificou-se que, em médio prazo, o empreendimento deverá contribuir, de forma difusa, para a descentralização relativa da oferta de emprego na RMSP. A interligação entre eixos radiais contribui para a reduzir as diferenças no grau de atratividade desses eixos para a instalação de atividades industriais e comerciais. Cada eixo radial tem a sua própria área de influência, que depende fundamentalmente das condições atuais de acesso e da quantidade e padrão de renda das pessoas nessa respectiva área, além de outras condicionantes.

Como a implantação do empreendimento aumenta a possibilidade de interligação direta entre eixos radiais, as áreas de influência se ampliam e as diferenças entre elas se reduzem.

- 10.04 Alteração dos perímetros de atendimento dos equipamentos públicos locais

Trata-se das alterações nos raios de atendimento de equipamentos de âmbito local em função da implantação do empreendimento, cujo impacto ocorre em função da interrupção permanente ou piora nas condições das vias transversais que conectam os usuários aos equipamentos públicos, independentemente do meio de transporte.

- 10.05 Melhoria no padrão de acesso a equipamentos públicos de importância metropolitana

Como demonstrado nas análises de tráfego, constatou-se ganhos de acessibilidade em equipamentos de importância metropolitana, especialmente aqueles dos setores de transporte, educação superior e lazer, propiciando benefícios à qualidade de vida da população que habita a RMSP. Dentre os equipamentos que tiveram seu acesso facilitado, pode-se citar os seguintes: aeroportos, parques metropolitanos e municipais, jardim botânico e jardim zoológico. 


\section{- 11.01 Mobilização social durante as etapas de planejamento e implantação}

A mobilização social em função do empreendimento começou mesmo antes da elaboração do EIA/RIMA, e foi considerado um impacto positivo, na medida em que envolveu a divulgação de informações sobre o projeto à população, e permitiu que as críticas, sugestões e reivindicações de prefeituras, comitês de bacias e entidades locais da sociedade civil fossem encaminhadas ao empreendedor.

Entretanto, previu-se que o impacto adquiriu maior intensidade na medida em que o processo de licenciamento foi progredindo. Os eventos que tendem a aumentar o nível de mobilização considerados foram: a divulgação e consulta pública do EIA/RIMA; a realização de Audiências Públicas, incluindo a presença de todos os órgãos públicos, conselhos e entidades não governamentais envolvidos ou interessados na discussão sobre o licenciamento do projeto e da obra; a emissão das licenças prévia e de instalação; e a divulgação do cadastro de desapropriações e reassentamento involuntário.

Esperou-se também certo aumento da mobilização social durante as obras. Impactos sobre as vizinhanças, em função de interrupções de vias, desvios provisórios, aumento da circulação de caminhões em vias locais, aumento do ruído, entre outros, podem gerar reclamações, que devem ser entendidas como uma forma de mobilização social, sejam elas apresentadas por associações de bairro, proprietários de imóveis, moradores de vias afetadas, etc.

Dessa forma, foram previstas medidas de comunicação social nas fases pré-construtiva e construtiva, capazes de potencializar este impacto, oferecendo um canal aberto não só às comunidades lindeiras ao traçado, mas a toda a população da RMSP.

\section{- 11.05 Desapropriação}

Para o impacto da desapropriação, estimou-se a área da faixa de domínio, em hectares, a ser desapropriada para a implantação do empreendimento. O valor é sujeito a variações em função de ajustes no detalhamento de projeto e nos perímetros de desapropriação que serão definidos após a realização do Cadastro Físico dos imóveis. Essas áreas são definidas em Decreto de Utilidade Pública, etapa inicial do processo de desapropriação, que, conforme assegura a legislação federal e estadual, adota como critério a avaliação justa e pelo valor de mercado de suas propriedades e benfeitorias afetadas.

O levantamento cadastral dos imóveis, com identificação dos proprietários e delimitação final dos polígonos de desapropriação, é realizado juntamente com o detalhamento do projeto de engenharia, que permite estabelecer com precisão o número de imóveis afetados e as áreas a serem desapropriadas.

\section{- 11.06 Relocação de Moradias}

Para efeito de avaliação ambiental no EIA, estimou-se o número de edificações afetadas, de maneira a permitir estabelecer uma ordem de grandeza e tipologia dos impactos esperados, com vistas à formulação de programas e medidas de mitigação e compensação. 
Os levantamentos foram feitos através de interpretação de imagens de satélite, que permitiram quantificar o número de edificações na faixa de domínio. A quantificação das edificações urbanas afetadas foi segregada por municípios, entre residenciais regulares e sub-normais (irregulares), e edificações isoladas em meio rural (chácaras e sítios). Para as situações irregulares, considerou-se a situação dos loteamentos frente à legislação municipal, sem considerar a situação individual de cada morador.

A quantidade é confirmada posteriormente em função do projeto executivo, sendo que ajustes de traçado podem ser feitos para evitar a remoção das edificações, assim como do resultado dos levantamentos de campo a serem realizados para os cadastros físico e social.

\section{- $\quad 11.07$ Aumento dos níveis de ruído durante a operação}

Os equipamentos que considerados mais sensíveis a aumentos no nível de ruído durante a construção e a operação são os de educação e de saúde situados próximos a ADA ou a áreas de apoio.

De maneira geral, os acréscimos de nível de ruído e vibração durante a construção decorrem do funcionamento de equipamentos e máquinas na obra; da movimentação de veículos a serviço das obras por vias locais; do desmonte de rochas por explosivos e da demolição de edificações. Os acréscimos, e consequentes impactos negativos sobre a população lindeira, têm a duração somente do período de execução das atividades acima listadas e podem ser parcialmente mitigadas com a operacionalização de medidas de regulagem de equipamentos e veículos e concentração, sempre que possível, de atividades geradoras de ruído em períodos diurnos. Consideradas a temporalidade das obras, a geração de ruídos de maior intensidade que poderiam provocar eventuais incômodos em receptores críticos, ou reclamações das comunidades lindeiras em geral, é transitória, variando inclusive com o desenvolvimento das frentes de obra.

Quanto à futura operação, a previsão preliminar de impactos acústicos no entorno do traçado foi realizada com a utilização do software CadnaA, da empresa alemã Datakustik, que realiza uma previsão dos impactos acústicos decorrentes da implantação de obras lineares através do cadastro de dados referentes à situação atual e à situação futura. Esse software utiliza o método de previsão de ruído rodoviário para a avaliação de impacto e concepção de medidas de atenuação integradas ao projeto de engenharia (e.g. pavimentos silenciosos, barreiras acústicas, etc.).

Na modelagem preliminar feita no presente EIA foram utilizados dados com as projeções de tráfego, por meio da inserção de dois tipos de dados: número de veículos, com diferenciação entre manhã, tarde e noite, e com especificação da porcentagem de veículos pesados nestes períodos, ou a inserção do VDM total, para o qual não é diferenciada a porcentagem de veículos pesados. Outros dados relevantes para a composição da modelagem referem-se:

- Ao tipo de revestimento da rodovia projetada;

- Ao limite de velocidade $(\mathrm{em} \mathrm{km} / \mathrm{h})$; 
- À fluidez do tráfego e;

- À geometria da via, incluindo, além da largura total das pistas de rolamento, greide projetado, os offsets de corte e aterro e as obras de arte projetadas.

As áreas mais críticas são aquelas em que a rodovia passa em nível próxima às áreas urbanas. A otimização do projeto de engenharia, com a adequação das seções e ajustes pontuais no traçado, contribuiu para a minimização dos impactos de ruído sobre as comunidades lindeiras. Complementarmente, após o detalhamento do projeto executivo, será realizada uma nova modelagem de previsão de ruído com o auxílio do software CadnaA para identificação das áreas críticas e simulações com implantação de dispositivos atenuadores, tais como substituição de pavimento, implementação de barreiras acústicas, variação de greide da pista, uso de barreiras de solo ou guarda-corpo, instalação de barreira New Jersey, entre outros. Eventuais soluções de mitigação com isolamento acústico em imóveis específicos também foram avaliadas pontualmente, quando necessário.

- 11.08 Alterações localizadas nas relações sociais entre comunidades de áreas urbanas consolidadas

Os impactos de interferências com fluxos de pedestres e com áreas urbanas (discutidos anteriormente) podem gerar um impacto adicional sobre a qualidade de vida da população da AII, devido às possíveis alterações nas relações de convivência e troca entre as comunidades de bairros que a rodovia acaba isolando ou dificultando a ligação. $\mathrm{Na}$ escolha do traçado, procurou-se desviar de áreas urbanas consolidadas. Além disso, as principais ligações viárias transversais foram mantidas, e passarelas implantadas nos pontos de maior demanda.

Dessa forma, foram listados os bairros que podem sofrer esse impacto, separados por município.

\section{- 11.09 Alterações na paisagem}

A implantação de uma rodovia com o padrão e o porte da rodovia implica em uma alteração significativa na paisagem natural ou antropizada em que será construída, tornando-se uma nova referência na paisagem regional. As alterações na paisagem ocorrem ao longo de todo o traçado em que a rodovia é implantada em superfície e viadutos. Dessa forma, para avaliar esse impacto, calculou-se a porcentagem da extensão desses trechos em relação ao todo.

Os impactos na paisagem são diferenciados em função de fatores como a topografia do terreno natural, existência de cobertura vegetal de porte florestal, padrão do uso e ocupação do solo, beleza cênica e a proximidade com outras edificações ou equipamentos de porte. Nos trechos de topografia mais acidentada, as alterações de relevo decorrentes dos cortes e aterros provocam alterações muito maiores na paisagem original do que nos trechos menos acidentados. 
A criação e revitalização de parques ao longo de determinados trechos, a implantação paisagismo na faixa de domínio e plantios compensatórios em áreas externas foram considerados medidas mitigadoras e/ou compensatórias. Nas áreas com urbanização mais consolidada ou em áreas de expansão urbana em consolidação, gera-se a demanda de reconfiguração e revitalização das áreas urbanas afetadas na estrutura urbana existente.

\section{- 11.10 Redução dos tempos de viagem de passageiros}

Trata-se do benefício para o setor de transporte gerado pela implantação da rodovia apresentado em item específico, que decorre da redução nos tempos de viagens devido ao aumento das velocidades médias na rede.

\section{- 11.11 Aumento das opções de emprego para a população motorizada}

A população residente na AII, que possui automóvel, poderá ter sua acessibilidade aumentada a locais de empregos que antes eram muito distantes, ou a novos locais de empregos que podem surgir nas áreas próximas às intersecções com acesso à rodovia. Qualquer redução nos tempos de deslocamento entre residência e trabalho representa um benefício de qualidade de vida à população, limitados àqueles que possuem veículos próprios e àqueles que se utilizam de transporte coletivo que se beneficiam com a melhoria geral do trânsito.

\section{- 12.01 Aumento nas receitas fiscais durante a construção}

Durante a fase de construção, uma parte significativa dos desembolsos a serem realizados retornam aos cofres públicos na forma de impostos ou taxas que incidem sobre a contratação da mão-de-obra, aquisição e aplicação de materiais e utilização de equipamentos. Assim, calculou-se a distribuição percentual da composição do custo direto e indireto da obra (mão-de-obra; materiais e equipamentos), separando em taxas e impostos que foram revertidas ao setor público.

\section{- 12.02 Aumento nas receitas fiscais durante a operação}

$\mathrm{Na}$ fase de operação, incidem sobre as despesas e receitas operacionais os mesmos encargos, contribuições, taxas e impostos incidentes sobre os custos de obra, porém com variações em virtude das diferentes composições dos custos de operação e construção.

Complementarmente, há o impacto direto sobre as finanças públicas municipais decorrentes da cobrança de ISS sobre as tarifas de pedágio, além do impacto indireto de acréscimo do IPTU em médio prazo, decorrente do processo de valorização imobiliária nas áreas próximas ou relativamente próximas às intersecções com acesso.

Além disso, existem impactos positivos que podem ocorrer sobre as fontes de arrecadação municipal, decorrentes da atração de novas atividades, empregos e domicílios nos locais de maior acessibilidade. 


\section{- 12.03 Impactos nos níveis de investimento privado}

A implantação do empreendimento potencializa os investimentos do setor privado nos municípios da AII, notadamente naqueles mais beneficiados pelos ganhos de acessibilidade.

A rodovia propicia melhor equalização da acessibilidade aos eixos radiais interligados permitindo também uma melhor redistribuição espacial de investimentos privados, o que pode trazer benefícios em termos de atratividade industrial e de logística à região.

Entretanto, destacou-se que, de acordo com as análises realizadas no âmbito da Avaliação Ambiental Estratégica, as alterações a serem induzidas pelo empreendimento não tem a intensidade suficiente para reverter ou neutralizar o processo de interiorização industrial que vem ocorrendo no Estado de São Paulo, cuja dinâmica decorre de fatores econômicos e regionais que não serão alterados pelo empreendimento.

\subsection{ESTUDO DE ANÁLISE DE RISCOS (EAR)}

Os estudos de análise de riscos foram realizados como documento base para a elaboração e implementação dos Programas de Gerenciamento de Riscos, tanto para a fase de construção como de operação, de forma a identificar os possíveis acidentes, suas chances de ocorrer (frequências), a severidade de seus impactos (consequências) e, ainda, permitir que seus riscos pudessem ser avaliados, reduzidos e gerenciados.

Os riscos foram analisados em três momentos diferentes: inicialmente no EIA, mapeando as áreas com riscos de escorregamentos e inundações nas áreas de influência do empreendimento e os riscos de vazamentos de produtos perigosos decorrentes de acidentes, visando identificar áreas urbanizadas e densamente ocupadas, os recursos hídricos, especialmente os mananciais de abastecimento público, bem como a existência de áreas protegidas. Posteriormente, foram analisados os riscos durante a construção, considerando os acidentes com potencial de danos ao meio ambiente, às instalações e à segurança dos colaboradores e da comunidade circunvizinha às obras. Por fim, foram analisados os riscos decorrentes da operação da rodovia.

No caso específico do Trecho Sul, por atravessar importantes áreas de mananciais de abastecimento público (represas Billings e Guarapiranga), foi realizado um estudo denominado “Análise de Riscos no Transporte Rodoviário de Produtos Perigosos”, por meio do qual foram avaliados os riscos de afetação da captação em caso de acidente durante a operação, a partir de modelagem e simulação de dispersão da pluma de produtos químicos. Este estudo foi realizado juntamente com o EIA, como requisito para atestar a viabilidade ambiental do empreendimento, bem como subsidiar a concepção de sistema de retenção de produtos perigosos e demais medidas gerenciais. Posteriormente, visando o cumprimento da LI, também foi realizado o Programa de Gerenciamento de Riscos 
(PGR), precedido da Análise de Vulnerabilidade do Rodoanel Sul, estabelecendo os mecanismos gerenciais para o transporte de produtos perigosos durante a operação.

Ademais, a identificação dos perigos, avaliação e classificação dos riscos foi realizada por meio da técnica Análise Preliminar de Perigos (APP). Trata-se de uma técnica estruturada com a finalidade de identificar os perigos existentes numa instalação ou atividade, causados por eventos indesejados, capazes de dar origem a acidentes que possam causar danos à segurança (pessoal e patrimônio) e ao meio ambiente.

A partir da identificação dos perigos foi possível categorizar dois fatores (frequência e severidade do efeito), que determinam o grau de risco associado a um acidente, propiciando, assim, as condições para a avaliação qualitativa dos riscos, a partir da combinação das categorias atribuídas a cada um desses fatores. Em seguida, foram identificadas as causas de cada um dos perigos e as suas respectivas consequências (efeitos), as quais dependem da evolução do acidente após a sua ocorrência.

Por fim, foram definidos as hipóteses acidentais e os respectivos procedimentos de atendimento às situações de emergência. As hipóteses acidentais foram contempladas nos Planos de Ação de Emergências (PAE), que incluíram as diferentes situações emergenciais passíveis de ocorrerem durante a realização das atividades na fase de obras e operacionais.

As hipóteses acidentais identificadas na APP, com potencial de causar danos ao patrimônio, às pessoas e ao meio ambiente foram:

- Hipótese 1: Danos pessoais.

- Hipótese 2: Escorregamento de grandes proporções, com risco de instabilização de encostas com ocupação antrópica.

- Hipótese 3: Escorregamento de grandes proporções com assoreamento de cursos d'água e perda de vegetação fora dos limites autorizados.

- Hipótese 4: Vazamento de produtos perigosos sobre cursos d'água e em áreas urbanas.

- Hipótese 5: Acidentes envolvendo o transporte e uso de explosivos.

- Hipótese 6: Incêndios Florestais.

- Hipótese 7: Contaminação do Ar.

- Hipótese 8: Atropelamento de Animais.

A análise de risco ambiental contou com o mapeamento das áreas com sensibilidade socioambiental, visando identificar as áreas naturalmente mais frágeis, que podem ter sua vulnerabilidade aumentada pelo efeito potencializador da inserção da rodovia no ambiente. Complementarmente, foi realizado análise de vulnerabilidade a acidentes com produtos perigosos. 


\subsection{PLANO BÁSICO AMBIENTAL (PBA)}

Apesar de o EIA propor uma relação de programas socioambientais, o detalhamento final das medidas ocorre no Plano Básico Ambiental - PBA, após o estabelecimento dos condicionantes da Licença Prévia - LP, pela qual pode solicitar programas adicionais aos propostos no EIA como requisito à obtenção da Licença de Instalação - LI. Dessa forma, para fins deste estudo, será apresentada neste a relação das Medidas e dos Programas Socioambientais consolidados no PBA e aprovados pelo órgão licenciador.

A formulação de cada programa obedeceu a critérios operacionais do empreendimento, de modo a permitir a separação das medidas por etapa predominante de implantação (planejamento/pré-construção, construção e operação) e pelos respectivos responsáveis pela execução ou gestão. Além disso, os Programas Ambientais seguiram as diretrizes definidas na Avaliação Ambiental Estratégica - AAE, e foram sendo compatibilizados e atualizados de maneira a incorporar a experiência adquirida nos estudos e obras dos trechos precedentes.

O Apêndice B apresenta os programas e suas respectivas medidas preventivas, mitigadoras ou compensatórias, os quais foram divididas em 3 conjuntos segundo as fases do empreendimento, a saber: o P1 - Programas com Início na Fase Pré-Construtiva, que representa o planejamento detalhado de todo o Sistema de Gestão Ambiental do empreendimento; o P2 - Programas da Fase de Construção, cuja implementação é realizada durante a execução das obras; e o P3 - Programas da Fase de Operação, aplicável durante a operação do empreendimento.

\subsection{MONITORAMENTO DA EXPANSÃO DA MANCHA URBANA}

Ao longo do processo de licenciamento ambiental do Rodoanel Mário Covas levantou-se a necessidade de atender aos questionamentos da sociedade e autoridades ambientais que manifestavam preocupações relativas aos seus impactos em termos locais de indução a alterações na dinâmica urbana e demográfica sobre áreas ambientalmente sensíveis, apesar da concepção do empreendimento ter previsto características técnicas para evitar expansão urbana indesejada - rodovia classe zero e de acesso controlado - e visar a estruturação do tráfego.

Nessa perspectiva, os órgãos licenciadores estipularam a exigência da estruturação de um programa de monitoramento da expansão da mancha urbana e alteração da zona rural (dinâmica demográfica associada a padrões particulares de uso e ocupação do solo), assim como da cobertura vegetal. Para tanto, foi institucionalizado um grupo técnico composto pela Dersa, Fundação Seade, Emplasa, Instituto Florestal e Secretaria de Estado 
de Economia e Planejamento para o desenvolvimento de metodologia de monitoramento e definição das estratégias, que foram reunidos num amplo estudo com sobre a "metodologia para monitoramento da ocupação urbana, cobertura vegetal nativa e dinâmica demográfica da área de influência do Rodoanel Mário Covas", que permitiu acompanhar indícios de mudança de uso e ocupação do solo, pressão demográfica e remoção de cobertura vegetal. Essa metodologia é objeto de apresentação, de forma sucinta, neste item.

O desenvolvimento dessa metodologia de monitoramento constituiu em importante e inédito instrumento de acompanhamento dos eventuais impactos de uma grande obra viária na dinâmica urbana, populacional e da cobertura vegetal em área ambientalmente sensível da maior região metropolitana brasileira, podendo servir de exemplo ou como base para outras iniciativas do gênero.

Conforme exigências do licenciamento ambiental, tal monitoramento deverá ser mantido ao longo de 20 anos, com acompanhamento sistemático dos indicadores definidos, de forma a permitir tomar medidas corretivas e de controle tão logo se identifiquem eventuais pressões indesejáveis na área monitorada, e mensurar os impactos demográficos, urbanísticos e ambientais originários da operação da rodovia.

O objetivo principal do monitoramento é fornecer referências técnicas capazes de subsidiar políticas e ações de mitigação de eventuais impactos não desejáveis gerados pelo Rodoanel Mário Covas, contribuindo com as instituições de planejamento, fiscalização e controle urbano-ambiental ao proporcionar subsídios que balizem tomadas de decisão ou encaminhamento a outras entidades competentes, no sentido de assegurar qualidade ambiental e ocupação ordenada da área de monitoramento.

\subsubsection{Definição das Áreas Monitoradas}

Para o estabelecimento de um sistema de acompanhamento das transformações do uso e ocupação do solo urbano, da cobertura vegetal e da dinâmica demográfica na área a ser monitorada, foi determinado uma Área de Interesse de Monitoramento - AIM, cujo espaço territorial engloba a Área Diretamente Afetada - ADA, a Área de Influência Direta - AID, e os hot spots - áreas prioritárias de interesse de monitoramento - definidos para uso do solo urbano, cobertura vegetal e dinâmica demográfica.

Devido às especificidades do monitoramento, definiu-se que a área a ser monitorada deveria ser a que representa a maior sensibilidade para as alterações no uso do solo urbano, na dinâmica demográfica e na cobertura vegetal, a partir do eixo do Rodoanel. Por exemplo: a AII é muito abrangente, incorporando territórios de ocupação consolidada da Região Metropolitana de São Paulo, o que a torna pouco sensível à percepção de alterações na dinâmica demográfica; já a AID é muito limitada para a observação na alteração do uso do solo urbano e na cobertura vegetal, enquanto a ADA 
restringe-se à via propriamente dita (área insuficiente para todas as dimensões a serem consideradas nas análises). A Área de Interesse de Monitoramento, além dos limites dos municípios e distritos do município de São Paulo, foi dividida em Unidades Territoriais de Estimativa da População - UTs e Parcelas Territoriais, conforme descrição a seguir.

a) Definição das Unidades Territoriais (UTs): são áreas que correspondem às agregações de setores censitários (A unidade mínima de informação para o sistema de referência de pesquisas domiciliares do IBGE). Esse procedimento visa obter pequenas áreas para estimação de população por meio de metodologia específica. As UTs caracterizam-se por serem homogêneas do ponto de vista socioeconômico / censitários, sobre os quais são levantados indicadores demográficos. A divisão do município nessas pequenas áreas foi feita por meio da metodologia de análise estatística espacial conhecida como "Árvore Geradora Mínima".

b) Definição da Parcelas Territoriais (PTs) de Quantificação dos Dados de Uso do Solo e Cobertura Vegetal: A partir das Unidades Territoriais (UTs) foram construídas as Parcelas Territoriais (PTs), que correspondem à segmentação das UTs a cada faixa de distância fixa a partir do eixo do Rodoanel. Como são construídas a partir dos setores censitários, as parcelas respeitam os limites dos distritos e monitoramento do uso do solo dos municípios da AIM.

c) Hot spots : Os hot spots são áreas prioritárias de monitoramento onde deverão ser levantadas informações censitárias diretas por meio de pesquisa de campo. Estes pontos compartilham entre si a qualidade de serem indicadores mais sensíveis a mudanças socioambientais. Além disso, todos eles originam-se do cruzamento de dados sócio territoriais de uma matriz de critérios, que se constitui no banco de dados relacionados a um sistema de georreferenciamento. Por intermédio desse instrumento, além de ser possível descobrir as áreas mais sensíveis e, portanto, prioritárias para o monitoramento (os hot spots), é possível também estabelecer os parâmetros quantitativos iniciais, como medida de controle das eventuais alterações, ou seja, a linha de base do estudo.

\subsubsection{Metodologia de Monitoramento das Áreas de Interesses}

O monitoramento abrange o uso do solo, a cobertura vegetal e a dinâmica demográfica, que possuem procedimentos metodológicos distintos, apresentados nos subitens a seguir. A metodologia de monitoramento partiu da composição de uma matriz com um conjunto de variáveis próprias para cada um desses três temas, cuja função foi inicialmente identificar os hot spots e posteriormente estabelecer os parâmetros quantitativos iniciais, como medida de controle das eventuais alterações.

A matriz de critérios para identificação de hot spot foi elaborada para classificar os elementos considerados indutores ou restritivos à ocupação urbana na AIM. Para tanto, 
foram selecionados um conjunto de indicadores a serem medidos na área de monitoramento, que são utilizados como parâmetros quantitativos responsáveis pelo monitoramento na área de abrangência e compõe as matrizes de critérios e avaliação.

\section{a) Metodologia de Monitoramento do Uso do Solo Urbano}

A composição da matriz de uso do solo se consolidou em quatro grupos de elementos com as seguintes funções:

- revelar a dinâmica da ocupação;

- conhecer as restrições de regulação às quais o território está sujeito a partir dos instrumentos urbanísticos definidos nos Planos Diretores municipais;

- definir e identificar os grandes equipamentos urbanos geradores de tráfego e fluxo de pessoas;

- avaliar a mobilidade a partir da estruturação da rede viária, acesso e cruzamentos existentes em relação à existência do Rodoanel.

A matriz de critérios para identificação de hot spots de uso do solo foi elaborada para classificar os elementos que induzem ou restringem a ocupação urbana nas áreas de influência do Rodoanel.

Foram considerados elementos indutores de ocupação:

- áreas com ocupação urbana incipiente com possibilidade de expansão e adensamento;

- instrumentos urbanísticos - Zona Especial de Interesse Social (Zeis) e Operação Urbana;

- infraestrutura e equipamentos de transportes (viário local/ terminal de trem e de ônibus);

- grandes equipamentos (com indução de aumento de tráfego / aumento de população).

Foram considerados elementos restritivos à ocupação urbana:

- ocupação urbana consolidada;

- instrumentos urbanísticos - Zona Especial de Interesse Ambiental (Zeia) e Operação Urbana;

- ausência de acesso viário e transporte (vias locais / estradas vicinais / terminais de ônibus e de trem).

As variáveis que integram a matriz de definição dos hot spots são consideradas elementos de monitoria por constituírem itens de impacto sobre a transformação do território, com relação às alterações de uso e ocupação do solo. A matriz foi composta por quatro grupos de elementos fundamentais, conforme a seguir:

1. Uso do solo: recurso utilizado para identificar as transformações urbanas quanto ao uso e ocupação do solo mapeado a partir de informações obtidas pelas imagens de satélite. Esse grupo foi subdividido em: a) área não ocupada; 
b) área em ocupação; c) parque (urbano e unidade de conservação); d) precário (favelas e assentamento de baixa renda); e) residencial (classe residencial e mista).

2. Instrumentos urbanísticos: recurso utilizado para identificar intervenções urbanísticas previstas nos planos diretores capazes de adensar a ocupação ou promover melhorias ao implementar seus instrumentos urbanísticos. Incluem as Zonas Especiais de Interesse Social - Zeis, Zonas Especiais de Interesse Ambiental - Zeias e Operações Urbanas.

3. Equipamentos de pressão demográfica e de tráfego (Grandes Equipamentos): Recurso utilizado para identificar aumento de circulação de pessoas, automóveis e caminhões, que gera pressões demográfica e de tráfego (gerador de população; polo gerador de tráfego e polo gerador de população e tráfego.

4. Mobilidade (Sistema Viário e Transporte): Este é um recurso utilizado para: calcular a distância a ser percorrida das UTs aos acessos e aos cruzamentos (em desnível) do Rodoanel com vias importantes para a circulação na AIM; identificar as facilidades de acesso pela presença de terminais de ônibus metropolitano e de trem; calcular a densidade do sistema viário existente conforme sua hierarquia (macrometropolitano, metropolitano, estrutural urbano e vicinal). Constituem o grupo: terminais de ônibus; acessos; sistema viário metropolitano e macrometropolitano; viário local; etc.

Todas as parcelas da AIM foram classificadas em grupos homogêneos. A partir de um conjunto de dados sobre a estrutura urbana extraído do mapeamento do uso e ocupação do solo, foram calculados indicadores. Esse conjunto de dados de cada parcela corresponde ao marco inicial da situação na AIM e esses parâmetros são utilizados posteriormente para monitoramento do Rodoanel quanto ao uso do solo. A cada atualização das informações, as parcelas são avaliadas e comparadas em relação à sua situação anterior (inclusive as parcelas hot spots).

A partir dessas variáveis, são identificadas as áreas de maior pressão de transformação do uso do solo (hot spot), que exigem mais atenção do monitoramento. Como formas de acompanhamento do uso do solo, as checagens de alteração poderão ser feitas acompanhando-se os hot spots e, para o restante da Área de Interesse do Monitoramento (AIM), nos intervalos definidos no cronograma de monitoria.

O monitoramento do uso do solo está vinculado à atualização do mapeamento do uso do solo urbano que por sua vez depende da aquisição de imagens orbitais. Para o restante da AIM, a evolução da expansão urbana formal poderá ser monitorada pelos pedidos de aprovação de empreendimentos residenciais, pelo GRAPROHAB, e não residenciais, pelo Conselho Estadual do Meio Ambiente (CONSEMA). Também são acompanhadas as anuências prévias de aprovação e emissão de alvarás pelas prefeituras que se inserem na Área de Interesse de Monitoramento (AIM). Além disso, vale-se, no tocante aos indícios de alteração da ocupação, do levantamento de campo da Pesquisa de Emprego e Desemprego (PED), da Fundação Seade. Pode-se ainda acompanhar Diário 
Oficial do Município, que publica as aprovações dos planos aprovados por lei; consultar os órgãos municipais competentes e mesmo os orçamentos anuais para identificar possíveis decisões de investimento; licenciamentos prévios e de operação da CETESB/CONSEMA, bem como dos licenciamentos municipais; quanto à mobilidade, a monitoria dos investimentos em transporte e sistema viário é feita a partir do acompanhamento dos programas e projeto de investimentos prioritários previstos no Plano Plurianual (PPA), uma vez que se trata de investimentos realizados pelo setor público (Empresa Metropolitana de Transportes Urbanos - EMTU, Companhia Paulista de Trens Metropolitanos - CPTM - e Companhia do Metropolitano de São Paulo Metrô).

\section{b) Metodologia de Monitoramento da Valorização e Desvalorização Imobiliária}

No que tange ao monitoramento da valorização e desvalorização imobiliária, foi desenvolvida uma pesquisa pela Emplasa afim de identificar órgãos produtores dessas informações, a estrutura de bases de dados organizadas e o acesso a elas, buscando encontrar alternativas para medição da valorização e propor o desenvolvimento de um indicador capaz de estimar o impacto da construção do Rodoanel na valorização/desvalorização do preço dos imóveis.

Um Parecer Técnico sobre o Impacto da construção do Rodoanel no preço dos imóveis realizado por expert na área de avaliação imobiliária, Andreina Nigriello, que é professora universitária na COPPE/UFRJ e FAU/USP, concluiu-se que:

- Os efeitos do Rodoanel no mercado imobiliário não podem ser medidos de forma isolada;

- Um indicador dos efeitos do Rodoanel, em conjunto com outras melhorias que ampliaram o padrão de urbanização da RMSP, é a mudança no uso e ocupação do solo resultante da ação do mercado imobiliário para a apropriação das vantagens de redução nos custos de circulação de pessoas e mercadorias que a nova via passou a oferecer.

Portanto, no trabalho elaborado pela Emplasa, na área de estudo adotada para avaliar os efeitos do Rodoanel, os perímetros que se destacam por alterações no uso e ocupação do solo também podem ser indicativos de áreas em que houve alteração no preço dos imóveis. Tais alterações podem ser atribuídas não apenas à presença do Rodoanel, mas a uma conjunção de fatores, como por exemplo a dinâmica do mercado imobiliário local e as restrições legais sobre o uso e ocupação do solo".

\section{c) Metodologia de Monitoramento da Dinâmica Demográfica}

Foram considerados três recortes espaciais para o monitoramento da dinâmica demográfica: a Área de Interesse de Monitoramento (AIM), os hot spots e as unidades territoriais específicas (UTs), explicadas anteriormente.

Para o monitoramento da dinâmica demográfica, foram identificados os setores censitários prioritários vinculados às parcelas territoriais a elas correspondentes. A decisão pelo uso dos setores censitários como a unidade a ser monitorada deve-se ao fato 
de estes serem as menores unidades de coleta de informações demográficas e, portanto, constituírem-se em banco de dados básicos para o monitoramento.

A experiência vivenciada pelos técnicos da Fundação Seade, responsável pelo monitoramento demográfico, mostrou que a solução adotada de usar os setores censitários como definidores dos hot spots não se mostrou eficiente nas porções mais periféricas, sobretudo naquelas compostas por favelas e loteamentos irregulares. Diferentemente das áreas mais consolidadas da cidade, nas periferias urbanas ocorre um duplo problema: a imprecisão de seus limites, uma vez que nessas áreas não existem muitos marcos espaciais definidos (feições urbanas - logradouro, córregos, etc.) ou, se existem, são confusos e pouco precisos, como no caso das favelas; e o difícil acesso a determinados locais, devido o tamanho das áreas e suas vias precárias.

A metodologia de definição dos hot spots (áreas que serão objeto de monitoramento da dinâmica demográfica) fundamentou-se nos seguintes passos:

- Identificação das Unidades Territoriais classificadas como vulneráveis (grupos 4, 5 e 6 do IPVS) e que possuem mais de 30\% de sua área com favelas ou assentamento precário;

- Identificação dos setores censitários que pertencem a essas UTs selecionadas;

- Classificação desses setores censitários segundo o uso do solo urbano da Emplasa;

- Cálculo da taxa de crescimento populacional anual desses setores censitários;

- Seleção dos setores censitários que apresentaram essa taxa igual ou superior a cinco vezes à da RMSP e que foram classificados como: Assentamento precário; Favelas; Áreas em ocupação.

A partir desses setores censitários foram selecionados aqueles que se localizam dentro da faixa de 1,0 km do eixo da rodovia; definidos os limites dos hot spots a partir da análise de imagens orbitais, segundo as feições urbanas.

O Quadro 14 a seguir apresenta as variáveis da dinâmica demográfica e a descrição, bem como as unidades de territorial de monitoramento, periodicidade, informações e fonte para cada variável do monitoramento. Esse conjunto de indicadores permite avaliar o crescimento populacional (ou decréscimo) de forma direta, como é o caso da taxa de crescimento populacional e do número de domicílios, e de forma indireta, caso do crescimento vegetativo. 
Quadro 14 - Variáveis, Unidades e Periodicidade do Monitoramento da Dinâmica Demográfica.

\begin{tabular}{|c|c|c|c|c|c|}
\hline Variáveis & Descrições & $\begin{array}{l}\text { Unidades de } \\
\text { monitoramento }\end{array}$ & Periodicidade & Informação & Fonte \\
\hline $\begin{array}{l}\text { Taxa de } \\
\text { crescimento } \\
\text { vegetativo } \\
\text { anual da } \\
\text { população }\end{array}$ & $\begin{array}{l}\text { Diferença entre o número de } \\
\text { nascimentos e óbitos, registrados } \\
\text { em um ano, segundo a residência } \\
\text { da ocorrência. Esse indicador } \\
\text { apresenta boa qualidade no nível } \\
\text { territorial das UTs e razoável } \\
\text { qualidade no nível de setores } \\
\text { censitários (hot spots). }\end{array}$ & UTs e Hot Spots & Anual & Registro Civil & SEADE \\
\hline $\begin{array}{c}\text { Taxa de } \\
\text { crescimento } \\
\text { da população } \\
\text { total }\end{array}$ & $\begin{array}{l}\text { Variação de população em uma UT } \\
\text { de um ano para outro. O cálculo é } \\
\text { feito pela estimava anual da } \\
\text { população para cada UT. As } \\
\text { estimativas são obtidas por meio de } \\
\text { modelos estatísticos, utilizando } \\
\text { dados de ligações de luz e água, } \\
\text { consumo de água e registros de } \\
\text { nascimentos e óbitos. Esse } \\
\text { indicador não pode ser calculado ao } \\
\text { nível de setores censitários, exceto } \\
\text { para comparação de anos de censos } \\
\text { (caso da seleção dos hot spots). }\end{array}$ & UTs & Anual & $\begin{array}{l}\text { Censos, } \\
\text { registros } \\
\text { administrativos } \\
\text { (estimação por } \\
\text { metodologia de } \\
\text { pequenas áreas) }\end{array}$ & $\begin{array}{c}\text { IBGE, } \\
\text { AES, } \\
\text { SEADE }\end{array}$ \\
\hline $\begin{array}{l}\text { Número de } \\
\text { residências }\end{array}$ & $\begin{array}{l}\text { Semestralmente as residências de } \\
\text { todos os setores censitários } \\
\text { identificados como hot spots serão } \\
\text { contados, buscando identificar } \\
\text { possíveis aumentos de população. }\end{array}$ & Hot spots & Semestral & $\begin{array}{l}\text { Pesquisa de } \\
\text { campo }\end{array}$ & SEADE \\
\hline $\begin{array}{c}\text { Área } \\
\text { ocupada } \\
\text { residencial }\end{array}$ & $\begin{array}{l}\text { Por meio de imagens de satélites e } \\
\text { modelos de reconhecimento de } \\
\text { ocupação do solo, são identificados } \\
\text { hot spots que apresentarem grande } \\
\text { diferença de ocupação não- } \\
\text { residencial para residencial. Esse } \\
\text { tipo de indicador não permite o } \\
\text { monitoramento ao nível de hot } \\
\text { spots. }\end{array}$ & Hot spots & Anual & $\begin{array}{l}\text { Imagens de } \\
\text { satélite, } \\
\text { registros } \\
\text { administrativos, } \\
\text { censos }\end{array}$ & $\begin{array}{l}\text { IBGE, } \\
\text { SEADE, } \\
\text { INPE }\end{array}$ \\
\hline
\end{tabular}

Fonte: Adaptado de DERSA/SEADE.

As quantidades estimadas para os hot spots e UTs são avaliadas e comparadas aos mesmos indicadores referentes à RMSP, à média observada para toda a AIM e a uma área de controle (a ser escolhida). Essa comparação permite a identificação de padrões atípicos de comportamento demográfico em UTs (possível ocorrência de novos hot spots) e hot spots.

\section{d) Metodologia de Monitoramento da Cobertura Vegetal Nativa}

O mapeamento da cobertura vegetal nativa foi realizado a partir da fotointerpretação das ortofotos, na escala de 1:25.000. A legenda utilizada para classificação das formações vegetais baseou-se nas proposições do Projeto RADAMBRASIL, de acordo com as unidades fisionômico ecológicas da cobertura vegetal nativa, apoiada pela Resolução $n^{\circ} 10$, de $1^{\circ}$ de outubro de 1993, que estabelece os parâmetros básicos para análise dos estágios de sucessão de Mata Atlântica. 
Para subsidiar a definição dos hot spots de vegetação nativa foi realizada uma análise de sua distribuição na Área de Interesse de Monitoramento - AIM ao longo do eixo da rodovia. A seleção dos hot spots de vegetação nativa foi realizada a partir da análise de variáveis ambientais que representam a distribuição e o estado de conservação da cobertura vegetal, sua relação com cursos d'água e nascentes, bem como a presença de fatores impactantes no uso do solo ao seu redor.

Dessa maneira, foi elaborada uma matriz com indicadores utilizados, atribuindose, aos mesmos, pesos, de acordo com sua importância relativa. Os intervalos foram definidos com base no monitoramento realizado, mas podem ser ajustados em função do resultado esperado na região de interesse.

Tabela 2 - Matriz de critérios de avaliação da cobertura vegetal nativa.

\begin{tabular}{|c|c|c|c|c|c|c|}
\hline Índices & $\begin{array}{c}\text { Unidade } \\
\text { de } \\
\text { Medida }\end{array}$ & Descrição & $\begin{array}{l}\text { Método de } \\
\text { Cálculo }\end{array}$ & \multicolumn{2}{|c|}{$\begin{array}{l}\text { Número / } \\
\text { Intervalo }\end{array}$} & Nota \\
\hline \multirow{6}{*}{ Fisionomias } & \multirow{6}{*}{ Unidade } & \multirow{6}{*}{$\begin{array}{l}\text { Uma maior diversidade de fisionomias } \\
\text { resulta em oferta de habitat e alimentos } \\
\text { mais diversificados para a fauna. Essa } \\
\text { variável possui correlação com a riqueza } \\
\text { de espécies, de modo que é considerada } \\
\text { um forte atributo para melhor representar a } \\
\text { biodiversidade. }\end{array}$} & \multirow{6}{*}{$\begin{array}{l}\mathrm{N}^{\mathrm{o}} \text { de unidades } \\
\text { vegetacionais por } \\
\text { parcela territorial. }\end{array}$} & \multicolumn{2}{|c|}{ número } & nota \\
\hline & & & & 1 & & 1 \\
\hline & & & & 2 & & 2 \\
\hline & & & & 3 & & 3 \\
\hline & & & & 4 & & 4 \\
\hline & & & & $>5$ & & 5 \\
\hline \multirow{6}{*}{ Hidrografia } & \multirow{6}{*}{$\mathrm{m}^{-1}$} & \multirow{6}{*}{$\begin{array}{l}\text { A presença de corpos d'água aumenta a } \\
\text { diversidade de habitats e possibilita a } \\
\text { permanência de maior diversidade } \\
\text { biológica, consideraram-se prioritárias } \\
\text { áreas que protejam maior extensão de } \\
\text { cursos d'água. }\end{array}$} & \multirow{6}{*}{$\begin{array}{l}\text { Extensão total dos } \\
\text { cursos d'água (m) } \\
\text { / área da parcela } \\
\text { territorial (ha) }\end{array}$} & de & $\mathbf{a}$ & nota \\
\hline & & & & 0,0000 & 0,0010 & 1 \\
\hline & & & & 0,0010 & 0,0020 & 2 \\
\hline & & & & 0,0020 & 0,0030 & 3 \\
\hline & & & & 0,0030 & 0,0050 & 4 \\
\hline & & & & $>0,0050$ & & 5 \\
\hline \multirow{6}{*}{ Nascentes } & \multirow{6}{*}{ Unidade } & \multirow{6}{*}{$\begin{array}{l}\text { Esta variável está diretamente } \\
\text { correlacionada com o índice de drenagem. } \\
\text { Considerando que a integridade dos } \\
\text { recursos hídricos e da fauna que deles } \\
\text { depende só pode ser assegurada se as } \\
\text { nascentes estiverem protegidas, foram } \\
\text { priorizadas áreas que protegem nascentes. }\end{array}$} & \multirow{6}{*}{$\begin{array}{c}\mathrm{N}^{\circ} \text { total de nascentes } \\
\text { por parcela } \\
\text { territorial }\end{array}$} & de & $\mathbf{a}$ & nota \\
\hline & & & & 0 & 10 & 1 \\
\hline & & & & 10 & 20 & 2 \\
\hline & & & & 20 & 50 & 3 \\
\hline & & & & 50 & 100 & 4 \\
\hline & & & & $>100$ & & 5 \\
\hline \multirow{6}{*}{$\begin{array}{l}\text { APP de rios, corpos } \\
\text { d'água e nascentes }\end{array}$} & \multirow{6}{*}{$\%$} & \multirow{6}{*}{$\begin{array}{l}\text { Baseado nas resoluções Conama n } \\
302 / 2002 \text { e no } \text { n }^{\circ} 03 / 2002 \text {, que dispõem } \\
\text { sobre parâmetros, definições e limites de } \\
\text { APPs de cursos e corpos d'água e } \\
\text { nascentes, foram geradas as APPs para } \\
\text { cada parcela. }\end{array}$} & \multirow{6}{*}{$\begin{array}{c}\text { Áreas de APP } \\
\text { de rios, corpos } \\
\text { d'água e nascentes } \\
\text { (ha) / área da parcela } \\
\text { territorial (ha) * } 100\end{array}$} & de & $\mathbf{a}$ & nota \\
\hline & & & & 0 & 20 & 1 \\
\hline & & & & 20 & 40 & 2 \\
\hline & & & & 40 & 60 & 3 \\
\hline & & & & 60 & 80 & 4 \\
\hline & & & & 80 & 100 & 5 \\
\hline \multirow{6}{*}{$\begin{array}{c}\text { Cobertura vegetal } \\
\text { nativa em APP de } \\
\text { rios, corpos d'água e } \\
\text { nascentes }\end{array}$} & \multirow{6}{*}{$\%$} & \multirow{6}{*}{$\begin{array}{l}\text { Além de avaliar a quantidade de APP } \\
\text { presente na parcela, avaliou-se também a } \\
\text { sua ocupação, levando em conta a } \\
\text { quantidade de cobertura vegetal nativa } \\
\text { presente na mesma. Esta variável é um } \\
\text { forte indicador de qualidade ambiental. }\end{array}$} & \multirow{6}{*}{$\begin{array}{l}\text { Cobertura vegetal } \\
\text { nativa em APP de } \\
\text { rios, corpos d'água e } \\
\text { nascentes (ha) da } \\
\text { parcela / área da } \\
\text { parcela territorial } \\
\text { (ha) } * 100 \\
\end{array}$} & de & $\mathbf{a}$ & nota \\
\hline & & & & 0 & 20 & 1 \\
\hline & & & & 20 & 40 & 2 \\
\hline & & & & 40 & 60 & 3 \\
\hline & & & & 60 & 80 & 4 \\
\hline & & & & 80 & 100 & 5 \\
\hline \multirow{6}{*}{$\begin{array}{c}\text { Cobertura vegetal } \\
\text { nativa }\end{array}$} & \multirow{6}{*}{$\%$} & & & de & $\mathbf{a}$ & nota \\
\hline & & & Cobertura vegetal & 0 & 20 & 1 \\
\hline & & occuada por todas as categorias de & nativa (ha) / área & 20 & 40 & 2 \\
\hline & & $\begin{array}{l}\text { ocupada por todas as categorlas de } \\
\text { vegetacão nativa existente na parcela. }\end{array}$ & da parcela territorial & 40 & 60 & 3 \\
\hline & & & (ha) $* 100$ & 60 & 80 & 4 \\
\hline & & & & 80 & 100 & 5 \\
\hline & & & & de & $\mathbf{a}$ & nota \\
\hline $\begin{array}{l}\text { Conectividade entre } \\
\text { fragmentos de }\end{array}$ & & $\begin{array}{l}\text { Total de fragmentos de vegetação nativa } \\
\text { conectados a determinadas distâncias na }\end{array}$ & $\begin{array}{l}\text { Nümero de } \\
\text { fragmentos }\end{array}$ & 2 & 10 & 1 \\
\hline vegetacão nativa a & Unidade & unidade territorial, reconhecendo que a & $\begin{array}{l}\text { Iragmentos } \\
\text { conectados a }\end{array}$ & 11 & 100 & 2 \\
\hline distâncias de 50m, & & conectividade é importante para aumentar & distâncias de 50m, & 101 & 1000 & 3 \\
\hline $100 \mathrm{~m}$ e $200 \mathrm{~m}$ & & os corredores ecológicos. & $100 \mathrm{~m}$ e $200 \mathrm{~m}$ & 1.001 & 10.000 & 4 \\
\hline & & & & $>10.000$ & & 5 \\
\hline
\end{tabular}




\begin{tabular}{|c|c|c|c|c|c|c|}
\hline Índices & $\begin{array}{l}\text { Unidade } \\
\text { de } \\
\text { Medida }\end{array}$ & Descrição & $\begin{array}{l}\text { Método de } \\
\text { Cálculo }\end{array}$ & \multicolumn{2}{|c|}{$\begin{array}{l}\text { Número / } \\
\text { Intervalo }\end{array}$} & Nota \\
\hline \multirow{6}{*}{$\begin{array}{c}\text { Estado de } \\
\text { conservação da } \\
\text { vegetação nativa }\end{array}$} & \multirow{6}{*}{$\%$} & \multirow{6}{*}{$\begin{array}{l}\text { Fatores de degradação ambiental, como } \\
\text { fogo, desmatamento e exploração seletiva, } \\
\text { conduzem à perda de diversidade } \\
\text { biológica. Por isso, considerou-se nesta } \\
\text { variável a proporção de áreas ocupadas } \\
\text { por vegetação secundária em estágio } \\
\text { avançado ou bem próxima de seu estado } \\
\text { original. Esse critério atende a uma das } \\
\text { mais importantes metas da conservação, } \\
\text { que é a persistência da diversidade. }\end{array}$} & \multirow{6}{*}{$\begin{array}{c}\text { Área de vegetação } \\
\text { nativa em melhor } \\
\text { estado de } \\
\text { conservação da } \\
\text { parcela (ha) / área da } \\
\text { parcela (ha). }\end{array}$} & de & $\mathbf{a}$ & nota \\
\hline & & & & 0 & 20 & 5 \\
\hline & & & & 20 & 40 & 4 \\
\hline & & & & 40 & 60 & 3 \\
\hline & & & & 60 & 80 & 2 \\
\hline & & & & 80 & 100 & 1 \\
\hline \multirow{6}{*}{$\begin{array}{l}\text { Uso do solo } \\
\text { impactante }\end{array}$} & \multirow{6}{*}{$\%$} & \multirow{6}{*}{$\begin{array}{l}\text { A vulnerabilidade do ecossistema depende } \\
\text { dos efeitos de borda e dos riscos de } \\
\text { desastres em função do uso das terras na } \\
\text { vizinhança. Dessa forma, consideraram-se } \\
\text { nesta variável os usos do solo nas áreas de } \\
\text { entorno de vegetação nativa, ocupadas por } \\
\text { atividades que oferecem maior ameaça aos } \\
\text { recursos naturais, como áreas residenciais, } \\
\text { industriais, infraestrutura de transportes, } \\
\text { mineração, empreendimentos comercias } \\
\text { de grande porte. }\end{array}$} & \multirow{6}{*}{$\begin{array}{l}\text { Área total dos usos } \\
\text { do solo de maior } \\
\text { impacto da parcela } \\
\text { (ha) / área da parcela } \\
\text { (ha) } * 100 .\end{array}$} & de & $\mathbf{a}$ & nota \\
\hline & & & & 0 & 20 & 5 \\
\hline & & & & 20 & 40 & 4 \\
\hline & & & & 40 & 60 & 3 \\
\hline & & & & 60 & 80 & 2 \\
\hline & & & & 80 & 100 & 1 \\
\hline \multirow{6}{*}{$\begin{array}{l}\text { Unidade de } \\
\text { conservação de } \\
\text { proteção integral e } \\
\text { de uso sustentável }\end{array}$} & \multirow{6}{*}{$\%$} & \multirow{6}{*}{$\begin{array}{l}\text { A presença de unidades de conservação } \\
\text { nas parcelas é um indicador fortemente } \\
\text { positivo para a integridade da vegetação } \\
\text { nativa e biodiversidade. }\end{array}$} & \multirow{6}{*}{$\begin{array}{l}\text { Área da Unidade de } \\
\text { conservação na } \\
\text { parcela (hectares) / } \\
\text { área da parcela } \\
\text { territorial (hectares) } \\
* 100\end{array}$} & de & $\mathbf{a}$ & nota \\
\hline & & & & 0 & 20 & 1 \\
\hline & & & & 20 & 40 & 2 \\
\hline & & & & 40 & 60 & 3 \\
\hline & & & & 60 & 80 & 4 \\
\hline & & & & 80 & 100 & 5 \\
\hline \multirow{6}{*}{$\begin{array}{l}\text { Zona de } \\
\text { amortecimento de } \\
\text { unidade de } \\
\text { conservação de } \\
\text { proteção integral }\end{array}$} & \multirow{6}{*}{$\%$} & \multirow{6}{*}{$\begin{array}{l}\text { Porcentagem da área da parcela territorial } \\
\text { ocupada por zona de amortecimento de } \\
\text { unidade de conservação de proteção } \\
\text { integral. }\end{array}$} & \multirow{6}{*}{$\begin{array}{l}\text { Zona de } \\
\text { amortecimento (ha) / } \\
\text { área da parcela } \\
\text { territorial (ha) } * 100\end{array}$} & de & $\mathbf{a}$ & nota \\
\hline & & & & 0 & 5 & 1 \\
\hline & & & & 5,1 & 10 & 2 \\
\hline & & & & 10,1 & 20 & 3 \\
\hline & & & & 20,1 & 50 & 4 \\
\hline & & & & 50,1 & 100 & 5 \\
\hline
\end{tabular}

Fonte: Adaptado de DERSA/SEADE.

Inicialmente, esta matriz é aplicada em todas as parcelas territoriais, atribuindose as respectivas notas para cada variável. Em seguida, as parcelas territoriais são agrupadas e atribuídos pesos para cada parcela, considerando a distância para o Rodoanel.

O acompanhamento das alterações da cobertura vegetal nativa é realizado por meio de imagens orbitais ou ortofotos e com trabalhos de campo. As principais variáveis avaliadas são a evolução da área de vegetação nativa, seu estado de conservação e evolução e as modificações do uso do solo no entorno dos fragmentos de vegetação.

\subsection{SISTEMA DE AVALIAÇÃO DE SUSTENTABILIDADE: ENVISION}

O Trecho Norte do Rodoanel passou por um processo de avaliação de estudo de caso, utilizando o sistema de classificação Envision. O Envision é um sistema de classificação para infraestrutura sustentável, que foi desenvolvido pelo Instituto de Infraestrutura Sustentável (ISI), em parceria com o Zofnass Program for Sustainable Infrastructure, da Universidade de Harvard. O ISI foi fundado pelo Conselho Americano 
de Empresas de Engenharia (ACEC), a American Public Works Association (APWA), e pela Sociedade Americana de Engenheiros Civis (ASCE).

O escopo desse estudo de caso foi apoiar a implementação da Estratégia de Infraestrutura Sustentável do BID (Banco Interamericano de Desenvolvimento), desenvolvido em dezembro de 2013, aprendendo lições de sustentabilidade de projetos de infraestrutura que foram desenvolvidos com o financiamento do Banco. Uma equipe de pesquisadores de Harvard, com o fornecimento de dados e informações de funcionários e consultores da DERSA, aplicou a metodologia de avaliação Envision para avaliar o Trecho Norte do Rodoanel, visando extrair lições aprendidas para a infraestrutura sustentável com esse estudo de caso e fornecer recomendações para melhorar a aplicabilidade da metodologia.

O estudo demonstrou as realizações do projeto e a gama de valores que poderiam ser manifestados por políticas e ações sólidas de sustentabilidade. Além disso, as principais conclusões foram resumidas em um relatório de síntese, o qual foi apresentado na reunião anual da International Association for Impact Assessment (IAIA) no Panamá.

O sistema de classificação Envision é uma ferramenta de avaliação e orientação de empreendimentos para projeto de infraestrutura sustentável, que abrange todas as fases do ciclo de vida de um empreendimento: planejamento, projeto, construção, operação e demolição. O sistema se aplica a todos os tipos e tamanhos de projetos de infraestrutura civil, tais como estradas, pontes, gasodutos, ferrovias, aeroportos, barragens, diques, aterros, sistemas de tratamento de água, e outros. Esse sistema não foi concebido para avaliar edifícios destinados exclusivamente à ocupação humana, tais como hospitais, escolas, escritórios ou residências. Embora inicialmente desenvolvido para os Estados Unidos e Canadá, o Envision pode ser aplicado em outros locais.

A Envision tem 60 critérios de sustentabilidade (chamados "créditos") organizados em cinco categorias:

1. Qualidade de Vida: concentra-se em como os projetos de infraestrutura interagem com a comunidade local, e como eles afetam a saúde e a segurança das populações, criam empregos significativos e respeitam os valores e tradições locais. Os membros da comunidade afetados pelo projeto são considerados partes interessadas importantes no processo de tomada de decisão. A categoria é dividida em três subcategorias: Propósito, Bem-Estar e Comunidade.

2. Liderança: enfatiza a governança de projetos eficaz, equitativa e transparente, fornecendo um conjunto claro de critérios para gestão, colaboração e sistemas organizacionais para planejamento de longo prazo. Esta categoria é dividida nas três subcategorias de colaboração, gerenciamento e planejamento.

3. Alocação de Recursos: lida com os materiais e recursos consumidos pela infraestrutura (durante a construção e as operações). Essa categoria está amplamente preocupada com a quantidade, a origem e as características desses recursos e seus impactos na sustentabilidade geral do projeto. Os recursos 
abordados incluem materiais físicos (tanto aqueles que são consumidos e que saem do projeto), energia e uso da água. Materiais, energia e água compõem as três subcategorias de alocação de recursos.

4. Mundo Natural: aborda os impactos que um projeto de infraestrutura tem sobre o meio ambiente, avaliando os efeitos sobre a biodiversidade e recursos naturais devido à seleção de locais, escolhas de projeto e práticas de construção, bem como procedimentos operacionais. Esses tipos de interações e impactos foram divididos em três subcategorias: Localização, Terra e Água e Biodiversidade.

5. Clima e Riscos: se concentra em dois conceitos principais: minimizar as emissões que podem contribuir para aumentar os riscos de curto e longo prazo e garantir que os projetos de infraestrutura sejam resilientes aos perigos de curto prazo ou possam se adaptar às condições futuras de longo prazo. A categoria Clima e Risco é dividida em duas subcategorias: Emissões e Resiliência.

O Apêndice $\mathbf{C}$ apresenta os critérios, indicadores e métricas utilizadas no estudo de caso do Trecho Norte do Rodoanel aplicado por pesquisadores de Harvard.

Cada crédito refere-se a um indicador específico de sustentabilidade. Esses créditos são classificados em uma escala de cinco pontos chamada de "nível de realização": "melhorado", "aprimorado", "superior", "conservador" e "restaurativo". Os critérios de avaliação são fornecidos para determinar se as qualificações para cada nível de realização foram cumpridas para um determinado crédito. Em cada uma dessas cinco categorias, há um crédito especial chamado "Inovar ou exceder os requisitos de crédito", que consiste na oportunidade de premiar o desempenho excepcional que aplica métodos inovadores dentro dos assuntos avaliados pelo Envision.

O nível "melhorado" de conquista é concedido para um desempenho que excede os requisitos regulatórios. Os níveis "aprimorado" e "superior" indicam melhorias graduais adicionais, enquanto que "conservador" geralmente indica desempenho que alcança um impacto nulo ou neutro. "Restaurativo" é o nível mais alto e é normalmente reservado para projetos que produzem um impacto positivo líquido geral. O sistema Envision pesa o valor relativo de cada crédito e nível de realização, atribuindo pontos. Os critérios de crédito estão documentados no Envision Guidance Manual, disponível para o público nos sítios do ISI (http://www.sustainableinfrastructure.org) e do Zofnass Program (http://www.zofnass.org).

As classificações de sustentabilidade são estabelecidas por meio de uma avaliação de desempenho que concede pontos para os cinco níveis de realização dentro de cada crédito, além dos pontos adicionais para desempenho inovador. Os projetos que aplicam o Envision e optam por uma revisão independente de terceiros do ISI (chamada "Verificação") podem ser qualificados para prêmios. Os níveis de classificação atribuídos estão fixados em 20\% (Bronze), 30\% (Prata), 40\% (Ouro) e 50\% (Platina).

Por meio de respostas a questionários, com o envolvimento de cerca de 40 profissionais, o projeto do Trecho Norte do Rodoanel recebeu a Medalha de Ouro. 


\section{CAPÍTULO 4 - ESTRUTURA DE AVALIAÇÃO DE DESEMPENHO DE SUSTENTABILIDADE}

Como resultado da pesquisa, foi proposta uma estrutura para avaliação de desempenho da sustentabilidade, considerando as interfaces urbano-rodoviárias, com base nos dados obtidos em ferramentas de avaliação de sustentabilidade aplicadas no planejamento do setor de transporte e no estudo de caso.

A estrutura foi organizada por fatores de avaliação, suportados por princípios de políticas nacionais e agendas de sustentabilidade. Para cada fator estabelecido, foi desenvolvido objetivo, metas e métricas específicas, visando contribuir para que agências de transporte possam medir o progresso de suas atividades em direção à sustentabilidade. Como produto final, foram desenvolvidas fichas de avaliação (vide Apêndice D), visando orientar a aplicação de indicadores nas etapas de tomada de decisão. Orientações gerais também foram fornecidas como diretrizes para aplicação da estrutura.

\subsection{SOBRE A ESTRUTURA DE AVALIAÇÃO}

O processo de decidir como, onde e quando implantar uma nova infraestrutura rodoviária normalmente envolve muitas partes interessadas em uma série de atividades políticas, de planejamento, econômicas, de engenharia e a participação social adequada, que são realizadas durante um longo período de tempo, abrangendo a consideração de vários fatores ambientais, sociais e econômicos, pautada em uma base institucional sólida, com eficiente sistema de gestão. A estrutura proposta oferece uma maneira de organizar a forma como podem ser utilizados indicadores, de modo que eles sirvam como uma ferramenta de apoio à decisão e de comunicação às partes interessadas.

A estrutura de avaliação de desempenho de sustentabilidade proposta neste trabalho fornece indicadores para uma avaliação abrangente no espaço urbanometropolitano, com ênfase no planejamento de infraestrutura rodoviária, por ser a matriz de transporte adotado no País e por possuir o maior potencial de influência nas questões que afetam a sustentabilidade urbana.

A tomada de decisões de empreendimentos de transporte geralmente começa com o reconhecimento de sua necessidade, das soluções conceituais e com o estabelecimento de objetivos e metas em amplas regiões. À medida que essa necessidade caminha para um consenso, o foco da tomada de decisão evolui para uma consideração das necessidades e soluções locais e específicas em nível de projeto, que exige um maior nível de detalhamento, bem como aumento de resoluções e escalas para apoiar tomada de decisões. Dessa forma, em função do processo de desenvolvimento de infraestrutura de 
transporte, da disponibilidade de dados e nível de detalhamento, entre outros, as questões devem ser tratadas de maneira diferenciada nas suas diferentes fases.

Neste trabalho, os indicadores estão organizados em fatores considerados mais relevantes em relação aos aspectos sócio-urbano-ambientais para apoiar as principais decisões nas fases de planejamento de uma nova infraestrutura rodoviária, definidas neste trabalho como: plano de longo prazo, programa, avaliação ambiental de projetos e monitoramento. Essas fases de tomada de decisão e as oportunidades com maior potencial de aplicação dos indicadores estão apresentadas na Figura 15.

Figura 15 - Fases de tomada de decisão em transporte de uso potencial da estrutura conceitual.

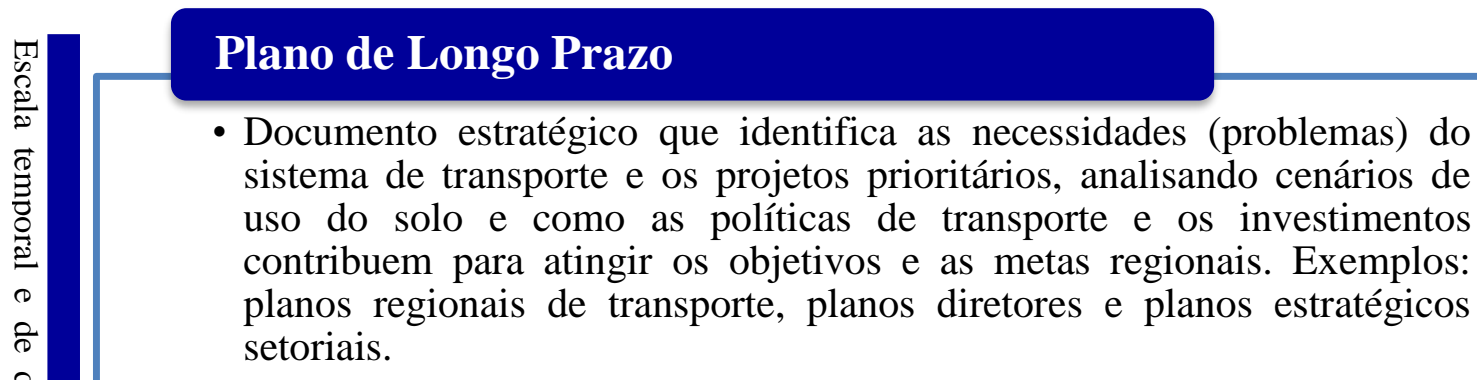

\section{Programa}

- Identificar as possíveis soluções de projetos, em nível conceitual, e as suas alternativas, focado em estratégias para obtenção e alocação mais eficiente de recursos nos projetos prioritários. Exemplos: programas de melhoria de transportes coletivos.

\section{Avaliação ambiental de projetos}

- Definição dos atributos específicos dos projetos selecionados durante a fase de programação, incluindo a avaliação dos impactos das múltiplas diretrizes e alternativas de traçado e a seleção da alternativa preferida. Exemplo: avaliação de impacto ambiental.

\section{Monitoramento}

- Observar tendências, identificar problemas e avaliar o progresso em direção aos objetivos e metas.

A compreensão das fases é importante para verificar como as mesmas se relacionam com os princípios da sustentabilidade, de forma a subsidiar o estabelecimento de objetivos, metas e ações de sustentabilidade, bem como selecionar os indicadores e medidas de desempenho que respeitem os momentos mais adequados para tomadas de decisão. As questões abordadas e as medidas usadas em vários estágios do processo podem se alterar à medida que uma agência passa de necessidades generalizadas para projetos específicos. 
Os Planos e Programas devem considerar os impactos com abrangência regional ou estadual, que devem ser analisados na fase preliminar de projetos, nos quais se destacam as principais características preventivas. Para a fase de Avaliação ambiental de projetos, os impactos das obras e da operação devem ser minuciosamente avaliados, contemplando a inclusão dos aspectos socioambientais no detalhamento do projeto de engenharia e na fase de construção. Já na fase de Monitoramento os impactos remanescentes na fase de operação devem ser acompanhados (e.g. indução de ocupação irregular, poluição do ar e da água, geração de ruídos, ocorrência de acidentes, etc).

De modo geral, a utilização de indicadores nesses estágios pode contribuir para o efetuar um diagnóstico atual e orientar as decisões sobre onde aplicar mais recursos, a partir de uma perspectiva sobre o desempenho futuro previsto, utilizando ferramentas preditivas, bem como preencher a lacuna entre o projeto e os níveis estratégicos, com base na avaliação dos resultados esperados de projetos individuais no alcance de metas.

Para abranger vários estágios e níveis de aplicação, a estrutura de avaliação foi concebida de forma genérica, visando permitir que as agências de transporte personalizem seus objetivos, metas, indicadores e medidas de desempenho, de modo flexível e modular, considerando a natureza multidimensional da sustentabilidade em seu contexto de aplicação. Ou seja, a instituição deve selecionar ou adaptar os indicadores fornecidos pela estrutura de forma seletiva, com base em suas necessidades específicas, considerando principalmente os seus objetivos e metas estratégicos e os fatores apropriados para a abordagem a que se pretende.

A estrutura foi composta por um número suficientemente grande de indicadores e medidas de desempenho, para que possam ser selecionados pelos potenciais usuários de acordo com sua aplicação de interesse e disponibilidade de dados ou viabilidade de coleta de dados. Com isso, pretende-se que a estrutura de avaliação se aplique a diversas agências de transporte, permitindo-as ajustar ao seu planejamento estratégico.

Ressalta-se que nem todos indicadores e medidas de desempenho são apropriados para todos os casos que requeiram o fator de avaliação, tampouco é recomendável a aplicação de todos em função da ineficiência e excessiva quantidade de recursos necessários. Assim, a partir dos indicadores contidos na estrutura, a instituição selecionará os indicadores de seu interesse, reduzindo a uma lista mais simplificada, considerando as suas metas, as lacunas na disponibilidade de dados, os limites de recursos e tempo para obtenção de dados, o interesse das partes interessadas, entre outros critérios.

Usualmente, os indicadores podem ser avaliados numericamente (percentual, intervalo, ordinal, escalar) ou verbal (escala semântica), ou seja, podem traduzir uma característica quantitativa ou qualitativa. Neste trabalho, priorizou-se indicadores que pudessem ser numericamente medidos, não descartando aqueles qualitativos julgados essenciais. Para a mensuração, foram fornecidas unidades relativas para quantificação de forma desagregada, como por exemplo per capita, por km, diferentes periodicidades, opções de escalas de unidades geográficas, etc., visando apoiar aplicações com tipos e 
níveis de detalhes específicos de análise. Permite-se, assim, que as medidas de desempenho possam ser adaptadas aos objetivos específicos, abrangências e limitações das agências de transportes interessadas.

Não foi objeto desta pesquisa apresentar as fontes potenciais de dados, uma vez que são significativamente diferentes entre estados e regiões. Os recortes espaciais e a periodicidade a serem utilizados pelos usuários da estrutura devem ser definidos de acordo com o indicador e o objetivo do interessado. No entanto, destaca-se que muitos dos dados necessários para esses indicadores podem estar disponíveis por meio de fontes existentes, como censos e pesquisas, estudos ambientais e de tráfego, pesquisas de viagens e outros relatórios. Outros dados podem ser coletados durante atividades regulares de planejamento e até mesmo fornecidos por outras instituições. Já alguns indicadores podem exigir a coleta de dados primários.

Além disso, a seleção dos indicadores não considerou as dificuldades para coletar os dados, mas simplesmente aqueles considerados pelo autor recomendáveis de mensuração ou potenciais de uso. Portanto, para sua plena aplicação, muitos gestores e instituições poderão necessitar de adequação em seus processos para coletar dados ou, até mesmo, descartar muitos indicadores selecionados, em função da indisponibilidade de dados, dos elevados custos de coleta de dados, da baixa relevância com o objeto de aplicação, entre outras questões.

Vale destacar, ainda, que alguns indicadores podem conter informações redundantes ou que se sobrepõem. Caberá ao interessado pela utilização selecionar aqueles indicadores que melhor se enquadram ao seu contexto de aplicação.

A seleção dos indicadores pautou-se na avaliação dos efeitos nos sistemas de transportes, observando a influência nas questões urbanas e regionais. O objetivo foi identificar indicadores que pudessem subsidiar tomada de decisões em sistema de transporte com utilização a nível regional, urbano e suburbano, visando a avaliação de políticas de transportes.

\subsection{CONSTRUÇÃO DA ESTRUTURA CONCEITUAL}

\subsubsection{Fatores de Avaliação de Desempenho}

Com base nos Princípios das políticas nacionais aplicáveis, nos fatores avaliados no estudo de caso e nos fatores amplamente abordados nas ferramentas de avaliação, foram estabelecidos os seguintes fatores de avaliação para compor a estrutura de avaliação.

Os fatores de avaliação selecionados estão apresentados no Quadro 15, seguidos da análise cruzada com os princípios, diretrizes ou agendas que os sustentam. 
Quadro 15 - Relação dos fatores de avaliação com Políticas, Normas ou Metas de Desenvolvimento Sustentável.

\begin{tabular}{|c|c|c|c|c|c|}
\hline $\begin{array}{l}\text { Fatores de } \\
\text { Avaliação }\end{array}$ & $\begin{array}{l}\text { Política } \\
\text { Urbana }\end{array}$ & $\begin{array}{c}\text { PN de } \\
\text { Transporte }\end{array}$ & $\begin{array}{c}\text { PN de Mobilidade } \\
\text { Urbana }\end{array}$ & $\begin{array}{c}\text { PN de } \\
\text { Meio } \\
\text { Ambiente }\end{array}$ & $\begin{array}{c}\text { Metas } \\
\text { ODS }\end{array}$ \\
\hline $\begin{array}{l}\text { Mobilidade e } \\
\text { Eficiência do } \\
\text { Sistema }\end{array}$ & - & $\begin{array}{l}\text { Princípio V (Art. } 3^{\circ} \text { ); } \\
\text { Objetivo I (Art. 4 }) \text {; } \\
\text { Diretriz I (Art. } 5^{\circ} \text { ) }\end{array}$ & $\begin{array}{l}\left.\text { Princípios IV e IX (Art. } 5^{\circ}\right) \\
\left.\text { Objetivo III (Art. } 7^{\circ}\right)\end{array}$ & - & 10.7 \\
\hline Acessibilidade & - & Objetivo I (Art. $4^{\circ}$ ); & $\begin{array}{l}\text { Princípio I (Art. 5 }{ }^{\circ} \text { ) } \\
\text { Objetivos II e III } \\
\quad\left(\text { Art. } 7^{\circ}\right) ; \\
\text { Direito IV (Art. 14); } \\
\text { Diretriz IV (Art. 24) }\end{array}$ & - & $\begin{array}{l}11.2 \\
11.7\end{array}$ \\
\hline Segurança & $\begin{array}{l}\text { Diretriz XIII } \\
\left(\text { Art. } 2^{\circ}\right)\end{array}$ & $\begin{array}{l}\left.\text { Objetivo II (Art. } 4^{\circ}\right) \\
\text { Diretriz I (Art. } 5^{\circ} \text { ) }\end{array}$ & $\begin{array}{l}\text { Princípio VI (Art. 5º; } \\
\text { Direito IV (Art. 14) }\end{array}$ & - & $\begin{array}{l}3.6 \\
10.7 \\
11.2\end{array}$ \\
\hline $\begin{array}{c}\text { Desenvolvimento } \\
\text { Econômico e Uso do } \\
\text { Solo }\end{array}$ & $\begin{array}{l}\text { Diretrizes IV, } \\
\text { VI, VII, XIV } \\
\quad\left(\text { Art. } 2^{\circ}\right)\end{array}$ & $\begin{array}{c}\text { Princípio III e VI (Art. } \\
\left.3^{\circ}\right) ; \\
\text { Objetivos IV, V, XI } \\
\text { (Art. 4 }) ; \\
\text { Diretriz III (Art. 5 }{ }^{\circ} \text { ) }\end{array}$ & $\begin{array}{l}\left.\text { Princípio II (Art. } 5^{\circ}\right) ; \\
\left.\text { Diretriz I, VI (Art. } 6^{\circ}\right)\end{array}$ & $\begin{array}{l}\text { Princípio II } \\
\left(\text { Art. } 2^{\circ}\right)\end{array}$ & $\begin{array}{c}8.1 \\
8.3 \\
9.1 \\
9.2 \\
17.11 \\
17.19 \\
\end{array}$ \\
\hline Qualidade do ar & - & - & - & $\begin{array}{l}\text { Princípio II } \\
\left.\text { (Art. } 2^{\circ}\right)\end{array}$ & $\begin{array}{c}3.9 \\
11.6 \\
12.4\end{array}$ \\
\hline $\begin{array}{l}\text { Mudanças } \\
\text { Climáticas }\end{array}$ & - & - & - & - & $\begin{array}{c}9.1 \\
11 . \mathrm{b} \\
13.1 \\
13.2 \\
13 . \mathrm{b}\end{array}$ \\
\hline Recursos Hídricos & $\begin{array}{l}\text { Diretriz } \\
\text { XVIII (Art. } \\
\left.2^{\circ}\right)\end{array}$ & - & - & $\begin{array}{l}\text { Princípio II } \\
\text { (Art. } 2^{\circ} \text { ) }\end{array}$ & $\begin{array}{c}3.9 \\
6.3 \\
6.6 \\
11.5 \\
12.4 \\
15.1\end{array}$ \\
\hline $\begin{array}{l}\text { Ecossistema, } \\
\text { Habitat e } \\
\text { Biodiversidade }\end{array}$ & - & - & - & $\begin{array}{l}\text { Princípio IV } \\
\text { (Art. } 2^{\circ} \text { ) }\end{array}$ & $\begin{array}{c}6.6 \\
15.1 \\
15.2 \\
15.5\end{array}$ \\
\hline Equidade & $\begin{array}{l}\text { Diretriz IX } \\
\left(\text { Art. } 2^{\circ}\right) \text {; }\end{array}$ & - & $\begin{array}{c}\text { Princípios III, VII e VIII } \\
\text { (Art. 5º; } \\
\text { Objetivo I (Art. } 7^{\circ} \text { ) }\end{array}$ & - & $\begin{array}{c}5.5 \\
5 . \mathrm{c} \\
9.1 \\
10.1 \\
11.1\end{array}$ \\
\hline Qualidade de Vida & $\begin{array}{l}\text { Diretrizes VI, } \\
\text { XII, XIX } \\
\left(\text { Art. } 2^{\circ}\right)\end{array}$ & $\begin{array}{c}\text { Princípio IV e VII } \\
\left.\text { (Art. } 3^{\circ}\right) ; \\
\left.\text { Objetivo XI (Art. } 4^{\circ}\right) ; \\
\text { Diretriz XVIII (Art. } 5^{\circ} \text { ) }\end{array}$ & $\begin{array}{l}\text { Princípio II (Art. } 5^{\circ} \text { ); } \\
\text { Diretriz IV (Art. } 6^{\circ} \text { ) } \\
\text { Objetivo IV } \\
\left(\text { Art. } 7^{\circ}\right)\end{array}$ & $\begin{array}{l}\text { Princípio V } \\
\text { (Art. } 2^{\circ} \text { ) }\end{array}$ & $\begin{array}{l}3.9 \\
11.4 \\
11.6 \\
11 . \mathrm{a}\end{array}$ \\
\hline
\end{tabular}


Os fatores selecionados estão resumidamente descritos a seguir:

- FA-01: Mobilidade e Eficiência do Sistema - mede a capacidade do sistema de transporte de facilitar o deslocamento eficiente de pessoas e bens até os destinos desejados, pelos diferentes modos de transporte. É preciso compreender os gargalos existentes nos sistemas de transportes, como os congestionamentos recorrentes, o tempo de viagem perdido e o volume de tráfego em relação à capacidade das vias.

- FA-02: Acessibilidade - refere-se à capacidade do sistema de transporte de conectar as pessoas aos destinos desejados por meio da análise espacial da população residencial, dos centros de emprego e de outras oportunidades de serviço ou recreação. Acessibilidade reflete a conveniência relativa do percurso como uma opção, podendo ser medida em termos de distância e tempo de viagem, enfatizando a disponibilidade de percursos onde as pessoas moram, trabalham e se conectam com os locais essenciais. Ao contrário da mobilidade, a acessibilidade considera o uso do solo e outros fatores de acessibilidade.

- FA-03: Segurança - representa a capacidade de os usuários do sistema chegarem ao seu destino com segurança. Os indicadores dessa categoria têm como objetivo medir a qualidade do serviço de transporte em termos de acidentes ou incidentes que são prejudiciais às pessoas, ao meio ambiente e aos bens. Como resultado, pode-se contribuir para identificar locais que necessitam de melhorias no sistema de transporte, observar os efeitos dessas melhorias e justificar investimentos adicionais para melhorar o nível de segurança.

- FA-04: Desenvolvimento Urbano e Uso do Solo - os efeitos sobre o uso do solo possuem estreita relação com os efeitos sobre os transportes e a circulação viária, os quais permitem analisar o quanto investimentos em transporte podem modificar as relações de acessibilidade com seu entorno e entre sub-regiões da uma região metropolitana, alterando vantagens locacionais para instalação de atividades econômicas e domicílios. Neste sentido, este fator analisa as alterações do uso do solo urbano (por exemplo residencial, comercial, industrial) e os benefícios econômicos mais amplos que podem advir como resultado de investimentos em transporte, principalmente em função das melhorias na cadeia de suprimentos, benefícios de acessibilidade e impactos macroeconômicos mais gerais, como produção econômica regional e geração de emprego.

- FA-05: Qualidade do Ar - visa garantir que as decisões de transporte sejam consistentes com as metas de qualidade do ar para uma região. Os requisitos atuais incluem o processo de conformidade de transporte, que exige que os projetos dentro de programas de melhoria de transporte não excedam os padrões de qualidade do ar. Nas regiões metropolitanas o problema da poluição do ar tem-se constituído numa das mais graves ameaças à qualidade de vida de seus habitantes. Em geral, os veículos automotores estão dentre os maiores responsáveis pela 
emissão de gases poluentes na atmosfera de áreas urbanas, os quais têm relação de direta com o tipo e consumo de combustíveis. Portanto, melhorar a qualidade do ar é um aspecto significativo de promover assentamentos urbanos sustentáveis.

- FA-06: Mudanças Climáticas - aborda os impactos das emissões de transporte no clima, quanto os possíveis impactos da mudança climática na infraestrutura de transporte, em função de eventos climáticos extremos. Ao mesmo tempo em que o setor de transporte é um dos principais responsáveis pelas emissões de gases de efeito estufa (GEE), por outro, os impactos das mudanças climáticas, como aumento da temperatura, aumento do nível do mar e eventos climáticos mais extremos, podem ter um impacto significativo na infraestrutura de transporte.

- FA-07: Recursos Hídricos - enfatiza a relação do sistema de transporte com os mananciais de abastecimento de água, considerando dois aspectos: os efeitos sobre a quantidade de água e os efeitos sobre a qualidade da água. Sistemas de transporte podem afetar a produtividade hídrica das bacias ou interferir com o sistema de abastecimento. Com relação à qualidade da água, durante a construção pode haver riscos de carreamento de solos e de eventuais derrames de produtos químicos, enquanto durante a operação, pode haver eventuais acidentes no transporte de produtos perigosos ou contribuições de cargas difusas. Por outro lado, existem ações que podem ajudar a proteger os recursos hídricos e os ecossistemas que dependem deles, melhorando a condição preexistente ou prevenindo ameaças futuras, como remoção de ocupação irregular, implantação de Parques e preservação da capacidade de autodepuração de sua várzea.

- FA-08: Ecossistema, Habitat e Biodiversidade - avalia os impactos sobre a biodiversidade, uma vez que a implantação de infraestruturas de transporte geralmente exige a supressão de vegetação e podem interferir em Unidades de Conservação, que acarreta na perda direta de habitat e provoca a fragmentação e isolamento de habitats existentes, criando obstáculos que limitam a migração e causam colisões com animais, resultando em mortandade da vida selvagem e preocupações de segurança para o usuário.

- FA-09: Equidade - diz respeito à distribuição do acesso às instalações (por exemplo, postos de trabalho e lazer), benefícios de decisões de investimento, e a exposição às externalidades negativas geradas pelo transporte. Para tanto, foca-se nos impactos dos vários fatores discutidos anteriormente nos grupos tradicionalmente desfavorecidos, como forma de comparar a diferença entre as condições de mobilidade, acessibilidade, custo de transporte, poluição, etc. proporcionadas aos grupos demográficos de baixa renda, de mobilidade reduzida, idosos, mulheres, entre outros.

- FA-10: Qualidade de Vida - sistemas de transporte podem afetar, positivamente ou negativamente, a qualidade de vida da população em uma variedade de maneiras. É difícil equilibrar os benefícios para os usuários e os efeitos sobre os 
moradores da comunidade, uma vez que os impactos podem ser positivos e negativos sobre as características físicas e sociais de uma comunidade local. Nesse sentido, este fator propõe-se a avaliar os impactos, no geral negativos, que podem afetar a qualidade de vida das comunidades locais, incluindo questões de segregação urbana, ruído, qualidade visual e riscos socioambientais.

\subsubsection{Objetivos de Transporte Sustentável (OTS)}

Para cada fator de avaliação, foi estabelecido um objetivo específico, denominado neste trabalho como Objetivos de Transporte Sustentável (OTS). Conforme informado anteriormente, esses objetivos expressam, de modo geral, onde se pretende chegar. Os Fatores de Avaliação associados aos Objetivos de Transporte Sustentável (OTS) definidos na estrutura de avaliação estão apresentados no quadro a seguir.

Quadro 16 - Fatores de avaliação associados aos OTS.

\begin{tabular}{|c|c|c|}
\hline Fatores de Avaliação & Código & Objetivos de Transporte Sustentável (OTS) \\
\hline $\begin{array}{l}\text { Mobilidade e } \\
\text { Eficiência do Sistema }\end{array}$ & OTS 1 & $\begin{array}{l}\text { Manter e melhorar a capacidade dos bens e das pessoas de se } \\
\text { deslocarem pelo sistema de transporte e pelas vias urbanas, com o } \\
\text { mínimo de atraso }\end{array}$ \\
\hline Acessibilidade & OTS 2 & $\begin{array}{l}\text { Fornecer sistemas de transporte que maximizem a acessibilidade para } \\
\text { todas as comunidades }\end{array}$ \\
\hline Segurança & OTS 3 & $\begin{array}{l}\text { Fornecer um sistema de transporte seguro para os usuários e o público } \\
\text { em geral }\end{array}$ \\
\hline $\begin{array}{l}\text { Desenvolvimento } \\
\text { Urbano e Uso do Solo }\end{array}$ & OTS 4 & $\begin{array}{l}\text { Garantir que o sistema de transporte apoie o desenvolvimento } \\
\text { socioeconômico integrado ao planejamento do uso do solo }\end{array}$ \\
\hline Qualidade do Ar & OTS 5 & $\begin{array}{l}\text { Melhorar a qualidade do ar de zonas saturadas, reduzindo a exposição } \\
\text { da população a níveis de poluição que excedem os limites seguros }\end{array}$ \\
\hline Mudanças Climáticas & OTS 6 & $\begin{array}{l}\text { Mitigar as mudanças climáticas e os seus impactos sobre o transporte e } \\
\text { a comunidade }\end{array}$ \\
\hline Recursos Hídricos & OTS 7 & $\begin{array}{l}\text { Proteger os recursos hídricos e os ecossistemas que dependem deles, } \\
\text { melhorando a qualidade da água e minimizando os impactos na } \\
\text { produtividade hídrica das bacias hidrográficas }\end{array}$ \\
\hline $\begin{array}{l}\text { Ecossistema, Habitat e } \\
\text { Biodiversidade }\end{array}$ & OTS 8 & $\begin{array}{l}\text { Proteger e melhorar os sistemas ambientais e ecológicos no } \\
\text { desenvolvimento e operação de sistemas de transporte }\end{array}$ \\
\hline Equidade & OTS 9 & $\begin{array}{l}\text { Fornecer um sistema de transporte que maximize ou mantenha a } \\
\text { equidade entre grupos e setores da sociedade. }\end{array}$ \\
\hline Qualidade de Vida & OTS 10 & $\begin{array}{l}\text { Melhorar a qualidade de vida resultante de todas as comunidades } \\
\text { afetadas pelo projeto e mitigar os impactos negativos sobre as mesmas }\end{array}$ \\
\hline
\end{tabular}




\subsubsection{Metas Conceituais}

As metas conceituais foram desenvolvidas a partir da interpretação da revisão bibliográfica realizada pelo autor, do estudo de caso e dos critérios estabelecidos pelas ferramentas de avaliação de sustentabilidade das agências de transporte, os quais foram fundamentados por equipes multidisciplinares especialistas em planejamento de transporte, acadêmicos e consultores.

As metas conceituais foram definidas como forma de estabelecer os caminhos para alcançar os OTS. As metas foram elaboradas de forma genérica para permitir a adaptação e inclusão de quantidades e prazos de referência pelos usuários da estrutura de avaliação, de acordo com o interesse do usuário.

Os OTS e as metas correspondentes estão apresentadas no quadro a seguir.

Quadro 17 - Metas conceituais correspondentes aos OTS.

OTS-01: Mobilidade e Eficiência do Sistema - Manter e melhorar a capacidade dos bens e das pessoas de se deslocarem pelo sistema de transporte e pelas vias urbanas, com o mínimo de atraso

\begin{tabular}{|c|c|c|}
\hline \multicolumn{2}{|c|}{ METAS } \\
\hline $\begin{array}{c}\text { MOB-01: Reduzir o } \\
\text { congestionamento recorrente }\end{array}$ & $\begin{array}{c}\text { MOB-02: Melhorar o tempo de } \\
\text { viagem }\end{array}$ & $\begin{array}{c}\text { MOB-03: Reduzir o volume de } \\
\text { tráfego, diversificando o sistema de } \\
\text { transporte }\end{array}$ \\
\hline
\end{tabular}

OTS-02: Acessibilidade - Fornecer sistemas de transporte que maximizem a acessibilidade para todas as comunidades

\section{METAS}

AC-01: Proporcionar às empresas melhoria de acesso aos recursos do mercado
AC-02: Proporcionar aos moradores melhoria de acesso a centros regionais
AC-03: Melhorar a acessibilidade aos diferentes modos de transporte urbano, como alternativa ao uso do automóvel

OTS-03: Segurança - Fornecer um sistema de transporte seguro para os usuários e o público em geral

\section{METAS}

SEG-01: Reduzir a

quantidade de acidentes de trânsito
SEG-02: Fornecer uma infraestrutura rodoviária segura
SEG-03: Melhorar a resposta a incidentes de trânsito

OTS-04: Desenvolvimento Econômico e Uso do Solo - Garantir que o sistema de transporte apoie o desenvolvimento socioeconômico integrado ao planejamento do uso do solo

\section{METAS}

US-01: Promover e induzir um crescimento urbano ordenado, misto e compacto
US-02: Integrar os sistemas de transporte com os planos de uso do solo
US-03: Minimizar o consumo da terra para as instalações de infraestrutura de transporte 
OTS-05: Qualidade do Ar - Melhorar a qualidade do ar de zonas saturadas, reduzindo a exposição da população a níveis de poluição que excedem os limites seguros

\section{METAS}

\begin{tabular}{|c|c|c|}
\hline $\begin{array}{c}\text { QA-01: Reduzir emissões de } \\
\text { poluentes atmosféricos } \\
\text { relacionados ao transporte }\end{array}$ & $\begin{array}{c}\text { QA-02: Cumprir os padrões } \\
\text { normativos de qualidade do ar }\end{array}$ & $\begin{array}{c}\text { QA-03: Evitar ou reduzir a } \\
\text { exposição da população aos } \\
\text { poluentes atmosféricos de origem } \\
\text { móvel }\end{array}$ \\
\hline
\end{tabular}

OTS-06: Mudanças Climáticas - Mitigar as mudanças climáticas e os seus impactos sobre 0 transporte e a comunidade

\section{METAS}

MC-01: Reduzir as emissões de gases de efeito estufa (GEE) de fontes de transporte
MC-02: Evitar riscos e vulnerabilidades às ameaças climáticas

OTS-07: Recursos Hídricos - Proteger os recursos hídricos e os ecossistemas que dependem deles, melhorando a qualidade da água e minimizando os impactos na produtividade hídrica das bacias hidrográficas

\section{METAS}

RH-01: Proteger os mananciais de abastecimento de água
RH-02: Garantir a consistência do planejamento de transporte com os planos de bacias hidrográficas
RH-03: Garantir o cumprimento do padrão normativo de qualidade da água
RH-04: Manter ou melhor a qualidade da água

OTS-08: Ecossistema, Habitat e Biodiversidade - Manter ou melhorar as funções ecológicas de ecossistemas e de áreas de habitats

\section{METAS}

EHB-01: Proteger os fragmentos de vegetação nativa e demais habitats

essenciais para a sobrevivência de espécies selvagens
EHB-02: Evitar interferências em áreas ambientalmente protegidas
EHB-03: Preservar as zonas úmidas de alta qualidade
EHB-04: Conservar a fauna nativa

OTS-09: Equidade - Fornecer um sistema de transporte que maximize ou mantenha a equidade entre grupos e setores da sociedade

\section{METAS}

EQ-01: Melhorar a equidade de acessos e mobilidade
EQ-02: Reduzir os custos de transporte para comunidades de baixa renda
EQ-03: Distribuir as externalidades de forma equitativa

OTS-10: Qualidade de Vida - Melhorar a qualidade de vida resultante de todas as comunidades afetadas pelo projeto e mitigar os impactos negativos sobre as mesmas

\section{METAS}

QV-01: Minimizar o ruído gerado na operação do projeto
QV-02: Minimizar a Poluição Visual
QV-03: Evitar ou minimizar a segregação urbana
QV-04: Minimizar o risco ambiental e à saúde e segurança humana 
Em que pese todos os objetivos e metas estarem alinhados aos princípios da sustentabilidade, muitas vezes, na prática, pode haver conflitos entre eles na tomada de decisão. Assim, para uma decisão sobre se determinada proposta ou iniciativa é ou não aceitável dentro de um contexto de sustentabilidade, é preciso equilibrar os conflitos entre eles. Para tanto, são apresentadas diversas ferramentas de avaliação neste trabalho que permite ao tomador de decisão ponderar o grau de importância entre as metas concorrentes. Nesses casos, destaca-se o uso das ferramentas de análises multicriteriais, por adotar ponderação entre os diferentes critérios, ajudando a escolher a alternativa que melhor se enquadra ao contexto.

\subsubsection{Indicadores de Sustentabilidade Selecionados}

Dentro dos fatores de avaliação estabelecidos, foram selecionados os indicadores julgados mais importantes a partir da revisão da literatura e com base nas práticas de avaliação adotadas no caso estudado. Vale ressaltar que, apesar de os indicadores serem originados a partir dos fatores de avaliação específicos, os resultados estão frequentemente correlacionados; logo, em muitos casos, os indicadores poderiam estar inseridos em mais de um fator.

Dentre aqueles mapeados, foram selecionados apenas os indicadores que mensurassem as metas conceituais, contribuindo para que os resultados de sua aplicação sejam utilizados pelas agências de transporte visando acompanhar seu progresso em direção às metas estabelecidas.

Os quadros a seguir mostram as metas e os indicadores desenvolvidos neste projeto, por fator de avaliação, sendo que cada indicador teve a confecção de uma ficha de avaliação específica.

\section{FA-01: MOBILIDADE E EFICIÊNCIA DO SISTEMA}

\begin{tabular}{|c|c|c|}
\hline Indicador & Descrição & Relevância \\
\hline $\begin{array}{l}\text { MOB-1.1. Alteração no } \\
\text { Nível de Serviço (LOS) }\end{array}$ & $\begin{array}{l}\text { Grau de letra qualitativa das } \\
\text { condições operacionais da } \\
\text { rodovia de A (deslocamento sem } \\
\text { restrição) a F (congestionamento } \\
\text { grave) }\end{array}$ & $\begin{array}{l}\text { Permite classificar, qualitativamente, as } \\
\text { condições operacionais dentro de um } \\
\text { fluxo de tráfego e as percepções dos } \\
\text { motoristas sobre essas condições. }\end{array}$ \\
\hline $\begin{array}{l}\text { MOB-1.2. Mudança na } \\
\text { relação volume / } \\
\text { capacidade (V / C) }\end{array}$ & $\begin{array}{l}\text { Número real de veículos que } \\
\text { usam um segmento de rodovia } \\
\text { em relação ao número de veículos } \\
\text { para os quais ele foi projetado } \\
\text { para lidar por um período de } \\
\text { tempo fixo }\end{array}$ & $\begin{array}{l}\text { Permite compreender o comportamento } \\
\text { do sistema viário, a fim de se prever os } \\
\text { efeitos causados por modificações nas } \\
\text { características da demanda e/ou da } \\
\text { oferta do sistema de transportes. }\end{array}$ \\
\hline
\end{tabular}




\begin{tabular}{|c|c|c|}
\hline \multicolumn{3}{|c|}{ MOB-02: Melhorar o tempo de viagem } \\
\hline Indicador & Descrição & Relevância \\
\hline $\begin{array}{l}\text { MOB-2.1. Atraso } \\
\text { recorrente }\end{array}$ & $\begin{array}{l}\text { Diferença entre o tempo de } \\
\text { viagem real exigido pelo } \\
\text { motorista para atravessar um } \\
\text { segmento de estrada e o tempo } \\
\text { com fluxo irrestrito }\end{array}$ & $\begin{array}{l}\text { Avalia o tempo perdido pelo motorista ou } \\
\text { pela carga em função da baixa eficiência } \\
\text { no sistema de transporte. }\end{array}$ \\
\hline $\begin{array}{c}\text { MOB-2.2. Tempo de } \\
\text { viagem }\end{array}$ & $\begin{array}{l}\text { Tempo necessário para percorrer } \\
\text { um ou mais segmentos da } \\
\text { estrada. }\end{array}$ & $\begin{array}{l}\text { É um elemento primordial no cálculo de } \\
\text { outras medidas de desempenho de } \\
\text { transporte. }\end{array}$ \\
\hline $\begin{array}{l}\text { MOB-2.3. Alteração no } \\
\text { Índice de Tempo de } \\
\text { Viagem }\end{array}$ & $\begin{array}{l}\text { Relação entre o tempo de uma } \\
\text { viagem real no período de pico e } \\
\text { o tempo de viagem de fluxo livre } \\
\text { ou desejado para aquela viagem. }\end{array}$ & $\begin{array}{l}\text { Avalia o nível de viagem focado no } \\
\text { período de pico de viagem, permitindo a } \\
\text { comparação entre alternativas de projeto. }\end{array}$ \\
\hline
\end{tabular}

\section{FA-02: ACESSIBILIDADE}

AC-01: Proporcionar às empresas melhoria de acesso aos recursos do mercado

\begin{tabular}{|c|c|c|}
\hline Indicador & Descrição & Relevância \\
\hline $\begin{array}{l}\text { AC-01.1. Acessibilidade } \\
\text { da força de trabalho }\end{array}$ & $\begin{array}{l}\text { Número de moradores ao alcance } \\
\text { dos empregadores da região }\end{array}$ & $\begin{array}{l}\text { Permite avaliar se o sistema de transporte } \\
\text { tem contribuído para que as empresas } \\
\text { tenham acesso à força de trabalho. }\end{array}$ \\
\hline $\begin{array}{l}\text { AC-01.2. Acessibilidade } \\
\text { de mercado }\end{array}$ & $\begin{array}{l}\text { Tempo médio de viagem aos } \\
\text { centros de mercado }\end{array}$ & $\begin{array}{l}\text { Avalia os resultados de melhoria de } \\
\text { acessibilidade aos centros de mercado a } \\
\text { partir do tempo médio de viagem. }\end{array}$ \\
\hline \multicolumn{3}{|c|}{ AC-02: Proporcionar aos moradores melhoria de acesso a centros regionais } \\
\hline Indicador & Descrição & Relevância \\
\hline $\begin{array}{l}\text { AC-02.1. Acessibilidade a } \\
\text { emprego }\end{array}$ & $\begin{array}{l}\text { Quantidade de empregos dentro } \\
\text { de um tempo de viagem razoável } \\
\text { para a população de uma região }\end{array}$ & $\begin{array}{l}\text { Permite avaliar a capacidade de conectar } \\
\text { as pessoas aos seus empregos, com tempo } \\
\text { de viagem razoável. }\end{array}$ \\
\hline $\begin{array}{l}\text { AC-02.2. Acessibilidade a } \\
\text { destinos essenciais }\end{array}$ & $\begin{array}{l}\text { Tempo ou distância média de } \\
\text { viagem para os destinos } \\
\text { essenciais da região }\end{array}$ & $\begin{array}{l}\text { Permite avaliar a melhoria da } \\
\text { acessibilidade aos destinos essenciais, } \\
\text { como escolas, serviços de saúde, áreas } \\
\text { recreacionais, etc. }\end{array}$ \\
\hline
\end{tabular}

\section{FA-03: SEGURANÇA}

SEG-01: Reduzir a quantidade de acidentes de trânsito

\begin{tabular}{|c|c|c|}
\hline Indicador & Descrição & Relevância \\
\hline $\begin{array}{c}\text { SEG-01.1. Acidentes de } \\
\text { Trânsito }\end{array}$ & $\begin{array}{l}\text { Ocorrências de acidentes de } \\
\text { trânsito }\end{array}$ & $\begin{array}{l}\text { Avalia a alteração no número de acidentes } \\
\text { de trânsito ou em uma interseção } \\
\text { específica, como resultado de } \\
\text { investimento em novas infraestruturas de } \\
\text { transporte. }\end{array}$ \\
\hline \multicolumn{3}{|c|}{ SEG-02: Fornecer uma infraestrutura rodoviária segura } \\
\hline Indicador & Descrição & Relevância \\
\hline $\begin{array}{l}\text { SEG-02.1. Condição de } \\
\text { Segurança Viária }\end{array}$ & $\begin{array}{l}\text { Identifica trechos rodoviários } \\
\text { com maior probabilidade de } \\
\text { ocorrência de acidentes }\end{array}$ & $\begin{array}{l}\text { A identificação de locais com maior } \\
\text { probabilidade de acidentes oferece } \\
\text { subsídios para identificar locais que } \\
\text { necessitam de medidas preventivas e que } \\
\text { provocam atrasos não recorrentes. }\end{array}$ \\
\hline
\end{tabular}




\begin{tabular}{|c|c|}
\hline SEG-03: Melhorar a resposta a incidentes de trânsito \\
\hline \multicolumn{1}{|c|}{ Indicador } & \multicolumn{1}{|c|}{ Descrição } \\
$\begin{array}{l}\text { SEG-03.1. Resposta a } \\
\text { incidentes de trânsito }\end{array}$ & $\begin{array}{l}\text { Relevância } \\
\text { A duração média de resposta a incidentes } \\
\text { é geralmente estimada para um corredor } \\
\text { ou região. O cálculo da duração do } \\
\text { incidente baseia-se no tempo entre a } \\
\text { notificação do incidente e a realização das } \\
\text { atividades de resposta. }\end{array}$ \\
\hline
\end{tabular}

\section{FA-04: DESENVOLVIMENTO URBANO E USO DO SOLO}

US-01: Promover e induzir um crescimento urbano ordenado, misto e compacto

\begin{tabular}{|c|l|l|}
\hline Indicador & \multicolumn{1}{c|}{ Descrição } & \multicolumn{1}{c|}{ Relevância } \\
\hline $\begin{array}{c}\text { US-01.1. Expansão } \\
\text { urbana }\end{array}$ & $\begin{array}{l}\text { Área de expansão urbana } \\
\text { potencialmente induzido por uma } \\
\text { nova infraestrutura de transporte. }\end{array}$ & $\begin{array}{l}\text { Permite quantificar o espraiamento } \\
\text { urbano, em especial a urbanização } \\
\text { irregular e desordenada. }\end{array}$ \\
\hline
\end{tabular}

US-02: Integrar os sistemas de transporte com os planos de uso do solo

\begin{tabular}{|c|l|l}
\hline \multicolumn{1}{|c|}{ Indicador } & \multicolumn{1}{c}{ Descrição } \\
\hline $\begin{array}{c}\text { US-02.1. Integração com } \\
\text { planos de uso do solo } \\
\text { Consistência das políticas de } \\
\text { transporte terrestre regionais com } \\
\text { planos locais e/ou regionais de uso } \\
\text { do solo. }\end{array}$ & $\begin{array}{l}\text { Relevância } \\
\text { Contribui para avaliar a consistência do } \\
\text { projeto com planos e políticas locais e / } \\
\text { ou regionais de uso do solo - por } \\
\text { exemplo, se o projeto atende uma área } \\
\text { designada de crescimento ou de } \\
\text { alteração de uso consistente com os } \\
\text { planos local e / ou regionais. }\end{array}$ \\
\hline
\end{tabular}

US-03: Minimizar o consumo da terra para as instalações de infraestrutura de transporte

\begin{tabular}{|c|l|l|}
\hline Indicador & \multicolumn{1}{|c}{ Descrição } \\
$\begin{array}{c}\text { US-03.1. Consumo de } \\
\text { terras para infraestrutura } \\
\text { de transporte }\end{array}$ & $\begin{array}{l}\text { Relevância } \\
\text { Quantifica o consumo de terra } \\
\text { necessário para implantação de } \\
\text { infraestrutura de transporte, ou seja, } \\
\text { a "pegada" do empreendimento. } \\
\text { instalação e sua faixa de domínio, e } \\
\text { pode incluir quaisquer parcelas } \\
\text { adicionais ou porções de parcelas que } \\
\text { não serão mais utilizáveis após a obra } \\
\text { (por exemplo, acesso desativado ou } \\
\text { outras formas que não são edificáveis). }\end{array}$ \\
\hline
\end{tabular}

\section{FA-05: QUALIDADE DO AR}

QA-01: Reduzir emissões de poluentes atmosféricos relacionados ao transporte

\begin{tabular}{|c|l|l|}
\hline Indicador & \multicolumn{1}{|c|}{ Descrição } & \multicolumn{1}{c|}{ Relevância } \\
\hline $\begin{array}{c}\text { QA-01.1. Emissões de } \\
\text { poluentes atmosféricos }\end{array}$ & $\begin{array}{l}\text { Quantifica as contribuições de } \\
\text { emissões atmosféricas de projetos } \\
\text { rodoviários }\end{array}$ & $\begin{array}{l}\text { Permite analisar se os projetos } \\
\text { contribuem para violações, aumento da } \\
\text { frequência ou severidade da poluição do } \\
\text { ar. }\end{array}$ \\
\hline QA-02: Cumprir os padrões normativos de qualidade do ar & Relevância \\
\hline Indicador & Descrição & $\begin{array}{l}\text { QA-02.1. Conformidade } \\
\text { com os padrões de } \\
\text { qualidade do ar }\end{array}$ \\
\hline $\begin{array}{c}\text { Quantifica as contribuições de } \\
\text { emissões atmosféricas de projetos } \\
\text { rodoviários }\end{array}$ & $\begin{array}{l}\text { Permite comparar as emissões } \\
\text { relacionadas ao transporte rodoviário na } \\
\text { região com o padrão normativo. }\end{array}$ \\
\hline
\end{tabular}




\begin{tabular}{|c|c|c|}
\hline \multicolumn{3}{|c|}{ QA-03: Evitar ou reduzir a exposição da população aos poluentes atmosféricos de origem móvel } \\
\hline Indicador & Descrição & Relevância \\
\hline $\begin{array}{c}\text { QA-03.1. População } \\
\text { expostas a poluição do ar }\end{array}$ & $\begin{array}{l}\text { Populações vulneráveis } \\
\text { potencialmente afetadas pelos } \\
\text { poluentes do ar de origem móvel }\end{array}$ & $\begin{array}{l}\text { Permite identificar os números e os } \\
\text { tipos de população vulneráveis aos } \\
\text { efeitos da poluição do ar (por exemplo, } \\
\text { unidades habitacionais, escolas, } \\
\text { hospitais, etc.), calculando a mudança } \\
\text { nos tipos e números de receptores } \\
\text { sensíveis potencialmente impactados } \\
\text { por um projeto de transporte. }\end{array}$ \\
\hline
\end{tabular}

\section{FA-06: MUDANÇAS CLIMÁTICAS}

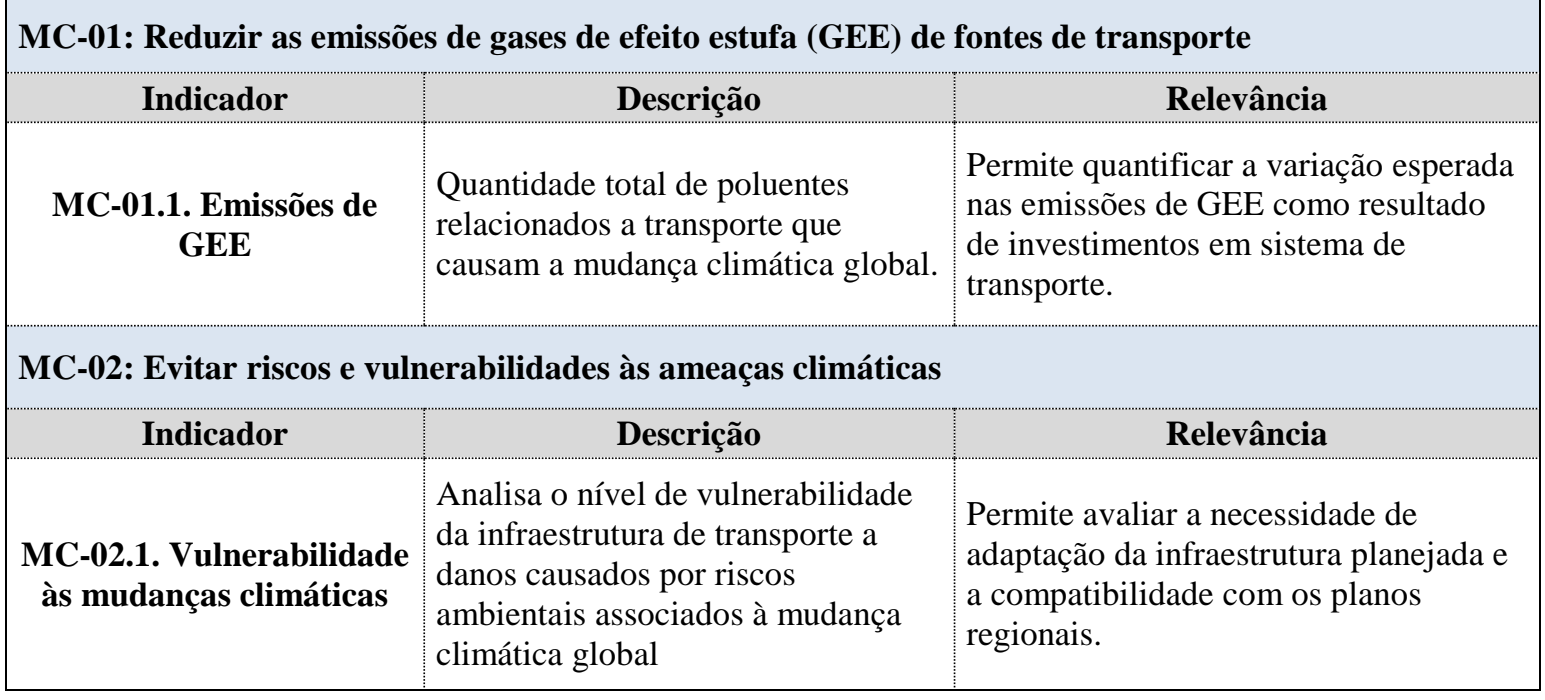

\section{FA-07: RECURSOS HÍDRICOS}

RH-01: Proteger os mananciais de abastecimento de água

\begin{tabular}{|c|l|l|}
\hline \multicolumn{1}{|c|}{ Indicador } & \multicolumn{1}{c|}{ Descrição } & \multicolumn{1}{c}{ Relevância } \\
\hline $\begin{array}{c}\text { RH-01.1. Interferência } \\
\text { com área de proteção a } \\
\text { mananciais }\end{array}$ & $\begin{array}{l}\text { Impacto na qualidade e na } \\
\text { quantidade de água no sistema de } \\
\text { produção de água de abastecimento. }\end{array}$ & $\begin{array}{l}\text { Permite avaliar os efeitos da } \\
\text { implantação de uma infraestrutura de } \\
\text { transporte em áreas de proteção de } \\
\text { mananciais. }\end{array}$ \\
\hline
\end{tabular}

RH-02: Garantir a consistência do planejamento de transporte com os planos de bacias hidrográficas

\begin{tabular}{|c|l|l|}
\hline Indicador & \multicolumn{1}{|c|}{ Descrição } & \multicolumn{1}{|c|}{ Relevância } \\
\hline $\begin{array}{c}\text { RH-02.1. Consistência } \\
\text { com os Planos de Bacias } \\
\text { Hidrográficas }\end{array}$ & $\begin{array}{l}\text { Consistência das políticas de } \\
\text { transporte terrestre com os planos } \\
\text { de bacia hidrográfica. }\end{array}$ & $\begin{array}{l}\text { Permite avaliar a compatibilidade de } \\
\text { alternativas de projeto com os objetivos } \\
\text { dos planos de bacia hidrográfica. }\end{array}$ \\
\hline
\end{tabular}




\begin{tabular}{|c|l|l|}
\hline RH-03: Garantir o cumprimento do padrão normativo de qualidade da água \\
\hline Indicador & \multicolumn{1}{|c|}{ Descrição } & \multicolumn{1}{|c|}{ Relevância } \\
\hline $\begin{array}{c}\text { RH-03.1. Conformidade } \\
\text { dos padrões de qualidade } \\
\text { da água }\end{array}$ & $\begin{array}{l}\text { Concentração de poluentes } \\
\text { contribuintes da construção ou } \\
\text { operação de um sistema de } \\
\text { transporte. }\end{array}$ & $\begin{array}{l}\text { Permite avaliar se o carreamento de } \\
\text { solos, os eventuais derrames de } \\
\text { produtos químicos ou as contribuições } \\
\text { de cargas difusas de uma infraestrutura, } \\
\text { podem alterar a qualidade da água } \\
\text { acima dos parâmetros estabelecidos } \\
\text { pela legislação. }\end{array}$ \\
\hline $\begin{array}{c}\text { RH-03.2. Cargas difusas } \\
\text { provenientes do } \\
\text { escoamento superficial de } \\
\text { rodovia }\end{array}$ & $\begin{array}{l}\text { Alteração na qualidade da água } \\
\text { devido à carga de poluente } \\
\text { proveniente do escoamento } \\
\text { superficial sobre o pavimento da } \\
\text { rodovia }\end{array}$ & $\begin{array}{l}\text { devido ao transporte de contaminantes } \\
\text { presentes sobre as superfícies e que são } \\
\text { carregados pela água da chuva. Esses } \\
\text { contaminantes são originados dos } \\
\text { veículos e da própria infraestrutura. }\end{array}$ \\
\hline
\end{tabular}

\section{FA-08: ECOSSISTEMA, HABITAT E BIODIVERSIDADE}

EHB-01: Proteger os fragmentos de vegetação nativa e demais habitats essenciais para a sobrevivência de espécies selvagens

\begin{tabular}{|c|c|c|}
\hline Indicador & Descrição & Relevância \\
\hline $\begin{array}{l}\text { EHB-01.1. Supressão de } \\
\text { vegetação nativa }\end{array}$ & $\begin{array}{l}\text { Impacto da construção do } \\
\text { transporte na qualidade e } \\
\text { quantidade de fragmentos de } \\
\text { vegetação nativa. }\end{array}$ & $\begin{array}{l}\text { Permite avaliar a degradação da } \\
\text { qualidade e quantidade de terra } \\
\text { essencial para a sobrevivência de } \\
\text { espécies-alvo de plantas ou animais, } \\
\text { decorrente da perda direta, da } \\
\text { fragmentação ou isolamento de habitats. }\end{array}$ \\
\hline
\end{tabular}

EHB-02: Evitar interferências em áreas ambientalmente protegidas

\begin{tabular}{|c|c|c|}
\hline Indicador & Descrição & \multicolumn{1}{c|}{ Relevância } \\
\hline $\begin{array}{c}\text { EHB-02.1. Interferência } \\
\text { com áreas ambientalmente } \\
\text { protegidas }\end{array}$ & $\begin{array}{l}\text { Impacto em áreas protegidas pela } \\
\text { legislação ambiental. }\end{array}$ & $\begin{array}{l}\text { Contribui para quantificar o impacto } \\
\text { direto da construção e indireto durante a } \\
\text { operação em áreas protegidas pela } \\
\text { legislação ambiental, como APP e UC. }\end{array}$
\end{tabular}

EHB-03: Preservar as zonas úmidas de alta qualidade

\begin{tabular}{|c|c|c|}
\hline Indicador & Descrição & Relevância \\
\hline $\begin{array}{l}\text { EHB-03.1. Relação de zonas } \\
\text { úmidas afetadas e criadas }\end{array}$ & $\begin{array}{l}\text { Impacto da construção de } \\
\text { infraestrutura de transportes na } \\
\text { quantidade de áreas úmidas em } \\
\text { comparação com as novas zonas } \\
\text { úmidas criadas ou recuperadas }\end{array}$ & $\begin{array}{l}\text { Contribui para as agências adotarem } \\
\text { uma perspectiva ecossistêmica e } \\
\text { abrangente para evitar, minimizar ou } \\
\text { mitigar os impactos do projeto em } \\
\text { zonas úmidas, as quais são responsáveis } \\
\text { por importantes funções biológicas ou } \\
\text { hidrológicas. }\end{array}$ \\
\hline $\begin{array}{l}\text { EHB-03.2. Consistência } \\
\text { com planos de zonas } \\
\text { úmidas }\end{array}$ & $\begin{array}{l}\text { Consistência entre planos de } \\
\text { zonas úmidas e planos de } \\
\text { transporte }\end{array}$ & $\begin{array}{l}\text { Para as regiões que possuem planos de } \\
\text { conservação e manejo de áreas úmidas, } \\
\text { esta medida avalia o grau em que os } \\
\text { planos de projeto de transporte são } \\
\text { consistentes com o planejamento para } \\
\text { conservação de zonas úmidas da região } \\
\text { e o grau de coordenação com } \\
\text { instituições responsáveis e demais } \\
\text { partes interessadas. }\end{array}$ \\
\hline
\end{tabular}




\begin{tabular}{|c|c|c|}
\hline \multicolumn{3}{|c|}{ EHB-04: Conservar a fauna nativa } \\
\hline Indicador & Descrição & Relevância \\
\hline $\begin{array}{c}\text { EHB-04.1. Atropelamento } \\
\text { de fauna silvestre }\end{array}$ & $\begin{array}{l}\text { Impacto dos projetos de transporte } \\
\text { no número e características das } \\
\text { colisões entre animais e veículos }\end{array}$ & $\begin{array}{l}\text { Ajuda a identificar pontos de travessia } \\
\text { com risco de atropelamento de fauna } \\
\text { nativa, subsidiando medidas de } \\
\text { prevenção e mitigação. Essa medida } \\
\text { fornece um perfil específico da espécie } \\
\text { para a quantidade e distribuição } \\
\text { espacial e temporal das colisões. }\end{array}$ \\
\hline
\end{tabular}

\section{FA-09: EQUIDADE}

EQ-01: Melhorar a equidade de acessos e mobilidade

\begin{tabular}{|c|l|l|}
\hline Indicador & \multicolumn{1}{|c}{ Descrição } \\
$\begin{array}{c}\text { EQ-01.1. Equidade no } \\
\text { transporte }\end{array}$ & $\begin{array}{l}\text { Relevância } \\
\text { Distribuição justa dos benefícios de } \\
\text { investimento em transporte }\end{array}$ & $\begin{array}{l}\text { Permite avaliar se o investimento em } \\
\text { uma ampliação de infraestrutura de } \\
\text { transporte irá distribuir, de maneira } \\
\text { justa, os benefícios de transporte entre } \\
\text { os diversos grupos. }\end{array}$ \\
\hline
\end{tabular}

EQ-02: Reduzir os custos de transporte para comunidades de baixa renda

\begin{tabular}{|c|c|c|}
\hline Indicador & Descrição & Relevância \\
\hline $\begin{array}{c}\text { EQ-02.1. Capacidade de } \\
\text { pagamento }\end{array}$ & $\begin{array}{l}\text { Capacidade de pagamento pelo } \\
\text { transporte de grupos } \\
\text { desfavorecidos. }\end{array}$ & $\begin{array}{l}\text { Permite avaliar a quantidade de pessoas } \\
\text { de baixa renda em termos de transporte } \\
\text { que se beneficiam de uma melhoria da } \\
\text { acessibilidade devido a programas ou } \\
\text { projetos de transportes }\end{array}$ \\
\hline \multicolumn{3}{|c|}{ EQ-03: Distribuir as externalidades de forma equitativa } \\
\hline Indicador & Descrição & Relevância \\
\hline $\begin{array}{l}\text { EQ-03.1. Justiça } \\
\text { socioambiental }\end{array}$ & $\begin{array}{l}\text { Distribuição dos impactos } \\
\text { socioambientais }\end{array}$ & $\begin{array}{l}\text { Permite avaliar a distribuição relativa } \\
\text { dos benefícios e custos do projeto na } \\
\text { população afetada, com ênfase nos } \\
\text { grupos desfavorecidos. }\end{array}$ \\
\hline
\end{tabular}

\section{FA-10: QUALIDADE DE VIDA}

QV-01: Minimizar o ruído gerado na operação do projeto

\begin{tabular}{|c|c|c|}
\hline Indicador & Descrição & Relevância \\
\hline $\begin{array}{l}\text { QV-01.1. Alteração dos } \\
\text { níveis de ruído }\end{array}$ & $\begin{array}{l}\text { Alteração no nível de ruído nas } \\
\text { proximidades do projeto ao longo } \\
\text { da operação da rodovia }\end{array}$ & $\begin{array}{l}\text { Permite avaliar o impacto sonoro na } \\
\text { população lindeira ao longo da operação } \\
\text { do projeto rodoviário, cujo impacto pode } \\
\text { afetar a saúde das pessoas }\end{array}$ \\
\hline \multicolumn{3}{|c|}{ QV-02: Minimizar a Poluição Visual } \\
\hline Indicador & Descrição & Relevância \\
\hline $\begin{array}{c}\text { QV-02.1. Qualidade } \\
\text { Visual }\end{array}$ & $\begin{array}{l}\text { Alteração nas características } \\
\text { visuais que definem a identidade } \\
\text { da comunidade }\end{array}$ & $\begin{array}{l}\text { Elementos visuais ou estéticos que } \\
\text { representam a identidade da comunidade } \\
\text { podem ser significativamente afetados } \\
\text { por novos projetos de transporte. Assim, } \\
\text { esse indicador contribui para medir o } \\
\text { impacto da intrusão visual de uma nova } \\
\text { infraestrutura de transporte. }\end{array}$ \\
\hline
\end{tabular}




\begin{tabular}{|c|c|c|}
\hline \multicolumn{3}{|c|}{ QV-03: Evitar ou minimizar a segregação urbana } \\
\hline Indicador & Descrição & Relevância \\
\hline $\begin{array}{l}\text { QV-03.1. Coesão } \\
\text { Comunitária }\end{array}$ & $\begin{array}{l}\text { Mudança nas conexões físicas em } \\
\text { nível de vizinhança que unem } \\
\text { moradores e empresas }\end{array}$ & $\begin{array}{l}\text { A segregação urbana prejudica as } \\
\text { conexões físicas de vizinhança que unem } \\
\text { moradores e empresas, afetando a coesão } \\
\text { geral da comunidade. Portanto, esse } \\
\text { indicador auxilia na mensuração do } \\
\text { impacto de um projeto nas conexões de } \\
\text { vizinhança, que pode ser medida pelo } \\
\text { número de residências e empresas a } \\
\text { serem realocadas; mudança prevista em } \\
\text { viagens a pé; mudança nos tempos de } \\
\text { viagem entre os pontos vizinhos da } \\
\text { comunidade; e principais percursos } \\
\text { cortados ou reconectados como resultado } \\
\text { de um projeto. }\end{array}$ \\
\hline \multicolumn{3}{|c|}{ QV-04: Minimizar o risco ambiental e à saúde e segurança humana } \\
\hline Indicador & Descrição & Relevância \\
\hline $\begin{array}{l}\text { QV-04.1. Riscos e } \\
\text { emergências } \\
\text { socioambientais }\end{array}$ & $\begin{array}{l}\text { Análise e gerenciamento de riscos } \\
\text { e o atendimento a emergências } \\
\text { socioambientais }\end{array}$ & $\begin{array}{l}\text { A implantação de infraestrutura e a } \\
\text { operação da rodovia oferecem diversos } \\
\text { riscos de danos ambientais e à saúde } \\
\text { humana. Nesse sentido, o indicador } \\
\text { contribui para quantificação de } \\
\text { elementos essenciais para a adequada } \\
\text { gestão dos riscos. }\end{array}$ \\
\hline
\end{tabular}

Para cada indicador, foi elaborado uma ficha de avaliação contendo informações que auxiliam na sua operacionalização, com destaque à disponibilização de medidas de desempenho, que fornecem exemplos de como o desempenho do indicador pode ser quantificado e avaliado. As fichas de avaliação constam no Apêndice D.

Ao todo, foram elaboradas 36 fichas de avaliação e, portanto, 36 indicadores foram propostos para avaliação da sustentabilidade urbana na fase de planejamento de uma infraestrutura rodoviária, contando com diversas medidas de desempenho sugeridas para a quantificação do indicador, observando as diversas fases de planejamento. 


\subsection{ORIENTAÇÕES GERAIS PARA APLICAÇÃO DA ESTRUTURA CONCEITUAL}

Este item descreve os fatores a serem considerados ao selecionar indicadores, identifica possíveis técnicas e oportunidades gerais para quantificação de indicadores e discute os principais desafios para aplicação em agências de transporte.

\subsubsection{Possibilidades de Uso}

Litman (2003) e CST (2001) afirmam que a sustentabilidade é geralmente avaliada usando um conjunto de indicadores mensuráveis para indicar tendências, comparar áreas e atividades, avaliar determinadas políticas e opções de planejamento e definir metas de desempenho. Ao permitir a comparação das condições atuais com cenários futuros, o uso de um conjunto abrangente e integrado de indicadores torna-se uma ferramenta com valor prático, possibilitando estabelecer linhas de base, prever problemas, avaliar alternativas, selecionar projetos e avaliar uma determinada organização.

É nesse sentido que os sistemas de indicadores têm se demonstrado como ferramentas importantes para auxiliar tomadas de decisão e medir o progresso rumo à sustentabilidade no transporte, uma vez que são adequados para quantificação (medição), ajudando a determinar como decisões individuais de curto prazo afetam objetivos estratégicos de médio e longo prazo. Complementarmente, contribui para demonstrar transparência às partes interessadas, com ações de comunicação interna e externa.

Os indicadores possuem múltiplas finalidades. Segundo Ramani et al. (2011) e Zietsman \& Ramani (2011), os indicadores podem ser usados como:

- Descrição: Ajuda a descrever o efeito do seu programa ou política e compreender os aspectos da agência de negócios ou ações em termos de status e tendências atuais.

- Avaliação: Podem ser usadas para avaliar seu progresso e diagnosticar quais problemas ou barreiras você está enfrentando que precisam ser abordados. Introduz um juízo de valor em relação ao desempenho atual e tendências, envolvendo o uso de metas, valores de referência ou tendências.

- Prestação de contas: Elas podem ser usadas para identificar o desempenho para o qual uma determinada agência é responsável, especificamente um baixo desempenho em uma área-chave que precisa ser melhorado para se atender a um nível desejado.

- Apoio à decisão: Eles podem ajudar a avaliar, comparar, priorizar e selecionar entre alternativas e opções com resultados mais sustentáveis. Algumas aplicações 
determinam se deve ou não prosseguir com a ação proposta ou para seleção de alternativas. Outras aplicações podem comparar o desempenho de uma meta para auxiliar decisões de continuar ou modificar um programa, prática ou projeto.

- Comunicação: Podem ser usadas para comunicar às partes interessadas internas e externas o que seu programa ou política está alcançando, por meio de índices, números, tabelas, gráficos, pontuação e outras ferramentas de visualização, tais como painéis de controle. Mais frequentemente métodos utilizados mostrar condições, comparações, tendências e aderência aos objetivos, metas e alvos.

A avaliação pode ser vista como uma extensão da descrição; da mesma forma, a prestação de contas ou de apoio à decisão decorre da prática de avaliação. A Comunicação, por outro lado, é mais uma aplicação global que está implícito no uso de todas as outras aplicações, mas também é uma aplicação específica. Em que pese as diversas aplicações específicas, em geral são amplamente utilizadas para auxiliar nas tomadas de decisões.

Figura 16 - Relação entre os tipos de aplicação.

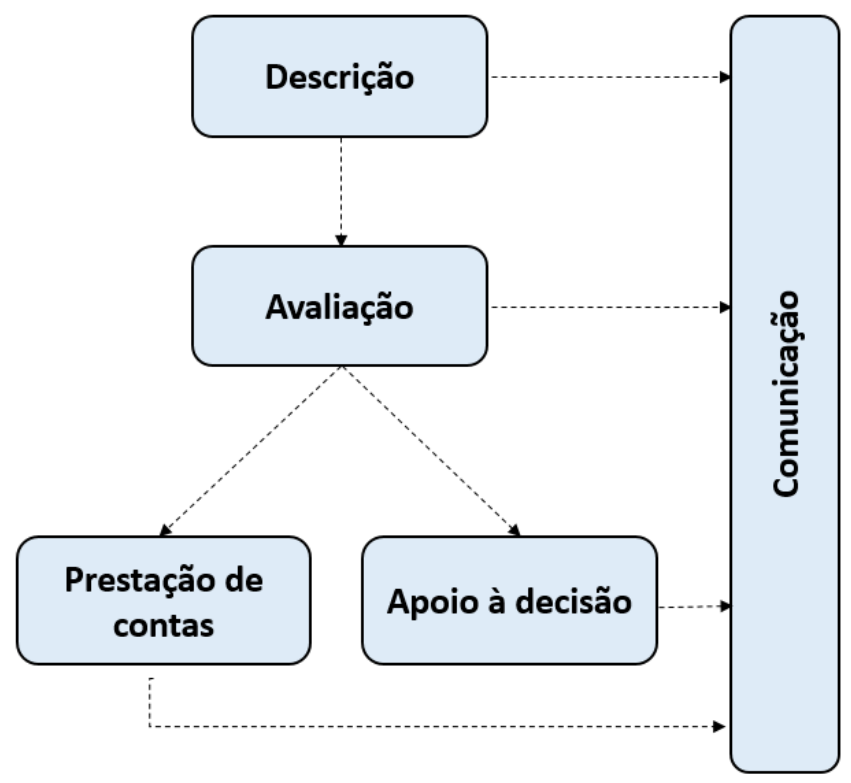

Fonte: Traduzido de Ramani et al. (2011)

Mitchell et al. (1995, apud MARSDEN et al., 2005) afirmam que os indicadores são necessários para dar sentido a "sistemas complexos" em que vivemos. Em particular, eles identificam quatro razões principais para usar indicadores, que são:

- Permitem a síntese de massas de dados;

- Mostram a posição atual em relação aos estados desejáveis;

- Demonstram progresso em direção a metas e objetivos;

- Comunicam o status atual às partes interessadas, para que possam ser tomadas decisões de gerenciamento eficazes que levem às metas estabelecidas. 
De qualquer maneira, apesar das principais aplicações das medidas de desempenho encontradas na literatura estarem listadas anteriormente, cabe ao interessado definir o melhor uso que atende às suas necessidades/finalidades. "O tipo de aplicação muitas vezes determina o tipo de medidas de desempenho a ser selecionado" (ZIETSMAN \& RAMANI, 2011). Uma vez definidos os objetivos organizacionais, os indicadores de desempenho são fundamentais para quantificar o desempenho de uma organização em relação a esses objetivos.

\subsubsection{Selecionando os Indicadores}

Indicadores são variáveis selecionadas e definidas para medir o progresso em direção a um objetivo, e devem ser capazes de refletir uma visão holística da sustentabilidade, ao invés de ficarem limitados a algumas áreas específicas. Portanto, os indicadores devem ser cuidadosamente selecionados para refletir os diversos impactos e perspectivas, sendo necessário, ao mesmo tempo, a viabilidade na coleta e análise. É importante que os usuários e analíticos de indicadores compreendam as suas perspectivas, premissas e limitações (LITMAN, 2008).

Embora o presente trabalho tenha proposto um conjunto de indicadores, a escolha exata dos indicadores para aplicação dependerá das prioridades, da negociação com as partes interessadas e do custo da obtenção dos dados. Os custos de coleta de dados e a facilidade de uso devem ser considerados ao selecionar os indicadores. No entanto, os indicadores não devem ser selecionados com base apenas na disponibilidade de dados, ou alguns objetivos importantes podem ser negligenciados e subestimados.

Vale ressaltar que a seleção de indicadores e medidas de desempenho em conjunto com as partes interessadas é um grande passo para tomar a decisão com maior aceitação pública, reduzindo o atraso na viabilização e entrega do empreendimento.

Os indicadores podem ser quantitativos ou qualitativos, e podem medir a realidade em termos absolutos ou relativos. Os indicadores quantitativos referem-se à informação medida numericamente, enquanto os qualitativos referem-se a outros tipos de informação, usualmente apresentados utilizando classificação com letras ou numeradas.

Muitos impactos são melhor avaliados usando indicadores relativos, como indicação de tendências ao longo do tempo, comparações entre diferentes grupos ou jurisdições, ou unidades como per capita ou por veículo. É recomendável que os indicadores sejam calculados de forma relativa e não em valores absolutos, a fim de possibilitar a avaliação entre diferentes cenários e localidades.

Litman (2008) alerta que os indicadores quantitativos, por serem considerados mais objetivos e fáceis de analisar, faz com que os impactos mais fáceis de mensurar tendam a ser mais valorizados, descartando-se aqueles considerados como "intangíveis"; o que não significa que sejam mais importantes. Por exemplo, as velocidades de tráfego 
de veículos são fáceis de medir, mas a capacidade de locomoção e a equidade, que são mais difíceis de quantificar, recebem menos consideração, sem justificativa de importância.

De acordo com Ramani et al. (2009), a seleção de medidas de desempenho adequadas é uma tarefa muito importante e deve se basear no tipo de análise (planejamento, operacional ou estratégica), nível de análise (projeto, rede ou regional) e a finalidade específica para a qual a medida deve ser usada (desempenho do sistema, seleção de projetos ou avaliação de impacto).

De toda maneira, a seleção de indicadores e medidas de desempenho apropriados é uma etapa de extrema importância, pois determinam os esforços para mensuração e seus resultados influenciam os tomadores de decisão, sendo que uma seleção equivocada pode levar a gastos excessivos de recursos e decisões equivocadas.

Assim, a estrutura proposta neste trabalho auxilia na sistemática para selecionar um subconjunto de indicadores, mediante prévia discussão conjunta com as partes interessadas, análise da viabilidade metodológica e relevância para o objeto de análise. Um modelo conceitual possível para utilização da estrutura é mostrado graficamente na figura abaixo.

Figura 17- Modelo conceitual de aplicação potencial da estrutura.

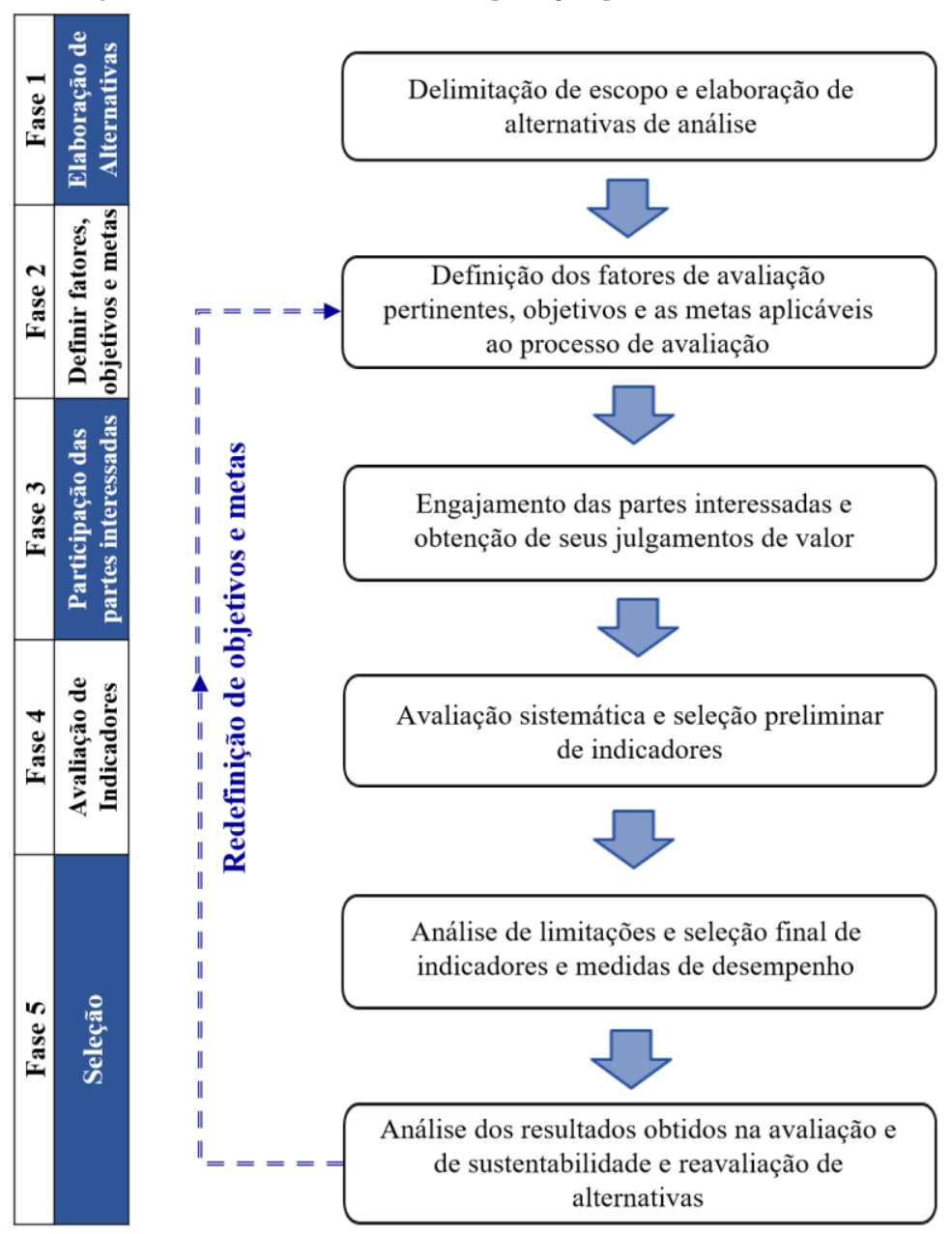


O Quadro 18 apresenta um conjunto de atributos para orientar a seleção de bons indicadores / medida de desempenho.

Quadro 18 - Atributos de bons indicadores de transporte.

Atributos

\begin{tabular}{c} 
Abrangência \\
\hline Relevância \\
\hline Comparável \\
\hline Mensurável \\
\hline $\begin{array}{c}\text { Qualidade de } \\
\text { dados }\end{array}$
\end{tabular}

\section{Compreensível}

Útil

Acessível e
transparente

Os indicadores devem refletir vários impactos econômicos, sociais e ambientais e várias atividades de transporte (como transporte pessoal e de carga). Uma gama adequada de estatísticas deve ser coletada para permitir vários tipos de análise.

Deve ser aplicável e compatível com as metas, objetivos, questões e estratégia da organização / projeto.

A coleta de dados deve ser padronizada para que os resultados sejam adequados para comparação entre várias jurisdições, períodos e grupos.

Os dados precisam estar disponíveis e serem viáveis para coletar com a qualidade adequada, e as ferramentas precisam existir para realizar os cálculos necessários. Quando um indicador não é mensurável, ele deve ser rejeitado.

Os métodos de coleta de dados devem refletir altos padrões para garantir que as informações sejam precisas e consistentes, baseando-se em informações de qualidade e origem conhecidas.

Os indicadores devem ser compreensíveis aos tomadores de decisão e ao público em geral. Deve ser de fácil entendimento, apresentando informações simples. Altos graus de agregação de informações podem reduzir a compreensão de um indicador e aumentar o risco de dupla contagem de elementos "ocultos" desse indicador.

Os indicadores devem ser úteis para os tomadores de decisão. A utilidade e o valor dos indicadores individuais podem variar em importância entre as fases do projeto, jurisdições e partes interessadas.

\begin{tabular}{cl} 
transparente & devem estar acessíveis para revisão de todas as partes interessadas. \\
\hline Custo efetivo & $\begin{array}{l}\text { O conjunto de indicadores deve ser econômico para ser coletado. O valor de decisão dos } \\
\text { indicadores deve compensar o custo de coletá-los. }\end{array}$ \\
\hline Efeitos líquidos & $\begin{array}{l}\text { Os indicadores devem diferenciar entre impactos líquidos (totais) e mudanças de impactos } \\
\text { em diferentes locais e períodos. }\end{array}$ \\
\hline
\end{tabular}

\begin{tabular}{cl}
\hline Nível de detalhe & $\begin{array}{l}\text { O tipo de dados e a escala devem ser apropriados para apoiar a análise desejada. Os dados } \\
\text { e os requisitos de escala podem mudar em estágios e medidas. }\end{array}$ \\
\hline Sensível & Deve detectar um certo nível de mudança que ocorre no sistema de transporte. \\
\hline Funcional & Deve ser adequado para estabelecer metas de desempenho utilizáveis. \\
\hline $\begin{array}{c}\text { Indicativo de } \\
\text { tendências }\end{array}$ & $\begin{array}{l}\text { Devem ser capazes de mostrar tendências ao longo do tempo e fornecer alertas } \\
\text { antecipados sobre problemas e tendências irreversíveis. }\end{array}$ \\
\hline Desagregação & $\begin{array}{l}\text { Os dados dos indicadores podem precisar ser desagregados para apoiar tipos específicos } \\
\text { de análise, como por atividade de viagem (modo, localização, período de tempo, tipo de } \\
\text { veículo, finalidade da viagem), demografia (idade, classe de renda, habilidade física, } \\
\text { grupo étnico) e área geográfica (particularmente por região urbana). }\end{array}$ \\
\hline $\begin{array}{c}\text { Unidades de } \\
\text { Referência }\end{array}$ & $\begin{array}{l}\text { Tratam-se de unidades de medida normalizadas para facilitar comparações, como por ano, } \\
\text { per capita, por quilômetro, por viagem, por veículo-ano etc. A seleção de unidades de } \\
\text { referência pode afetar como os problemas são definidos e as soluções priorizadas. }\end{array}$ \\
$\begin{array}{c}\text { Metas de } \\
\text { desempenho }\end{array}$ & $\begin{array}{l}\text { As metas de desempenho são objetivos mensuráveis específicos a serem atingidos em um } \\
\text { prazo estabelecido. Essas metas são úteis para motivar e avaliar o progresso em direção à } \\
\text { sustentabilidade. }\end{array}$ \\
\hline
\end{tabular}

Fontes: Baseado em Zietsman (2000), Litman (2003, 2008, 2016), Costa (2003), Gudmundsson (2004), Marsden et al. (2005), Jeon (2007), SHRP 2 (2009), Ramani et al. (2009), Zietsman \& Ramani (2011). 
Mesmo na intenção de contemplar todos os atributos listados acima, a possibilidade de conciliar todos esses critérios é diminuta. Portanto, deve-se julgar os critérios que sejam considerados mais importantes pelos envolvidos no caso em particular, preferencialmente com o máximo de envolvimento das partes interessadas.

Ao selecionar indicadores, é importante ser realista, levando em consideração a disponibilidade, a clareza e a utilidade dos dados na tomada de decisões, bem como a habilidade e a viabilidade de coleta de dados pela organização interessada, evitando, sobretudo, que o conjunto de indicadores selecionados não resulte em interpretações equivocadas.

Corroborando com SHRP 2 (2009), os esforços na mensuração de indicadores devem se concentrar naqueles vitais, sem o uso de um número excessivo ou redundantes, pois pode sobrecarregar o usuário final e "ofuscar" informações importantes. Do ponto de vista operacional, recomenda-se restringir os indicadores a um número suficiente para julgamento, reduzido o bastante para não dificultar ou inviabilizar a aplicação. Portanto, utilizar um número excessivo de indicadores ou que não sejam relevantes para o contex to de aplicação seria um esforço desnecessário e sem benefícios esperados.

Alguns indicadores podem ser identificados por meio de processos top-down relativas aos princípios fundamentais da política brasileira. Outros são melhores desenvolvidos através de participação das partes interessadas, pois isso pode assegurar que os aspectos mais importantes sejam medidos e que os usuários finais compreenderão os resultados.

“As partes interessadas, especialmente aquelas responsáveis pelos resultados, devem estar envolvidas na decisão sobre o que medir, como medir e como transmitir os resultados" (SHRP 2, 2009). O envolvimento da comunidade afetada na definição dos indicadores é uma importante oportunidade de participação social e de apresentar resultados de desempenho mais transparente pelos seus responsáveis, em busca de constatar necessidade de melhorias.

De acordo com Philippi Jr., Malheiros e Aguiar (2005), o processo de elaboração dos indicadores deve ser participativo, envolvendo especialistas na área em diferentes setores da sociedade, possibilitando uma definição conjunta de objetivos e metas para a elaboração dos indicadores.

Para Oltean-Dumbrava et al. (2014, apud FURBEG, 2014) existem duas abordagens gerais para o desenvolvimento de estruturas de sustentabilidade para projetos de infraestrutura: a abordagem top-down e uma abordagem bottom-up. Na abordagem de top-down, a estrutura de sustentabilidade e os critérios de sustentabilidade são definidos por especialistas, enquanto no bottom-up são feitas por várias partes interessadas. Os autores afirmam que é preferível combinar essas abordagens, denominada como metodologia TDBU, pois a abordagem top-down pode resultar na negligência de critérios importantes que só seriam identificáveis através de consultas com as partes interessadas, enquanto a abordagem bottom-up poderia implicar um processo que leva muito tempo e 
a um modelo que é muito complexo. Na metodologia TDBU, especialistas fornecem uma definição para a sustentabilidade, uma estrutura prévia e sugestões para critérios e indicadores de sustentabilidade, enquanto o papel das partes interessadas é comentar e validar os critérios de sustentabilidade sugeridas.

\subsubsection{Principais Técnicas de Coleta e Tratamento de Dados}

Dentre as técnicas e oportunidades para coleta de dados que podem ser utilizadas para fornecer dados para sistemas de medição de desempenho com o uso de indicadores, SHRP 2 (2009) destaca-se as seguintes:

1. Uso de sensoriamento remoto: A tecnologia de sensoriamento remoto é usada em conjuntos de dados que seriam demasiadamente caros e/ou demorados de coletar por meio de levantamento de campo. A disponibilidade de imagens de sensoriamento remoto fornece informações básicas valiosas para o planejamento de longo prazo e seleção de alternativas. Os recursos necessários, incluem: coleta de dados (fotografia aérea e imagem de satélite); software de processamento de imagens; educação e treinamento de funcionário; desenvolvimento de métodos específicos para análise e tradução de imagens; e desenvolvimento de formatos de apresentação de informação eficazes.

2. Aplicações de SIG (Sistema de Informações Geográficas): As ferramentas baseadas em SIG incorporam várias camadas de dados (layers) e facilitam tarefas de análise específicas. Essa técnica é de extrema utilidade para planejadores, engenheiros de projeto e equipes de estudos ambientais. Aplicações específicas incluem análise integrada com base em dados de transporte, ambientais, uso do solo, sociais e culturais; fornecimento de sobreposições regionais de planos, programas e projetos de outras instituições; análise da vulnerabilidade das instalações de transporte relacionadas a mudanças climáticas; etc.

3. Modelagem e simulação matemática: Além de poder utilizar indicadores para calcular as condições existentes, a utilização de simulação e modelagem matemática permite avaliar também cenários futuros. As aplicações potenciais incluem a avaliação de impacto para propostas de programas e projetos, assim como análise das implicações de vários cenários de interesse. $\mathrm{Na}$ área de transporte tem sido comum o uso para simular alterações de tráfego, previsão de impacto sonoro, modificação do uso e ocupação do solo / expansão urbana e análise de vulnerabilidade.

4. Parcerias Interinstitucionais: As organizações podem compartilhar dados e informações quando se trata de sustentabilidade. As agências ambientais e de transporte, as secretarias, os institutos e os conselhos gestores de Unidades de Conservação nos níveis federal, estadual e municipais dispõem de uma grande quantidade de dados que são úteis para apoiar estruturas de avaliações de 
desempenho com uso de indicadores. As parcerias podem ser realizadas em todos os níveis do governo e com empresas privadas, quando for o caso, para fortalecer ainda mais as iniciativas de compartilhamento de dados, alavancar os recursos de monitoramento existentes e, em conjunto, buscar o desenvolvimento de novos conjuntos de dados e ferramentas que atendam às necessidades comuns e coletivas.

5. Compartilhamento de dados: Um pré-requisito para a integração e o compartilhamento de dados em diferentes produtores e usuários de dados é a disponibilidade de metadados que documentam o conteúdo do conjunto de dados, a derivação, a precisão e a adequação para fins específicos.

Para análise dos resultados obtidos com o uso de indicadores, usualmente, adotase valores de referência para comparação/avaliação; acompanha-se tendências de resultados a partir de uma série histórica; qualifica-se os resultados em bom ou ruim; estabelecem-se escalas, definindo os dois extremos que representem os melhores e piores valores possíveis; entre outras possibilidades. A escala de 0 a 1 ( 0 corresponde ao pior cenário e 1 corresponde ao melhor cenário) é normalmente usada para combinar os resultados de todo o conjunto de indicadores em uma base comum. Mais detalhes sobre o cálculo dos extremos de escala para as medidas de desempenho são apresentados em Ramani et al. (2009).

Para comparação de alternativas para tomada de decisão, deve-se escolher os critérios e indicadores pertinentes, atribuir pesos aos indicadores, utilizando uma análise multicriterial. A alocação de pesos pode ser uma questão controversa devido à sua subjetividade e possível impacto nos resultados finais, com base em juízos de valor sobre a importância relativa dos diferentes fatores de sustentabilidade. Por outro lado, o uso de pesos também permite que o analista e o tomador de decisão ajustem pesos de acordo com a importância relativa dos critérios em uma arena política aberta, incorporando efetivamente os objetivos e prioridades regionais ao longo do tempo.

O planejamento de infraestrutura de transporte pressupõe a simulação de cenários para auxiliar as tomadas de decisão. Nesse sentido, a utilização de ferramentas de modelagem matemática se mostram fundamentais para alcançar resultados mais sustentáveis. É pertinente que os cenários façam parte dos estudos socioambientais e sejam discutidos de forma mais ampla com representantes da sociedade. Com cenários e seus desdobramentos mais precisos e claros, as informações podem contribuir para tomadas de decisão mais assertivas e facilitar o entendimento e participação pública nas decisões.

O EIA e a AAE, pela natureza prospectiva, são estudos que deveriam contemplar as modelagens matemáticas, com informações reais da capacidade de suporte do território, de forma a se obter uma previsão dos impactos dos usos propostos e das demandas a serem geradas. Dessa forma, a utilização de simulações de cenários por modelagem matemática ajuda a compreender se as alternativas avaliadas estão no 
caminho da sustentabilidade, uma vez que permite conhecer previamente problemas futuros e as potencialidades, nas mais diferentes escalas espaciais e temporais, para antecipar soluções.

Com o avanço da tecnologia, a simulação de cenários por modelagem matemática tem aplicações bastante amplas, contando com inúmeros softwares para auxiliar os profissionais na simulação e interpretação dos resultados, com interface "amigável", permitindo gerenciar os cenários em função da base de dados inserida no sistema. Dentre as aplicações no setor de transporte mais usuais encontradas na literatura, pode-se listar as seguintes: simuladores urbanos, alteração de fluxo de tráfegos, emissão de poluentes atmosféricos, predição de ruído ambiental, análise de vulnerabilidade e avaliação de risco.

\subsubsection{Comunicação com as Partes Interessadas}

De maneira geral, as partes interessadas são indivíduos ou organizações que são afetadas ou afetam o desenvolvimento do empreendimento. As partes interessadas desempenham um papel importante na definição das questões gerenciais do empreendimento. Portanto, capturar sua contribuição é um componente crucial do processo de desenvolvimento do projeto (EL-GOHARY et al., 2006).

As partes interessadas são grupos ou indivíduos que têm participação nos vários procedimentos e etapas de um empreendimento rodoviário e são bastante diversificados, em termos de atribuições, qualificações e experiências profissionais, nível funcional / institucional, o que torna o processo do desenvolvimento das atividades muito complexo. As partes interessadas em infraestruturas rodoviárias abrangem uma ampla variedade de pessoas e organizações. Quanto maior a complexidade, intervenção e abrangência do empreendimento, mais diversificadas e numerosas serão as partes interessadas.

O governo é tradicionalmente visto como o principal stakeholder diretamente envolvido no desenvolvimento da infraestrutura rodoviária. É o governo que tem o papel de viabilizar os empreendimentos e, com isso, fornecer condições de acesso à população. Usualmente os políticos envolvidos buscam atender às pressões e interesses de seus eleitores e de políticos locais no sentido de obtenção de verbas para a execução do empreendimento ou, muitas vezes, apoiam-se nele por interesses eleitorais.

El-Gohary et al. (2006) classificaram as partes interessadas em infraestrutura em três tipos:

- Stakeholder responsável - refere-se a uma organização ou a um indivíduo que possui algum grau de responsabilidade ou responsabilidade em relação ao processo de desenvolvimento;

- Stakeholder afetado - refere-se a uma organização ou pessoa que é afetada direta ou indiretamente pelo processo de desenvolvimento; e 
- Stakeholder interessado - refere-se a uma organização ou pessoa que não é diretamente afetada pelo projeto, mas que gostaria de participar e fornecer sua opinião no processo de desenvolvimento da infraestrutura.

Para que um empreendimento rodoviário seja concretizado, são necessários a identificação e o engajamento das partes interessadas para viabilizar e aperfeiçoar o projeto, tanto internas e externas, como contrários ou não ao plano, programa ou projeto. Dessa forma, para facilitar a comunicação dos resultados da avaliação, os potenciais stakeholders foram agrupados e classificados, conforme figura a seguir:

Figura 18 - Grupos de partes interessadas de empreendimentos rodoviários, seguindo a classificação de El-Gohary et al. (2006).

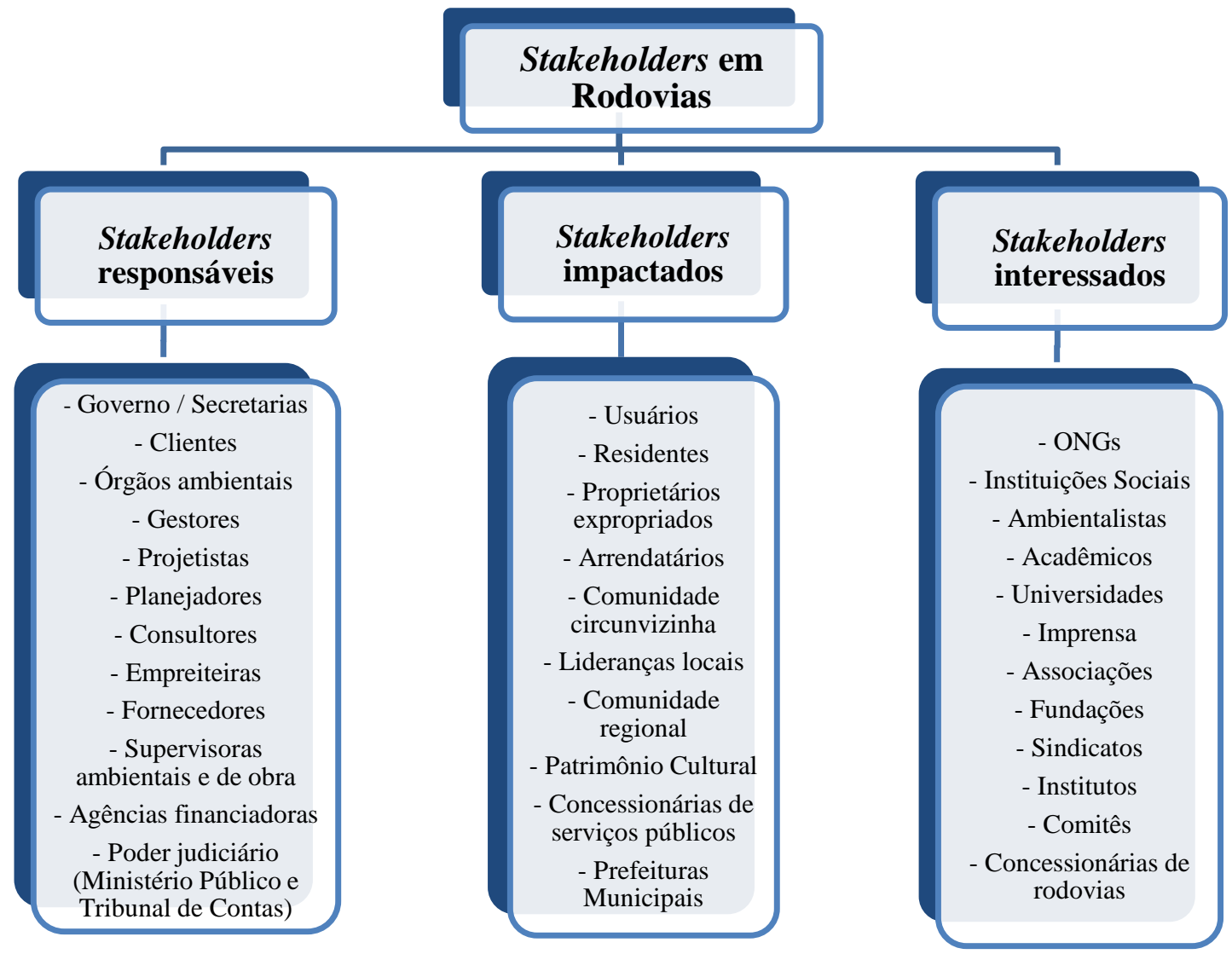

Cada grupo se relaciona com o empreendedor responsável de uma forma específica. Os "responsáveis" visam garantir que o empreendimento seja executado com a qualidade técnica e recursos necessários, dentro dos requisitos legais. Os "impactados", por sua vez, não querem que o empreendimento os prejudiquem de alguma forma ou, quando inevitável, que seja o mínimo possível ou que sejam compensados, retirando o máximo de vantagens do empreendimento. Já os “interessados" pressionam os responsáveis de acordo com os seus interesses ou objetivos, podendo reivindicar algum item de discordância, fomentam o desenvolvimento da tecnologia e a produção de informações. 
A interação complexa entre os fatores de transporte, uso do solo e múltiplas partes interessadas dificulta a implementação de iniciativas de sustentabilidade nos empreendimentos rodoviários. Como possuem visões, interesses e competências diversos, normalmente, as partes interessadas defendem posições conflitantes entre si.

Diante disso, a utilização de indicadores para a identificação e consideração dos componentes relevantes para as diversas partes interessadas facilita a negociação e tratativas entre os atores envolvidos. Além disso, quando se define os indicadores dentro de um ambiente colaborativo, as partes interessadas de diferentes setores (governo local, agências de transporte, empresas, comunidades, etc.) podem construir a apropriação da estratégia e desenvolver mecanismos conjuntos para implantação. Para cada um deles, podem ser traçadas as estratégias de relacionamento e de atendimento às necessidades e expectativas de cada grupo de interesse, incluindo-os nos processos gerenciais.

É necessário reconhecer que a sustentabilidade requer abordagens multi e transdisciplinares para identificar e enfrentar ameaças e riscos críticos para a sustentabilidade provenientes de infraestrutura rodoviárias em futuros de curto, médio e longo prazo. Isso ajudará a atingir os objetivos de sustentabilidade e, ao mesmo tempo que contribui para satisfazer as necessidades das partes interessadas, resultando em uma situação "ganha-ganha".

\subsubsection{Desafios Esperados}

O desenvolvimento de métricas para empreendimentos de transporte enfrenta vários desafios. Um deles é a própria seleção e a definição das métricas, seguido da sua adoção e utilização dessas métricas por um grande número de empreendedores.

A obtenção de dados aplicáveis e completos, que representem a linha base e as previsões futuras, pode ser um grande desafio para usar medidas de desempenho para avaliação de sustentabilidade, visto que muitos dados geralmente não estão disponíveis e devem ser obtidos e previstos para serem usados. Isso requer tempo e recursos (financeiros, humanos e materiais) que podem não estar disponíveis ou previstos, acarretando no desinteresse pelos funcionários de agências, entre outros.

Ramani et al. (2011) listaram os seguintes desafios que dificultam a implementação e uso de indicadores em agências de transportes, sendo as principais:

a. Transformar metas em ações mensuráveis - Muitas agências são capazes de identificar, concordar e definir metas que incluem conceitos de sustentabilidade, mas encontram dificuldades para implementar programas que ajudarão a alcançar esses objetivos. Identificar formas de rastrear efetivamente o progresso em direção a essas metas também é um desafio.

b. Entender os trade-offs - As agências estão lutando para entender, medir e acompanhar as inter-relações entre os aspectos da sustentabilidade e como 
determinar as implicações desses trade-offs.

c. Escopo externo à agência - Alcançar a sustentabilidade requer a cooperação de muitas agências e entidades com uma série de responsabilidades. As agências de transporte, por exemplo, entendem que muitas das questões não estão dentro de sua jurisdição. Ainda há uma falta de compreensão de como as políticas e práticas das agências de transporte se encaixam no conceito mais amplo de sustentabilidade e discordância sobre quais deveriam ser os papéis institucionais apropriados das agências de transporte.

d. Medição no nível de projeto - As agências consideram que é mais fácil considerar os impactos à sustentabilidade em escala regional e é difícil mensurá-los projeto a projeto.

e. Consistência de dados - A disponibilidade de dados consistentes e confiáveis entre as jurisdições pode ser um fator limitante na medição do desempenho da sustentabilidade.

f. Priorização - Numa recessão econômica, algumas agências concluíram que não tinham outra escolha a não ser colocar a sustentabilidade em segundo plano enquanto lutavam com cortes orçamentários e outras prioridades concorrentes.

g. Conceitos difíceis de medir - As agências ainda estão lutando em como medir tudo de maneira significativa. Por exemplo, é difícil medir efetivamente a igualdade de gênero no transporte.

h. Implementando as informações - As medidas de desempenho de sustentabilidade são frequentemente citadas pelos tomadores de decisão, mas ainda não está claro o quanto elas realmente influenciam as decisões tomadas. Muitos funcionários entendem a missão geral, mas não entendem claramente como ela se relaciona diretamente com o trabalho deles.

i. Custo - Em alguns casos, pode ser difícil provar que o custo mais alto para alcançar um resultado de sustentabilidade vale a pena o trade-off; em outros casos, práticas sustentáveis são sinônimo de redução de custos.

Talvez um dos desafios mais importantes a ser enfrentado no Brasil seja a mudança institucional para o desenvolvimento e implementação de políticas e programas de transporte sustentáveis. O progresso na sustentabilidade do transporte depende da capacidade das agências de transporte de reconhecer seus limites organizacionais.

Além disso, a falta de uma regulamentação que trate explicitamente da sustentabilidade no transporte não incentiva as agências de transporte os elementos importantes de forma integrada. Enquanto isso, muitas agências de transporte brasileiras estão tratando a agenda de sustentabilidade sob uma forma não integrada visando cumprir o mínimo estabelecido em normas ambientais, sociais e setoriais existentes, tomando decisões com foco a curto prazo e sem a utilização de ferramentas flexíveis e fáceis de usar que facilite a análise quantitativa. 


\section{CAPÍTULO 5 - CONSIDERAÇÕES FINAIS}

Esta pesquisa contribui para incorporar considerações de sustentabilidade em planejamento de transporte rodoviário. O estudo apresenta o estado da arte e as práticas de abordagem de sustentabilidade em infraestrutura de transporte. A partir da revisão bibliográfica, este trabalho contribuiu para o alinhamento de conceitos, relacionando o transporte com a sustentabilidade urbana. A pesquisa apresentou ainda várias formas e tipos de aplicações de avaliação em infraestrutura de transporte alinhadas aos princípios da sustentabilidade, identificando ferramentas e abordagens diversas.

Além disso, ao fornecer conceitos de sustentabilidade urbana e aplicados aos transportes, bem como apresentar um estudo de caso de infraestrutura rodoviária, o trabalho contribui conceitualmente e metodologicamente para que futuros investimentos em transporte sejam realizados considerando aspectos estratégicos para a sustentabilidade. A ênfase dada no planejamento rodoviário foi considerada relevante por se tratar da matriz de transporte do Brasil, pela projeção de crescimento de demanda e por interferir significativamente no alcance dos objetivos da sustentabilidade urbana.

Com a compreensão da relação de rodovias com as questões urbanas significativas e com a análise de ferramentas de avaliação existentes e de um estudo de caso, foi possível obter informações que subsidiaram a estruturação de fatores relevantes que devem ser considerados no planejamento de rodovias em regiões metropolitanas. Essa estruturação consistiu numa tentativa de sistematizar os estudos de avaliação em critérios e indicadores que poderão ser considerados nas tomadas de decisão em novas infraestruturas. Dessa forma, o projeto atingiu seu objetivo geral, ao desenvolver uma estrutura para auxiliar na avaliação da sustentabilidade em rodovias, composta por objetivos, metas e indicadores.

Tendo em vista a subjetividade que envolve o tema Sustentabilidade e a relação complexa entre o transporte e as questões urbanas, a estrutura de avaliação emergiu da necessidade de tornar o planejamento de infraestrutura de transporte mais operacional e mensurável, que poderá auxiliar gestores e tomadores de decisão a ampliar suas perspectivas de planejamento, considerando fatores de sustentabilidade de forma mais integrada, uma vez que sistematiza indicadores associados a objetivos e metas estratégicos.

A partir da estrutura sistematizada, espera-se que o trabalho contribua mais especificamente para:

- Promover tomadas de decisões na fase de planejamento de rodovias baseadas nos princípios da sustentabilidade urbana;

- Conectar os princípios da sustentabilidade com ações práticas na implantação de novos empreendimentos rodoviários;

- Auxiliar no desenvolvimento de estudos, políticas, planos, programas e projetos; 
- Apoiar a avaliação de alternativas de traçado em nível de projeto e avaliação de impactos socioambientais significativos;

- Auxiliar empreendedores rodoviários na gestão proativa dos impactos urbano-ambientais;

- Ajudar agências de transporte a aplicarem os conceitos de sustentabilidade no planejamento de novas infraestrutura;

- A estruturação de sistemas de dados e informações, possibilitando o desenvolvimento de uma plataforma web;

- O desenvolvimento de ferramentas para mensurar a sustentabilidade em infraestrutura de transporte, ajudando os usuários a identificarem lacunas na concepção de novos empreendimentos;

- Melhorar a comunicação com as diversas partes interessadas;

- Incentivar gestores e projetistas a adotarem abordagens mais sustentáveis.

Espera-se, sobretudo, que a estrutura conceitual resultante desta pesquisa possa contribuir para que agências de transporte, em qualquer nível organizacional, coloquem em prática a sustentabilidade, a partir da sua aplicação (ou adaptação) em seu planejamento estratégico, considerando cada vez mais a coordenação interinstitucional, a participação pública e demais partes interessadas.

Apesar de os usuários potenciais da estrutura de medição de desempenho serem as agências de transporte, os órgãos municipais e ambientais também podem encontrar elementos úteis para ajuda-los no planejamento ou avaliação de sistemas de transporte. Ao permitir a visualização dos avanços, das tendências e do desempenho dos resultados de planos de transporte, contribuirá também para corrigir os rumos das políticas regionais e planejamentos territoriais através de uma gestão integrada dos empreendedores com as demais instituições envolvidas na gestão de territórios municipais e metropolitanos.

Em função dos potenciais impactos indiretos das rodovias no contexto territorial, os indicadores propostos poderão proporcionar as seguintes aplicações práticas:

- Prover uma visualização síntese dos resultados alcançados, da evolução da situação socioeconômica e ambiental das áreas de influência, bem como das influências dos empreendimentos estruturantes e dos projetos e intervenções previstos;

- Medir os impactos, os resultados e o desempenho de ações e processos previstos em Planos Diretores;

- Monitorar e medir o impacto da evolução e dinâmica das realidades econômicas, sociais, urbanas e ambientais da região de interesse; 
- Permitir entendimento sobre a estrutura e dinâmica demográfica, destacando os diversos espaços em relação a sua expansão, densidade, grau de urbanização e estratificações sociais;

- Identificar os fluxos metropolitanos abrangendo informações sobre as mobilidades e trocas no interior da região metropolitana e sua relação com os polos metropolitanos existentes.

Ressalta-se, no entanto, que a estrutura não deve considerada um produto definitivo, mas sim uma ideia em construção, que abarca as principais questões relacionadas ao tema, promovendo a operacionalização do planejamento de infraestrutura rodoviária, ou de outros modos. Com isso, espera-se que a mesma sirva como referência para outras que vierem a ser elaboradas.

Quanto ao conjunto de indicadores selecionados neste trabalho, é importante ressaltar que a constituição se apresenta de forma genérica, buscando contemplar uma diversidade de aplicações potenciais, o que exige uma adaptação dos mesmos para cada espaço geográfico e tipos de estudos a ser realizado, a partir de uma seleção prévia daqueles que mais retratam a realidade investigada, os objetivos estabelecidos e as condições locais.

Por se tratar de uma estrutura conceitual e genérica, recomenda-se que, após definido o escopo de aplicação e antes da aplicação da estrutura, promova-se um processo de escolha dos indicadores com a participação e consulta a especialistas, atores locais, institucionais e a população, como forma de melhor captar as expectativas, anseios e necessidades das partes interessadas. Esse processo poderia ser realizado utilizando métodos de consulta, como brainstorm, estudo delphi, entrevistas, atribuição de peso, etc., para definir quais serão os indicadores a serem mensurados, dentre aqueles viáveis. A viabilidade, por sua vez, deve considerar a compreensão das limitações de uso, uma vez que as agências de transporte e demais interessados têm diferentes níveis de experiência e recursos disponíveis.

Considerando que não foi possível a aplicação da estrutura desenvolvida neste projeto de pesquisa como uma ferramenta de uso em um caso real, especialmente em função da complexidade de obtenção dos dados, custos e reduzido tempo disponível para uma pesquisa em nível de mestrado, a sua utilização pode demonstrar fragilidades práticas que não foi possível identificar neste trabalho, ainda que sua elaboração tenha se baseado em estudos de caso e em estruturas existentes internacionalmente. Dessa forma, é recomendável a aplicação em um empreendimento real, com vista ao refinamento da ferramenta e obtenção de feedback de especialistas para aperfeiçoamento.

Por apresentar uma vasta discussão a respeito dos princípios orientadores de sustentabilidade aplicados ao transporte e dos métodos de avaliação, o conteúdo e os resultados desta pesquisa poderia assumir a forma de um roteiro metodológico para que profissionais do setor de transporte tomem decisões cada vez mais sustentáveis, em nível estratégico e preliminar. 
De todo modo, entende-se que o uso de estruturas de avaliação apenas será prática recorrente e consolidada no Brasil a partir da institucionalização e normatização de sistema de indicadores aplicáveis à empreendimentos de transportes, com estruturas de governança - pública e privada - mais comprometidas e transparentes com a população, que inclua o uso de indicadores como ferramenta nos processos decisórios. É nesse sentido, que esta pesquisa pode ser considerada como um tímido começo, para encorajar novos esforços no desenvolvimento de um conjunto de indicadores, com mais precisão e padronização na avaliação da sustentabilidade em instituições brasileiras.

Por fim, num sentido mais amplo, entende-se que o estudo tem o potencial de contribuir para uma reflexão mais ampla sobre temas que envolvem a implantação de empreendimentos de grande impacto no ambiente urbano e, com isso, incentive o desenvolvimento de cidades cada vez mais justas, democráticas e sustentáveis para toda a população.

\subsection{RECOMENDAÇÕES DE TRABALHOS FUTUROS}

A estruturação de objetivos, metas e indicadores podem ser um passo inicial no sentido de se desenvolver uma ferramenta prática para avaliar a sustentabilidade de uma nova rodovia, podendo ser aplicada em certificações e classificação de novos empreendimentos, a partir do estabelecimento de métricas com pontuações e créditos.

A ferramenta poderia auxiliar no desenvolvimento de um Sistema de Apoio à Tomada de Decisão, baseado nos fundamentos da sustentabilidade, construído em sistema computacional, para auxiliar em tomadas de decisões cada vez mais lógicas na seleção e avaliação de alternativas estratégicas. Para tanto, é necessário avançar em estudos de pesquisas de banco de dados, métodos de simulação e informatização da estrutura.

Com relação à obtenção de dados, essenciais para alcançar resultados mais confiáveis, recomenda-se o avanço em estudos que estabeleçam uma padronização das práticas de coleta de dados e de mensuração de indicadores, haja vista os inúmeros softwares, fontes existentes, metodologias, modelos e escalas que podem ser utilizadas no cálculo. A partir de uma padronização, será possível realizar a classificação e comparação entre políticas, planos, programas e projetos de transporte de diferentes localidades do País, com resultados mais confiáveis.

Assim, como recomendações para estudos e desenvolvimento de trabalho futuros, destacam as seguintes:

- Identificar fontes de dados necessários para quantificar os indicadores, definir as formas de obtê-los e desenvolver equações para quantificá-los; 
- Desenvolver uma ferramenta de análise, de fácil uso e boa representação gráfica, na forma de uma calculadora baseada em planilhas, que podem quantificar os indicadores selecionados;

- Executar aplicações piloto da ferramenta de análise em estudos de caso, tanto com dados compilados para um cenário que represente as condições atuais, como cenários que representam projeções futuras;

- Elaborar um guia para usuários interessados no uso da ferramenta de análise, na forma de um roteiro metodológico para o planejamento de infraestrutura.

Os resultados das recomendações acima podem ser potencializados se a ferramenta for desenvolvida em uma plataforma específica, preferencialmente web, permitindo ampla aplicação. Assim, essa ferramenta poderia incluir um banco de dados de indicadores organizados em torno dos vários fatores de planejamento identificados nas diferentes áreas. Para cada um desses fatores, a ferramenta da web pode fornecer informações descritivas, documentação pertinente e legislação envolvida, bem como relatórios de estudos de caso para ilustrar o uso prático de indicadores.

Os dados de entrada necessários para calcular os indicadores podem estar disponíveis ou interligados com banco de dados de outras instituições, integrando-se as bases de dados das instituições envolvidas ou dispor de orientações para levantamento de dados primários. A promoção de um banco de dados único, organizado e o acesso livre às partes interessadas, pode contribuir para a integração interinstitucional.

O sistema integrado pode ser desenvolvido com análises pré-programadas, de modo que a inserção de novas informações no banco de dados (como por exemplo um novo empreendimento inscrito no Graprohab ou licenciado, a atualização de censos, entre outros) sejam automaticamente considerados na avaliação de outra instituição, identificando áreas onde ocorrem alterações e que podem afetar o seu planejamento.

Considerando ainda que o projeto focou na fase de planejamento, sugere-se, também, a ampliação de estudos e desenvolvimento de ferramenta aplicável às outras fases de um empreendimento de infraestrutura rodoviária, como projeto, construção, operação e manutenção, bem como aos demais modos de transporte (ferroviário, hidroviário, etc.). Além disso, sugere-se ampliar a ferramenta para as questões econômicas, as quais são extremamente importantes para viabilização de infraestruturas.

Acredita-se que a criação de uma estrutura adequada de coleta de dados e mensuração, pode-se promover políticas públicas de controle, auxiliar tomadas de decisão e estabelecer os meios de divulgação dos resultados às partes interessadas (internas e externas), fortalecendo os processos democráticos, a transparência e a participação social.

Além disso, ainda que a estrutura seja aperfeiçoada e torne-se amplamente operacional, o sucesso de uso dependerá da capacitação e treinamentos gestores para a aplicação de indicadores de sustentabilidade. 


\section{REFERÊNCIAS}

AASHTO - American Association of State Highway and Transportation Officials. 2009. Transportation and Sustainability Best Practices Background. Disponível em: http://environment.transportation.org/pdf/sustainability_peer_exchange/AASHTO_Sust PeerExh_BriefingPaper.pdf. Acesso em 10 de jun. 2018.

ACSELRAD, H. Discursos da sustentabilidade urbana. Revista Brasileira de Estudos Urbanos e Regionais, Rio de Janeiro, n. 1, p. 79-89, maio 1999.

ACSELRAD, H. A duração das cidades: sustentabilidade e risco nas políticas urbanas. 2 ed. Rio de Janeiro: Lamparina, 2009a, 256p.

AMEKUDZI, A; MEYER, M.; ROSS, C. Transportation Planning for Sustainability Guidebook. Sustainability Evaluation and Planning Guidance for Transportation Systems. 2011. Instituto de Tecnologia da Geórgia.

AGENDA 21 BRASILEIRA, 2000, p. 155.

AGUM, R.; RISCADO, P.; MENEZES, M. Políticas Públicas: Conceitos e Análise em Revisão. Revista Agenda Política, Vol.3 - n.2, p. 12-42, julho/dezembro 2015.

ANDRADE, M. O.; TAVARES, L. M. Impactos da duplicação de uma rodovia federal sobre a mobilidade e acessibilidade em uma pequena cidade nordestina. Revista Produção e Desenvolvimento, v.3, n.3, p.101-116, dez., 2017.

Barton, H. (2000). Conflicting perceptions of neighbourhood. Sustainable Communities: the Potential for Eco-Neighbourhoods. Earthscan: London; 86-104.

BELLEN. Hans Michael Van. Indicadores de Sustentabilidade: Uma análise comparativa. Rio de Janeiro: FGV, 2006. 256 p.

BELLIA, V.; BIDONE, E. D. Rodovias, recursos naturais e meio ambiente. Niterói: EDUFF/DNER, 1993. 360 p.

BRASIL. Departamento Nacional de Infraestrutura de Transportes. Norma DNIT 003/2002 - PAD: Criação e Cadastramento de anel ou contorno rodoviário Padronização. Rio de Janeiro: Diretoria de Planejamento e Pesquisa. Coordenação Geral de Estudos e Pesquisas Rodoviárias, 2002.

BRASIL. Conselho Nacional de Meio Ambiente. Resolução CONAMA n. 01, de 23 de janeiro de 1986. Estabelece as definições, as responsabilidades, os critérios básicos e as diretrizes gerais para uso e implementação da Avaliação de Impacto Ambiental como um dos instrumentos da Política Nacional do Meio Ambiente. Diário Oficial da União, Brasília, DF, 17 de fevereiro de 1986.

BRASIL. Conselho Nacional de Meio Ambiente. Resolução CONAMA n. 237, de 19 de dezembro de 1997. Dispõe sobre a revisão e complementação dos procedimentos e critérios utilizados para o licenciamento ambiental. Diário Oficial da União, Brasília, DF, 22 de dezembro de 1997.

BRASIL. Constituição Federativa do Brasil de 05 de outubro de 1988. Diário Oficial da União, Brasília, DF, 06, de outubro de 1988. 
BRASIL. Lei Federal n. 10.257 de 10 de julho de 2001. Regulamenta os artigos 182 e 183 da Constituição Federal, estabelece diretrizes gerais da política urbana e dá outras. Diário Oficial da União, Brasília, DF, 11 de julho de 2001 e retificado em 17 de julho de 2001.

BRASIL. Lei Federal n. 6.938, de 31 de agosto de 1981 (alterada pela Lei no 7804 de 18 de julho de 1989.) Dispõe sobre a Política Nacional do Meio Ambiente, seus fins e mecanismos de formulação e aplicação, e dá outras providências. Diário Oficial da União, Brasília, DF, 02 de setembro de 1981.

BRASIL. Lei $n$. 12.587, de janeiro de 2012. Institui as diretrizes da Política Nacional de Mobilidade Urbana; revoga dispositivos dos Decretos-Leis nos 3.326, de 3 de junho de 1941, e 5.405, de 13 de abril de 1943, da Consolidação das Leis do Trabalho (CLT), aprovada pelo Decreto-Lei n. 5.452, de 1o de maio de 1943, e das Leis nos 5.917, de 10 de setembro de 1973, e 6.261, de 14 de novembro de 1975; e dá outras providências. Disponível em: <http://www.planalto.gov.br/ccivil_03/_Ato20112014/2012/Lei/L12587.htm>. Acesso em: 03 de dez. de 2018.

Bueno, P.C., Vassallo, J.M., and Cheung, K. "Road infrastructure design for optimizing sustainability. literature review". TRANSYT Working Paper 2013-01-EN. Universidad Politécnica de Madrid, Spain.

CASTRO, M. D. L. Participação da sociedade civil e da administração pública no processo de Avaliação de Impacto Ambiental no Município de São Paulo - Brasil. 2018. Tese (Doutorado em Ciências) - Faculdade de Saúde Pública, Universidade de São Paulo. São Paulo, 2018.

CAVALCANTI, Cristina Kanya Caseli; BRANCO, Larissa Ferrer; BRUNA, Gilda Collet. Mobilidade em cidades. In: PHILIPPI JR., A. BRUNA, G. C. (Org.). Gestão Urbana e Sustentabilidade 40. São Paulo: Manole, 2018. p.1020-1037.

CETESB. Companhia Ambiental do Estado de São Paulo. (2014) P4.261-Risco de Acidente de Origem Tecnológica - Método para decisão e termos de referência. São Paulo, 2. Ed. 140p. Homologada pela Decisão de Diretoria - D.D. n. 073/2014/I, de 25/03/14. Publicada no Diário Oficial do Estado de São Paulo - Caderno Executivo I, v.124 (64) de 04/04/2014, Poder Executivo, Seção I, p. 83.

CONFEDERAÇÃO NACIONAL DO TRANSPORTE (Brasil). Pesquisa CNT de rodovias 2015: relatório gerencial. Brasília: CNT: SEST: SENAT, 2015. 420p. Disponível em: $<$ http://pesquisarodoviascms.cnt.org.br/Relatorio\%20Geral/PESQUISA_CNT2015_BAI XA.pdf>. Acesso em: 16 set. 2016.

COSTA, M. S. Mobilidade urbana sustentável: um estudo comparativo e as bases de um sistema de gestão para Brasil e Portugal. 2003. Dissertação (Mestrado em Engenharia Civil) - Escola de Engenharia de São Carlos, Universidade de São Paulo, São Carlos. 2003.

COSTA, M. S; SILVA, A. N. R. \& RAMOS, R. A. R. (2005). Sustainable urban mobility: a comparative study and the basis for a management system in Brazil and Portugal. WIT Transactions on The Built Environment, Vol 77. WIT Press www.witpress.com, ISSN 1743-3509 (on-line) 
DEPARTAMENTO NACIONAL DE INFRAESTRUTURA DE TRANSPORTES DNIT. Diretoria de Planejamento e Pesquisa. Coordenação Geral de Estudos e Pesquisa. Instituto de Pesquisas Rodoviárias. Manual para atividades ambientais rodoviárias. - Rio de Janeiro, 2006. 437 p.

DEPARTAMENTO NACIONAL DE INFRAESTRUTURA DE TRANSPORTE DNIT. Diretoria Executiva. Instituto de Pesquisas Rodoviárias. Manual de Implantação Básica de Rodovia. 3. ed. Rio de Janeiro, 2010a. 617p.

DEPARTAMENTO NACIONAL DE INFRAESTRUTURA DE TRANSPORTE DNIT. Diretoria Executiva. Instituto de Pesquisas Rodoviárias. Manual de Projeto Geométrico de Travessias Urbanas. 3. ed. Rio de Janeiro, 2010b. 617p.

DERSA - DESENVOLVIMENTO RODOVIÁRIO S/A; FESPSP - FUNDAÇÃO ESCOLA DE SOCIOLOGIA E POLÍTICA DE SÃO PAULO. Estudo de impacto ambiental do Rodoanel Metropolitano de São Paulo - Trecho Oeste. São Paulo, 1997, 8 v. Relatório técnico.

DERSA- DESENVOLVIMENTO RODOVIÁRIO S.A., Rodoanel Metropolitano de São Paulo - Trecho Norte: Estudo Funcional de Alternativas de Traçado, Planservi Engenharia, São Paulo, 1999.

DERSA - DESENVOLVIMENTO RODOVIÁRIO S.A; PROTAN Engenharia S/C Ltda. Estudo de impacto ambiental do Rodoanel Mario Covas - Trechos Norte, Leste e Sul. São Paulo, 2002. 9 v. Relatório técnico.

DERSA - DESENVOLVIMENTO RODOVIÁRIO S.A; FESPSP - FUNDAÇÃO ESCOLA DE SOCIOLOGIA E POLÍTICA DE SÃO PAULO. Avaliação Ambiental Estratégica do Programa Rodoanel. São Paulo, 2004a, 8 v. Relatório técnico.

DESENVOLVIMENTO RODOVIÁRIO S.A - DERSA; FESPSP - FUNDAÇÃO ESCOLA DE SOCIOLOGIA E POLÍTICA DE SÃO PAULO. Estudo de Impacto Ambiental do Trecho Sul Modificado - Programa Rodoanel Mário Covas. São Paulo, 2004b. 10v. Relatório Técnico.

DERSA - DESENVOLVIMENTO RODOVIÁRIO S.A.; CONSÓRCIO JGP - PRIME. Estudo de impacto ambiental (EIA) e relatório de impacto ambiental (RIMA) do Rodoanel Mario Covas - Trecho Leste. São Paulo, 2009. 11 v. Relatório técnico.

DERSA - DESENVOLVIMENTO RODOVIÁRIO S.A.; CONSÓRCIO JGP - PRIME. Estudo de impacto ambiental (EIA) e relatório de impacto ambiental (RIMA) do Rodoanel Mario Covas - Trecho Norte. São Paulo, 2010. 7 v. Relatório técnico.

Devuyst D. Introduction to sustainability assessment at the local level. In: Devuyst D, editor. How green is the city? Sustainability assessment and the management of urban environments. New York: Columbia University Press; 2001. pp. 1- 41.

ECOCITY, 2001. Urban development towards appropriate structures for sustainable transport. Publishable Final Report (Deliverable 18). Ecocity EVK4-CT-2001-00056.

El-Gohary, N.M., Osman, H. and El-Diraby, T.E. (2006). "Stakeholder Management for Public Private Partnerships." International Journal of Project Management, 24, p.p 595604. 
EPA - UNITED STATES ENVIRONMENTAL PROTECTION AGENCY. Guide to Sustainable Transportation Performance Measures, 2011.

FIDIC - INTERNATIONAL FEDERATION OF CONSULTING ENGINEERS. (2012).

State of the World Report 2012 (pp. 1-45). Disponível em: <http://fidic.org/sites/default/files/sow2012-0822-electronic.pdf >. Acesso em: 03 de julho de 2018.

FREIRIA, R. F. Direito, Gestão e Políticas Públicas Ambientais. Editora SENAC. São Paulo, 2011.

Furberg, Anna; Molander, Sverker; Wallbaum, Holger. Literature Review of Practices in Sustainability Assessment of Transport Infrastructures - Identification of Issues and Knowledge Gaps. Department of Energy and Environment. Division of Environmental System Analysis. Chalmers University of Technology Göteborg, Sweden, 2014.

GIATTI, Leandro Luiz; URBINATTI, Alberto Matenhauer; MARTINS, Ana Maria Bedran. Nexos de sustentabilidade urbana e perspectivas ampliadas de políticas públicas. In: PHILIPPI JR., A. BRUNA, G. C. (Org.). Gestão Urbana e Sustentabilidade 3. São Paulo: Manole, 2018. p. 56-82.

GIL, Antônio Carlos. Como elaborar projetos de pesquisa. $3^{a}$. ed. São Paulo: Editora Atlas S.A., 1996.

GIL, Antônio Carlos. Como elaborar projetos de pesquisa. $4^{\mathrm{a}}$ ed. São Paulo: Editora Atlas S.A., 2002.

GLASSON, J.; THERIVEL, R; CHADWICK, A. Introduction to Environmental Impact Assessment. 2. Ed. London: UCL Press, 1999. 496 p.

GOVERnO DO ESTADO DE SÃO PAULO. Plano Diretor de Desenvolvimento de Transporte - PDDT Vivo 2000 - 2020. São Paulo: Secretaria dos Transportes do Estado de São Paulo / Desenvolvimento Rodoviário S.A, 2000 (Relatório Executivo).

GUDMUNDSSON, H. Sustainable Transport and Performance Indicators. Issues in Environmental Science and Technology. n. 20, 2004, pp. 35-63.

GUIMARÃES, T.; LUCAS, K. (2017). O papel da equidade no planejamento de transportes no brasil. XXXI Congresso Nacional de Pesquisa em Transporte da ANPET. Recife.

GVces. Aplicação de Indicadores de Intensidade em Instrumentos Econômicos. Centro de Estudos em Sustentabilidade da Escola de Administração de Empresas de São Paulo da Fundação Getulio Vargas. São Paulo, p. 143. 2015.

HABITAT-III. Documentos temáticos da Habitat III. United Nations Conference on Housing and Sustainable Urban Development. Ecossistemas Urbanos e Gestão de Recursos. 16. Nova York, 2015. Disponível em: http://habitat3.org/wpcontent/uploads/16-Ecossistemas-Urbanos-e-Gestão-de-Recursos_final.pdf. Acesso em: 27 de jan. 2019. 
HOUGHTON, N. Ecologically Sustainable Development: Indicators and Decision Process. Report 319, ARRB Transportation Research, Vermont South, Australia, March 1998.

HAUGHTON, G. 1999. Environmental justice and the sustainable city. Journal of Planning Education and Research 18: 233-243.

INSTITUTO DE PESQUISA ECONÔMICA APLICADA - IPEA. Mobilidade urbana sustentável: conceitos, tendências e reflexões. 2016. Disponível em: <http://www.ipea.gov.br/portal/images/stories/PDFs/TDs/td_2194.pdf>. Acesso em 07 de jan. 2019.

IPCC - Intergovernmental Panel on Climate Change. Fifth Assessment Report - AR5 (2014). Disponível em: <https://www.ipcc.ch/site/assets/uploads/2018/02/SYR_AR5_FINAL_full.pdf>. Acesso em 19 de nov. 2018.

JEON, C. M. Incorporating sustainability into transportation planning and decision making: definitions, performance measures, and evaluation. 2007. Dissertação (Mestrado em Engenharia). School of Civil and Environmental Engineering Georgia Institute of Technology, Geórgia, 2007.

JEON, C. M.; AMEKUDZI, A. (2005). Addressing Sustainability in Transportation Systems: Definitions, Indicators and Metrics. ASCE Journal of Infrastructure Systems, Vol. 11, n. 10, pp, 31-50. March 2005.

Lautso,K.; Spiekemann, K; Wegener, M.; Sheppard, I.; Steadman P.; Martino A.; Doming, R.; Gayda, S. (2004); PROPOLIS - Final Report, 2nd Edition, Finland. Disponível em:

<http://www.spiekermann-wegener.de/pro/pdf/PROPOLIS_Final_Report.pdf $>$. Acesso em jan. de 2019.

Lavell, A., M. Oppenheimer, C. Diop, J. Hess, R. Lempert, J. Li, R. Muir-Wood, and S. Myeong, 2012: Climate change: new dimensions in disaster risk, exposure, vulnerability, and resilience. In: Managing the Risks of Extreme Events and Disasters to Advance Climate Change Adaptation [Field, C.B., V. Barros, T.F. Stocker, D. Qin, D.J. Dokken, K.L. Ebi, M.D. Mastrandrea, K.J. Mach, G.-K. Plattner, S.K. Allen, M. Tignor, and P.M. Midgley (eds.)]. A Special Report of Working Groups I and II of the Intergovernmental Panel on Climate Change (IPCC). Cambridge University Press, Cambridge, UK, and New York, NY, USA, pp. 25-64. Disponível em https://www.ipcc.ch/site/assets/uploads/2018/03/SREX-Chap1_FINAL-1.pdf. Acesso em 07 de dez de 2018.

LENCIONI, S. Concentração e centralização das atividades urbanas: uma perspectiva multiescalar. Reflexões a partir do caso de São Paulo. Revista de Geografia Norte Grande, 39: 7-20 (2008).

LIM, S.K. Framework and Processes for Enhancing Sustainability Deliverables in Australian Road Infrastructure Projects, 2009. 348 p. Tese de Doutorado, School of Urban Development Faculty of Built Environmental and Engineering / Queensland University of Technology, Melbourne, Austrália, 2009. 
LITMAN, T. e D. BURWELL (2006) Issues in Sustainable Transportation. International Journal of Global Environmental Issues, v. 6, n. 4, p. 331-347.

LITMAN, Todd (2008). Well Measured: Developing Indicators for Comprehensive and Sustainable Transport Planning, Victoria Transport Policy Institute - VTPI. Disponível em: <www.vtpi.org>. Acesso em: 13 de abril de 2018.

Litman, Todd; Brenman, Marc (2012). A New Social Equity Agenda For Sustainable Transportation. Victoria Transport Policy Institute. Disponível em: http://www.vtpi.org/equityagenda.pdf. Acesso em 28 de nov. de 2018.

LITMAN, T. (2016). Well Measured: Developing Indicators for Sustainable and Livable Transport Planning, Victoria Transport Policy Institute - VTPI. Disponível em: <www.vtpi.org>. Acesso em: 28 de setembro de 2018.

LITMAN, T. (2018). Evaluating Transportation Equity. Victoria Transport Policy Institute. Disponível em: 〈http://www.vtpi.org/equity.pdf>. Acesso em 15 de ago de 2018.

McHARG, I. L. A comprehensive highway route selection method. Highway Research Record (246): p.1-15. 1968.

MACLAREN, V. W. (1996). Urban sustainability reporting. Journal of the American Planning Association, Chicago, v.62, n.2, p.184-202.

MAGLIO, Ivan Carlos; PHILIPPI JR., Arlindo. Sustentabilidade ambiental e mudanças climáticas: desafio para o planejamento urbano das cidades. In: PHILIPPI JR., A. BRUNA, G. C. (Org.). Gestão Urbana e Sustentabilidade 18. São Paulo: Manole, 2018. p. 428-453.

MALHEIROS, T. F.; PHILIPPI JR., A.; COUTINHO, S. M. V. (2008). Agenda 21 nacional e indicadores de desenvolvimento sustentável: contexto brasileiro. Revista Saúde e Sociedade, São Paulo, v. 17, n. 1, p. 7-20, mar.

MALHEIROS, T. F.; COUTINHO, S. M. V.; PHILIPPI JR, A.. Desafios do uso de indicadores na avaliação da sustentabilidade. Em: PHILIPPI JR; A.; MALHEIROS, T. F. (eds.). Indicadores de Sustentabilidade e Gestão Ambiental. Barueri-SP: Manole, 2012. p. 1-30. (Coleção Ambiental).

MARINS, K. R. de C. C. Proposta metodológica para planejamento energético no desenvolvimento de áreas urbanas - O potencial da integração de estratégias e soluções em morfologia e mobilidade urbanas, edifícios, energia e meio ambiente: o caso da operação urbana Água Branca, no município de São Paulo. 2010. Tese (Doutorado em Arquitetura e Urbanismo) - Faculdade de Arquitetura e Urbanismo, Universidade de São Paulo. São Paulo, 2010.

Marsden, G., Kelly, C., Snell, C. And Forrester, J. (2005) Improved Indicators for Sustainable Transport and Planning, Draft Deliverable C1, DISTILLATE project, Institute for Transport Studies and Stockholm Environment Institute - York. Disponível em:

$<$ http://www.distillate.ac.uk/outputs/Deliverable\%20C1\%20Indicators\%20specification \%20v9.pdf $>$. Acesso em: 20 de mar de 2019. 
MARSDEN, G et al. (2011). Framework for Sustainability Assessment by Transportation Agencies. Transportation Research Record: Journal of the Transportation Research Board, 2242 (2242). 9 - 18. ISSN 0361-1981.

Martland, C. D. Toward more sustainable infrastructure: project evaluation for planners and engineers. Hoboken, NJ: Wiley, 2012.

MEYER, Michel D. e MILLER, Eric J. Urban Transportation Planning: a decisionoriented approach, second edition. Mc Graw-Hill Companies, 1984.

MINISTÉRIO DAS CIDADES (2004), Política Nacional de Mobilidade Urbana Sustentável. Disponível em:

<http://www.ta.org.br/site/banco/7manuais/6politicanacionalmobilidadeurbanasustentav el.pdf>. Acesso em 28 de dez. 2018

MME/EPE. (2014). PDE 2013-2022 - Plano Decenal de Expansão de Energia - Relatório Final. Rio de Janeiro: EPE.

MÖRTBERG U, Haas J, ZETTERBERG A, et al. (2013) Urban ecosystems and sustainable urban development-analysing and assessing interacting systems in the Stockholm region. Urban Ecosystems 16: 763-782.

MUENCH, S. T., ARMSTRONG, A., \& ALLEN, B. (2012). Sustainable roadway design and construction in federal lands highway program. Transportation Research Record: Journal of the Transportation Research Board, 2271(-1), 19-30. doi:10.3141/2271-03.

NCE, New Climate Economy. Seizing the global opportunity: partnerships for better growth and a better climate. The Global commission on the economy and climate: Washington, 2015. Disponível em: 〈http://www.fao.org/3/a-az422e.pdf>. Acesso em 26 de abril de 2018.

Ness, B., Urbel_Piirsalu, E., Anderberg, S., Olsson, L., 2006. Categorising tools for sustainability assessment. Ecol. Econ. 60, 498-508.

OCDE - ORGANIZAÇÃO DE COOPERAÇÃO E DESENVOLVIMENTO ECONÔMICO, 1996. Environmental criteria for sustainable transport: Report on phase 1 of the project on Environmentally Sustainable Transport (EST). OECD report, OECD/GD(96), Paris, 96 p.

[ONU] MOBILIZING SUSTAINABLE TRANSPORTE FOR DEVELOPMENT. 2016a. Analysis and Policy Recommendations from the United Nations SecretaryGeneral's High-Level Advisory Group on Sustainable Transport. Disponível em: $<$ https://www.mobilize.org.br/midias/pesquisas/mobilizando-o-transporte-sustentavelpelo-desenvol.pdf >. Acesso em 03 de jan. de 2019.

ONU - ORGANIZAÇÃO DAS NAÇÕES UNIDAS. Conferência das Nações Unidas para Habitação e Desenvolvimento Urbano Sustentável (Habitat III). Nova Agenda Urbana. Quito, Equador, 2016. Disponível em: <http://www.habitat3.org/the-new-urbanagenda> Acesso em: 21 ago. 2018.

ONU - ORGANIZAÇÃO DAS NAÇÕES UNIDAS. Conferência das Nações Unidas sobre o Meio Ambiente e Desenvolvimento. Declaração do Rio sobre meio ambiente e desenvolvimento. Brasília, DF: MMA, 1992. Disponível em: 
<http://www.mma.gov.br/port/sdi/ea/documentos/convs/decl_rio92.pdf >. Acesso em: 25 jan. 2018.

ONU - ORGANIZAÇÃO DAS NAÇÕES UNIDAS. Agenda 2030 para o Desenvolvimento Sustentável: transformar nosso mundo. Nova Iorque, 2015. Disponível em: <www.nr.undp.org/...agenda2030/undp-br-Agenda2030-completo-pt-br-2016.pdf> Acesso em: 25 set. 2018.

Pope, J., Annandale, D., Morrison-Saunders, A., 2004. Conceptualising sustainability assessment. Impact Assess. Project Appraisal 23 (4), 293-302.

POLÍTICA NACIONAL DE TRANSPORTES: Caderno das Estratégias Governamentais / Ministério dos Transportes, Portos e Aviação Civil. Brasília: MTPA, 2018. 1 v.: grafs., II.

POLÍTICA NACIONAL DE TRANSPORTES: Livro de Estado/ Ministério dos Transportes, Portos e Aviação Civil. Brasília: MTPA, 20181 v.: gráfs., II.

PROGRAMA CIDADES SUSTENTÁVEIS, 2016. Disponível em: <http://www.cidadessustentaveis.org.br/>. Acesso em: 07 jan 2018.

RAMANI, T., ZIETSMAN, J., EISELE, W., ROSA, D., SPILLANE, D. and BOCHNER, B. (2009). Developing sustainable transportation performance measures for txdot's strategic plan: technical report. Texas Transportation Institute The Texas A\&M University System College Station, Texas 77843-3135. Disponível em: <http://tti.tamu.edu/documents/0-5541-1.pdf>. Acesso em 20 de ago. de 2018.

RAMANI, T., POTTER, J., DEFLORIO, J., ZIETSMAN, J., REEDER, V. (2011). A Guidebook for Sustainability Performance Measurement for Transportation Agencies. National Cooperative Highway Research Program. Transportation Research Board. 191p. WASHINGTON, D.C. Disponível em: http://nap.edu/14598. Acesso em: 13 de jul. de 2018.

REIS, Lineu Belico; MARTINI, José Sidnei Colombro; GRIMONI, José Aquiles Baesso. Energia na gestão urbana sustentével. In: PHILIPPI JR., A. BRUNA, G. C. (Org.). Gestão Urbana e Sustentabilidade 32. São Paulo: Manole, 2018. p.795-827.

SAETA, F. P. Sustentabilidade urbana: o desafio da construção de indicadores de sustentabilidade urbana. 2012. Dissertação (Mestrado em Arquitetura e Urbanismo) Universidade Presbiteriana Mackenzie. São Paulo, 2012.

Sala, Serenella; Ciuffo, Biagio; Nijkamp, Peter. 2015. A systemic framework for sustainability assessment. Ecological Economics 119 (2015) 314-325. Disponível em: <http://dx.doi.org/10.1016/j.ecolecon.2015.09.015>. Acesso em 15 de mar de 2018.

SAUNDERS, M., LEWIS, P. and THORNHILL, A. (2000). Research Methods for Business Students - Second Edition, Pearson Education Limited, UK..

SEMOB - SECRETARIA NACIONAL DE TRANSPORTE E DA MOBILIDADE URBANA. Ministério das Cidades. PlanMob - Caderno de Referência para Elaboração de Plano de Mobilidade Urbana. 2015. 
Sheate W, Dagg S, Richardson J, Aschemann R, Palerm J, Steen U. Integrating the environment into strategic decision-making: conceptualizing policy SEA. Eur Environ 2003;13(1):1-18.

SHIBAO, Fabio Ytoshi; DOS SANTOS, Mario Roberto; MONTEIRO, David Costa. Sustentabilidade urbana: logística, modais e redes de carga. In: PHILIPPI JR., A. BRUNA, G. C. (Org.). Gestão Urbana e Sustentabilidade 35. São Paulo: Manole, 2018. p. 887-911.

SHRP 2 - SECOND STRATEGIC HIGHWAY RESEARCH PROGRAM (2009). Performance Measurement Framework for Highway Capacity Decision Making. Cambridge Systematics. Transportation Research Board. 113 p. ISBN 978-0-309-128858 | DOI 10.17226/14255. Disponível em: <http://nap.edu/14255>. Acesso em 15 de nov. de 2018.

SILVA JÚNIOR, S. B. Rodovias em áreas urbanizadas e seus impactos, na percepção dos pedestres. 2006. Dissertação (Mestrado em Engenharia Urbana) - Universidade Federal de São Carlos. São Carlos, 2006.

SOTTO, Debora; PHILIPPI JR., Arlindo. Operações urbanas consorciadas: alternativas para requalificação urbana sustentável. In: PHILIPPI JR., A. BRUNA, G. C. (Org.). Gestão Urbana e Sustentabilidade 19. São Paulo: Manole, 2018. p. 454-477.

SOUZA, C. D. R.; D’AGOSTO, M. A. Modelo de quatro etapas aplicado ao planejamento de transporte de carga. Journal of Transport Literature, v. 7, p. 207-234, 2013.

SOUZA, C. Políticas Públicas: uma revisão da literatura. In: Revista Sociologias (republicação), nr. 16, ano 8, p. 20-45. Porto Alegre, 2006.

THÉRIVEL, R.; WILSON, E.; THOMPSON, S.; HEANEY, PRITCHAR, D. Strategic Environmental Assessment. London: Earthscan, 1992. 181p.

UNEP. Environmental Impact Asessment Training Resource Manual. 2002. Disponível em:

<https://wedocs.unep.org/bitstream/handle/20.500.11822/26503/EIA_Training_Resourc e_Manual.pdf?sequence=1\&isAllowed=y>. Acesso em $29 \mathrm{dez}$. 18 .

UNISDR - United Nations Office for Disaster Risk Reduction. Como construir cidades mais resilientes. um guia para gestores públicos locais. Genebra, 2012. Disponível em: <http://www.unisdr.org/files/26462_guiagestorespublicosweb.pdf>. Acesso em 27 de jan. de 2019.

VASCONCELLOS, Eduardo Alcântara. Transporte urbano nos países em desenvolvimento: reflexões e propostas. São Paulo: Editora Unidas, 1996.

VERGARA SC. Sugestão para estruturação de um projeto de pesquisa. São Paulo: Fundação Getúlio Vargas; 1991. (Cadernos de Pesquisa, 2)

VILLAÇA, Flávio. Espaço intra-urbano no Brasil. São Paulo: Studio Nobel/FAPESP/Lincoln Institute, 2001.

VTPI (2005), Online TDM Encyclopedia, VTPI. Disponível em: <www.vtpi.org>. Acesso em 13 de ago. 2018. 
WCED - WORLD COMMISSION ON ENVIRONMENT AND DEVELOPMENT. Our Common Future. Oxford: Oxford University Press, 1987. 400p.

WRI BRASIL. DOTS nos Planos Diretores: Guia para inclusão do Desenvolvimento Orientado ao Transporte Sustentável no planejamento urbano. $1^{\text {a }}$ edição. 2018. Disponível em <http://wricidades.org >. Acesso em: 20 jun. 2018.

Yin, R. K. 2003. Applications of case study research: Sage Publications, Inc.

Zegras, C., I. Poduje, W. Foutz, E. Ben-Joseph, O. Figueroa. 2004. Indicators for Sustainable Urban Development. Chapter 7 in From Understanding to Action: Sustainable Urban Development in Medium-Sized Cities in Africa and Latin America (M. Keiner, C. Zegras, W. Schmid, D. Salmerón, Eds.), Springer, Dordrecht, the Netherlands.

Zietsman, J. Incorporating Sustainability Performance Measures into the Transportation Planning Process. Ph.D. Dissertation, Texas A\&M University, December 2000.

ZIETSMAN, J., and RILETT, L. R. (2002). Sustainable transportation: Conceptualization and performance measures. Rep. SWUTC/02/167403-1, Southwest Region University. Transportation Center, Texas A\&M Univ. System, College Station, Texas.

Zietsman, J., \& Ramani, T. (2011). Sustainability Performance Measures for State DOTS and Other Transportation Agencies. Final Report. Texas Transportation Institute. The Texas A\&M University System College Station, Texas. 


\section{APÊNDICE A}

\section{IMPACTOS POTENCIAIS POR COMPONENTE AMBIENTAL}

\begin{tabular}{|c|c|c|c|c|c|c|c|c|c|}
\hline \multirow{2}{*}{$\begin{array}{r}\text { Componente } \\
\text { C.1 Meio Físico }\end{array}$} & \multirow{2}{*}{\multicolumn{2}{|c|}{$\begin{array}{r}\text { Impactos Ambientais } \\
\text { I.1 Impactos no Meio Físico }\end{array}$}} & \multicolumn{6}{|c|}{ Atributos } & \multirow{2}{*}{$\begin{array}{c}\text { Elegibilidade } \\
\text { Sim/Não }\end{array}$} \\
\hline & & & $\mathbf{V}$ & $\mathbf{I}$ & $\mathbf{A}$ & $\mathbf{R}$ & $\mathbf{I}$ & $\mathbf{P}$ & \\
\hline \multirow{5}{*}{ C.1.01 Terrenos } & \multirow{5}{*}{$\begin{array}{l}\text { I.1.01 } \\
\text { Impactos } \\
\text { Potenciais nos } \\
\text { Terrenos }\end{array}$} & $\begin{array}{l}\text { 1.01 Alteração da morfologia do relevo e da } \\
\text { estabilidade das encostas e aumento da susceptibilidade } \\
\text { à erosão por terraplenagem }\end{array}$ & - & M & $\mathrm{ADA}$ & PR & I & $\mathrm{TA}$ & NÃO \\
\hline & & $\begin{array}{l}1.02 \text { Alteração da estabilidade das encostas e aumento } \\
\text { da susceptibilidade à erosão por escavação de túneis }\end{array}$ & - & M & ADA & PR & I & TA & NÃO \\
\hline & & 1.03 Aumento das áreas impermeabilizadas & - & $\mathrm{B}$ & ADA & I & $\mathrm{I}$ & $\mathrm{P}$ & SIM \\
\hline & & $\begin{array}{l}\text { 1.04 Aumento do risco de contaminação de solo por } \\
\text { combustíveis e lubrificantes durante a construção }\end{array}$ & - & B & ADA & $\mathrm{TR}$ & I & TA & NÃO \\
\hline & & $\begin{array}{l}1.05 \text { Alteração do risco de contaminação de solo por } \\
\text { vazamento de produtos perigosos durante a operação }\end{array}$ & +- & $\mathrm{B} ; \mathrm{B}$ & $\begin{array}{l}\text { ADA; } \\
\text { AID; } \\
\text { AII e R }\end{array}$ & TR; I & I; I & $\mathrm{P} ; \mathrm{P}$ & SIM \\
\hline \multirow{6}{*}{$\begin{array}{l}\text { C.1.02 Recursos } \\
\text { hídricos superficiais }\end{array}$} & \multirow{6}{*}{$\begin{array}{l}\text { I.1.02 } \\
\text { Impactos } \\
\text { Potenciais nos } \\
\text { Recursos } \\
\text { Hídricos } \\
\text { Superficiais }\end{array}$} & $\begin{array}{l}\text { 2.01 Alterações no regime fluviométrico de cursos } \\
\text { d'água }\end{array}$ & - & $\mathrm{B} ; \mathrm{M}$ & AID & PR & I & $\mathrm{P}$ & SIM \\
\hline & & $\begin{array}{l}\text { 2.02 Alteração dos níveis de turbidez dos corpos } \\
\text { hídricos durante a construção }\end{array}$ & - & M & $\begin{array}{l}\text { ADA; } \\
\text { AID }\end{array}$ & $\mathrm{TR}$ & I & TA & NÃO \\
\hline & & $\begin{array}{l}2.03 \text { Assoreamento de cursos d'água durante a } \\
\text { construção }\end{array}$ & - & M & $\begin{array}{l}\text { ADA; } \\
\text { AID }\end{array}$ & PR & I & $\mathrm{C}$ & NÃO \\
\hline & & $\begin{array}{l}\text { 2.04 Alteração da qualidade da água durante a } \\
\text { construção }\end{array}$ & - & B & $\begin{array}{l}\text { ADA; } \\
\text { AID }\end{array}$ & PR & I & $\mathrm{C}$ & NÃO \\
\hline & & $\begin{array}{l}\text { 2.05 Alteração da distribuição do risco de } \\
\text { contaminação dos corpos hídricos durante a operação }\end{array}$ & +- & B & $\begin{array}{l}\text { ADA; } \\
\text { AID; } \\
\text { AII; R }\end{array}$ & I; TR & I & $\mathrm{P} ; \mathrm{P}$ & SIM \\
\hline & & $\begin{array}{l}\text { 2.06 Alteração na qualidade dos corpos hídricos pelo } \\
\text { escoamento das águas pluviais (cargas difusas) durante } \\
\text { a operação }\end{array}$ & +- & $\mathrm{B} ; \mathrm{B}$ & $\begin{array}{l}\text { AID; } \\
\text { AID }\end{array}$ & I & $\mathrm{CP}$ & $\mathrm{P}$ & SIM \\
\hline
\end{tabular}




\begin{tabular}{|c|c|c|c|c|c|c|c|c|c|}
\hline Componente & \multicolumn{2}{|r|}{ Impactos Ambientais } & \multicolumn{6}{|c|}{ Atributos } & \multirow{2}{*}{$\begin{array}{c}\text { Elegibilidade } \\
\text { SIM }\end{array}$} \\
\hline \multirow{3}{*}{$\begin{array}{l}\text { C.1.03 Recursos } \\
\text { hídricos } \\
\text { subterrâneos }\end{array}$} & \multirow{3}{*}{$\begin{array}{l}\text { I.1.03 } \\
\text { Impactos } \\
\text { Potenciais nos } \\
\text { Recursos } \\
\text { Hídricos } \\
\text { Subterrâneos }\end{array}$} & $\begin{array}{l}\text { 3.01 Alteração no regime de fluxo das águas } \\
\text { subterrâneas (rebaixamento) }\end{array}$ & - & B & $\begin{array}{l}\text { ADA; } \\
\text { AID }\end{array}$ & I & $\mathrm{CP}$ & $\mathrm{P}$ & \\
\hline & & $\begin{array}{l}3.02 \text { Risco de contaminação do lençol freático durante } \\
\text { a construção }\end{array}$ & - & $\mathrm{B}$ & ADA & $\mathrm{TR}$ & I & $\mathrm{TA}$ & NÃO \\
\hline & & $\begin{array}{l}\text { 3.03 Risco de contaminação do lençol freático durante } \\
\text { a operação }\end{array}$ & - & B & $\mathrm{ADA}$ & $\mathrm{TR}$ & I & $\mathrm{P}$ & SIM \\
\hline \multirow{2}{*}{$\begin{array}{l}\text { C1.04 } \\
\text { Ar }\end{array}$} & \multirow{2}{*}{$\begin{array}{l}\text { I.1.04 } \\
\text { Impactos } \\
\text { Potenciais na } \\
\text { Qualidade do Ar }\end{array}$} & 4.01 Impactos na qualidade do ar durante a construção & - & $\mathrm{M}$ & $\begin{array}{l}\text { ADA; } \\
\text { AID }\end{array}$ & $\mathrm{TR}$ & I & $\mathrm{TA}$ & NÃO \\
\hline & & 4.02 Impactos na qualidade do ar durante a operação & +- & $\mathrm{B} ; \mathrm{M}$ & R; AID & I; I & $\mathrm{I} ; \mathrm{I}$ & $\mathrm{P} ; \mathrm{P}$ & SIM \\
\hline C.2 Meio Biótico & \multicolumn{2}{|c|}{ I.1 Impactos no Meio Biótico } & $\mathbf{V}$ & I & $\mathbf{A}$ & $\mathbf{R}$ & I & $\mathbf{P}$ & Sim/Não \\
\hline \multirow{5}{*}{$\begin{array}{l}\text { C.2.01 Cobertura } \\
\text { vegetal }\end{array}$} & \multirow{5}{*}{$\begin{array}{l}\text { I. } 2.01 \\
\text { Impactos } \\
\text { Potenciais na } \\
\text { Vegetação }\end{array}$} & $\begin{array}{l}\text { 5.01 Redução da cobertura vegetal da área diretamente } \\
\text { afetada }\end{array}$ & - & M & ADA & I & I & $\mathrm{P}$ & SIM \\
\hline & & $\begin{array}{l}5.02 \text { Risco de supressão de espécies protegidas e/ou em } \\
\text { listas de ameaça de extinção }\end{array}$ & - & B & $\mathrm{ADA}$ & PR & I & $\mathrm{L} ; \mathrm{P}$ & SIM \\
\hline & & $\begin{array}{l}\text { 5.03 Ampliação do grau de fragmentação florestal e } \\
\text { instalação do efeito de borda }\end{array}$ & - & M & AID & I & I & $\mathrm{P}$ & SIM \\
\hline & & $\begin{array}{l}\text { 5.04 Alteração do nível de risco da ocorrência de } \\
\text { incêndios nas florestas remanescentes no entorno da } \\
\text { rodovia }\end{array}$ & - & M & $\begin{array}{l}\text { ADA; } \\
\text { AID }\end{array}$ & PR & $\begin{array}{l}\mathrm{MP} \\
\mathrm{LP}\end{array}$ & $\mathrm{P}$ & SIM \\
\hline & & $\begin{array}{l}\text { 5.05 Efeitos nas comunidades ribeirinhas pelas } \\
\text { interferências nos cursos d'água e nas planícies aluviais }\end{array}$ & - & M & AID & $\mathrm{PR}$ & I & $\mathrm{P}$ & SIM \\
\hline \multirow{3}{*}{ C.2.02 Fauna } & \multirow{3}{*}{$\begin{array}{l}\text { I. } 2.02 \\
\text { Impactos } \\
\text { Potenciais na } \\
\text { Fauna }\end{array}$} & $\begin{array}{l}\text { 6.01 Alteração local do número e da composição das } \\
\text { comunidades de vertebrados terrestres como } \\
\text { decorrência da redução e fragmentação de habitats }\end{array}$ & - & M & $\begin{array}{l}\text { ADA; } \\
\text { AID }\end{array}$ & I & $\begin{array}{l}\mathrm{CP} \\
\mathrm{MP}\end{array}$ & $\mathrm{L} ; \mathrm{P}$ & SIM \\
\hline & & 6.02 Interferências com corredores ecológicos & - & $\mathrm{B}$ & AID & PR & I & $\mathrm{P}$ & SIM \\
\hline & & $\begin{array}{l}\text { 6.03 Afugentamento de fauna, aumento dos riscos de } \\
\text { atropelamento e da pressão de caça }\end{array}$ & - & B & AID & I & $\mathrm{I} ; \mathrm{CP}$ & $\mathrm{P}$ & SIM \\
\hline
\end{tabular}




\begin{tabular}{|c|c|c|c|c|c|c|c|c|c|}
\hline Componente & \multicolumn{2}{|r|}{ Impactos Ambientais } & \multicolumn{6}{|c|}{ Atributos } & \multirow{2}{*}{$\begin{array}{l}\text { Elegibilidade } \\
\text { NÃO }\end{array}$} \\
\hline & & $\begin{array}{l}\text { 6.04 Riscos de predação e doenças para a fauna } \\
\text { silvestre devido ao possível adensamento da fauna } \\
\text { sinantrópica nas frentes de obras }\end{array}$ & - & $\mathrm{B}$ & ADA & $\mathrm{TR}$ & $\mathrm{CP}$ & $\mathrm{C}$ & \\
\hline & & $\begin{array}{l}\text { 6.05 Impactos na fauna aquática dos cursos d'água a } \\
\text { serem desviados/canalizados }\end{array}$ & - & B & AID & $\mathrm{TR}$ & I & $\mathrm{C}$ & NÃO \\
\hline & & $\begin{array}{l}\text { 6.06 Alteração no nível e distribuição espacial do risco } \\
\text { de contaminação da fauna aquática e edáfica por } \\
\text { acidentes com produtos perigosos }\end{array}$ & - & $\mathrm{B}$ & AID & I & I & $\mathrm{P}$ & SIM \\
\hline C.3 Meio Antrópico & \multicolumn{2}{|c|}{ I.1 Impactos no Meio Antrópico } & $\mathbf{V}$ & $\mathbf{I}$ & $\mathbf{A}$ & $\mathbf{R}$ & I & $\mathbf{P}$ & Sim/Não \\
\hline \multirow{9}{*}{$\begin{array}{l}\text { C.3.01 } \\
\text { Infraestrutura } \\
\text { viária, tráfego e } \\
\text { transportes }\end{array}$} & \multirow{9}{*}{$\begin{array}{l}\text { I.3.01 } \\
\text { Impactos } \\
\text { Potenciais na } \\
\text { Infraestrutura } \\
\text { Viária, no } \\
\text { Tráfego e nos } \\
\text { Transportes }\end{array}$} & $\begin{array}{l}\text { 7.01 Modificações temporárias no padrão local de } \\
\text { distribuição do tráfego durante a construção }\end{array}$ & - & $\mathrm{B} ; \mathrm{M}$ & AID & $\mathrm{TR}$ & I & TA & NÃO \\
\hline & & $\begin{array}{l}\text { 7.02 Aumento na circulação de veículos pesados na } \\
\text { malha viária local durante a construção }\end{array}$ & - & M & AID & $\mathrm{TR}$ & I & TA & NÃO \\
\hline & & $\begin{array}{l}7.03 \text { Deterioração do pavimento de vias públicas } \\
\text { utilizadas pelos veículos a serviço das obras }\end{array}$ & - & M & AID & TR & $\mathrm{CP}$ & $\mathrm{C}$ & NÃO \\
\hline & & $\begin{array}{l}7.04 \text { Impactos nos níveis de carregamento do sistema } \\
\text { viário da região }\end{array}$ & +- & $\mathrm{M} ; \mathrm{A}$ & $\begin{array}{l}\text { AID; } \\
\text { AII; R; } \\
\text { D }\end{array}$ & PR; PR & $\begin{array}{l}\mathrm{CP} \\
\mathrm{CP}\end{array}$ & $\mathrm{P} ; \mathrm{P}$ & SIM \\
\hline & & $\begin{array}{l}\text { 7.05 Melhoria da acessibilidade entre rodovias radiais } \\
\text { da RMSP }\end{array}$ & + & M & $\mathrm{R}$ & I & I & $\mathrm{P}$ & SIM \\
\hline & & $\begin{array}{l}\text { 7.06 Benefícios socioeconômicos devidos à redução } \\
\text { dos tempos de viagem }\end{array}$ & + & A & $\mathrm{D}$ & I & I & $\mathrm{P}$ & SIM \\
\hline & & $\begin{array}{l}\text { 7.07 Alterações no padrão de segurança do tráfego } \\
\text { intraurbano e redução de acidentes }\end{array}$ & +- & $\mathrm{B} ; \mathrm{B}$ & $\begin{array}{l}\text { AII; } \\
\text { AII }\end{array}$ & PR; PR & $\begin{array}{l}\mathrm{CP} \\
\mathrm{CP}\end{array}$ & $\mathrm{P} ; \mathrm{P}$ & SIM \\
\hline & & $\begin{array}{l}\text { 7.08 Melhoria no grau de confiabilidade dos usuários } \\
\text { no sistema viário metropolitano }\end{array}$ & + & $\mathrm{B}$ & $\mathrm{R}$ & $\mathrm{TR}$ & MP & $\mathrm{L}$ & SIM \\
\hline & & $\begin{array}{l}\text { 7.09 Redução dos custos de manutenção da malha } \\
\text { viária intraurbana da RMSP }\end{array}$ & + & B & $\mathrm{R}$ & PR & $\mathrm{MP}$ & $\mathrm{L}$ & SIM \\
\hline
\end{tabular}




\begin{tabular}{|c|c|c|c|c|c|c|c|c|c|}
\hline \multirow[t]{5}{*}{ Componente } & \multicolumn{2}{|r|}{ Impactos Ambientais } & \multicolumn{6}{|c|}{ Atributos } & \multirow{2}{*}{$\begin{array}{c}\text { Elegibilidade } \\
\text { SIM }\end{array}$} \\
\hline & & $\begin{array}{l}\text { 7.10 Redução de problemas decorrentes da circulação } \\
\text { de cargas altas }\end{array}$ & + & M & $\mathrm{R}$ & I & I & $\mathrm{P}$ & \\
\hline & & $\begin{array}{l}\text { 7.11 Favorecimento da intermodalidade no transporte } \\
\text { de cargas }\end{array}$ & + & A & $\mathrm{R}$ & I & $\mathrm{CP}$ & $\mathrm{P}$ & SIM \\
\hline & & $\begin{array}{l}\text { 7.12 Interferências com fluxos transversais de } \\
\text { pedestres }\end{array}$ & - & M & AID & PR & I & $\mathrm{P}$ & SIM \\
\hline & & 7.13 Redução das Emissões de Gases de Efeito Estufa & + & A & $\mathrm{D}$ & I & I & $\mathrm{P}$ & SIM \\
\hline \multirow{5}{*}{$\begin{array}{l}\text { C.3.02 Estrutura } \\
\text { urbana }\end{array}$} & \multirow{5}{*}{$\begin{array}{l}\text { I.3.02 } \\
\text { Impactos } \\
\text { Potenciais na } \\
\text { Estrutura } \\
\text { Urbana }\end{array}$} & $\begin{array}{l}\text { 8.01 Indução à ocupação de terrenos vagos e áreas não } \\
\text { urbanizadas }\end{array}$ & +- & B & $\begin{array}{l}\text { AII; } \\
\text { AII }\end{array}$ & $\mathrm{I} ; \mathrm{I}$ & $\begin{array}{l}\mathrm{CP} \\
\mathrm{CP}\end{array}$ & $\mathrm{P} ; \mathrm{P}$ & SIM \\
\hline & & 8.04 Alterações dos valores imobiliários & +- & $\mathrm{M} ; \mathrm{B}$ & $\begin{array}{l}\text { AII; } \\
\text { AID }\end{array}$ & PR; PR & $\begin{array}{l}\mathrm{MP} \\
\mathrm{CP}\end{array}$ & $\mathrm{P} ; \mathrm{P}$ & SIM \\
\hline & & $\begin{array}{l}8.05 \text { Aumento do grau de atratividade para usos } \\
\text { residenciais }\end{array}$ & + & M & $\begin{array}{l}\text { AID; } \\
\text { AII }\end{array}$ & $\mathrm{TR}$ & $\mathrm{CP}$ & $\mathrm{L}$ & SIM \\
\hline & & $\begin{array}{l}\text { 8.06 Aumento do grau de atratividade para atividades } \\
\text { econômicas }\end{array}$ & + & A & $\begin{array}{l}\text { AID; } \\
\text { AII }\end{array}$ & $\mathrm{TR}$ & $\begin{array}{c}\mathrm{CP} \\
\mathrm{MP} \\
\mathrm{LP} \\
\end{array}$ & $\mathrm{L} ; \mathrm{P}$ & SIM \\
\hline & & 8.07 Ruptura da malha urbana & - & B & AID & I & I & $\mathrm{P}$ & SIM \\
\hline \multirow{5}{*}{$\begin{array}{l}\text { C.3.03 Atividades } \\
\text { econômicas }\end{array}$} & \multirow{5}{*}{$\begin{array}{l}\text { I.3.03 } \\
\text { Impactos } \\
\text { Potenciais nas } \\
\text { Atividades } \\
\text { Econômicas }\end{array}$} & $\begin{array}{l}\text { 9.01 Melhoria no padrão de acessibilidade às } \\
\text { atividades econômicas }\end{array}$ & + & M & AII & I & $\mathrm{CP}$ & $\mathrm{P}$ & SIM \\
\hline & & $\begin{array}{l}9.02 \text { Geração de empregos diretos e indiretos durante a } \\
\text { construção }\end{array}$ & + & $\mathrm{M}$ & $\mathrm{D}$ & $\mathrm{TR}$ & I & $\mathrm{TA}$ & NÃO \\
\hline & & $\begin{array}{l}\text { 9.03 Geração de empregos diretos e indiretos durante a } \\
\text { operação }\end{array}$ & + & B & $\mathrm{R}$ & I & $\mathrm{MP}$ & $\mathrm{P}$ & SIM \\
\hline & & $\begin{array}{l}\text { 9.04 Desativação de atividades econômicas localizadas } \\
\text { na ADA }\end{array}$ & - & B & ADA & I & I & $\mathrm{P}$ & SIM \\
\hline & & 9.05 Descentralização da oferta de emprego & + & M & AII; R & PR & $\mathrm{CP}$ & $\mathrm{P}$ & SIM \\
\hline
\end{tabular}




\begin{tabular}{|c|c|c|c|c|c|c|c|c|c|}
\hline Componente & \multicolumn{2}{|r|}{ Impactos Ambientais } & \multicolumn{6}{|c|}{ Atributos } & \multirow{2}{*}{$\begin{array}{c}\text { Elegibilidade } \\
\text { NÃO }\end{array}$} \\
\hline \multirow{6}{*}{$\begin{array}{c}\text { C.3.04 } \\
\text { Infraestrutura física } \\
\text { e social }\end{array}$} & \multirow{6}{*}{$\begin{array}{l}\text { I.3.04 } \\
\text { Impactos } \\
\text { Potenciais na } \\
\text { Infraestrutura } \\
\text { Física e Social }\end{array}$} & 10.01 Interferências com redes de utilidades públicas & - & B & AID & TR & I & TA & \\
\hline & & $\begin{array}{l}10.02 \text { Interferências com planos de expansão de redes } \\
\text { de utilidades públicas }\end{array}$ & - & B & AID & $\mathrm{TR}$ & I & $\mathrm{C}$ & NÃO \\
\hline & & 10.03 Relocação de equipamentos públicos sociais & - & $\mathrm{B}$ & $\mathrm{ADA}$ & TR & $\mathrm{CP}$ & $\mathrm{C}$ & NÃO \\
\hline & & $\begin{array}{l}10.04 \text { Alteração dos perímetros de atendimento dos } \\
\text { equipamentos públicos locais }\end{array}$ & - & $\mathrm{B}$ & AID & I & I & $\mathrm{P}$ & SIM \\
\hline & & $\begin{array}{l}\text { 10.05 Melhoria no padrão de acesso a equipamentos } \\
\text { públicos de importância metropolitana }\end{array}$ & + & A & $\mathrm{R}$ & I & I & $\mathrm{P}$ & SIM \\
\hline & & $\begin{array}{l}10.06 \text { Alteração do padrão de acesso a equipamentos } \\
\text { públicos durante a construção }\end{array}$ & - & M & $\begin{array}{l}\text { ADA; } \\
\text { AID }\end{array}$ & $\mathrm{TR}$ & I & TA & NÃO \\
\hline \multirow{9}{*}{$\begin{array}{l}\text { C.3.05 Qualidade de } \\
\text { vida }\end{array}$} & \multirow{9}{*}{$\begin{array}{l}\text { I.3.05 } \\
\text { Impactos } \\
\text { Potenciais na } \\
\text { Qualidade de } \\
\text { Vida da } \\
\text { População }\end{array}$} & $\begin{array}{l}\text { 11.01 Mobilização social durante as etapas de } \\
\text { planejamento e implantação }\end{array}$ & + & A & $\mathrm{R}$ & I & I & $\mathrm{P}$ & SIM \\
\hline & & $\begin{array}{l}11.02 \text { Aumento dos níveis de ruído e vibração durante } \\
\text { a construção }\end{array}$ & - & M & AID & TR & I & $\mathrm{C}$ & NÃO \\
\hline & & $\begin{array}{l}11.03 \text { Interrupções de tráfego local durante a } \\
\text { construção }\end{array}$ & - & B & AID & $\mathrm{TR}$ & I & $\mathrm{C}$ & NÃO \\
\hline & & $\begin{array}{l}11.04 \text { Interrupções de serviços públicos durante a } \\
\text { construção }\end{array}$ & - & B & AID & $\mathrm{TR}$ & I & TA & NÃO \\
\hline & & 11.05 Desapropriação & - & A & $\mathrm{ADA}$ & I & $\mathrm{CP}$ & $\mathrm{P}$ & SIM \\
\hline & & 11.06 Relocação de Moradias & +- & $\mathrm{M} ; \mathrm{A}$ & $\begin{array}{l}\text { ADA; } \\
\text { ADA }\end{array}$ & $\mathrm{I} ; \mathrm{I}$ & $\mathrm{CP} ; \mathrm{I}$ & $\mathrm{P} ; \mathrm{P}$ & SIM \\
\hline & & 11.07 Aumento dos níveis de ruído durante a operação & - & M & AID & PR & I & $\mathrm{P}$ & SIM \\
\hline & & $\begin{array}{l}\text { 11.8 Alterações localizadas nas relações sociais entre } \\
\text { comunidades de áreas urbanas consolidadas }\end{array}$ & - & M & AID & PR & $\mathrm{CP}$ & $\mathrm{P}$ & SIM \\
\hline & & 11.09 Alterações na paisagem & +- & $\mathrm{M} ; \mathrm{A}$ & $\begin{array}{l}\text { AID; } \\
\text { AID }\end{array}$ & $\mathrm{I} ; \mathrm{I}$ & MP; I & $\mathrm{P} ; \mathrm{P}$ & SIM \\
\hline
\end{tabular}




\begin{tabular}{|c|c|c|c|c|c|c|c|c|c|}
\hline \multirow[t]{3}{*}{ Componente } & \multicolumn{2}{|r|}{ Impactos Ambientais } & \multicolumn{6}{|c|}{ Atributos } & \multirow{2}{*}{$\frac{\text { Elegibilidade }}{\text { SIM }}$} \\
\hline & & 11.10 Redução dos tempos de viagem de passageiros & + & B & $\mathrm{R}$ & PR & I & $\mathrm{P}$ & \\
\hline & & $\begin{array}{l}\text { 11.11 Aumento das opções de emprego para a } \\
\text { população motorizada }\end{array}$ & + & $\mathrm{B}$ & $\mathrm{R}$ & $\mathrm{PR}$ & $\mathrm{CP}$ & $\mathrm{P}$ & SIM \\
\hline \multirow{4}{*}{$\begin{array}{l}\text { C.3.06 Finanças } \\
\text { Públicas }\end{array}$} & \multirow{4}{*}{$\begin{array}{l}\text { I.3.06 } \\
\text { Impactos nas } \\
\text { Finanças } \\
\text { Públicas }\end{array}$} & $\begin{array}{l}\text { 12.01 Aumento nas receitas fiscais durante a } \\
\text { construção }\end{array}$ & + & $\mathrm{B}$ & $\mathrm{D}$ & I & I & TA & SIM \\
\hline & & 12.02 Aumento nas receitas fiscais durante a operação & + & B & $\mathrm{D}$ & I & $\mathrm{CP}$ & $\mathrm{P}$ & SIM \\
\hline & & 12.03 Impactos nos níveis de investimento privado & + & M & AII & I & MP & $\mathrm{P}$ & SIM \\
\hline & & $\begin{array}{l}\text { 12.04 Aumento das demandas por infraestrutura física } \\
\text { e social }\end{array}$ & - & $\mathrm{B}$ & AID & $\mathrm{TR}$ & I & TA & NÃO \\
\hline $\begin{array}{l}\text { C.03.07 Patrimônio } \\
\text { Arqueológico, } \\
\text { Histórico e Cultural }\end{array}$ & \begin{tabular}{|l|} 
I.3.07 Impactos \\
Potenciais sobre \\
o Patrimônio \\
Arqueológico e \\
Cultural
\end{tabular} & $\begin{array}{l}\text { 13.01 Interferência com o patrimônio arqueológico, } \\
\text { histórico e cultural }\end{array}$ & + & $\mathrm{B}$ & ADA & PR & I & $\mathrm{TA}$ & NÃO \\
\hline
\end{tabular}

\section{Legenda:}

\begin{tabular}{|c|c|c|c|c|c|}
\hline V: vetor & - = negativo & $+=$ positivo & & & \\
\hline I: intensidade & $\mathrm{B}=$ baixa & $\mathrm{M}=$ média & $\mathrm{A}=$ alta & & \\
\hline A: Abrangência Geográfica & ADA = Área Diretamente Afetada & AID = Área Influência Direta & $\begin{array}{l}\text { AII = Área de } \\
\text { Influência Indireta }\end{array}$ & $\mathrm{R}=$ Regional & $\mathrm{D}=$ Difusa \\
\hline R: Reversibilidade & $\mathrm{TR}=$ totalmente reversível & $\mathrm{PR}=$ parcialmente reversível & $\mathrm{I}=$ irreversível & & \\
\hline I: Tempo de indução & $\mathrm{I}=$ imediato & $\mathrm{CP}=$ curto prazo & MP = médio prazo & $\mathrm{LP}=$ longo prazo & \\
\hline P: Tempo de permanência & $\mathrm{TA}=$ termina ao fim da ação & $\mathrm{C}=$ curta & $\mathrm{L}=$ longa & $\mathrm{P}=$ permanente & \\
\hline
\end{tabular}




\section{APÊNDICE B}

\section{PROGRAMAS AMBIENTAIS E MEDIDAS PREVENTIVAS, MITIGADORAS OU COMPENSATÓRIAS}

\begin{tabular}{|c|c|c|c|}
\hline & PROGRAMA & \multicolumn{2}{|r|}{ MEDIDAS } \\
\hline \multirow{3}{*}{ P1.01 } & \multirow{3}{*}{$\begin{array}{l}\text { Programa de Estruturação Institucional } \\
\text { para Gestão Socioambiental do Rodoanel }\end{array}$} & M1.01.01 & Instituição do Conselho de Apoio à Implantação \\
\hline & & M1.01.02 & Estruturação da DERSA para Gestão Social e Ambiental \\
\hline & & M1.01.03 & Gestão de Orçamento Ambiental \\
\hline \multirow{11}{*}{ P1.02 } & \multirow{11}{*}{$\begin{array}{l}\text { Programa de Detalhamento do Projeto de } \\
\text { Engenharia para Atender as } \\
\text { Condicionantes Ambientais }\end{array}$} & M1.02.01 & Otimização do Balanço de Materiais por Subtrecho \\
\hline & & M1.02.02 & Minimização das Necessidades de Substituição de Solos \\
\hline & & M1.02.03 & Minimização das Interferências com Fluxos Transversais de Veículos e Pedestres \\
\hline & & M1.02.04 & Estudos para Adequação do Projeto Visando à Mitigação de Ruído em Receptores Críticos \\
\hline & & M1.02.05 & Previsão de Tubos-camisa para Passagens de Utilidades Públicas \\
\hline & & M1.02.06 & Adequação do Projeto Executivo de Drenagem \\
\hline & & M1.02.07 & Planejamento das Travessias de Fauna \\
\hline & & M1.02.08 & Planejamento dos Locais para Implantação de Caixas de Contenção de Vazamentos \\
\hline & & M1.02.09 & $\begin{array}{l}\text { Levantamento de Passivos Ambientais na Faixa de Domínio e Elaboração de Projetos de } \\
\text { Recuperação }\end{array}$ \\
\hline & & M1.02.10 & $\begin{array}{l}\text { Planejamento dos Locais para Baias para Transbordo de Cargas de Veículos com } \\
\text { Vazamentos }\end{array}$ \\
\hline & & M1.02.11 & Posicionamento Estratégico de Retornos Operacionais \\
\hline
\end{tabular}




\begin{tabular}{|c|c|c|c|}
\hline & & M1.02.12 & Planejamento de Barreiras Corta-fogo \\
\hline & & M1.02.13 & Projetos de Remanejamento de Interferências \\
\hline & & M1.02.14 & Planejamento de Desvios Provisórios Durante a Execução das Obras \\
\hline & & M1.02.15 & Projetos de Relocação de Vias Locais e Acessos Privados \\
\hline & & M1.02.16 & Avaliação de Propostas para a inserção do projeto na paisagem \\
\hline P1.02.1 & $\begin{array}{l}\text { Subprograma de Gerenciamento de Áreas } \\
\text { Contaminadas }\end{array}$ & - & - \\
\hline \multirow{3}{*}{ P1.03 } & \multirow{3}{*}{$\begin{array}{l}\text { Programa de Licenciamento Ambiental } \\
\text { Complementar das Obras }\end{array}$} & M1.03.01 & Programa Antecipada de Gestões de Licenciamento \\
\hline & & M1.03.02 & Estudos e levantamentos necessários às licenças e autorizações \\
\hline & & M1.03.03 & $\begin{array}{l}\text { Acompanhamento das Gestões de Licenciamento sob Responsabilidade das Construtoras } \\
\text { Contratadas }\end{array}$ \\
\hline \multirow{7}{*}{ P1.04 } & \multirow{7}{*}{$\begin{array}{l}\text { Programa de Incorporação de Condições } \\
\text { Ambientais nos Editais de Contratação de } \\
\text { Obra }\end{array}$} & M1.04.01 & Incorporação de critérios ambientais no planejamento dos Lotes para contratação de obras \\
\hline & & M1.04.02 & Inclusão de Instrução de Controle Ambiental das Obras em anexo aos editais de licitação \\
\hline & & M1.04.03 & Inclusão de descrição dos procedimentos de Gestão Ambiental nos editais de licitação \\
\hline & & M1.04.04 & Incorporação de dispositivos de controle de impacto nas planilhas de quantidades dos Editais \\
\hline & & M1.04.05 & $\begin{array}{l}\text { Especificação das responsabilidades no atendimento a emergências ambientais durante a } \\
\text { construção }\end{array}$ \\
\hline & & M1.04.06 & Código de Posturas para os trabalhadores \\
\hline & & M1.04.07 & $\begin{array}{l}\text { Definição de exigências técnicas e organizacionais para as atividades de Gestão Ambiental } \\
\text { sob responsabilidade das construtoras }\end{array}$ \\
\hline \multirow{3}{*}{ P1.05 } & \multirow{3}{*}{ Programa de Comunicação Social Prévia } & M1.05.01 & Divulgação Geral do Empreendimento \\
\hline & & M1.05.02 & Captação e Atendimento a Consultas e Reclamações \\
\hline & & M1.05.03 & Operacionalização de Centros de Informação \\
\hline
\end{tabular}




\section{P2 - Fase Durante a Construção}

Programa

\section{Medidas}

\begin{tabular}{|c|c|c|c|}
\hline & Programa & & Medidas \\
\hline \multirow{9}{*}{ P2.01 } & \multirow{9}{*}{$\begin{array}{l}\text { Programa de Planejamento Ambiental Contínuo } \\
\text { da Construção }\end{array}$} & M2.01.01 & Controle da liberação das frentes de obra \\
\hline & & M2.01.02 & Projeto de Drenagem Provisória \\
\hline & & M2.01.03 & Análise de Planos Ambientais de Construção \\
\hline & & M2.01.04 & $\begin{array}{l}\text { Cadastramento ambiental e homologação de fornecedores e prestadores de serviços de apoio } \\
\text { à construção }\end{array}$ \\
\hline & & M2.01.05 & Programação conjunta das atividades da obra \\
\hline & & M2.01.06 & Planejamento de desvios provisórios durante a execução de obras \\
\hline & & M2.01.07 & Controle das atividades de supressão de vegetação \\
\hline & & M2.01.08 & $\begin{array}{l}\text { Procedimentos para planejamento, implantação, remoção e recuperação de acessos } \\
\text { provisórios e estradas de serviço em áreas de várzea }\end{array}$ \\
\hline & & M2.01.09 & Controle da destinação do material excedente \\
\hline P2.01.01 & $\begin{array}{l}\text { Subprograma de Mobilização e Desmobilização } \\
\text { de Mão-de-obra }\end{array}$ & - & - \\
\hline \multirow{6}{*}{ P2.02 } & \multirow{6}{*}{$\begin{array}{l}\text { Programa de Adequação Ambiental de } \\
\text { Procedimentos Construtivos }\end{array}$} & \multicolumn{2}{|r|}{ ICA 00} \\
\hline & & M2.02.01 & Controle de poluição, organização e limpeza \\
\hline & & M2.02.02 & Medidas de controle das atividades de limpeza e supressão de vegetação \\
\hline & & M2.02.03 & Medidas de sinalização de obra \\
\hline & & M2.02.04 & Procedimentos de desativação e recuperação \\
\hline & & M2.02.05 & Cadastro de Edificações Lindeiras \\
\hline P2.03 & & M2.03.01 & Planejamento e Controle Ambiental das Obras \\
\hline
\end{tabular}




\begin{tabular}{|c|c|c|c|}
\hline & \multirow{2}{*}{$\begin{array}{l}\text { Programa de Operacionalização de Sistemas de } \\
\text { Gestão Ambiental pelas Construtoras Contratadas }\end{array}$} & M2.03.02 & Treinamento Ambiental da Mão-de-obra \\
\hline & & M2.03.03 & Licenciamento Ambiental de Instalações Administrativas e Industriais \\
\hline P2.04 & $\begin{array}{l}\text { Programa de Supervisão e Monitoramento } \\
\text { Ambiental da Construção }\end{array}$ & & \\
\hline P2.04.1 & $\begin{array}{l}\text { Subprograma de Monitoramento da Qualidade das } \\
\text { Águas Superficiais }\end{array}$ & & \\
\hline P2.04.2 & $\begin{array}{l}\text { Subprograma de Monitoramento da Qualidade das } \\
\text { Águas Subterrâneas }\end{array}$ & & \\
\hline P2.04.3 & $\begin{array}{l}\text { Subprograma de Monitoramento de Material } \\
\text { Particulado em Receptores Críticos }\end{array}$ & & \\
\hline P2.04.4 & $\begin{array}{l}\text { Subprograma de Monitoramento de Ruído nas } \\
\text { Frentes de Obra e em Receptores Críticos }\end{array}$ & & \\
\hline P2.04.5 & Subprograma de Monitoramento de Vibração & & \\
\hline P2.04.6 & $\begin{array}{l}\text { Subprograma de Minimização das Interferências } \\
\text { nas Relações e Fluxos entre Bairros }\end{array}$ & & \\
\hline P2.04.7 & $\begin{array}{l}\text { Plano de Gerenciamento de Resíduos Sólidos } \\
\text { (PGRS) }\end{array}$ & & \\
\hline \multirow{16}{*}{ P2.05 } & \multirow{16}{*}{$\begin{array}{l}\text { Programa de Gestão da Saúde Ocupacional e } \\
\text { Segurança }\end{array}$} & \multirow{16}{*}{-} & Elaboração do PISST \\
\hline & & & Estruturação Organizacional para Gestão da Saúde Ocupacional e Segurança do Trabalho \\
\hline & & & Inspeções de Segurança (Auto-Monitoramento) \\
\hline & & & Inspeções em Subcontratadas \\
\hline & & & Auditoria Periódica de Instalações \\
\hline & & & Funcionamento do SESMT e da CIPA \\
\hline & & & Operacionalização do PPRA \\
\hline & & & Operacionalização do PCMSO \\
\hline & & & Operacionalização do PCMAT \\
\hline & & & Reuniões de Avaliação \\
\hline & & & Reuniões de Auditoria Interna \\
\hline & & & Análise Prevencionista de Tarefas \\
\hline & & & Elaboração, Revisão e Aprimoramento dos PTS \\
\hline & & & Treinamento em Saúde e Segurança do Trabalho \\
\hline & & & Manejo de Não-Conformidades \\
\hline & & & Investigação de Acidentes \\
\hline
\end{tabular}




\begin{tabular}{|c|c|c|c|}
\hline & & & Estatísticas de Acidentes \\
\hline & & & Elaboração dos Relatórios do Programa \\
\hline \multirow{5}{*}{ P2.06 } & \multirow{5}{*}{$\begin{array}{l}\text { Programa de Atendimento a Emergências } \\
\text { Ambientais Durante a Construção }\end{array}$} & H1 & $\begin{array}{l}\text { Escorregamentos de grandes proporções, com risco de instabilização de encostas com } \\
\text { ocupação antrópica; }\end{array}$ \\
\hline & & $\mathbf{H 2}$ & $\begin{array}{l}\text { Escorregamento de grandes proporções com assoreamento de cursos d'água e perda de } \\
\text { vegetação fora dos limites autorizados; }\end{array}$ \\
\hline & & $\mathbf{H 3}$ & Vazamento de produtos perigosos sobre cursos d’água e em áreas urbanas; \\
\hline & & H4 & Acidentes envolvendo o transporte e uso de explosivos; \\
\hline & & H5 & Incêndios florestais \\
\hline \multirow{2}{*}{$\mathbf{P 2 . 0 7}$} & \multirow{2}{*}{$\begin{array}{l}\text { Programa de Planejamento e Controle Ambiental } \\
\text { de Desativação e/ou Interrupção Temporária de } \\
\text { Frentes de Obra }\end{array}$} & M2.07.01 & Desmobilização Temporária de Obras \\
\hline & & M2.07.02 & Comunicação Social Durante o Período de Paralisação \\
\hline \multirow{3}{*}{ P2.08 } & \multirow{3}{*}{$\begin{array}{l}\text { Programa de Gerenciamento de Desapropriações e } \\
\text { Indenizações }\end{array}$} & M2.08.01 & Operacionalização da Gestão do Programa \\
\hline & & M2.08.02 & Realização do Cadastro Físico e Laudos de Avaliação \\
\hline & & M2.08.03 & $\begin{array}{l}\text { Gerenciamento dos processos judiciais para imissão de posse e adjudicação das } \\
\text { propriedades }\end{array}$ \\
\hline \multirow{5}{*}{ P2.09 } & \multirow{5}{*}{$\begin{array}{l}\text { Programa de Compensação Social e } \\
\text { Reassentamento Involuntário }\end{array}$} & M2.09.01 & Operacionalização da Gestão do Programa \\
\hline & & M2.09.02 & Realização do Cadastro Social \\
\hline & & M2.09.03 & Elaboração do Plano de Reassentamento \\
\hline & & M2.09.04 & Implantação do Plano de Reassentamento \\
\hline & & M2.09.05 & Monitoramento da Reinserção Social da População Reassentada \\
\hline \multirow{4}{*}{ P2.10 } & \multirow{4}{*}{$\begin{array}{l}\text { Programa de Prospecção, Resgate Arqueológico e } \\
\text { Preservação do Patrimônio Arqueológico, } \\
\text { Histórico e Cultural }\end{array}$} & Modulo 1 & Prospecções intensivas e avaliação do patrimônio arqueológico e histórico-cultural \\
\hline & & Modulo 2 & Resgate e curadoria de materiais arqueológicos \\
\hline & & Modulo 3 & Monitoramento arqueológico \\
\hline & & Modulo 4 & Educação patrimonial e inclusão social da arqueoinformação \\
\hline P2.11 & $\begin{array}{l}\text { Programa de Atendimento aos Termos de } \\
\text { Compromisso de Recuperação Ambiental }\end{array}$ & - & - \\
\hline P2.11.1 & $\begin{array}{l}\text { Subprograma de Execução dos Plantios } \\
\text { Compensatórios e outras Práticas de Restauração } \\
\text { Florestal }\end{array}$ & - & - \\
\hline P2.11.2 & $\begin{array}{l}\text { Subprograma de Apoio a Projetos de Restauração } \\
\text { Florestal }\end{array}$ & - & - \\
\hline P2.11.3 & Subprograma de Ampliação de Áreas Protegidas & - & - \\
\hline
\end{tabular}




\begin{tabular}{|c|c|c|c|}
\hline P2.11.4 & $\begin{array}{l}\text { Subprograma de Recuperação de Corpos Hídricos } \\
\text { Urbanos }\end{array}$ & - & - \\
\hline \multirow{3}{*}{ P2.12 } & \multirow{3}{*}{ Programa de Comunicação Social na Construção } & M2.12.01 & Divulgação Geral do Empreendimento \\
\hline & & M2.12.02 & Captação e Atendimento a Consultas e Reclamações \\
\hline & & M2.12.03 & Operacionalização de Centros de Informação \\
\hline \multirow{3}{*}{ P2.13 } & \multirow{3}{*}{ Programa de Apoio a Unidades de Conservação } & M2.13.01 & Apoio à Gestão das UC de Proteção Integral existentes na AII \\
\hline & & M2.13.02 & Apoio à implantação de Parques Municipais localizados na Área de Entorno \\
\hline & & M2.13.03 & Apoio a Unidades de Conservação \\
\hline \multirow{4}{*}{ P2.14 } & \multirow{4}{*}{ Programa de Conservação de Flora e Fauna } & P2.14.1 & Subprograma de Resgate de Flora durante a Construção \\
\hline & & P2.14.2 & Subprograma de Afugentamento e Resgate de Fauna durante a Construção \\
\hline & & P2.14.3 & Subprograma de Monitoramento de Animais Domésticos durante a Construção \\
\hline & & P2.14.4 & Subprograma de Planejamento e Monitoramento das Travessias de Fauna \\
\hline \multirow{7}{*}{ P2.15 } & \multirow{7}{*}{$\begin{array}{l}\text { Programa de Relações com as Prefeituras } \\
\text { Municipais Durante a Construção }\end{array}$} & M2.15.01 & Avaliação das Medidas Mitigadoras e Compensatórias propostas na LP \\
\hline & & M2.15.02 & $\begin{array}{l}\text { Avaliação das demandas de articulação com as prefeituras decorrentes dos demais } \\
\text { Programas Socioambientais }\end{array}$ \\
\hline & & M2.15.03 & Concepção das Estratégias de Implementação das Ações \\
\hline & & M2.15.04 & Negociação com as Prefeituras Municipais \\
\hline & & M2.15.05 & Articulação de ações de apoio à etapa de construção \\
\hline & & M2.15.06 & Estudo de tráfego no sistema viário municipal e adequações necessárias para operação \\
\hline & & M2.15.07 & Estudos de intervenções para adequada inserção urbana \\
\hline P2.16 & $\begin{array}{l}\text { Monitoramento Florestal e de Fauna em Áreas } \\
\text { Adjacentes ao Empreendimento }\end{array}$ & - & - \\
\hline P2.16.1 & $\begin{array}{l}\text { Subprograma de Monitoramento Florestal em } \\
\text { Áreas Adjacentes ao Empreendimento }\end{array}$ & - & - \\
\hline P2.16.2 & $\begin{array}{l}\text { Subprograma de Monitoramento de Fauna em } \\
\text { Áreas Adjacentes ao Empreendimento }\end{array}$ & - & - \\
\hline P2.17 & $\begin{array}{l}\text { Programa de Monitoramento Direcionado para as } \\
\text { Populações de Bugios (Alouatta clamitans) }\end{array}$ & - & - \\
\hline
\end{tabular}




\section{P3 - Fase de Operação}

\section{PROGRAMA}

\section{MEDIDAS}

P3.01 Programa de Supervisão Ambiental da Operação

M3.01.01 Acompanhamento do cumprimento de todas as exigências vinculadas à Licença de Operação

M3.01.02 Avaliação contínua do desempenho ambiental da operação

M3.02.01 Inventário periódico e gerenciamento de passivos ambientais

P3.02 Programa de Gestão Ambiental da Operação

M3.02.02 Controle de cargas difusas

M3.02.03 Plano de Gestão de Resíduos

M3.02.04 Manutenção da forração vegetal e paisagismo na faixa de domínio

M3.03.01 Monitoramento de cargas difusas

M3.03.02 Monitoramento de ruído durante a operação

M3.03.03 Monitoramento da qualidade do ar

P3.03 Programa de Monitoramento Ambiental da Operação

M3.03.04 Monitoramento continuado de plantios fora da faixa de domínio

M3.03.05 Monitoramento de fauna durante a operação

M3.03.06 Monitoramento de tráfego

M3.03.07 Monitoramento de fluxos de pedestres

Programa de Segurança do Trabalho e Saúde Ocupacional na Operação

M3.04.01 Incorporação das atividades de operação no Plano de Trabalho do SESMT 


\begin{tabular}{|c|c|c|c|}
\hline & & M3.04.02 & Incorporação das atividades de operação no Plano de Trabalho da CIPA \\
\hline & & M3.04.03 & Incorporação do pessoal contratado para operação no PCMSO \\
\hline & & M3.04.04 & Elaboração de PPRA específico para a operação \\
\hline & & M3.04.05 & $\begin{array}{l}\text { Supervisão da conformidade de prestadores de serviços que apoiarão a operação da rodovia } \\
\text { com a legislação de segurança do trabalho e saúde ocupacional }\end{array}$ \\
\hline \multirow{2}{*}{ P3.05 } & \multirow{2}{*}{$\begin{array}{l}\text { Programa de Atendimento a Emergências } \\
\text { Ambientais Durante a Operação }\end{array}$} & M3.05.01 & $\begin{array}{l}\text { Plano de Ação de Emergência e Programa de Gerenciamento de Riscos para acidentes com } \\
\text { produtos perigosos }\end{array}$ \\
\hline & & M3.05.02 & Plano de Contingência para Combate a Incêndio \\
\hline \multirow{3}{*}{ P3.06 } & \multirow{3}{*}{$\begin{array}{l}\text { Programa de Relações com as Comunidades } \\
\text { Lindeiras Durante a Operação }\end{array}$} & M3.06.01 & Comunicação social durante a operação \\
\hline & & M3.06.02 & Atendimento à consultas e reclamações \\
\hline & & M3.06.03 & Educação Ambiental \\
\hline \multirow{2}{*}{ P3.07 } & \multirow{2}{*}{$\begin{array}{l}\text { Programa de Apoio à Proteção e Recuperação } \\
\text { de Mananciais Durante a Operação }\end{array}$} & M3.07.01 & Monitoramento de usos lindeiros e apoio à fiscalização \\
\hline & & M3.07.02 & Análise e avaliação de requerimento de acessos \\
\hline P3.08 & $\begin{array}{l}\text { Programa de Reforço da Capacidade do Sistema } \\
\text { Viário Local }\end{array}$ & M3.08.01 & Monitoramento do tráfego no sistema viário local \\
\hline P3.09 & $\begin{array}{l}\text { Programa de Apoio à Proteção e Recuperação } \\
\text { de Mananciais Durante a Operação }\end{array}$ & & \\
\hline
\end{tabular}




\section{APÊNDICE C}

\section{CRITÉRIOS, INDICADORES E MÉTRICAS - ENVISION}

\begin{tabular}{|c|c|c|c|c|}
\hline Categorias & Temas & Critério & Objetivo & Métrica \\
\hline \multirow[b]{3}{*}{$\underset{10}{0}$} & \multirow{3}{*}{ Propósito } & $\begin{array}{l}\text { QL 1.1 Melhorar a Qualidade } \\
\text { de Vida da Comunidade }\end{array}$ & $\begin{array}{l}\text { Melhorar a qualidade de vida resultante de todas as } \\
\text { comunidades afetadas pelo projeto e mitigar os impactos } \\
\text { negativos sobre as mesmas. }\end{array}$ & $\begin{array}{l}\text { Medidas usadas para avaliar as necessidades } \\
\text { comunitárias e a melhora da qualidade de vida, } \\
\text { minimizando os impactos negativos. }\end{array}$ \\
\hline & & $\begin{array}{l}\text { QL 1.2 Estimular o } \\
\text { Crescimento e o } \\
\text { Desenvolvimento Sustentável }\end{array}$ & $\begin{array}{l}\text { Apoiar e estimular o crescimento e desenvolvimento } \\
\text { sustentável, incluindo melhoras em criação de trabalho, } \\
\text { desenvolvimento de capacidade, produção, atratividade } \\
\text { empresarial e habitabilidade. }\end{array}$ & $\begin{array}{l}\text { Avaliação dos impactos do projeto no } \\
\text { crescimento e desenvolvimento econômico } \\
\text { sustentável da comunidade. }\end{array}$ \\
\hline & & $\begin{array}{l}\text { QL } 1.3 \text { Desenvolver as } \\
\text { Capacidades e Habilidades } \\
\text { Locais. }\end{array}$ & $\begin{array}{l}\text { Expandir o conhecimento, competências e a capacidade } \\
\text { da mão-de-obra da comunidade em melhorar sua } \\
\text { habilidade em crescer e se desenvolver. }\end{array}$ & $\begin{array}{l}\text { O grau no qual o projeto irá melhorar o nível, } \\
\text { as habilidades diversas e as capacidades do } \\
\text { emprego local. }\end{array}$ \\
\hline$\underset{0}{0}$ & \multirow{4}{*}{ Comunidade } & $\begin{array}{l}\text { QL 2.1 Melhorar a saúde } \\
\text { pública e segurança }\end{array}$ & $\begin{array}{l}\text { Levar em consideração as implicações na saúde e } \\
\text { segurança do uso de novos materiais, tecnologias ou } \\
\text { metodologias para além de cumprir os requisitos locais. }\end{array}$ & $\begin{array}{l}\text { Esforços para exceder os requisitos de saúde e } \\
\text { segurança, levando em consideração os riscos } \\
\text { adicionais na aplicação de novas tecnologias, } \\
\text { materiais e metodologias. }\end{array}$ \\
\hline$\underset{0}{20}$ & & $\begin{array}{l}\text { QL } 2.2 \text { Minimizar o Ruído e as } \\
\text { Vibrações }\end{array}$ & $\begin{array}{l}\text { Minimizar ruídos e vibrações gerados durante a } \\
\text { construção e operação do projeto final para manter e } \\
\text { melhorar a habitabilidade da comunidade. }\end{array}$ & $\begin{array}{l}\text { O nível nos quais ruídos e vibrações será } \\
\text { reduzido durante a construção e a operação do } \\
\text { projeto. }\end{array}$ \\
\hline$\stackrel{\infty}{2}$ & & $\begin{array}{l}\text { QL 2.3 Minimizar a Poluição } \\
\text { Luminosa }\end{array}$ & $\begin{array}{l}\text { Prevenir o brilho excessivo, luz durante a noite e luz } \\
\text { direcionada ao céu para conservar energia e reduzir o } \\
\text { ofuscamento. }\end{array}$ & $\begin{array}{l}\text { A que nível a iluminação atende a regulação } \\
\text { mínima de segurança, mas não se propaga em } \\
\text { áreas além dos limites do terreno, nem cria } \\
\text { brilho obstrusivo e perturbador. }\end{array}$ \\
\hline & & $\begin{array}{l}\text { QL 2.4 Melhorar o Acesso e a } \\
\text { Mobilidade da Comunidade }\end{array}$ & $\begin{array}{l}\text { Locar, criar e construir o projeto de forma que facilite a } \\
\text { congestão do tráfego, melhore o acesso e a mobilidade, } \\
\text { previna o crescimento urbano desordenado e promova, } \\
\text { pelo contrário, uma melhora na habitabilidade da } \\
\text { comunidade. }\end{array}$ & $\begin{array}{l}\text { Nível no qual o projeto melhora o acesso e a } \\
\text { caminhabilidade, redução nas horas comutadas } \\
\text { e horários cruzados para instalações existentes } \\
\text { e transporte. Melhora no uso seguro } \\
\text { considerando todos os modos de transporte (ex. } \\
\text { Veículo pessoal, comercial, trânsito, bicicleta e } \\
\text { pedestre). }\end{array}$ \\
\hline
\end{tabular}




\begin{tabular}{|c|c|c|c|c|}
\hline Categorias & Temas & Critério & Objetivo & Métrica \\
\hline \multirow[b]{5}{*}{$\underset{8}{\infty}$} & & $\begin{array}{l}\text { QL } 2.5 \text { Incentivar Modos } \\
\text { Alternativos de Transporte }\end{array}$ & $\begin{array}{l}\text { Melhorar a acessibilidade de transporte não motorizado e } \\
\text { de transporte público. Promover transportes alternativos e } \\
\text { reduzir o congestionamento. }\end{array}$ & $\begin{array}{l}\text { O nível no qual o projeto tem aumentado a } \\
\text { caminhabilidade, uso do transporte público e } \\
\text { transporte não motorizado. }\end{array}$ \\
\hline & & $\begin{array}{l}\text { QL 2.6 Melhorar a } \\
\text { Acessibilidade, a Segurança e a } \\
\text { Sinalização de Obras. }\end{array}$ & $\begin{array}{l}\text { Melhorar a acessibilidade, segurança e a sinalização de } \\
\text { caminhos do usuário no local do projeto e seus arredores. }\end{array}$ & $\begin{array}{l}\text { Clareza, simplicidade, legibilidade e confiança } \\
\text { geral da população na sinalização de caminhos, } \\
\text { beneficio do usuário e proteção. }\end{array}$ \\
\hline & \multirow{3}{*}{ Bem-estar } & $\begin{array}{l}\text { QL 3.1 Preservar os Recursos } \\
\text { Históricos e Culturais }\end{array}$ & $\begin{array}{l}\text { Preservar ou restaurar sítios históricos e culturais } \\
\text { significantes e recursos relacionados para melhorar } \\
\text { recursos culturais comunitários. }\end{array}$ & $\begin{array}{l}\text { Sumário de passos tomados para identificar, } \\
\text { preservar ou restaurar patrimônios culturais. }\end{array}$ \\
\hline & & $\begin{array}{l}\text { QL 3.2 Preservar as Vistas e o } \\
\text { Caráter Local }\end{array}$ & $\begin{array}{l}\text { Criar o projeto de forma a manter o caráter local da } \\
\text { comunidade e não impactar negativamente nas vistas da } \\
\text { comunidade. }\end{array}$ & $\begin{array}{l}\text { Profundidade dos esforços em identificar vistas } \\
\text { importantes da comunidade e aspectos da } \\
\text { paisagem local, incluindo comunidades e } \\
\text { incorporando-as no design do projeto. }\end{array}$ \\
\hline & & $\begin{array}{l}\text { QL } 3.3 \text { Melhorar o Espaço } \\
\text { Público }\end{array}$ & $\begin{array}{l}\text { Melhorar os espaços públicos incluindo parques, praças, } \\
\text { instalações recreativas, ou refúgios de vida selvagem para } \\
\text { melhorar a habitabilidade da comunidade. }\end{array}$ & $\begin{array}{l}\text { Planos e comprometimentos em preservar, } \\
\text { conservar, melhorar e/ou restaurar os } \\
\text { elementos definidores do espaço público. }\end{array}$ \\
\hline \multirow{3}{*}{$\begin{array}{l}0 \\
0 \\
0 \\
0 \\
0 \\
0 \\
0 \\
0 \\
0 \\
0 \\
0\end{array}$} & & $\begin{array}{l}\text { QL 4.1- Identificar e abordar as } \\
\text { necessidades das mulheres e } \\
\text { comunidades diversas } \\
\text { (indígenas ou } \\
\text { afrodescendentes) }\end{array}$ & $\begin{array}{l}\text { Melhorar a qualidade de vida das mulheres e dos diversos } \\
\text { grupos que vivem nas comunidades do entorno do projeto } \\
\text { e mitigar potenciais impactos negativos. }\end{array}$ & $\begin{array}{l}\text { As medidas tomadas para avaliar as } \\
\text { necessidades das mulheres e das diversas } \\
\text { comunidades e melhorar a sua qualidade de } \\
\text { vida. }\end{array}$ \\
\hline & & $\begin{array}{l}\text { QL } 4.2 \text { - Estimular e Promover } \\
\text { a Capacitação Econômica das } \\
\text { Mulheres }\end{array}$ & $\begin{array}{l}\text { Promover a capacitação econômica das mulheres através } \\
\text { de meios de subsistência sustentáveis, aquisições locais, } \\
\text { criação de emprego, capacitação e programas de } \\
\text { treinamento. }\end{array}$ & $\begin{array}{l}\text { Avaliação do impacto do projeto nos meios de } \\
\text { subsistência e capacidades das mulheres. }\end{array}$ \\
\hline & & $\begin{array}{l}\text { QL } 4.3 \text { - Melhorar o Acesso e a } \\
\text { Mobilidade das Mulheres e } \\
\text { Comunidades Diversas (Povos } \\
\text { Indígenas ou } \\
\text { Afrodescendentes) }\end{array}$ & $\begin{array}{l}\text { Localizar, projetar, e construir o projeto compreendendo } \\
\text { os vários padrões e necessidades de mobilidade dos } \\
\text { diferentes grupos sociais. }\end{array}$ & $\begin{array}{l}\text { O nível em que o projeto melhora o acesso, } \\
\text { mobilidade e segurança das mulheres e } \\
\text { diversos grupos. }\end{array}$ \\
\hline
\end{tabular}




\begin{tabular}{|c|c|c|c|c|}
\hline Categorias & Tema & Critério & Objetivo & Métrica \\
\hline \multirow{6}{*}{$\underbrace{\infty}_{0}$} & \multirow{4}{*}{ Colaboração } & $\begin{array}{l}\text { LD 1.1 Proporcionar } \\
\text { Compromisso e Liderança } \\
\text { Efetivos }\end{array}$ & $\begin{array}{l}\text { Proporcionar compromisso e liderança efetivos } \\
\text { para atingir metas de sustentabilidade do projeto. }\end{array}$ & $\begin{array}{l}\text { Demonstração de compromisso significante do } \\
\text { proprietário e da equipe de projeto aos } \\
\text { princípios de sustentabilidade e melhora no } \\
\text { desempenho sustentável. }\end{array}$ \\
\hline & & $\begin{array}{l}\text { LD 1.2 Estabelecer um Sistema } \\
\text { de Gerenciamento Sustentável }\end{array}$ & $\begin{array}{l}\text { Criar um sistema de gerenciamento de projeto } \\
\text { que possa gerenciar o escopo, a escala e a } \\
\text { complexidade de um desempenho sustentável. }\end{array}$ & $\begin{array}{l}\text { As políticas organizacionais, autoridades, } \\
\text { mecanismos e processos de negócios que têm } \\
\text { sido postos em prática e que o julgamento que } \\
\text { eles são suficientes para o escopo, escala e } \\
\text { complexidade do projeto, levando em } \\
\text { consideração os impactos ambientais, sociais e } \\
\text { de governança. }\end{array}$ \\
\hline & & $\begin{array}{l}\text { LD } 1.3 \text { Promover a } \\
\text { Colaboração e o Trabalho em } \\
\text { Equipe }\end{array}$ & $\begin{array}{l}\text { Eliminar elementos de projeto conflitantes e } \\
\text { otimizar o sistema usando metodologias de } \\
\text { projeto e entrega integrados e processos } \\
\text { colaborativos. Isso vai exigir não apenas a equipe } \\
\text { de construção, mas as diferentes partes } \\
\text { envolvidas, proprietário, gerente de projeto, entre } \\
\text { outros. }\end{array}$ & $\begin{array}{l}\text { O nível da colaboração dentro da equipe de } \\
\text { projeto e o grau no qual o processo de entrega } \\
\text { do projeto incorpora sistemas de projeto } \\
\text { completos e abordagens de entrega. }\end{array}$ \\
\hline & & $\begin{array}{l}\text { LD 1.4 Proporcionar a } \\
\text { Participação das Partes } \\
\text { Interessadas }\end{array}$ & $\begin{array}{l}\text { Estabelecer programas sólidos e significantes } \\
\text { para identificação, engajamento e participação } \\
\text { das partes interessadas nas decisões do projeto. }\end{array}$ & $\begin{array}{l}\text { O nível no qual as partes interessadas do } \\
\text { projeto são identificadas e engajadas nas } \\
\text { decisões do projeto. }\end{array}$ \\
\hline & \multirow[t]{2}{*}{ Gerenciamento } & $\begin{array}{l}\text { LD } 2.1 \text { Buscar Oportunidades } \\
\text { de Sinergia nos Subprodutos }\end{array}$ & $\begin{array}{l}\text { Reduzir o desperdício, melhorar o desempenho } \\
\text { do projeto e reduzir os custos do projeto } \\
\text { identificando e procurando oportunidades para } \\
\text { utilizar subprodutos indesejados ou materiais } \\
\text { descartados e recursos de operações próximas. }\end{array}$ & $\begin{array}{l}\text { O nível no qual a equipe de projeto identificou } \\
\text { as necessidades dos materiais do projeto, } \\
\text { procurou nas instalações próximas recursos de } \\
\text { subprodutos que poderiam atender a estas } \\
\text { necessidades e captou oportunidades de } \\
\text { sinergias. }\end{array}$ \\
\hline & & $\begin{array}{l}\text { LD 2.2 Melhorar a Integração } \\
\text { das Infraestruturas }\end{array}$ & $\begin{array}{l}\text { Criar o projeto levando em consideração as } \\
\text { relações operacionais entre outros elementos da } \\
\text { infraestrutura da comunidade, resultando em uma } \\
\text { melhora geral da eficiência e eficácia da } \\
\text { estrutura. }\end{array}$ & $\begin{array}{l}\text { A que nível o design do projeto integra-se com } \\
\text { a infraestrutura existente e planejada da } \\
\text { comunidade e resulta em uma melhora final na } \\
\text { eficiência e eficácia. }\end{array}$ \\
\hline
\end{tabular}


LD 3.1 Planejar

Monitoramento e Manutenção

a Longo Prazo

Planejamento

LD 3.2 Abordar Regulamentos

e Políticas Conflitantes

LD 3.3 Estender a Vida Útil
Pôr em prática planos e recursos suficientes para assegurar, de forma prática, que a proteção ecológica, mitigação e medidas de melhoramento sejam incorporadas ao projeto e possam ser efetivadas.

Trabalhar com oficiais para identificar e abordar

leis, normas, regulamentos ou politicas que podem, involuntariamente, criar barreiras na implementação de infraestruturas sustentáveis.

Estender a vida útil de um projeto desenhando-o de uma forma que resulte em um projeto completo que seja mais durável, flexível e resiliente.
Compreensão e detalhe dos planos de monitoramento e manutenção a longo prazo e do comprometimento dos recursos no financiamento das atividades.

Esforços para identificar e mudar leis, normas, regulamentos e/ou políticas que podem, involuntariamente, entrar em contradição com as metas, objetivos e práticas sustentáveis.

A que nível a equipe de projeto incorpora o pensamento completo de ciclo de vida à melhora da durabilidade, flexibilidade e resiliência do projeto.

\section{Categorias}

Tema

Critério

Objetivo

Métrica

\begin{tabular}{|c|c|c|c|}
\hline \multirow{6}{*}{ 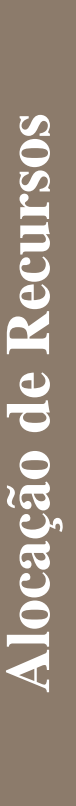 } & \multirow{6}{*}{ Materiais } & $\begin{array}{l}\text { RA } 1.1 \text { Reduzir a Energia Final } \\
\text { Incorporada }\end{array}$ & $\begin{array}{l}\text { Conservar energia reduzindo a energia final } \\
\text { incorporada dos materiais do projeto durante a } \\
\text { vida do projeto. }\end{array}$ \\
\hline & & $\begin{array}{l}\text { RA 1.2 Apoiar Práticas de } \\
\text { Aquisições Sustentáveis }\end{array}$ & $\begin{array}{l}\text { Obtenção de materiais e equipamentos de } \\
\text { fabricantes e fornecedores que implementam } \\
\text { práticas sustentáveis. }\end{array}$ \\
\hline & & $\begin{array}{l}\text { RA } 1.3 \text { Usar Materiais } \\
\text { Reciclados }\end{array}$ & $\begin{array}{l}\text { Reduzir o uso de materiais virgens e evitar enviar } \\
\text { materiais utilizáveis para aterros, através da } \\
\text { especificação de materiais reutilizáveis, } \\
\text { incluindo estruturas e materiais com conteúdo } \\
\text { reciclável. }\end{array}$ \\
\hline & & $\begin{array}{l}\text { RA 1.4 Utilizar Materiais } \\
\text { Regionais }\end{array}$ & $\begin{array}{l}\text { Minimizar os custos e os impactos de transporte } \\
\text { e manter o s benefícios regionais através da } \\
\text { especificação de fontes locais. }\end{array}$ \\
\hline & & $\begin{array}{l}\text { RA 1.5 Desviar Resíduos dos } \\
\text { Aterros Sanitários }\end{array}$ & $\begin{array}{l}\text { Reduzir o gasto e desviar o fluxo de resíduos dos } \\
\text { aterros sanitários. }\end{array}$ \\
\hline & & $\begin{array}{l}\text { RA } 1.6 \text { Reduzir o Trajeto dos } \\
\text { Materiais Escavados }\end{array}$ & $\begin{array}{l}\text { Minimizar o movimento do solo e outros } \\
\text { materiais escavados fora do local da obra, a fim } \\
\text { de reduzir o transporte e os impactos ao meio } \\
\text { ambiente. }\end{array}$ \\
\hline
\end{tabular}

Percentagem da redução da energia final incorporada da avaliação do ciclo de vida.

Percentagem dos materiais adquiridos de fabricantes que atendam aos requisitos de uma prática sustentável.

Percentagem dos materiais de projeto que são reusados ou reciclados. Percentagem dos materiais do projeto por
tipo e peso ou volume encontrados dentro de uma requerida distância.

Percentagem total dos resíduos desviados da eliminação.

Percentagem de materiais escavados mantidos no local. 


\begin{tabular}{|c|c|c|}
\hline \multirow{7}{*}{ 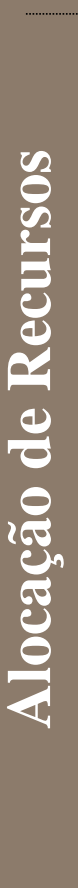 } & & $\begin{array}{l}\text { RA 1.7 Prever Desconstrução e } \\
\text { Reciclagem }\end{array}$ \\
\hline & \multirow{3}{*}{ Energia } & $\begin{array}{l}\text { RA } 2.1 \text { Reduzir o Consumo de } \\
\text { Energia }\end{array}$ \\
\hline & & $\begin{array}{l}\text { RA 2.2 Usar Energias } \\
\text { Renováveis }\end{array}$ \\
\hline & & $\begin{array}{l}\text { RA 2.3 Estabelecer e Monitorar } \\
\text { os Sistemas de Energia }\end{array}$ \\
\hline & \multirow{3}{*}{ Água } & $\begin{array}{l}\text { RA 3.1 Proteger a } \\
\text { Disponibilidade de Água Doce }\end{array}$ \\
\hline & & $\begin{array}{l}\text { RA } 3.2 \text { Reduzir o Consumo de } \\
\text { Água Potável }\end{array}$ \\
\hline & & $\begin{array}{l}\text { RA 3.3 Monitorar os Sistemas } \\
\text { de Água }\end{array}$ \\
\hline
\end{tabular}

\section{Categorias}

NW 1.1 Preservar os Habitats
Nobres

Encorajar a futura reciclagem, up-cycling, e reuso através de um projeto de desmontagem fácil e eficiente no fim da vida útil do projeto.

Conservar energia reduzindo o consumo geral de energia de operação e manutenção durante a vida do projeto.

Atender as necessidades energéticas através de fontes de energias renováveis.

Assegurar o funcionamento eficiente e vida útil

extensa especificando o comissionamento e a

monitoração do desempenho do sistema de energia.

Reduzir o impacto na disponibilidade

quantidade e qualidade de água doce.

Reduzir o consumo geral de água potável e

encorajar o uso de água cinzenta, água reciclada

e águas pluviais para atender as necessidades por água.

Implementar programas para monitoramento de

desempenho do sistema de água e seus impactos no recebimento de água.
Percentagem dos componentes que podem ser facilmente separados para desmontagem e desconstrução.

Percentagem das reduções alcançadas.

Nível no qual os recursos de energia renovável são incorporados ao projeto.

Comissionamento terceirizado de sistemas elétricos/mecânicos e documentação do sistema monitorando o equipamento no projeto.

A extração de água como uma função dos recursos de água disponíveis, e o nível no qual o projeto usa recursos de água doce e reabastece-los em sua fonte.

Percentagem da redução do uso de água.

Documentação dos sistemas de monitoração do projeto.
Objetivo

Evitar implantar o projeto - e o do terreno da construção - em locais que foram identificados como de alto valor ecológico.

Proteger, amortecer, melhorar e restaurar áreas designadas como pântanos, zonas ribeirinhas e corpos d'agua fornecendo zonas de projeção natural, vegetação e zonas de proteção de solo.

\section{Métrica}

Evitar habitats de alto valor ecológico e estabelecimentos de zonas de proteção.

O tamanho da zona de proteção estabelecida ao redor de todos os pântanos, zonas ribeirinhas e corpos d'agua. 


\begin{tabular}{|c|c|c|c|c|}
\hline \multirow{7}{*}{ 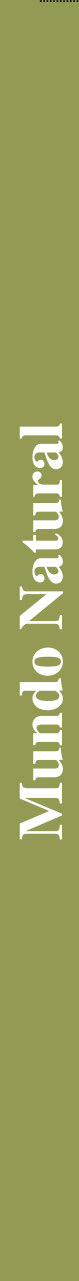 } & \multirow{5}{*}{ Localivação } & $\begin{array}{l}\text { NW } 1.3 \text { Preservar Terras de } \\
\text { Alto Valor de Cultivo }\end{array}$ & $\begin{array}{l}\text { Identificar e proteger solos designados como } \\
\text { terras agrícolas nobres, áreas agrícolas singulares } \\
\text { ou de importância nacional. }\end{array}$ & $\begin{array}{l}\text { Percentagem de terras agrícolas nobres evitadas } \\
\text { durante o desenvolvimento. }\end{array}$ \\
\hline & & $\begin{array}{l}\text { NW 1.4 Evitar Zonas de } \\
\text { Geologia Adversa }\end{array}$ & $\begin{array}{l}\text { Evitar desenvolvimento em formações } \\
\text { geológicas adversas e salvaguardar aquíferos, } \\
\text { para reduzir riscos naturais e preservar os } \\
\text { recursos hídricos subterrâneos de alta qualidade. }\end{array}$ & $\begin{array}{l}\text { Nível no qual riscos naturais e aquíferos } \\
\text { sensíveis são evitados e funções geológicas são } \\
\text { mantidas. }\end{array}$ \\
\hline & & $\begin{array}{l}\text { NW 1.5 Preservar Funções de } \\
\text { Várzeas }\end{array}$ & $\begin{array}{l}\text { Preservar várzeas, incluindo zonas ribeirinhas, } \\
\text { limitando o desenvolvimento e seus impactos } \\
\text { para manter as capacidades e competências da } \\
\text { gerencia de água e mitigar contra os impactos da } \\
\text { mudança climática. }\end{array}$ & $\begin{array}{l}\text { Esforços para evitar várzeas ou manter o } \\
\text { desenvolvimento prévio das mesmas. }\end{array}$ \\
\hline & & $\begin{array}{l}\text { NW 1.6 Evitar a Construção } \\
\text { Inadequada em Encostas } \\
\text { Íngremes }\end{array}$ & $\begin{array}{l}\text { Proteger encostas íngremes de construções } \\
\text { inapropriadas e inadequadas a fim de evitar } \\
\text { exposições e riscos de erosões, deslizamento de } \\
\text { terras e outros perigos naturais. }\end{array}$ & $\begin{array}{l}\text { Nível no qual o desenvolvimento em encostas } \\
\text { íngremes é evitado ou no qual a erosão é } \\
\text { controlada e outras medidas usadas para } \\
\text { proteger o projeto final assim como outras } \\
\text { estruturas de baixo declive. }\end{array}$ \\
\hline & & NW 1.7 Preservar Greenfields & $\begin{array}{l}\text { Conservar terras verdes não desenvolvidas } \\
\text { (greenfields) locando os projetos em terrenos já } \\
\text { desenvolvidos (greyfields), e/ou em terrenos } \\
\text { contaminados classificados como brownfields. }\end{array}$ & $\begin{array}{l}\text { Percentagem do terreno equivalente à área } \\
\text { greyfield ou o uso e limpeza de terrenos } \\
\text { classificados como brownfields. }\end{array}$ \\
\hline & \multirow[b]{2}{*}{ Terra e Água } & $\begin{array}{l}\text { NW } 2.1 \text { Gerenciar Águas } \\
\text { Pluviais }\end{array}$ & $\begin{array}{l}\text { Minimizar o impacto da infraestrutura na } \\
\text { quantidade e na qualidade do escoamento das } \\
\text { águas pluviais. }\end{array}$ & $\begin{array}{l}\text { Capacidade de infiltração e evapotranspiração } \\
\text { do terreno e o retorno das capacidades } \\
\text { predesenvolvidas através de medidas de } \\
\text { desenvolvimento de baixo impacto (DBI*). }\end{array}$ \\
\hline & & $\begin{array}{l}\text { NW } 2.2 \text { Reduzir o Impacto de } \\
\text { Pesticidas e Fertilizantes }\end{array}$ & $\begin{array}{l}\text { Reduzir fontes não pontuais de poluição } \\
\text { reduzindo a quantidade, toxicidade, } \\
\text { biodisponibilidade e persistência de pesticidas e } \\
\text { fertilizantes, ou através da eliminação da } \\
\text { necessidade do uso desses materiais. }\end{array}$ & $\begin{array}{l}\text { Esforços feitos para reduzir a quantidade, } \\
\text { toxicidade, biodisponibilidade e persistência de } \\
\text { pesticidas e fertilizantes usados no terreno, } \\
\text { incluindo a seleção de espécies de plantas e o } \\
\text { uso de técnicas de gestão integrada de pragas. }\end{array}$ \\
\hline
\end{tabular}




\begin{tabular}{|c|c|c|c|c|}
\hline \multirow{5}{*}{ 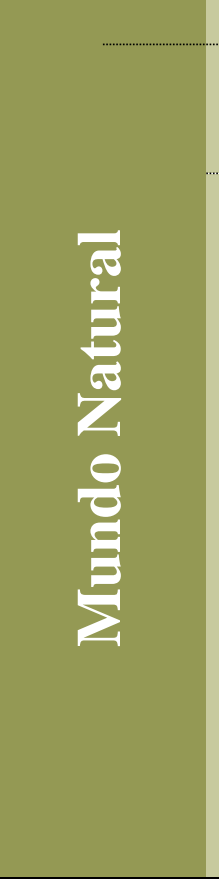 } & & $\begin{array}{l}\text { NW } 2.3 \text { Prevenir a } \\
\text { Contaminação das Águas } \\
\text { Superficiais e Subterrâneas }\end{array}$ & $\begin{array}{l}\text { Preservar os recursos de água doce incorporando } \\
\text { medidas para prevenir poluentes de contaminar } \\
\text { águas superficiais e subterrâneas e monitorar os } \\
\text { impactos das operações. }\end{array}$ & $\begin{array}{l}\text { Programas do projeto instituídos para prevenir } \\
\text { e monitorar a contaminação das águas } \\
\text { superficiais e subterrâneas. }\end{array}$ \\
\hline & \multirow{4}{*}{ Biodiversidade } & $\begin{array}{l}\text { NW 3.1 Preservar a } \\
\text { Biodiversidade das Espécies }\end{array}$ & $\begin{array}{l}\text { Proteger a biodiversidade preservando e } \\
\text { restaurando espécies e habitats. }\end{array}$ & Nível de proteção do habitat. \\
\hline & & $\begin{array}{l}\text { NW } 3.2 \text { Controlar Espécies } \\
\text { Invasoras }\end{array}$ & $\begin{array}{l}\text { Uso apropriado de espécies não invasivas e } \\
\text { controle ou eliminação das espécies invasoras } \\
\text { existentes. }\end{array}$ & $\begin{array}{l}\text { Nível no qual as espécies invasoras têm sido } \\
\text { reduzidas ou eliminadas. }\end{array}$ \\
\hline & & $\begin{array}{l}\text { NW } 3.3 \text { Restaurar Solos } \\
\text { Alterados }\end{array}$ & $\begin{array}{l}\text { Restaurar solos que foram alterados durante a } \\
\text { construção e desenvolvimentos prévios para } \\
\text { trazer de volta as funções ecológicas e } \\
\text { hidrológicas. }\end{array}$ & Percentagem dos solos alterados restaurados. \\
\hline & & $\begin{array}{l}\text { NW 3.4 Manter as Funções dos } \\
\text { Pântanos e das Águas } \\
\text { Superficiais }\end{array}$ & $\begin{array}{l}\text { Manter e restaurar as funções de ecossistema de } \\
\text { córregos, pântanos, corpos d'água e suas áreas } \\
\text { ribeirinhas. }\end{array}$ & $\begin{array}{l}\text { Número de funções mantidas e restauradas. As } \\
\text { quatro funções avaliadas neste crédito são: } \\
\text { conexão hidrológica, qualidade da água, habitat } \\
\text { e transporte de sedimentos. }\end{array}$ \\
\hline Categorias & Tema & Critério & Objetivo & Métrica \\
\hline \multirow{2}{*}{ 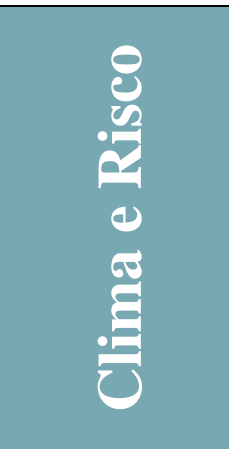 } & \multirow[t]{2}{*}{ Emissão } & $\begin{array}{l}\text { CR 1.1 Reduzir a Emissão de } \\
\text { Gases de Efeito Estufa }\end{array}$ & $\begin{array}{l}\text { Conduzir uma análise detalhada do ciclo de vida } \\
\text { do carbono e usar esta avaliação para reduzir a } \\
\text { quantidade antecipada das emissões gerais dos } \\
\text { gases de efeito estufa durante o ciclo de vida do } \\
\text { projeto, reduzindo a contribuição do projeto nas } \\
\text { mudanças climáticas. }\end{array}$ & $\begin{array}{l}\text { Emissões equivalentes (Co2e) do ciclo de vida } \\
\text { do dióxido de carbono. }\end{array}$ \\
\hline & & $\begin{array}{l}\text { CR } 1.2 \text { Reduzir a Emissão de } \\
\text { Poluentes Atmosféricos }\end{array}$ & $\begin{array}{l}\text { Reduzir a emissão de seis critérios poluentes: } \\
\text { partículas (incluindo poeira), ozônio troposférico, } \\
\text { monóxido de carbono, óxidos de enxofre, óxidos } \\
\text { de nitrogênio, e chumbo, assim como odores } \\
\text { nocivos. }\end{array}$ & $\begin{array}{l}\text { Medidas de poluidores atmosféricos } \\
\text { comparados com os usados na norma. }\end{array}$ \\
\hline
\end{tabular}




\begin{tabular}{|c|c|c|c|c|}
\hline & \multirow{5}{*}{ Resiliência } & $\begin{array}{l}\text { CR 2.1 Avaliar as Ameaças } \\
\text { Climáticas }\end{array}$ & $\begin{array}{l}\text { Desenvolver uma Avaliação de Impactos } \\
\text { Climáticos detalhada e plano de adaptação. Este } \\
\text { plano inclui uma avaliação de vulnerabilidade, } \\
\text { uma avaliação de riscos, bem como uma avaliação } \\
\text { adaptação, e identifica os riscos e as respostas aos } \\
\text { efeitos da mudança climática. }\end{array}$ & $\begin{array}{l}\text { Sumário dos passos tomados na preparação } \\
\text { para a alteração do clima e desastres naturais. }\end{array}$ \\
\hline$\frac{8}{2}$ & & $\begin{array}{l}\text { CR 2.2 Evitar Riscos e } \\
\text { Vulnerabilidades }\end{array}$ & $\begin{array}{l}\text { Evitar riscos e vulnerabilidades que possam criar } \\
\text { altos custos a longo prazo e riscos para as } \\
\text { comunidades afetadas. }\end{array}$ & $\begin{array}{l}\text { Avaliação de potenciais riscos a longo prazo, } \\
\text { vulnerabilidades e riscos devido às mudanças a } \\
\text { longo prazo assim como mudanças climáticas e } \\
\text { o nível no qual estes foram resolvidos no } \\
\text { design do projeto. }\end{array}$ \\
\hline \multirow[t]{3}{*}{$\underset{\theta}{\sigma}$} & & $\begin{array}{l}\text { CR 2.3 Preparar para } \\
\text { Adaptação a Longo Prazo }\end{array}$ & $\begin{array}{l}\text { Preparar sistemas de infraestrutura que sejam } \\
\text { resilientes às consequências da mudança climática } \\
\text { a longo prazo, que sejam capazes de desempenhar } \\
\text { sua função adequadamente em condições } \\
\text { climáticas alteradas, ou se adaptar a outras } \\
\text { mudanças de cenário climático a longo prazo. }\end{array}$ & $\begin{array}{l}\text { O nível no qual o projeto tem sido desenhado } \\
\text { para resiliência e adaptação a longo prazo. }\end{array}$ \\
\hline & & $\begin{array}{l}\text { CR 2.4 Preparar para Riscos a } \\
\text { Curto Prazo }\end{array}$ & $\begin{array}{l}\text { Aumentar a perspectiva de resiliência e } \\
\text { recuperação a longo prazo do projeto, diminuindo } \\
\text { os riscos a curto prazo induzidos pelo homem e } \\
\text { pela natureza, ou riscos súbitos. }\end{array}$ & $\begin{array}{l}\text { Passos tomados para melhorar as medidas de } \\
\text { proteção além das regulações existentes. }\end{array}$ \\
\hline & & $\begin{array}{l}\text { CR } 2.5 \text { Gerenciar os Efeitos de } \\
\text { Ilhas de Calor }\end{array}$ & $\begin{array}{l}\text { Minimizar superfícies com um alto índice de } \\
\text { reflexão solar (SRI) para reduzir a acumulação de } \\
\text { calor localizado e gerenciar microclimas. }\end{array}$ & $\begin{array}{l}\text { Percentual do terreno que atende ao critério de } \\
\text { índice de reflexão solar (SRI). }\end{array}$ \\
\hline
\end{tabular}




\section{APÊNDICE D}

FICHAS DE AVALIAÇÃO DE DESEMPENHO 


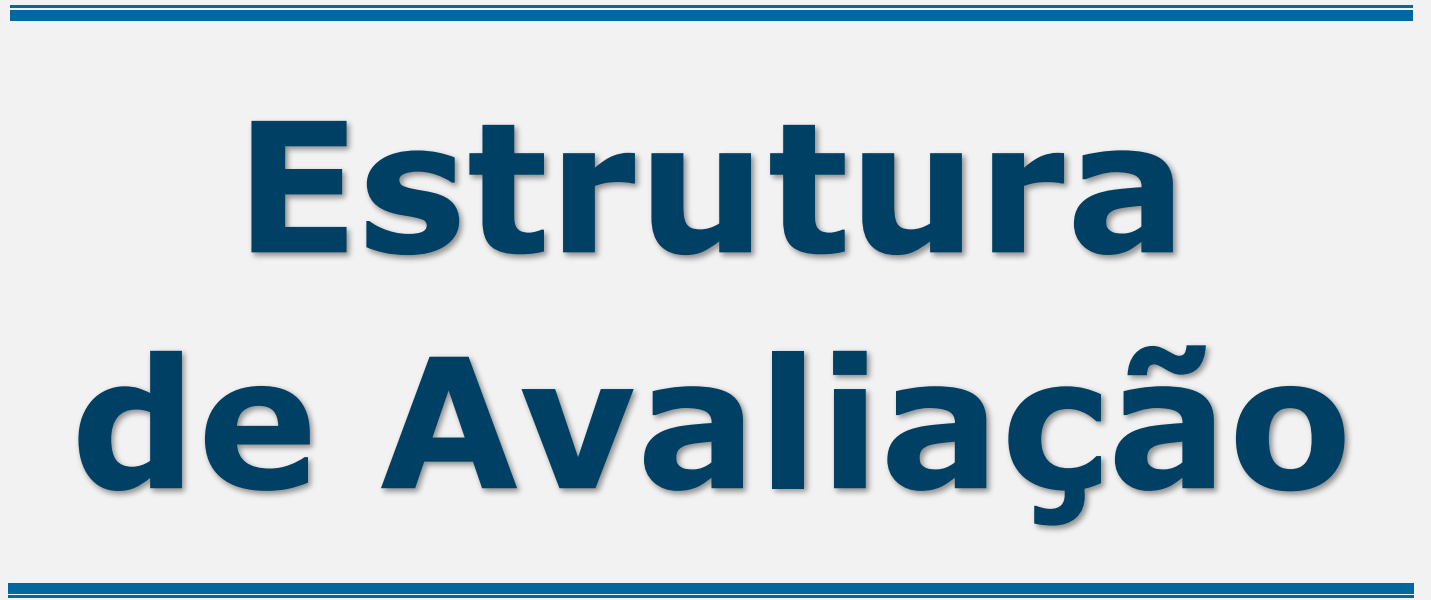




\section{FA-01.}

Mobilidade e

Eficiência do

MOB-1.1. Alteração no Nível de Serviço (LOS)

sistema

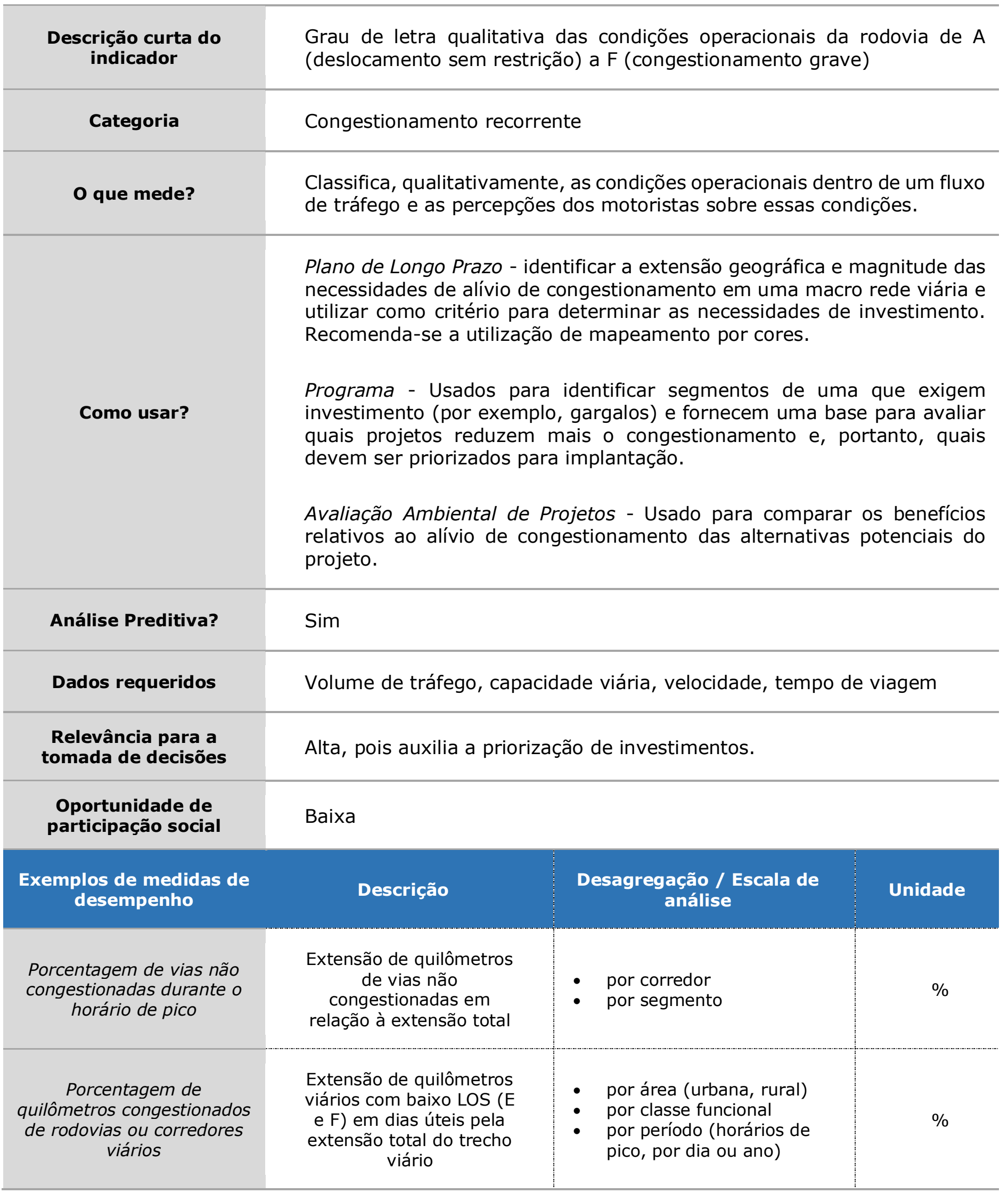


FA-01.

Mobilidade e

Eficiência do

Sistema

\section{MOB-1.2. Mudança na relação volume / capacidade} $(\mathrm{V} / \mathrm{C})$

\begin{tabular}{|c|c|}
\hline $\begin{array}{l}\text { Descrição curta do } \\
\text { indicador }\end{array}$ & $\begin{array}{l}\text { Número real de veículos que usam um segmento de rodovia em relação } \\
\text { ao número de veículos para os quais ele foi projetado para lidar por um } \\
\text { período de tempo fixo }\end{array}$ \\
\hline Categoria & Congestionamento recorrente \\
\hline \multirow[t]{2}{*}{ O que mede? } & $\begin{array}{l}\text { Permite compreender o comportamento do sistema viário, a fim de se } \\
\text { prever os efeitos causados por modificações nas características da } \\
\text { demanda e/ou da oferta do sistema de transportes, refletindo na } \\
\text { qualidade da operação. }\end{array}$ \\
\hline & $\begin{array}{l}\text { Quanto menor o valor da relação, menor é o congestionamento. Valor } 1 \\
\text { significa que a via opera no limite da capacidade. }\end{array}$ \\
\hline \multirow{4}{*}{ Como usar? } & $\begin{array}{l}\text { Plano de Longo Prazo - Usado para identificar a extensão geográfica e a } \\
\text { magnitude das necessidades de alívio de congestionamento na malha } \\
\text { rodoviária regional e/ou estadual, contribuindo para identificar } \\
\text { necessidades de futuros investimentos. É interessante ser representado } \\
\text { em mapa com diferenciação de cores. }\end{array}$ \\
\hline & $\begin{array}{l}\text { Programa - Utilizados para identificar segmentos de um corredor que } \\
\text { requerem investimento (por exemplo, gargalos) e fornecem uma base } \\
\text { para avaliar quais projetos reduzem mais o congestionamento, ajudando } \\
\text { nas decisões de programação para implantação de projetos a curto, médio } \\
\text { e longo prazo. }\end{array}$ \\
\hline & $\begin{array}{l}\text { Avaliação Ambiental de Projetos - Utilizada para comparar os benefícios } \\
\text { relativos ao alívio de congestionamento de possíveis alternativas de } \\
\text { projeto. }\end{array}$ \\
\hline & $\begin{array}{l}\text { Monitoramento - Usado para confirmação dos resultados obtidos nos } \\
\text { estudos preditivos, bem como atualizar a programação de implantação de } \\
\text { projetos. }\end{array}$ \\
\hline Análise Preditiva? & Sim \\
\hline Dados requeridos & Volume de tráfego, capacidade viária \\
\hline $\begin{array}{l}\text { Relevância para a } \\
\text { tomada de decisões }\end{array}$ & Alta, pois auxilia a priorização de investimentos. \\
\hline $\begin{array}{l}\text { Oportunidade de } \\
\text { participação social }\end{array}$ & $\begin{array}{l}\text { Média, contribuindo para justificar investimentos às comunidades } \\
\text { diretamente impactadas e aos beneficiários pelo futuro projeto. }\end{array}$ \\
\hline
\end{tabular}


FA-01.

Mobilidade e

Eficiência do

Sistema

\section{MOB-1.2. Mudança na relação volume / capacidade $(\mathrm{V} / \mathrm{C})$}

Exemplos de medidas de desempenho análise

Unidade

Percentual da distância percorrida por veículo que ocorre em vias com uma relação $V / C$ superior a 0,8 (ou outro limite);

Alteração da relação $V$ / C
Razão entre a extensão de um segmento de rodovia que possui uma relação $\mathrm{V} / \mathrm{C}$ superior a determinado limite (e.g. 0,8) com um determinado segmento (ou sua totalidade) de rodovia.

Diferença entre a relação $\mathrm{V} / \mathrm{C}$ atual com o resultado do estudo preditivo tendencial ou de implantação de um determinado projeto
- $\quad$ por classe funcional

- por tipo de veículo

- por região

- por projeto

- por classe funcional

- por trecho congestionado

- $\quad$ por trecho de interesse

- por período (horários de pico, por dia ou ano)

Razão entre a extensão de Porcentagem de kmrodovia operando sob capacidade excedente

quilômetros operando sob determinados limites V / C pela extensão total da rodovia
- por período

- $\quad$ por n horas por dia

- por segmento rodoviário
Número

decimal 


\begin{tabular}{|l|l|}
\hline $\begin{array}{c}\text { Descrição curta do } \\
\text { indicador }\end{array}$ & $\begin{array}{l}\text { Diferença entre o tempo de viagem real exigido pelo motorista para } \\
\text { percorrer um segmento da rodovia e o tempo com fluxo irrestrito (ou seja, } \\
\text { em velocidade representativa, com boas condições climáticas e sem } \\
\text { interferência de tráfego) no mesmo segmento da rodovia. }\end{array}$ \\
\hline Categoria & Tempo de viagem \\
\hline O que mede? & $\begin{array}{l}\text { Mede o tempo perdido (atraso) pelo motorista ou pela carga em função } \\
\text { da baixa eficiência no sistema de transporte em um segmento de rodovia } \\
\text { ou uma determinada rota, corredores ou regiões selecionadas. }\end{array}$ \\
\hline
\end{tabular}

Plano de Longo Prazo - Usado para identificar a extensão e magnitude das necessidades de alívio de congestionamento na rede de rodovias de uma região ou de um estado e subsequentes necessidades de investimento em todo o estado.

Como usar?

Análise Preditiva?

Dados requeridos

Relevância para a tomada de decisões
Programa - Utilizados para identificar segmentos de um corredor que requerem investimento (por exemplo, gargalos) e fornecem uma base para avaliar quais projetos reduzem mais o atraso, bem como apoiar a seleção de projetos que proporcionam maior alívio de congestionamento.

Avaliação Ambiental de Projeto - Usada como justificativa do projeto (objetivo e necessidade de sua implantação) e para comparar os benefícios relativos ao alívio de congestionamento de possíveis alternativas do projeto.
Sim. Utiliza-se de modelos de previsão de tempo de viagens, avaliando o cenário atual, tendencial e com os investimentos em transporte.

Volume de tráfego, velocidade e tempo de viagem

Alta, pois auxilia a priorização de investimentos, a partir dos custos e benefícios resultantes da eficiência do sistema. Tem, ainda, forte relação na qualidade de vida da população que utiliza o sistema de transporte rotineiramente.

Oportunidade de participação social
Alta, podendo ser utilizada como informação relevante para aceitação popular de um determinado projeto. 
FA-01.

Mobilidade e

Eficiência do

MOB-2.1. Atraso recorrente

Sistema

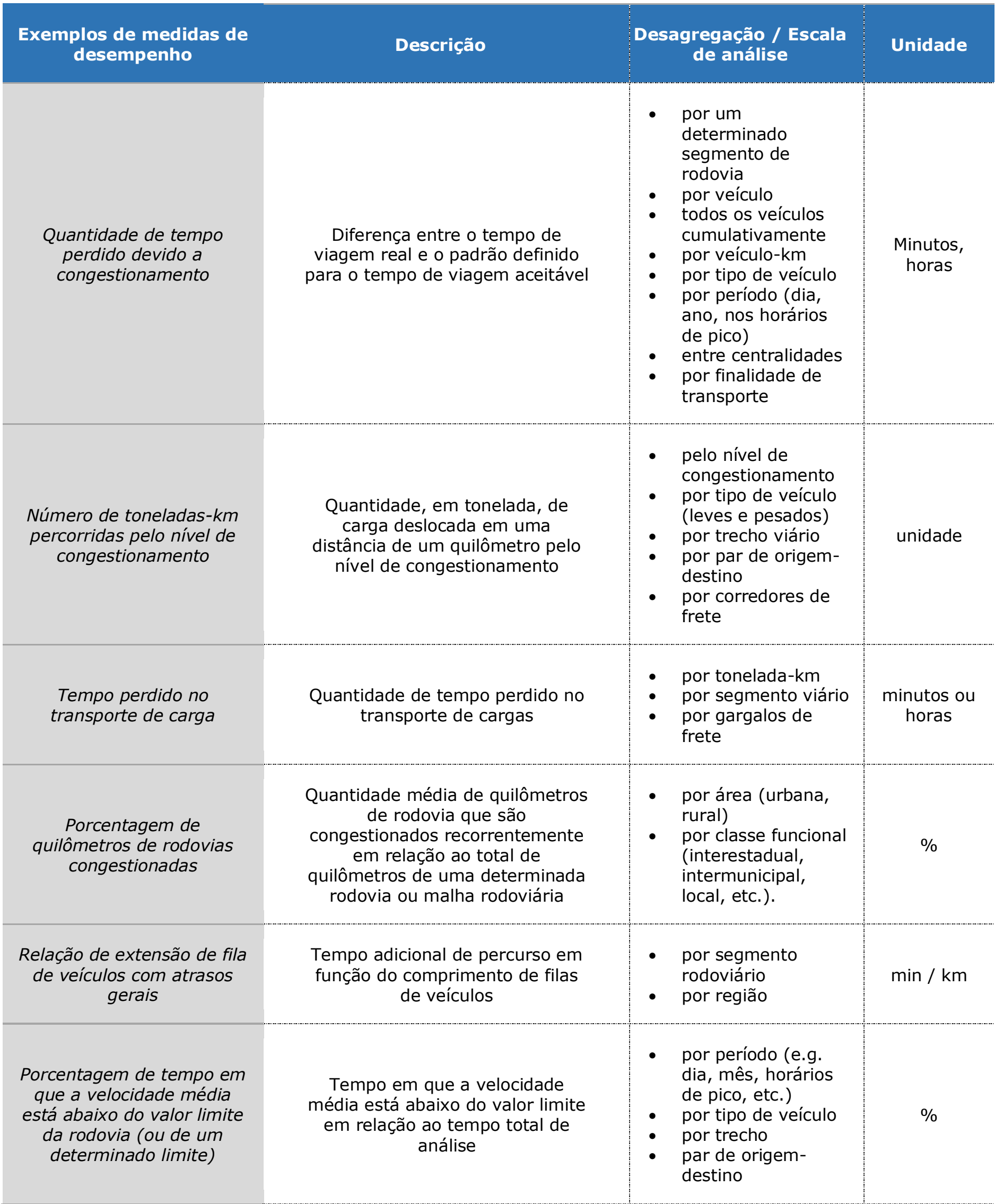


FA-01.

Mobilidade e

Eficiência do

MOB-2.1. Atraso recorrente

Sistema

\begin{tabular}{|c|c|c|c|}
\hline $\begin{array}{c}\text { Média anual da extensão de } \\
\text { vias congestionadas }\end{array}$ & $\begin{array}{c}\text { Média aritmética mensal (dos dias } \\
\text { úteis) da extensão de vias } \\
\text { congestionadas nos horários de } \\
\text { pico (manhã e tarde) }\end{array}$ \\
$\begin{array}{c}\text { Duração de } \\
\text { congestionamento }\end{array}$ & $\begin{array}{c}\text { por região } \\
\text { por estado } \\
\text { por nível de } \\
\text { congestionamento }\end{array}$ \\
\hline
\end{tabular}


FA-01.

Mobilidade e

Eficiência do

MOB-2.2. Tempo de viagem

Sistema

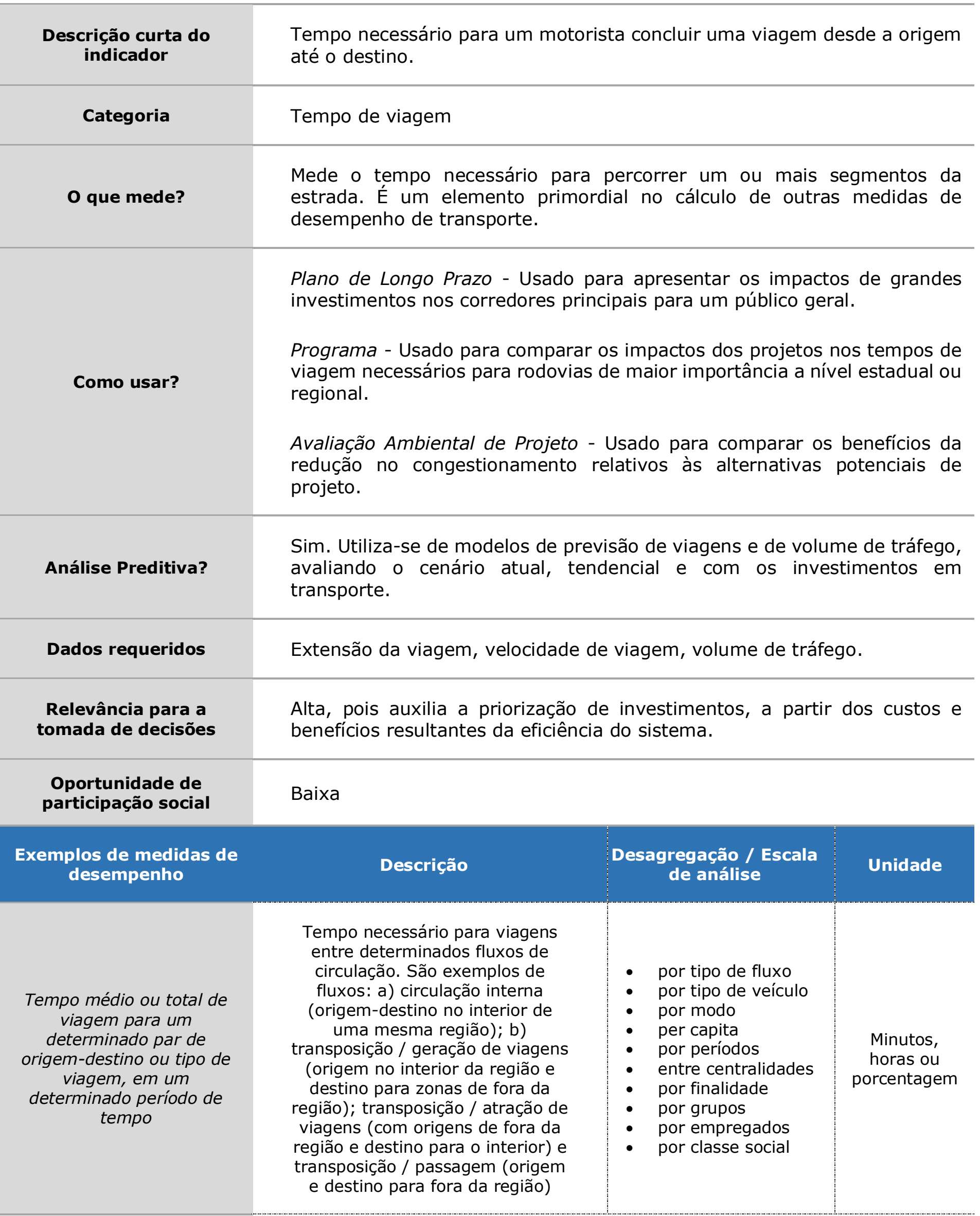


FA-01.

Mobilidade e

Eficiência do

MOB-2.2. Tempo de viagem

Sistema

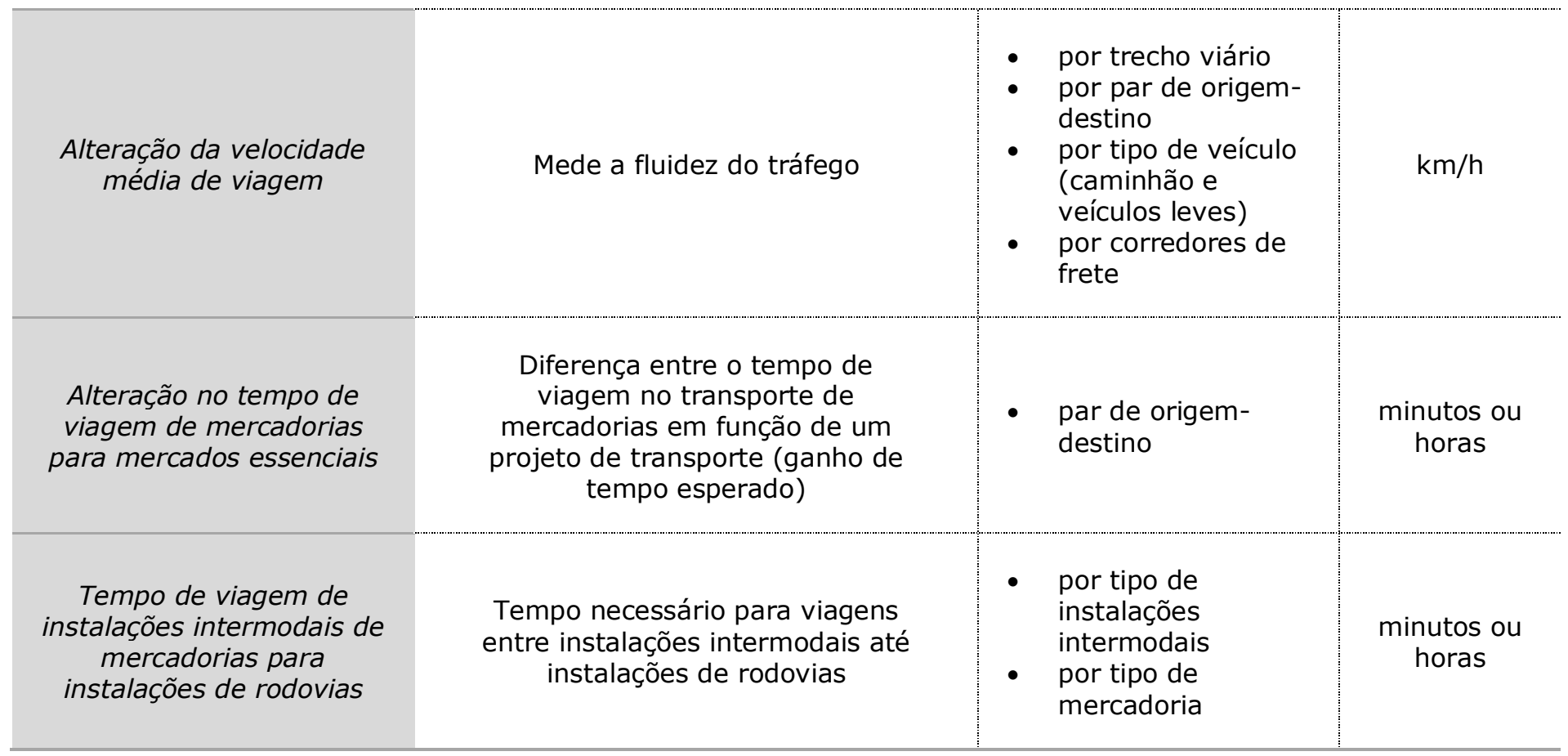


FA-01.

Mobilidade e

Eficiência do

MOB-2.3. Alteração no Índice Tempo de Viagem

Sistema

\begin{tabular}{|c|c|c|c|}
\hline $\begin{array}{l}\text { Descrição curta do } \\
\text { indicador }\end{array}$ & \multicolumn{3}{|c|}{$\begin{array}{l}\text { Alteração na relação do tempo de viagem real de uma viagem comparado } \\
\text { ao tempo de viagem irrestrito. }\end{array}$} \\
\hline Categoria & \multicolumn{3}{|l|}{ Tempo de viagem } \\
\hline O que mede? & \multicolumn{3}{|c|}{$\begin{array}{l}\text { Geralmente focado em viagens de período de pico. É calculado como a } \\
\text { razão do tempo de viagem real necessário para uma viagem e o tempo } \\
\text { de viagem de fluxo livre ou desejado para aquela viagem. O tempo fluxo } \\
\text { livre é o tempo necessário quando se viaja a uma velocidade } \\
\text { representativa de boas condições climáticas e com densidade de tráfego } \\
\text { baixa o suficiente para que não seja afetada pelas interações com outros } \\
\text { veículos. } \\
\text { Normalmente, os Índices de Tempo de Viagem são calculados por } \\
\text { corredor viário para combinações comuns de origem-destino. }\end{array}$} \\
\hline \multirow[b]{2}{*}{ Como usar? } & \multicolumn{3}{|c|}{$\begin{array}{l}\text { Plano de Longo Prazo - Uma média dos índices de tempo de viagem entre } \\
\text { instalações pode ser usada para entender as tendências de } \\
\text { congestionamento ao longo do tempo ou para comparar regiões ou } \\
\text { estados. }\end{array}$} \\
\hline & \multicolumn{3}{|c|}{$\begin{array}{l}\text { Programa - Usado para identificar instalações ou corredores que } \\
\text { requerem investimento ou para comunicar um problema de mobilidade a } \\
\text { um público geral. Pode ser usado para avaliar o impacto no nível do } \\
\text { projeto. }\end{array}$} \\
\hline Análise Preditiva? & \multicolumn{3}{|c|}{$\begin{array}{l}\text { Sim. Utiliza-se de modelos de previsão de viagens e de volume de tráfego, } \\
\text { avaliando o cenário atual, tendencial e com os investimentos em } \\
\text { transporte. }\end{array}$} \\
\hline Dados requeridos & \multicolumn{3}{|c|}{$\begin{array}{l}\text { Tempo de viagem congestionado, tempo de viagem de fluxo livre, } \\
\text { extensão da viagem, velocidade de viagem. }\end{array}$} \\
\hline $\begin{array}{l}\text { Relevância para a } \\
\text { tomada de decisões }\end{array}$ & \multicolumn{3}{|c|}{$\begin{array}{l}\text { Alta, pois auxilia a priorização de investimentos, a partir dos custos e } \\
\text { benefícios resultantes da eficiência do sistema. }\end{array}$} \\
\hline $\begin{array}{l}\text { Oportunidade de } \\
\text { participação social }\end{array}$ & \multicolumn{3}{|l|}{ Média } \\
\hline $\begin{array}{l}\text { Exemplos de medidas de } \\
\text { desempenho }\end{array}$ & Descrição & $\begin{array}{l}\text { Desagregação / Escala } \\
\text { de análise }\end{array}$ & Unidade \\
\hline Índice de mobilidade & $\begin{array}{c}\text { Quilômetro-pessoa de viagem } \\
\text { dividido por quilômetros-veículo } \\
\text { de viagem, vezes a velocidade } \\
\text { média }\end{array}$ & $\begin{array}{l}\text { - } \quad \text { por modo; } \\
\text { por corredores de } \\
\text { fretes importantes }\end{array}$ & - \\
\hline
\end{tabular}


FA-02.

Acessibilidade
AC-01.1. Acessibilidade da força de trabalho
Descrição curta do indicador

Categoria

O que mede?

Como usar?
Número de moradores ao alcance dos empregadores da região

Acesso a recursos do mercado

A acessibilidade da força de trabalho permite calcular a mudança no tempo médio de viagem para os principais centros de emprego ou o percentual de trabalhadores dentro de um tempo definido de deslocamento dos centros de emprego.

Plano de Longo Prazo - Usado para avaliar um aspecto da competitividade econômica de uma região ou estado - a capacidade de fornecer uma reserva de trabalho suficiente para os empregadores.

Programa - Usados para identificar e comparar mudanças de acessibilidade de diferentes projetos ao longo de uma rota.

Avaliação Ambiental de Projeto - Usada para comparar alternativas potenciais.

Sim. Geralmente, é estimado usando um modelo de previsão de viagens regionais no nível de análise de tráfego.

Dados requeridos

Relevância para a tomada de decisões

Oportunidade de participação social

Exemplos de medidas de desempenho

Mudança no tempo médio de viagem para os principais centros de emprego como resultado do projeto

Variação no número (ou porcentagem) dos trabalhadores que podem alcançar seu local de trabalho ou centralidades com facilidade
Descrição

População e emprego por zona; tempos de viagem entre sub-regiões;

Alta, pois auxilia a priorização de investimentos.

Média

Unidade
Desagregação / Escala de análise

Diferença no tempo médio de viagem para as

principais centralidades que oferecem empregos

Diferença entre o número (ou porcentagem) dos trabalhadores que podem alcançar seu local de trabalho em até $X$ (minutos ou quilômetros) de viagem, dividido pelo total de trabalhadores $* 100$ empregadores com

pregadores em relação

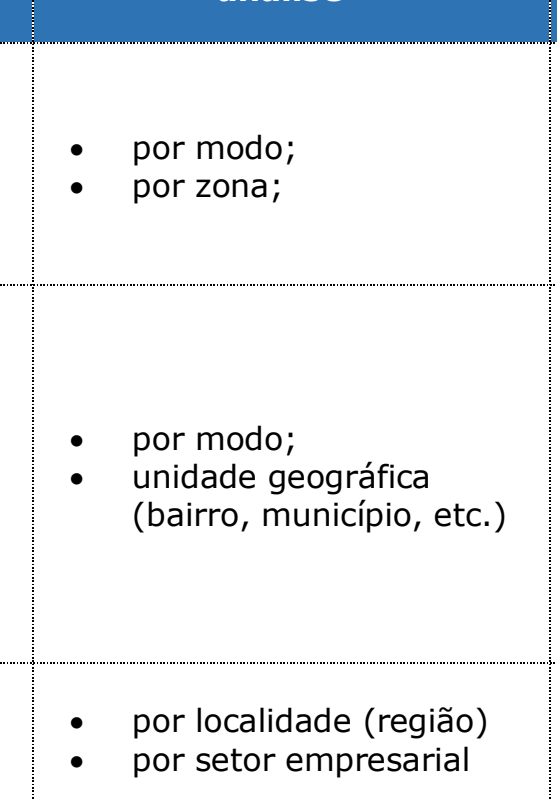

minutos 
FA-02.

Acessibilidade

dificuldades em acessar a oferta de mão de obra desejada devido ao transporte

AC-01.1. Acessibilidade da força de trabalho

ao total, que têm

dificuldades em conseguir

mão de obra desejada em função do álcool
- $\quad$ por qualificação da mão de obra 
FA-02.

Acessibilidade

\section{AC-01.2. Acessibilidade de mercado}

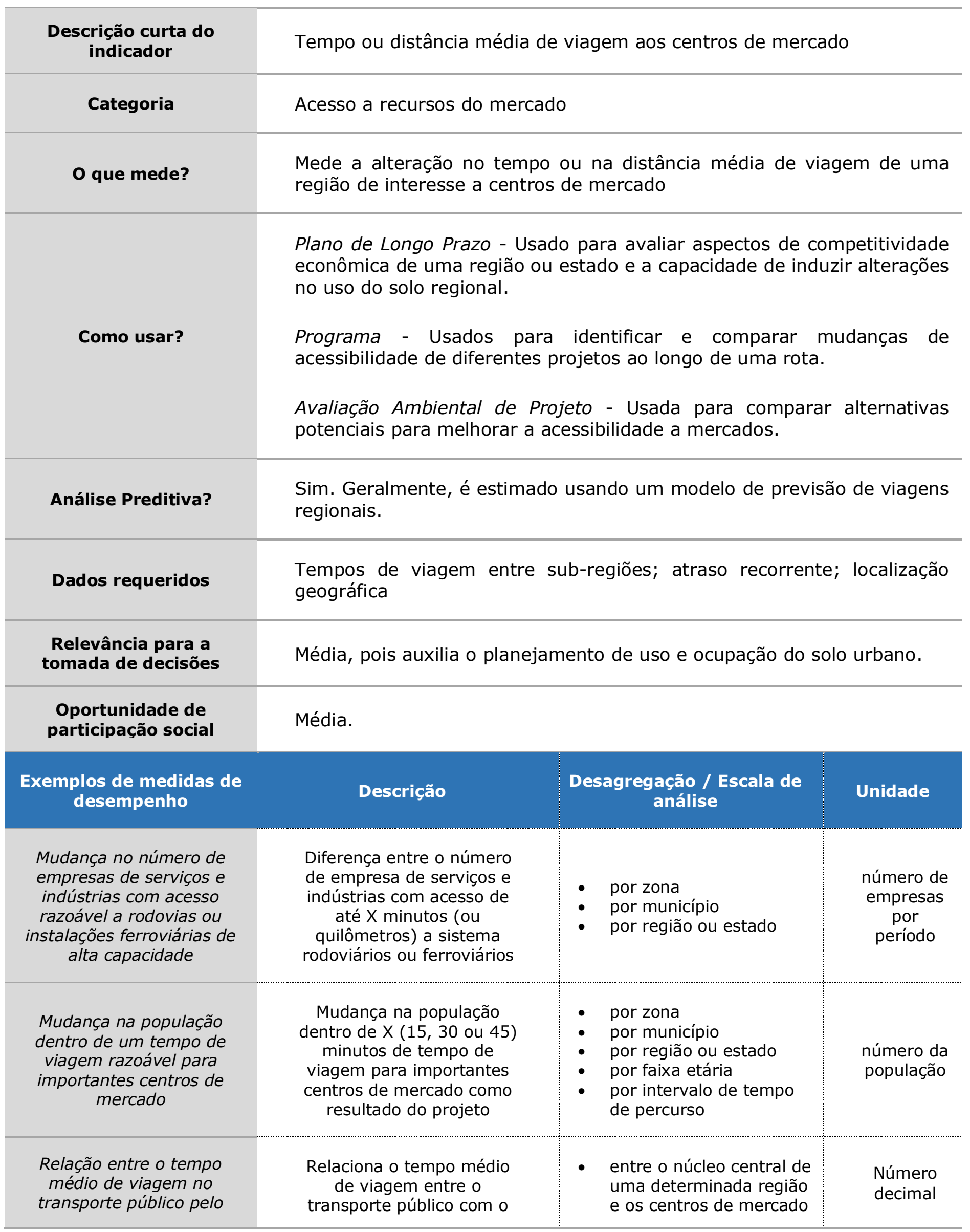


FA-02.

Acessibilidade

tempo médio de viagem por automóvel

AC-01.2. Acessibilidade de mercado

uso de automóvel,

mostrando a vantajosidade

do tipo de transporte a ser escolhido
- $\quad$ por tipo de transporte público 
FA-02.

Acessibilidade

\section{AC-02.1. Acessibilidade a empregos}

\begin{tabular}{|c|c|c|c|}
\hline $\begin{array}{l}\text { Descrição curta do } \\
\text { indicador }\end{array}$ & \multicolumn{3}{|c|}{$\begin{array}{l}\text { Quantidade de empregos dentro de um tempo de viagem razoável para a } \\
\text { população de uma região }\end{array}$} \\
\hline Categoria & \multicolumn{3}{|l|}{ Acesso a centros regionais } \\
\hline \multirow{2}{*}{ Como usar? } & \multicolumn{3}{|c|}{$\begin{array}{l}\text { Plano de Longo Prazo - Usado para avaliar aspectos de competitividade } \\
\text { econômica de uma região ou estado e a capacidade de induzir alterações } \\
\text { no uso do solo regional em função da oferta de trabalho. }\end{array}$} \\
\hline & \multicolumn{3}{|c|}{$\begin{array}{l}\text { Avaliação Ambiental de Projeto - Usada para comparar alternativas } \\
\text { potenciais para melhorar a acessibilidade a zonas com oferta de empregos } \\
\text { por comunidades específicas. }\end{array}$} \\
\hline Análise Preditiva? & \multicolumn{3}{|c|}{$\begin{array}{l}\text { Sim. Geralmente, é estimado usando um modelo de previsão de viagens } \\
\text { regionais. }\end{array}$} \\
\hline Dados requeridos & \multicolumn{3}{|c|}{ População e emprego por zona; tempos de viagem entre sub-regiões; } \\
\hline $\begin{array}{l}\text { Exemplos de medidas de } \\
\text { desempenho }\end{array}$ & Descrição & $\begin{array}{c}\text { Desagregação / Escala de } \\
\text { análise }\end{array}$ & Unidade \\
\hline $\begin{array}{l}\text { Porcentagem da população } \\
\text { dentro de } X \text { minutos ou } \\
\text { quilômetros do emprego }\end{array}$ & $\begin{array}{l}\text { Número de trabalhadores } \\
\text { (ou moradores) de } \\
\text { determinada zona que } \\
\text { consegue alcançar seu } \\
\text { emprego (ou determinado } \\
\text { centro comercial) dentro de } \\
\text { X minutos (e.g. 15, } 30 \text { ou } \\
45 \text { min), em relação ao } \\
\text { total de trabalhadores (ou } \\
\text { de moradores) da mesma } \\
\text { região de análise }\end{array}$ & $\begin{array}{ll}\text { - } & \text { por zona } \\
\text { - } & \text { por município } \\
& \text { por região ou estado }\end{array}$ & $\%$ \\
\hline $\begin{array}{l}\text { Mudança no número (ou } \\
\text { porcentagem) de empregos } \\
\text { dentro do tempo (ou } \\
\text { distância) de viagem }\end{array}$ & $\begin{array}{l}\text { Mudança no número (ou } \\
\text { porcentagem) de postos de } \\
\text { trabalho acessíveis dentro } \\
\text { de X minutos (e.g. 15, } 30 \text { e }\end{array}$ & $\begin{array}{ll}\text { - } & \text { por zona } \\
\text { - } & \text { por zonas agregadas } \\
\text { - } & \text { por região } \\
\text { - } & \text { por modo }\end{array}$ & $\begin{array}{l}\text { número ou } \\
\%\end{array}$ \\
\hline
\end{tabular}


FA-02.

Acessibilidade

\begin{tabular}{|c|c|c|}
\hline razoável para a população & $\begin{array}{c}45 \text { minutos) de tempo de } \\
\text { viagem (ou de X } \mathrm{X} \text { metros de } \\
\text { distância) dos centros } \\
\text { populacionais }\end{array}$ & $\begin{array}{l}\text { por classe social } \\
\text { por faixa de renda }\end{array}$ \\
\hline $\begin{array}{c}\text { Tempo médio para o } \\
\text { deslocamento dos } \\
\text { trabalhadores de seus } \\
\text { domicílios aos locais de } \\
\text { trabalho (movimentos } \\
\text { pendulares) }\end{array}$ & $\begin{array}{c}\text { Alteração no tempo médio } \\
\text { gasto no deslocamento } \\
\text { entre a moradia e o local de } \\
\text { trabalho }\end{array}$ & $\begin{array}{l}\text { por modo } \\
\text { por tipo de transporte } \\
\text { poletivo e individual), } \\
\text { por classe social } \\
\text { paixa de renda }\end{array}$ \\
\hline
\end{tabular}

\section{AC-02.1. Acessibilidade a empregos}

gasto no deslocamento trabalho 


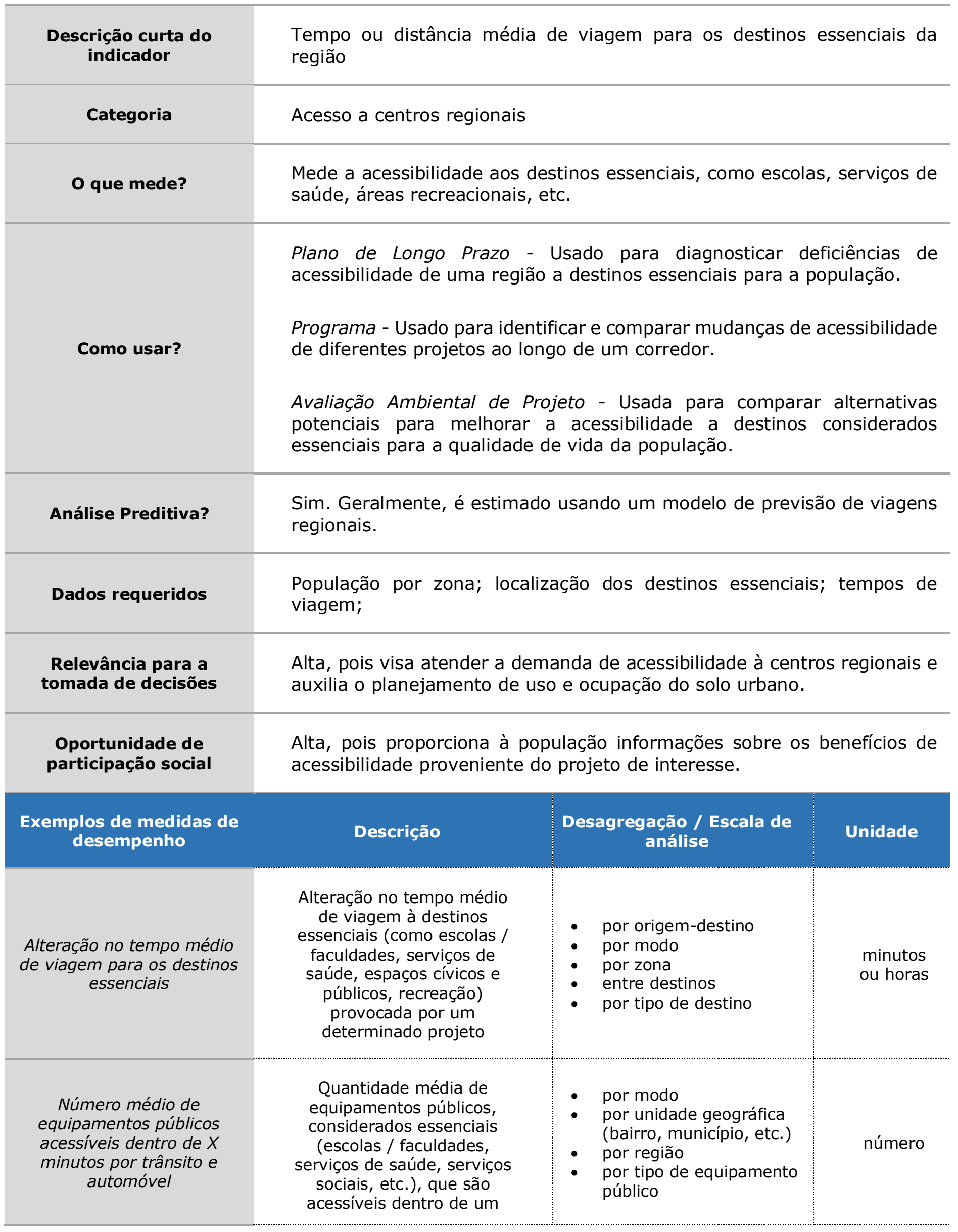




\begin{tabular}{|c|c|c|c|}
\hline & $\begin{array}{c}\text { período razoável (e.g. 15, } \\
30 \text { ou } 45 \text { min) por trânsito } \\
\text { e automóvel }\end{array}$ & & \\
\hline $\begin{array}{c}\text { Porcentagem da população } \\
\text { que pode alcançar } \\
\text { convenientemente um } \\
\text { destino específico }\end{array}$ & $\begin{array}{l}\text { Número de pessoas que } \\
\text { podem alcançar um destino } \\
\text { específico dentro de } X \\
\text { minutos/horas, não mais do } \\
\text { que a um raio Y de } \\
\text { distância, em relação ao } \\
\text { total da população }\end{array}$ & $\begin{array}{ll}\text { - } & \text { por tipo de grupos } \\
\text { - } & \text { por classe social } \\
\text { - } & \text { por faixa de renda } \\
& \text { geográfica (bairro, } \\
& \text { município, etc.), } \\
\text { - } \quad \text { por centros comerciais } & \text { por tipo de transporte } \\
& \text { (coletivo e individual) }\end{array}$ & $\%$ \\
\hline $\begin{array}{c}\text { Porcentagem da } \\
\text { população/domicílios dentro } \\
\text { de X quilômetros (ou } \\
\text { minutos) dos acessos ao } \\
\text { sistema rodoviário }\end{array}$ & $\begin{array}{c}\text { Número total de } \\
\text { pessoas/domicílios que } \\
\text { podem alcançar os acessos } \\
\text { de um sistema rodoviário } \\
\text { em até } X \text { quilômetros (ou } \\
\text { minutos) em relação ao } \\
\text { total de pessoas }\end{array}$ & - por unidade geográfica & $\%$ \\
\hline $\begin{array}{l}\text { Facilidade de acesso a } \\
\text { áreas verdes, de lazer ou } \\
\text { recreação em áreas } \\
\text { urbanas }\end{array}$ & $\begin{array}{c}\text { População residente com } \\
\text { acesso a áreas verdes ou } \\
\text { de lazer, dentro de um raio } \\
\text { de X metros (e.g. } 500 \mathrm{~m}) \\
\text { das mesmas }\end{array}$ & $\begin{array}{l}\text { - } \quad \text { por modo } \\
\text { - por bairro } \\
\text { - } \quad \text { por zona tipo/classe de área }\end{array}$ & número \\
\hline $\begin{array}{l}\text { Distância média de } \\
\text { caminhada às escolas }\end{array}$ & $\begin{array}{c}\text { Média das maiores } \\
\text { distâncias entre os limites } \\
\text { da região e as escolas da } \\
\text { mesma. Ou, quando houver } \\
\text { disponibilidade de } \\
\text { informação, este indicador } \\
\text { pode ser medido pela } \\
\text { distância média de } \\
\text { caminhada dos alunos até } \\
\text { as residências }\end{array}$ & $\begin{array}{ll}\text { - } & \text { por zona } \\
\text { - } & \text { por bairro }\end{array}$ & metros \\
\hline
\end{tabular}


FA-03.

Segurança

\section{SEG-01.1. Acidentes de Trânsito}

\begin{tabular}{|l|l|}
\hline $\begin{array}{c}\text { Descrição curta do } \\
\text { indicador }\end{array}$ & Ocorrências de acidentes de trânsito. \\
\hline Categoria & Acidentes \\
\hline O que mede? & $\begin{array}{l}\text { Os acidentes de trânsito podem ser calculados para segmentos } \\
\text { rodoviários, estradas, rotas, corredores ou regiões, tanto de forma geral } \\
\text { ou para níveis variados de severidade de acidentes (fatalidade, lesão, } \\
\text { danos à propriedade), por tipo de falha, etc. A taxa de colisão para um } \\
\text { segmento de estrada pode ser comparada à taxa de colisão média em } \\
\text { todo o estado para todas as estradas da mesma classificação funcional } \\
\text { ou uma média regional para criar uma taxa de colisão ou índice. }\end{array}$ \\
\hline
\end{tabular}

Plano de Longo Prazo - Usado para fornecer uma avaliação geral da segurança do sistema de transporte, identificar instalações com problemas de segurança e locais com necessidade de investimento em nível de projeto.

Programa - Usado para identificar e comparar locais com taxas elevadas de acidentes e que, portanto, devem ser devidamente considerados no planejamento de projetos, especificamente aqueles que devem prosseguir com a programação de curto e longo prazo. Quando analisado por tipo de colisão, é usado para identificar os tipos de soluções aplicáveis (por exemplo, medidas de engenharia, programas educacionais, fiscalização, resposta a emergências). Utilizando-se de fatores de redução de falhas, pode-se estimar possíveis benefícios de segurança de projetos específicos.

Avaliação Ambiental de Projetos - Usado para comparar possíveis alternativas de projeto.

Monitoramento - Usado para avaliar a eficácia das medidas de controle e locais com incidência de acidentes.

Sim. Geralmente, é estimado usando um modelo de previsão de viagens regional no nível da zona de análise de tráfego, mas pode ser agregado.
Análise Preditiva?

Dados requeridos
Dados de incidentes (quantitativos, níveis de severidade, fatores causais, tipos de acidentes).
Relevância para a tomada de decisões
Alta, pois auxilia a priorização de investimentos.
Oportunidade de participação social 


\begin{tabular}{|c|c|c|c|}
\hline $\begin{array}{l}\text { Exemplos de medidas de } \\
\text { desempenho }\end{array}$ & Descrição & $\begin{array}{c}\text { Desagregação / Escala de } \\
\text { análise }\end{array}$ & Unidade \\
\hline $\begin{array}{l}\text { Alteração no número de } \\
\text { acidentes }\end{array}$ & $\begin{array}{l}\text { Número de acidentes ao } \\
\text { longo de um } \\
\text { determinado período } \\
\text { (anual, determinados } \\
\text { meses ou dias) }\end{array}$ & $\begin{array}{l}\text { - } \quad \text { por localização (segmento } \\
\text { viário, rodovia, por região, } \\
\text { por município); } \\
\text { - } \quad \text { por gravidade (fatalidade, } \\
\text { lesão, danos); } \\
\text { - por tipo de ocupação } \\
\text { lindeira; } \\
\text { - por faixa horária; } \\
\text { - por tipo de acidente; } \\
\text { - por tipo de veículo }\end{array}$ & Número \\
\hline $\begin{array}{c}\text { Alteração no número de } \\
\text { acidentes por tonelada-km } \\
\text { percorrido }\end{array}$ & $\begin{array}{c}\text { Variação no número de } \\
\text { acidentes a cada } \\
\text { tonelada-quilômetro } \\
\text { percorrida }\end{array}$ & $\begin{array}{l}\text { - } \quad \text { por tipo de carga; } \\
\text { - } \text { por corredor logístico }\end{array}$ & Número \\
\hline Índice de acidentes fatais & $\begin{array}{l}\text { Número de mortes em } \\
\text { acidentes de trânsito por } \\
100 \text { mil habitantes }\end{array}$ & $\begin{array}{l}\text { - } \quad \text { por ano; } \\
\text { - } \quad \text { por volume de tráfego; } \\
\text { - } \quad \text { por segmentros; } \\
\text { - } \text { por região }\end{array}$ & Número \\
\hline $\begin{array}{l}\text { Número de acidentes com } \\
\text { pedestres e ciclistas }\end{array}$ & $\begin{array}{l}\text { Quantidade de acidentes } \\
\text { de trânsito envolvendo } \\
\text { pedestres e ciclistas }\end{array}$ & $\begin{array}{l}\text { - } \quad \text { por período; } \\
\text { - } \quad \text { por localização } \\
\text { - } \text { cruzamento }\end{array}$ & Número \\
\hline $\begin{array}{l}\text { Tempo médio de } \\
\text { recorrência entre acidentes }\end{array}$ & $\begin{array}{l}\text { Tempo médio em que } \\
\text { ocorre algum acidente } \\
\text { com vítima }\end{array}$ & $\begin{array}{l}\text { - } \quad \text { por rodovia; } \\
\text { - } \quad \text { por localização; } \\
\text { pegmento viário }\end{array}$ & $\begin{array}{l}\text { Horas ou } \\
\quad \text { dias }\end{array}$ \\
\hline $\begin{array}{c}\text { Acidentes de trânsito por } \\
100 \text { milhões de Veículos- } \\
\text { Quilômetros }\end{array}$ & $\begin{array}{c}\text { Número de acidentes de } \\
\text { trânsito ocorridos a cada } \\
100 \text { milhões de veículos- } \\
\text { quilômetros }\end{array}$ & $\begin{array}{ll}\text { - } & \text { por tipo de severidade } \\
\text { (fatal e com ferimento) } \\
\text { - } \quad \text { por tipo de rodovia } \\
\text { (urbana, rural, etc.) }\end{array}$ & Número \\
\hline
\end{tabular}


FA-03.

Segurança
SEG-02.1. Condição de segurança viária

\begin{tabular}{|c|c|}
\hline O que mede? & $\begin{array}{l}\text { Avalia o nível de segurança viária e oferece subsídios para identificar } \\
\text { locais que necessitam de medidas preventivas e de controle, a partir da } \\
\text { identificação de locais com maior probabilidade de acidentes e de } \\
\text { gravidade de danos. }\end{array}$ \\
\hline \multirow{3}{*}{ Como usar? } & $\begin{array}{l}\text { Plano de Longo Prazo - Usado para fornecer uma avaliação geral da } \\
\text { segurança do sistema de transporte, identificar instalações com } \\
\text { problemas de segurança e locais com necessidade de investimento em } \\
\text { nível de projeto. }\end{array}$ \\
\hline & $\begin{array}{l}\text { Programa - Usado para identificar e comparar locais com riscos elevados } \\
\text { de acidentes e que, portanto, devem ser devidamente considerados no } \\
\text { planejamento de projetos. Também pode ser usado para identificar e } \\
\text { comparar locais que podem ter desafios significativos na confiabilidade da } \\
\text { viagem, pois são locais que normalmente provocam atrasos não } \\
\text { recorrentes. }\end{array}$ \\
\hline & $\begin{array}{l}\text { Avaliação Ambiental de Projetos - Usado para comparar possíveis } \\
\text { alternativas de traçado e concepção de projeto. } \\
\text { Monitoramento - Usado para identificar os locais de maiores riscos de } \\
\text { acidentes e acompanhar as taxas, visando providenciar e manter as } \\
\text { medidas de segurança nos locais adequados. }\end{array}$ \\
\hline Dados requeridos & $\begin{array}{l}\text { Quantitativos de dispositivos de proteção; cadastro de vias; volume de } \\
\text { tráfego; normas de segurança. }\end{array}$ \\
\hline $\begin{array}{l}\text { Relevância para a } \\
\text { tomada de decisões }\end{array}$ & Alta, pois as questões estão relacionadas à prevenção de acidentes. \\
\hline $\begin{array}{l}\text { Oportunidade de } \\
\text { participação social }\end{array}$ & Baixa \\
\hline $\begin{array}{l}\text { Exemplos de medidas de } \\
\text { desempenho }\end{array}$ & $\begin{array}{c}\text { Desagregação / Escala de } \\
\text { análise }\end{array}$ \\
\hline $\begin{array}{l}\text { Porcentagem da extensão } \\
\text { do sistema que estão em } \\
\text { desacordo com as normas } \\
\text { de segurança }\end{array}$ & $\begin{array}{l}\text { Seções, em extensão, da } \\
\text { rodovia que não atendem aos } \\
\text { padrões de segurança em } \\
\text { relação à extensão total }\end{array}$ \\
\hline
\end{tabular}




\begin{tabular}{|c|c|c|c|}
\hline $\begin{array}{l}\text { Locais com maiores taxas } \\
\text { de acidentes }\end{array}$ & $\begin{array}{c}\text { Locais com maiores taxas de } \\
\text { acidentes (acidentes por } \\
\text { volume de tráfego), listando e } \\
\text { mapeando-os. }\end{array}$ & $\begin{array}{ll}\text { - } & \text { Por projeto } \\
\text { - } & \text { Por tipo de acidente } \\
\text { - } & \text { Por tipo de fatores } \\
& \text { causais } \\
\text { - } & \text { Por região }\end{array}$ & número \\
\hline $\begin{array}{c}\text { Número de locais com taxa } \\
\text { de colisão superior à média } \\
\text { nacional (acidentes por } \\
\text { volume de tráfego) }\end{array}$ & $\begin{array}{l}\text { Quantidade de locais em que } \\
\text { as taxas de colisão são } \\
\text { superiores à média nacional }\end{array}$ & $\begin{array}{l}\text { - } \quad \text { Por sistema } \\
\text { - } \quad \text { Por empreendimento } \\
\text { - } \quad \text { Por unidade geográfica }\end{array}$ & número \\
\hline $\begin{array}{l}\text { Percentual de extensão de } \\
\text { segmento rodoviário com } \\
\text { geometria insegura }\end{array}$ & $\begin{array}{l}\text { Extensão da rodovia com } \\
\text { curvas ou graus excessivos, } \\
\text { raio mínimo ou rampa máxima }\end{array}$ & $\begin{array}{l}\text { - } \quad \text { Por rodovia } \\
\text { - } \quad \text { Por projeto }\end{array}$ & $\%$ \\
\hline $\begin{array}{l}\text { Número de vias urbanas } \\
\text { atravessadas em nível }\end{array}$ & $\begin{array}{l}\text { Número de cruzamentos em } \\
\text { nível com viário urbano }\end{array}$ & $\begin{array}{l}\text { - } \quad \text { Por rodovia } \\
\text { - } \quad \text { Por projeto }\end{array}$ & número \\
\hline $\begin{array}{c}\text { Porcentagem de pista sob } \\
\text { monitoramento e vigilância } \\
\text { do tráfego }\end{array}$ & $\begin{array}{l}\text { Extensão da rodovia que é } \\
\text { contemplada por alguma } \\
\text { medida de monitoramento ou } \\
\text { vigilância operacional eficiente }\end{array}$ & $\begin{array}{ll}\text { - } & \text { Por rodovia } \\
\text { - } & \text { Por projeto } \\
\text { - } & \text { Por tipo de recurso } \\
& \text { (câmera, ronda, etc.) }\end{array}$ & $\%$ \\
\hline $\begin{array}{l}\text { Quantitativos (ou } \\
\text { percentual) de medidas de } \\
\text { engenharia para prevenção } \\
\text { e proteção de acidentes de } \\
\text { tráfego }\end{array}$ & $\begin{array}{l}\text { Quantidade (ou porcentagem) } \\
\text { de medidas implantadas (ou } \\
\text { previstas) em uma rodovia, } \\
\text { tais como cercas de } \\
\text { direcionamento e passagens } \\
\text { de fauna, barreiras de } \\
\text { proteção (flexível, New Jersey, } \\
\text { etc.), barreiras físicas contra } \\
\text { explosão e colisões, etc.) }\end{array}$ & $\begin{array}{ll}\text { - } & \text { Por sistema / rede } \\
\text { - } & \text { Por rodovia existente } \\
\text { - } & \text { Por projeto } \\
\text { - } & \text { Por tipo de medida }\end{array}$ & $\begin{array}{c}\text { número } \\
\text { ou } \%\end{array}$ \\
\hline $\begin{array}{c}\text { Porcentagem da extensão } \\
\text { com ocupação urbana } \\
\text { lindeira no trecho com } \\
\text { necessidade de desmonte } \\
\text { de rocha }\end{array}$ & $\begin{array}{l}\text { Extensão de trecho com } \\
\text { necessidade de desmonte de } \\
\text { rocha com ocupação urbana } \\
\text { lindeira em relação ao trecho } \\
\text { total com necessidade de } \\
\text { desmonte de rocha }\end{array}$ & - $\quad$ Por projeto & $\%$ \\
\hline
\end{tabular}


Descrição curta do indicador

Categoria

O que mede?

Como usar?

Análise Preditiva?

Dados requeridos

Relevância para a tomada de decisões
Alteração no tempo médio para atender aos incidentes de trânsito

\section{Resposta a incidentes}

A duração média de resposta a incidentes é geralmente estimada para um corredor ou região, calculando-se a duração de incidentes baseada no tempo entre a notificação do incidente e a realização das atividades de resposta, considerando os diversos marcos (por exemplo, remoção de veículos para o acostamento, retirada completa ou quando o último atendente deixa a cena do incidente). Pode ser calculado para diferentes tipos de incidentes, com base em sua gravidade.

Plano de Longo Prazo - Usado para fornecer uma avaliação geral do estado do gerenciamento de operações no sistema de transporte e definir caminhos para o gerenciamento de operações.

Programa - Usado para fornecer uma avaliação regional e possíveis benefícios de segurança de projetos específicos. A partir da identificação dos benefícios de segurança em nível de projeto, decide-se quais projetos devem ser priorizados.

Avaliação Ambiental de Projetos - Usado para identificar problemas e soluções para atendimento emergencial durante a operação viária, baseado nos tempos de resposta e na concepção de projeto.

Monitoramento - Usado para avaliar a eficácia das medidas de atendimento emergencial de vias em operação.

Sim, mas tem maior aplicação em rodovia em operação. Pode ser estimado usando tempo de viagem entre os atendentes (bombeiro, SAMU, Serviço de Atendimento ao Usuário - SAU, etc.) até pontos de interesse na via planejada, bem como em tempos de atendimentos em outras rodovias em operação.

Dados de incidentes (quantitativos, níveis de severidade, fatores causais, tipos de acidentes). Dados de resposta a incidentes.

Alta, pois ajuda a promover a confiabilidade do sistema, reduzindo atrasos não-recorrente no tempo de viagem devido a incidentes, auxilia a priorização de investimentos, e subsidia ajuste no projeto para otimizar o atendimento emergencial.
Oportunidade de participação social
Média, com oportunidade em comunicar os benefícios promovidos no atendimento a incidentes. 


\begin{tabular}{|c|c|c|c|}
\hline $\begin{array}{l}\text { Exemplos de medidas de } \\
\text { desempenho }\end{array}$ & Descrição & $\begin{array}{c}\text { Desagregação / Escala de } \\
\text { análise }\end{array}$ & Unidade \\
\hline $\begin{array}{l}\text { Tempo médio de chegada } \\
\text { dos serviços de emergência }\end{array}$ & $\begin{array}{c}\text { O tempo médio } \\
\text { calculado como a soma } \\
\text { dos tempos, desde o } \\
\text { primeiro chamado até a } \\
\text { chegada ao local da } \\
\text { equipe de emergência e } \\
\text { seus equipamentos, } \\
\text { dividida pelo número de } \\
\text { atendimentos a } \\
\text { emergências no mesmo } \\
\text { período. }\end{array}$ & $\begin{array}{l}\text { - } \quad \text { por período (mês ou ano) } \\
\text { por tipo de socorrista } \\
\text { (bombeiro, SAMU, SAU, } \\
\text { etc.) } \\
\text { - por tipo e gravidade }\end{array}$ & $\begin{array}{l}\text { minutos e } \\
\text { segundos }\end{array}$ \\
\hline $\begin{array}{c}\text { Duração média de } \\
\text { interrupção do tráfego } \\
\text { decorrente de incidentes }\end{array}$ & $\begin{array}{c}\text { Tempo médio entre o } \\
\text { horário da ocorrência } \\
\text { até o horário de } \\
\text { liberação total do } \\
\text { tráfego }\end{array}$ & $\begin{array}{l}\text { - } \quad \text { por projeto / rodovia } \\
\text { - } \quad \text { por segmento crítico } \\
\text { por tipo de incidente }\end{array}$ & $\begin{array}{l}\text { minutos } \\
\text { ou horas }\end{array}$ \\
\hline $\begin{array}{l}\text { Porcentagem de incidentes } \\
\text { que interrompem o tráfego } \\
\text { por mais de } X \text { minutos }\end{array}$ & $\begin{array}{c}\text { Total de incidentes que } \\
\text { interrompem o tráfego } \\
\text { por X minutos (p.ex. 10, } \\
15,30 \text { min) em relação } \\
\text { ao total de incidentes }\end{array}$ & $\begin{array}{ll}\text { - } & \text { por região } \\
\text { - } \quad \text { por rodovia } \\
\text { por período (mês ou ano) }\end{array}$ & $\%$ \\
\hline $\begin{array}{l}\text { Tempo médio de } \\
\text { atendimento à ocorrência }\end{array}$ & $\begin{array}{l}\text { Tempo médio decorrido } \\
\text { desde a notificação de } \\
\text { um incidente até a } \\
\text { conclusão do } \\
\text { atendimento }\end{array}$ & $\begin{array}{l}\text { - } \quad \text { por período (mês ou ano) } \\
\text { - } \quad \text { por socorrista } \\
\text { - } \quad \text { para remoçava do veículo no } \\
\text { acostamento ou da cena do } \\
\text { incidente } \\
\text { - para retirada de todos os } \\
\text { colaboradores da cena do } \\
\text { incidente }\end{array}$ & $\begin{array}{l}\text { minutos } \\
\text { ou horas }\end{array}$ \\
\hline
\end{tabular}




\begin{tabular}{|l|l|}
\hline $\begin{array}{c}\text { Descrição curta do } \\
\text { indicador }\end{array}$ & $\begin{array}{l}\text { Área de ocupação urbana potencialmente induzida por uma nova } \\
\text { infraestrutura de transporte }\end{array}$ \\
\hline Categoria & Mancha Urbana \\
\hline O que mede? & $\begin{array}{l}\text { Quantifica as manchas urbanas que podem ser potencialmente induzidas } \\
\text { pela infraestrutura de transporte, em função do crescimento econômico } \\
\text { associado a um novo projeto. A mensuração desse indicador deve utilizar } \\
\text { modelos de previsão que abordam as relações entre transporte, economia } \\
\text { e uso do solo. }\end{array}$ \\
\hline
\end{tabular}

Plano a Longo Prazo - Usado para avaliar alternativas de planos regionais com base nos impactos cumulativos de uso do solo e crescimento urbano esperados de vários níveis ou tipos de investimento em transporte.

Programa - Usado para apoiar estratégias consistentes de projetos de transporte estruturantes combinados e uso do solo.

Avaliação Ambiental do Projeto - Usado para avaliar impactos indiretos no desenvolvimento e seleção de alternativas de um determinado projeto

Como usar? nas áreas de influência direta (AID) e áreas de influência indireta (AII), bem como auxiliar no desenvolvimento de estratégias de mitigação e/ou potencialização dos impactos.

Monitoramento - Usado para avaliar a indução de alterações na dinâmica urbana e demográfica sobre áreas ambientalmente sensíveis durante a operação da infraestrutura de transporte, visando fornecer referências técnicas capazes de subsidiar políticas e ações de mitigação de eventuais impactos não desejáveis, e contribuindo com as instituições de planejamento, fiscalização e controle urbano-ambiental.

Análise Preditiva?

Dados requeridos

Relevância para a tomada de decisões

Oportunidade de participação social
$\operatorname{Sim}$

Projeções de população, renda e emprego com e sem projeto; localização do crescimento futuro e uso do solo por tipo.
Alta, pois permite constatar o impacto regional provocado pelo desenvolvimento econômico e espraiamento urbano, em especial contribuindo para identificar a urbanização irregular e desordenada.

Alta, no sentido de fornecer informações de projeção de desenvolvimento. 


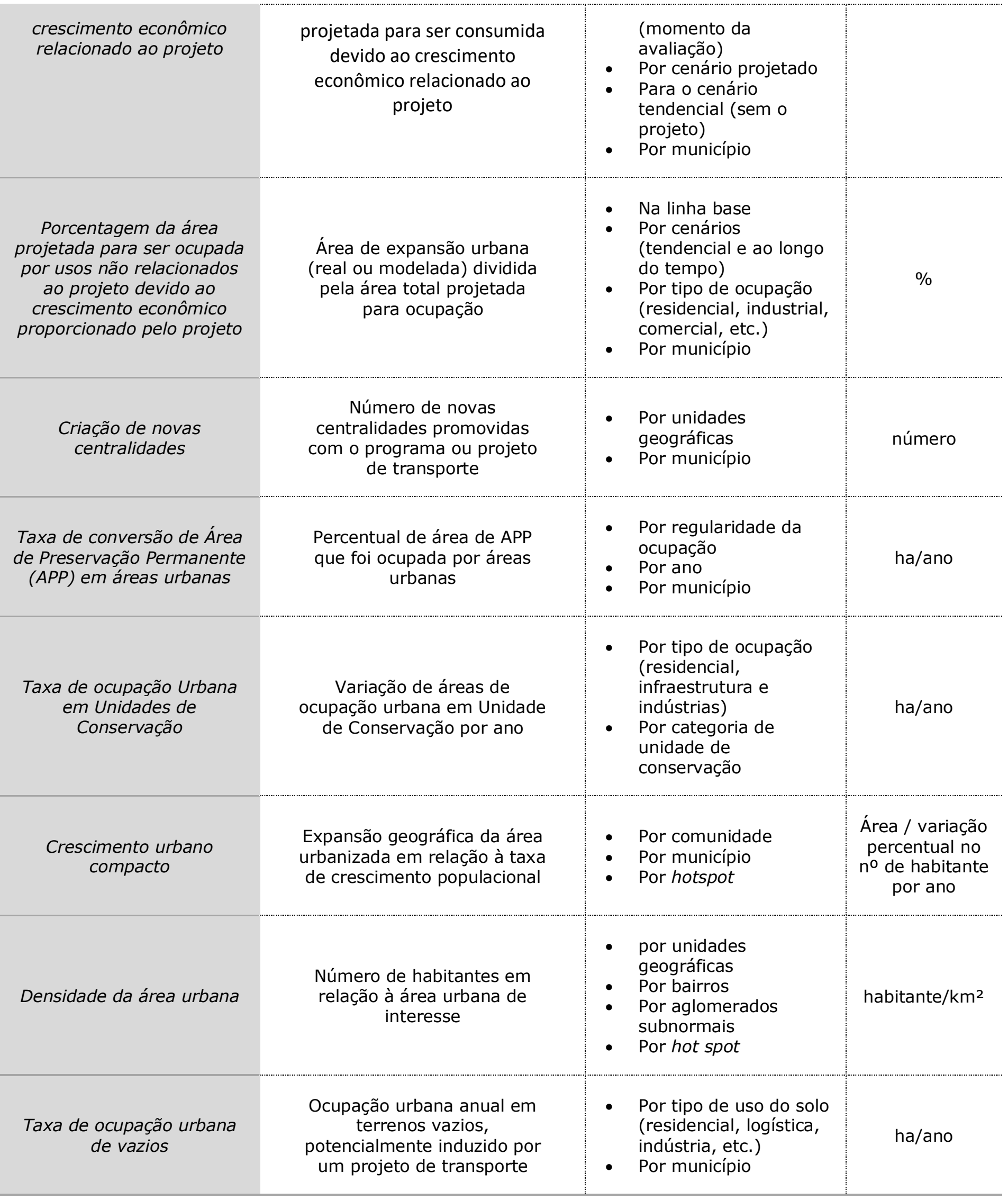


FA-04.

Desenvolvimento

Urbano e Uso do

US-02.1. Integração com planos de uso do solo

Solo

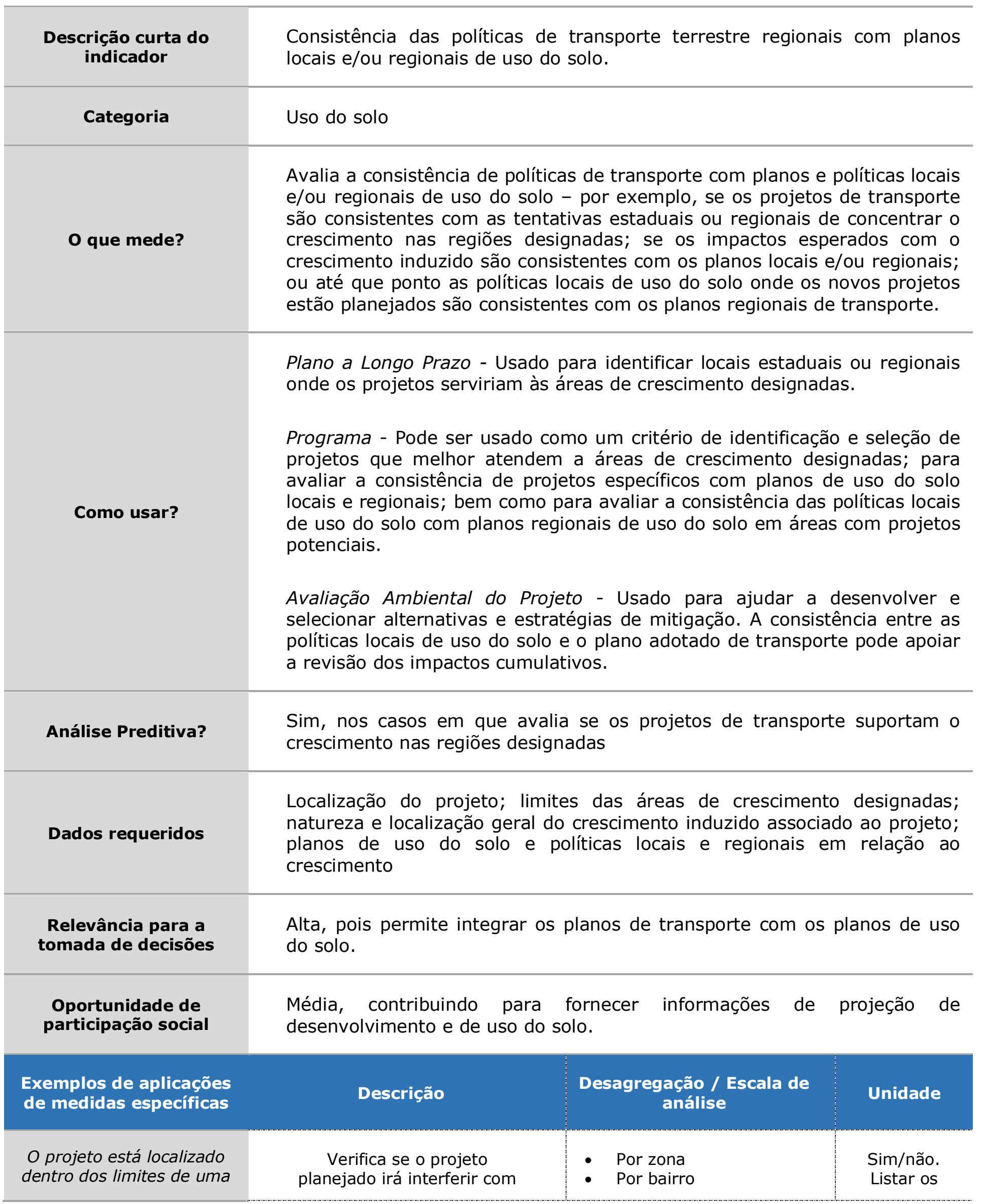




\begin{tabular}{|c|c|c|c|}
\hline $\begin{array}{c}\text { área designada para } \\
\text { expansão urbana ou de } \\
\text { centralidade? }\end{array}$ & $\begin{array}{l}\text { áreas designadas para } \\
\text { expansão urbana ou de novas } \\
\text { centralidades. }\end{array}$ & $\begin{array}{l}\text { - } \quad \text { Por município } \\
\text { - } \quad \text { Por projeto }\end{array}$ & $\begin{array}{l}\text { pontos } \\
\text { positivos e } \\
\text { negativos. }\end{array}$ \\
\hline $\begin{array}{l}\text { O projeto atende } \\
\text { diretamente a uma } \\
\text { centralidade de } \\
\text { crescimento designada? }\end{array}$ & $\begin{array}{l}\text { Verifica se o projeto atende } \\
\text { uma centralidade de } \\
\text { crescimento designada (e.g. } \\
\text { previsão de acesso), servindo } \\
\text { diretamente a esta área. }\end{array}$ & $\begin{array}{ll}\text { - } & \text { Por zona } \\
\text { - } & \text { Por bairro } \\
\text { - } & \text { Por município } \\
\text { - } & \text { Por projeto }\end{array}$ & $\begin{array}{l}\text { Sim/não. } \\
\text { Listar os } \\
\text { pontos } \\
\text { positivos e } \\
\text { negativos. }\end{array}$ \\
\hline $\begin{array}{c}\text { As jurisdições locais estão } \\
\text { permitindo as unidades } \\
\text { habitacionais de maneira } \\
\text { consistente com a } \\
\text { estratégia de crescimento } \\
\text { regional? }\end{array}$ & $\begin{array}{c}\text { Verifica se o poder público } \\
\text { municipal concede } \\
\text { licenças/alvarás/autorizações } \\
\text { para habitação de forma } \\
\text { compatível com o crescimento } \\
\text { regional. }\end{array}$ & $\begin{array}{ll}\text { - } & \text { Por região } \\
\text { - } & \text { Por estado } \\
\text { - } & \text { Por município }\end{array}$ & $\begin{array}{c}\text { Sim/não. } \\
\text { Delimitar as } \\
\text { áreas } \\
\text { incompatíveis } \\
\text {. }\end{array}$ \\
\hline $\begin{array}{l}\text { O crescimento projetado } \\
\text { devido ao projeto está } \\
\text { alinhado com a visão e } \\
\text { planos locais e regionais? }\end{array}$ & $\begin{array}{c}\text { Verifica se o crescimento } \\
\text { urbano induzido pelo projeto, } \\
\text { baseado em modelos, é } \\
\text { compatível com a visão e } \\
\text { planos locais e regionais de } \\
\text { uso do solo. }\end{array}$ & $\begin{array}{l}\text { - Por previsão de impactos } \\
\text { do crescimento } \\
\text { - } \quad \text { Por objetivo de } \\
\text { crescimento estabelecido } \\
\text { nos planos locais e } \\
\text { regionais } \\
\text { - Por plano local ou } \\
\text { regional } \\
\text { - Por densidade de } \\
\text { ocupação (alta e baixa) } \\
\text { Por localização de } \\
\text { crescimento }\end{array}$ & Diversas \\
\hline $\begin{array}{l}\text { O projeto é consistente } \\
\text { com as políticas locais e } \\
\text { regionais de uso do solo }\end{array}$ & $\begin{array}{c}\text { Verifica se o projeto é } \\
\text { consistente com as políticas } \\
\text { locais e regionais de uso do } \\
\text { solo. }\end{array}$ & $\begin{array}{l}\text { - } \quad \text { Por projeto } \\
\text { - } \quad \text { Por políticas e planos } \\
\text { - } \quad \text { Por unidade geográfica } \\
\text { (região, zona, município, } \\
\text { bairro) }\end{array}$ & $\begin{array}{l}\text { Sim/não. } \\
\text { Identificar os } \\
\text { pontos } \\
\text { positivos e } \\
\text { negativos. }\end{array}$ \\
\hline $\begin{array}{c}\text { Há acessos ao } \\
\text { empreendimento de } \\
\text { transporte ou locais } \\
\text { vulneráveis de construção } \\
\text { de acessos irregulares que } \\
\text { favoreça a ocupação } \\
\text { informal? }\end{array}$ & $\begin{array}{l}\text { Verifica se há acesso previsto } \\
\text { em projeto e locais } \\
\text { vulneráveis à construção de } \\
\text { acessos irregulares em locais } \\
\text { que possam contribuir para } \\
\text { uma ocupação irregular ou } \\
\text { desordenada, como, por } \\
\text { exemplo, em áreas com } \\
\text { restrição urbana-ambiental, o } \\
\text { espraiamento urbano, etc. }\end{array}$ & $\begin{array}{l}\text { - Por unidade geográfica } \\
\text { - } \quad \text { Por projeto }\end{array}$ & $\begin{array}{l}\text { Sim/não. } \\
\text { Listar e } \\
\text { mapear os } \\
\text { trechos. }\end{array}$ \\
\hline
\end{tabular}


FA-04.

Desenvolvimento

Urbano e Uso do

Solo

\section{US-03.1. Consumo de terras para infraestrutura de transporte}

\begin{tabular}{|ll}
$\begin{array}{c}\text { Descrição curta do } \\
\text { indicador }\end{array}$ & $\begin{array}{l}\text { Consumo de terra necessário para implantação de infraestrutura de } \\
\text { transporte, ou seja, a "pegada" do empreendimento. }\end{array}$ \\
\hline Categoria & Uso do solo \\
\hline O que mede? & $\begin{array}{l}\text { Mede a área física da infraestrutura e sua faixa de domínio, e pode incluir } \\
\text { quaisquer parcelas adicionais ou porções de parcelas que não serão mais } \\
\text { utilizáveis após a obra (por exemplo, acesso desativado ou outras formas } \\
\text { que não são edificáveis). }\end{array}$
\end{tabular}

\begin{tabular}{|c|c|c|c|}
\hline Como usar? & \multicolumn{3}{|c|}{$\begin{array}{l}\text { Avaliação Ambiental do Projeto - Usada para avaliar alternativas de traçado } \\
\text { e desenvolver estratégias de mitigação, bem como avaliar projetos } \\
\text { individuais para minimizar a pegada da obra e sua relação com áreas } \\
\text { sensíveis. }\end{array}$} \\
\hline Análise Preditiva? & \multicolumn{3}{|l|}{ Sim } \\
\hline Dados requeridos & \multicolumn{3}{|c|}{$\begin{array}{l}\text { Pegada da obra; limite da faixa de domínio e do Decreto de Utilidade } \\
\text { Pública (DUP); mapeamento do uso e ocupação do solo por tipo. }\end{array}$} \\
\hline $\begin{array}{l}\text { Oportunidade de } \\
\text { participação social }\end{array}$ & \multicolumn{3}{|c|}{$\begin{array}{l}\text { Alta, pois permite mostrar às partes interessadas as áreas que sofrerão } \\
\text { intervenção do empreendimento, causando relocação habitacional, perda } \\
\text { produtiva, danos à vegetação, etc. }\end{array}$} \\
\hline $\begin{array}{l}\text { Exemplos de aplicações } \\
\text { de medidas específicas }\end{array}$ & Descrição & $\begin{array}{c}\text { Desagregação / Escala de } \\
\text { análise }\end{array}$ & Unidade \\
\hline $\begin{array}{l}\text { Quantidade de área } \\
\text { necessária para } \\
\text { implantação de } \\
\text { infraestrutura de } \\
\quad \text { transporte }\end{array}$ & $\begin{array}{l}\text { Total de área consumida para a } \\
\text { implantação da infraestrutura } \\
\text { (desapropriação, cessão de uso, } \\
\text { aquisições etc.) }\end{array}$ & $\begin{array}{l}\text { - } \quad \text { per capita; } \\
\text { - } \text { por tipo (terras } \\
\text { agrícolas, pastagens, } \\
\text { florestais, zonas úmidas, } \\
\text { urbanizadas, parques } \\
\text { urbanos, área de } \\
\text { expansão urbana, etc); }\end{array}$ & hectares \\
\hline $\begin{array}{l}\text { Área Diretamente Afetada } \\
\qquad(A D A)\end{array}$ & $\begin{array}{l}\text { Área de intervenção necessária à } \\
\text { implantação de um } \\
\text { empreendimento, incluindo a obra } \\
\text { bruta, suas estruturas de apoio, } \\
\text { caminhos de serviço, e demais } \\
\text { instalações necessárias }\end{array}$ & $\begin{array}{l}\text { - por tipo (áreas públicas } \\
\text { e privadas, urbanizadas, } \\
\text { vegetacionais, } \\
\text { mineração, agrícolas, } \\
\text { pecuária, áreas } \\
\text { legalmente protegidas, } \\
\text { etc.); }\end{array}$ & hectares \\
\hline
\end{tabular}




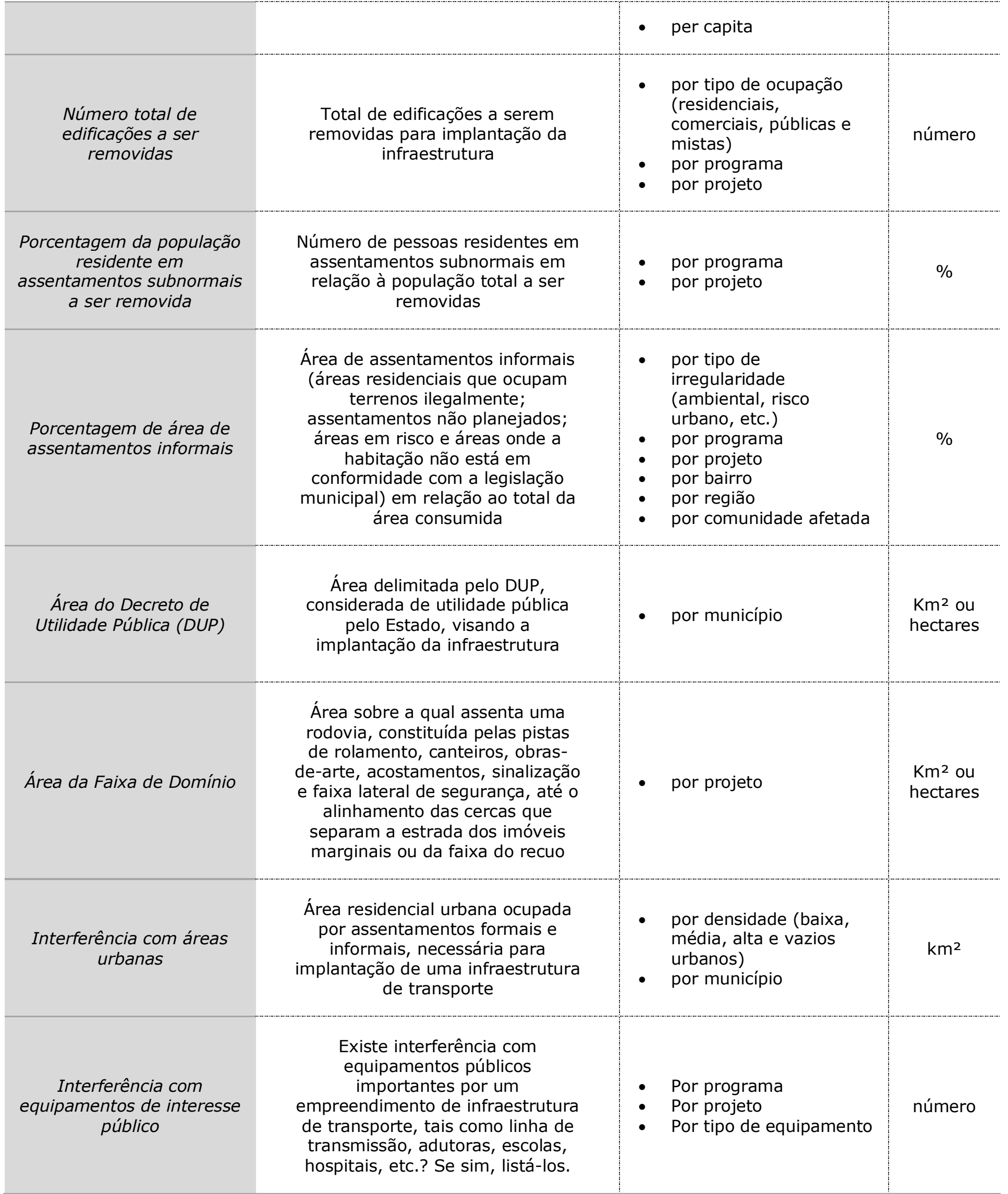




\section{FA-05.}

Qualidade do Ar

QA-01.1. Emissões de poluentes atmosféricos

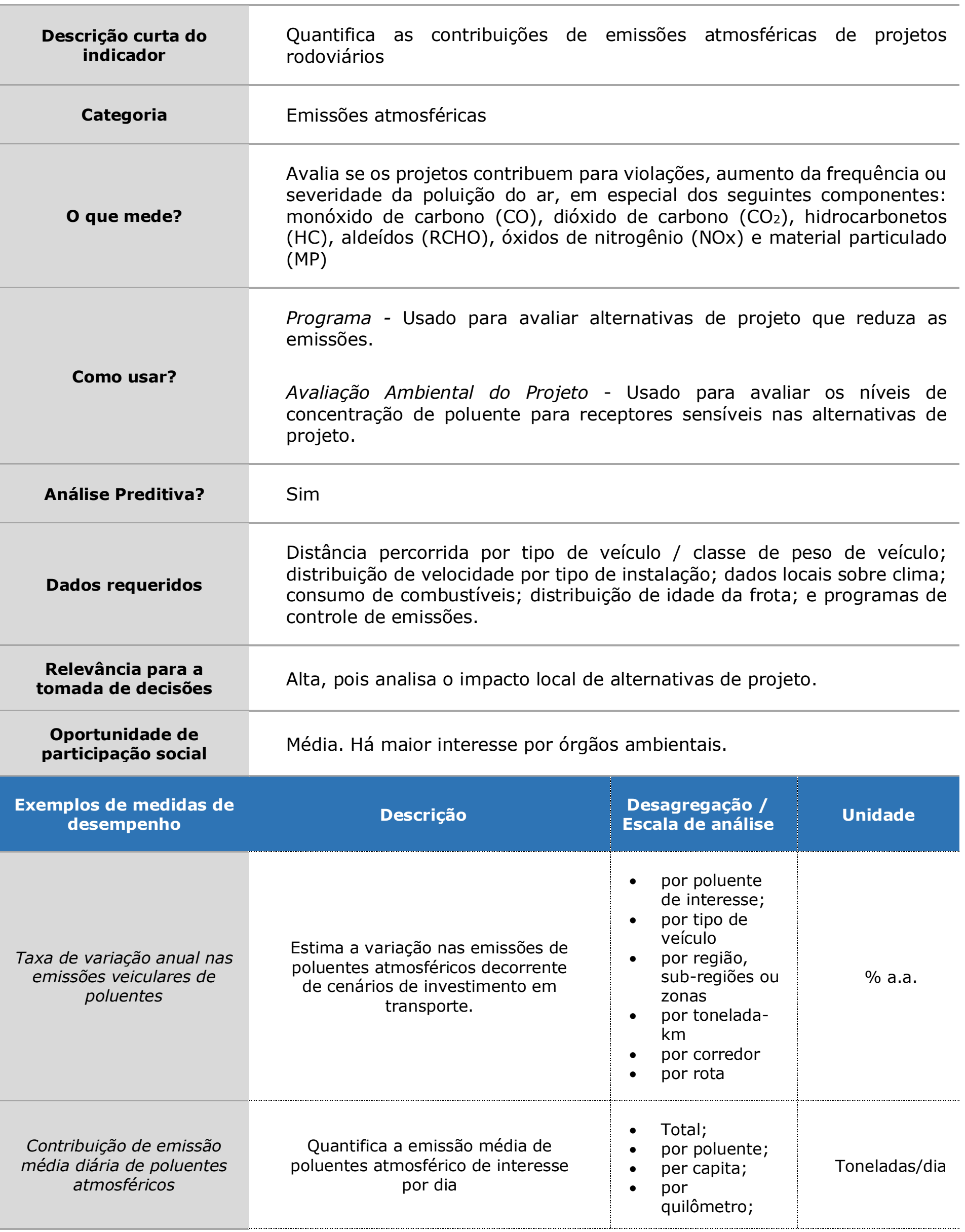




\begin{tabular}{|c|c|c|c|}
\hline & & $\begin{array}{l}\text { - } \quad \text { por tipo de } \\
\text { veículo }\end{array}$ & \\
\hline $\begin{array}{c}\text { Variação na densidade de } \\
\text { emissões }\end{array}$ & $\begin{array}{l}\text { Os volumes diários de emissões } \\
\text { veiculares por macrozona podem } \\
\text { ser apresentados em termos de } \\
\text { "densidade de emissões", por km² } \\
\text { de área urbana da macrozona. Este } \\
\text { indicador é uma proxy da } \\
\text { concentração teórica que o volume } \\
\text { diário de emissões causaria se } \\
\text { diluído homogeneamente no } \\
\text { compartimento espacial } \\
\text { representado pela área urbana da } \\
\text { macrozona até o limite da camada } \\
\text { de mistura. Permite ter uma ideia } \\
\text { da distribuição espacial da poluição } \\
\text { de origem veicular na metrópole. }\end{array}$ & - por macrozona & $\%$ \\
\hline $\begin{array}{c}\text { Variação dos fatores que } \\
\text { contribuem para alteração } \\
\text { de emissões de poluentes } \\
\text { atmosférico }\end{array}$ & $\begin{array}{l}\text { Quantificar a variação dos fatores } \\
\text { contribuintes para alteração das } \\
\text { emissões atmosféricas }\end{array}$ & $\begin{array}{l}\text { - alteração no } \\
\text { número de } \\
\text { viagens de } \\
\text { veículos; } \\
\text { alteração na } \\
\text { distância } \\
\text { percorrida; } \\
\text { melhoria na } \\
\text { fluidez do } \\
\text { tráfego; etc. }\end{array}$ & $\begin{array}{l}\text { Número ou } \\
\text { porcentagem }\end{array}$ \\
\hline $\begin{array}{l}\text { Porcentagem de extensão } \\
\text { em rampa máxima (E.g. } \\
\text { superiores a } 6 \% \text { ) }\end{array}$ & $\begin{array}{c}\text { Identifica e quantifica trechos com } \\
\text { rampas mais íngremes em } \\
\text { projetos, as quais contribuem para } \\
\text { o aumento do consumo de } \\
\text { combustíveis e, consequentemente, } \\
\text { emitem mais poluentes }\end{array}$ & - por projeto & $\%$ \\
\hline
\end{tabular}




\begin{tabular}{|c|c|c|c|}
\hline $\begin{array}{l}\text { Descrição curta do } \\
\text { indicador }\end{array}$ & \multicolumn{3}{|c|}{$\begin{array}{l}\text { Compara as emissões relacionadas ao transporte rodoviário em } \\
\text { determinada região com o nível desejado para garantir que os padrões de } \\
\text { qualidade do ar sejam atendidos. }\end{array}$} \\
\hline Categoria & \multicolumn{3}{|c|}{ Conformidade da qualidade do ar } \\
\hline O que mede? & \multicolumn{3}{|c|}{$\begin{array}{l}\text { Compara-se a quantidade de emissões de fontes móveis estabelecidas no } \\
\text { plano de qualidade do ar do estado com quantidade real de emissões } \\
\text { geradas por fontes móveis rodoviárias, que é estimada pela combinação } \\
\text { de saídas de modelos de viagens e emissões. Para novos projetos, essa } \\
\text { medida deve se concentrar nas mudanças esperadas para as emissões } \\
\text { no status de conformidade que resultariam ao longo do tempo com os } \\
\text { novos projetos em operação. }\end{array}$} \\
\hline \multirow{3}{*}{ Como usar? } & \multicolumn{3}{|c|}{$\begin{array}{l}\text { Plano a Longo Prazo - Usado para avaliar a contribuição das emissões do } \\
\text { projeto dentro das áreas de saturadas e não-saturadas. }\end{array}$} \\
\hline & \multicolumn{3}{|c|}{$\begin{array}{l}\text { Programa - Usados para avaliar as diferenças relativas de emissões entre } \\
\text { alternativas dentro de uma sub-região ou corredor. }\end{array}$} \\
\hline & \multicolumn{3}{|c|}{$\begin{array}{l}\text { Avaliação Ambiental do Projeto - Usado para avaliar impactos na } \\
\text { conformidade dentro de determinadas regiões que resultariam com os } \\
\text { projetos em avaliação. }\end{array}$} \\
\hline Análise Preditiva? & \multicolumn{3}{|l|}{ Sim } \\
\hline Dados requeridos & \multicolumn{3}{|c|}{$\begin{array}{l}\text { Distância percorrida por tipo de veículo / classe de peso de veículo; } \\
\text { distribuição de velocidade por tipo de instalação; dados locais sobre } \\
\text { clima; consumo de combustíveis; distribuição de idade da frota; e } \\
\text { programas de controle de emissões. }\end{array}$} \\
\hline $\begin{array}{l}\text { Relevância para a } \\
\text { tomada de decisões }\end{array}$ & \multicolumn{3}{|c|}{ Alta, pois analisa o impacto regional de alternativas de projeto. } \\
\hline $\begin{array}{l}\text { Oportunidade de } \\
\text { participação social }\end{array}$ & \multicolumn{3}{|l|}{ Baixa. } \\
\hline $\begin{array}{l}\text { Exemplos de medidas de } \\
\text { desempenho }\end{array}$ & Descrição & $\begin{array}{c}\text { Desagregação / Escala de } \\
\text { análise }\end{array}$ & Unidade \\
\hline $\begin{array}{l}\text { Concentração média anual } \\
\text { diária de poluentes } \\
\text { atmosféricos em áreas } \\
\text { urbanas como resultado de } \\
\text { investimentos em projetos } \\
\text { rodoviários }\end{array}$ & $\begin{array}{l}\text { Número total de } \\
\text { concentrações de poluente } \\
\text { registradas no ano dividida } \\
\text { pelo número de dias medidos }\end{array}$ & $\begin{array}{l}\text { - } \quad \text { por poluente } \\
\quad \text { por padrão (primário } \\
\text { ou secundário) }\end{array}$ & $\begin{array}{c}\mu \mathrm{g} / \mathrm{m}^{3} \text { ou } \\
\mathrm{ppm}\end{array}$ \\
\hline $\begin{array}{l}\text { Frequência em que a } \\
\text { qualidade do ar excede o }\end{array}$ & $\begin{array}{l}\text { Tempo (número de horas ou } \\
\text { dias) por ano em que a } \\
\text { qualidade do ar excede o }\end{array}$ & - por poluente & $\begin{array}{l}\text { horas ou } \\
\quad \text { dias }\end{array}$ \\
\hline
\end{tabular}




\begin{tabular}{|c|c|c|c|}
\hline $\begin{array}{c}\text { padrão normativo em áreas } \\
\text { urbanas }\end{array}$ & $\begin{array}{c}\text { padrão normativo em áreas } \\
\text { urbanas }\end{array}$ & & \\
\hline $\begin{array}{l}\text { Número de dias em que o } \\
\text { Índice de qualidade do ar } \\
\text { (IQA) é considerado ruim, } \\
\text { muito ruim ou péssimo }\end{array}$ & $\begin{array}{c}\text { Média aritmética calculada } \\
\text { para cada indicador, de } \\
\text { acordo com os resultados de } \\
\text { várias estações da rede de } \\
\text { medição }\end{array}$ & $\begin{array}{l}\text { - por zona; } \\
\text { - por município; } \\
\text { - por região }\end{array}$ & $>81$ \\
\hline $\begin{array}{l}\text { Porcentagem de tempo em } \\
\text { que os limites normativos } \\
\text { para a qualidade do ar são } \\
\text { considerados inadequados }\end{array}$ & $\begin{array}{c}\text { Porcentagem do tempo } \\
\text { durante o ano em que a } \\
\text { qualidade do ar é } \\
\text { considerada inadequada em } \\
\text { áreas urbanas }\end{array}$ & $\begin{array}{ll}\text { - } & \text { por zona; } \\
\text { - } & \text { por município; } \\
\text { - } & \text { por região }\end{array}$ & $\%$ \\
\hline
\end{tabular}




\section{FA-05.}

Qualidade do Ar

\begin{tabular}{|c|l|}
\hline $\begin{array}{c}\text { Descrição curta do } \\
\text { indicador }\end{array}$ & Populações vulneráveis à poluição do ar decorrente do investimento \\
\hline Categoria & Exposição à poluição do ar \\
\hline O que mede? & $\begin{array}{l}\text { Identifica o número e tipo de população vulneráveis aos efeitos da } \\
\text { poluição do ar (por exemplo, unidades habitacionais, escolas, hospitais, } \\
\text { etc.) próximos à rodovia, permitindo calcular a mudança nos tipos e } \\
\text { números de receptores sensíveis potencialmente impactados por um } \\
\text { projeto de transporte. }\end{array}$ \\
\hline
\end{tabular}

Como usar?

Análise Preditiva?

Dados requeridos

Relevância para a tomada de decisões

Oportunidade de participação social

\section{Exemplos de medidas de} desempenho

\section{Variação da população próxima às fontes de emissão}

Variação da população total beneficiada e afetada

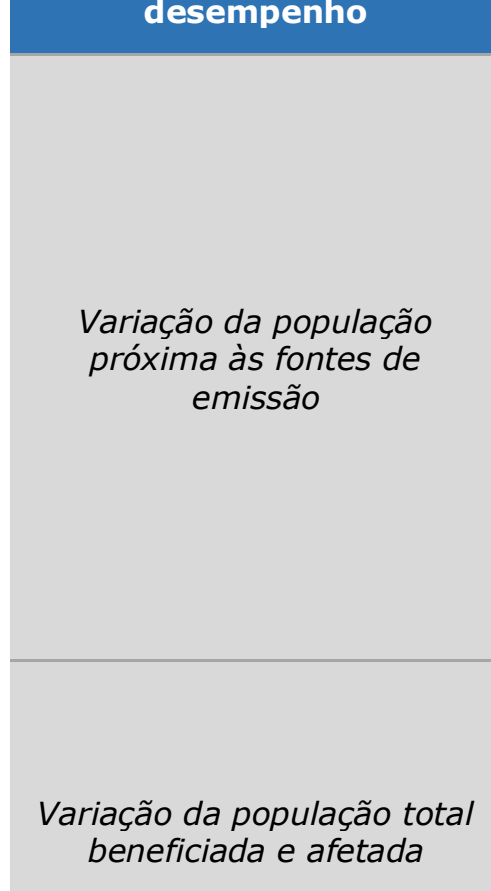

(a)

Avaliação Ambiental do Projeto - Usado para avaliar impactos na população, benefícios e custos, dentro de determinadas regiões em decorrência de alternativas de traçado em avaliação.

\section{Sim}

Projeção de mudança da população residente; variação das emissões de cada parâmetro.

Alta, pois permite avaliar a apropriação pela população dos benefícios e custos de um investimento em transporte, para vários cenários.

Média 


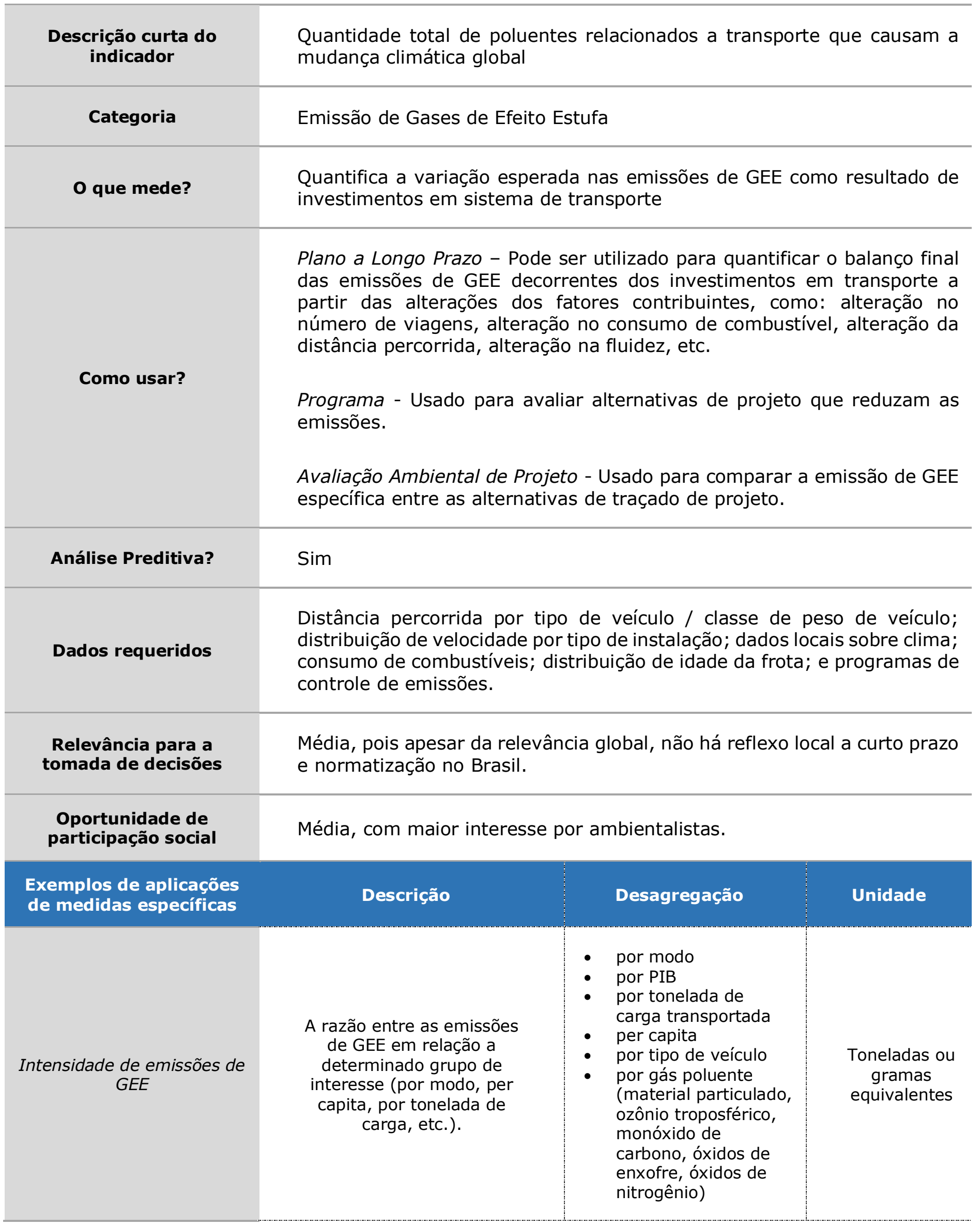


FA-06.

Mudanças

Climáticas

MC-01.1. Emissões de Gases de Efeito Estufa

\begin{tabular}{|c|c|c|c|}
\hline $\begin{array}{l}\text { Emissão média diária de } \\
\text { GEE por quilômetro }\end{array}$ & $\begin{array}{l}\text { Quantidade de emissão de } \\
\text { GEE para cada quilômetro } \\
\text { percorrido }\end{array}$ & $\begin{array}{ll}\text { - } & \text { por modo } \\
\text { - } & \text { por automóveis leves } \\
& \text { e pesados } \\
\text { - } & \text { por gás de interesse }\end{array}$ & $\begin{array}{c}\text { Tonelada de } \\
\text { GEE } \\
\text { equivalente } \\
\text { /km }\end{array}$ \\
\hline $\begin{array}{l}\text { Contribuição de transporte } \\
\text { para a quantidade total de } \\
\text { GEE emitido }\end{array}$ & $\begin{array}{l}\text { Percentual de emissão de } \\
\text { GEE do setor de transporte, } \\
\text { como proporcionalidade das } \\
\text { emissões de outros setores }\end{array}$ & - por região & $\%$ \\
\hline $\begin{array}{c}\text { Sequestro de carbono pelas } \\
\text { práticas de manejo de } \\
\text { vegetação }\end{array}$ & $\begin{array}{l}\text { Variação líquida na } \\
\text { quantidade de carbono } \\
\text { armazenado na biomassa } \\
\text { suprimida para implantação } \\
\text { de infraestrutura de } \\
\text { transporte com aquela } \\
\text { sequestrada a partir de } \\
\text { práticas de manejo de } \\
\text { vegetação relacionadas a } \\
\text { construção e operação }\end{array}$ & $\begin{array}{l}\text { - por empreendimento } \\
\text { de infraestrutura }\end{array}$ & Toneladas \\
\hline
\end{tabular}




\section{FA-06. \\ Mudanças \\ Climáticas \\ MC-02.1. Vulnerabilidade da infraestrutura às mudanças climáticas}

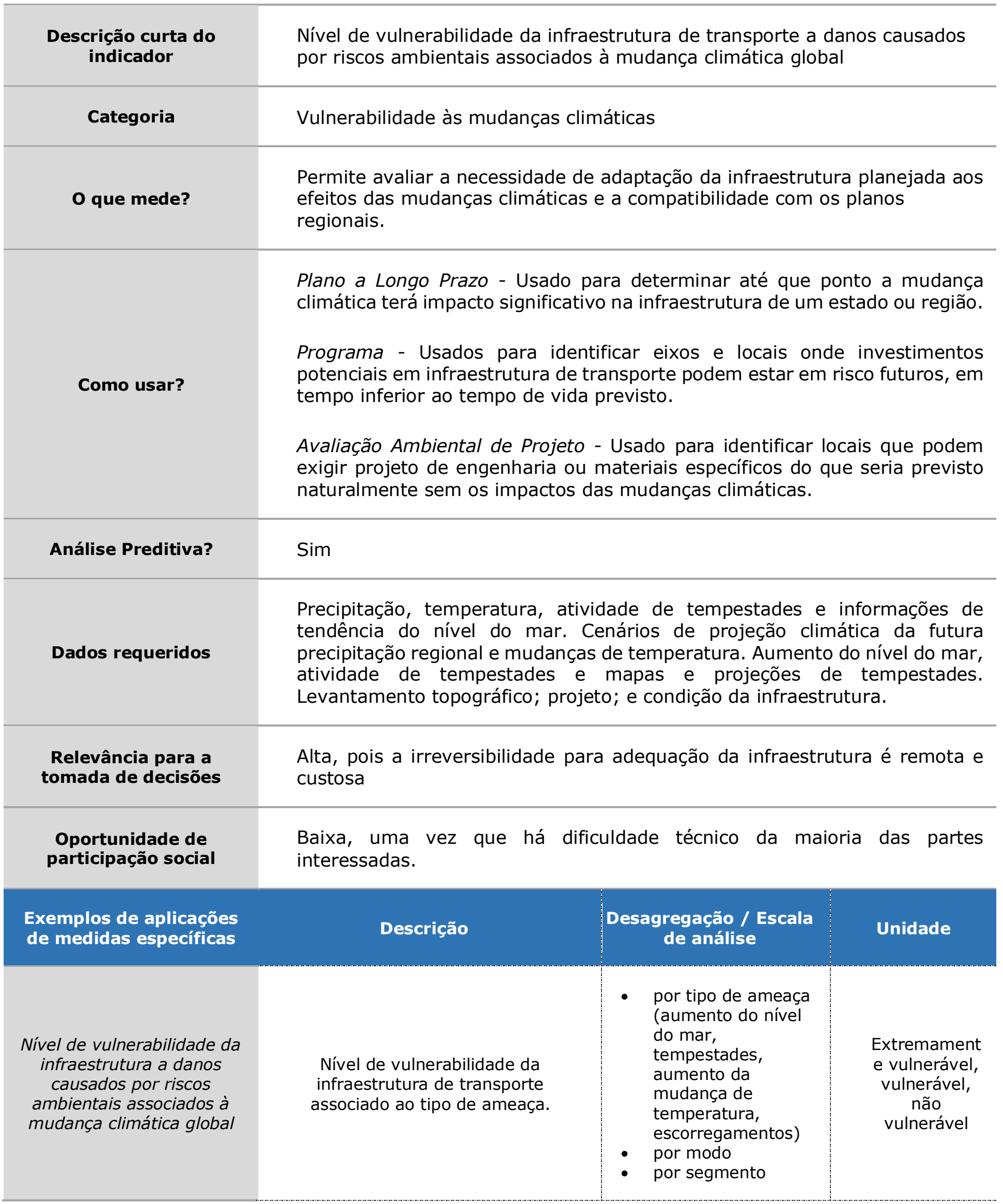


FA-06.

Mudanças

Climáticas

MC-02.1. Vulnerabilidade da infraestrutura às mudanças climáticas

Compatibilização com Plano Municipal de Mudanças Climáticas
Existência de Plano Municipal de Mudanças Climáticas aprovado e

compatibilização com suas diretrizes
Impactos humanos e materiais dos eventos climáticos extremos

Avaliação das Ameaças Climáticas

\section{Descrever os impactos}

financeiro e materiais potenciais e o número estimado de pessoas afetados, decorrentes da implementação da infraestrutura de transporte

Há Avaliação de Impactos Climáticos detalhada e um plano de adaptação? Este plano deve incluir uma avaliação de vulnerabilidade, uma avaliação de riscos, uma avaliação adaptação, bem como identificar os riscos e as respostas aos efeitos da mudança climática, contemplando tanto a

infraestrutura de transporte como as comunidades afetadas, no curto e longo prazo.
- $\quad$ por município ou região

- por município

- por bairro

- $\quad$ por tipo de impacto

Descritivo

- $\quad$ por projeto

- por comunidade

- $\quad$ por tipo de risco
Descritivo 

mananciais

Descrição curta do indicador

Categoria

Como usar?

Análise Preditiva?

Dados requeridos

Relevância para a tomada de decisões

Tendências

Oportunidade de participação social
Impacto da construção na quantidade de água no sistema de produção de água de abastecimento

Avalia os efeitos da implantação de uma infraestrutura de transporte em áreas de proteção de mananciais na produção de água de abastecimento, estimado pela previsão do aumento da impermeabilização dentro de uma bacia hidrográfica que resulta da construção direta da instalação e do desenvolvimento induzido por um projeto de transporte. A impermeabilização, baseado no desenvolvimento, é uma medida de segunda ordem que pode ser calculada com base no crescimento esperado induzido de um projeto (consultar Fator de Uso do Solo).

Produtividade de Mananciais

Programa - Usado para sinalizar projetos que provavelmente induzirão o crescimento próximo receptores sensíveis.

Avaliação Ambiental de Projetos - Usado para avaliar o impacto cumulativo das alternativas potenciais.

\section{$\operatorname{Sim}$}

Superfície impermeável; estimativas de crescimento induzido

Alta, em virtude da importância de preservação das áreas prioritárias para garantir a produtividade hídrica.

Quanto menor a intervenção, melhores resultados esperados; salvo quando o empreendimento for utilizado para remoção de ocupações irregulares e contenção da expansão urbana nas áreas de proteção.

Média

Exemplos de medidas de desempenho
Descrição
Desagregação / Escala de análise
Unidade
Aumento de superfícies impermeáveis em Áreas de Proteção e Recuperação de Mananciais devido à construção direta da infraestrutura de transporte

Aumento de superfícies impermeáveis em Áreas de Proteção e Recuperação de

Mananciais devido ao desenvolvimento induzido
Aumento percentual da área a ser impermeabilizada para a construção de um empreendimento em relação à totalidade da APRM

Aumento percentual da área potencialmente impermeabilizada em função da indução de novas
- Por bacia hidrográfica

- Por projeto

porcentagem

- Por bacia hidrográfica

- Por projeto porcentagem 
FA-07. Recursos Hídricos
RH-01.1. Interferência com a produção hídrica de mananciais

\begin{tabular}{|c|c|c|c|}
\hline $\begin{array}{c}\text { pela construção de novas } \\
\text { instalações }\end{array}$ & $\begin{array}{c}\text { ocupações em Áreas de } \\
\text { Proteção e Recuperação de } \\
\text { Mananciais }\end{array}$ & & \\
\hline $\begin{array}{c}\text { Interferência com cursos } \\
\text { d'água contribuintes } \\
\text { atravessados }\end{array}$ & $\begin{array}{l}\text { Número total de córregos, } \\
\text { rios, lagos, etc., que } \\
\text { contribuem para produção de } \\
\text { água de um manancial, } \\
\text { atravessado por uma } \\
\text { infraestrutura de transporte }\end{array}$ & $\begin{array}{l}\text { - } \quad \text { Por projeto } \\
\text { - } \quad \text { Por classificação }\end{array}$ & número \\
\hline $\begin{array}{l}\text { Proximidade do projeto de } \\
\text { transporte com pontos de } \\
\text { captação de água }\end{array}$ & $\begin{array}{l}\text { Distância da infraestrutura } \\
\text { de transporte com os pontos } \\
\text { de captação de água, } \\
\text { contados a partir da linha de } \\
\text { projeção ou do ponto de } \\
\text { lançamento de água }\end{array}$ & $\begin{array}{ll}\text { - } & \text { Por projeto } \\
\text { - } & \text { cor ponto de } \\
\text { - } & \text { Portação de água } \\
\text { (montantionamento e jusante) }\end{array}$ & $\begin{array}{l}\text { Metros ou } \\
\text { quilômetros }\end{array}$ \\
\hline
\end{tabular}


Descrição curta do indicador

(n)

o que mede?

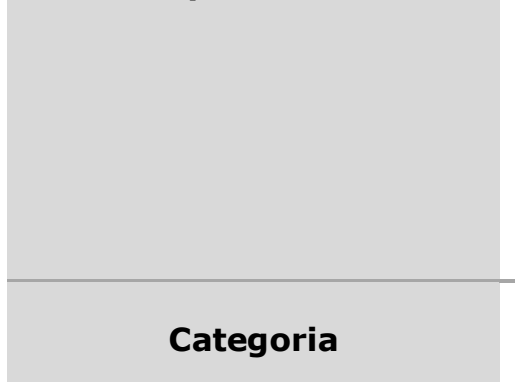

Para regiões que possuem planos de gestão de recursos hídricos ou de bacias hidrográficas, pode ser feita uma avaliação do nível em que os projetos de transporte são consistentes com esses planos, bem como as agências de transporte coordenam o planejamento com os interesses das agências de recursos hídricos e demais partes interessadas relacionadas à água.

Essa medida é avaliada usando uma avaliação qualitativa do nível em que as melhorias de transporte contribuem ou prejudicam as metas de recursos hídricos, qualidade da água e planos de gestão de bacias hidrográficas.

Consistência entre os planos de gestão de recursos hídricos e de bacias hidrográficas e os planos de projetos de transporte

Consistência com planos de recursos hídricos.

Plano a Longo Prazo - Usado para fortalecer a credibilidade das metas ambientais de um plano de longo prazo.

Programa - Usados para identificar áreas dentro de um corredor que podem exigir uma avaliação mais substancial dos impactos da qualidade da água ao buscar projetos de transporte.

Avaliação Ambiental de Projetos - Pode ser usado para avaliar a conformidade de projetos de transporte com esforços de planejamento da qualidade da água.

Análise Preditiva?

Dados requeridos

Relevância para a tomada de decisões

Tendências

\section{Sim}

Planos de gestão relacionados com recursos hídricos; planos de transporte.

Alta, em virtude da necessidade de compatibilização entre planos de diversos setores.

Quanto menor a interferência negativa e maior a potencialização com as metas de planos de recursos hídricos, melhores serão os resultados esperados com projetos de transporte.
Oportunidade de participação social
Alta, podendo abrir ampla discussão com comitês e sociedade civil relacionados a planos de recursos hídricos e bacia hidrográfica. 
Nível em que o projeto contribui para as metas e objetivos estabelecidos em plano de gestão de recursos hídricos e de bacias hidrográficas

Nível de coordenação do empreendedor responsável pelo projeto com a agência de recursos hídricos local para alinhar o projeto com metas e objetivos

O projeto espera impactos sobre os recursos hídricos sensiveis de alta prioridade, conforme identificados em um plano de recursos hídricos?
Verificação se os projetos de transporte planejados estão alinhados aos objetivos e metas dos planos de gestão de recursos hídricos e de bacias hidrográfica

Verificação da coordenação da agência de transporte com as agências de recursos hídricos e de bacias hidrográficas, para

Avaliação dos impactos da infraestrutura de transporte sobre os recursos hídricos sensíveis e com prioridade de conservação ou recuperação
- $\quad$ por projeto

- por bacia hidrográfica

- por abrangência do plano

- por projeto

- por bacia hidrográfica

- por abrangência do plano

- $\quad$ por classe dos corpos d’água

- por projeto

- por bacia hidrográfica

- por abrangência do plano 


\section{Descrição curta do indicador}

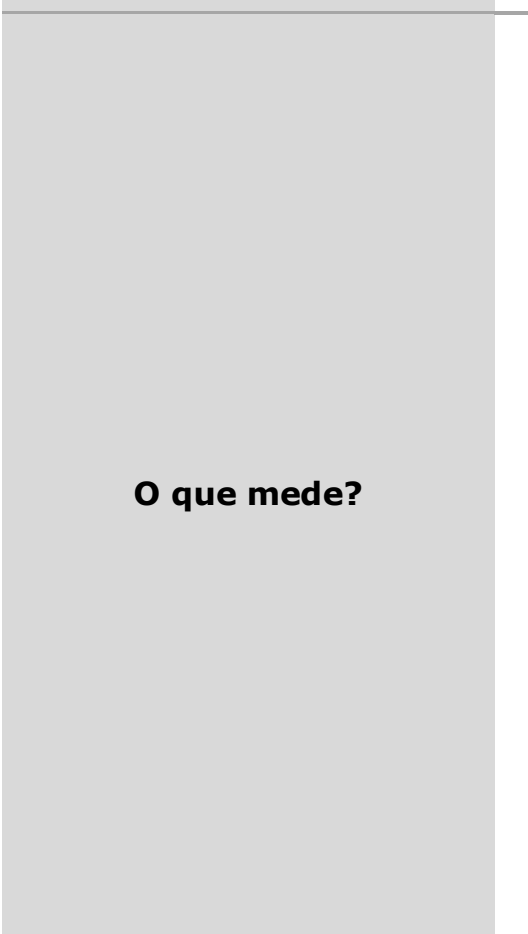

Categoria

Como usar?

Análise Preditiva?

Dados requeridos
Consistência do impacto do projeto de transporte na qualidade da água com os padrões normativos de qualidade da água

Esta medida estima as alterações nas características físico-químicas e biológicas de um determinado corpo d’água devido a um projeto de transporte em relação aos padrões normativos vigentes de qualidade da água e de lançamento de efluentes.

Os padrões de qualidade da água são definidos para cada corpo de água com base em sua classe de enquadramento e seus usos específicos, por exemplo, abastecimento para consumo humano, recreação de contato primário (natação), proteção de comunidades aquáticas, entre outros. Os valores máximos são estabelecidos para cada parâmetro relacionados em cada uma das classes de enquadramento.

Meios específicos para estimar os impactos nos padrões de qualidade da água ou os padrões de lançamento de efluentes envolvem: identificar os corpos d'água potencialmente afetados pelo projeto e as respectivas classes, os valores máximos de lançamento e os padrões de qualidade da água estabelecidos para eles; estabelecer informações de referência sobre a qualidade da água e avaliar as cargas de poluentes disponíveis antes de exceder os limites permitidos; e simular as cargas estimadas de poluentes devido à construção ou operação da infraestrutura de transporte.

Padrões de qualidade da água.

Plano a Longo Prazo - Usado para entender o impacto do sistema global de transporte sobre recursos hídricos significativos.

Programa - Usados para identificar áreas dentro de um corredor ou conjunto de projetos que podem exigir uma avaliação mais substancial dos impactos da qualidade da água ao definir os projetos de transporte.

Avaliação Ambiental de Projetos - Usada para determinar como minimizar os impactos na qualidade da água durante o projeto.

$\operatorname{Sim}$

Identificação e mapeamento de corpos d’água receptores e suas respectivas classes de enquadramento; valores máximos dos parâmetros para lançamento de efluentes; caracterização físico-química e biológica das águas residuárias e do curso hídrico; vazões de cursos d’água e de lançamento de efluente.
Relevância para a tomada de decisões
Alta, para área de mananciais, uso para balneabilidade e áreas de preservação ambiental. 


\begin{tabular}{|c|c|c|c|}
\hline Tendências & \multicolumn{3}{|c|}{$\begin{array}{l}\text { Para padrões de lançamento de efluentes, quanto maiores forem os valores } \\
\text { das concentrações de um determinado parâmetro, tende-se a piorar a } \\
\text { qualidade da água }\end{array}$} \\
\hline $\begin{array}{l}\text { Oportunidade de } \\
\text { participação social }\end{array}$ & \multicolumn{3}{|c|}{$\begin{array}{l}\text { Baixa, pois devem ser observados os padrões e critérios já definidos pela } \\
\text { legislação. }\end{array}$} \\
\hline $\begin{array}{l}\text { Exemplos de medidas de } \\
\text { desempenho }\end{array}$ & Descrição & $\begin{array}{l}\text { Desagregação / Escala } \\
\text { de análise }\end{array}$ & Unidade \\
\hline $\begin{array}{l}\text { Capacidade de suporte do } \\
\text { corpo receptor }\end{array}$ & $\begin{array}{l}\text { Valor máximo de } \\
\text { determinado poluente que o } \\
\text { corpo hídrico pode receber, } \\
\text { sem comprometer a } \\
\text { qualidade da água e seus } \\
\text { usos determinados pela } \\
\text { classe de enquadramento }\end{array}$ & $\begin{array}{ll}- & \text { por recurso hídrico } \\
\text { - } & \text { por projeto } \\
\text { - } & \text { por parâmetro }\end{array}$ & Diversos \\
\hline $\begin{array}{l}\text { Cargas de poluentes } \\
\text { disponíveis antes de } \\
\text { exceder os limites } \\
\quad \text { permitidos }\end{array}$ & $\begin{array}{c}\text { Carga de poluentes } \\
\text { disponíveis para serem } \\
\text { lançados em um curso } \\
\text { d’água sem que os limites } \\
\text { permitidos sejam excedidos }\end{array}$ & $\begin{array}{l}\text { - } \quad \text { por poluente } \\
\text { - } \quad \text { por recurso hídrico } \\
\text { por bacia hidrográfica }\end{array}$ & $\mathrm{mg} / \mathrm{L}$ \\
\hline $\begin{array}{c}\text { Concentrações médias de } \\
\text { poluentes, metais diversos, } \\
\text { sólidos suspensos e } \\
\text { orgânicos tóxicos no } \\
\text { escoamento superficial } \\
\text { (runoff) }\end{array}$ & $\begin{array}{c}\text { Concentração média de } \\
\text { poluentes, metais e sólidos } \\
\text { suspensos e orgânicos } \\
\text { tóxicos provenientes da água } \\
\text { pluvial que escoa } \\
\text { superficialmente sobre a } \\
\text { plataforma e deságua em } \\
\text { corpos hídricos }\end{array}$ & $\begin{array}{l}\text { - } \quad \text { por recurso hídrico } \\
\text { - } \quad \text { por bacia hidrográfica } \\
\text { - } \text { por projeto }\end{array}$ & $\mathrm{mg} / \mathrm{L}$ \\
\hline
\end{tabular}




\section{RH-03.2. Cargas difusas provenientes do escoamento superficial de rodovia}

\section{Descrição curta do indicador}

O que mede?

\section{Categoria}

Como usar?

Análise Preditiva?

Dados requeridos
Alteração na qualidade da água devido à carga de poluente proveniente do escoamento superficial sobre o pavimento da rodovia

Esta medida estima o impacto na qualidade da água devido ao transporte de contaminantes presentes sobre as superfícies e que são carregados pela água da chuva. Esses contaminantes são originados dos veículos e da própria infraestrutura, e incluem poeira, solo e vegetação, borracha de pneus, desgastes do asfalto, metais de frenagem, óleo e graxas, restos de combustíveis e outros fluidos gotejados de motores, resíduos diversos lançados por usuários, entre outros.

A denominação "difusa" vem do fato de os resíduos terem diversos pontos de origem e se encontrarem espalhados em grandes áreas, o que traz dificuldades para o seu controle. Dependendo da localização, esta poluição de escoamento pode ser transportada diretamente para corpos d'água (córregos, lagos, várzeas, zonas úmidas, mananciais e pontos de captação de água, etc.).

As concentrações mais altas desses contaminantes tendem a ser transportadas durante o início da primeira chuva intensa após um período seco, o chamado carga de lavagem ou first flush, uma vez que normalmente há mais materiais acumulados no pavimento. Os principais contaminantes de interesse são: nutrientes; metais; compostos derivados do petróleo, tais como hidrocarbonetos aromáticos policíclicos (PAHs), benzeno, tolueno, etil-benzeno e os xilenos (BTEX); sedimentos; agrotóxicos.

Padrões de qualidade da água.

Plano a Longo Prazo - Usado para identificar estradas com impactos significativos de escoamento existentes devido ao alto volume de tráfego e à proximidade de receptores sensíveis.

Programa - Usados para sinalizar projetos perto de receptores sensíveis que podem aumentar significativamente o escoamento.

Avaliação Ambiental de Projetos - Usado para identificar os impactos esperados das alternativas do projeto nos receptores sensíveis e possíveis medidas que podem minimizar o escoamento ou diminuir seus impactos.

\section{$\operatorname{Sim}$}

Identificação de corpos d’água receptores; pontos de captação de água; enquadramento das classes de água; valores máximos para recebimento de águas; concentração de poluentes; volume de tráfego; área impermeabilizada.

Relevância para a tomada de decisões
Alta, especialmente na divulgação de informação dos locais de captação de água, ainda que sejam informais. 


\section{RH-03.2. Cargas difusas provenientes do escoamento superficial de rodovia}

Oportunidade de participação social
Baixa, pois devem ser observados os padrões e critérios já definidos pela legislação, servindo mais como informativo à população.
Exemplos de medidas de desempenho
Descrição

\section{Desagregação / Escala} de análise
Unidade
Carga de poluente durante eventos de carga de lavagem ou first flush

Extensão de rios, lagos e de costa oceânica prejudicada pelo escoamento de rodovias

Mudança global nas cargas de poluentes devido à implantação da rodovia

Proximidade da rodovia com usuários da água

Concentração de Efeito Não Observado - CENO e os padrões de qualidade da água para corpos de água específicos
Carga de poluentes coletados nos 10 minutos iniciais de chuva em determinados pontos de descarga do escoamento superficial (runoff), após um período de estiagem (e.g. 5 dias sem chuva)

Extensão de corpos d 'água receptores que sofrem alteração na qualidade da água
- por ano

- por parâmetro (cádmio, zinco, hidrocarboneto totais ou policíclicos, cobre, etc.)

- $\quad$ por ponto crítico

- por bacia hidrográfica

- por classe

- para resultados acima do limite normativo
De acordo com o parâmetro

metros ou quilômetros
Alteração global na carga de poluentes com a implantação da rodovia. Por exemplo, a diferença da carga difusa com a carga despejada por expropriados.

Distância da rodovia (ou da saída d água da rodovia) com os usos preponderantes da água, atuais e futuros
Maior concentração do efluente, que não causa efeito deletério estatisticamente significativo na sobrevivência e reprodução dos organismos, em um determinado tempo de exposição, nas condições de ensaio
- por bacia hidrográfica

- para usos a jusante

- por tipo de uso

- para captação d’água
De acordo com o parâmetro

metros

- por recurso hídrico

- por agente químico
- por um determinado período

- $\quad$ por determinadas

porcentagem

- por recurso hídrico

- por agente químico

- por um determinado período
Menor concentração do efluente que causa efeito deletério, estatisticamente significativo, para sobrevivência e reprodução dos organismos, em um determinado tempo de exposição, nas condições de ensaio. 
FA-08.

Ecossistema,

Habitat e

Biodiversidade

\begin{tabular}{|c|c|c|c|}
\hline $\begin{array}{l}\text { Descrição curta do } \\
\text { indicador }\end{array}$ & \multicolumn{3}{|c|}{$\begin{array}{l}\text { Impacto da construção de infraestrutura de transporte na degradação da } \\
\text { qualidade e quantidade de áreas essenciais para a sobrevivência de } \\
\text { espécies nativas de plantas ou animais }\end{array}$} \\
\hline Categoria & \multicolumn{3}{|c|}{ Preservação de espécies nativas } \\
\hline O que mede? & \multicolumn{3}{|c|}{$\begin{array}{l}\text { Mede a alteração na qualidade e quantidade de vegetação nativa e a } \\
\text { degradação dos habitats essenciais para a sobrevivência da fauna nativa } \\
\text { como resultado da implantação de infraestrutura de transporte. }\end{array}$} \\
\hline \multirow{5}{*}{ Como usar? } & \multicolumn{3}{|c|}{$\begin{array}{l}\text { Plano a Longo Prazo - Usado para entender locais de habitats } \\
\text { significativos e de vegetação nativa primária e estágio avançado ou médio } \\
\text { que podem ser impactados por instalações de transporte e projetos em } \\
\text { potencial. }\end{array}$} \\
\hline & \multicolumn{3}{|c|}{$\begin{array}{l}\text { Programas - Usados para sinalizar projetos que provavelmente afetarão } \\
\text { significativamente os habitats e/ou fragmentos vegetação nativa devido à } \\
\text { sua localização. }\end{array}$} \\
\hline & & & \\
\hline & \multicolumn{3}{|c|}{$\begin{array}{l}\text { Avaliação Ambiental de Projeto - Usada para ajudar as agências de } \\
\text { transporte a determinarem como minimizar os impactos ao habitat e } \\
\text { reduzir a supressão de vegetação nativa durante os estudos de } \\
\text { alternativa de traçado e licenciamento ambiental. }\end{array}$} \\
\hline & \multicolumn{3}{|c|}{$\begin{array}{l}\text { Monitoramento - Permite o acompanhamento da redução de área de } \\
\text { vegetação nativa ou de habitats decorrentes da indução de alteração do } \\
\text { uso do solo promovida pelo investimento em transporte. }\end{array}$} \\
\hline Análise Preditiva? & \multicolumn{3}{|l|}{ Sim } \\
\hline Dados requeridos & \multicolumn{3}{|c|}{$\begin{array}{l}\text { Espécies ameaçadas de extinção; áreas de habitat, prioritariamente } \\
\text { aquelas utilizadas pelas espécies ameaçadas de extinção ao longo de todo } \\
\text { o seu ciclo de vida; valor funcional de cada área de habitat identificada } \\
\text { para cada espécie; tamanho das áreas de habitat; localização de áreas de } \\
\text { habitat; dados de localização do projeto; área de comunidades vegetais } \\
\text { nativas; área de perturbação prevista. }\end{array}$} \\
\hline $\begin{array}{l}\text { Relevância para a } \\
\text { tomada de decisões }\end{array}$ & \multicolumn{3}{|c|}{ Alta, pois tem o potencial de impacto significativo ao meio natural. } \\
\hline $\begin{array}{l}\text { Oportunidade de } \\
\text { participação social }\end{array}$ & \multicolumn{3}{|c|}{ Média, com grande potencial de envolvimento de instituições ambientais } \\
\hline $\begin{array}{l}\text { Exemplos de aplicações } \\
\text { de medidas específicas }\end{array}$ & Descrição & $\begin{array}{c}\text { Desagregação / Escala de } \\
\text { análise }\end{array}$ & Unidade \\
\hline Fragmentação de habitat & $\begin{array}{l}\text { Hectares de habitat } \\
\text { fragmentado por uma }\end{array}$ & $\begin{array}{l}\text { - } \quad \text { por projeto } \\
\text { - por tipo de habitat }\end{array}$ & hectares \\
\hline
\end{tabular}

\section{EHB-01.1. Perda de habitat e de vegetação nativa} truca áce de espécies nativas de plantas ou animais 
FA-08.

Ecossistema,

Habitat e

EHB-01.1. Perda de habitat e de vegetação nativa

Biodiversidade

\begin{tabular}{|c|c|c|c|}
\hline & $\begin{array}{l}\text { determinada infraestrutura } \\
\text { de transporte }\end{array}$ & - $\quad$ por fauna de interesse & \\
\hline $\begin{array}{c}\text { Mudança na extensão de } \\
\text { bordas florestais }\end{array}$ & $\begin{array}{l}\text { Diferença entre a extensão } \\
\text { de trecho de uma } \\
\text { infraestrutura de transporte } \\
\text { limítrofe a fragmentos } \\
\text { florestais, antes e após a } \\
\text { implantação de } \\
\text { determinado projeto }\end{array}$ & $\begin{array}{l}\text { - } \quad \text { por projeto } \\
\text { - } \\
\text { regener estágio de } \\
\end{array}$ & quilômetros \\
\hline $\begin{array}{c}\text { Preservação de habitats de } \\
\text { alta qualidade para a fauna } \\
\text { silvestre }\end{array}$ & $\begin{array}{l}\text { Diferença entre a área com } \\
\text { habitats de alta qualidade } \\
\text { (zonas úmidas, fragmentos } \\
\text { de floresta nativa, etc.) da } \\
\text { alternativa de traçado } \\
\text { viável de menor custo com } \\
\text { a alternativa escolhida }\end{array}$ & - $\quad$ por tipo de habitat & hectares \\
\hline $\begin{array}{c}\text { Porcentagem do saldo da } \\
\text { área de restauração } \\
\text { florestal compensada em } \\
\text { relação à área total de } \\
\text { fragmentos de vegetação } \\
\text { nativa suprimida }\end{array}$ & $\begin{array}{c}\text { Diferença entre a } \\
\text { quantidade de área de } \\
\text { vegetação nativa } \\
\text { compensada com a área de } \\
\text { vegetação nativa } \\
\text { suprimida, em relação ao } \\
\text { total de área de vegetação } \\
\text { nativa suprimida }\end{array}$ & $\begin{array}{l}\text { - } \quad \text { por programa } \\
\text { - } \quad \text { por projeto }\end{array}$ & porcentagem \\
\hline $\begin{array}{c}\text { Área de intervenção em } \\
\text { Áreas Prioritárias para } \\
\text { Conservação da } \\
\text { Biodiversidade }\end{array}$ & $\begin{array}{c}\text { Quantidade de áreas } \\
\text { prioritárias para } \\
\text { conservação da } \\
\text { biodiversidade passíveis de } \\
\text { intervenção direta ou } \\
\text { indireta decorrente de } \\
\text { programas ou projetos de } \\
\text { transporte }\end{array}$ & $\begin{array}{ll}\text { - } & \text { por bioma } \\
\text { - } & \text { por projeto } \\
\text { - } & \text { por programa }\end{array}$ & hectares \\
\hline $\begin{array}{c}\text { Variação da porcentagem } \\
\text { de cobertura de vegetação } \\
\text { nativa }\end{array}$ & $\begin{array}{c}\text { Variação da área ocupada por } \\
\text { vegetação nativa de uma } \\
\text { determinada unidade territorial } \\
\text { em relação à totalidade desta } \\
\text { mesma área }\end{array}$ & $\begin{array}{ll}\text { - } & \text { por estágio sucessional } \\
\text { (primária, secundária, } \\
\text { inicial) } \\
\text { - } \quad \text { por município } \\
\text { - } \quad \text { por parcela territorial } \\
\text { - } \quad \text { por hot spot } \\
\text { por fragmento florestal }\end{array}$ & porcentagem \\
\hline
\end{tabular}


FA-08.

Ecossistema,

Habitat e

EHB-01.1. Perda de habitat e de vegetação nativa

Biodiversidade

Conectividade entre fragmentos de vegetação nativa

Alteração na composição e estrutura do habitat

Variedade de fisionomias

Número de projetos que protegem espécies sensíveis ou restauram o habitat
Número total de fragmentos de vegetação nativa conectados a determinadas distâncias (e.g. $50 \mathrm{~m}, 100 \mathrm{~m}$ e $200 \mathrm{~m}$ ) na unidade territorial

Análise da composição, abundância e riqueza e suas relações com a estrutura do habitat e se existe variação espacial significativa na composição de espécies

Número de unidades vegetacionais, como correlação da oferta de habitat com a biodiversidade

Quantidade de projetos na região de interesse com o objetivo de proteger espécies sensíveis ou de restauração de habitat.

Listar os projetos existentes.
- por estágio sucessional (primária, secundária, inicial)

- por município

- por parcela territorial

- por hot spot

- por fragmento florestal

- por parcela de monitoramento

unidade

- por fragmento florestal

- $\quad$ por parcela territorial

- $\quad$ por espécie de interesse

- por unidade territorial

- $\quad$ por tipo de habitat unidade

diversas

unidade

unidade 


\section{EHB-02.1. Interferência com áreas ambientalmente protegidas}

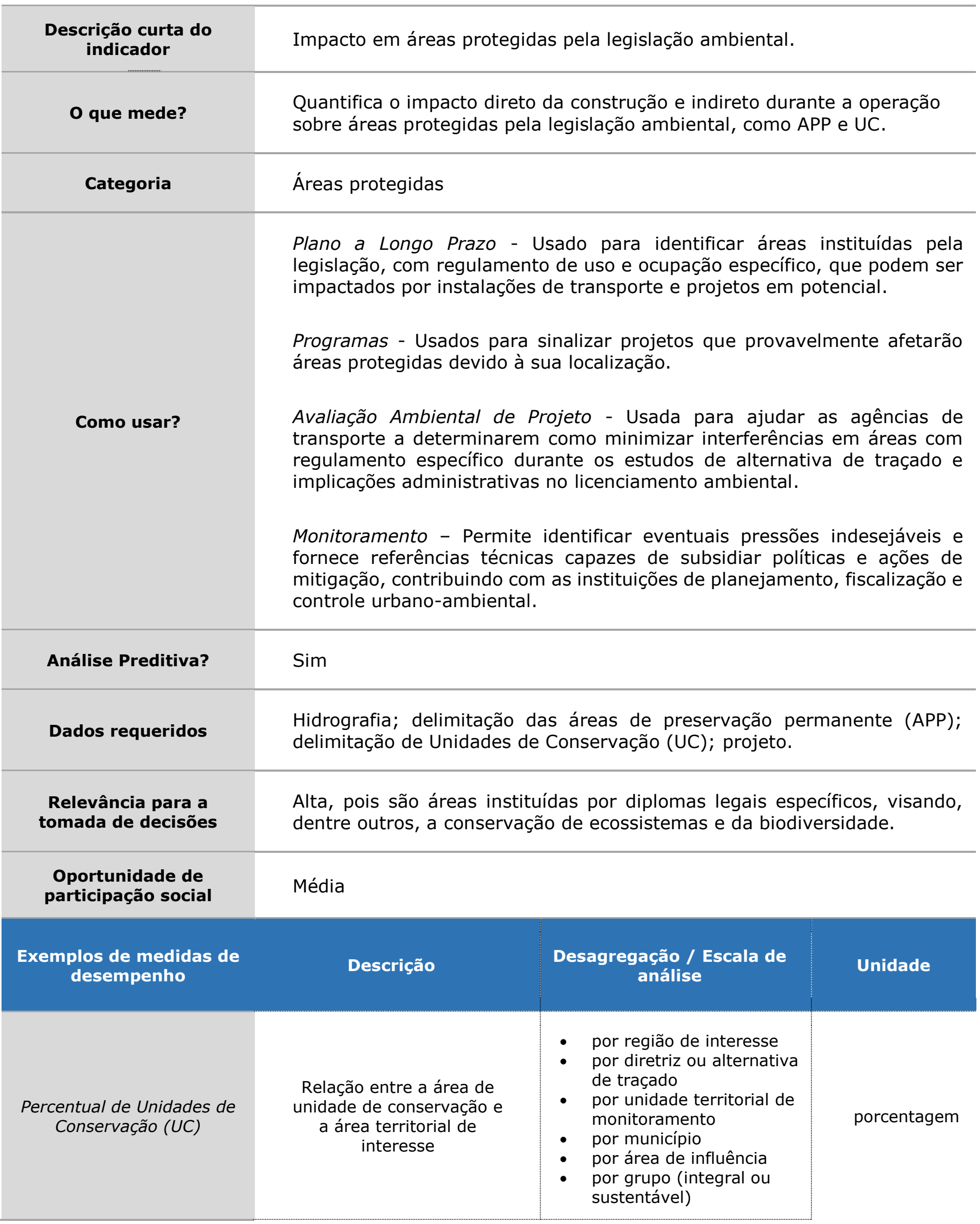




\section{EHB-02.1. Interferência com áreas ambientalmente protegidas}

Porcentagem da área disponível para restauração florestal em Unidades de Conservação
Quantidade de áreas degradadas nas Unidades de Conservação localizadas na área de influência de empreendimentos

- por categoria (parques, reservas, etc.)

Porcentagem da área ocupada por zona de amortecimento de unidade de conservação de proteção integral

Percentual de Área de Preservação Permanente $(A P P)$
Relação entre a área de preservação permanente e a área territorial de interesse
Ocupação de zona de amortecimento de unidade de conservação de proteção integral
- por parcela territorial

- por diretriz ou alternativa de traçado porcentagem

- por categoria (parques, reservas, etc.)
- por município

- por grupo (integral ou sustentável)
- $\quad$ por unidade territorial

- $\quad$ por diretriz ou alternativa de traçado

- por município

- por área de influência

- na faixa de domínio
Percentual de cobertura vegetal nativa em Área de Preservação Permanente $(A P P)$
Relação da quantidade de APP com cobertura de vegetação nativa presente nas APP's da área de interesse
- $\quad$ por unidade territorial

- por município

- por área de influência

- na faixa de domínio porcentagem

porcentagem
Consistência com planos de manejo e/ou de recursos naturais
Avalia, qualitativamente, até que ponto os planos de transporte que identificam projetos específicos são consistentes com o planejamento de recursos naturais (planos de conservação e manejo de vida selvagem, habitat, biodiversidade ou recursos) 


\section{EHB-03.1. Relação entre as zonas úmidas afetadas e criadas} Descrição curta do
indicador

O que mede?

Categoria

Como usar?

Análise Preditiva?

Dados requeridos

Relevância para a tomada de decisões

Tendências

Oportunidade de participação social
Impacto da construção de infraestrutura de transportes na quantidade de áreas úmidas em comparação com as novas zonas úmidas criadas ou recuperadas

Demonstra o impacto líquido de suas atividades em zonas úmidas, comparando as áreas úmidas destruídas durante a construção do projeto versus áreas úmidas criadas ou recuperadas. O mapeamento da localização e da qualidade das áreas úmidas de alto valor fornece informações importantes aos planejadores e interessados, determinando quantos hectares de áreas úmidas poderão ser afetados por projetos de construção de transporte. O sensoriamento remoto oferece uma abordagem interessante para identificar áreas úmidas de alto valor por meio da interpretação de imagens aéreas.

Zonas úmidas

Plano a Longo Prazo - Usado para entender o estado geral ou a qualidade das áreas úmidas em um estado ou região (ou seja, hectares totais) e acompanhar o impacto ou o progresso na restauração de áreas úmidas ao longo do tempo.

Programas - Usados para identificar as áreas úmidas e as respectivas qualidades em um corredor e rastrear a história de destruição e substituição de áreas úmidas naquele corredor ao longo do tempo.

Avaliação Ambiental de Projeto - Usada para ajudar as agências de transporte a evitarem interferências em áreas úmidas durante os estudos de alternativa de traçado e propor métodos construtivos para minimizar os impactos na sua qualidade.

Não

Bancos de dados de agências ambientais (federais, estaduais ou municipais), pesquisa primária, análise de imagem, vistoria de campo.

Alta, pois são áreas com importantes funções biológicas ou hidrológicas.

Uma proporção maior geralmente indica maiores benefícios ecológicos. 
FA-08.

Ecossistema,

Habitat e

Biodiversidade

\section{EHB-03.1. Relação entre as zonas úmidas afetadas e criadas}

Exemplos de medidas de desempenho

Descrição

Desagregação / Escala de análise

Unidade

Balanço entre áreas úmidas destruídas e as áreas criadas ou recuperadas

Diferença entre a superfície de áreas úmidas destruídas e as áreas úmidas criadas ou recuperadas.

- por ano

- por projeto

- por região de interesse

hectares

- por bacia hidrográfica

Zonas úmidas de alto

Perdas de zonas úmidas de alta qualidade

valor afetadas para construção de

infraestrutura de transportes

Percentual de zonas úmidas substituídas ou protegidas

Distribuição percentual de zonas úmidas substituídas ou protegidas em relação a todas à área total

traçado

- $\quad$ por projeto

hectares que podem sofrer

Mudança esperada na função ecológica das áreas úmidas como resultado da mitigação alteração da função ecológica em razão da mitigação da construção ou operação de uma infraestrutura de transporte
- $\quad$ por alternativa de traçado

- $\quad$ por projeto

- por região de interesse

- por bacia hidrográfica

- por região

- por área de influência hectares 


\section{EHB-03.2. Consistência com planos de conservação de zonas úmidas}

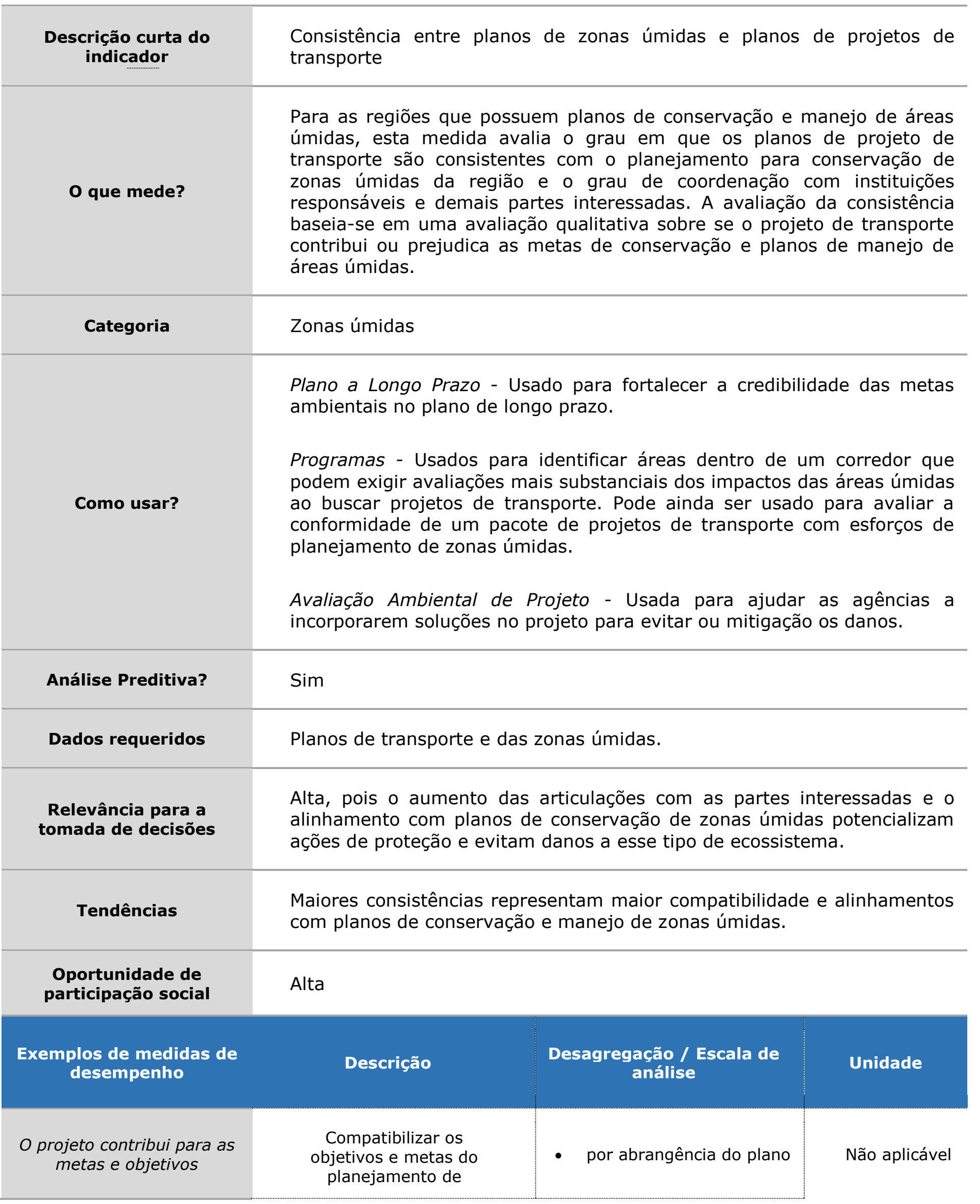


FA-08.

Ecossistema,

Habitat e

Biodiversidade

EHB-03.2. Consistência com planos de conservação

de zonas úmidas

identificados no plano de zonas úmidas?

Coordenação com a agência local de áreas úmidas (ou recursos naturais) para alinhar o projeto com as metas e objetivos

transporte com o plano

de conservação de zonas úmidas

Analisar o nível de coordenação do empreendedor e/ou planejador com as agências responsáveis pela conservação das áreas úmidas, visando o alinhamento dos objetivos e metas

Impactos do projeto em áreas úmidas de alta qualidade, conforme identificado em planos de zonas úmidas
Avaliação do impacto de um projeto nas áreas úmidas de alta qualidade identificadas em planos
- $\quad$ por área de jurisdição

Não aplicável
- $\quad$ por projeto 


\begin{tabular}{|c|c|}
\hline $\begin{array}{l}\text { Descrição curta do } \\
\text { indicador }\end{array}$ & $\begin{array}{l}\text { Impacto dos projetos de transporte no número e características das } \\
\text { colisões entre animais e veículos }\end{array}$ \\
\hline O que mede? & $\begin{array}{l}\text { Identifica os pontos de travessia com risco de atropelamento de fauna } \\
\text { nativa, subsidiando medidas de prevenção e mitigação, tais como } \\
\text { concepção de projeto que permita o livre fluxo da fauna (OAE e túneis), } \\
\text { passagens de fauna, cercas direcionadoras, etc. Essa medida fornece um } \\
\text { perfil específico da espécie para a quantidade e distribuição espacial e } \\
\text { temporal das colisões. }\end{array}$ \\
\hline Categoria & Fauna silvestre \\
\hline \multirow{3}{*}{ Como usar? } & $\begin{array}{l}\text { Plano a Longo Prazo - Usado para identificar locais no sistema de transporte } \\
\text { que impactam significativamente as espécies e a segurança dos usuários. } \\
\text { Programa - Usados para ajudar na determinação de como minimizar os } \\
\text { impactos na vida selvagem durante o planejamento do corredor e } \\
\text { identificar oportunidades de conectar áreas de habitat. }\end{array}$ \\
\hline & $\begin{array}{l}\text { Avaliação Ambiental de Projetos - Usado para avaliar as alternativas de } \\
\text { traçado e do projeto para seus possíveis impactos à vida selvagem e as } \\
\text { medidas mitigadoras nos principais corredores ecológicos. }\end{array}$ \\
\hline & $\begin{array}{l}\text { Monitoramento - Usado para acompanhar o número, as espécies e os locais } \\
\text { de atropelamentos de fauna silvestre, bem como a efetividade das medidas } \\
\text { mitigadoras implementadas, subsidiando a complementação e correção de } \\
\text { novas medidas. }\end{array}$ \\
\hline Análise Preditiva? & Sim \\
\hline Dados requeridos & $\begin{array}{l}\text { Locais de atropelamentos de fauna crônicos; migração de fauna conhecida } \\
\text { ou prevista; áreas de habitat; áreas de conservação; levantamento de } \\
\text { fauna; corredores ecológicos. }\end{array}$ \\
\hline $\begin{array}{l}\text { Relevância para a } \\
\text { tomada de decisões }\end{array}$ & $\begin{array}{l}\text { Alta, pois o conhecimento antecipado das principais ocorrências de } \\
\text { travessia de fauna permite que a agência evite a inserção de uma } \\
\text { infraestrutura no local ou, na impossibilidade, desenvolva projetos que } \\
\text { evite os impactos de atropelamento de fauna (e.g. túneis e OAEs) e inclua } \\
\text { passagens (inferior e superior) de fauna, visando a preservação das } \\
\text { espécies e a segurança dos usuários. }\end{array}$ \\
\hline
\end{tabular}

Tendências

Quanto maiores os números de atropelamentos de fauna, piores são os resultados de medidas preventivas e mitigadoras. 
FA-08.

Ecossistema,

Habitat e

EHB-04.1. Atropelamento de fauna silvestre

Biodiversidade

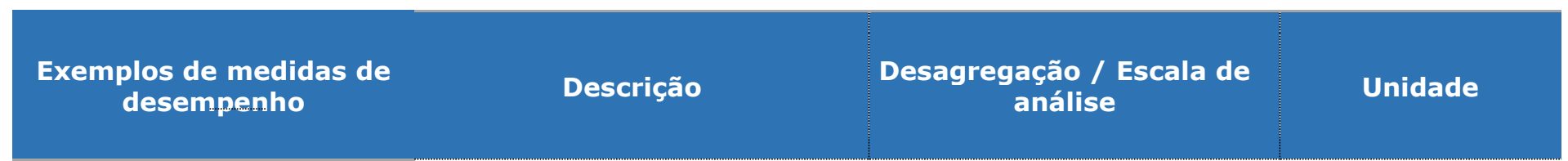

Aumento da densidade das espécies

Tamanho da população de espécies indicadoras

Número de colisões de veículos com animais contidos na lista de espécies ameaçadas de extinção

Alteração no número de colisões entre veículos e animais
Acompanha a densidade de espécies em períodos antes e após a

implementação de projeto. Deve-se verificar os períodos e épocas com os aumentos e diminuições de atropelamentos.

Identificar espécies ameaçadas, endêmicas e generalistas.

Identificar espécies características do ecossistema da região.

Selecionar espécies específicas da fauna com características de animais com alta mobilidade.

Quantifica o número de colisões com animais contidos na lista de espécie ameaçadas de extinção ou com algum grau de ameaça. Utilizar lista de espécies da IUCN (União Internacional para Proteção da Natureza), do IBAMA (O Instituto Brasileiro do Meio

Ambiente e dos Recursos Naturais Renováveis) e listas Estaduais (exemplo: Fauna Ameaçada de Extinção no Estado de São Paulo).

Verificar após a instalação de medias mitigadoras, as alteração nos números de atropelamentos com avaliação da efetividade dos projetos implementados.
- Por zona de interesse

- Por hotspot

- Por segmento da rodovia.
Número/área

- Por áreas com maiores possibilidades de registros.

Número
- Por empreendimento em operação

- Por projeto

- Por quilômetro da rodovia.

Número
- Por rodovia

- Por corredor ecológico

- Por local com medida implementada

Número

- Por quilômetro da rodovia.
Taxa de colisões entre veículos e animais por quilômetro
Número de atropelamento de animais por ano dividido
- Por rodovia

- Por região
Número / quilômetro-ano 
FA-08.

Ecossistema,

Habitat e

EHB-04.1. Atropelamento de fauna silvestre

Biodiversidade

\begin{tabular}{|c|c|c|c|}
\hline & $\begin{array}{l}\text { pelo total de quilômetros } \\
\text { monitorado }\end{array}$ & $\begin{array}{l}\text { - Em unidade de } \\
\text { conservação }\end{array}$ & \\
\hline $\begin{array}{l}\text { Número de espécies de } \\
\text { fauna nativa identificadas } \\
\text { na área de influência do } \\
\text { empreendimento por classe }\end{array}$ & $\begin{array}{l}\text { Identificar todos os } \\
\text { animais da fauna nativa } \\
\text { atropelados pela classe e } \\
\text { espécie. Quantificar o } \\
\text { número de espécies } \\
\text { identificadas por classe. }\end{array}$ & $\begin{array}{l}\text { - Por zona de interesse } \\
\text { - } \quad \text { Por rodovia } \\
\text { Por quilômetro da } \\
\text { rodovia. }\end{array}$ & Número \\
\hline $\begin{array}{l}\text { Número de projetos de } \\
\text { preservação e proteção de } \\
\text { espécies ameaçadas ou de } \\
\text { restauração florestal }\end{array}$ & $\begin{array}{l}\text { Levantar e identificar } \\
\text { projetos realizados ou em } \\
\text { implantação relacionados } \\
\text { com a fauna nativa local. }\end{array}$ & $\begin{array}{l}\text { - } \quad \text { Por projeto } \\
\text { - } \quad \text { opr rodovia em } \\
\text { - Por unidade de } \\
\text { conservação na área de } \\
\text { influência }\end{array}$ & Número \\
\hline $\begin{array}{c}\text { Variação percentual em } \\
\text { número de espécies nativas }\end{array}$ & $\begin{array}{l}\text { Verificar as flutuações } \\
\text { entre os atropelamentos } \\
\text { a sazonalidade dos } \\
\text { registros. }\end{array}$ & $\begin{array}{l}\text { - Por zona de interesse } \\
\text { - } \quad \text { Por rodovia } \\
\text { Por quilômetro da } \\
\text { rodovia }\end{array}$ & $\%$ \\
\hline $\begin{array}{l}\text { Número de passagens de } \\
\text { fauna }\end{array}$ & $\begin{array}{c}\text { Quantidade de passagens } \\
\text { de fauna para atravessar } \\
\text { a rodovia }\end{array}$ & $\begin{array}{l}\text { - Por rodovia } \\
\text { - } \quad \text { Por quilômetro } \\
\text { (superior, inferior, } \\
\text { sobre o túnel da } \\
\text { rodovia, sob OAE's, } \\
\text { etc.) }\end{array}$ & Número \\
\hline $\begin{array}{l}\text { Percentual da rodovia com } \\
\text { proteção de fauna }\end{array}$ & $\begin{array}{l}\text { Extensão total da rodovia } \\
\text { com alguma proteção } \\
\text { prevista para a fauna } \\
\text { silvestre, como } \\
\text { passagens de fauna, } \\
\text { cercas direcionadoras, } \\
\text { livre passagem pela } \\
\text { rodovia (OAE, túnel), etc, } \\
\text { em relação à extensão } \\
\text { total. }\end{array}$ & $\begin{array}{l}\text { - } \quad \text { Por rodovia } \\
\text { - } \quad \text { Por projeto } \\
\quad \text { proteção de medida de }\end{array}$ & $\%$ \\
\hline
\end{tabular}




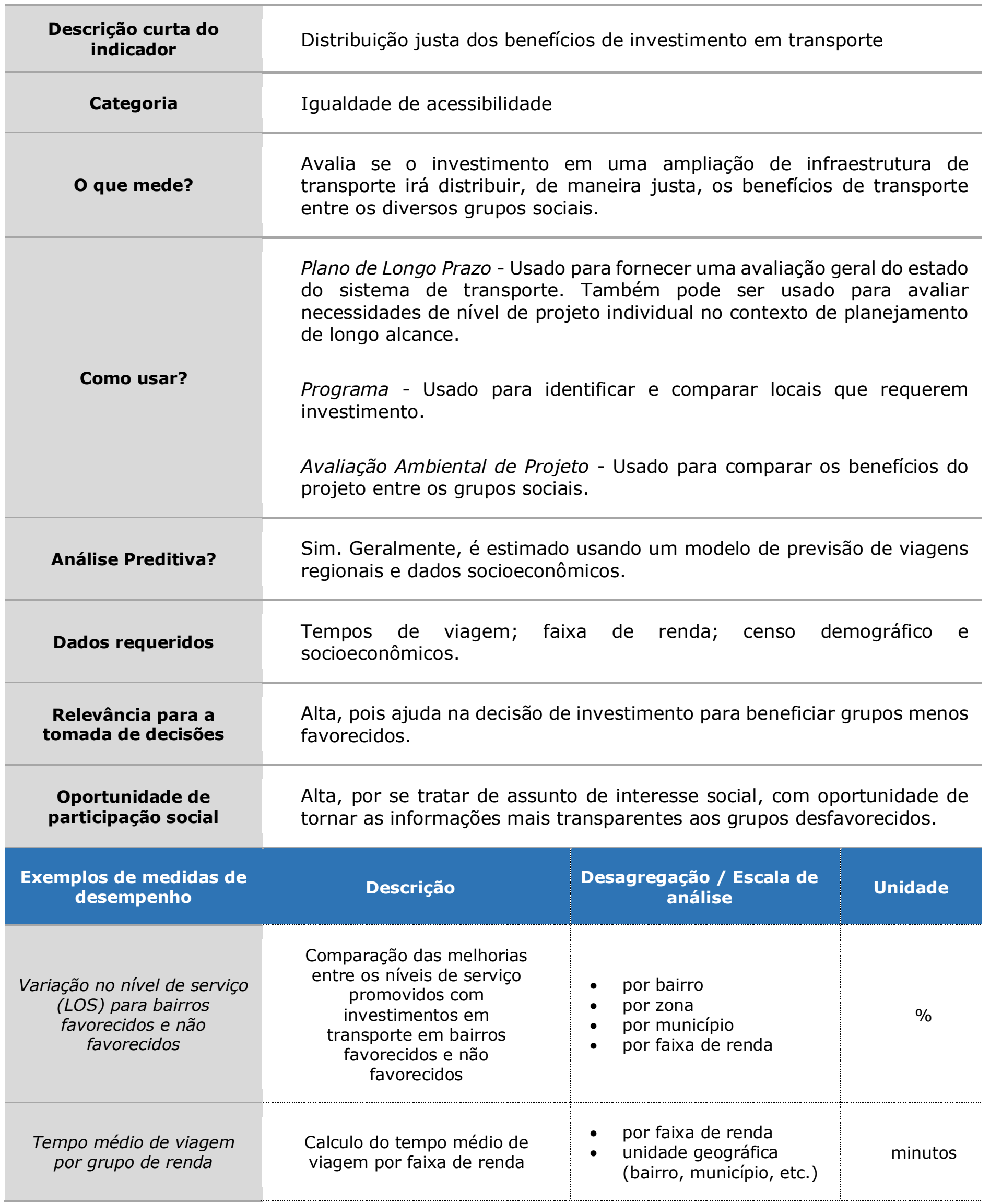




\section{FA-09. Equidade}

Oferta de transporte para pessoas com mobilidade reduzida

Variação de horas de atraso para populações desfavorecidas em comparação com toda a população

Mudança no acesso a empregos e mercados para populações desfavorecidas em comparação com toda a população

\section{EQ-01.1. Equidade no transporte}

Capacidade média diária de veículos especiais de transporte público para deslocamento de pessoas com mobilidade reduzida

- por frota

- porzona

- por bairro

número ou

Alteração do tempo perdido no trânsito pela população desfavorecida em comparação com a média da população

Alteração no nível de acessibilidade, em tempo de viagem, a empregos e mercados para população desfavorecidas em comparação com toda a população
- por município

- por bairro

minutos

- por município

- por bairro

- por zona minutos 


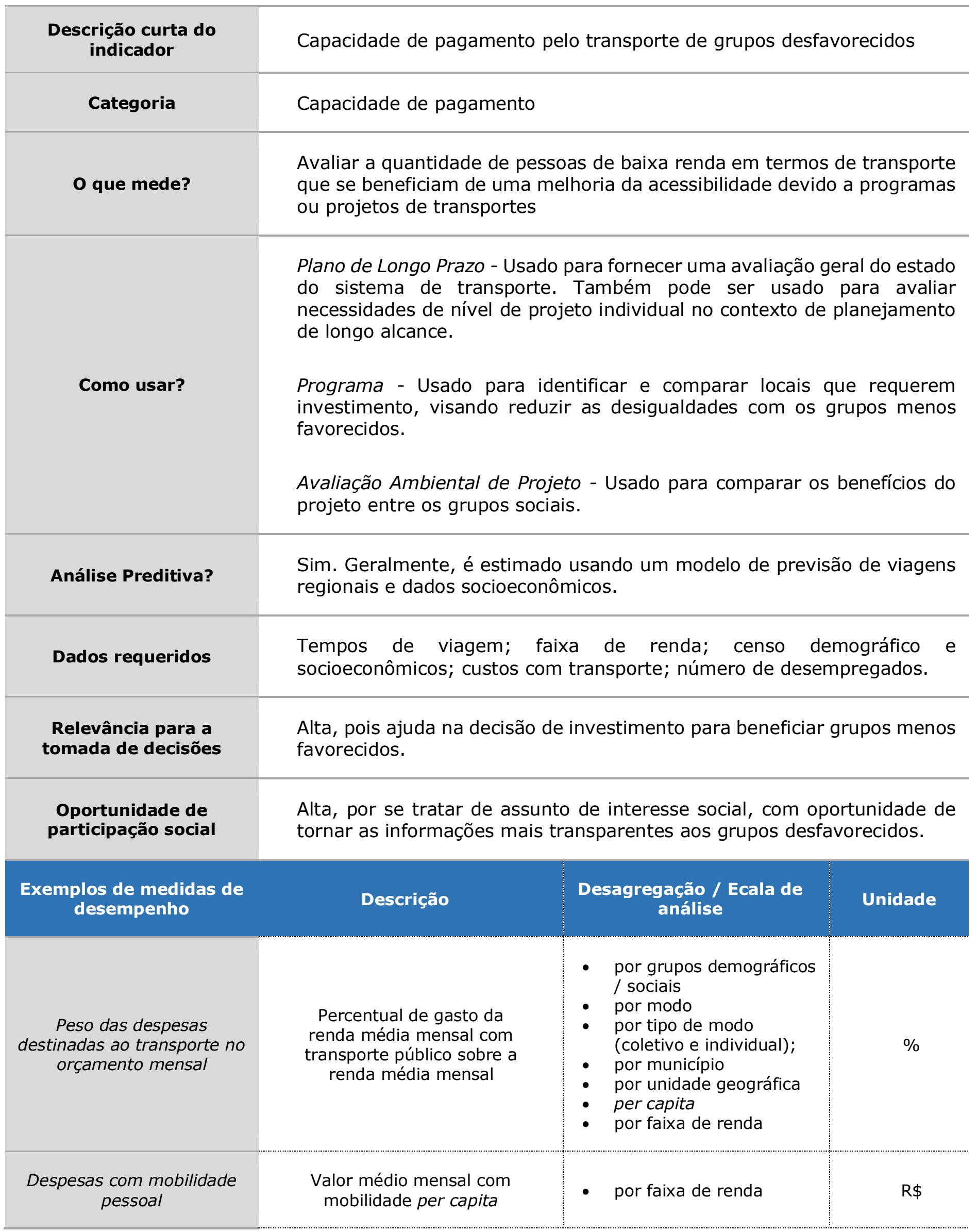




\section{FA-09. Equidade}

Parcela de domicílios de baixa renda que gastam mais de $X \%$ dos seus orçamentos em transporte

Variação relativa no índice de custos de transporte

Redução dos custos de transporte atribuíveis a uma melhoria na infraestrutura de transporte

Variação na proporção de pessoas desfavorecidas em termos de transporte para populações não desfavorecidas, que se beneficiam de uma melhoria da acessibilidade devido a programas ou projetos de transportes

Percentagem de desempregados ou grupos de baixa renda da região que citam o acesso ao transporte como principal barreira à procura de emprego

\section{EQ-02.1. Capacidade de pagamento}

Percentual de domicílio que comprometem a renda em X \% (e.g. 20\%) com transporte

- por município

- por bairro

Variação do custo anual do transporte em relação à receita anual

- por carga

- por modo

Percentual de redução dos custos de transporte como benefício de investimento em infraestrutura de transporte

- por viagem

- por tempo de viagem

Alteração na proporcionalidade de pessoas mais favorecidas e não favorecidas em função da melhoria de acessibilidade promovida por investimento em transporte
Quantidade de desempregados ou população de baixa renda que possuem dificuldades de transporte para procurar emprego
- por unidade geográfica (bairro, zona, município, etc.)

- por município

- por bairro
- por zona 


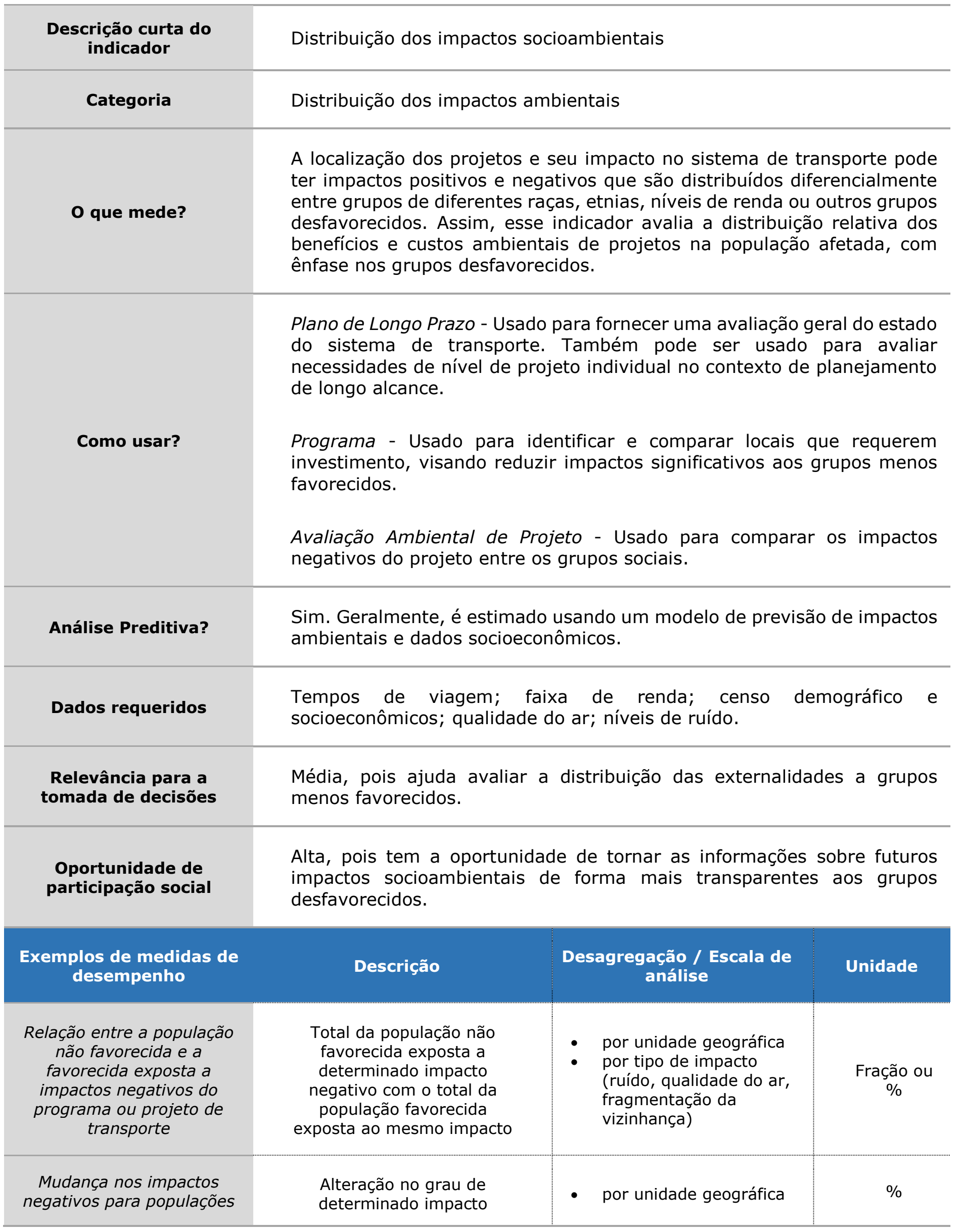


desfavorecidas em comparação com toda a população negativo para populações desfavorecidas em relação ao total da população
- $\quad$ por tipo de impacto (níveis de ruído, qualidade do ar e conectividade) 


\section{QV-01.1. Alteração dos níveis de ruído}

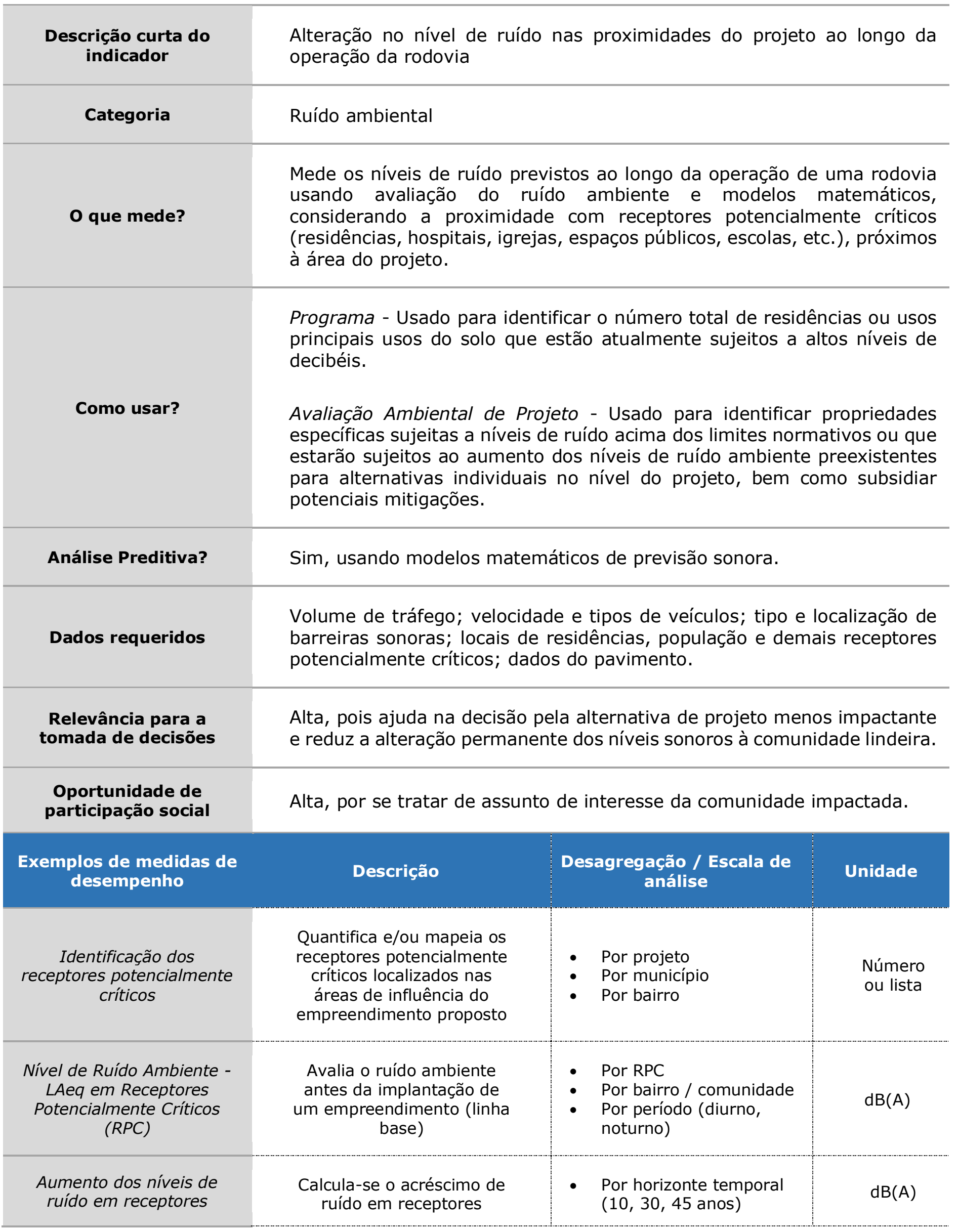




\section{QV-01.1. Alteração dos níveis de ruído}

sensíveis (escolas, igrejas, hospitais, residências,

locais públicos de reunião, etc.)

Número de residências expostas a ruído acima dos limites normativos

População residencial exposta a níveis de pressão sonora acima dos padrões normativos

Porcentagem de sistema de transporte que demandará medidas de atenuação acústica

Área urbanizada impactada com níveis de ruído

Número de residências em que o nível de ruído diminui do nível de ruído preexistente (linha base) sensíveis face à operação da rodovia

Refere-se ao número de

residências que estarão

expostas a níveis de ruído acima dos limites

estabelecidos pelas normas (locais, estaduais, federais), em função do sistema de transporte

Quantidade (ou percentual) de pessoas que habitam um determinado local exposta a níveis de pressão sonora maior que $X$ decibéis (e.g. 60 dBA), cuja causa é atribuível ao sistema de transporte

Extensão da infraestrutura que exige tratamento acústico para mitigar o ruído a níveis aceitáveis em relação ao total

Área urbanizada (ou número de edificações) que sofrerá acréscimo de níveis sonoros em relação à linha base
- Por projeto

- Por receptores sensíveis

- Por período (diurno, noturno)

- Por horizonte temporal (10, 30, 45 anos)

- Por projeto

- Por unidade geográfica (bairro, município)

- Por segmento rodoviário

número

- Por horizonte temporal $(10,30,45$ anos $)$

Quantidade de residências que se beneficiarão com a redução dos níveis sonoros em função da redução do volume de tráfego proporcionados por um novo empreendimento
- Por projeto

- Por unidade geográfica (bairro, município)

- Por projeto

- $\quad$ Por tipo de medida (e.g. barreiras acústicas, pavimento silencioso, etc.)

- Por projeto

- Por unidade geográfica (bairro, município)

- Por faixa de variação (5, 10,15 ou maior que 15 decibéis)

número ou

$\%$

$\mathrm{km}^{2}$ ou

número

- Por unidade geográfica

número 


\section{QV-02.1. Qualidade visual}

\begin{tabular}{|l|l|}
\hline $\begin{array}{l}\text { Descrição curta do } \\
\text { indicador }\end{array}$ & $\begin{array}{l}\text { Alteração nas características visuais que definem a identidade da } \\
\text { comunidade }\end{array}$ \\
\hline Categoria & Intrusão visual \\
\hline Mede o impacto da intrusão visual de uma nova infraestrutura de \\
transporte, que pode provocar alteração em elementos visuais ou \\
estéticos que representam a identidade de uma comunidade. \\
O impacto de um projeto na qualidade visual pode ser medido pelo \\
número de casas ou outros edifícios dos quais o empreendimento \\
proposto seria visível, se um ou mais elemento da paisagem (natural ou \\
cultural) seria parcial ou totalmente bloqueado de um número \\
significativo de pontos de vista, ou outro método a ser definido. A coleta \\
de dados para mensuração dessas medidas pode ser realizada por meio \\
de uma combinação de pesquisas de preferência visual, análise com SIG \\
(Sistema de Informações Geográficas) de linha de visão (pontos de vistas) \\
e outras técnicas de modelagem.
\end{tabular}

Programa - Usados para identificar áreas com recursos e elementos visuais significativos ou áreas onde os recursos visuais são ou poderão ser afetados significativamente pela infraestrutura de transporte.

Como usar?

Avaliação Ambiental de Projeto - Usada para avaliar as alternativas de traçado e do projeto por seu impacto na qualidade visual, podendo subsidiar a definição de medidas mitigadoras para ser incorporadas no projeto executivo.

Análise Preditiva?

Dados requeridos

Sim, inserindo o projeto em modelos digitais do terreno.

Cadastro das edificações; mapeamento do uso do solo; levantamento planialtimétrico; localização dos principais elementos da paisagem natural e cultural.

Relevância para a tomada de decisões

\section{Oportunidade de participação social}

Média, pois ajuda na decisão pela alternativa de projeto menos impactante à comunidade lindeira e ajuda na aceitação social do projeto.

Alta, por se tratar de assunto relevante de interesse da comunidade impactada.

Exemplos de medidas de desempenho

Número de casas ou outros edifícios de que o projeto será visível

Descrição

Desagregação / Escala de análise

Unidade

- Por projeto

Quantidade de casas ou edifícios que podem visualizar a infraestrutura projetada
- Por faixa de distância (e.g. até 100, 200 ou 300 metros)

- Por bairro 


\section{FA-10. Qualidade de vida}

\section{QV-02.1. Qualidade visual}

\begin{tabular}{|c|c|c|c|}
\hline & & - $\quad$ Por município & \\
\hline $\begin{array}{l}\text { Principais elementos da } \\
\text { paisagem bloqueados de } \\
\text { um ponto de vista }\end{array}$ & $\begin{array}{c}\text { Quantidade de elementos } \\
\text { relevantes da paisagem que } \\
\text { serão, parcialmente ou } \\
\text { totalmente, bloqueados } \\
\text { pela infraestrutura } \\
\text { projetada }\end{array}$ & $\begin{array}{ll}\text { - } & \text { Por projeto } \\
\text { - } & \text { Por tipo de elemento } \\
\text { - } & \text { (natural ou cultural) } \\
\text { - } & \text { Por bairro } \\
\text { Punicípio }\end{array}$ & $\begin{array}{l}\text { Número. } \\
\text { Listar os } \\
\text { elementos } \\
\text { principais. }\end{array}$ \\
\hline $\begin{array}{c}\text { Porcentagem de perímetro } \\
\text { do empreendimento } \\
\text { protegidos por vegetação } \\
\text { natural ou objeto nativo } \\
\text { similar }\end{array}$ & $\begin{array}{l}\text { Extensão do perímetro do } \\
\text { empreendimento que é } \\
\text { protegido por vegetação } \\
\text { natural ou objeto nativo } \\
\text { similar, em relação ao } \\
\text { perímetro total }\end{array}$ & $\begin{array}{l}\text { - } \quad \text { Por projeto } \\
\text { - Por faixa de distância } \\
\text { (visto a 100, } 200 \text { ou } 300 \\
\text { metros) }\end{array}$ & $\%$ \\
\hline $\begin{array}{c}\text { Qualidade estética de } \\
\text { trechos viários em áreas } \\
\text { urbanizadas }\end{array}$ & $\begin{array}{c}\text { Medidas de valorização } \\
\text { estética e paisagística de } \\
\text { trechos viários que } \\
\text { atravessam áreas } \\
\text { urbanizadas }\end{array}$ & $\begin{array}{ll}\text { - } & \text { Por projeto } \\
\text { - } & \text { Por bairro } \\
\text { - } & \text { Por comunidade } \\
\text { - } & \text { Por município }\end{array}$ & $\begin{array}{l}\text { Lista e } \\
\text { descrição } \\
\text { das } \\
\text { medidas }\end{array}$ \\
\hline $\begin{array}{c}\text { Área (ou percentual) de } \\
\text { inserção urbana }\end{array}$ & $\begin{array}{l}\text { Área da infraestrutura } \\
\text { projetada dentro de zonas } \\
\text { urbanizadas, a ser } \\
\text { construída em superfície } \\
\text { (terrapleno) ou OAE`s } \\
\text { (pontes e viadutos) }\end{array}$ & $\begin{array}{l}\text { - } \quad \text { Por projeto } \\
\text { - } \quad \text { Por bairro } \\
\text { - } \quad \text { Por município } \\
\text { - } \quad \text { Por comunidade }\end{array}$ & $\mathrm{Km}^{2}$ ou $\%$ \\
\hline
\end{tabular}




\section{QV-03.1. Coesão Comunitária}

\begin{tabular}{|c|c|c|}
\hline $\begin{array}{l}\text { Descrição curta do } \\
\text { indicador }\end{array}$ & \multicolumn{2}{|c|}{$\begin{array}{l}\text { Mudança nas conexões físicas em nível de vizinhança que unem } \\
\text { moradores e empresas }\end{array}$} \\
\hline Categoria & \multicolumn{2}{|l|}{ Segregação Urbana } \\
\hline O que mede? & \multicolumn{2}{|c|}{$\begin{array}{l}\text { Mede o impacto causado pela segregação urbana, o qual prejudica as } \\
\text { conexões físicas de vizinhança que unem moradores e empresas, } \\
\text { afetando a coesão geral da comunidade. Esse indicador pode ser medido } \\
\text { pelo número de residências e empresas a serem realocadas; mudança } \\
\text { prevista em viagens a pé; mudança nos tempos de viagem entre os } \\
\text { pontos vizinhos da comunidade; e principais percursos cortados ou } \\
\text { reconectados como resultado de um projeto. }\end{array}$} \\
\hline \multirow{2}{*}{ Como usar? } & \multicolumn{2}{|c|}{$\begin{array}{l}\text { Programa - Usado para identificar projetos em bairros com problemas } \\
\text { potenciais de segregação ou oportunidades para melhorar a coesão por } \\
\text { meio de projetos. }\end{array}$} \\
\hline & \multicolumn{2}{|c|}{$\begin{array}{l}\text { Avaliação Ambiental de Projeto - Usado para avaliar alternativas de } \\
\text { traçado que impactam a coesão da comunidade e subsidiar concepção de } \\
\text { projetos para sua mitigação. }\end{array}$} \\
\hline Análise Preditiva? & \multicolumn{2}{|c|}{$\begin{array}{l}\text { Sim, inserindo sobrepondo o projeto em imagens e/ou com o } \\
\text { mapeamento do uso e ocupação do solo, bem como utilizando modelos } \\
\text { de viagens. }\end{array}$} \\
\hline Dados requeridos & \multicolumn{2}{|c|}{$\begin{array}{l}\text { Dados de população e habitação do censo demográfico - IBGE ou similar; } \\
\text { dados sobre localizações de empresas; mapeamento do sistema viário; } \\
\text { dados de modelos de viagens / percursos. }\end{array}$} \\
\hline $\begin{array}{l}\text { Relevância para a } \\
\text { tomada de decisões }\end{array}$ & \multicolumn{2}{|c|}{$\begin{array}{l}\text { Alta, pois ajuda na decisão pela alternativa de projeto menos impactante } \\
\text { à comunidade lindeira e ajuda na aceitação social do projeto. }\end{array}$} \\
\hline $\begin{array}{l}\text { Oportunidade de } \\
\text { participação social }\end{array}$ & \multicolumn{2}{|c|}{$\begin{array}{l}\text { Alta, por se tratar de assunto relevante de interesse da comunidade } \\
\text { impactada. }\end{array}$} \\
\hline $\begin{array}{l}\text { Exemplos de medidas de } \\
\text { desempenho }\end{array}$ & Descrição & $\begin{array}{c}\text { Desagregação / Escala de } \\
\text { análise }\end{array}$ \\
\hline $\begin{array}{l}\text { Interferência com habitação } \\
\quad \text { e unidades produtivas }\end{array}$ & $\begin{array}{l}\text { Número de edificações a } \\
\text { ser removidas e/ou } \\
\text { realocadas devido ao } \\
\text { programa ou projeto }\end{array}$ & $\begin{array}{l}\text { - por tipo (habitacionais, } \\
\text { equipamentos públicos, } \\
\text { comerciais, rurais, etc.) } \\
\text { - por regularidade (formal } \\
\text { ou sub-normal) } \\
\text { - por comunidade } \\
\text { - por tamanho }\end{array}$ \\
\hline
\end{tabular}




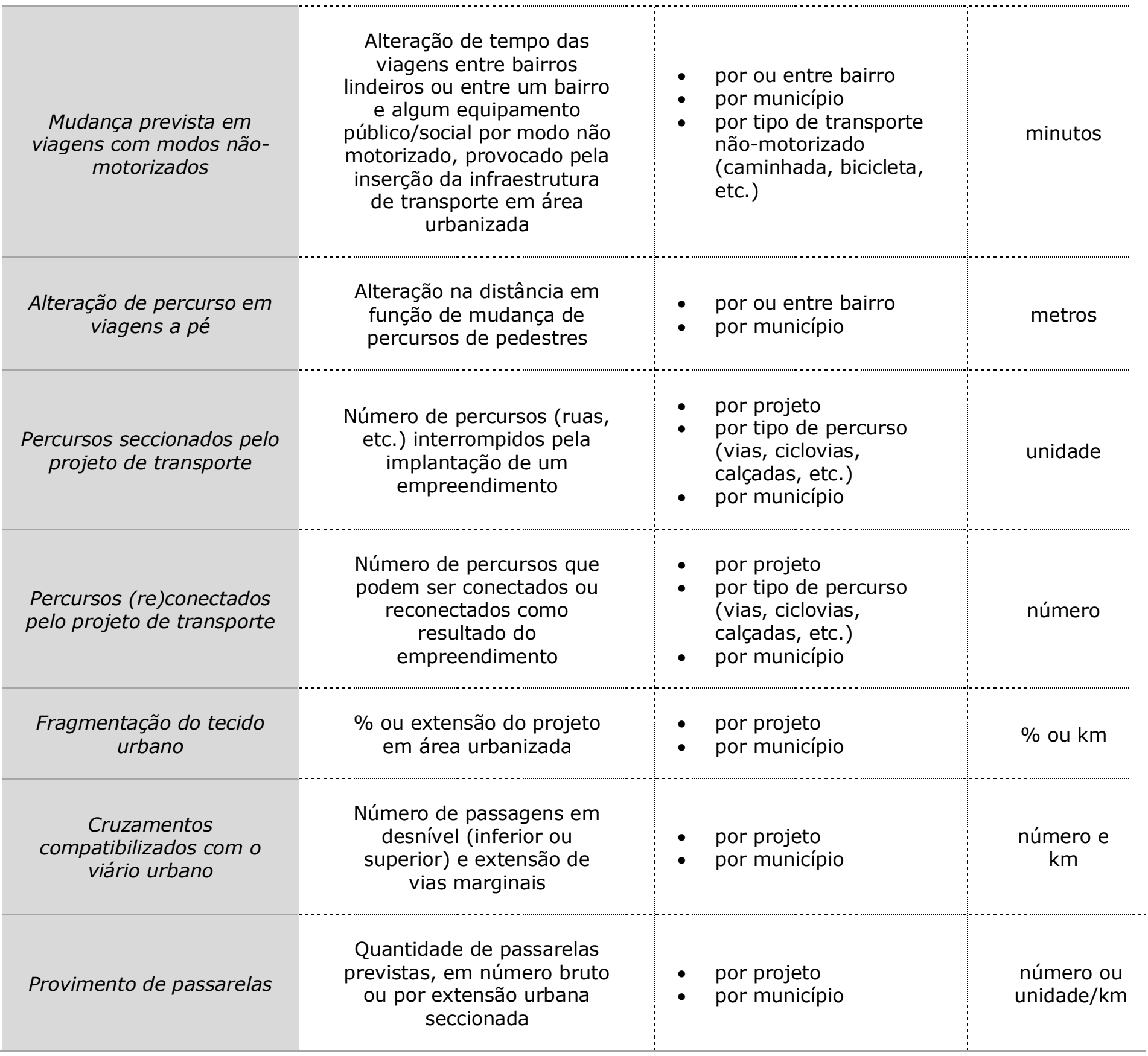




\section{QV-04.1. Riscos e emergências socioambientais}

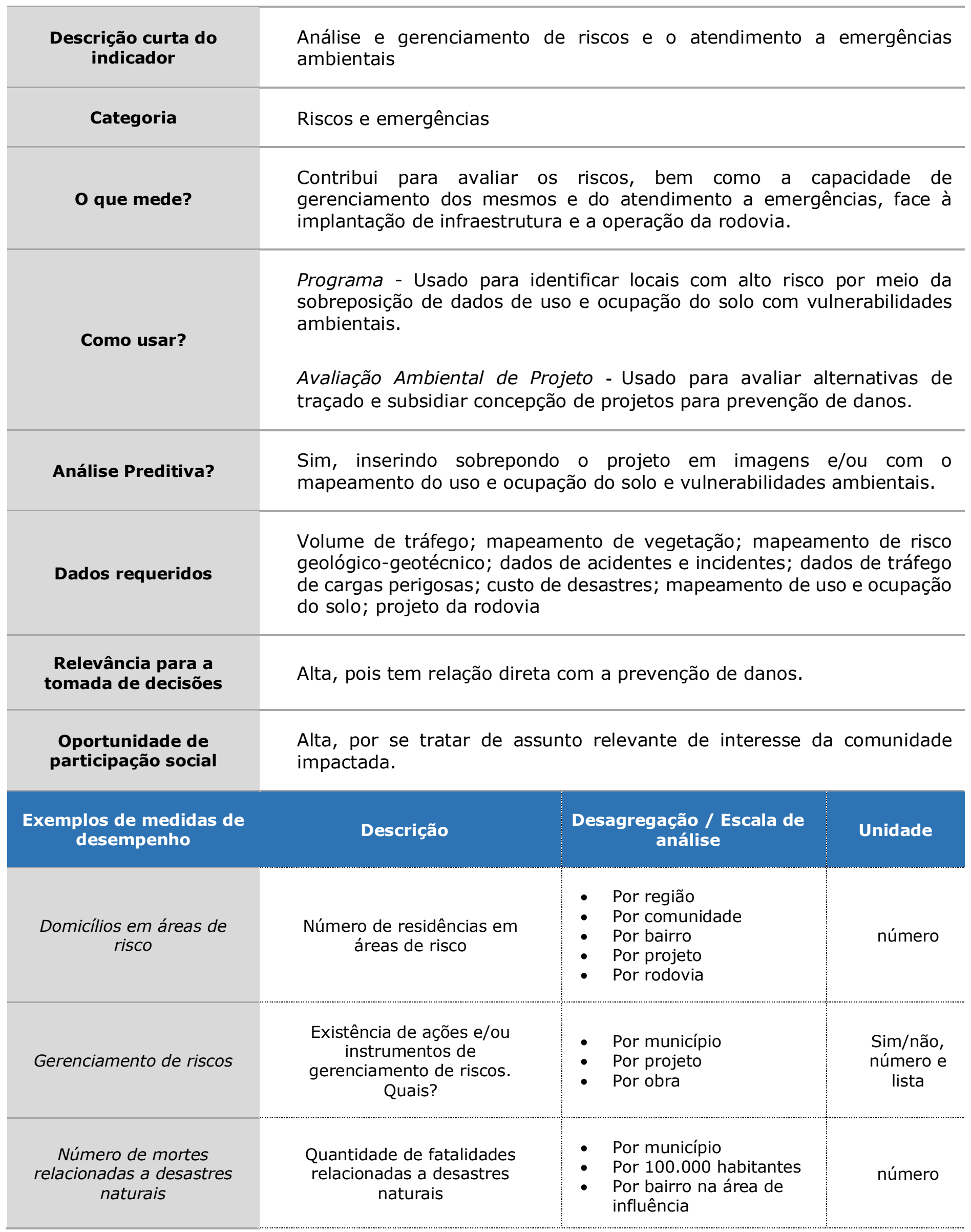




\section{QV-04.1. Riscos e emergências socioambientais}

\begin{tabular}{|c|c|c|c|}
\hline & & - $\quad$ Por ano & \\
\hline $\begin{array}{c}\text { Atualização dos planos de } \\
\text { emergência }\end{array}$ & $\begin{array}{c}\text { Porcentagem de planos de } \\
\text { emergência ambientais em } \\
\text { vigor / atualizados em } \\
\text { relação ao total de planos } \\
\text { necessários }\end{array}$ & $\begin{array}{ll}\text { - } & \text { Por projeto } \\
\text { - } & \text { Por rodovia }\end{array}$ & $\%$ \\
\hline $\begin{array}{c}\text { Tráfego de cargas } \\
\text { perigosas }\end{array}$ & $\begin{array}{l}\text { Número de viagens } \\
\text { transportando cargas } \\
\text { perigosas por ano }\end{array}$ & - Por ano & $\begin{array}{l}\text { Volume de } \\
\text { tráfego / } \\
\text { ano }\end{array}$ \\
\hline $\begin{array}{c}\text { Alteração no número de } \\
\text { incidentes/acidentes } \\
\text { envolvendo produtos } \\
\text { perigosos }\end{array}$ & $\begin{array}{c}\text { Variação do número de } \\
\text { incidentes/acidentes que } \\
\text { envolvem o transporte de } \\
\text { produtos perigosos } \\
\text { acidentes em função de } \\
\text { programas e projetos de } \\
\text { transportes }\end{array}$ & $\begin{array}{ll}\text { - } & \text { Por modo } \\
\text { - } & \text { Por projeto } \\
\text { - } & \text { Por rodovia } \\
\text { - } & \text { Por segmento rodoviário } \\
\text { - } & \text { Por tipo de produto } \\
\text { - } & \text { Perigoso } \\
\text { - } & \text { Por volumo de tráfego }\end{array}$ & número \\
\hline $\begin{array}{c}\text { Quantidade de materiais } \\
\text { perigosos derramados em } \\
\text { incidente/acidente de } \\
\text { transporte }\end{array}$ & $\begin{array}{l}\text { Quantidade de materiais } \\
\text { perigosos derramados em } \\
\text { função de acidentes } \\
\text { durante o transporte }\end{array}$ & $\begin{array}{ll}\text { - } & \text { Por modo } \\
\text { - } & \text { Por projeto } \\
\text { - } & \text { Por rodovia } \\
\text { - } & \text { Por tipo de produto } \\
\text { - } & \text { perigoso } \\
\text { - } & \text { Por tipo de acidente } \\
\text { - } & \text { Por volume de tráfego }\end{array}$ & $\mathrm{m}^{3}$ \\
\hline $\begin{array}{c}\text { Perda econômica devido a } \\
\text { desastres }\end{array}$ & $\begin{array}{l}\text { Quantidade de perdas } \\
\text { econômicas e de } \\
\text { infraestrutura incorrida } \\
\text { como um resultado direto } \\
\text { de desastres }\end{array}$ & $\begin{array}{ll}\text { - } & \text { Por ano } \\
\text { - } & \text { Por tipo de perda } \\
\text { Por tipo de desastre } \\
\text { (alagamento, } \\
\text { escorregamento, etc.) } \\
\text { Por unidade geográfica } \\
\text { (região, município ou } \\
\text { bairro) }\end{array}$ & número \\
\hline $\begin{array}{l}\text { Afetados por eventos } \\
\text { climáticos extremos }\end{array}$ & $\begin{array}{l}\text { Registros de afetados ou } \\
\text { vulneráveis à eventos } \\
\text { climáticos extremos como } \\
\text { alagamentos, } \\
\text { deslizamentos, enxurradas, } \\
\text { inundações, dentre outros }\end{array}$ & - $\quad$ Por região de interesse & número \\
\hline $\begin{array}{c}\text { Monitoramento e alertas de } \\
\text { desastres naturais }\end{array}$ & $\begin{array}{c}\text { Existência de um centro de } \\
\text { monitoramento e alertas de } \\
\text { desastres naturais }\end{array}$ & - Por região de interesse & $\begin{array}{l}\text { sim/não. } \\
\text { Listar. }\end{array}$ \\
\hline $\begin{array}{l}\text { Alteração tempo de } \\
\text { resposta a emergências } \\
\text { com a comunidade }\end{array}$ & $\begin{array}{l}\text { Tempo de resposta de } \\
\text { emergência atual versus } \\
\text { tempo de resposta de } \\
\text { emergência previsto }\end{array}$ & $\begin{array}{l}\text { - } \quad \text { Por bairro } \\
\text { - } \quad \text { Por comunidade } \\
\text { - } \quad \text { Por segmento rodoviário }\end{array}$ & minutos \\
\hline
\end{tabular}




\section{QV-04.1. Riscos e emergências socioambientais}

\begin{tabular}{|c|c|c|c|}
\hline & $\begin{array}{c}\text { (modelado) após a } \\
\text { conclusão do projeto, } \\
\text { necessário para que grupos } \\
\text { de combate a emergências } \\
\text { (polícia, bombeiros, defesa } \\
\text { civil, médicos, etc.) possam } \\
\text { chegar a uma comunidade }\end{array}$ & & \\
\hline $\begin{array}{l}\text { Redução das viagens } \\
\text { dentro da malha urbana }\end{array}$ & $\begin{array}{c}\text { Redução no número e/ou na } \\
\text { extensão das viagens dentro } \\
\text { da malha urbana em } \\
\text { decorrência do desvio do } \\
\text { volume de tráfego para um } \\
\text { novo empreendimento } \\
\text { rodoviário, em particular de } \\
\text { veículos com cargas perigosas }\end{array}$ & $\begin{array}{l}\text { - } \quad \text { Por projeto } \\
\text { - } \quad \text { Por trecho viário urbano } \\
\text { - } \quad \text { Por município } \\
\text { Pogião }\end{array}$ & $\begin{array}{l}\text { Número } \\
\text { e/ou } \\
\text { metros }\end{array}$ \\
\hline $\begin{array}{c}\text { Percentual da rodovia } \\
\text { protegida contra vazamento } \\
\text { de produtos perigosos }\end{array}$ & $\begin{array}{c}\text { Extensão da rodovia provida } \\
\text { de sistema de drenagem com } \\
\text { contenção produtos perigosos, } \\
\text { como caixas de retenção, } \\
\text { trechos sem saída d'água e } \\
\text { dispositivos de retardamento } \\
\text { do escoamento desses } \\
\text { produtos }\end{array}$ & $\begin{array}{l}\text { - } \quad \text { Por rodovia } \\
\text { - Por projeto } \\
\text { - Por segmento }\end{array}$ & $\%$ \\
\hline $\begin{array}{c}\text { Porcentagem de florestas } \\
\text { remanescentes no entorno } \\
\text { da rodovia protegidas } \\
\text { contra a ocorrência de } \\
\text { incêndios }\end{array}$ & $\begin{array}{l}\text { Extensão das florestas } \\
\text { remanescentes no entorno da } \\
\text { rodovia que dispõe de medidas } \\
\text { de proteção contra a } \\
\text { ocorrência de incêndios, em } \\
\text { relação à extensão total de } \\
\text { florestas no entorno }\end{array}$ & $\begin{array}{l}\text { - } \quad \text { Por rodovia } \\
\text { - } \quad \text { Por projeto } \\
\text { - Por medida de proteção }\end{array}$ & $\%$ \\
\hline $\begin{array}{c}\text { Possibilidade de afetação } \\
\text { de pontos de captação de } \\
\text { água por produtos } \\
\text { perigosos }\end{array}$ & $\begin{array}{l}\text { Tempo ou distância de um } \\
\text { vazamento de produto } \\
\text { perigoso alcançar um ponto de } \\
\text { captação de água para } \\
\text { abastecimento }\end{array}$ & $\begin{array}{l}\text { - } \quad \text { Por rodovia } \\
\text { - } \quad \text { Por projeto }\end{array}$ & $\begin{array}{l}\text { Minutos } \\
\text { ou } \\
\text { metros }\end{array}$ \\
\hline
\end{tabular}

